\title{
LIFESTYLE AND ENTERTAINMENT IN YANGZHOU
}

\section{Edited by \\ Lucie Olivová and Vibeke Børdahl}

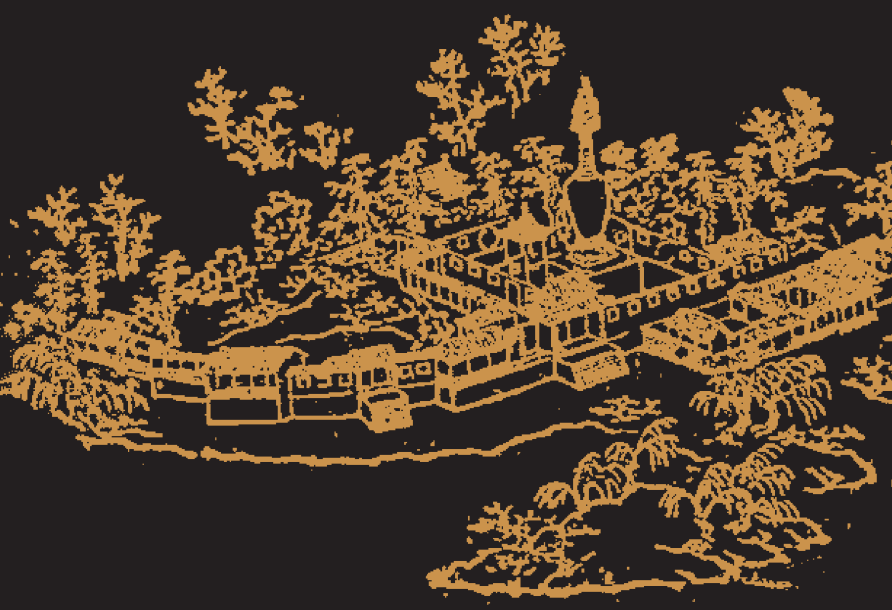

1

$\rightarrow$

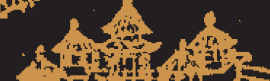

30

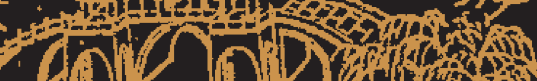
1) Wing
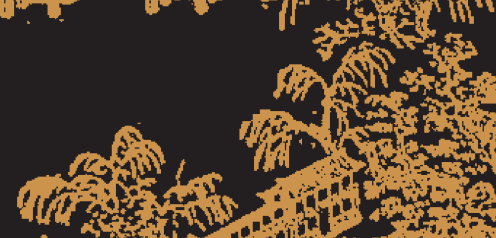

$x+12$

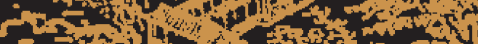

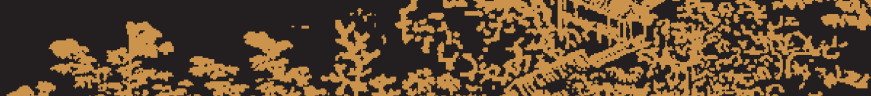

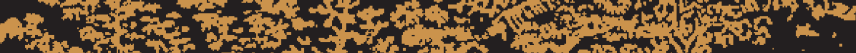

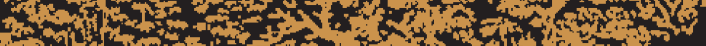
$-7 y_{1}$ 
Lifestyle and Entertainment in Yangzhou 


\section{NORDIC INSTITUTE OF ASIAN STUDIES}

\section{NIAS Studies in Asian Topics}

16 Leadership on Java Hans Antlöv and Sven Cederroth (eds)

17 Vietnam in a Changing World Irene Nørlund, Carolyn Gates and Vu Cao Dam (eds)

18 Asian Perceptions of Nature Ole Bruun and Arne Kalland (eds)

19 Imperial Policy and Southeast Asian Nationalism Hans Antlöv and Stein Tonnesson (eds)

20 The Village Concept in the Transformation of Rural Southeast Asia Mason C Hoadley and Christer Cunnarsson (eds)

21 Identity in Asian Literature Lisbeth Littrup (ed.)

22 Mongolia in Transition Ole Bruun and Ole Odgaard (eds)

23 Asian Forms of the Nation Stein Tonnesson and Hans Antlöv (eds)

24 The Eternal Storyteller Vibeke Børdahl (ed.)

25 Japanese Influences and Presences in Asia Marie Söderberg and lan Reader (eds)

26 Muslim Diversity Leif Manger (ed.)

27 Women and Households in Indonesia Juliette Koning, Marleen Nolten, Janet Rodenburg and Ratna Saptari (eds)

28 The House in Southeast Asia Stephen Sparkes and Signe Howell (eds)

29 Rethinking Development in East Asia Pietro P. Masina (ed.)

30 Coming of Age in South and Southeast Asia Lenore Manderson and Pranee Liamputtong (eds)

31 Imperial Japan and National Identities in Asia, 1895-1945 Li Narangoa and Robert Cribb (eds)

32 Contesting Visions of the Lao Past Christopher Goscha and Soren Ivarsson (eds)

33 Reaching for the Dream Melanie Beresford and Tran Ngoc Angie (eds)

34 Mongols from Country to City Ole Bruun and Li Naragoa (eds)

35 Four Masters of Chinese Storytelling Vibeke Bordahl, Fei Li and Huang Ying (eds)

36 The Power of Ideas Claudia Derichs and Thomas Heberer (eds)

37 Beyond the Green Myth Peter Sercombe and Bernard Sellato (eds)

38 Kinship and Food in South-East Asia Monica Janowski and Fiona Kerlogue (eds)

39 Exploring Ethnic Diversity in Burma Mikael Cravers (ed.)

40 Politics, Culture and Self: East Asian and North European Attitudes Ceir Helgesen and Søren Risbjerg Thomsen (eds)

41 Beyond Chinatown Mette Thunø (ed.)

42 Breeds of Empire: The 'Invention' of the Horse in Southeast Asia and Southern Africa 1500-1950 Greg Bankoff and Sandra Swart

43 People of Virtue: Reconfiguring Religion, Power and Moral Order in Cambodia Today Alexandra Kent and David Chandler (eds)

44 Lifestyle and Entertainment in Yangzhou Lucie Olivová and Vibeke Børdahl (eds) 


\title{
LIFESTYLE AND
}

\section{ENTERTAINMENT IN} YANGZHOU

\author{
Edited by \\ Lucie B. Olivová and Vibeke Børdahl
}

\% MiaSPRess 
Lifestyle and Entertainment in Yangzhou

Edited by Lucie Olivová and Vibeke Børdahl

NIAS Studies in Asian Topics Series, No. 44

First published in 2009 by NIAS Press

NIAS - Nordic Institute of Asian Studies

Leifsgade 33, 2300 Copenhagen S, Denmark

E-mail: books@nias.ku.dk

Online: http://www.niaspress.dk

(C) NIAS - Nordic Institute of Asian Studies 2009

While copyright in the volume as a whole is vested in NIAS Press, copyright in the individual chapters belongs to their authors. No chapter may be reproduced in whole or part without the express permission of author, publisher and editors.

\section{British Library Cataloguing in Publication Data}

Lifestyle and entertainment in Yangzhou. - (NIAS studies in Asian topics ; no. 44)

I. Arts - China - Yangzhou 2. Yangzhou (China) -

Civilization

I. Olivova, Lucie II. Bordahl, Vibeke

$700.9 ' 51222$

ISBN 978-87-7694-035-5

The publication of this book was assisted by grants from the Chiang Ching-kuo Foundation for International Scholarly Exchange, Taibei, the Nordic Institute of Asian Studies, Copenhagen, and the Norwegian Research Council, Oslo. 
In Memory of Yi-li Kao 1974-2009 



\section{Contents}

Illustrations $\quad$ ix

Preface $\quad$ xv

Contributors $\quad$ xix

Introduction

Lucie B. Olivová and Vibeke Børdahl xxi

\section{Part I: City of Sights}

1 Building History and the Preservation of Yangzhou

Lucie B. Olivová

2 Gathering in a Ruined City: Metaphor, Practice and Recovery in Post-Taiping Yangzhou

Tobie Meyer-Fong

3 The Fashionable City? Glimpses of Clothing Culture in Qing Yangzhou

Antonia Finnane

4 The Culture of Yangzhou Residential Gardens

Věna Hrdličková

5 A Traveler's Tale of Two Cities: Yangzhou, Shanghai

Malcolm McKinnon

\section{Part II: Books and Literature}

6 Yangzhou Printing and Book Culture in the Qing Period J. S. Edgren

7 Pleasures of a Man of Letters: Wang Shizhen in Yangzhou, 1660-1665

Li Hsiao-t'i

8 Early Qing Yangzhou in Shi Chengjin's Vernacular Vignettes

Roland Altenburger

9 Local Fiction of the Yangzhou Region: Qingfengzha

Margaret B. Wan 


\section{Part III: Performance and Entertainment}

10 Yangzhou Local Theatre in the Second Half of the Qing

Colin Mackerras

11 Kunqu in Yangzhou Then and Now Lindy Li Mark

12 Written Scripts in the Oral Tradition of Yangzhou Storytelling Vibeke Børdahl

13 The Traditional Style of Storyhouses in Yangzhou

Fei Li

14 Life in the Green Lofts of the Lower Yangzi Region

Stefan Kuzay

\section{Part IV: The Yangzhou School of Painting}

15 The Study of Forgeries of Paintings by the Yangzhou Eccentrics Zhuang Sue

16 Traveling to the Frontier: Hua Yan's Camel in Snow

Ginger Cheng-chi Hsü

17 The Landscape Albums of Huang Shen

Yi-li Kao

18 Illustrious Icons and Flower Garlands: Defining Buddhist Imagery in Eighteenth-Century Yangzhou Painting

Kristen E. Loring

References

441

Index 


\section{Illustrations}

\section{FIGURES}

I.I Southern gate, Nanmen, state before (2005) and after the restoration (2007). 4

I.2 Yuansheng temple, with built-in apartments. Yangzhou historical city, Old Town. September 2007.

I.3 Tablets, old and new, fixed on protected historical monuments. 23

I.4 A stone slab on Wenhe Street, with Jiang Zemin's inscription. 26

I.5 View of a Yangzhou lane, with the new pavement. September 2007.

2.I Exterminating the Yue Bandits. Woodcut showing the Qing forces fighting the Taipings in 1854 .

3.I A lady being photographed. Illustration from Xinwen huabao, Guangxu reign.

4.I The Wind Pavilion, Feng ting, in He Garden.

4.2 Rockery stuck onto the wall, with the Moon Pavilion, Tiebi shan yue ting, in He Garden.

4.3 The Pavilion in the Heart of the Pond, Shuixin ting, in He Garden. 8I

4.4 A solitaire stone in He Garden.

4.5 Door opening in the shape of a crescent-moon, in He Garden. 84

5.I Front page of a report to the British Parliament of an attack on British missionaries at Yangzhou in August 1868.

5.2 Metal trading area and the Grand Canal, at the eastern end of Taiping Road, Yangzhou. October 2005.

5.3 Ba Guai Memorial Hall: The main exhibition hall with lifesize clay figurines.

5.4 Min Zhen, Eight Children Playing. Yangzhou Museum. IO3

6.I Huaihai ji [Huaihai Collection], II73. IIO

6.2 Zhu Dongpo xiansheng shi [Mr Dongpo's Poems with Annotation], I2I3. III

6.3 Daode jing [Classic of the Way and the Virtue] or Laozi, I58I. II4

6.4 Quan Tang shi [Complete Tang Poetry], I707. II6 
6.5 Peiwen yunfu [Peiwen Phrase-dictionary Arranged According to Rhymes], I7II.

6.6 Libian [Dictionary of Clerical Script], I7I8.

6.7 Yizhuan [Tang Commentary on the Yijing], 1756.

6.8 Yangzhou huafang lu [Pleasure Boats of Yangzhou], I795.

6.9 Zhongding kuanzhi [Inscriptions on Bronze Vessels], I802.

7.I Luo Pin, A Joint Portrait of Wang Shizhen and Zhu Yizun. 1773. British Museum, London.

8.I Idealized portrait of Shi Chengjin, from Chuan jia bao, I739 edition. I5O

8.2 Table of contents for Yuhua xiang, 1726 edition.

8.3 Map of the city of Yangzhou, based on Yangzhou fu zhi (I8Io), with indicated sites as mentioned in Yuhua xiang and Tongtian le stories.

9.I The scoundrel, Pi Fengshan or Pi Wulaizi, Qingfengzha (I819).

9.2 The virtuous girl, Sun Xiaogu, Qingfengzha (I8I9).

9.3 A sample page from Qingfengzha (I8I9) with examples of Yangzhou dialect. I85

Io.I A scene from the traditional Yangzhou drama, Yangju, Zhenzhu ta [Pearl Pagoda]. October 2005.

I0.2 Young members of the audience at the performance of Zhenzhu ta being shown a camera by a foreigner. October 2005.

II.I The scene Shiseng [The Bully Priest] from the Liuye qupu collection.

II.2a-b An actor from the Nanjing Kunqu Troupe is painting his face for the performance of a comic role. Nanjing, 23 October 2005.

II.3 Nanjing Kunqu Troupe poses with participants of the 'Workshop on Lifestyle and Entertainment in Yangzhou'. Nanjing, 23 October 2005.

I2.I Dai Buzhang (1925-2003) performs in Copenhagen 1996.

12.2 A page from the script of Western Han.

12.3 Fei Junliang (I89I-I952). Yangzhou quyi zhi 1993.

I2.4 A double page from the script of Three Kingdoms.

I2.5 Fei Zhengliang (b. I93I) (artist name of Fei Li) performs the episode 'Beheading Yan Liang' from Three Kingdoms. Copenhagen 1996.

13.I A street in the Jiaochang area of Yangzhou, 1997.

13.2 The stage of the Great Enlightenment Storytellers' House, Daguangming shuchang, in the Jiaochang area, 1997.

13.3 Storytelling and tea in the Great Enlightenment Storytellers' House, 1997. 275

13.4 Props of Yangzhou storytelling, 2000. 277

13.5 The audience in the Great Enlightenment Storytellers' House, I997. 280 
13.6 Entrance to the Great Enlightenment Storytellers' House from the main street, I997.

I4.I Front page of Shiba mo [The Eighteen Ways of Massage]. 290

I4.2 Frontpage of Da chahui [A Visit to the Teahouse]. 296

15.I Li Shan, Five Pines. Undated. The Palace Museum, Beijing. 319

15.2 Li Shan, Five Pines. 1744. Chinese History Museum, Beijing. 320

15.3 Li Shan, Five Pines. 1747. Duoyun Xuan, Shanghai. 321

15.4 Li Shan, Five Pines. Album leaf, 1736. Collector unknown. 322

15.5 Li Shan, Five Pines. Undated. Tokyo National Museum. 323

15.6a Wang Shishen, Plum and Orchid. Leaf 2 of Album of Plum Blossoms.

Tadashi Moriya's Collection. $\quad 324$

15.6b Wang Shishen, Plum and Orchid. Leaf 5 of Album of Plum Blossoms. Private Collection, USA.

15.7a Zheng Xie, Orchids in a Pot. Yantai Museum. 328

15.7b Li Fangying, Orchids in a Broken Pot. Yangzhou Museum. 329

15.8a Li Shan, Bamboo. J. S. Elliott Collection, Princeton University Museum. 330

I5.8b Li Shan, Bamboo. Sichuan Museum. 330

I5.8c Li Shan, Bamboo. S. M. Nickerson Collection, The Art Institute, Chicago. 330

I5.8d Luo Pin, Bamboo. The Palace Museum, Beijing. 33I

15.9 Seals of Yibai shanren. (I) Li Fangying, (2) Li Shan, (3) Li Shan, (4) Li Shan, (5) Lin Gao.

15.IOa Gao Fenghan, Flowers, Tree and Rock. I749. Nanjing Museum. 334

I5.Iob Huang Shen, Chrysanthemum. I728. The Palace Museum, Beijing. 334

I5.IIa Li Fangying, Flowers. I746. Shoudu Museum, Beijing. 335

I5.IIb Gao Fenghan, Splendid Peonies. 1736. Collection of Juanqin Zhai. 335

15.12a Li Shan, Charcoal, Pine and Bamboo. 1736. Association of the Artists of China.

15.12b Li Shan, New Year Offerings. 1736. Fine Arts Museum, The Chinese University of Hong Kong.

15.13a Gao Fenghan, Lotus Offerings. I739. The Palace Museum, Beijing. 338

15.13b Huang Shen, Plum Blossoms in Vase. Collection unknown. 338

15.I4a Li Shan, Silkworms and Mulberry. A leaf from the Flower Album, 1753. Liaoning Provincial Museum.

15.I4b Li Shan, Silkworms and Mulberry. A leaf from the Flower Album, I740. The Palace Museum, Beijing. 340

I5.15 Jin Nong, Jade Teapot in Spring. 176I. Nanjing Museum. 
I6.I Hua Yan, Camel in Snow. I746. The Palace Museum, Beijing. 348

I6.2 Hua Yan, Camel in Snow, detail.

I6.3a-b Attributed to G. Castiglione, J.-D. Attiret, I. Sichelbarth and Chinese court painters, Imperial Banquet in the Garden of Ten Thousand Trees. I755. The Palace Museum, Beijing. Sections on the left and on the right. 350-35I

I6.4 Figure. A woodblock print from Sancai tuhui I3:I4a.

16.5 Hua Yan, Tian Mountain under the Snow. I755. The Palace Museum, Beijing.

I6.6 Liu Guandao, Khubilai Khan Hunting. I280. The National Palace Museum, Taibei.

I6.7 G. Castiglione, Xuediandiao from Pictures of Ten Thoroughbreds. 1743. The National Palace Museum, Taibei.

16.8 Surprise Assault on a Mountain Encampment, from the series The Pacification of the Western Regions. 1773. Copper plate engraving. The National Palace Museum, Taibei.

I6.9 G. Castiglione, Laiyuanliu from Four Afghan Horses. I763. The National Palace Museum, Taibei (section 2).

I6.Io Figure. A woodblock print from Sancai tuhui I4:22a. 362

I6.II Hua Yan, Tian Mountain under the Snow, detail.

I6.I2 Gao Fenghan, Ye Fanglin, and Zhang Heng, Leaving for the Frontier. I740. Palace Museum, Beijing.

I7.I Huang Shen, Zhong Kui, the Demon Queller. I73I. Nanjing Museum. 377

I7.2 Huang Shen, Climbing Xiaogu Mountain. I74O. Ji'nan Municipal Museum. 378

17.3 Huang Shen, Mooring at Hukou through the Night. I729. Museum Rietberg, Zürich.

17.4 Huang Shen, Strolling in Xiangcheng Mountain. 1729. Museum Rietberg, Zürich.

17.5 Huang Shen, Sightseeing in Qiuping Pavilion. I729. Museum Rietberg, Zürich.

I7.6 Huang Shen, Songmen Mountain. 1734. Guangdong Provincial Museum. 38I

I7.7 Huang Shen, Jiangnan Scene. I734. Guangdong Provincial Museum. 38I

I7.9 Huang Shen, Landscape Album. 1738. Sen-oku Hakko kan Museum, Kyoto. 383

I7.8 Huang Shen, Landscape Album. I735. The Palace Museum, Beijing. 383

I7.Io Huang Shen, Landscape Album. I735. The Palace Museum, Beijing. $\quad 384$

I7.II Huang Shen, Landscape Album. 1737. Guangdong Provincial Museum. $\quad 385$

I7.12 Huang Shen, Landscape Album. 1737. Guangdong Provincial Museum. $\quad 386$ 
17.13 Huang Shen, Jiaohu in Autumn. I740. Ji'nan Municipal Museum. $\quad 387$

I7.I4 Huang Shen, Overlooking Yangziji. I740. Ji'nan Municipal Museum . $\quad 387$

17.15 Huang Shen, Landscape Album. I755. Leaf I. San Diego Museum of Art. 388

I7.16 Huang Shen, Landscape Album. 1755. Leaf 2. San Diego Museum of Art. 389

17.17 Huang Shen, Landscape Album. I755. Leaf 5. San Diego Museum of Art. 390

17.18 Huang Shen, Landscape Album. I755. Leaf 7. San Diego Museum of Art. 39I

17.19 Huang Shen, Landscape Album. I755. Leaf 3. San Diego Museum of Art. 392

17.20 Huang Shen, Landscape Album. I755. Leaf io. San Diego Museum of Art. 393

I7.21 Huang Shen, Landscape Album. I755. Leaf 6. San Diego Museum of Art. 395

17.22 Huang Shen, Landscape Album. I755. Leaf 9. San Diego Museum of Art. 396

17.23 Huang Shen, Landscape Album. 1755. Leaf 8. San Diego Museum of Art. 397

17.24 Huang Shen, Landscape Album. I755. Leaf 4. San Diego Museum of Art. 398

I8.I Jin Nong, Sakyamuni. I760. Tianjin Museum. 406

18.2 Liang Kai, Sakyamuni Descending the Mountain after Asceticism. Tokyo National Museum. $\quad 408$

I8.3 Jin Nong, Banana Tree and Buddhist Figure. Undated. Shanghai Museum. 4I2

18.4 Jin Nong, Figure and Landscape Album. I759. Leaf 2. The Palace Museum, Beijing.

18.5 Hua Yan, A Duck Bathing in an Expanse of Peaches. 1742. The Palace Museum, Beijing.

18.6 Hua Yan, Bird and Flower Album. I742. Leaf 7. Shanghai Museum. $\quad 424$

18.7 Hua Yan, Bird and Flower Album. 1742. Leaf 8. Shanghai Museum. $\quad 426$

18.8 Hua Yan, Bird and Flower Album. I742. Leaf 2. Shanghai Museum. $\quad 428$

\section{TABLES}

8.I Dating of the Yuhua xiang and Tongtian le stories. I6I

8.2 Sites mentioned in the Yuhua xiang and Tongtian le stories. $\quad$ I65

I2.I The School of Western Han. 250

I2.2 Wu School of Three Kingdoms. 258 



\section{Preface}

T n the spring of 2003 a scholarly network, called 'Yangzhou Club', was established 1 on the website of 'Chinese Storytelling' www.shuoshu.org by the editors of the present volume, who had both been engaged in Yangzhou studies for many years. The 'Club' was to serve as a cross-disciplinary platform for scholarly exchange and cooperation. The first activity of this network was the organization of an international workshop, Lifestyle and Entertainment in Yangzhou, where researchers from East and West gathered from 20-22 October 2005 in a dialogue on life and art in the old cultural town of Yangzhou.

With support from the Norwegian Research Council and the Nordic Institute of Asian Studies it became possible to arrange the workshop in Yangzhou. We collaborated with colleagues and friends from Yangzhou, the local co-organizers of the event, Fei Li 費力, long-time leader of the storyteller's organization in Yangzhou, who also contributed a chapter to this volume, and Huang Ying 黄瑛, of Yangzhou University, who offered extraordinary help with all the local arrangements and further translated the chapter by Fei Li into English. We were also very happy to have a highly qualified guide, Wu Wen 吳雯, at our side throughout the conference.

The workshop was mainly concerned with the pre-modern and modern period from the Qing dynasty to our present time, and it attracted the interest of the foremost international scholars in the field from Asia, Australia, Europe and the USA, covering a well-balanced spectrum of topics. The academic fields included history, garden aesthetics, book printing, literature, traditional theatre, oral literature and painting. Yangzhou storytellers, storysingers and actors were invited as active participants in the workshop, and their performances formed an integrated part of the scholarly program.

One of the special ideas of the workshop was that the participants should not only discuss but also experience traditional 'lifestyle and entertainment in Yangzhou'. The proceedings were held in situ, not only in order to emphasize the city's physical and cultural resources, but also to offer the participants the special atmosphere of being together in the very places where the topics of our research belonged. Each panel, session and activity took place in the physical settings most appropriate to the contents. For example, the panel about Yangzhou history was held in the former mansion of one of the famous salt merchants of Yangzhou, the Wang Family 
Mansion, Wangshixiaoyuan 汪氏小苑; the session on local publishing was held at the Guangling Historical Printing House, Guangling guji keyinshe 廣陵古籍刻印社; the discussion of Yangzhou performance traditions took place in the open theatre on the lake of the He Family Garden, He yuan 何園; the discussion about Yangzhou garden architecture took place in one of the halls of the Bamboo Garden, Ge yuan 个園. In addition we were welcomed by the brand-new and magnificent Yangzhou Double Museum, Shuangbowuguan 雙博物館, where we could enjoy the original paintings and other artefacts.

Over the course of the three-day workshop, participants were treated to a broad assortment of performances and experiences of the local culture. A visit to the storyteller's house Daguangming shuchang 大光明書場, where the participants mingled with the local audience, was combined with a walk in the alleys and lanes of the old city. One evening was devoted to a dinner-party with twelve local scholars; another took place in the company of storytellers and storysingers. Gao Zaihua 高再華 of the Kang School of Yangzhou storytelling performed from the Three Kingdoms; Ren Dekun 任德坤 and Ma Xiaolong 馬曉龍 of the Wang School performed from Water Margin. The storysingers Shen Zhifeng 沈志鳳 and Xu Guiqing 徐桂清 gave a sampling of Yangzhou storysinging. There was a trip to local opera in the neighbouring Ganquan county, as well as outings organized especially for the workshop, such as a boat-trip on the Slender West Lake with a troupe of Yangzhou ballad singers, where some of the famous singers of this tradition, Zhan Guozhang 詹國章 and Nie Feng 聶峰, performed. As our two boats, rowed in the traditional way by Yangzhou girls, arrived midstream, we were passed by flower boats with small operatic troupes singing arias as entertainment for the general public along the shores of the lake and in the boats. Arriving at the pier of the Daming Temple, Daming si 大明寺, the rowing girls on their own initiative sang some of their work-songs, letting us experience a singing technique and atmosphere so very different from the professional tradition of ballad and opera. On the initiative of Lindy Li Mark from among the workshop participants and Josh Stenberg of the Jiangsu Province Kun Opera, Jiangsu sheng Kunju yuan 江蘇省崑劇院, a visit to Nanjing was arranged the day after the workshop, where the participants were invited by the Kunqu Troupe to see a special selection of scenes from their repertoire, namely Kunqu scenes where Yangzhou dialect is used by the humoristic roles.

The present volume is a result of this workshop, and we think of it as the second activity of the Yangzhou Club. We wish to express our deepest appreciation to the friends in Yangzhou without whose strong engagement and indispensable help the project could not have been envisaged, much less carried through in such an enchanting atmosphere. We are also much in debt to Iva Zemanová, from Palacký University, who gave excellent assistance in the preparation of the general list of References. Our sincere thanks are also due to the foundations who have given generous 
support for the workshop and the book: The Norwegian Research Council, Oslo, the Nordic Institute of Asian Studies, Copenhagen, and the Chiang Ching-kuo Foundation, Taibei.

Since most of the contributors (ourselves included) are not native English speakers, we knew at an early point that we would need help in this respect. Malcolm McKinnon during our meeting in 2005 promised to help with the manuscript, and we felt much reassured. Malcolm's editing has meant considerable linguistic improvement, but more than that: his incisive textual criticism gave a clarity and finish to most of the chapters for which we are extremely grateful.

Vibeke Børdahl and Lucie B. Olivová

Oslo and Prague

As the book is about to go to the press we have received the sad message that Yi-li Kao, born Is April 1974, passed away on Io March. A gifted scholar of Chinese art, she joined the Yangzhou Club and took part in our workshop in Yangzhou 2005. Then only 3I years old, she was the youngest of us all. Her husband Mark Wang wrote to us: 'The next time you are opening a long Chinese scroll painting or calligraphy, please think of Yi-li and she will smile.' In this spirit we dedicate Lifestyle and Entertainment in Yangzhou to her memory with friendship and love.

V.B. and L.O. 24 March 2009 



\section{Contributors}

Roland Altenburger, Department of Sinology, Institute of East Asian Studies, University of Zürich, Switzerland

Vibeke Børdahl, Nordic Institute of Asian Studies, Copenhagen, Denmark

J. S. Edgren, Chinese Rare Books Project, Princeton University, Princeton, USA

Fei Li, Society of Yangzhou Performed Literature, Yangzhou quyi xiehui, Yangzhou, China

Antonia Finnane, Department of History, University of Melbourne, Victoria, Australia

Věna Hrdličková, Department of East Asia, Charles University, Prague, Czech Republic

Ginger Cheng-chi Hsü, Department of History of Art, University of California, Riverside, USA

Yi-li Kao, San Diego Museum of Art, San Diego, California, USA

Stefan Kuzay, Institute for Asian and African Languages and Cultures, University of Helsinki, Finland

Li Hsiao-t'i, Institute of History and Philology, Academia Sinica, Taibei, Taiwan

Kristen Loring, Department of Art History, University of California, Los Angeles, USA

Colin Mackerras, Department of International Business and Asian Studies, Griffith University, Queensland, Australia

Lindy Li Mark, Department of Anthropology, California State University, Hayward, USA

Malcolm McKinnon, School of History, Philosophy, Political Science and International Relations, Victoria University of Wellington, New Zealand

Tobie Meyer-Fong, Department of History, Johns Hopkins University, Baltimore, Maryland, USA

Lucie B. Olivová, Department of Asian Studies, Palacký University, Olomouc, Czech Republic

Margaret B. Wan, Department of Languages and Literature, University of Utah, Salt Lake City, Utah, USA

Zhuang Sue, Department of Arts, Taibei National University of the Arts, Guandu, Taiwan 



\section{Introduction}

\section{Lucie B. Olivová and Vibeke Børdahl}

7 he volume you are holding originated in the international workshop, Lifestyle 1 and Entertainment in Yangzhou, held in October 2005 in that very city, one of the most important centers of traditional culture in China. The workshop engaged participants from many different places in a dialogue on oral and visual arts, history and literature, covering mainly the pre-modern and modern periods, from the Qing dynasty to our present time. From the late seventeenth century for around 150 years, Yangzhou was a striking example of economic vitality which in turn underpinned an extraordinary intellectual productivity and artistic creativity. It was a city where the worlds of merchants and scholars merged to set new standards of taste and to create a rich cultural milieu in many ways contrasting with that of other major cities in the region. Yet the rhythm of life, habits and customs, as well as spiritual engagement, remained deeply grounded in the local lifestyle, and persisted through the nineteenth century when rise gave way to decline - a development which has continued to prompt debate well beyond these pages.

While the book does not presume to provide a complete survey of the many traditions and arts of Yangzhou, it does open the door to a wealth of them. In eighteen chapters we bring together authors of three generations, from thirty to eighty years of age, including pioneers of studies related to Yangzhou. The contributors come from different disciplines and use different research methods. Thus a variety of approaches are represented, with a view to expanding and diversifying the picture of Yangzhou culture.

The chapters are grouped into four parts: I, City of Sights, with five chapters about the urban history and material culture; II, Books and Literature, with four chapters about the printing culture and literature; III, Performance and Entertainment, with five chapters about the theatrical and storytelling arts and teahouse entertainment; and IV, Yangzhou School of Painting, with four chapters which analyze selected works of some of the famous 'eccentric' masters.

In the first chapter of Part I, Lucie B. Olivová ponders questions of traditional and modern urban planning. She provides an overview of the historical development of Yangzhou, while setting the remembrance of the past against the city's preservation as it can be observed today. In the following chapters the town's lifestyle in former times is discussed. In Chapter 2 Tobie Meyer-Fong explores the role of social gather- 
ing and individual memory from the diaries of those who lived through the Taiping seizure and occupation of Yangzhou during the 1850s. In a different vein, Antonia Finnane, in Chapter 3, details local clothing fashions through three centuries, using luxury consumption habits as a criterion of the city's stagnation on one side, and modernity on the other. Chapter 4 by Věna Hrdličková is devoted to the art of Yangzhou residential gardens, their aesthetic conceptions and characteristic features, drawing on old written sources as well as the surviving examples. In Chapter 5, Malcolm McKinnon takes up a challenging topic when he looks - with a traveler's eye, as it were - for some of the roots of Shanghai's modernity in a seemingly traditional and decaying Yangzhou.

In Part II, J. S. Edgren's opening Chapter 6 demonstrates, among other things, the long history of fine printing in the Yangzhou prefecture and the unique contribution of Yangzhou printers to the imperial publishing projects of the middle Qing period. The chapters which follow all depict Yangzhou as a setting for literary endeavor. In Chapter 7, Li Hsiao-t' i 李孝悌 revives the particular social and political milieu in which the renowned poet-official Wang Shizhen conducted his literary activities while serving as a prefect of Yangzhou in the middle of the seventeenth century. Chapter 8 by Roland Altenburger introduces a body of Yangzhou narratives by a local author Shi Chengjin (1660-ca 1739), demonstrating that these vernacular vignettes were not intended as a regionalist literary project, but nevertheless contain a wealth of information on the city's social history. In Chapter 9, Margaret B. Wan explores the concept of the 'local novel' as exemplified by the so-called 'storyteller' novel Qingfengzha [Qingfeng Sluice] (1819), seeing this narrative with its widespread use of dialect as an alternative to national bestsellers for the less affluent, rural and small city 'natives.'

Part III deals with performance and entertainment, opening with two chapters about theatrical styles high and low. In Chapter 10, Colin Mackerras studies patrons and audiences, demonstrating the significance of private sponsorship of Yangzhou theatre troupes and the nationwide success of certain theatre stars during the eighteenth century. In Chapter 11, Lindy Li Mark scrutinizes the performance and plays of Kunqu, a supra-regional elite variety of theatre that once had a leading role in Yangzhou entertainment. One of the interesting influences from Yangzhou on this genre is the occasional use of Yangzhou vernacular dialect alongside Suzhou vernacular dialect in the comic roles. The three chapters which follow all explore storytelling and the teahouse milieu in which it took place. In Chapter 12, Vibeke Børdahl discusses the role of written notebooks or 'scripts' for the oral transmission and performance of Yangzhou storytelling, Yangzhou pinghua. What kind of language style do extant scripts from the late Qing and early Republican period reflect? How do they compare to performances of corresponding episodes as recorded during the last decade? In Chapter 13, Fei Li 費力, a researcher but also a former 
storyteller, describes the performance sites - Yangzhou's storytelling houses - as they functioned in his childhood and youth, and how they later changed. Chapter 14 by Stefan Kuzay provides a first-hand view of teahouse and courtesan culture as reflected in a rare collection of popular songbooks, acquired by a Finnish diplomat in the Lower Yangzi valley around the turn of the twentieth century.

Part IV, on the fine arts, concentrates on the so-called Yangzhou eccentrics, the eighteenth-century artists who later came to set aesthetic standards for the entire field of modern Chinese painting. In Chapter 15, Zhuang Sue 莊素娥 scrutinizes one of the chief problems concerning the study of the 'eccentrics,' that of the existence of numerous forgeries. She brings up examples of genuine, forged and ghost-made paintings, and presents an eight-point check-list for detecting fakes. In Chapter 16, Ginger Cheng-chi Hsü traces the quest for 'exotic scenery' on the 'new frontier,' not only in Hua Yan's paintings of camels, but more broadly as an expression of both a collective trend in eighteenth-century society and of the Qing expansion into northern and western regions. In Chapter 17, Yi-li Kao analyzes three surviving albums of the Jiangnan landscape by Huang Shen, an artist in fact most renowned as a figurative painter. Finally, the novel approach of Jin Nong and Hua Yan to Buddhist imagery, using contemporary styles and hinting at historic allusions, is at the center of Kristen E. Loring's Chapter 18.

With such multiple perspectives, Lifestyle and Entertainment in Yangzhou conveys a kaleidoscopic view of the city as a site of leisure and play, combined with rich insights into the political, social and physical history of the region. It tells how these arts were practiced and enjoyed, and how they were experienced by people from Yangzhou itself, as well as observed by people from a distance. Far from being a standard narrowly-defined academic project, the book is a collaborative enterprise that has resulted in a collection of essays each of which adds details and considerations that enrich the whole. It is our hope that these pages will prove useful for those who are curious about this place in China - Yangzhou - and will provide a nuanced understanding of its culture then and now. 



\section{Part I}

\section{City of Sights}





\section{1}

\section{Building History and the}

\section{Preservation of Yangzhou}

\section{Lucie B. Olivová}

W ithout hesitation, Yangzhou 揚州 is considered a beautiful town. Its beauty has many facets: its setting, with the many waterways; the atmosphere of the densely built-up areas; the individual buildings: and, last but not least, the treasury of local culture, past and present, ranging from painting and lacquerware to performing arts and cuisine. As this list suggests, Yangzhou is admired for material as well as spiritual reasons. The genius loci is particularly strong in this town, and continues to attract and excite visitors. The remembrance of the past reaches into the remote times when the emperor Sui Yangdi 隋煬帝 or the Tang poet Du Mu 杜牧 stayed here. The vivid character their ways of life gave to Yangzhou came to be seen, rightfully or not, to be of its essence. There are a number of other historical figures whose fame is semi-legendary: the monk Jianzhen 堅貞, the essayist Ouyang Xiu 歐 陽修, the poet Su Dongpo 蘇東坡, the merchant Marco Polo, the calligrapher Zheng Banqiao 鄭板橋. ${ }^{1}$ Old poems about Yangzhou are recited or read, and the validity of what they say is never challenged, in spite of the centuries and many events which separate the Yangzhou of their times from the present.

In contrast to the historical imagination, the historical built-up space is quite tangible. When inspecting what has been preserved of the town's built legacy, one realizes that most of the 'historical' town structures are relatively new, dating from the late Qing and Republican eras. Not too many older monuments have survived. It would be naive, for example, to look for the famous gardens described in the late eighteenth century work Yangzhou huafang $l u$ 揚州畫舫銶 [Pleasure Boats of Yangzhou]. Gardens are, by their very nature, rather fragile and without constant care they become dilapidated within a few years. Destruction caused by natural calamities or war, decay and new construction in the times of economic growth can all endanger the built heritage. Yangzhou certainly experienced destruction, and we shall look into who was responsible. The Qianlong 乾隆 period (1736-1795) saw a great deal of building, but after that time development was relatively limited. The deterioration in the economy did not favor big building projects, and this, ironically, helped Yangzhou protect its heritage and the magical atmosphere that it evoked. After the birth of a new China, however, urban development and reconstruction 
were carried out periodically, usually without consultation. Some old structures were demolished, to be rebuilt in a distinct new way. Subsequently, the government decreed the protection and preservation of selected monuments and sites. With these elements in mind, this chapter will examine the shaping of historic Yangzhou into the city we know today.

\section{THE EARLY BUILDING HISTORY}

The simplified historical survey ${ }^{2}$ that follows highlights changes in the location and layout of the town, which were prompted by war and the attendant destruction on the one hand, and the impact of the Grand Canal on the other. Chinese culture is often seen to be characterized by persistence, and city layout is cited as a phenomenon which has remained unchanged in the course of centuries. In fact, while the
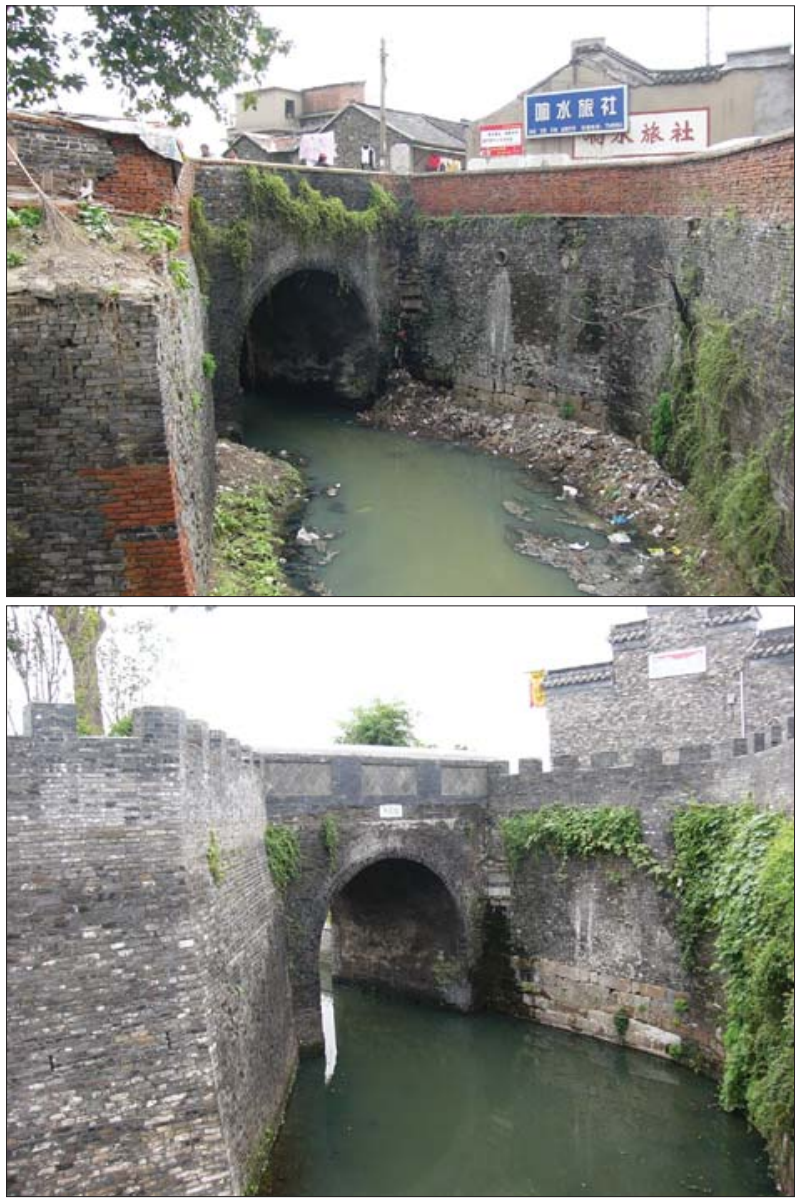

Figure 1.1 Southern Gate (Nanmen 南門), state before (2005) and after the restoration (2007). Note the crenelated walls, and alteration of the background houses. Photo by Lucie B. Olivová. 
archaeological evidence of actual towns and surviving examples from the time of the Ming dynasty on prove that the standard form and layout is found in some administrative centres (mostly capital cities), the majority of walled towns (Yangzhou being one of them) had layouts which diverged from the ideal.

Yangzhou is located in Jiangsu 江蘇 province, north of the Yangzi 揚子. To the east lies flat land, to the northwest rises the Shugang 蜀崗 ridge. The origins of Yangzhou go back to the Warring states period, when Fu Chai 夫差, the king of Wu 吳 (r. 495-473 BC), founded a fortress on the slopes of the Shugang ridge, at a safe distance from the waters of the Yangzi River, and had the Hangou 干阝溝 canal built. In 319 BC, under the administration of Chu 楚, the dowry town ( $y i$ 邑) of Guangling 廣陵 was built, lasting through the Han dynasty until early in the period of disunion; fifteen out of its sixteen ruling Han princes were buried near Guangling. ${ }^{3}$ In AD $45 \mathrm{I}$ and 459 Guangling was destroyed. ${ }^{4}$ Bao Zhao's 鮑照 Rhapsody of city overgrown with weed (Wucheng $f u$ 無城賦) describes the disaster; hence Wucheng became a toponym used by writers and poets in the following centuries, although it has never been an official name for the city. The second destruction was inflicted in 548 by the imperial army trying to suppress the notorious warrior Hou Jing 侯景 who had rebelled against the Liang dynasty.

Yangzhou's first era of prominence came with the Sui dynasty. In 587, a new canal was built. Yang Guang 楊廣, then the emperor's son, was stationed here in 589. He renamed the town Jiangdu 江都, the 'City on the River,' and further developed it. During his next stay in 605, he had the Hangou canal reconstructed, and a palace built. As the emperor Yangdi 煬帝, he fled there in 6I8, only to be murdered by his own guards. ${ }^{5}$ Under the Tang dynasty, three districts were administered from Yangzhou, ${ }^{6}$ and the region had approximately 460,000 inhabitants (Wu Zihui 200I: 222). In 1987, exploration of the city walls revealed that the Tang city was made of two walled urban units: zicheng 子城 (also yacheng 牙城) in the north near Shugang, on the site of the former Han fortress Guangling, and luocheng 羅城 (also dacheng 大城) to the south-east. The latter occupied a larger, oblong area. The units were divided by a wall and the newly built Guanhe 官河 canal, running from west to east. Yangzhou therefore did not quite meet the criteria of the ideal Chinese city with a regular concentric layout, based on ancient cosmology. The shift of the original settlement area was caused by the construction of the Grand Canal, Da yunhe 大 運河, the key waterway which has kept drawing the town to itself ever since. After the mid-Tang, when the imperial capital moved from Shaanxi 陝西 to the east, and therefore closer to Yangzhou, trade began to flourish in the city. The office of transport commissioner, Jiang Huai zhuanyun shi 江淮轉運使, was established here to expedite the transport of tax grain through the Grand Canal. Overseas goods were traded by Persians, of whom there was a community in Yangzhou, while the ninthcentury Arab geographer Ibn Kherdadbeh regarded Yangzhou as one of the four 
greatest ports in China (Wu Jiaxing 1988: 5). Once the Tang dynasty fell, however, the town was repeatedly plundered in wars, commerce halted, waterways decayed to the extent that some could not be navigated and Guazhou 瓜州 took over the role of the main regional port. ${ }^{7}$

Perhaps the most interesting modification of the layout of Yangzhou occurred briefly in the late Song period, when it had three walled districts, two military and one commercial. Their layout is indicative of the recurrent tendency both to draw nearer to the Grand Canal and to protect the town from the north. They were not concentric, but were placed alongside each other on an imaginary southeast to northwest diagonal. The largest one, known as Song dacheng 宋大城, was the town proper. It had been walled already in 908 under the Latter Zhou 後周, along the existing canals. The two smaller northern districts were garrisons. The so-called baosai cheng 寶塞城 was founded in II68, on the site of the former Tang fortress, following the Jurchen destruction of II29. ${ }^{8}$ The other northern garrison called jiacheng 夾城 was built much later, in I255, in the closing years of the Southern Song dynasty, when Mongol expansion was being felt. Finally in I269 a fourth fortress, pucheng 固城, was built at the Level Mountain Hall, Pingshan tang 平山堂. However, the fortresses were never used, since Yangzhou capitulated to the Mongols without fighting in 1276 . The northern districts of the former triple or quadruple town were not maintained; only the town proper, i.e. the south district, had its walls rebuilt. Marco Polo mentions the Yuan dynasty fortifications, the perimeter of which measured ca $5.3 \mathrm{~km}$. (Fig. I.I.)

Yangzhou experienced economic recovery under the Yuan dynasty. Shipping docks were established, as also in Ganzhou 贑州 and Quanzhou 泉州, to build vessels for the campaign against Japan, and from I277 Yangzhou hosted the salt transport administration, Liang Huai du zhuanyunyan shisi 兩淮都轉運鹽使司 (Wu Jiaxing I988: $85)$ ?

Wars at the end of the Yuan dynasty drastically reduced the population. ${ }^{10}$ Reconstructed city walls protected only the south-west section of the former Song dacheng. Canals leading to the Grand Canal were silted, and transport was interrupted until the sixteenth century. By then, the population had increased again, and the relatively small walled area had gradually outgrown the eastern city wall in the direction of the Grand Canal-Yangzi River junction, which had developed in importance by mid-Ming times. In consequence, the port of Yangzhou regained its former importance, with a trade in salt, grain, silk and cotton. In 1556, the newly populated eastern district was surrounded by a new city wall, to protect against pirates. ${ }^{11}$ Informally called the New Town, Xincheng 新城, it was separated from the Old Town, Jiucheng 舊城, by the existing eastern section of the city wall, which stood until the early twentieth century. Two main streets crossed the New Town from west to east, in continuation of the two main streets in the Old Town. Another two quasi- 
straight main streets penetrated almost the whole length of the New Town from north to south. In between these axes lay a fine web of lanes and back-alleys which did not follow the regular layout. The local density of population oscillated between 300 and 560 persons per hectare. Whereas the Old Town hosted institutions and offices, this New Town was essentially residential, commercial and recreational: here lay tea- and pleasure-houses (Zhongguo chengshi jianshe shi 1982: 105). ${ }^{12}$ In addition, a few spacious gardens were built outside the walls: in the reign of the Wanli 萬曆 emperor the prefect Wu Xiu 吳秀 built Meihua ling 梅花嶺; in late Ming times, the Zheng 鄭 brothers built Ying yuan 影園 and Xiu yuan 休園.

The collapse of the Ming dynasty brought another series of misfortunes. In June I644, the Ming general Gao Jie 高傑 laid siege to Yangzhou. A month later Shi Kefa 史克法, the chief commander resident in Nanjing 南京, agreed with Gao Jie to garrison Guazhou and made Yangzhou his own strategic base. As is well known, Shi Kefa refused to capitulate to the Manchus, who took Yangzhou on 20 May I645 and massacred its inhabitants. ${ }^{13}$ Historians assume that the ransacking and fire did not bring a total architectural destruction. The layout of the town was not changed; city walls were not demolished, though probably damaged, and within two years renovated (Meyer-Fong 2003a: 20). Records, if any, do not provide us with exact accounts of the damage inflicted in 1644 and 1645 , but give generalized statements of loss, e.g. a traveller in 1653 described Yangzhou as 'ruined. ${ }^{14}$ Nor is the reconstruction precisely recorded. The 1675 edition of the prefectural gazetteer has the earliest data; it makes mention of the construction of Wenxuan lou 文選樓 in $165 \mathrm{I}$ and the restoration of Pingshan tang in I674 (Meyer-Fong 2003a: 20, I33). The prefectural yamen 衙門 was renovated: it may have been destroyed in 1645 or may not have been. The dredging of the city canal was carried out in the early I690s (MEYER-Fong 2003a: 2I). The city elite gathered together the means to reconstruct famous sites which became the destinations for literary outings: the gatherings at Red Bridge, Hongqiao 紅橋 (also 虹橋, Rainbow Bridge) in 1662 and 1664, and their instigator, the prefect and poet Wang Shizhen 王士禎, was revered by the next generations. But the revival of Yangzhou was not obvious until the turn of the century, which opened the long and prosperous eighteenth century of peace and stability.

\section{THE GOLDEN AGE}

Under Qing rule, Yangzhou became a major administrative centre. The Yangzhou prefecture, $f u$ 府, was one of the nine prefectures of Jiangsu province, as under the previous dynasty, but it had more authority. ${ }^{15}$ Among the lower administrative institutions it supervised, the offices (yamen) of Jiangdu and Ganquan counties were stationed in the Old and New Towns, respectively. Next, the headquarters of the Liang Huai salt control, Liang Huai du zhuanyunyan shisishu 兩淮都轉運鹽使司署 
(abbreviated as yanyun shisishu 鹽運使司署) were located in the New Town, and the office of Liang Huai salt censor, yanzheng 鹽政 (formerly xunyan yushi 巡鹽禦史), was located in the Old Town. ${ }^{16}$ There also was the post, guanyi 舘驛; the Jiangdu county college, xianxue 縣學; the Jiangdu granary, xianji gucang 縣級穀倉; and a number of other official entities. The proliferation of offices brought petitioners and business people into the town. Notable amongst the latter were salt merchants from Huizhou 惠州 and other places (Jiangxi 江西, Hu Guang 湖廣, Guangdong 廣東), who then became 'the dominant economic force and the social elite' (FInNANe 2004: I73). Their patronage of arts and education, sponsorship of learning, support for social relief or public building brought Yangzhou to its economic and cultural zenith.

Developments prompted by the Kangxi 康熙 emperor's visits to Yangzhou signalled a new era of growth. ${ }^{17}$ His southern tours, nanxun 南巡, were meant to be inspections, with tax relief and water conservancy the principal issues to be addressed, but locals greeted the ruler with much splendor. For Kangxi's stay in Yangzhou in I705, a travel lodge xinggong 行宮 was built in the monastery Gaomin si 高旻寺, on an island in the Southern Canal, Nanhe 南河. His visits also gave a boost to new cultural enterprises, such as the establishment of a printing house on the grounds of the town's biggest monastery, Tianning $s i$ 天寧寺. Its series of major publications was opened with Quan Tang shi 全唐詩 [Complete Collection of Tang Poems] in I707.

Such developments passed unnoticed in the eyes of regular visitors, however. The future advisor of the Qianlong emperor Sun Jiagan 孫嘉洤, wrote - in the closing years of the Kangxi reign - this about Yangzhou:

There is nothing to see in the town. The Sui Labyrinth and the Twenty-Four Bridge are gone; the Daoist Temple of Agate Blossoms, Qionghua guan 璸 花觀, lies in ruins. North of the city is the Tianning Monastery, once the retreat of Xie Dongshan 謝東山 (Xie An 謝安 of Eastern Jin 晉 dynasty). In the western part of that monastery lies the Apricot Garden. There I stayed, in monks' apartments. Bamboos and trees grow in the Apricot Garden and it is endowed with fragrance and solitude. Looking from the terrace into the clear, deep pond, I imagined the elegant ways of Wang [Xizhi] 王羲之 and Xie [An]. To the east of the Apricot Garden is the Rainbow Bridge, with pavilions set in orderly fashion along the water's edge. Travellers equipped with wine like to go by boat further north, to the Shugang ridge, where Ouyang Wenzhong 歐陽 文忠 (Ouyang Xiu) built the Level Mountain Hall. To the right of the Apricot Garden is the High Sky Monastery, Gaomin si, with a well. When Zhang Youxin 張友新 wrote his book about tea, he ranked the water from that well as the fifth best in the Yangzi region.

(Quoted from Gu Yiping 1989: 2I $)^{18}$

Sun Jiagan recorded these impressions in his Record of a journey to the South, Nanyou $j i$ 南遊記, in I72I. Obviously, he was familiar with the poetic memories with which 
Yangzhou had been endowed, and searched for historical symbolic sites, for example one of the Sui palaces, which had been immortalized in Rhapsody about the Labyrinth, Milou fu 迷樓賦, by the Song poet Li Gang 李綱. But the labyrinth was long gone, and indeed later in the Song dynasty was replaced by a Buddhist temple ( $Z_{\text {HaO }}$ Weihang I99I: I70). The Twenty-Four Bridge was said to have been built by the emperor Sui Yangdi, and had inspired many poems, including one by $\mathrm{Du} \mathrm{Mu}$. The history of the Agate Blossoms Temple can be traced back to the Han dynasty, and that of the Level Mountain Hall, Pingshan tang, to the year I048. Sun Jiagan must have found it in a good condition, though, after the relatively recent visit of the emperor in $1705 .{ }^{19}$ His disappointment was subjective; he ached for a cultural legacy which belonged to antiquity and could hardly be sated by a boat trip from the Rainbow Bridge to Pingshan tang, for a visitor like him the only attraction in Yangzhou at that time.

Qianlong's twelve visits to Yangzhou in the second half of the eighteenth century ${ }^{20}$ led to fundamental change, prompting building and re-decorating on a massive scale. Corvée labourers built the Imperial Pier, Yu matou 禦碼頭, the paved Imperial Road, $Y u$ dao 禦道, and the Travel Lodge with the Imperial Garden, Yu huayuan 禦 花園, the latter two both at Tianning si. In I782, when the Siku quanshu 四庫全書 [Complete Library of the Four Treasuries] project was completed, a suitable building in that garden was renamed Wenhui ge 文匯閣, and adapted to be the repository of one of the three Siku quanshu sets sent to Jiangnan 江南. $^{21}$ In a distinctive gesture suggestive of the true meaning of loyalty, in 1772 Qianlong ordered the grave of the general Shi Kefa - reportedly already overgrown in 1653 - to be restored and a memorial shrine to be erected, which would house Shi Kefa's portrait, a stone stele and a spirit tablet. ${ }^{22}$

Public funds were used for the above-mentioned works, yet significantly, the imperial presence also prompted private building. Where the emperor trod, salt merchants followed. Many were rich enough to afford to engage in construction and to pursue a luxurious life. Not a few unreliable stories about their enormous wealth were recorded. ${ }^{23}$ Before long, the space between Tianning si and the Northern city gate was closely built up with rich houses. The Baozhang 保障 Canal had been repeatedly broadened, and finally, in expectation of the emperor's second visit in 1757 , the canal-turned-lake was renamed 'Slender West Lake,' Shou Xihu 瘦 西湖, after the West Lake at Hangzhou 杭州. Garden suburbs expanded along the route dredged from the Imperial pier to Pingshan tang. Half way, on an islet occupied by the Lianxing 蓮性 Temple, the exotic White Pagoda was erected. ${ }^{24}$ Together with the nearby Five Pavilions Bridge Wuting qiao 五亭橋 (also Lianhua qiao 蓮花僑), they obviously copied the Beihai 北海 lake in Beijing, which is also dominated by a White Pagoda and has a Five Dragons Pavilion, Wulong ting 五龍亭, built on the water. They reflected the desire to emulate the court style, the 'imperial Beijing fashion,' a desire that dominated Yangzhou at that time. 
It is slightly absurd that such an alien structure as the White Pagoda became Yangzhou's landmark.

The extravagant landscaping and structures were made to offer twenty-four scenic views to the emperor, but they would have never existed were there not rich owners who could rise to the challenge of his visits. Ambitious to host the emperor, landowners developed and redeveloped their gardens. In 1780 and again in 1784 , the Qianlong was duly hosted at Kangshan caotang 康山草堂, owned by Jiang Chun 江 春. ${ }^{25}$ Wealthy salt merchants like him were chiefly from Huizhou. Gardens which belonged to locals, tuzhu 土主, were usually smaller, and sometimes still commercially used, although they were gradually replaced with the 'display' gardens (Finnane 2004: 19I). By that time, gardens were the definitive symbol of Yangzhou. ${ }^{26}$ The heyday for the excessive construction of large residential gardens was the Qianlong era, especially the I750s and I76os. However, the term 'eight gardens of Yangzhou,' popular at the time, alluded to gardens on Baozhang lake created under Kangxi, when 'from outside the city wall, the rich and the powerful have built gardens and pavilions. ${ }^{27}$ In the mid-eighteenth century, outer gardens extended along the Slender West Lake as far as the foot of the Shugang ridge, whilst new gardens were mostly built in the south and west suburbs, whereas gardens inside the town were mostly built in the area of Nanhe xia 南河下[South canalside] Street in the New Town (ZHU Jiang 1990: 86). Not only were residences designed as gardens, but so also were official and public compounds such as regional halls, huiguan 會館, family temples, citang 祠堂, academies, shuyuan 書院, restaurants, brothels and spas.

The town began to overflow the city walls and waterways which delineated the urban core, a fact which attests to a secure environment. Gardens developed to the west, while commercial areas developed on the eastern side, which gave onto the Grand Canal and the Yangzi River. The heart of the city was found in the western part of the very densely populated New Town. Here were teahouses, storytellers' auditoriums, wine shops and other places of amusement. Its actual center became what had been the relatively spacious Parade Ground, Jiaochang 教場, after the barracks and training grounds, which used to occupy it, were relocated outside the western city wall in 1767 . The residents of the New Town were socially mixed, ranging from merchants and salt officials to artists who lived in the northwestern section of of this district (FInNAne 2004: 179). The area with brothels ran along the Xiao Qinhuai 小 秦淮 Canal; it was from its northern end that the pleasure boats embarked. ${ }^{28}$

This golden age of Yangzhou was immortalized by Li Dou 李斗 (?-18I7) in his book Yangzhou huafang lu, with illustrations which form the most complex pictorial record of Yangzhou gardens from that time. ${ }^{29}$ The book was written between 1764 and 1795 , when some of the richest men in China lived in and spent their money in Yangzhou. It imprinted Yangzhou with an identity typified by beautiful women, fine scenery, leisure and entertainment. Since Li Dou was there to portray it, and since 
his fascinating book became so popular and influential, we tend to view Yangzhou as it was described then, and understandably link Yangzhou's glory with the Qianlong era.

\section{WHEN DID YANGZHOU REALLY DECAY ?}

Li Dou's contemporary Shen Fu 沈復 was well aware that the wave of building and spending was transitory. At that time, he wrote, 'You'd more likely watch a dressedup beauty, than [a woman] washing laundry by a creek. I was fortunate to be here [in Yangzhou] when the Emperor came to the South . . . seeing so much splendour rarely happens in one's lifetime' (Fusheng liuji 浮生六記, quoted from Gu Yiping 1989: 35). But soon enough the tide ebbed. From the last decade of the Qianlong reign through the first quarter of the nineteenth century, corruption in the Yangzhou salt trade persisted, and the reforms adopted did not bring a sound solution. However, they diminished the number of Yangzhou salt merchants. The wealthiest ones began to leave, their households declined and their gardens were gradually abandoned (Finnane 2004: 30I-07). Along Nanhe xia Street, alternative regional associations, huiguan, were established to meet the needs of merchants of more limited means. ${ }^{30}$

It would be incorrect to assume that the overall condition in Yangzhou abruptly deteriorated. True, the desolate state of certain gardens, which used to be the town's chief attraction, could not escape the attention of visitors, and was lamented in travel diaries. On the other hand, the poet Gong Zizhen 龍自珍 visited Yangzhou repeatedly in the 1820 s and 30 , and found it a relatively wealthy place, pleasant and suitable for enjoyment (Gu Yiping 1989: 43-44; Kung Tzu-chen 1994: 418-22). New gardens were built during the nineteenth century, this time within the city walls; the city 'retreated into itself' and stopped growing in area (FINNANE 2004: 17, 210). But at the same time its population increased. In I772, Yangzhou prefecture had approximately 2,421,000 inhabitants; in I820, their number rose to 3,267,500. By one estimate, half of that population lived in Yangzhou itself (WU Zihui 200I: 224). Moreover, as ever, Yangzhou residents loved to spend money and enjoy themselves, though on a more modest scale. Crafts and storytelling still centred on the lively market Jiaochang, and the pleasure districts continued to flourish. Hanjiang sanbai yin 干江三百吟 [Three Hundred Tunes of River Han], Lin Sumen's 林蘇門 collection of songs, zhuzhici 竹枝詞 [bamboo-branch songs], about Yangzhou customs from I808, speaks of the many luxury items on sale: women's fashion and make-up, foods, fashionable Western goods. Yangzhou dictated fashion to the extent that women in Shanghai 上海 would choose between the Suzhou 蘓州 style and the Yangzhou style in the I84Os and early I850s (FINNANE 2004: 223).

Yangzhou was thus a place for consumers, but it also had sufficient substance, both material and scholarly, to nourish and develop learning. The remaining salt 
merchants, increasingly of local origin, continued to sponsor literature and science. For example, in 1794 the private Anding 安定 Academy, where scholars from the Yangzhou prefecture were trained, received donations from salt merchants, and enlarged its buildings (Ji Xiaofeng 1996: 40). Most notably, this was the epoch of the Yangzhou School of Learning, Yangzhou xuepai 揚州學派, an important movement whose pivotal figure was Ruan Yuan 阮 元 (I764-I849), a local scholar of humble origins. The movement favoured Song learning over that of the Han dynasty, combined historical and philological studies, and extended into the study of astronomy, mathematics, music and theatre. Interestingly, the Yangzhou scholars of this time often investigated subjects related to their region (FINNANE 2004: 265).

The Yangzhou of the the Jiaqing 嘉慶 reign (1796-1820) may have declined when compared to the previous century, but it remained opulent and populous. Its prosperity, however, depended on administrative structures and imperial patronage, and was mostly created by men of other than local origin. Although Yangzhou remained wealthy and attractive, the poverty of the surrounding rural regions which had no natural resources and no industry - not even a textile industry comparable to that of Suzhou and other Jiangnan towns - put its prosperity at risk. The beginning of the nineteenth century also coincided with a severe crisis in hydraulic management. Merchants were unable to provide the financial aid needed for the repair of dikes in 1805 , and a state subsidy was not available until I813. Moreover, in spite of the repair works, the hydraulic system and waterways collapsed during the Daoguang 道光 reign (I82I-I850). Famine spread through the rural areas and Yangzhou was periodically swamped with miserable refugees (FInNANE 2004: II, 170, 307).

\section{THE TAIPING STORM}

The foregoing indicates that for Yangzhou, the Jiaqing and Daoguang reigns were a period of transition, rather than of decline (Finnane 2004: 299). The ultimate destruction came suddenly, upon the arrival of the Taiping 太平 army in the region in $1853 .{ }^{31}$ Yangzhou was embroiled in the turmoil of war for many years, until the summer of 1864. The misery it endured produced a radical transformation, physical damage and destruction being accompanied by an irreversible loss of Yangzhou's primacy amongst Chinese cities. To understand the extent to which the cityscape of Yangzhou was utterly changed by the Taiping Rebellion, it might be useful to recapitulate the events of this period, even though this is somewhat of a digression. ${ }^{32}$ After a siege of eleven days, the Taiping forces took Nanjing on I9 March 1853. There they installed their 'Heavenly Capital,' Tianjing 天京, and then advanced toward the Grand Canal: grain transported along the canal had to supply Nanjing. Thus, Yizheng fell on 29 March, Guazhou on 3I March, and Yangzhou on I April I853 - the last defended in vain by 40,000 soldiers (RecLus 1972: 69). Shortly after, 
on I6 April, the imperial army led by Qishan 琦善 reached the suburbs of Yangzhou and established the Northern Camp, Jiangbei daying 江北大營, of 16,000 men, on the northern and western sides of the town (SHEN Jiarong, Jiang Zhiliang I993: 49-50). The Southern Camp, Jiangnan daying 江南大營, was established near the port of Pukou 浦 $\square$ west of Nanjing, under the command of Xiang Rong 向榮, whose troops had pursued the Taiping forces all the way from Guangxi. (The third imperial camp, near Zhenjiang, was destroyed in early July i853. Reclus 1972: I07.) Although the imperial camps harassed Taiping forces on the southern bank for three years, the Taiping army effectively controlled the junction of the Yangzi and the Grand Canal. Operating some Io,ooo junks, they were shipping grain from Zhenjiang and Yangzhou to supply Nanjing with provision (SHEN Jiarong, Jiang Zhiliang 1993: 44). The disruption of the region hampered imperial shipments of grain and salt, ${ }^{33}$ and so in June 1853 the Qing government experimentally levied a new tax on merchandise, lijin 嶅金, in ten counties of the Yangzhou prefecture (Hummel 1967: 438; SHEN Jiarong, Jiang Zhiliang 1993: 50).

Facing catastrophe, the inhabitants of occupied Yangzhou complied, and many posted the characters shun 順 or zun 尊 on doors to express submission (WANG Hong 2000: 4I; Finnane 2004: 308). ${ }^{34}$ The Taiping Order, Tianchao tianmu zhidu 天朝天目制 度, enforced as in any other occupied town, meant the abolition of trade, the segregation of men and women, the prohibition of opium, alcohol, gambling, bound feet and prostitution (SHEN Jiarong, JiAng Zhiliang I993: 25-28). A direct witness recorded that regulations concerning official management and production were imposed just as the Taipings had done in Nanjing. Those who refused to comply received smaller portions of food than 'brothers and sisters' (Luo Ergang I978: 279-80). Many people were displaced; those who could, fled the town; a number of those who stayed were either forced into the Taiping army, or taken to Nanjing as hostages. ${ }^{35}$ On 8 May I853, Li Kaifang 李開芳 and Lin Fengxiang 林鳳祥, the Taiping commanders of Yangzhou, set off for the Northern campaign ${ }^{36}$ taking a strong detachment of soldiers along. 'Nine tenths' of Yangzhou's inhabitants joined them, including boys over twelve or thirteen years of age (WANG Hong 2000: 4I), while parents, wives and small children went to Nanjing as hostages (RECLUS 1972: 69). ${ }^{37}$ The Taiping order partly paralyzed agricultural production; granaries had of course been looted. As a result, many more died of hunger, but also of infectious diseases. The losses were enormous, not just in Yangzhou but throughout the region, for example the town of Wuxi 無錫 had up to 340,000 inhabitants in 1830, but only 72,000 in 1865. An eyewitness who stayed in Yangzhou from February to July I853, and came back after the Taiping forces were gone, described the pitiful conditions in the town:

Casualties were mainly due to epidemics. There were not enough coffins, and so three or even five corpses had to be placed in a cotton sash and buried in one pit ... Temples and offices were full of corpses, even streets. When every plant 
was eaten, people boiled soils and leather bags ... During the occupation, Yangzhou was under siege, and no food could be imported into the town. When the Taipings left, only a few thousand stayed behind. The Imperial army had the city gates closed and did not allow anyone to pass. Consequently, more people died of hunger.

(Anonymous, Guangling shigao 廣陵史稿 [History of Guangling - A Draft]; quoted in Luo Ergang 1978: 275-76).

The Taipings left Yangzhou after nine months, during which 'Qishan fought desperately to regain the town' (Hummel i967: 7II). They left suddenly on 26 December 1853 , in reaction to a purge in the Taiping leadership (WANG Hong 2000: 4I), and Qishan entered Yangzhou the following day. As the author of Guangling shigao, cited above, recalled, the Qing return was marked by rape and violence, so that people regretted that they had not left with the Taipings. He added that Taiping occupants 'only' gathered riches and treasures, but Qishan set everything on fire (Luo Ergang 1978: 277-78).

After this reoccupation the only place on the northern bank of the Yangzi still occupied by the Taipings was Guazhou, the main port in that region. The Taipings continued to harass Yangzhou, while the imperial army continued to harass Guazhou (Teng 1971: 139). With Yangzhou freed, the imperial Northern Camp gradually relocated to the south. In a tactic aimed at recovering Guazhou, that city was encircled in 1855 by a forty-mile-long trench and earthern wall. In early April I856, the Taipings advanced and destroyed the wall; the imperial army retreated to the north (SHEN Jiarong, Jiang Zhiliang I993: 57).

The balance of forces reversed in favour of the Taipings in spring I856. They attacked the Northern Camp in the first days of April, and on the sth re-entered Yangzhou, taking a lot of grain and shipping it to the hinterland (WANG Hong 200I: 4I). This second occupation of Yangzhou lasted just twelve days; it seems that the Taipings' only object was the grain supplies (SHEN Jiarong, JIANG Zhiliang I993: 52). In May and June 1856 , the Taipings overcame the imperial Southern Camp, the forces of which had been demoralized by then (TENG 1966: I2I, n27; SHEN Jiarong, JIANG Zhiliang I993: 52) and retreated as far as Danyang 丹陽. ${ }^{38}$ The debilitation of the imperial camps in June 1856 opened the way for the advance of the Taipings to Jiangxi and Wuhan 武漢 (Shen Jiarong, Jiang Zhiliang 1993: 15). This was the major defeat of the imperial forces, when the military power of the Taipings had reached its zenith (TENG I97I: I39).

However, in August and September 1856, the Taiping leadership went through internal dissensions, the so-called Incident at the Heavenly Capital, Tianjing shibian天 京事變, which turned out to be the beginning of the end. In the remaining period I856I864 the Taiping posture was defensive not offensive (TENG I97I: I43). In Jiangsu, the 
Qing army re-established the Southern Camp near Nanjing, and the Northern Camp near Yangzhou in May I857. The latter had 15,000 soldiers, although the commander's post remained vacant. On 27 December I857 the imperial forces regained Zhenjiang and, finally, Guazhou, which had been occupied for four years and eight months; reportedly, the Taipings left Guazhou of their own free will (SHEN Jiarong, Jiang Zhiliang 1993: 57). The imperial forces of the Southern camp then encircled Nanjing in spring 1858, and regained Jiujiang 九江 after five years. The Taipings appointed a new leadership in August I858, with positive results, which affected Yangzhou. In September 1858 the troops of the both imperial camps were repeatedly beaten, the Northern camp was destroyed (SHEN Jiarong, JiAng Zhiliang 1993: 59), and on 27 or 29 September Pukou - the port west of Nanjing - was lost. The commander-in-chief of the Northern Camp Dexing'a 德興阿 took refuge in Yangzhou (Hummel 1967: 7II). The Taiping pursuers attacked Yangzhou and on 9 October 1858 occupied it for the third time. Again, they left after twelve days, and continued pursuing Dexing'a to Liuhe 六合, which fell on the 24th while Dexing' fled to safety in Guazhou (SHEN Jiarong, JiAng Zhiliang I993: 59). At this point, the morale of his imperial troops collapsed (Hummel 1967: 7II). Moreover, in November Zeng Guofan 曾国藩 and his Hunan Braves were defeated near Nanjing, in the battle of Sanhe 三河. By the end of 1858 , the Taiping positions in the Yangzhou region were again secure, and so they remained until at least 1862 . The city lay in the Taiping dominion, but was not itself re-occupied by the Taipings. They attacked it several times from their bases at Yizheng and Liuhe, with great losses on both sides. This happened, for example, in May I860, the Taipings attacking Yangzhou without success, although they had won control of Changzhou 常州 and Suzhou during the same campaign. In I863, with Nanjing under siege by the imperial army, the Taipings attacked Anjing 安景 and Yangzhou, hoping that their action would divert the imperial forces from Nanjing. They did not make gains and the plan had to be abandoned. In this part of China, the Taipings were finally defeated when they lost Nanjing on I9 July I864, and their king comitted suicide. For Yangzhou, the epilogue was played out on Io January I868 when a former Taiping commander Lai Wenguang 賴汶光 was defeated and captured near Yangzhou, and executed in the town (RECLUS 1972: 25I).

\section{REBUILDING ON THE RUINS}

For eleven years from I853 to I864 Yangzhou and its inhabitants had endured an unimaginable ordeal. The destruction was near total, only memories, if anything, were left. There is no systematic account of the damage. Jin Anqing 金安清, the salt commissioner in I853, wrote that 'the rebels wreaked havoc [in Yangzhou], and destroyed all the famous sites' (Meyer-Fong 2003a: 192). Some of the reputed sites, destroyed in that year, were: 
Ouyang $c i$ 歐陽祠 - the memorial hall of Ouyang Xiu in Pingshan tang. It was rebuilt by the salt commissioner Fang Junyi 方濬頣 in I879 (ZHAO Weihang I99I: 165).

Anding shuyuan 安定書院 - an academy founded in I662, renovated in I734 and enlarged in 1794. In I868, it was reinstalled in Dongguan 東關 Street (JI Xiaofeng 1996: 40). It fell into disuse after the abolition of imperial examinations.

Meihua shuyuan 梅花書院 - an academy built in $1734,{ }^{39}$ and rebuilt in I777. In I866, the academy was rebuilt at Dongguan Street, in I868 moved to Zuowei Street. In 1928 it became a state school; nowadays it is a primary school ( $\mathrm{LI}_{\mathrm{I}}$ Baohua 200I: I28).

Wenchang ge 文昌閣 - a round pavilion on the city canal, built in 1585 and rebuilt in 1586. It was badly damaged; only a skeleton remained, which still was left in disrepair thirty years later (FInNAne 2004: 310). The current building is a late Qing structure.

Tianning si 天寧寺 - this, the biggest monastery in Yangzhou, was burnt. Before long, monks rebuilt the gate, the meditation hall, the kitchen, and the Guanyin shrine; they also built an ossuary for those killed in the fighting (Yangzhou fuzhi 1874: 5:22a). In 1865, the salt commissioner Fang Junyi sponsored its reconstruction. The library and Huayan ge 華嚴閣 at the rear were built in I88I and I9II respectively (ZHAO Weihang I99I: 22).

Wenhui ge 文匯閣 - the Imperial library for Siku quanshu, built in 1775. The books were burnt and the building was never rebuilt.

Guanyin shan chansi 觀音山禪寺 - a Buddhist temple founded in 1387. Its major buildings were renovated in the Guangxu 光緒 reign. The interior equipment was destroyed in the Cultural Revolution, the present statuary dates from after I984 (WANG Hong 2000: 64).

Yangzhou tie Fo 揚州鉄佛 - the revered 'Yangzhou iron bodhisattva' from the above temple was demolished (SHEN Jiarong, Jiang Zhiliang I993: 30).

Gaomin si 高旻寺 - the whole complex was destroyed, and reconstruction was only partial through the years of the Republic (WANG Hong 2000: 57). A school now stands on the grounds of the imperial lodge.

Fuyuan'an 福緣庵 - a monastery located outside Nanmen 南門, on the southern bank of the Guanhe Canal, which housed the complete edition of Buddhist canons, donated by Prince Yi 怡 in I784. Rebuilt in the Tongzhi 同治 reign, not extant (WeI Minghua 200I: 227).

Baichi wutong ge 百尺梧桐閣 - the famous garden built in the late seventeenth century by Wang Maolin 汪惁麟 in the Dongguan area has not been rebuilt (Li Baohua 200I: I22). 
Jiufeng yuan 九峰園 - formerly Nan yuan 南園, built in the early Qing dynasty by Wang Yushu 汪玉樞, it became one of the 'eight gardens of Yangzhou.' The Qianlong emperor renamed it Jiufeng yuan (Nine Peaks Garden). After the Taiping wars, the garden ceased to exist. In I98I, the site was reconfigured into the Lotus Pond Park, Hehua chi gongyuan 荷花池公園 (ZHAO Weihang I99I: 2I, 224).

Wuting qiao 五亭橋 - the five pavilions on the bridge were burnt, and rebuilt at the end of the Qing dynasty (WANG Hong 2000: 76).

Wenfeng ta 文峰塔 - a seven-storey tower next to Wenchang Temple, built in 1582. Already damaged by an earthquake in I668, it was burnt down to bricks, but later reconstructed (WANG Hong 2000: 69).

The Taipings primarily targeted Buddhist and Daoist temples and official complexes, but spared buildings which were of use to them and which therefore simply changed masters. In Nanjing Taiping commanders moved into existing luxury residences and had them redecorated; the murals discovered in 1952 at the palace, wangfu 王府, at the Tangzi jie 堂子街 Street were painted by artisans from Yangzhou. Tales about the engagement of Zheng Changchun 正長春, Li Kuangji 李匡濟, Hong Fuxiang 洪福祥 and other Yangzhou artisans in Tianjing still circulated in the twentieth century. ${ }^{40}$ Book engravers and printers were needed by the Taipings, so the printing industry at Yangzhou was not discontinued (Luo Ergang 1978: 283-85). The civil and military offices in Yangzhou were completely destroyed (Yangzhou fuzhi 1874: 5:28a), but the Taipings saved and profited from city walls and the great Wanfu 萬福 Bridge near Yangzhou; ${ }^{41}$ the gazebo Siwang ting 四望 亭 and the White pagoda - with scaffolding attached for the purpose - served as watch towers (WANG Hong 2000: 42).

After the annihilation of the Taiping kingdom in 1864, Yangzhou recovered slowly, having neither the spirit nor the means for reconstruction. Some restoration took place in the Tongzhi reign, as can be seen from the above list; but the government was still being criticized in the I890s for neglecting restoration work (FINNANE 2004: 309). Moreover for decades incessant natural calamities and social disorder in the region brought waves of refugees into the city. Economic hard times and poverty continued. Yangzhou did not produce cotton for commercial gain; grain too was amassed only for despatch to Beijing (Finnane 2004: 226-27). Production in the city revolved around artistic crafts, but there were now few customers. The place to go and earn a living was Shanghai, where Yangzhou men were hired as labourers; the intelligentsia also found Shanghai more rewarding. The depressive state of the city was fostered by the attitudes of the locals, unwilling or unable 'to exert themselves to the full' (FInnane 2004: 3II). The decay of Yangzhou in the twilight of the Qing was a metaphor for all China. 


\section{DERISION AND CONTEMPT}

At the outbreak of the Xinhai 辛亥 revolution in I9II, the local commander Xu Baoshan 徐寶山 stayed loyal to the imperial cause, and pacified Taizhou, Xinghua, Yancheng 鹽城 and Dongtai. But bribed with 250,000 yuan by Yuan Shikai 袁世凱 he changed sides and stayed in power, being regarded as the local 'militarist.' Yangzhou therefore was on the wrong side when the Republic was born, and one would be inclined to say that it paid a political price. Prefectures were abolished under the new administration, thus the Yangzhou prefecture ceased to exist, and its name was practically erased from the maps. Jiangdu xian 縣, merged with Ganquan, became the new regional center (WANG Wenqing 1993: 747); Yangzhou, still the biggest town on the northern bank of the Yangzi, was degraded and its profile kept low. It gained the image of 'a sorry place, poor, backward and without prospects. ${ }^{32}$ The leisurely lifestyle of the elite, once envied, now seemed decadent. ${ }^{43}$ Westernized modernity was on display at the luxurious hotel Lüyang lüshe 綠楊旅社, built in I9II-I9I2 in the center of the city, but measures that might have improved the well-being of most of Yangzhou's inhabitants were seldom introduced. There was scarce running water or electricity, no railway line, almost no telephone connection.

In 1934 Yi Junzuo 易君左, a journalist who fled the perturbed Shanghai, wrote about his impressions of Yangzhou in a booklet titled Xianhua Yangzhou 閒話揚州 [Chatting At Leisure About Yangzhou], which Yangzhou citizens found offensive. In summer 1934, they organized as Yangzhou jiuyi tuan 揚州究易團. The name contains a pun; ' jiu yi' 究易 may mean the organization 'to correct errors' but also 'to correct Mr. Yi.' The organization charged Yi Junzuo at Zhenjiang court and won the case. Yi Junzuo was fined 800 yuan, his book was withdrawn from public libraries and its further publication prohibited; the publisher was Zhonghua shuju 中華書局 (WEI Minghua 200I: II2-I3). ${ }^{44}$ After Yi Junzuo died on Taiwan in May 1972, the journal Chunqiu 春秋 published his controversial essay, once more provoking the protests of Yangzhou citizens (WANG Hong 200I: 80-8I).

The commander Xu Baoshan was assassinated in I9I3; the details of the case were never clarified. Local gentry had his garden residence on the Slender West Lake rebuilt in I9I5 as the public Xu Baoshan Park, Xu yuan 徐園, with a memorial shrine citang 祠 堂, and a stele to commemorate him (Zhao Weihang I99I: I88). ${ }^{45} \mathrm{Xu}$ Baoshan died when an antique exploded in his hand; indeed the Yangzhou antique market flourished until 1949, because the grave economic conditions forced owners to sell their valuables. During his visit in April 1937 the literary historian A Ying 阿英 marvelled at how many rare books were on offer in Yangzhou. Valuable book collections, however, were usually sold in Shanghai or other big centers. For example, the reputed Cehai lou 測海 樓 library of 8020 titles (247,759 volumes) was sold to Beijing, a fact which caused much discontent among the locals (WEI Minghua 200I: 232, 262). 
Republican Yangzhou was less and less a place for tourists, and those who came with expectations were disappointed, like the noted writer Yu Dafu 郁達夫 (FInNANE 2004: 5). The White Pagoda - the famous Yangzhou landmark - continued in a poor condition in the ruins of Lianxing Temple, which had been burnt by the Taipings. Only a part of the former garden territory along Slender West Lake, the Yechun yuan 冶春園 garden, was restored in 1924-1927, with a gallery and pavilions along the bank, as well as precious trees and plants (WANG Hong 2000: 58, 77). It would be one-sided, however, not to mention the public construction works carried out at the time. These included the completion of the motor road to Guazhou in $1922,{ }^{46}$ the demolition of the city wall separating the Old and New Town in $1916,{ }^{47}$ the opening of a passage through the Southern Gate Citadel in 1927, the repair of dikes in 1934 (in response to a devastating flood in August I93I), and the construction of an airport in I935 (WANG Hong 200I: I85-88, ZhaO Weihang I99I: 23I).

The Japanese invasion interrupted all such endeavors. As the Japanese army advanced into Jiangsu in November 1937, the Chinese provincial government retreated through town after town, including Yangzhou; it found shelter in neighbouring provinces, first Anhui and finally, in autumn 1939, Jiangxi. Yangzhou was occupied by the Japanese on I4 December 1937 and remained part of the Japanese zone until the end of the Second World War eight years later. ${ }^{48}$ The pro-Japanese weixin 維新 [reform and modernization] government was proclaimed on 28 March 1938, and its subordinate Jiangsu branch on I May, in Suzhou. When the city of Xuzhou 徐 州 fell on I9 May I938, Northern Jiangsu, Subei 蘇北, was declared to be under Japanese control. The weixin government administered only ten counties, including Jiangdu; consequently Yangzhou housed the county administration. On 30 March I940 the weixin governement was replaced with Wang Jingwei’s 汪精衛 government which had been set up in Nanjing. Wang Jingwei controlled 36 counties, including Jiangdu. Economic production grew 22-fold from 1939 to May I943, especially textile production, and some rural areas grew grain specifically for Japanese consumption. A new currency was introduced and taxes were periodically increased. The economy grew but people became much poorer. From a military point of view, Yangzhou formed a military region together with Yizheng, one which numbered 2000 troops; part of the Japanese 'Central China Army' was also stationed there. From the point of view of the Guomindang 國民黨 Jiangsu government based in Northern Jiangxi, Jiangdu belonged to the Huai'an 淮安 military base. After late 1938, both the 4th and 8 th armies operated in the region. There was incessant fighting in the following years, with first one side and then the other advancing (SHEN Jiarong, JiAng Zhiliang I993: 46I-90). Fighting went on in the immediate vicinity of Yangzhou, but it did not damage the town proper, nor bring the Japanese occupation to an end.

The civil war of 1946-1949, which determined the path of modern China, spread to Jiangsu only in its final stage. Fierce fighting in northern Jiangsu began in 
November 1948 around Xuzhou, and continued until the conquest of Nanjing on 24 April 1949. Yangzhou was taken relatively early, on 25 January i949. The initial rule of the Yangzhou military administration committee, Yangzhou shi junshi guanzhi weiyuanhui 揚州市軍事管制委員會, was in due course replaced by the rule of the Communist Party Municipal Committee, Yangzhou shiwei 揚州市委, with Du Ganquan 杜乾全 as secretary, and also as mayor. On 2I April 1949 Yangzhou was reinstalled as an administrative centre: the capital of one of the five territories of Northern Jiangsu, Subei wu zhengqu 蘇北五政區, along with Taizhou, Yancheng, Huaiyang 淮 陽, and Nantong 南通; the Subei headquarters were in Taizhou (SHEN Jiarong, JiAng Zhiliang I993: 604).

\section{THE PROTECTION OF ARCHITECTURAL MONUMENTS IN THE AGE OF CONSTRUCTION}

The writer Wang Hong 王鴻, born in I93I, recalls from his first visit to Yangzhou in 1949 the plentiful and various shops in the central Yuanmen qiao 轅門橋 area, where 'whatever one needed, one could get,' and the bustle and noise around him (WANG Hong 200I: I8). These were the first impressions of a young boy from the countryside; yet through more experienced eyes, Yangzhou was a provincial town of just 80,000 inhabitants, ${ }^{49}$ with no industry comparable to that found in Changzhou, Nantong, Wuxi or Suzhou. In the same book, he recollected that at the beginning of the I950s, there were just two factories and a few workshops in the town. Drawings from the time show rubble lying in streets with bumpy pavements, and electricity still rare (FInNANE 2004: I4), even though three electric plants had been built before the war. Wang Hong thought strangers regarded Yangzhou as a 'lanky, sick, crooked old fellow, yige shouxiao de jibing chanshen de laoren 一個瘦小的疾病維身的老人, and the persisting impression that Yangzhou was 'old, small and thin,'gu xiao shou 古小 瘦, annoyed the locals (WANG Hong 200I: 2).

If it is a justifiable observation that Yangzhou had been intentionally humbled and neglected during the Republic, then the communist leaders may have partly reacted against the Republic in trying to revive Yangzhou. The new government was determined to reconstruct and modernize. ${ }^{50}$ Yangzhou's historical layout was heavily encroached upon. First, the city walls were torn down between I95I and I953, making space for a 4320 meters' circuit on the perimeter. The historical town did not have streets wide enough for automobile transport; only rickshaws could pass through the many narrow lanes. To resolve this, new streets were driven through the built-up area: the east-west corridor made of Jiangdu Street beyond the former walls, Guangling Street and Ganquan Street; the north-south corridor made of Shi Kefa Street beyond the former walls, Guoqing 國慶 Street and Dujiang 渡江 Street. The principal intersection lay in the commercial area of Yuanmen qiao, where the 
main shops (baihuo 百貨 department store, Xinhua 新華 bookshop, hardware) were concentrated. Still another broad boulevard was created in 1952, by filling in the Wenhe 汶河 Canal, one of the main canals, which was silted up at the time. The new Wenhe Street was lined with presentable residential houses, shops, and the Grand Hotel, Da jiujia 大酒家; the city authorities considered it imperative that their architecture should draw on classical decorative motifs.

In the early I980s these streets nonetheless became insufficient for the city's rising volume of traffic and a broad new west-east thoroughfare was built across the city, creating the sequential Shita lu 石塔路, Sanyuan lu 三元路 and Qionghua lu 瓊花路. During construction, the builders did take care to save monuments, namely the Stone Pagoda erected in 838 , the Song dynasty gingko tree yinxing 銀杏, the Song dynasty water well, the round Wenchang Pavilion, the gardens Cui yuan 翠園 and Zhen yuan 珍園, the gate of the Liang Huai salt control office, the Little Qinhuai quarter, the temples Qionghua guan and Shuangzhong $c i$ 雙忠詞. Trees and plants were given extra space, and any new buildings lining the street had to be built in an elegant, heritage

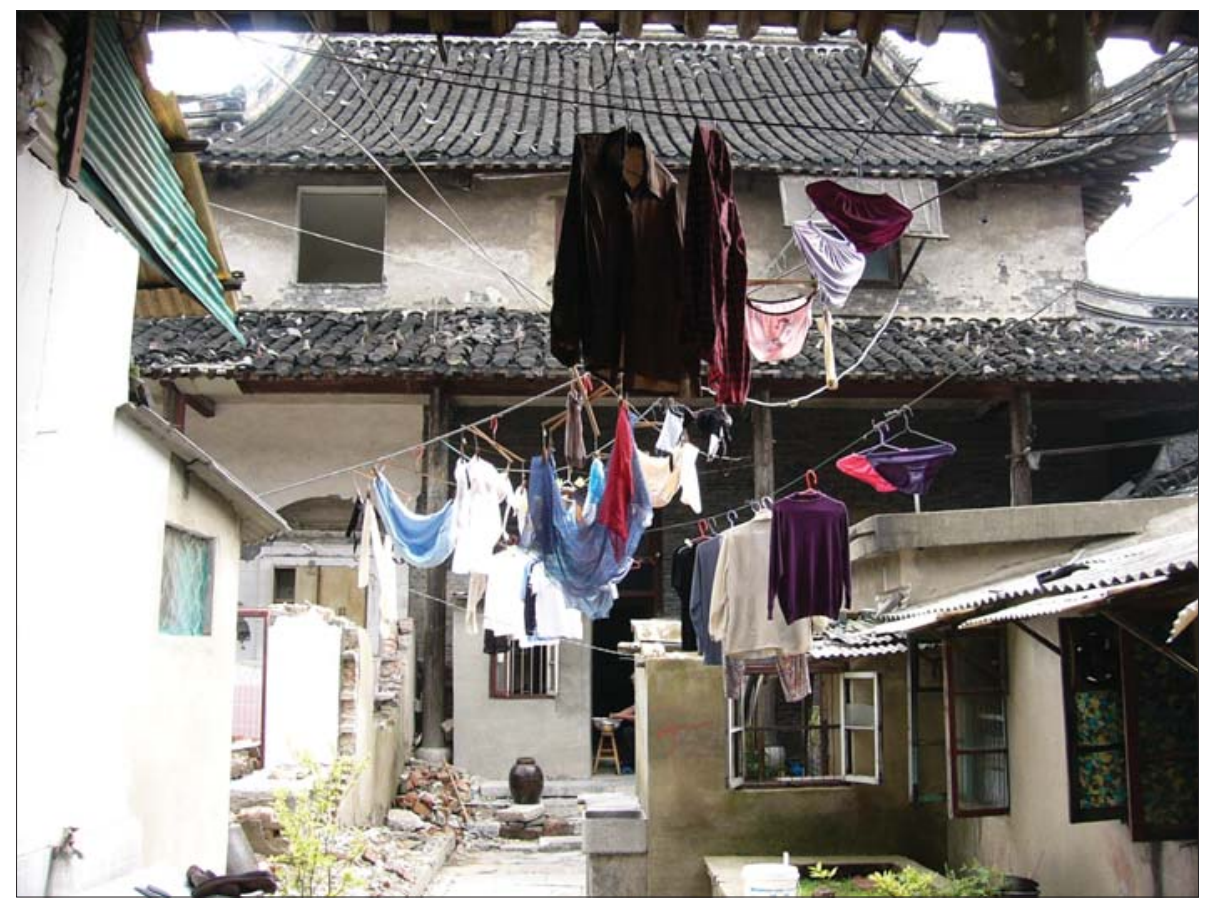

Figure 1.2 Yuansheng Temple, with built-in apartments. Yangzhou historic city, Old Town. September 2007. Photo by Lucie B. Olivová.). Buildings which could not be adapted were simply sealed, for example the Evangelical church on Guoqing lu 國慶路. Under such circumstances, there was a mixed record of protection and preservation for these places. 
style, some with concave gables and eaves characteristic of traditional architecture. The city government was located at the junction of this thoroughfare with the main north-south road, at the site of the former salt control office. ${ }^{51}$ The new thoroughfare was proudly described as 'the vernal spirit road across Yangzhou, ten miles long,' chunfeng shili Yangzhou lu 春風十里揚州路, or 'the road of historic spectacle through dynasties,' Tang Song Yuan Ming Qing, cong gu kan dao jin 唐宋元明清, 從古看到今. In the 1990s, it was expanded and renamed Wenchang zhonglu 文昌中路, its eastern end leading to the Jiefang 解放 Bridge built over the Grand Canal. On the periphery of the historical town, some fifty roads were added by the late 1980s, creating a web of linkages between old city and new developments (ZhaO Weihang I99I: 225; ZHU Zhu 1989: 102). In Yangzhou, as in any other town in China (or indeed, in the world) which had the means to rebuild, the old architectural layout was sacrificed in order to make way for traffic and development, and caused irreversible damage. Ordinary houses which were out of the way survived, paradoxically because of a lack of funds for their reconstruction, but they had been neglected after 1956, when private enterprise was made the people's property, gong si he ying 公私合營 (WEI Minghua 200I: 70).

Selected monuments in China were declared protected in 1957. In Yangzhou, this directive concerned the main hall of Daming si 大明寺, open to public viewing, and a few other structures. In 1962, a second group of monuments followed, bringing the total in Yangzhou to I48, thirty-two of which are presently open to the public. Protected objects could be complexes, e.g. the former residence of the celebrated storyteller Wang Shaotang 王少堂; 52 single buildings, for example towers, or parts of buildings, for example carved stone portals. Not only historical objects, but also places commemorating modern history appeared on the list, such as the Martyrs' cemetery, Wansong ling 萬松嶺 in the Shugang mountains, built in 1954 ( $Y$ WB: passim). Being on the list did not automatically guarantee adequate maintenance, however. It meant that the object was placed under the care of a certain work unit, and put to an alternative use as a school, depository, factory (e.g. the Wang mansion, Wangshi xiao yuan 汪氏小苑), or official institution. The residents often had to move out. In contrast, some monasteries or elite residences were divided into many small residential units, for example the Yuansheng 願生 Temple (Fig. I.2). ${ }^{53}$

During the turmoil of the 1960s and 1970s, breathtaking acts of vandalism were carried out all over China in the name of a 'cultural' revolution. Religious institutions and monuments were the obvious objects of angry attacks. In Yangzhou, the Mosque of the Immortal's Crane Xianhe si 仙鶴寺, one of the biggest mosques in China, founded in the thirteenth century, was severely damaged; the interior equipment of the Guanyin Temple in the northern suburbs was completely destroyed (WANG Hong 2000: 64-65); the stone archway in front of Qionghua guan, from I592, was demolished. Carved stone portals on many old mansions were ruthlessly smashed, ${ }^{54}$ and the fact that some were protected monuments did not save them. The 
attacks also targeted the memory of historical personages: the tomb of the painter Shitao 石濤 on Pingshan tang was ruined; the inscription on Shi Kefa's memorial stele at Meihua ling 梅花嶺 smashed (WANG Hong 2000: 293-94); the grave of Zheng Banqiao, which had been moved to Xinghua in 1964, was dug open and the remains scattered (WEI Minghua 200I: 259-60). He yuan 何園, a major garden of great cultural significance, opened to the public in $1959,{ }^{55}$ was closed again and became the site of a radio factory. The calligrapher Xuesong 雪松 recalls a childhood memory:

In 1969, my father was transferred to the radio factory. Who would have thought that the factory was set up in the He Garden! The New Year's day turned out to be his turn on duty, and I was to keep him company. The next morning, I sneaked into the garden. The garden, with towering trees, was bleak as before. Withered grass grew over the pathways. Fallen leaves were floating in a black pond; rubbish, wires, dead flowers and rotten wood were piled on the bank. Pavilions were partitioned into rows of offices and workshops. I walked to the southern gallery, to see that the calligraphic slabs were plastered over, and 'Long live the policy of proletariat' was written on the plaster. It was difficult to come across calligraphy in those times, and I had heard that there were three slabs with inscriptions by Yan Lugong 彥魯公 (Yan Zhenqing 彥真卿, a Tang calligrapher) in the garden. Seeing that there was nobody around, I tried to scratch the plaster. With nails broken, I finally exposed one character. At first I frowned at the thought of those who had plastered over them, but then I realized how shrewd they were. Piled slabs were burnt, and stelae smashed. But these three slabs survived thanks to the slogans. For the moment they were hidden, but sooner or later they would be uncovered for the appreciation of everyone.

(Quoted from Du Hai 2002: 34).

In 1981 the central government ordered provinces to compile new lists of protected monuments, because 'some monuments vanished in the Cultural revolution, whereas
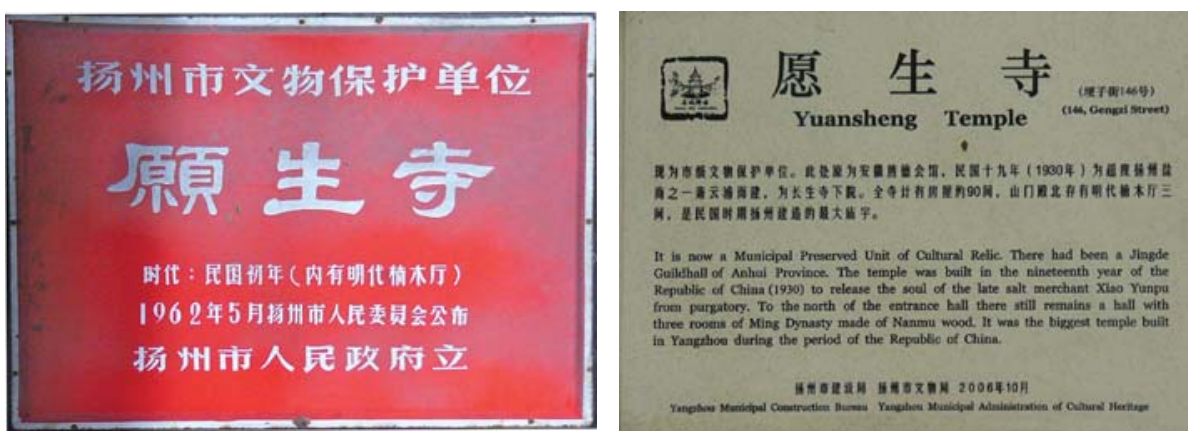

Figure 1.3 Tablets, old and new, fixed on protected historic monuments. Photo by Lucie B. Olivová. 
other monuments deserved to be added' (Jiangsu sheng wenwu baohu danwei mingdan 1982: I). The revision was completed in 1982 and introduced a classification of monuments as provincial level shengji 省級, city level shiji 市級 and county level xianji 縣 級. In 1988 national monuments, quanguo zhongdian 全國重點, were gazetted; the only ones in Yangzhou listed were the gardens Ge yuan 个園 and He yuan. Thus, in China, there are sites of national, provincial and local commemoration, but officials also distinguish between monuments from the first, second or third group, i.e. the monuments declared in 1957, 1962, or $1982 .{ }^{56}$ Since 1982 new protected architectural objects have been declared almost every year. Besides, some monuments are on international lists (The World Heritage List of UNESCO, the World Technical Construction, etc.), or have been proclaimed as protected objects of international significance, like the Slender West Lake area (proclaimed guoji zhongdian fengjing mingshengqu 國際重點風景名勝區 in 1988). The whole city of Yangzhou appeared on the list of ' 24 historic and cultural cities' selected by the central government in 1982 . Being on any of these lists entitles the owner or local authority to funds needed for maintenance, and attracts tourists. Tourism, foreign and increasingly domestic, is a booming enterprise in today's China (Fig. I.3).

The list of Yangzhou city protected monuments, Yangzhou shi wenwu baohu danwei 揚州市文物保護單位, compiled in 2002, ${ }^{57}$ includes four national monuments: the gardens Ge yuan and He yuan, promoted in 1988, the remnants of the Tang dynasty town wall, promoted in 1995, and Puhaddin's tomb, promoted in 200I. At the provincial level there are sixteen momuments, for example the temples Tianning si and Xifang si 西方 寺, declared 1982; the mosque Xianhe si, the monastery Chongning si 崇寧寺 and the Catholic church, declared 1995; the Wu residence and the home of the writer Zhu Ziqing 朱自清, declared 2002. Interestingly enough, the Bridge with Five Pavilions had been placed on the provincial list as early as 1982, whereas the White Pagoda, Lianxing si baita 蓮性寺白塔, was declared a city level monument only in $2002 .{ }^{58}$ Four of the monuments protected by the province are not open to the public, including the former Buddhist monastery Chongning si, which now houses the 'Administration of National Heritage,' or Cultural Relics Office, Wenwu ju 文物局. 59

As to their preservation, it seems that the monuments added to the list in I982 and since have been carefully repaired and are better maintained than their predecessors on the 1957 and 1962 lists. Notably, the complex of Tianning si was renovated in 1984-1987 at a cost of more than I.4 million yuan, and in 1988 it was made the site of the Yangzhou Museum (ZhaO Weihang 199I: 23). Between 1982 and I99I the Yangzhou government spent more than ten million yuan on the restoration of historic gardens and scenic areas (Meyer-Fong 2003b: 247). We can note the function in 2002 of the surviving residential gardens; dating from late Qing to 1932, and protected at the city level since 1962: Ge yuan and He yuan became the city's major monuments open to public; ${ }^{60} Y i$ pu 逸戋 a private residence; Ping yuan 平 
園 a research institute lodge; Liu zhuang 劉莊 a police station; Wei pu 蔚圃 a street committee office; Zhen yuan a hotel; Yilu 怡盧 a kindergarten; the Wang mansion a tourist destination; Paolu 匏盧 the Research Institute of Relics; and since I982: Xiao pangu 小盤谷 a lodge of the Yangzhou office of commerce; Cui yuan 萃園 a hotel; Yangshi xiaozhu 楊氏小筑 a private residence (YWB: 2-4).

What methods were applied when reconstructing monuments? A peculiar way of preserving an old wooden structure that stood in the way of a development was to dismantle and relocate it. For example, the impressive main hall Dafo dian 大佛 殿, built in the Ming dynasty, once the main sanctuary at the Buddhist monastery Xingjiao si 興教寺 in the grounds of the Tian Jiabing Middle Schoool (formerly Yangzhou Fifth Middle School), was relocated to the Agate Blossom Temple Qiongbua guan during its large-scale rebuilding in $1993 .{ }^{61}$ At present, shifting buildings from their original sites is not favored. If old buildings stood in the way of traffic, or did not comply with present-day needs, they were likely to have been pulled down. A famous building, however, was most likely to have been replaced by a modern structure in historicizing style. This was the case of the Red Bridge, connected to the literary excursions of the poet Wang Shizhen 王士禎. The outdated bridge with one arch was replaced in 1973 by a bigger one with three arches and a deck wide enough to accommodate four traffic lanes (ZHU Zhu 1989: 37). Speaking of restorations of monuments, Chinese architects generally engage in far more rebuilding and replacement, where their colleagues from other countries would just retouch and conserve, or make it visually clear which part was original and which is new, as the Japanese do. In countless Chinese cities the problem of old shabby districts was solved by area clearance. In Yangzhou, the destruction of old houses came to a halt in 199I. It certainly was very uncommon when in 2007 the whole precinct south of the Jiaochang was demolished, to be replaced. Based on hearsay, houses in historic style are expected there. ${ }^{62}$

Nonetheless, the Chinese are becoming more and more aware of the value of their cultural heritage, and are making efforts to preserve it, sometimes motivated by patriotism and ideology, sometimes by tourism and economic gain. Among the monuments renovated with expertise and care were the neo-gothic Catholic church, renovated in 1985 , before it appeared on the list of protected provincial monuments; and the fabulous He yuan garden, renovated in 1989, after it appeared on that list. The garden Erfen mingyue lou 二分明月樓 was repaired at a great cost by the city in I99I-I992. The Wu Residence, Wu daotai zhaidi 吳道台宅第, located on the People's Hospital grounds, and formerly a conglomeration of some sixty family units, was reconstructed to its original state in 1996-97, at a cost of 28 million RMB, and became a public museum in $2005 .{ }^{63}$

As China becomes prosperous, it is quite common for long vanished buildings to be rebuilt in their supposed original form. At first, the trend could have been regarded 


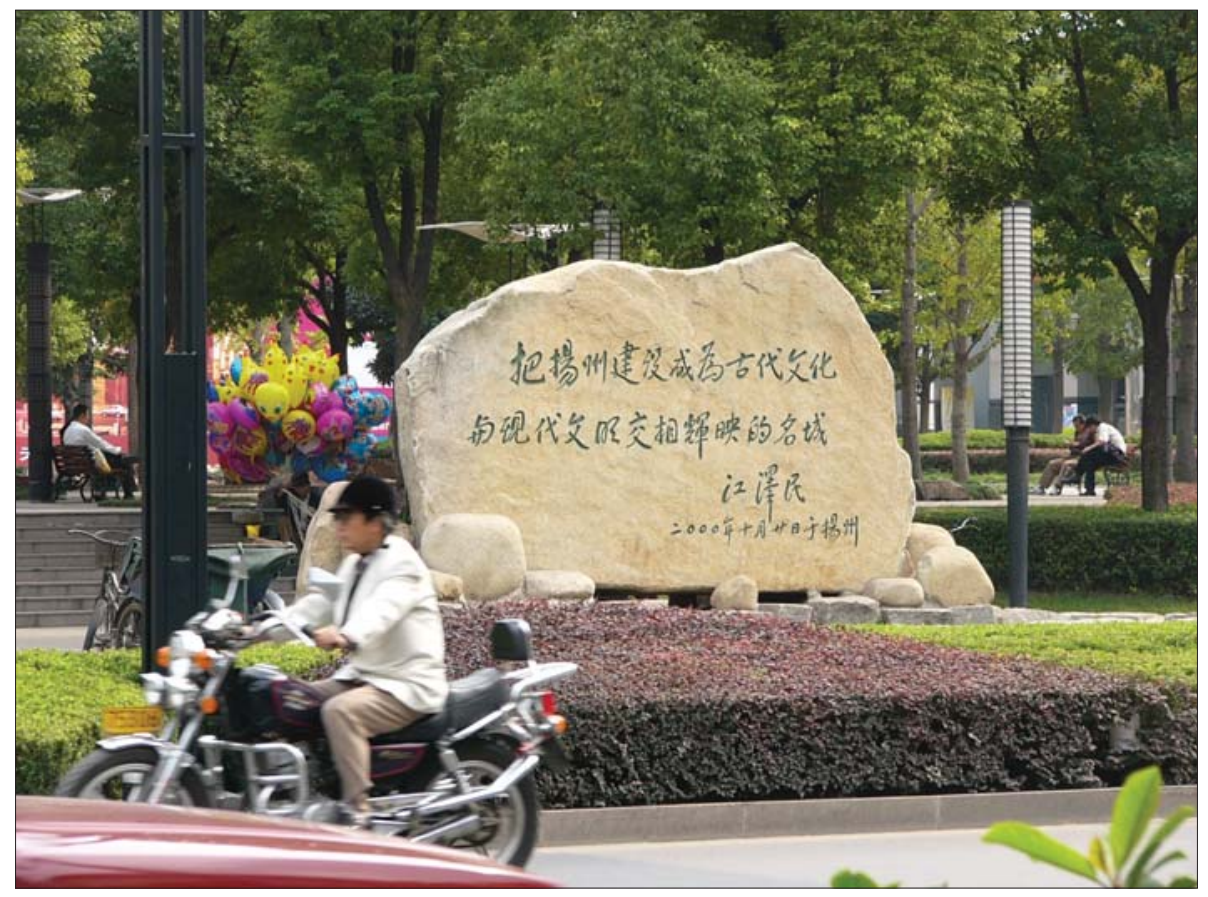

Figure 1.4 A stone slab on Wenhe Road, with Jiang Zemin's inscription from 20th October 2000: 'Let us build up Yangzhou into the dazzling famous town where historic culture and modern cultivation meet.' Photo by Lucie B. Olivová.

as purism rather than historicism, as in the case of the memorial hall of the monk Jianzhen, following his I20oth anniversary in 1963. The hall was designed by the prominent architect Liang Sicheng 梁思成 and completed after his death, in 1973, in the Daming Monastery. That happened decades before the current movement. More recently, in 1993-1996, the 73 meters high Qiling ta 栖靈塔 pagoda was re-erected on the original site at the same monastery (WEI Minghua 200I: 7I). The shape of the structure from $\mathrm{AD} 6 \mathrm{OI}$ is not documented; the new 'replica' draws on the notion of Sui pagodas, but its size is possibly exaggerated. Last but not least, Yin'en gong yuan 迎恩公園, the park of the embankment associated with the emperor Qianlong's arrival in Yangzhou, has been developed, with garden pavilions housing restaurants and teahouses, on the Caohe 漕河 Canal, to echo the ambience of Qianlong's disembarkation in Yangzhou. Lovely as it is, it seems to be at most a historical fantasy.

More parks have been laid out in the place of vanished historical gardens, for example the already mentioned Lotus Pond Park. Being called 'a garden-city,' Yangzhou has developed several new parks - naturally in the traditional style. In 1982 the spacious Zhuyu wan 茱英灣 Park, with zoological and botanical gardens, was developed at the confluence of the Grand Canal and the Old Canal, Gu yunhe 古運河. In 1988 a new 
park Shu ren yuan 樹人園 was created on the western side of Yangzhou Middle School. The banks of the old waterways Xiao Qinhuai and Erdao he 二道河 were remade and laid out as green space in 1987 and in I99I, respectively. The project of 'turning public space green,' gong gong lühua 公共綠化, spelt out in 1988, gave much thought to the presence of trees and plants in the urban zone, including the protection of old trees. There are at present ninety-three gingkos over one hundred years old in the town. On I8 July i985, following the result of a popular vote, the city designated the gingko and willow to be the trees that would symbolize Yangzhou, and the agate blossom, qionghua 瓊花, to be the symbolic flower (ZhaO Weihang I99I: I38-47).

\section{THE NEW CITY PLANNING}

When Yangzhou joined the prestigious group of Chinese historical and cultural cities in 1982, its government declared it would not only protect the historical town (gucheng 古城), but also take the opportunities of the open economy by encouraging water transport on the Yangzi, by rebuilding the port, and by embarking on other

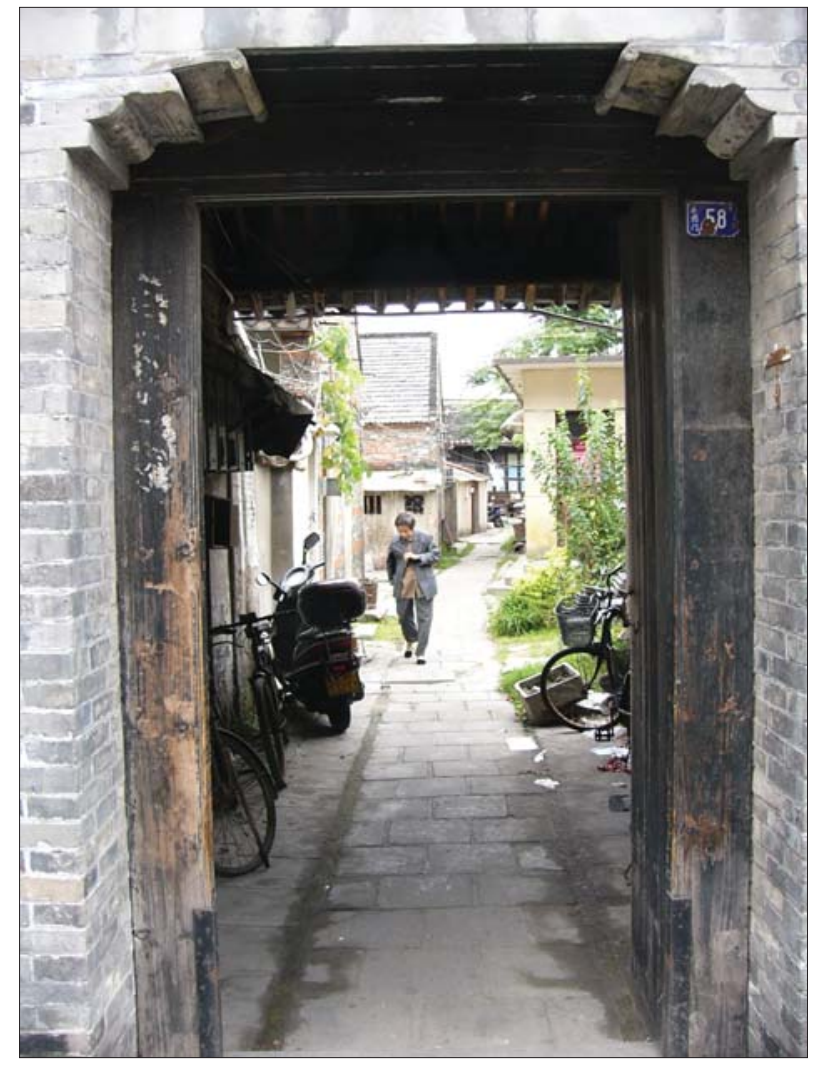

Figure 1.5 View of a Yangzhou lane, with the new pavement. September 2007. Photo by Lucie B. Olivová. 
similar developments. By then, however, Yangzhou was beginning to lose its architectural identity, as the writer Ai Xuan 艾煊, born in 1922, had observed. On his first visit in the early 1950s the tower Wenfeng ta, forty meters tall, used to be the most eye-catching structure around, but in 1987 it was hidden amidst tall buildings, which have mushroomed, as in many other cities. ${ }^{64}$ Yet economic prosperity and continuing growth did not bring further devastation to historical Yangzhou. In 1988 , the government adopted strict protective policies concerning the height, size, form and style of new structures. It proclaimed five protective directives, wu tiao baobu xian 五條保護綫, in the support of:

1. the historical town and a new image along Wenchang zhong lu Street;

2. local souvenirs and handcrafts along Wenhe beilu Street;

3. tourism in respect of the traditional culture along Yanfu lu 鹽阜路 Street;

4. sightseeing on boats along the Xiao Qinhuai Canal;

5. streets that embodied the historical character of the town: Dongguan jie 東関街, 65 Caiyi jie 彩衣街, Xianxue jie 縣學街, and Ximen jie 西門街;

The government also delimitated four protected areas, si kuai baohu diduan 四塊保 護地段:

1. the central market area of the Parade Ground, Jiaochang, which best reflects local customs;

2. the area between Nanhe xia and Guangling lu - which has old mansions and gardens;

3. Ge yuan garden - which best reflects the leisure activities of the traditional culture;

4. Ren feng li 人丰里 - the area with old lanes (ZhaO Weihang I99I: 225).

Not all of these ideas came to fruition. For example the boat trips along Xiao Qinhuai Canal do not take place, but on the other hand boat trips across the Slender West Lake abound. Other directives were fully realized, for example a folk art museum, the jade museum and the arts and crafts museum - the most obvious purpose of which is to sell their merchandise to tourists - are all now to be found along Yanfu lu Street (as proposed in directive 3). Yangzhou regained a solid position on the tourist map of China, and during the season receives a stream of Chinese tourist groups, though fewer foreigners.

The protected area of the historical town is partly delimitated by the Old Canal. It lies within the area of the former city walls and along the Slender West Lake, and equates with the once booming Qianlong city, but its old buildings mostly date from the later Tongzhi reign or shortly after. Beyond the old city, planning was to be 
carried out according to the slogan 'port in the South, [residential] city in the North; [historical] town in the East, [business] district in the West,' nan gang, bei shi; dong cheng, xi qu 南港, 北市, 東城, 西區 (Zhao Weihang I99I: 225). Unlike so many other municipalities, Yangzhou wisely did not try to reconstruct the old quarters to meet contemporary needs, but aimed to develop a modern administrative and business center approximately six kilometers to the west, then still countryside. In due course, a spacious new district, much larger than the historical city, did grow up. It is here that the major institutions - city government, bus station and railroad station, ${ }^{66}$ leading industrial and commercial companies, as well as cultural institutions (e.g. the new Yangzhou 'Double' Museum, opened in October 2005) - were established in a number of grand structures. Along with the rail link, the road system, which now leads onto the bridge across the Yangzi, Yangzi er qiao 揚子二橋, brought an end to the city's geographical separation from the other major centers in Jiangsu province and opened endless new perspectives. It may be noted in passing that the development of Yangzhou got much stimulation and backing from the fact that the former Chinese president Jiang Zemin 江澤民 is a Yangzhou native. ${ }^{67}$ The inscriptions he wrote during his visits to the city adorn several places: they are, for example, carved in a stone slab on Wenhe lu (Fig. I.4) and above the front entrance of the new railway station. ${ }^{68}$

Placing the new city at a safe distance from the historical town created the basic conditions for preserving the latter. At the same time, its renovation was placed high on the Yangzhou government agenda, being one of the 'ten actual deeds,' shi jian shishi 十件實事, proclaimed in I99I. The historical complexes that were put to alternative use, disfigured and kept out of sight behind cheap extensions, are still gradually being renovated, or even rebuilt, ${ }^{69}$ starting from the north-eastern section of the historical town. The difference between the renovated northeast and the southern part, which is next to follow, is striking. Then there are the less obvious, but no less costly steps which have greatly improved the quality of life, for example placing water and sewage pipes below new paving in all streets and lanes in 2002 (Fig. I.5).

The effects of the reorientation of the goals of the city planners are becoming increasingly visible, while more and more marble tablets remind passers-by of protected historical buildings, regardless of their current state.

Compared with many other Chinese towns, the measures for protecting Yangzhou's heritage, undertaken by its leaders since the I990s, were better founded, based on cautious reflection and the gathering of expertise. Indeed, a delegation led by the mayor of Yangzhou toured Germany and the Netherlands in 2002 in order to learn about the protection of their historical towns. The commitment to preserve the architectural legacy in Yangzhou seems very strong, and so far is effective. However, the new urban planning policy would not have been possible without a change in values. The officials and architects had to overcome feelings 
of embarrassment over an old city which supposedly embodied backwardness. Only when they reinvented the value and meaning of $g u$ 古 [old] could historical Yangzhou, endowed with old features and atmosphere, turn into a valuable subject, deserving care and pride.

I began this article by emphasizing the vivid and constant remembrance of the past, which both inhabitants and passing visitors of Yangzhou foster. In conclusion, I return to that idea to remind readers that not only the historical built-up space, which was the main subject of this chapter, but also the cultural imagination, which was just hinted at, shape Yangzhou's unique appearance.

\section{NOTES}

1 Jianzhen stayed in Daming si 大明寺 from 7I4 until 753, when he finally left for Japan. Ouyang Xiu took office in Yangzhou in I048; Su Dongpo in I092; Polo presumably in I282. Zheng Banqiao lived in Yangzhou from 1753 until his death in 1765 (Wang Cheng 200I, passim).

2 Compiled from Wang Hong 200I, Wu Jiaxing 1988, Huang Jilin 2005, Yangzhou museum exhibition at Tianning si, 2004, and other materials.

3 The other prince was buried at Dantu 丹徒. In the vicinity of Guangling, there are some 400 Han tombs; two of the princely tombs were thoroughly excavated and explored, and in $1992 \mathrm{a}$ museum was opened at the site.

4 It is customary in Chinese culture to number phenomena in groups of four: thus 'four total destructions of Yangzhou' are remembered, in the years 45I, 548, II29 and I645.

5 The tomb of Sui Yangdi was rediscovered in the northern suburb by Ruan Yuan 阮元, in the Jiaqing 嘉慶 reign. Ruan Yuan had a tombstone erected there (WANG Hong 200I: IO).

6 In 624, the town was renamed Yangzhou, but in the eighth century again renamed Guangling.

7 There is rich archaeological evidence from the Tang dynasty; some 700 ceramics were found. More evidence on the later period was brought to light by the discovery in 1975 of the tomb of the Southern Tang princess Xunyang 旬陽 (buried in 927), and of the 24-meters-long ship, built in Northern Song, unearthed in 1960. See Wu Jiaxing 1988: 69-72.

8 In II27, Zhao Gou 趙構 (the emperor Gaozong 高宗 of Southern Song) made Yangzhou his temporary capital. But at the beginning of II29, after a year and three months, the Jurchens took Xuzhou 徐州. Zhao Gou sailed on boats from Guazhou to Zhenjiang 鎮江 and fled south to Hangzhou. I00,000 Chinese troops failed to protect the region, and Yangzhou suffered a ransacking by the Jurchens: only a few thousand inhabitants survived and both town and port were burnt to the ground. The tragedy was described by Jiang Kui 姜酸 in his poem Yangzhou man 揚州慢, composed in II79. Yangzhou, as a commercial center, diminished in size and importance. Guazhou and Zhenjiang met the same fate. In II30 the Jin 金 army - retreating from Hangzhou - was defeated at Guazhou (Wu Jiaxing: 72-73).

9 The Mongols brought along foreign thoughts and faiths. In Yangzhou, this trend is represented by Puhaddin, a I6th generation descendant of Mohammed, who preached there in 1265-I274, that is, before the Yuan dynasty. Puhaddin was buried with honour to the east of Yangzhou - the site of his splendid tomb now lies within the town. 
10 When the Wu 吳 (Ming) army occupied Yangzhou in 1357, only I6 families were left in the town, everyone else had fled; in 1393 , the population of Yangzhou prefecture was a mere 730,000, comparable only to that of the late Han 漢 (Wu Zihui 200r: 223).

11 For a decade from I552, pirates attacked Jiangsu every year, looting, killing and burning houses. In Yangzhou prefecture, several towns were repeatedly attacked. While the port of Guazhou became a frequent target, Yangzhou was attacked once, in 1557. People tried to sail across the Grand Canal to safety, and thousands were either killed by pirates or drowned. The last ransacking happened at Xinghua 興化 in I562 (WANG Wenqing 1993: 669, 67I).

12 Finnane also notes that the binuclear urban pattern of planned and unplanned settlement, typical of Yangzhou, was reflected in the pattern of social life (FInNANe 2004: 190).

13 The tragic events were recorded day by day by Wang Xiuchu 王秀楚, and other writers: Zheng Yuanxun 鄭元勳 and Zong Hao 宗影. For an analysis of these sources, see FInNANE 2004: 79-89. A handscroll by a woman named Shi Wu, depicting the pillage of Yangzhou and the suicide of her mother, is kept in the Shi Kefa memorial in Yangzhou.

14 Namely, the historian Tan Qian 談遷 (1594-1658), who wrote that Yangzhou 'had been ruined in the chaos of the preceding decade' (Meyer-Fong 2003a: 22).

15 The prefecture now presided over two departments, zhou 州: Gaoyou 高郵 and Taizhou 泰 州, and six counties, xian 縣: Jiangdu, Ganquan 甘泉 (detached from Jiangdu), Yizheng 儀征, Xinghua, Baoying 寶應 and Dongtai 東台 (WANG Wenqing 1993: 747).

16 The corruption and mismanagement in these offices were so common that they were repeatedly abolished and reintroduced. (SPENCE 1988: 173-75). Theoretically, the controller, yanyun shi, administered both the production and the sales of salt; the censor, xunyan yushi, was in charge of the surveillance of the administration. As Finnane observed, in practice, the salt controller was the most powerful official (FInNAne 2004: 133).

17 Kangxi visited Yangzhou four times: in 1689, 1703, 1705 and 1707. On his first and third tours in I684 and 1699, he only passed through (SPENCE 1988: I24-5I).

18 All translations in this chapter are by L. Olivová.

19 The history of Pingshan tang is described in chapter 4 of Building Culture in Early Qing Yangzhou (Meyer-Fong 2003a: I28-64). It became a Confucian shrine, honouring Ouyang Xiu, after a renovation in 1674. Its reputation was raised following the Emperor's visit in 1705 . Thereafter, the site became more and more popular; it was renovated again in 1736 , and a special gazetteer was compiled about it in 1765 .

20 Qianlong imitated his grandfather, and also toured the south six times, in 1751, 1757, 1762, I765, I780 and I784. He visited Yangzhou on both the outward and return legs of each journey (Wu Jianhua 1990: 5I-52).

21 On the management of that library, see Finnane 2004: 270.

22 The emperor was moved to build the memorial when a portrait of Shi Kefa and letters by him were rediscovered. The events were recounted by Li Dou in Yangzhou huafang lu. For an English translation, see BоRотA 1996: 63.

23 See, for example, Li Dou i979: I48-49.

24 Particularities concerning the building of the White Pagoda are not known, only the names of the officials in charge of its repeated reconstructions, and the years when the emperor visited the site (ZHU Jiang 200I: 316). A scarcity of facts has not prevented numerous tales about the 
pagoda being told. For example it is said to have been built overnight by private interests to please Qianlong. In one version, a eunuch advised salt merchants to build a replica of the pagoda in Beihai 北海. The merchants were perplexed, but the next morning the emperor was delighted to see a white pagoda from his window. The eunuch, jealous of the merchants, found an excuse and rushed to the pagoda, only to discover that it was made of salt. He threatened the merchants, who then had no other choice than to build a solid white pagoda of bricks (Yangzhou minjian gushi ji 1989: 162). Other versions credit the salt magnate Jiang Chun 江春 with the building. He had reputedly paid a large sum to obtain a plan of the pagoda from a eunuch (WEI Minghua 200I: 252-53. Also see Zhang Daoyou 200I: 15-16, or Meyer-Fong 2003a: I86).

25 Jiang Chun (I72I-93) did not gain this honour by chance. He had contributed to the emperor's military campaigns, and in 1763 had captured the eunuch Zhang Feng 張鳳 who had absconded from the palace. The emperor conferred various titles on Jiang Chun, but annulled them when a scandal erupted at the Salt Commission, headed by him for forty years. Nevertheless, Jiang Chun was after all invited to the celebration of elders in Beijing, given by the emperor. In folklore, he is said to be 'the commoner whom the emperor befriended,' albeit he had passed the first level examination (ZHU Zongzhou 1991: 17-20).

26 Residential gardens were built long before this, though. The image can be found in poems, e.g. by the ninth-century poet Yao He 姚合, who noticed that people in Yangzhou frequently lived in gardens, and that the town was built on canals: yuanlin duoshi zhai, chema shaoyu chuan 園林多是 宅, 車馬少於船 (quoted from Li Baohua 200I: 40).

27 From an essay by Kong Shangren 孔尚任, written in I688 (Meyer-Fong 2003a: 50). The 'eight gardens' were: Wangxima yuan 王洗馬園, Bian yuan 市園, Yuan yuan 員園, He Yuan 賀園 (also Dong yuan 東園), Yechun yuan 冶春園, Nan yuan 南園 (renamed Jiufeng yuan 九峰園 by the emperor in 1762), Ying yuan 影園, and Xiao yuan 篠園 (ZHU Jiang 1990: 80).

28 Pleasure boats - a practical, popular and fancy means of transport, something like street-trams in San Francisco today - became the symbol of Yangzhou. They were chosen for the title of Yangzhou huafang lu (Li Dou 1979 [I795]: 404-07), the last chapter of which recorded the number and condition of pleasure boats available. Over the igth century, several books borrowed the title '[placename] huafang lu,' but they dealt with 'sing-song' girls and prostitutes; not biographically, but in the form of lists of names with comments on the looks and abilities of the women. I assume that this habit of giving the lives of 'sing-song' girls the title Huafang l $u$ was derived from Li Dou. After all, he included a chapter on the pleasure-quarter Xiao Qinhuai. This was risky during the rigid Qianlong era, but may have inspired later books to take that narrow focus (Olivoví 200I: 135-36).

29 It is unclear who painted them. The poet Wang Chang 王这 wrote that the salt censor Gao Heng 高恆 himself drew a series of twenty-four vistas of the beautifully reconfigured area, and presented it to the emperor on his visit in 1757 (WANG Chang 1988: 300). As reaffirmed by Wang Chang and Yuan Mei 袁枚, this series was later used for Yangzhou huafang lu (Olivoví 200I: I4O-4I). The illustrations, however, number thirty-one. Recently, the name of Liu Maoji 劉茂吉 has appeared in a caption under the reproduced pictures, without further comment (Li Baohua 200I: 4I, 105, 217).

30 The best preserved house of a regional association dates from after the Taiping: it is Lingnan huiguan 嶺南會館, built in 1869 at Xincang xiang 新倉巷 (ZHu Zhu 1989: 107; also Finnane 204: 178).

31 The Taiping military campaign started at the beginning of I85I, when the spiritual leader Hong Xiuquan 洪秀全 proclaimed the Heavenly Kingdom, tianguo 天国. It was speedy: in twenty- 
seven months, the Taiping armies had passed from Guangxi 廣西 across Hunan 湖南, Hubei 湖北, Jiangxi and Anhui 安徽, eventually reaching Jiangsu.

32 It is difficult to get an objective and complete picture from the materials available. Western historians tend to investigate the ideology and social system, and less the actual warfare. For modern Chinese historians, Taiping history is a sensitive topic; it is considered 'improper' to say anything negative about it, or to describe the effect which the wars inflicted. Plundering and killing is therefore euphemized as 'the Xianfeng 咸豐 years' or the unspecified 'bing huo' 兵火 [soldiers and fire]. I ought to mention, however, the exhibition 'Taipings at Yangzhou,' Taiping xia Yangzhou 太平下揚州, which opened in the Yangzhou museum on I October 1953, under the auspices of the Communist party regional committee. The exhibition was publicized with great zeal, since the Communist party saw the Taipings as a precusor. It lasted a month, and was accompanied by lectures and other happenings, e.g. performances of a historical drama staged by a Yangju 揚劇 theatrical group. The staff of the museum and of the Municipal Library, who jointly prepared the exhibition, were able to discover written documents previously unknown, and gather oral testimonies (Luo Ergang 1978: 274). It goes without saying that the way of presenting the materials was highly non-objective. Taiping history was never again presented in Yangzhou on a comparable scale.

33 The Liang Huai salt administration, yanyun shi, had temporarily moved to Taizhou (WeI Minghua 200I: 258).

34 See also Meyer-Fong's Chapter 2, note 8 in this book.

35 According to the testimony of Lindesay Brine, I00,000 people were taken from the towns in Jiangbei to Nanjing to built fortifications (ReCLUs 1972: 69).

36 This campaign failed, and both Lin Fengxiang and Li Kaifang were executed in Beijing in I855.

37 In September 1854, because of hunger in Nanjing, many hostages were let go (Reclus 1972: II2).

38 There, on 9 August 1856, the imperial commander Xiang Rong 'hanged himself' (Shen Jiarong, JiAng Zhiliang 1993: 52). Cf. 'was fatally wounded' (Reclus 1972: II2); 'broken by this humiliation [of defeat, he] fell ill and died' (Spence 1996: 237); 'died' (Teng 197I: 139).

39 The complex with three shrines, several classrooms, and 64 dormitories was built by the salt merchant Ma Yueguan 馬曰琯. In 1743 it merged with the Anding academy, and in 1777 became again an independent institution (Ji Xiaofeng 1996: 44).

40 In peacetime, these artisans painted images for countless earth-god shrines, tudi miao 土地 廟, which stood practically on every street. Before the god's birthday on the 2nd day of the 2nd month, shrines had to be redecorated with the habitual designs: lions, dragons, flowers and birds, episodes from Sanguo 三国 and Shuihu 水滸. On the festive days, people went around the town and enjoyed the newly painted pictures (Luo Ergang 1978: 283).

41 Wanfu qiao was built in I849, six kilometres east of Yangzhou. It was east-west oriented, a huge cross-beam construction combined with supporting stone arches on each end. This was the biggest bridge in the area, more than 500 meters long. See a photograph in WANG Hong 200I: 33, taken in late Qing.

42 In the words of Fei Xiaotong 費孝通, quoted in Finnane 2004: I52.

43 Nonetheless, the elite was still visible. The two biggest traditional mansions now preserved were built or rebuilt in this period along Nanhe xia: the residential complex of the salt merchant Liao Keting 廖可亭 in 1908, and that of the salt merchant Wang Yongyi 王泳沂 in I919. 
44 The outrage over Yi Junzuo's book provoked responses from other writers, for example Cao Juren 曹聚仁 who wrote a review titled Xianhua Yangzhou 閒話揚州, and Zhu Ziqing 朱自清 who wrote Shuo Yangzhou 說揚州. Both articles were published in the journal Renjian shi 人間世 in 1934. Zhu Ziqing later wrote the well-known essay Wo shi Yangzhou ren 我是揚州人, first published in Renwu zazhi 人物雜誌 in I94I.

45 Under the Communists, Xu Baoshan was perceived negatively; in $195 \mathrm{I}$ his shrine in the $X u$ yuan park was turned into a restaurant, equipped with Qing furniture from another garden residence. The name of the park remained unchanged, and the stele was also left in place (ZHAO Weihang 1991: 189). However, a positive political evaluation of others was reflected in steps such as the repairing of Ruan Yuan's tomb and grove, which became a public park in 1952. Shi Kefa's memorial hall, however, was not on the protected list until 1982.

46 The road was built despite violent resistance by locals who feared that the graves would be disturbed (Zhang Daoyou 200I: 250-5I). Although there was a bus route from Guazhou, travellers in 1932 still had the option of taking a boat pulled by oarsmen (Meyer-Fong 2003b: 243).

47 A section south of Xiao Dongmen 小東門 had already been pulled down in 19I0, and replaced by a theatre; another section north of Xiao Dongmen was pulled down in I9II, and replaced by a park (WANG Hong 200I: 188).

48 The Japanese advance was accompanied by ruthless violence; more than 400 people were massacred at the Wanfu bridge near Yangzhou (Shen Jiarong, Jiang Zhiliang 1993: 462), just one of the many tragic incidents.

49 Much less than I.5 million at the end of the Qianlong reign (Wu Zihui 200I: 224), or the estimated 355,500 in 1994 .

50 Reconstruction of major canals and dams took place throughout the whole region. The 40o-kilometer-long section of the Grand Canal, in the direction of Xuzhou, was repaired between the years 1958 and 1960, with eight new locks built. The first of them was Shiqiao chuanzha 施橋 船閘 in the southern suburb of Yangzhou. The Wanfu Dam, Wanfu zha 萬福閘, was built in 1959 on the rudiments of Wanfu qiao, mentioned earlier. It was the biggest hydraulic project in the Huai 淮 river basin: a 468 -meter-long dam, supported by 65 arches, with a road on the top. Such massive constructions, made possible through the availability of cheap labour, were continued in the I960s and I970s. The major hydraulic project of the Cultural Revolution was the Jiangdu water pump system, chou shui zhan 抽水站. Made of 4 pumps, I2 control gates, jie zhi zha 節制 閘, and 4 lock gates, chuan zha 船閘, it was built from 1961 to 1977. In the period 1969-1975, the Guazhou Dam was built, for the purposes of both irrigation and hydro-electricity supply. The Yangzhou Dam, which yielded fields and protects Yangzhou from floods, was built in 1970-1972, and reconstructed in I99I (ZHAO Weihang I99I: 132-37)

51 Of the premises of the historical salt administration, only the gate, menting 門廳, has survived. Currently, the complex is under reconstruction, and the city government has moved to the new Western district.

52 At Wanzi jie 灣子街, No. Io Sanduo xiang 三多巷. Wang Shaotang was still alive then; he died in 1968.

53 Yuansheng si at Gengzi 埂子 Street was erected in 1930; it replaced the former Anhui association, Jingde huiguan 旌德會館. The main worship hall with a nanmu 楠木 wood skeleton, just behind the gate, dates from the Ming dynasty. Declared a city monument in May 1962, it has been divided into small apartments, and still so functioned in September 2007. 
54 The list of Yangzhou monuments from 2002 includes 24 carved portals, all protected since I962 ( $Y$ WB: items IIO-I33). In the notes it is added that I4 portals had been broken, seven during the Cultural Revolution.

55 The He Garden was confiscated after the civil war, and became the property of the army, who established the Second Short-course Middle School, Er su zhongxue 二速中學, there. On the tenth anniversary of the founding of the PRC, in 1959, a part of the garden was opened to the public (Du Hai 2002: 33).

56 On the list from 2002, however, the Ist and 2nd groups are merged, and all the monuments concerned have the date 1962 ; see $Y W B$.

57 Here abbreviated as $Y W B$. I am grateful to officials from the Ministry of Culture of the PRC for handing me a copy of this internal document.

58 Also Lianxing si was rebuilt and monks now live in the 3-storey enclosure in the back yard, behind the busy temple shrine. The building is massive, although hidden amid trees, like the pagoda. In the view of a Chinese visitor, the monastery 'is small and was rebuilt only to impress tourists' (September 2007).

59 It is a common practice in many Chinese towns for the Wenwu ju to occupy historic buildings, often the Confucian temple, wenmiao 文廟. In this way, the preservation and maintenance of such a building is secured.

60 The Ge yuan was built by the salt commissioner Huang Zhijun 黃至筠, in the Jiaqing reign; the He yuan was built by the official He Zhidao 何芷舠 in 1883 as an addition to the old Jixiao shanzhuang 寄嘯山莊.

61 According to the board with information on the temple's history, at Qionghua guan, October 2005. See also ZhaO Weihang I99I: 39.

62 The situation reminds one of whole sections of historical towns pulled down and rebuilt in a historicist manner, although the houses are much larger, and suitable for tourists, as in the so-called Old Town of Huizhou, Huizhou gucheng 惠州古城 in Shexian 倽縣, southern Anhui, or the Old Street in Yangliuqing 楊柳青 near Tianjin 天津, and elsewhere.

63 The residence was built in 1904 by Wu Yinsun 吳引孫 (185I-1920), who held high office in Zhejiang. He had the complex built in the Zhejiang vernacular style, except for one building in the fashionable Western style. The empty Cehai lou library is a part of the complex. Wu Yinsun lived there until I9II, when he moved to Shanghai. During the occupation, the residence had a Japanese owner, was damaged by fire in 1945, and was later transferred to People's Hospital ownership.

64 Ai Xuan's essay 'The landmark of Yangzhou' was originally published in Yangzhou wenxue 5, 1987, no. 6, and again in Gu Yiping 1989: 297-98. Tall buildings are mostly found on Wenhe Street and Wenchang Central Street; these are high enough to overtop the Wenfeng Tower, but are far from being 'skyscrapers' of fifteen storeys or more. One of the exceptions is the Guangyuan Dingshan 廣源頂山 Hotel, a pink tower of peculiar shape, with I4 storeys, built on the southern edge of the historical town.

65 The site of the gate of Dongguan was recently excavated, and rebuilt in an open archaeological site in 2007, called Dongguan yizhi 東関遺址. Another such site, showing a part of the Song fortification system, lies inside the Southern gate, Nanmen, on the opposite side of the town.

66 The opening of the railway line between Nanjing and Yangzhou in April 2004 was a great achievement. The existing railway line from Shanghai to Nanjing excluded Yangzhou, running 
as it did - and still does - on the left bank of the Yangzi, with the closest station in rival Zhenjiang. A project for a railway passing through Yangzhou was first discussed in 1896, and again in I9I3 (from Guazhou to Qingjiangpu 清江浦), but with no success (WANG Hong 200I: I83-84). The building of the new railway was partly supported by a six billion RMB private investment; the station building was designed by Bruce W. Halferty, an architect from Los Angeles, then based in Shanghai who has worked extensively in China since 1993. The architecture is a modern interpretation of traditional forms: the extruded elliptic roof is conceived as an inverted traditional roof; along the ceiling runs a colonnade, again a historical reference. The walls are made of transparent glass, with stone at the base. According to the Railway Department statistics, passenger traffic in 2006 reached over 4000 persons per day - that is, not very many!

67 See, for example, his speech in the overseas edition of Renmin ribao, haiwai ban 人民日報海外 版, I2 March 1990, where he mentioned the number of monuments in his native town, and praised their restoration and protection.

68 On calligraphy as an expression of political power, see HAY 2005.

69 For example, Dong quanmen 東圈門, the gate built in 1530 to protect the Liang Huai Salt Administration Bureau. The wooden pavilion on the brick wall is a new structure from 2000. 


\section{Gathering in a Ruined City}

\section{Metaphor, Practice and Recovery in Post- Taiping Yangzhou}

\section{Tobie Meyer-Fong}

$\mathrm{T}$

The Taiping 太平 War lasted for more than a decade (I850-I864) as government forces, local militias, foreign mercenaries, Taipings and other loosely affiliated rebels struggled to achieve dominance over urban strongholds and to maintain control over their own unruly troops. In the process, lives, buildings, and texts - the building blocks of community and cultural heritage - were decimated, ruined and scattered. At the same time, with its virulently anti-Manchu rhetoric and Christian-influenced religiosity, the Taiping movement fundamentally challenged the Qing political and ideological regime. In the aftermath of disaster, communities engaged in processes of gathering, literal and figurative, physical and metaphorical. While the tumultuous events of this war have been rewritten strategically (by the ream) in what must be one of the more voluminous and politicized historiographies in the modern China field, little attention has been paid to questions of destruction and recovery. Beyond the stunningly awful, and possibly inaccurate, statistic of twenty million dead first proposed by foreign missionaries in the mid-nineteenth century, the historiography offers noticeably little mention of destruction and loss of life. ${ }^{1}$

Instead, damage remains buried beneath political imperatives. The Chinese historiography bears the traces of its own history of forgetting, through which the war became first an antecedent to the anti-Manchu nationalist revolution of I9II, then a proto-Communist revolution and peasant uprising to those ideologically intent on 1949. Most recently, in the I990s, it has become a strange hybrid combining the old markers of proto-revolution with renewed interest in strongman heroes loyal to the Qing state at all cost. ${ }^{2}$ Western historians, by contrast, have tended to view the rebellion through the exotically familiar narrative of a (possibly mad) leader who claimed to be God's second son, and thus have tended to produce psychological studies of the Taiping leader or detailed analyses of the Taiping leadership's political and religious ideology (Fig. 2.I). ${ }^{3}$ 
Lost in all this are salient questions of damage and its commemoration. How were bodies collected and disposed of? How did people respond to political rupture, displacement and personal grief? How did war affect the practice of daily life and what were the effects of traumatic events on regional economic, social and cultural hierarchies? How did ordinary subjects - and the imperial state and its agents - translate, politicize and commemorate the terrifying events that those who lived through this period witnessed and felt? What gestures were used in order to recuperate some sense of stability and normalcy after a shattering disaster? What systems of belief and authority did these gestures embody, and how effective were they at bringing the desired order into being? What tensions lie buried beneath these homogenizing efforts at commemoration and restoration? In response to these many questions, this chapter will examine the motif of 'gathering' as it appears in texts produced in the immediate aftermath of the Taiping Rebellion, using this term as a window into the social, cultural and emotional responses to a nineteenth-century catastrophe.

The word gathering promises a literal and figurative reconstitution of people and places through the coming together of constituent parts, whether human, communal or material. It suggests active processes of reconstitution and normalization that also edit out communal tensions and undesirable ideologies. According to Webster's Dictionary, gathering means an assembly or meeting of people or the collection of food and raw materials from the wild. ${ }^{4}$ By extension, the word gathering can describe the compilation of written materials, as for an anthology or work of history. It also, in common usage, can refer to an informal party. The Chinese word $j i$ 集 covers a similar semantic range, and is used to describe parties or banquets, the coming together of friends and family, community gatherings like market fairs (the term $j i$ appears, for example, in the names of villages that hosted periodic markets). ${ }^{5}$ It can refer to the physical act of bringing together resources, as for the renovation of a building, or personnel as in a militia, and to the collection of texts, as in the compilation of anthologies. Another term, cai 採, particularly as used in the compound caifang 採 訪, also evokes something of the sense of the English word gathering, for it, together with fang, means the collection of information through the process of conducting on-site investigation and interviews (Hanyu dacidian 1993, vol. 6: 690). These terms, $j i$ and caifang, analyzed together here, but with the recognition that they operate in tension and have somewhat different resonances, appear with considerable frequency in late nineteenth-century Chinese sources, particularly, it would seem, those that respond to the cataclysmic events of the Taiping Rebellion. They describe activities carried out by a range of actors, state and local, elite and commoner, including parties sponsored by local elites, the compilation of scattered texts, the composition of local histories, the collection of oral testimony, and the commemoration of dead martyrs through ritual and research. These acts of gathering fitted into, and subtly 
transformed, the broader constellation of interactions between the political center and the locale. By looking at these various modes of gathering, I hope to call attention to the deeply felt need to restore, or reinvent, the idea of normal, everyday life in a post-war world, both in the particular context of nineteenth-century China and more generally, while at the same time suggesting the ways in which these processes of remembering (and forgetting) the recent past were embedded in changing political dynamics.

This chapter explores the implications of gathering, in practice and as metaphor, for the imperfect and (indeed) never completed processes of collective recovery in one damaged community, Yangzhou, during the decades that followed the Taiping War. Key sources for this study include reprinted archival documents on the suppression of the rebellion, a local history of Yangzhou prefecture published in I874, a manuscript diary recording a local man's daily life in 1863 (supplemented by other diaries and memoirs produced during and after the rebellion), commemorative collections honoring the martyred dead, poetry anthologies, and sub-statutes detailing the evolving practices associated with Qing military commemoration. Central figures will include Fang Junyi 方濬䫫 (I8I5-I889), the post-Taiping salt controller, renovator of scenic sites, overseer of the gazetteer project, and energetic collector

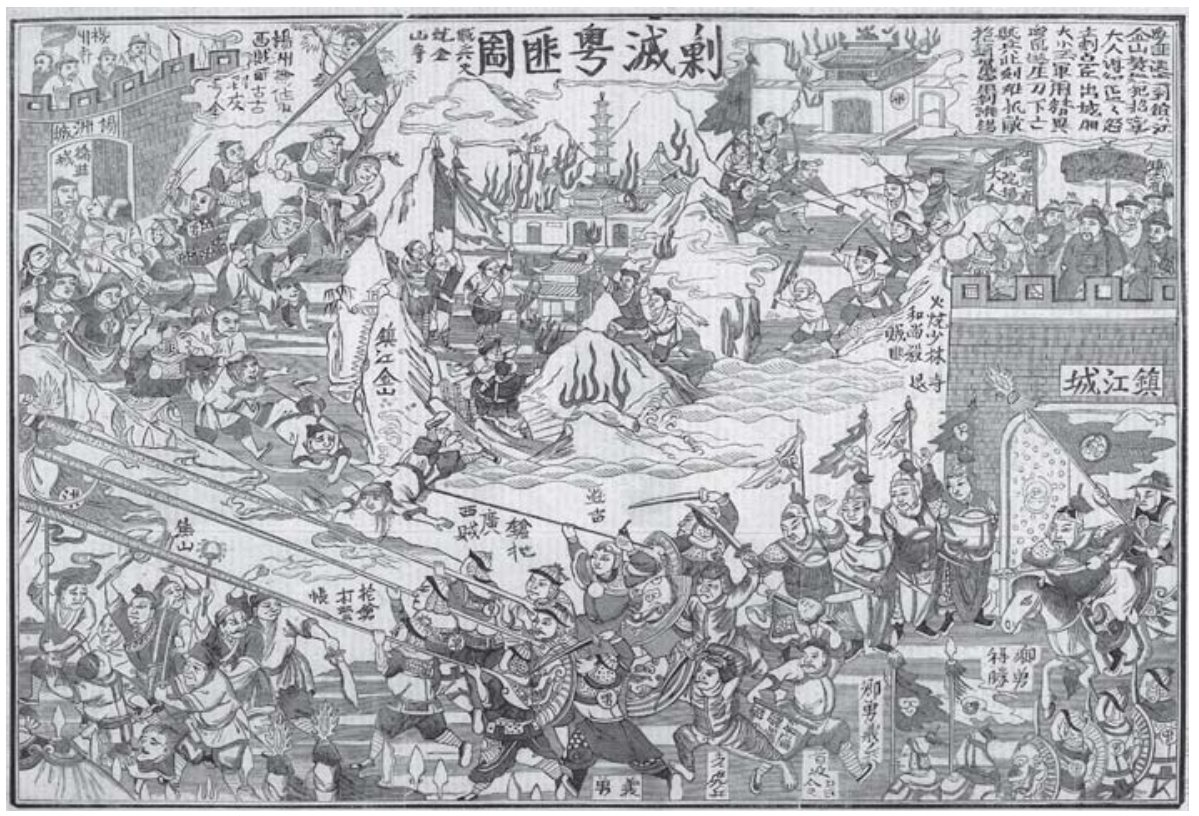

Figure 2.1 Exterminating the Yue Bandits. This woodcut shows the Qing forces fighting the Taipings in 1854 - with the Qing forces at Zhenjiang and the Taipings at Yangzhou. (Mansell/Time Life Pictures/Getty Images). 
of oral histories of the rebellion, who was later excoriated by some biographers for his luxurious living and lewd poetry, and Jin Changfu 金長福 (I797-I87I), diarist, militia organizer, compiler of scattered texts, literary socialite, eater of noodles, and participant in the compilation of the gazetteer. ${ }^{6}$

\section{SHATTERING}

To understand the imperative to gather and thus reconstitute, we need first to probe the extent of the damage. We know almost intuitively that the damage must have been extreme. Yangzhou, renowned in the eighteenth century for its wealth and decadence becomes again, as it was in the much more distant past, a city destroyed. Documents suggest the scope of the disaster seen through its assembled pieces: the breaking of the city wall, the burning of the city by government forces, death of city residents by suicide and in battle, and the havoc wrought by intense fighting in the near suburbs. In a series of quatrains, diarist Jin Changfu draws upon and disrupts the glamour of standard allusions that once stood for the city. In so doing, he depicts the devastation that the city had suffered over the past decade, describing the once celebrated Red Bridge as belonging to the Yellow Underworld, and the city itself as a hungry land of ghosts and corpses. He writes:

The bones of war are sunk and buried below Horse Hill.

Summoned they erupt into view amid a layer of white clouds.

Without emotion - the Iron Buddha ought to shed some tears.

With spring rain on a freezing night, the ghosts respectfully accept a plate.

In distant wilderness we take turns racing a slow cart.

On Shu Ridge the grass grows long as the sun sets in the west.

Qingming and Cold Food Days [festivals for the dead] have both passed us by.

Only a handful of households have noodles and rice to take to the graves.

(Jin Changfu, Guihai riji)

How did it happen, this shattering of local society, the shards of which local actors and their metropolitan counterparts struggled, often in vain, to gather and thus put back together again?

For the people of Yangzhou, the rebellion began with rumors: an accelerating trickle of hearsay and anxiety as the rebels moved from the central Yangzi toward the delta in late February I853. The rebel official Lin Fengxiang 林鳳祥 and his comrades, having recently occupied the nearby cities of Nanjing (where they established the capital of the Taiping Heavenly Kingdom), Zhenjiang 鎮江 and Yizheng 儀徵, were 
said to be planning to continue their eastward campaign and occupy Yangzhou. One local man proposed appeasement - offering food to placate the rebels - but was overruled by others who organized a small militia to capture the conciliator and defend the city. These defensive efforts failed, however, when government reinforcements did not arrive and rebel troops attacked the city by land and water. Betrayed by their leaders, who, according to at least one source, had actively encouraged the attempt to pay off the rebels, the local populace hung banners indicating their surrender (Zhang Yiguo 2004: 323). The city fell on March 2nd. Those in charge of its administration and defense abandoned their posts and fled by boat, and were later dismissed in absentia for their cowardice. Many dozens of residents committed suicide or died in battle, and their deeds are recorded, or gathered, in various published martyrologies as well as in various locations in the gazetteer. ${ }^{8}$

Qing forces then began a prolonged siege of the occupied city making repeated if feeble attempts to recapture it. Deforestation and the disruption of agriculture in the near-suburbs evidently characterized this period, as the imperial troops of the Jiangbei garrison settled into positions, chopped down trees, and excused their own failings with claims of bad weather, incomplete understanding of the local situation, the presence of tens of thousands of well-armed rebels both within the city and on nearby waterways, and the continued lack of troop reinforcements ( $Q Z F Z Y$, v. 5: 585). Some of the city's administrative functions, including offices related to the Lianghuai salt monopoly, were relocated to nearby towns, disrupting the centrality of the occupied prefectural seat (Yangzhou fuzhi 1874: 24:9a-b). In the meantime, the rebels occupied the strategically and administratively important walled city, as well as several important temples in the scenic area northwest of the city wall, for a period of nine months. We can infer a certain amount of damage to the city from accounts of loyal martyrs who died in fires and street battles, and from battles over rebel defenses established among the scenic sites in the northwest suburbs. ${ }^{9}$ For example, in late April and early May imperial forces launched a successful attack on the rebel stronghold at the Ocean of the Law Temple, Fahai si 法海寺, from Guanyin Mountain Guanyin shan 觀音山, wrecked rebel defenses at Five Terraces Mountain Wutai shan 五台山, and burned three rebel camps at Twenty-Four Bridge, Ershisi qiao 二十四橋 (Yangzhou fuzhi 1874: 24:6b).

Judging from their reports to the central government, the Qing officials' principal concerns appear to have been acquiring additional supplies, clarifying the central government's instructions, preventing the rebels from launching a campaign north from Yangzhou, sniping at their factional opponents, and obtaining state honors for those who died in battle. Their attempts to retake the city on several occasions were met with strategic fires set along the city wall. ${ }^{10}$ One report points out that the rebels were better equipped with guns, grain, money, cannons, gunpowder and boats than the Qing forces, and that in addition to their original following of 'true 
believers' from the southwest, numbering approximately 20,000, the rebels had been very successful at 'coercing' ordinary people into their army. By contrast, in spite of official propaganda distributed in the region and in the rebel camps claiming that 'those who scatter and run away will be spared, and those who kill rebels will be richly rewarded,' the Qing armies were unable to attract broad support, and the imperial forces and their militia allies repeatedly failed to retake the city (QZFZY, vol. 5: 585).

Late in I853 Qing forces 'liberated' Yangzhou, but only after the erstwhile rebel occupiers suddenly retreated to the walled town of Guazhou 瓜洲. Qishan 琦善 reported to the court that his forces had entered the city and had taken action to relieve the suffering of the local populace by providing food to as many as 10,000 elderly, infirm and female residents. He also claimed that only ten per cent of all urban residences had been destroyed in the course of occupation and recapture, and while he observes that the local militias had been somewhat unruly when they entered the city, he states that the damage was limited and repairs to the city wall and to cannons abandoned by the rebels were well under way (QZFZY, vol. II: 528).

A few days later, however, Jinkang 晉康, another Manchu official, sent a secret memorandum to the throne reporting that the forces under Qishan had behaved disgracefully, pillaging the city's pawnshops for booty and seizing clothing literally off the people's backs. He writes that while some might consider this looting to be the soldiers' rightful reward for punishing the rebels (and perhaps those civilians that harbored them) their refusal to open the gates to allow private philanthropists into the city to distribute food could not be excused. Moreover, he reports that after the recapture of the city, militias working for the imperial government killed many people, and set fires throughout the city, to the extent that 'smoke and flames cloud the air and block out the sun and sky' (QZFZY, vol. II: 543-545). Jinkang further notes that the court ought to be more attentive to the concerns of ordinary people, if only in order to prevent them from turning to the rebel side. Later accounts of the city's post-war reconstruction suggest that the damage inflicted on the city in 1853 was considerable and terrifying. The role of Qing and militia forces in perpetrating that damage remains unmentioned (and unmentionable) in the gazetteer and official campaign histories, although it figures centrally in post-Qing accounts sympathetic to the rebels.

In spite of the restoration of Qing control over the prefectural seat, the strategically important triangle defined by Nanjing, Zhenjiang and Yangzhou remained unstable for more than a decade. Indeed, on two more occasions Yangzhou city fell to the rebels, only to be recaptured after intense fighting and much shorter periods of occupation. During this period of endemic warfare, the near-suburbs suffered terrible damage, as did the key transportation arteries in the vicinity. The nearby county seat at Yizheng was nearly decimated, despite a tradition of local activism 
that fueled high levels of militia participation. The countryside northwest of the city experienced a terrifying period of burning and looting immediately after the rebels captured the prefectural seat in I858, and continued to suffer periodic fighting until Nanjing was recaptured and the rebellion was suppressed.

The literal and figurative shattering of local society was met with material and emotional re-gathering and reconstruction. Once the war was over, it was of necessity narrated through the lens of official interpretation inflected by local circumstances. The gazetteer chronology draws heavily on the officially sanctioned campaign history. In the interstices, we find newly gathered material that subtly inserts a local perspective, if one that is inevitably favorable to the Qing side. During the first decades of the restoration that followed the war, the Qing state-as-symbol provided orthodox interpretive frameworks that at least formally shaped processes of gathering, reconstruction and commemoration - and literally erased, burned or buried the material and textual traces of the Taiping crisis. This official overwriting had its physical counterpart in the post-war reconstruction of the city's memory landscape and quotidian infrastructure.

\section{SOCIAL GATHERINGS}

Against the backdrop of the region's once scenic sites, the practice of gathering with friends and associates continued to structure the daily lives of the region's educated elite. Such gatherings seem to have been a mark of desired, if not realized, social normalcy, even as they provided an arena for ongoing cultural production. Catastrophe did not put an end to socializing and poetizing. Instead it added new dimensions: nostalgia for past times and places, and an intense desire to reconstitute connections to a collectivity of peers. The salt official Fang Junyi's sponsorship of the restoration of at least some Yangzhou social venues during the early I870s suggests a desire to return to the normal practices and sites of elite sociability. ${ }^{11}$ Writing both during and after the war, diarists recorded daily social interactions, including visits, parties and banquets, as well as the exchange of letters between friends and relatives. Participants were not immune to, nor were they ignorant of, the impact of the war on local society. Traces of the disaster intrude into literary description through distorted imagery, literary references and historical allusions. It seems almost as if these men sought to inoculate themselves against the war's effects by way of their socializing.

Written in 1863 , Jin Changfu's diary provides a daily record of social gatherings with recent memories of the then still-ongoing war not far in the background. A native of Gaoyou 高郵 county and thus of Yangzhou prefecture, Jin Changfu had friends and family throughout the region. Apparently a talented interpreter of literary and historical texts, as well as a prolific poet, Jin Changfu repeatedly failed to 
pass the civil service examinations, eventually abandoning that route to government service. ${ }^{12}$ After Yangzhou fell to the rebels in 1853 , he dedicated himself to militia defense and was rewarded with a symbolic promotion to the minor post of 'Instructor. ${ }^{13}$ While his primary residence during 1863 , the year for which we have access to his diary, was Taizhou 泰州, a county seat northeast of Yangzhou, some of his many sons lived in the near-suburbs of the prefectural seat and many of his associates also had residences in the city itself. ${ }^{14}$ Evidence in the diary suggests that Jin Changfu was living in Yangzhou at the time of the rebel occupation in 1853 . He paid several visits to Yangzhou during the diary year, and attended parties there, for on at least several occasions he makes note of the status of the city's scenic sites in his poetry. He evidently participated in the 1874 gazetteer project: his name appears first on a list of section editors in the book's front matter, although he died just as the project was getting under way.

Jin Changfu's diary consists primarily of a daily record of his active social life. On a typical day, he visited or was visited by several friends, sent letters, and took his meals in the company of acquaintances or relatives, often in local restaurants or noodle shops. ${ }^{15} \mathrm{He}$ makes note of numerous outings to famous sites, gardens and temples in Taizhou and other regional venues, including some that were still under construction and others that were ruined or occupied at various points during the war. ${ }^{16} \mathrm{He}$ also mentions books read and returned, poetry manuscripts exchanged, gifts given, works of art inscribed and appreciated, and banquets hosted and reciprocated. Family gatherings receive much notice in the diary. Jin Changfu had at least eleven sons, and their comings and goings are well recorded in the diary. He sometimes corresponded with his daughters-in-law, although his wife (or more likely, wife and concubines) is never mentioned.

The war intrudes, sometimes subtly, into the chronological record of Jin Changfu's social life. He notes that a friend visited to discuss 'current events,' or that 'I received a letter with the information that there are rebels in Tianchang 天長 [Anhui] and they are heading for Yangzhou. Martial law was declared and the prefectural examinations had to be cancelled.' He records having mailed two copies of a book celebrating the lives of loyalty martyrs along with his calling card and letters to two men in Yangzhou and mentions on another occasion that he investigated recent rumors related to the war. More substantially, the war intrudes by way of poems, essays and letters interpolated into the record of daily activities, some of which contain disturbing echoes of wartime violence and destruction. With one such poem, Jin Changfu inserts a note indicating that he had fled the fighting in 1853 , seeking refuge in Beihu 北湖, and that in that year, he held his annual lustration party in a garden that had belonged to the renowned scholar-official Ruan Yuan 阮元 (I764-I849) a generation earlier. He includes poems on the scenic sites of Yangzhou, filled with depressing references to past glories, now ruined, and current pain. ${ }^{17} \mathrm{He}$ 
includes a biography of his friend's mother who committed suicide in Zhejiang when the rebels burned through the region in 1860 and the Qing archers proved utterly useless. He notes that her body remained intact after her suicide, a mark of her moral purity, and concludes that she is worthy of state honors that will further augment her reputation.

The diarist's juxtapositions of war, moral imperatives and literary sociability can be jarring, although they are probably representative of his life experience. He inserts a ballad that he had composed in honor of a female relative who committed suicide after escaping capture by the rebels in I858 at the age of 24 . The poem is grimly descriptive: the narration of her last days begins with the 'ghost birds' of Yizheng calling from dawn to dusk beneath a baleful star. The young relative vows to die when she hears that the rebels are approaching, but she is forced to flee with her husband and son, taking to roads already filled with 'wolves and other beasts.' Separated from her family, she and another local woman hide in a roadside shrine, and are later found, their hanging corpses still lifelike, the absence of decay underscoring their virtue. He writes that 'The world is lacking in heroines like this, her drops of blood are worthy of inscription in metal and stone. Praise in truth illuminates the flawless virtue of jade ... What survives in text is goodness beyond slander.' He ends by noting that her death offers an immortal admonition and example to her son and husband, who will thus become great scholars. This poem is followed by a light work describing peach blossoms cleansed by a light rain at a tourist venue in Taizhou.

This contrast between the experience of war and Jin Changfu's social life is characteristic of the diary. It suggests that Jin Changfu had an utterly normal social life for a man of his place, social position and age. Yet, in a set of four poems honoring the officers, gentry and commoners who died in battle or committed suicide, composed on a visit to Yangzhou's northwest suburbs, he includes several gut-wrenching lines about roads filled with dead babies and children, the noxious miasma of war tormenting the great and righteous community, and complains that the wages of the local militia have been unpaid. He offers commentary: 'Eleven years have elapsed since war broke out in this region. Old friends are dead and buried. Those that remain are scattered like stars at dawn. Feeling sad about the past and tragic in the present, I composed these four poems. '18 He adds another two poems describing the city of Yangzhou as a silent ruin, in an inevitable repetition of its ancient past, while also alluding to its more general decline. The city's great trades, in fish and salt, are no longer what they once were, he notes, concluding his poem: 'Those days of poems and wine, are alas distant feasts.' And then he continues again, transcribing a poem on a similar theme recently composed by a friend for the Huaihai Poetry Club, Huaihai shishe 淮海詩社, a group that had thirty-three members and gathered even during the war. 


\section{COMMEMORATING}

Even as he attended parties and composed poetry on themes both serious and frivolous, Jin Changfu prepared materials on behalf of the families of loyalty martyrs and submitted their cases for official commemoration. The use of state honors to reward the virtuous dead had an important history as part of the politics of commemoration in Qing China. The state had mandated the conferral of honors on virtuous subjects through an expanding number of sub-statutes in the collected Qing Institutes, Precedents and Sub-statutes, Qing Huidian shili 清會典事例, beginning in the early eighteenth century. This only accelerated with the Taiping Rebellion, when the extraordinary number of deaths caused a proliferation of honors and awards, the streamlining of bureaucratic procedures, and the expanded involvement of local and military officials and community elites in the process of investigation and commemoration.

Jin Changfu appears to have taken a leading role in the gathering of information about the honorable dead. In a letter to Yan Duanshu 晏端書, a native of the prefecture serving as an official in Guangzhou, Jin Changfu describes his activities with the self-deprecating language typical of a formal letter to a social superior:

Formerly, I was involved in the investigation of martyred gentry and commoners. The combined total for the city and countryside [thus far] is more than I500 names. As Transport Commander Wu has repeatedly said in his memoranda to the throne, we are still in the process of examining and recording in hopes of avoiding waste and omissions. First we have invited the special honor of a dynastically sanctioned commemorative arch, and second we hope to embody the excellent values that your honor has promoted. I only regret that my knowledge is not broad and I have not diligently applied myself to collecting and organizing the evidence and I am afraid that in the long run the [martyrs] will have inexhaustible resentment and regret.

In addition to this letter, Jin Changfu's diary also records specific occasions on which he submitted documents to the Yangzhou Bureau to Honor the Loyal, Baozhong $j u$ 裹忠局. Several of his poems suggest the significance attached to state honors, highlighting the way that commemoration at least in theory gave meaning to loss. Jin Changfu concludes one graphic poem narrating the experiences of a family that lost ten members by praising the man who submitted this family's documents for state honors. In this context, meaning appears to be situated in state recognition and inscription. A member of the local elite, he used tools and language borrowed from a (now weakened but clearly not yet totally irrelevant) center, as he recast his experiences of the war in terms of moral triumph. In the context of the diary, commemorative activities appear alongside pleasure outings, weather reports, poetry 
exchanges and banquets. Thus, participation in the documentation of martyrs fitted into his daily itinerary and experience.

What Jin Changfu calls the Yangzhou Bureau to Honor the Loyal is most likely an alternate name for, or the local branch of, the Liangjiang Bureau to Gather and Investigate the Loyal and Righteous, Liangjiang caifang zhongyi ju 兩江採訪忠義局, a semi-official bureau created in I860 by Zeng Guofan 曾國藩 almost immediately after he took office as governor-general of Liangjiang. The main function of this new institution was to seek information on 'the meritorious and exemplary deaths of officials, gentry, gentlemen, ladies and militia men who died in battle or were martyred,' to arrange for imperial recognition and honors, and to publish a record of their deaths in book form. ${ }^{19}$ Bureau publications not only record previous findings, but also solicit new ones, thereby perpetuating the function of the bureau itself. The editors include the relevant government documents in order to clarify and disseminate state policies regarding official commemoration and compensation for the benefit of those interested in obtaining similar honors for their own family members (Liangjiang zhongyi lu I887, fanli 2a). The editors express hope that extra volumes will be sent to the villages for further dissemination of procedural information to the descendants of those that died, in order that they might eventually submit dossiers, and to 'publicize the truth' about recent events to a wider audience (Liangjiang zhongyi lu $\mathrm{i} 887$, fanli $2 \mathrm{~b}$ ).

The bureau's commemorative program neutralized potentially disruptive events by positioning them within a structured network among provincial officials, local elite, and the central authorities. Like the publishing bureau and the bureau to oversee the publication of the gazetteer, the Bureau to Gather and Investigate the Loyal and Righteous combined new forms of local and official activism with pre-existing symbolism associated with state sanction. Like the other newly founded bureaus, it placed the act of gathering and investigating, or caifang, at least nominally front and center: its main activity was described as collecting and disseminating the 'facts' about martyred officials, local elites and commoners in order to ensure that they received appropriate honors and that their families were granted proper compensation to cover their funeral expenses. By the early I870s, the agents carrying out these tasks were intended to be local men of education, impartial gentry and elders employed in the bureaus. While the center imagined these processes as fundamentally local, particularly as its resources diminished, the editors make insistent reference to their participation in a large and highly bureaucratic system of state honors in their 'Principles of Inclusion' (Liangjiang zhongyi lu I887, fanli Ib). Clearly the bureaucracy at least in principle carried symbolic weight. And yet, in spite of this emphasis on formal, centrally sanctioned procedure, the bureau and its operatives still commanded room for local independence and the inclusion of those not honored by the state. Indeed, much of the momentum for changing the system of state honors into an arena for 
local initiative appears to have come from provincial officials empowered by their successful suppression of the rebellion, as well as the lack of resources available to a besieged and overwhelmed center. ${ }^{20}$

Local elites like Jin Changfu participated in a process of self-conscious and institutionalized gathering and rewriting of lived experience through the Qing system of official honors and awards. Paradoxically, this occurred against the background of diminished state authority and increased emphasis, militarily, administratively and otherwise, on local power. It would seem that local elites appropriated the language of imperially bestowed honors to further enhance their own position and sphere of operations, underscoring their autonomy by highlighting their commitment to the empire. To the local officials and elites who constituted and staffed new bureaus for the investigation of chastity and loyalty martyrs, who submitted lists of deceased family members for honors and compensation, and who read published lists of local dead or visited shrines, these nineteenth century changes may have helped to make moral sense of local suffering - and in the case of Yangzhou may have provided an opportunity to demonstrate retrospectively the virtue of a community that had been occupied by the enemy on three occasions, and whose loyalty to the throne was thereby compromised. Participation in the processes of state-sponsored honors may thus have provided occasion for local elites to enhance their authority (moral and secular), and created occasions for provincial officials to try and re-engage local elites. Thus, even as the disaster was recorded in terms of the destruction and reconstruction of infrastructure, it was also translated from ambivalent and complex experiences into morally absolute (and thus morally legible) memories, which reinscribed the city and its residents into the historical record as victims and martyrs through imperially sanctioned channels dominated and thus transformed by an activist local elite.

\section{REBUILDING}

Destruction and reconstruction, shattering and gathering - processes locked in opposition, but linked, inevitably, in experience and memory. In late nineteenthcentury Yangzhou, both the act of restoration and the retelling of it were at least ostensibly carried out under official auspices, as part of a state-local partnership to sponsor and record the rebuilding process. In the sections of the gazetteer dealing with administrative buildings, the city wall, philanthropic organizations, cemeteries, religious institutions and famous sites, we find a litany framed by the dates of destruction and reconstruction, and by practical efforts to dispose of remains and restore order. The gazetteer seems to oscillate between the fact of destruction and the fact of reconstruction. The disaster itself, at center, and, perhaps beyond explanation, 
is not explained, perhaps in order to displace blame for the disaster from the regime and its agents.

During the post-war period, local officials and elites gathered materials and personnel to reconstitute the city's physical spaces that had been damaged in the fighting. They sought both to recreate the semblance of a functioning administrative environment, and perhaps thereby to restore some measure of legitimacy to damaged state institutions, and to reconstruct the sites of local memory by rebuilding the places that had, in the past, infused the local landscape with cultural meaning. Fang Junyi, in his capacity as a salt monopoly official played a critical role in organizing the reconstruction of the city, and, as the instigating force behind the 1874 gazetteer, also helped shape the way the rebuilding was recorded.

The act of gathering material, money and manpower posed distinct challenges in the aftermath of disaster. These difficulties are enumerated by Jiang Chaobo 蔣超伯 in the essay he wrote to commemorate Fang Junyi's patronage of one of Yangzhou's most symbolically significant sites, Level-with-Mountains Hall, Pingshan tang 平山 堂. The renovation of the hall, with its echoes of Ouyang Xiu 歐陽修 (IOO7-IO72), the Northern Song statesman and literary giant, had performed an important function in the reconstitution of elite society in the Kangxi period (Meyer-Fong 2003, Chapter 4). Jiang Chaobo alludes to this, but points out that those days were not as difficult as his own. He thus rewrites the historical violence of the conquest period (more than two centuries earlier) as relatively restrained, in contrast with the remembered violence of his own experience which is, of course, described in more graphic terms. He continues:

More recently we had the disaster of the Southern rebels. The offices of the civil and military officials were all completely burned down. The shops and houses of the merchants and ordinary residents were all completely knocked down. The gardens and forests were completely laid waste. The carpenters and craftsmen were all bound and tossed in ditches. When I checked the old site, there wasn't even a fragment of brick or tile remaining.

(Yangzhou fuzhi 1874: 5:28a).

The author here underscores the totality of the disaster and thus the monumentality of the renovator's task. The reference to the craftsmen explains the high cost of repair, and the destruction of the forests accounts for the high price of materials. Combined, these factors justify the inability of local residents to carry out the basic functions of recovery, such as the repair of schools and the reinstitution of rituals to the city god and other local deities, on their own. The author thus highlights the critical role played by the newly arrived salt controller who inspired an outpouring of new plans and calculations for the restoration of the prefecture, and indeed who animated the local elites' natural impulse to philanthropy and 'gathering.' He places 
the salt controller's renovation of the hall among a constellation of projects ranging from clearing roads to fixing canals, projects which were said to have inspired the reconstruction of the city's physical, moral, philanthropic and cultural infrastructure. In other words, he tells us, by literally gathering materials and manpower for the renovation of Pingshan Hall, Fang Junyi created a venue that at least potentially laid the foundation for the symbolic re-gathering and regeneration of (elite) community, anchored rhetorically in its connection to what was by then much compromised imperial authority.

In an essay of his own, this one carved on a stone stele, Fang Junyi describes the renovation of Tianning Temple, Tianning si 天寧寺, one of the city's largest Buddhist institutions and the site of an imperial lodge built for the Qianlong emperor's Southern Tours. ${ }^{21}$ The temple burned to the ground in 1853 , and, at the time of Fang Junyi's writing, had recently been restored. Fang Junyi presents the temple's recent destruction as the antithesis of its glory days during the Southern Tours. Each of the two moments is described lavishly with richly layered allusions. The Qianlong golden age is evoked through the standard signifiers for peace and prosperity, the Xianfeng era disaster through the rhetoric of absolute ruin and loss. The rebellion is portrayed as inevitable, even natural; it is characterized as a 'pestilence' that arrived in Yangzhou 'spreading chaos. ${ }^{22}$ Fang Junyi positions himself as the project's organizer and patron, and thus the agent of order.

Among the gazetteer entries referring to the renovation of particular sites, temples and philanthropic institutions, we find numerous mentions of Fang Junyi's involvement. He is described as the motivating force behind the renovation (and sometimes relocation) of sites like Pingshan Hall, Gulin Hall 谷林堂, Luochun Hall 洛春堂, and the Seductive Spring Poetry Club (Yechun shishe 冶春詩社). Many of these sites were associated with cultural icons like Ouyang Xiu, Su Shi 蘇軾, or Wang Shizhen 王士禛, whose political and literary stature had given the city and its sites meaning in earlier periods. Some tried to transfer these associations to Fang Junyi himself. One commentator noted that Fang's poems at first followed Wang Shizhen's style and later emulated Bai Juyi 白居易 and Lu You 陸游. ${ }^{23}$ In his essay on Pingshan Hall, Jiang Chaobo notes that '[Fang Junyi] saw this hall as the remaining trace of Ouyang Xiu and $\mathrm{Su}$ Shi and had the inspired desire to rebuild it.' Later in the essay he adds, 'Beginning in the Song, Yangzhou has been decadent indeed! Fang Junyi alone stands alongside the two sages Ouyang Xiu and Su Shi in showing commitment and diligence.' (Yangzhou fuzhi 1874: 5:28b) By renovating these particular sites, Fang Junyi, Jiang Chaobo and the gazetteer writers who recorded their deeds, sought to create an analogy between those men and their times - and their own.

Response to disaster required activism, and who better than the salt controller to provide guidance and leadership? After all, as Fang Junyi points out in his introduction to the gazetteer, beginning in the eighteenth century it had been his 
predecessors in the salt monopoly, and not the magistrate, who had played the leading role in editing the local history of the 'Great Metropolis of the Southeast' whose 'great men of outstanding virtue are renowned everywhere and whose great scholars are numerous and in constant supply. ${ }^{24}$ At the time Fang Junyi wrote this preface, his portrait of Yangzhou was already obsolete, as was his self-identification with the more powerful men of the past. The salt monopoly had been reconfigured in I831, and later the tax transport ships had been rerouted out to sea. The city and the canal that made it central, and indeed Fang Junyi's office which once had made it prosperous, were all much reduced even before the rebellion. Fang Junyi adopts the mannerisms of an old style salt monopoly official, and positions himself in the role of cultural arbiter modeled after great officials and literary connoisseurs of the past. But while he occupied the office and tried his best to gather the material, ultimately both he and the state he represented lacked the gravitas needed for the role to maintain its legitimacy. After all, as one early twentieth-century biographer noted, Fang Junyi was subsequently undone by his own sharp wit and extraordinary decadence. Moreover, the biographer continues, although his literary collection was abundant, running to more than fifty chapters, it was not in fact very good poetry (FeI Xingjian 1985: 202: 598). And in spite of attempted reconstruction, the renovation of Yangzhou remained incomplete: the city never recovered.

\section{COLLECTING}

The damage and attendant need for reconstruction extended to the city's literary heritage as well: contemporaries noted the extreme dearth of written materials in Yangzhou after the war and a later work speculated that seventy to eighty per cent of the once textually rich prefecture's books were lost in the conflagration (Jiangdu xianzhi 1925 [1937 reprint] 30:I8b). The gathering and restoration or reprinting of texts and information by necessity also played an important role in the effort to recapture local heritage and sense of place. Moreover, even as the Qing state encouraged local elites and officials to expurgate Taiping memory by eliminating all textual evidence of their heretical regime, those same officials and elites also gathered materials more sympathetic to the Qing perspective. Not only were the names and stories of local martyrs collected for the purposes of official commemoration and enshrinement, as we shall see in greater detail below, but texts from the pre-Taiping past were assembled ostensibly to ensure their survival, narratives testifying to the horrifying events of recent memory were compiled and published, and, in a characteristically nineteenth-century gesture (and perhaps in the absence of more conventional sources), local elites were sent out into the field to collect materials for the gazetteer. 
With regard to texts, we find a powerful imperative to gather in the late nineteenth century. Writers repeatedly justify their own projects in relation to literary losses suffered during the war. Nostalgia for the once abundant book collections for which the prefecture had been famous suffuses post-war writings. Books became sites for reflections on loss and remembrance, touchstones for those interested in cultural (and physical) restoration. The symbolic power of text was enhanced by the threat of loss. Writing had long since represented an avenue to personal (and cultural) immortality, and anxieties of preservation historically animated a desire to collect, and thus preserve. Anthologies (again, $j i$ 集 or textual 'gatherings') were an important vehicle for ensuring the survival of people and values - and memories or experiences of a particular place and time that they embodied (Zeituin 2003: 87, Meyer-Fong 2004b: 17). Hence, as in other historical moments when civilization and its texts were threatened with extinction, the post-Taiping period was marked by efforts to search for, collect, collate and publish written materials (old and new). And yet, in this particular time and place, in the absence of pre-war and wartime texts, new words had to be produced, and on-site investigation and the gathering of oral testimony became an important element in post-war literary and historical writing. This latter activity, called caifang 採訪 in Chinese, is identified frequently by the editors of the late nineteenth-century Yangzhou gazetteer as part of their research practice. ${ }^{25}$ The term itself may allude at least obliquely to a more ancient use of the term cai in the compound caifeng 採風, the collecting of 'airs' or folksongs by the ruler or his representatives. Such songs were thought to be a gauge of popular sentiment and by extension a measure of the state of the empire. The practice of 'gathering' was closely associated with Confucius himself and carried substantial ideological weight as one of the duties of righteous rulership. The gathering of texts and information may therefore also have had a political function: to reassure the faltering Qing state of the virtue and satisfaction of the populace as reflected in collected material.

During the first decades after the war, officials and local elites sought to reassemble the prefecture's lost textual heritage. For example, we find several poetry collections devoted to surviving works on local themes and a set of biographies featuring local painters, all produced in the immediate aftermath of the war, with the authors in many cases citing recent loss as a motivating factor. ${ }^{26}$ Some members of the local literary elite, including the diarist Jin Changfu, assembled excerpts from earlier texts, creating a literary scrapbook on local events, people and places. ${ }^{27}$ Such textual gathering seems to have been understood as the emotional counterpart of physical rehabilitation. Thus, even as Fang Junyi portrayed himself as a leader in the prefecture's reconstruction, he also self-represented as the officially appointed defender of local texts and preserver of the local past, particularly through his leadership on officially sponsored projects and through his activities as the patron of at least two personal histories. 
As noted above, Fang Junyi presented himself as the official responsible for the I874 local history, justifying that project in relation to the loss of textual heritage. He notes that even [some of the] printing boards from the old gazetteer had been lost and scattered in the chaos of the rebellion. ${ }^{28}$ Fang Junyi also organized a group of local eminences and scholarly sojourners into a bureau to oversee the production of a new edition of the gazetteer, again noting that the project was inspired by the loss of documents that had occurred during the war. ${ }^{29}$ One of these was Yan Duanshu, the former vice censor in chief and governor of Zhejiang with whom Jin Changfu had corresponded in 1863 , and who had since returned home to Yangzhou prefecture. Another was Qian Zhenlun 錢真論, a former director of studies in the directorate of education who had come to Yangzhou as the head of the renowned Anding academy 安定書院. In his preface, Fang Junyi praises their contribution, noting that thanks to these gentlemen something good has come about in the aftermath of the extreme chaos of the war. ${ }^{30}$

In a similar project, Fang Junyi was charged with founding the Huainan Publishing Bureau, Huainan shuju 淮南書局, a semi-official entity with the mission of gathering and reprinting endangered writings. This was one of several such bureaus created by Zeng Guofan, one each in five cities devastated by the rebellion: Yangzhou, Nanjing, Suzhou, Hangzhou and Wuchang. ${ }^{31}$ In his introduction to one of the bureau's products, a biographical collection honoring the men and women of Yangzhou who had died during the Qing conquest of the city in I645 and who subsequently had received honorific titles and sacrifices from the state whose founding they had resisted, Fang Junyi explains the work done by the bureau and the institutional arrangements behind it, as well as the meaning of this particular selection:

In 1868, I was transferred from Guangdong to the Lianghuai salt monopoly offices [in Yangzhou]. Because of the lingering effects of the war, many local documents had been scattered and lost. Therefore, all large prefectures were asked to establish bureaus and to print books and the literati of these communities were asked to work on prefectural gazetteers. Moreover, because this prefecture is strategically located at the intersection of north and south, the natives of the prefecture who died in the war are too numerous to be counted. Thus I ordered all of the local officials to turn their attention to investigating and recording the dead in order to honor them and so that their cases would not be forgotten. Liu Baonan's 劉寶 楠 [the collection's deceased author] son, Gongmian 恭冕, sent the book to me from Nanjing. I read it several times, and saddened and respectful I realized that this prefecture's spirit of loyalty, righteousness, chastity and martyrdom surpasses that of other jurisdictions. Its current condition certainly has its historical antecedents ...

(Fang Junyi's preface, Liu Baonan: I87I) 
Here Fang Junyi makes an explicit analogy between the act of collecting texts for publication and the gathering of information about local martyrs for official honors. The two types of deeds seem almost interchangeable in function: they reinforce the realization by Fang Junyi, and by implication others, that in spite of exposure to the Taiping heterodoxy, this locale is deeply and essentially pure, loyal and righteous. This analogy is facilitated to some extent by the parallel between the martyrs from the Qing conquest two centuries earlier honored in Liu Baonan's book and those more recent martyrs whose dossiers were being collected by officials in his own lifetime. Martyrs gathered and publicized, their deeds embodied in published texts, were to give the prefecture moral heft and a kind of emotional, if highly stylized, immortality. Moreover, the same personnel, local officials and gentry, were to be organized into bureaus and charged with publishing and gathering data, in a state-private partnership to salvage local society and its constituent people, sites and texts.

\section{HAUNTING}

The dead too had to be gathered. Human remains had to be disposed of, necessitating the construction of cemeteries. ${ }^{32}$ Moreover, those who had died violent deaths had to be placated, honored and restored to the community. ${ }^{33}$ A metaphorical gathering of souls, nearly all of them low-ranking members of the local elite, appears in the 'Miscellaneous Matters' section of the Yangzhou prefectural gazetteer published in I874. Here we find a collection of righteous suicides: men and women who killed themselves on one of the three occasions when the city fell to the rebels, listed either individually or in family groups. Each entry consists of a brief biographical statement indicating the social position of the deceased, in most cases including their name(s), native place and official or marital status, followed by a suicide poem or statement testifying to their dying sentiments. Such final statements conventionally were made in a limited range of media: inscribed on walls, on clothing, or on the writer's body. ${ }^{34}$

Grace S. Fong has examined suicide poems by women for traces of individual subjectivity and agency expressed through gestures of performative 'self-inscription' (FONG 200I: III, II4). The eleven entries in the gazetteer, however, manifest conventionalized language and values. Moreover, they appear as part of a collective textual body. These poems thus must be read in terms of community values, rather than as vehicles for personal expression. ${ }^{35}$ Given the content of the suicide poems assembled here, it seems apparent that the editors chose this configuration of entries in order to highlight the persistence of orthodox values in Yangzhou despite the violence and heterodox ideological pressure associated with the recent war. ${ }^{36}$ In 
other words, these texts make sense collectively as building blocks in an editorial intervention, rather than as emotional assertions of individual subjectivity.

The gathering of spirits enacted by the gazetteer editors has both literal and figurative dimensions. First, the editors literally gathered their materials, here again relying on established techniques of compilation to ensure the survival of an orthodox version of community memory. They used texts, here relying in particular on two commemorative volumes celebrating local martyrs to the Qing cause, the Yangcheng xunnan lu 揚城殉難錄 [A Record of Martyrs at Yang(zhou) City] and its sequel, the $X u$ Yangcheng xunnan $l u$ 續揚城殉難錄. They also studied these matters in person, turning to their neighbors and associates to collect and investigate new voices and stories. These latter materials are explicitly identified in the gazetteer as 'new gatherings' or xin cai 新採. This emphasis on direct investigation alludes to the local scholarly tradition associated with the native son and intellectual giant, Ruan Yuan, who had become for many survivors a symbolic marker of the region's pre-war achievements. ${ }^{37} \mathrm{By}$ assembling texts and gathering information the editors sought to position themselves as arbiters of collective memory working within a revived and still prestigious local tradition. At the same time they assert communal adherence to imperial standards of virtuous conduct. Second, and figuratively, the suicides presented to the reader by the editors are, by virtue of their inclusion, 'gathered' into the city's moral community, a figurative gathering apparent in the ideologically charged final testaments quoted ostensibly verbatim in the gazetteer.

The suicide poems assembled here for the most part present the individual as the embodiment of established collective values. Indeed, all but one of the men portray themselves as loyal subjects of the emperor, righteous descendants of their patrilines, filial sons of their parents, or as a combination of the three. Rage, regret and sorrow feature prominently among their admittedly stylized and formulaic emotions. Thus, Wu Zhen 吳楨, a student, inscribed a suicide lyric on the wall before starving himself to death. His poem highlights his suffering in the 'endangered city,' his pain at the suffering of others, his 'thousand-year rage' at recent events, and the unsullied purity of his family's reputation. To his poem, Wu Zhen appends a brief commentary, reading 'For a long time, my family has suffered inside the city. For three days, I have taken neither water nor broth. Above, I return the emperor's benevolence, and below, I honor my ancestors' commands. My flesh and bones will have many companions. This is to be regretted. 38

Similarly, Fang Zhixing 方之杏 (no relation to Fang Junyi), a native of Yizheng living in Yangzhou, starved himself to death when the city wall fell. He left a verse written in four character lines reading: 'When the food is gone, my body is lost. I am righteous and feel no shame. Below, I comfort my ancestors, and above I face my lord and dynasty. A sister and two grandsons die with me in this room. My son will return and the corpses will be buried in the ruined valley. ${ }^{39}$ Here, like Wu Zhen, 
Fang Zhixing positions himself in relation to both ancestors and sovereign. He thus asserts a connection to his patriline, the community of deceased ancestors alluded to in the third line. At the same time, he posits a personal link to the dynasty, laying claim to a set of reciprocal and hierarchical relationships demanded by his prior official service. Fang Zhixing's suicide might then be read as a dependent's protest against his superior's failings, and not simply an expression of loyalty to the emperor.

While expressions of loyalty to state and patriline are implicitly gendered male, one woman among the righteous suicides presents her death using similar conventions. The woman and her husband lived as sojourners in Yangzhou. When the city fell to the rebels in 1853, they were both martyred (Yangzhou fuzhi 1874: 24: 33b). The gazetteer editors reproduce her two suicide poems, which detail her sense of obligation as an imperial subject, the evanescence of her flesh and bones, and the immortality of her words, inscribed for future people to read in a room filled with lingering fragrance. Her husband's poem follows hers and makes no reference to morality or obligation. Instead, he alludes to the city's romantic charms - the mists and flowers of the third lunar month, the two parts of moonlight, the Thirteen Towers of the pleasure district - all now ruined and overgrown. Her words have moral force and thus she takes precedence, while his merely narrate loss, and thus he occupies a secondary position. Zhang Hao'an's 張浩庵 otherwise unnamed wife, Jin shi 金氏, who hanged herself in 1858 , left an earthy inscription reading 'From ancient times, there have been people who have died. Whose life doesn't end like this? In innocence, and with laughter, in the Nine Springs [i.e. the underworld] I will encourage ghosts to kill the rebels, even as I have done in the years when I was alive!' (Yangzhou fuzhi 1874: 24:34a)

The gazetteer editors have chosen as exemplars individuals who ostensibly used their final words to assert their moral purpose. In their often formulaic self-presentation, these suicides identify themselves as legitimate members of interlocking communities: family, locale and empire. They are filial, loyal and decidedly not on the social margins, in spite of their placement in a section of the gazetteer conventionally (but not in this edition) devoted mainly to tales of the weird or supernatural. Their violent deaths confer the power to haunt and influence the world of the living, while their words assert, at least by implication, that they are among the virtuous, and thus not 'ghosts,' who are by definition malevolent outsiders (EASTMAN I988: 48). The words and actions of these suicides thus render their posthumous selves morally and politically orthodox and worthy of inclusion in the official local history and among the emperor's subjects. By presenting such individuals as a group, in other words, by 'gathering them,' the editors of the gazetteer harnessed these potentially destabilizing dead to the community, and, at least implicitly, asserted through them the righteousness of local society as a whole. 


\section{CONCLUSION}

Gathering implies selection. Not everything is picked up for inclusion, and as we have seen in the post-Taiping context some experiences are necessarily elided to eliminate ambiguity and produce moral clarity. The community, inevitably, becomes virtuous. Deaths are translated into honorable martyrdom. Ghosts are rehabilitated as loyal subjects and filial sons. Scenic sites, once destroyed, become renewed emblems of community values. Texts, rediscovered and compiled, testify to a culturally rich local past. Alternative possibilities disappeared from the written record: deliberately eliminated, as in the case of rebel documents, or overwhelmed by the collected images of collective righteousness. Protestations of absolute orthodoxy were used as talismans to preserve a disintegrating moral order. And, ironically, there was much less space for compromise and ambiguity than there had been during the Qing conquest two centuries earlier.

Gathering is the opposite of chaos (luan 亂); it implies order and moral governance. Even social gatherings testify to normalcy and order and to the strength of the reciprocal and hierarchical relationships at the center of an ideal social (and moral) universe. To its nineteenth-century practitioners, gathering represented an antidote to the heterodoxy that threatened to disrupt community and shatter the values that underlay the late Qing version of Confucian civilization. The emphasis on morality as an antidote to society's ills in this context meant that community leaders sublimated other sources of social tension as they frantically gathered the remnants of a half-remembered or imagined ideal.

Gathering suggests conscious representation: an act of community agency carried out before an implied audience. The use of formal commemorative gesture and the rhetoric of loyalty and virtue suggest that local actors imagined themselves gathering under the watchful eye of the imperial state. Certainly the state furnished the vocabulary, the symbolism and the notions of orthodox practice invoked by officials and elites in Yangzhou in the aftermath of the rebellion. Some of the processes of gathering described above depended on the existence of a particular form of state ideology for meaning. The empire as symbol was the collective that animated commemorative and restorative practice. As the Qing collapsed in the early twentieth century, the sense of community and meaning expressed through state honors gradually dissolved. Without adequate funds, renewed scenic sites were incomplete copies of their predecessors and seemed somehow devoid of older resonances. Collected texts collected dust, unread. And as the emotional, cultural and social contexts changed, old-style social gatherings looked corrupt, unsuited to a fragile world threatened by foreign and domestic forces of disorder. The post-war culture of gathering was rendered obsolete under new regimes more interested in rereading the rebels as revolutionary antecedents. Against this background, the significance that had been gathered dissipated. And processes of forgetting were at the same time set into motion. 


\section{ACKNOWLEDGEMENTS}

I would like to thank participants in the Yangzhou workshop, the History Department Seminar at Johns Hopkins University, and William T. Rowe, Mary Rankin, Janet Theiss, Michael Chang, Harold L. Kahn, Brian Platt and Jordan Sand for their comments on earlier versions of this chapter. I am also grateful to the staff of the Asia Division at the Library of Congress, the Nanjing Library, the Nanjing University Library, the Chinese Academy of Sciences Library, and the Beijing Library, Beihai Branch. Finally, I would like to thank Antonia Finnane for directing me to the woodblock print depicting the battle between Qing forces and the Taipings. The image appears here with the permission of Getty Images/Time and Life Pictures.

\section{NOTES}

1 See for example, HaIl 1964: xiii. He cites the i883 revised edition of Samuel Wells Williams' classic work, The Middle Kingdom: A Survey of the Geography, Government, Literature, Social Life, Arts, and History of the Chinese Empire and its Inhabitants, stating that '. . . it has been estimated by foreigners living at Shanghai that, during the whole period from $185 \mathrm{I}-1865$, fully twenty millions of human beings were destroyed in connection with the Tai-ping rebellion.' Contemporary sources refer to a population loss of as high as, or higher than, 50\% in some of the major cities of the Yangzi Delta. In his diary, Jin Changfu refers on one occasion to the loss of half of Yangzhou's residents in 1853 , although this might be an example of poetic license.

2 For accounts of the Chinese historiography, see XIA Chuntao 2002 and Jian Youwen I964. To give a sense of the scope of this historiography JIANG Bingzheng 1984 includes 5,000 items, including articles, monographs and source collections published between I853 and I98I. Scholarly and popular interest in the pro-Qing military figure, Zeng Guofan, after 1990 has been particularly striking: he is the subject of novels, television serials, and many publishers have issued variously constituted collections of his writings.

3 A notable exception is James Cole's local study of a community militia in Zhejiang (Cole 198I).

4 Webster's Ninth New Collegiate Dictionary. 1990. Springfield, MA: Merriam-Webster, p. 508.

5 For the full range of definitions, see Hanyu dacidian 漢語大辭典. 1993. Shanghai: Hanyu dacidian chubanshe, v. II, p. 798.

6 On Fang Junyi's lewd poetry, one of his contemporaries noted that when Fang was in Huishan 'there was a young girl whose name was Fine Treasure. He presented her with a couplet reading "I don't know who picked the Fine leaves, It is as if having entered Treasure mountain I returned empty-handed." The words are very funny and the eroticism is not shallow . . This gentleman is romantic and finds joy in himself. He is not suited to serve in high office.' See Jin Liang 1985, 062: 256. On his taste for luxurious living, see FeI Xingjian 1985, 202: 598.

\section{See Fu Nanqiao, Xianfeng sannian bikou riji.}

8 Yangzhou fuzhi 1874, 24: Ia-b cites Pingding Yuefei jilue 平定粵非紀略 [Official history of the campaign to suppress the Yue rebels] and 'Newly gathered information.' On the hanging of banners, see ZHOU Cun 1957: 17. Zhou Cun interprets banners bearing the character shun 順 ('submission') as indicative of popular enthusiasm for the rebels. His analysis is, however, shaped by his position as part of the CCP party establishment at a time when the Taiping rebels were 
understood to be the antecedent of the Communist party. On the combination of naval and land forces, see Qing zhengfu zhenya Taiping tianguo dang'an shiliao. 1994, vol. 5: 376. In subsequent citations, this will be abbreviated as QZFZY. According to this document, the defenders were badly outnumbered by the rebels.

9 See Yangcheng xunnan xulu in Chen Henghe 1995, I: 2b. Yangzhou fuzhi 1874, 24:6a-b, 8a. See also Meyer-Fong 2004: 224.

10 For examples of strategically placed fires set by the rebels, see Yangzhou fuzhi 1874, 24:8a and 9 a.

11 The city and its famous sites already had entered a period of decline even before the Taiping war. The gardens and scenic venues that had survived the reorganization of the salt monopoly in I83I (and thus the general diminishing of Yangzhou's fortunes) were wiped out completely by the war. On the changes to the salt monopoly, see Hummel 1943: vol. 2, 710-II. On the decline of Yangzhou's famous sites, see Ouyang Zhaoxiong, Jin Anqing 1997: 46-7. The author of this piece, Jin Anqing 金安清 is the man called Meisheng 眉生 who makes frequent appearances in Jin Changfu's diary. Evidence in support of this conclusion can be found in a poem composed in honor of Jin Anqing's relocation to Yangzhou, written by Zhao Yu 趙瑜, a Taizhou man who had many friends in common with Jin Changfu. (ZhaO Yu, 3:30a)

12 According to Zhang Dejian's 張德堅 preface to Jin Changfu’s unpublished poetry collection, Jin wrote no fewer than I0,000 poems during his lifetime, although most of these were lost in the fighting. Jin Changfu, Hongxue yinguan shiji yijuan 紅雪吟館詩集一卷, manuscript in the Nanjing Library collection. The collection, consisting of two hundred and ten poems, was compiled by Jin Changfu's son, style-named Xiaofang 小舫, at the urging of a younger contemporary, Yuan Jin 袁 錦. Yuan Jin's preface, which describes the compilation process, is dated early summer I879. Jin Changfu's biography, marked as the product of 'New Gathering' appears in the Literary Talents section of the Yangzhou fuzhi 1874, 13:30b.

$13 \mathrm{He}$ died in I87I at the age of 75 sui. That his militia service garnered an official title suggests that he benefited from a new route to status that opened up during the rebellion.

14 According to his diary entry for the mid-autumn festival (Isth day of the 8th lunar month), he had been living in Taizhou for only two years. The salt monopoly offices shifted to Taizhou during the rebel occupation. Taizhou was less directly impacted by the fighting than Yangzhou and appears to have offered a place of refuge to those Yangzhou residents who could afford to make the move.

15 Jin Changfu also refers to several of these restaurants in a manuscript collection of bamboobranch poems on local themes held in the Nanjing Library. There he notes that Yiyi lou 宜宜樓 and Xinxin lou 新新樓 were both wineshops known for their exquisite brewing technique and that the teashops in town were divided into 'Nanjing shops, Jingjiang shops, Suzhou shops, Yangzhou shops, and Taizhou shops.' Such gustatory observations are typical of the Bamboo Branch genre, which typically evoke local products and customs in a light and playful tone. At the same time, they also appear to reflect Jin's personal interest in food consumed among friends. Jin Changfu, et al. Hailing zhuzhici liujuan xu erjuan 海陵竹枝詞六卷續二卷. Unpaginated manuscript.

16 For example, Xiaoxiangyan 小香岩 which he describes as one of the best scenic sites in Taizhou, although it was not yet complete. He describes ruined sites in Yangzhou in several of the poems, and also includes poetry on famous venues in Zhenjiang, a city south of the Yangzi that was occupied by the rebels for an extended period. 
17 For example: 'The beacon fires at Thunder Pool line the old imperial way/Jade Hook Path surrounds the Sui Palace/Pity the poor peach blossoms of March for in the river's bed/They flow past the ruined city - refusing to turn red!' And: 'Bush bandits came here twelve years ago today/ The books I read then have withered to smoke and decay/Nobles with their titles have scattered as with the wind they dash/The remains of their homes have been sold for petty cash.'

18 One of the poems is accompanied by a note reading: 'After the catastrophe, blood from the war soaked into the earth. The grasses grew to several feet tall and the leaves were as big as poles. Eating them could kill a person.' The last line of the last poem, which depicts ghosts, apparitions and skeletons, reads 'When will the blood of war vanish from my lapel?'

19 Liangjiang zhongyi lu 1887 , 'Editorial Principles,' ra. This source is one of the resulting publications - consisting of thirty case files detailing the deeds of the honorable dead of Yangzhou. Liangjiang is the super-province charged with administrative oversight of Yangzhou prefecture. Similar institutions were subsequently set up in other provinces, and many of them published similar accounts.

20 Liangjiang zhongyi lu $\mathrm{1} 887$, fanli, Ib. The authors comment that there are those who merit inclusion but who have not yet received formal recognition. In these cases, the gruesome facts surrounding their deaths warrant inclusion despite the absence of official honors.

21 For discussion of Tianning Temple in the eighteenth century, see Meyer-Fong 2003, Chapter 5.

22 Fang Junyi, Stele Inscription on the Rebuilding of Tianning Temple, Yangzhou fuzhi I874, $5: 22 a-23 b$.

23 See Yang Jianmao's 楊健禁 preface to Fang Junyi’s poetry collection, the Erzhixuan shichao 二 知軒詩鈔, quoted in QIan Zhonglian 1989, vol. I4: 10205.

24 Fang Junyi, Preface, Yangzhou fuzhi 1874, Ib. Even his contemporaries recognized the city's decline, dating it to the I830s, and arguing that the rebellion had destroyed what was left of its former glories. By the early twentieth century, Yangzhou was referred to as the 'Gateway to Jiangbei' or the 'Metropolis of Jiangbei,' in other words, as the central place of a backward, impoverished and unproductive region, and never again as the 'Metropole of the Southeast.'

25 The term does not appear in previous editions, and appears to be a typical late-nineteenthcentury usage. This is not unique to the Yangzhou case; the same phenomenon can be seen in other gazetteers, including Nanjing's. Fei Siyan 費絲言, personal communication.

26 WANG Yun 1995a [1883]. In his preface, Wang Yun 汪鋆 frames his compilation as an explicitly commemorative work, devoted to preserving the memory of the prefecture's famous painters, many of whom had died in the war.

27 This two-part collection of anecdotes and fragments is called Old Events in Yangzhou and Recent Events in Yangzhou (Guangling jinshi, Guangling jiushi). Jin Changfu is meticulous about citing his source texts, although it is possible that he may have been recording each piece from memory.

28 Fang Junyi's preface, Yangzhou fuzhi 1874, Ia.

29 Yan Duanshu 晏端書, Preface, Yangzhou fuzhi 1874, Ia. Both Fang Junyi and Yan Duanshu describe the process of gathering staff and materials for the rewriting of the gazetteer in their prefaces.

30 Fang Junyi's preface, Yangzhou fuzhi 1874, 2A. The last bit is a close paraphrase of Fang Junyi's words.

31 This can be read as part of Zeng Guofan's larger project: 'to restore peace and order and to promote the rehabilitation of learning in South China ...' Hummel 1943: 753. Fang Junyi's 
appointment as head of this bureau may suggest a personal/patronage tie between Fang Junyi and Zeng Guofan.

32 Nineteen charitable cemeteries were created in the area around the prefectural seat. In addition, the gazetteer reports that a special cemetery for the people who were martyred in the city in I853, a refugee cemetery, and a 'loyal and righteous' cemetery at Guazhou town to accommodate the many northern soldiers who died in the region had all been established within two decades after the war's end. Yangzhou fuzhi 1874, 5:18a-b.

33 For example, in a letter to Yan Duanshu embedded in his diary, Jin Changfu expressed concern that the martyred dead might be angry or regretful if they were not appropriately honored.

34 For the history of the suicide poem, or juemingci 絕命詞, from the Western Han (206 BC-AD 8) through the Qing, see Fong 200I: III. The examples from the I874 gazetteer (Yangzhou fuzhi) include writings by men and women inscribed on walls, and writings by women inscribed on articles of clothing.

35 Fong rejects the possibility that male literati turned female suicide poets into 'unmitigated ventriloquist productions.' FONG 200I: I4I. Here, I would like to make the case that the editors of the gazetteer are using such texts precisely as ventriloquist productions.

36 In another manifestation of anxiety about the Taiping as religious heterodoxy, local officials and elites applied to the court for recognition of local temples as 'orthodox.' In many cases, the temples chosen for official recognition also were sites of divine intervention against the rebels. See for example the account of Xiannü miao 仙女廟 in Yangzhou fuzhi 1874, 5:Ib.

37 On Ruan Yuan and direct investigation, see Meyer-Fong 2003: i19. For Ruan Yuan as reference point for post-war remembrance, see pp. I23-4. For an anecdote in which Ruan Yuan 'predicted' the disaster of the Taiping Rebellion in 1840 from the sudden appearance of smoke at the base of the city wall near Lesser East Gate, Xiao Dongmen 小東門, see Yangzhou fuzhi 1874, 24:31a. This story appears immediately before the first of the eleven entries accompanied by suicide poems discussed in this section.

38 Yangzhou fuzhi 1874, 24: 3Ib. The editors cite Yangcheng xunnan lu.

39 Yangzhou fuzhi 1874, 24:32b. 


\section{The Fashionable City? \\ Glimpses of Clothing in Qing Yangzhou}

\section{Antonia Finnane}

E arly in 1932, after Japanese forces had invaded Shanghai, the education department of Jiangsu province shifted from the provincial capital, Zhenjiang, to Yangzhou. The director of publications for the department at that time was Yi Junzuo 易君左 (I898-I972), a writer of some note who took advantage of his enforced stay in Yangzhou to set down a few impressions of the city.. The result of his jottings was a short book called Chatting at Leisure about Yangzhou, Xianhua Yangzhou 閒話揚州, which caused a minor furore due to its depiction of Yangzhou men as collaborators with the Japanese and of Yangzhou women as prostitutes. The portrayal of the city itself also enraged the local people. It was a place mired in the past, according to Yi Junzuo: dirty, dilapidated, reflecting poorly on the nation. ${ }^{1}$

Among the striking images of stagnation and decay presented in the book was one of 'unmodernized' women. Apart from those who worked as labourers, the women of Yangzhou presented an air of listlessness quite at odds with the risorgimento spirit of the times. In Yi Junzuo's eyes, their clothes and adornment were dreadfully provincial and dated. Old women sat by their doorways smoking pipes, the middle-aged wore old-fashioned trousers bound at the ankles, the young wore flowers in their hair. 'There are very few,' he wrote, 'who have become modern' (Yi Junzuo I934: I6).

Very different were the comments of a visitor of much earlier times, the Ming survivor Li Gan 李淦 (b. 1626), who in the I690s was struck by the extent to which people in Yangzhou were preoccupied with being well-dressed and up-to-date. 'In all the empire,' he remarked, 'it is only in the prefectural city and suburbs of Yangzhou that clothes have to follow the times ...' He drew the reader's attention to 'concubines leaving their wealthy homes to go out [who] wrap themselves in $y u$ silk, [and] protect their calves with brocaded and embroidered silk ...' (HAY 20OI: I2). ${ }^{2}$ Fine clothes were an aspect of Yangzhou social life on which others commented in the late seventeenth century - the poet Kong Shangren 孔尚任 (I648-I7I8) and the essayist Wei Xi 魏禧 (I624-I68I) among others - attesting to the city's prosperity in the middle years of the Kangxi reign (I66I-I722) (STRASSBERG I983: I44).

We should expect the place and its residents to have changed over this long time period. In the late seventeenth century the vigorous ruler of a new dynasty was 
rebuilding and expanding an empire that had been shattered in the inter-dynastic war of half a century earlier. Yangzhou, having been laid waste during that war, was by the I690s experiencing strong economic growth. In the 1930s, by contrast, it was a provincial backwater in a divided country, well removed from centers of dynamic change such as Shanghai or even Zhenjiang. China as a whole was in a position not too different to the situation in the I630s, with a weak central government presiding over economic malaise, natural disasters, popular unrest, and internal challengers, as well as with enemies pressing on the borders.

The two eras were also differentiated by their vestimentary regimes. In the late seventeenth century, Chinese people were still adjusting to the cultural impact of the Manchu conquest. Men had to wear their hair in queues, Manchu-style, and their gowns (if they were of the gown-wearing class) were cut much closer to the body than had been the case during the Ming. Han women were explicitly expected to avoid dressing like Manchus, but the very existence of a new ruling class meant that they too, were negotiating new cultural terrain in dress and adornment. Judging by Li Gan's statement, they were also enjoying exposure to a new range of fabrics, a consequence of the expansion of the silk industry.

By the I930s, queues were things of the past, and so was Manchu rule. Men still wore long gowns but the hems were rising. The body-hugging qipao 旗袍, which in the I930s became a standard form of dress for urban women, was radically different from any form of dress worn in China the turn of the century. ${ }^{3}$ While fashions of the 1930 s showed the imprint of a complex interweaving of historical influences combining East and West, it is plain that the 'far West' (Europe and North America) had replaced the 'near West' of Inner Asia as the major contemporary source of exogenous inspiration in dress styles. Clothing items such as silk stockings, highheeled shoes, suits and ties were not yet common in inland towns, but they were visible on the horizon of the changing sartorial domain.

These differences notwithstanding, an odd symmetry pertains between the earlier and later commentaries. Li Gan was a native of Xinghua, a poor county town lying in the middle of the flood-prone marshy lands to Yangzhou's north-west. Having graduated under the Southern Ming, he avoided office under the Qing and lived in semi-seclusion. He would necessarily have been struck by the flamboyant life-styles of people in Yangzhou, a city populated by wealthy merchants and many officials. His mention of concubines is a reminder of how closely concubinage was associated with the salt merchants of Huizhou, who dominated the merchant elite in Yangzhou and of whom it was said that 'with regard to concubines, prostitutes and lawsuits, they squandered gold like dust' (Ho Ping-ti 1954: I44).

Yi Junzuo, by contrast, was a native of Hunan but recently resident in Zhenjiang, which had undergone extensive urban renovation since being made provincial capital in 1928. More importantly, he had lived for many years in Shanghai, the crucible of 
modernity in twentieth-century China and its undisputed fashion capital. Yangzhou, situated at what had been a great transport junction (the Grand Canal, just north of the Yangzi), was relatively sheltered from the currents of time and change that were carrying Shanghai away from the past. Life proceeded there at a slower pace, virtually within another time zone. Its relocation from the centre to the periphery of Chinese cultural life was summed up by Yu Dafu 郁達夫 who in 1935 advised Lin Yutang 林語堂 that 'the villas of the salt merchants and the minions of the local gentry are better imagined in your dreams in Shanghai' than in Yangzhou itself (Yu Dafu 1935: 3-6). Shanghai had in effect replaced Yangzhou, just as in some respects it had replaced Suzhou (MARMÉ 2005), in the urban hierarchy of the Lower Yangzi Delta. Implicit in each commentary, then, is a comparative perspective related to the position of Yangzhou in that hierarchy.

\section{YANGZHOU AND SHANGHAI: FASHIONABLE PLACES IN DIFFERENT ERAS?}

Is it possible to imagine Yangzhou as the equivalent of Shanghai in an earlier world of fashion? In Shanghai and the Edges of Empires, Meng Yue argues that Shanghai's cosmopolitanism developed dialectically out of an older cosmopolitanism encapsulated in Yangzhou, a city that had lost position in the empire as China painfully changed orientation, cumbersomely, like a great elephant shifting weight from one side to the other. Drawing particularly on evidence from gardens in both Yangzhou and Shanghai, she emphasizes 'the fact that until the i88os, the landscape of urban interiors in Shanghai very much continued, even revived, the kind of cross-cultural cosmopolitanism in urban landscapes of the Chinese cities before this point' (Meng Yue 2006: 150).

If this pattern of continuity-cum-revival bears scrutiny, it should be evident in other cultural domains as well. In literature, one comparison that immediately suggests itself is the domain of the novel. Yangzhou produced what was arguably the first 'city novel' in the I840s, a story of called Fengyue meng 風月夢 [Illusion of Romance]. This, notes Patrick Hanan, was later rewritten as a Shanghai novel. The Yangzhou streets through which the original characters walked were translated into Shanghai streets, peopled by an adapted cast of characters (Hanan 1998: 349). Interestingly, this novel pays close attention to clothing, which we would expect to show some Western influence in late nineteenth-century Shanghai but surprisingly shows that influence already in Yangzhou some decades earlier, insofar at least as it refers to the use of imported fabrics.

The term fashion can credibly be used of clothing trends in late nineteenthcentury Shanghai. From the I850s onward, Shanghai was manifestly engaged in 
communication with the West, the self-proclaimed birthplace of fashion, and soon emerged as a major industrial producer of textiles. Its fashionable instincts were evident in its print culture quite early in the Treaty Port era, as demonstrated by Wu

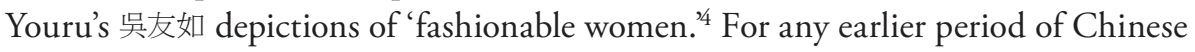
history, however, the thorny question of 'What is fashion?' immediately presents itself. If fashion is regarded peculiarly as an aesthetic and practice connected with industrial capitalism (ENTw HISTLE 2000: 46-47), then it is plainly anachronistic to talk about clothing in China in terms of fashion before the late nineteenth century, at earliest, whether with reference to Shanghai or not.

It is worth bearing in mind, however, that the word fashion is bandied about with impunity in histories of pre-industrial Europe, where the same problem of anachronism is surely present. Among attempts to overcome the resulting analytical tensions is Efrat Tseëlon's tri-part periodization of European fashion, in which the earliest or 'classical' era of fashion is deemed to lie between the fourteenth and eighteenth centuries. In these centuries the expansion of trade and the rise of urban elites were posing a challenge to the feudal order, and material culture (including clothing culture) was showing the effects. ${ }^{5}$ As it happens, comparable changes took place in late imperial China. It seems feasible, then, to talk about fashion in Yangzhou within this framework, on the basis of evidence of the patterns of production and consumption of clothing between the late sixteenth and early nineteenth centuries. Meng Yue's research moreover encourages a view of this period of vestimentary history as segueing into the next, in which Shanghai emerged as the undisputed fashion capital of China.

What is the evidence for 'fashion' in China before modern times? Useful articles by two Taiwan scholars, Lin Li-yueh 林麗月 and Wu Jen-shu 巫仁恕, have identi-

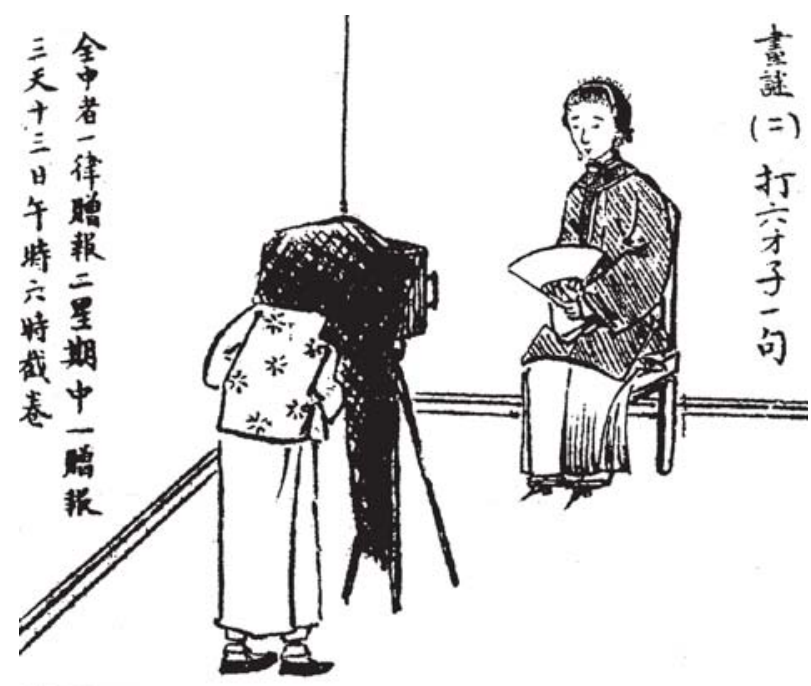

Figure 3.1 A lady being photographed. Newspaper illustration from Xinwen huabao 新聞畫報 [News Pictorial], Guangxu reign (1875-1908). 
fied a lively clothing culture in late Ming China, one evident in the reactions of late Ming gentry-men to the changing clothes styles they observed on the street (Lin Li-yueh 1999: III-57; Wu Jen-shu 1999: 55-I09). A clear expression of the changes and the reactions can be found in a local gazetteer from Tongzhou 通 州, within Yangzhou prefecture, where clothing is described as subject to 'rapid changes, known as contemporary styles, shiyang 時樣. This is what is called outrageous dress, fuyao 服妖’ (Lin Li-yueh 1999: I25). Similar comments were made about clothing in a large number of cities in the lower Yangzi delta, where cash-cropping, cottage industry and interregional trade were producing high levels of urban prosperity. Hats were a particular focus of fashion, especially among young men. Gu Qiyuan 顧起元 (1565-1628) wrote of hats in Nanjing that formerly, 'officials wore the biretta, scholars the square hat, and that was all. In recent years every day there is a difference, every month something new. So what gentlemen wear now goes by all sorts of names: the Han cap, the Jin cap, the Tang cap . . ' and so on (Wu Renshu 1999: 68). Accordingly, from the end of the sixteenth century, an extraordinary variety of headgear was available in the hat shops of Yangzhou (Wu Renshu 2007).

\section{TRACES OF A LOCAL FASHION}

Yangzhou was not, however, a great participant in the production of cloth or clothing. Its major commercial interest was salt, and its richest residents were salt merchants, of whom we have already noticed that it was said that 'they squandered gold like dust.' These habits of conspicuous consumption were not especially conducive to thrift and industry. In the late sixteenth century travelers could buy locally made 'platformsoled shoes' in Yangzhou, but these were of 'inferior materials'; the customer was better off waiting till he reached Nanjing, where sturdy, durable footwear could be purchased (Ko 2005: 2I4). At this time, according to a late Ming gazetteer, 'the women [of Yangzhou] have nothing to do but sit around making up their faces . . . Their hair ornaments are of worked gold and jade, with pearls and kingfisher feathers added here and there. Their bedding is finely embroidered, their underclothing bright and gay. They are extravagant to the last degree' (Jiangdu xianzhi 1597: 7.28b-29a). Two centuries later, shoe-making in Yangzhou had improved: Lin Sumen 林蘇 門 (1748-1809?), a native of the city, contrasted the fashionable butterfly shoes of his home town favorably with those made in Suzhou and Hangzhou (Lin Sumen I808: 6.2a; see also Ko 2005: 215). But the classic 'women's work' - spinning and weaving - was still hardly known in this locality. While in Tongzhou women were busy 'weaving all sorts of cloth,' and in Suzhou they were employed at the imperial silk workshops 'embroidering dragon robes,' in Yangzhou they 'gadded about with nothing at all to do' (Gui Chaowan 1972: 5.3a). 
The evidence referred to here is derived from a moral discourse based on an ideal division of labour in which men delved and women span. A closer look reveals that young girls in Yangzhou were in fact taught handicraft skills, and were likely to resort to spinning and, less commonly, weaving, if left widowed with dependants (See Finnane 2004). But household enterprise in Yangzhou, to the degree that it flourished at all, can have had no great commercial value. Indeed, with the exception of Tongzhou and Haimen to the east, the districts north of the Yangzi and south of the Huai, broadly divided between Yangzhou and Huai'an prefectures, were largely devoid of any textile industry, whether cotton or silk. In the early nineteenth century, Kong Luhua 孔璐華, the wife of local scholar-official Ruan Yuan, recorded in a poem her efforts to introduce silkworm breeding in Yangzhou: 'Here, on the northern shore of the Yangzi, cocoons are few./ I brought silk worm eggs from Zhejiang and began to raise them in the house...' (WEI, Betty 2006: 244). In the later nineteenth century local officials were still complaining about the absence of a silk industry in Huai'an, which they held was due to women 'being lazy and liking just to have a good time' (Huai'an fu zhi, 2.6b-7a).

A consequence of the dearth of a textile industry north of the Yangzi was a lively trade in imported textiles, which in the eighteenth century was dominated by merchants from Wuxi, Zhenjiang, and other places in southern Jiangsu (Zheng Zhanggan 1989: I5O). Despite this dependence, it is evident that clothing and accessories in Yangzhou had a regional or local character. In his famous account of the massacre in Yangzhou in 1645, Wang Xiuchu 王秀楚 inadvertently refers to this aspect of Chinese vestimentary culture when he describes some women in the company of the enemy as 'dressed in the Yangzhou fashion' (Wang Xiuchu 1964, vol. 2: 230). Another woman, again in the company of soldiers, he identifies as 'a native of the city,' apparently on grounds of how she was dressed (in 'splendid and gaudy clothes') as well as by how she behaved. By such descriptions, Wang Xiuchu showed himself to be not a local, and it is indeed common to find outsiders making reference to the way people dressed when criticizing the tone of Yangzhou society. Wei Xi, in a pious account of the reconstruction of Pingshan Hall, part of a temple complex outside Yangzhou, wrote of the local people that they 'have a great lust for gain, love parties and excursions, procure singers and pursue courtesans, wear fine clothes and live for the pleasure of the moment in order to show off their splendor to others' [Owen 1997: I05]

Local or regional distinctiveness in clothing does not in itself suggest fashion; nor does sumptuousness. Both of these features may be present in a given clothing culture without fashion also being present. As we have seen, however, Li Gan, writing not much later than Wei Xi, testified to a certain dynamism in Yangzhou dress when he commented on clothes there having to 'follow the times.' A much later writer, Li Dou 李斗, wrote at greater length on the same topic. Li Dou, the great chronicler of eighteenth-century Yangzhou, was a local man, registered in the 
county of Yizheng. Unlike the seventeenth-century critics, he wrote affectionately of the city and its customs, including habits of dress and adornment. He re-iterated Li Gan's observation about the volatility of fashions in China, writing that 'clothes worn in Yangzhou are always in the newest style, xin yang 新樣.' It is not clear what this may have meant in terms of cut, but he went into detail about the fabric, with particular reference to colour:

Ten and more years ago, it was eight-roundels satin; that gave way to [shades of] the ocean lotus and curved jade orchid; then it was triple-blue, vermilion, black, vault grey, ochre, and now it's sorghum red and peach red, known as $F u$ 福 colours because the troops of General Fu [Kang'an] 福康安 wore these colours when they passed through Yangzhou on their way to attacking the Taiwan rebels.

(Li Dou 2004 [1795]: 194).

Fashionable dressers sourced their cloth in Satins (duanzi 緞子) Street, also known as Many Sons (duozi 夕子) Street by virtue of a linguistic turn in the local patois (Li Dou 2004 [I795]: 194). Located in the south-west of the New City, north of the customs barrier and near to the Parade Ground, this was the busy heart of commerce in Yangzhou. The shoppers were mainly men: it was rare to see a woman in the streets of a Chinese city except for prostitutes, servants and the indigent. The fashions Li Dou refers to here may indeed have been men's fashions. The impact on local style of the Taiwan campaign suggests as much.

We do not have to journey too far to encounter women's fashion in Yangzhou, for in Kingfisher Street, near to Satins Street, was a shop that specialized in women's hairpieces and adornments. According to Li Dou, the women of Yangzhou dressed their hair differently from women in other places. They paid close attention to hairstyles, using hairpieces called 'butterfly, gazing at the moon, flower basket, bending the neck, Arhat roll, lazy comb, pair of flying swallows, pillow pine, eight-faced Guanyin' and cultivating hair-dos with names such as 'sable-covered brow' and 'fishwife's headband' (Li Dou 2004 [1795]: 195). Given the relative paucity of materials on fashions in the early to middle years of the Qing, it is interesting to note that references to Yangzhou women's hairstyles can be found also in the preceding century. In a poem written in 1679, the scholar-official Wang Maolin 汪禁麟 reveals that the Qingming festival was one occasion on which women's fashions were exposed to the public gaze, and his mention of 'the seductive ladies' new hairstyles' (Meyer-Fong 1999: 65) shows that hairstyles were then, as later, an important mode of fashion. When considered in tandem with information on hats in the late Ming, hairstyles also point to the significance of the head as a specific site of fashion. It may be that in this relatively conservative clothing culture, fashion was most readily to be seen at the peripheries: shoes, headwear, accessories. 
While local styles were most likely to attract comment from observers, it is clear that fashions were communicated between major centres of consumption, and no doubt from urban to rural areas as well (WeI Minghua 1998: 153). The mobility of merchants and the geographical reach of their business interests must have been among factors contributing to the dissemination of fashions. For example, silk merchants from Zhenjiang, on the south bank of the Yangzi, were major suppliers of the Yangzhou textiles market (Li Dou 2004 [1795]: 194). Situated at the confluence of the Yangzi River and the southern branch of the Grand Canal, Zhenjiang was the funnel through which goods passed from south to north and vice versa, and as such was an obvious point of cultural transfer. The local dialect in Zhenjiang was closer to Yangzhou dialect than was the language spoken in places like Suzhou and Wuxi, and it is possible that for reasons of cultural as well as geographical proximity, Zhenjiang was a logical base for southern merchants who traded with the north.

Another obvious line of communication in fashions lay in retail networking through small businesses with branches in different places. Wei Minghua’s 韋明鏵 research on old shop sign-boards, laozihao 老字號, suggests that these links were operative in Qing Yangzhou. One prominent shop-front in Yangzhou was Wu Shaoxi's 伍少西 in Gengzi 埂子 Street, which bore a sign painted by the individualist painter Yang Fa 楊法 (b. 1696). This business specialized in the manufacture of woollen socks and felt shoes, but it was not originally a Yangzhou undertaking. Its origins lay in a Nanjing business established in the late Ming (WEI Minghua 2000: 15I-56). As Wei Xi wrote, 'The customs of Yangzhou are, in fact, a melting pot for people from every corner of the land' [Owen 1997: I05]. Better known is another Yangzhou enterprise, the Dai Chunlin 戴春林 cosmetics and incense shop, which bore a signboard inscribed by Dong Qichang 董其昌 (I555-1636). This shop established a number of branches, including in Taizhou to the east, and later in Shanghai (WeI Minghua 2000: 157-62). Yi Junzuo apparently knew of this shop before arriving in Yangzhou, and made his way to it on an early excursion (YI Junzuo 1934: I4-I5).

\section{LOCAL FASHION, WORLD CONTEXT}

Trade links with the wider world were also significant. In the Ming dynasty, Mongolian and Korean influences were evident in fashion trends disseminated from Beijing. From the late Ming, trade with Europe began to show an effect, especially in accessories - spectacles, for instance, and then watches. From the second half of the eighteenth century English wool was imported in increasing quantities, too little ever to satisfy British merchants but sufficient to make an impression on the textile trade in China. In 1755, someone in Canton bought nearly 5000 'long ells' (i.e., lengths of serge) from a single British cargo (Morse 1926, vol. V: 32). In I808, shoemakers in Yangzhou were using English wool to line the butterfly shoes that Lin 
Sumen described with such pride (Lin Sumen I808: 6.2a). In I8I6, a British party passing through Jiangxi concluded that they must be drawing close to Guangdong province when they began to see 'British woollen cloth for sale and occasionally ... a few other objects of European manufacture' (STAUnTON 1824: 360). Whatever the Qianlong emperor may have had to say to Lord Macartney concerning the ability of the Qing empire to supply all its own needs, it is plain that exotic goods excited the interest of his subjects and were absorbed into their material surrounds.

In the longer term, British trade meant major infrastructural changes in China. Situated near to a crucial junction on the inland waterway system, Yangzhou was destined to be marginalized by the diversion of important trade movements to a coastal route. Before this occurred, it enjoyed, for an inland Chinese town, an unusually good position in the nineteenth-century world of goods. Lin Sumen's inventory of commodities available in Yangzhou in the opening years of the nineteenth century show a fashionable society in full swing: local people were struggling with a downturn in the salt trade but they were also enjoying new consumer products: table napkins, wind screens, rain covers for sedan chairs, watches and clocks, imported or locally made, and novel pets including chickens and rats from Canton. They were also wearing new sorts of clothes: the cicada jacket, the yellow grass-cloth jacket, the happy bird gown, the Arhat wrapper, melon-skin caps, louts-leaf collars, hundredpleat skirts of crepe, jackets with sleeves that were becoming ever wider with the passage of the years; and shoes, including butterfly shoes and scented lotus slippers, which may not have been absolutely new in design but were certainly sought after for their design features. ${ }^{6}$

The growth of trade with the West, and a rise in imports after the Opium War, meant an increase in Western goods in Yangzhou. In Hanshang Mengren's 邗上蒙人 Illusion of Romance, Fengyue meng 風月夢, a cast of dandies and courtesans parades through Yangzhou in clothing and accessories that are notable for including numerous items of Western origin: a hat of English broadcloth, a portmanteau of multicolored English printed cloth, a serviette or napkin also of English printed cloth, watches which might or might not have been imported. Western-style paintings are for sale in the marketplace, and Western currency is used [Hanshang Mengren I988 [1848]: IO, I4, 28, 30, 37, 54]. A memoir called Dream of Yangzhou, Yangzhou meng 揚州夢, published slightly later than this novel but intended as a record of Yangzhou in the I840s, contains references to a comparable range of foreign imports, including tin lamps, 'foreign tobacco' (i.e. opium), watches, down, furs, and woolen cloth [JiAOdong Zhou Sheng 1978: 45]. Of watches, the author noted that formerly they were comparable to private tutors in cost, affordable only when one had a lot of money: 'nowadays, however, clocks and watches are cheap, and have become popular possessions.' Of woolen cloth, he wrote that he favoured it for winter wear, and liked it on account of its hard feel. 
With the exception of obviously Western products, it is not easy to identify the sources of inspiration for the various pieces of raiment itemized in such works, but from the little that we know it is clear that Yangzhou fashions moved in rhythm with developments elsewhere in urban China. In the greater Jiangnan region, as Wei Minghua shows, 'Yangzhou style' competed with 'Suzhou style,' and in the early years of the nineteenth century both were in evidence in Shanghai (WeI Minghua 1998: 152). Particular Yangzhou fashions of this time can be identified elsewhere in the urban system. As we have seen, butterfly shoes were popular in Hangzhou and Suzhou as well as in Yangzhou, and what Lin Sumen had to say about them suggests that there may have been some spirit of competition among the manufacturers of these shoes. Wide sleeves are another phenomenon mentioned in different contexts. A feature of Han women's dress, wide sleeves were a heritage of Ming styles and were one of the design elements that differentiated Han from Manchu clothing. In Yangzhou, at least, the most expensive jackets had heavily embroidered sleeves that in Lin Sumen's time had expanded from one (Chinese) foot to half as wide again, rendering the garment as cumbersome as the crinoline later worn by fashionable women in the West (Lin Sumen I808: 6.4b. 49-50). Over time, Han and Manchu styles of dress influenced each other. The long Han jacket, $a o$ 襖, was never as long as the Manchu robe, but it was certainly much longer than the waist-length, $r u$ 襦, which it appears to have displaced entirely during the eighteenth century (FInNANE 2007: 49-50). Correspondingly, the Manchu robe as worn by fashionable young women began to acquire wide sleeves in keeping with the trend in early nineteenthcentury Han fashions, incurring the emperor's wrath when they made an appearance in Beijing (RAwSKI 1998: 4I).

To this point, the words fashion and fashions have been used uncritically to refer to tastes, trends, and changes in clothing styles in a period that has been loosely compared to Efrat Tseëlon's 'classical' period of fashion in Europe. The nineteenth century was a period of political and cultural transition, in Europe as in China, and properly to historicize Yangzhou's clothing culture requires thought about the differences between the nineteenth century and the eighteenth in this particular cultural domain. Those differences, supposing that they exist, must surely bear on how we think about fashion, and about defining fashion, in China.

One obvious difference lies in the density of detail in literary sources. The nineteenth-century sources are unquestionably richer in their range of references to clothing than anything found in the eighteenth century. Indeed, there are few obvious sources for concentrated research into the material culture of the city dating earlier than Li Dou's Yangzhou huafang lu 揚州畫舫錄 [Pleasure Boats of Yangzhou] in 1795 , although incidental information can be quarried from gazetteers, merchant manuals, and literary sources. In fact, in the quantity and variety of its literary products, the last century of Qing rule is not unlike the late Ming; and in the wealth 
of commentary on clothing the two periods also seem comparable. Nonetheless, sporadic references to dressing with the times, repeated at intervals from the late sixteenth century through to the nineteenth, does suggest that a fashionable impulse was a constant in Yangzhou's clothing culture during these centuries.

At the same time, a strengthening of this impulse is detectable in the nineteenth century, due primarily to the litanies of goods contained in works such as Lin Sumen's collection of verses, Hanshang Mengren's novel, and Zhou Sheng's 周生 memoir. Although the relationship between what is written and the phenomenon to which the written word refers is not self-evident, it is assumed here that the writers were responding to an intensification of commodity culture. More goods, and a greater variety of goods, were now available in the Yangzhou marketplace; foreign trade was helping to enlarge the possibilities of consumption; and a greater degree of detail had entered into assessments of sartorial performance. While attention to clothing is a characteristic of all classical fiction, detailed descriptions of garments and accessories are not.

Zhou Sheng's Dream of Yangzhou, the latest of these works, assumes importance as the last great celebratory record of Yangzhou in the ancien régime, before the Taiping 太平 Rebellion had ravaged the low Yangzi valley and the Second Anglo-French Expedition opened up the northern coastal trade route. A native of Zhenjiang, Zhou Sheng has been identified as Zhou Boyi 周伯義 (I823-I895), a minor literary figure who combined studies in astronomy, geography, and military affairs with expertise in martial arts (Wu Chunyan, Lu Lin 2004). He arrived in Yangzhou in I842, probably soon after the conclusion of the Opium War, during which the Grand Canal had been blockaded and Yangzhou temporarily cut off from the south. He appears to have spent the greater part of his twenties living there, before being fleeing the Taiping rebels. His memoir is remarkable both for its detailed account of material life in Yangzhou (how furniture was made - including a smaller, prettier style of wardrobe, what sort of window coverings were available, what constituted a good dumpling, what sort of vessel was used to serve warm wine) and also for the author's tendency to place the various things he discusses in the context of human actions and emotive responses. Due to the latter feature, this little book provides quite a good history of the social life of things in nineteenth-century Yangzhou.

A few passages will suffice to reveal how sensitive the writer was to style, cost, and issues of connoisseurship in relationship to his own clothing and those of his circle. Women's clothing, for instance, he saw as inherently expensive due both to excessive embellishment and to a factor fundamental to any fashionable regime, which is the tendency of a style to become outdated:

A women's overgarment, $y i$ 衣, can be ruinously expensive. With wide borders in lotus design and coordinating ivory or gold braided [stitching], it will be 
three to four times the usual price. Then there is the periodic turnover in search of something new. Once the style is outdated, huayang yi gu 花樣一古, then the garment will be put away on some high shelf. That is really wasteful.

(JiaOdong Zhou Sheng 1978: 44). ${ }^{7}$

This comment is amusingly consistent with the reputation of Zhenjiang natives for tight-fistedness, to which the author elsewhere refers. Any interest in economy, however, is more than matched by an interest in taste. It was important to him to know exactly how to judge and appreciate the quality of fabrics, among other things, and such connoisseurship constituted one criterion by which he assessed his position in the social hierarchy:

The courtesans did not even know the names of the brocade from which their jackets were made or the embroidered cloth used for their bedding, and they did not know, either, how to treasure them. When Yue'er saw my jacket, made of Huzhou crepe, she referred to it as Sichuan silk, praising its simplicity! When talking to me, she wiped her tears away with the finely worked material of her bed-curtains. The world really does contain this kind of people - rice pouring out of their bags, and houses piled high with embroidered kerchiefs.

(JiAODONG Zhou Sheng I978: 45).

Elsewhere, he showed himself as an object of ridicule on account of what he was wearing:

When the weather suddenly cleared, I was walking along the street still in my stilt shoes [used in wet weather]. Some people scoffed at me saying, 'What heavy rain!' Only wet-and-dry shoes have oiled soles without stilts, suitable for both sunny and rainy days. Most people wear these on overcast days.

Despite the many novel items of wear mentioned in this work, some of what Zhou Sheng has to say about vestimentary culture in Yangzhou is predictably consistent with what we know about the urban society of the preceding century. Li Dou, for example, remarked on the custom of Yangzhou people to wear flowers in their hair. Zhou Sheng elaborates:

Jasmine and West Coast Creeper are attractive flowers that beautiful women like to wear as decorations in their hair or use for designs in silver thread on their pillows. They can also be put into a bag to be held in the hand for their scent. Old flower sellers string these flowers on copper wire in the shape of birds or weave them into flower baskets to hang inside mosquito nets, where they will last for two days.

(JiaOdong Zhou Sheng 1978: 53). 
A new element in the socio-economic life of Yangzhou becomes apparent at the conclusion of this paragraph when Zhou Sheng refers to the price of one of the flower baskets. This was reckoned not in copper cash but in foreign coin.

Did the flow of foreign currency through Yangzhou signify a new tempo in social life? Did the new, foreign things in the smaller, more elegant Yangzhou wardrobe mean that a different sort of fashion regime was in the making? More research on the clothing market and on the discourse of clothing in other Jiangnan cities is needed before answers to these questions can be provided. It may be that in fashion, as in the urban interiors studied by Meng Yue, Shanghai in the late nineteenth century was continuing, even reviving, an urban culture that had flourished in eighteenth-century Yangzhou; but it also may prove to be the case that what now looks like a period of transition, the nineteenth century, produced something quite distinctive, and that the fashion regime described by Zhou Sheng in Yangzhou was as peculiar to its time as the man himself, with his curious range of interests and areas of expertise.

Zhou Sheng died in I895, three years before Yi Junzuo was born, but in 1936 his Dream of Yangzhou was re-published by World Book Company, Shijie shuju 世界書 局. This may have been prompted by the wave of publicity about Yangzhou generated by the publication of Chatting at Leisure about Yangzhou in 1934. If so, Yi Junzuo would have seen in it a justification of his own portrait of Yangzhou, for much of Dream of Yangzhou is about the prostitutes with whom Zhou Sheng consorted. Such a reading, however, would have been possible only with a wilful disregard of fundamental differences between the worlds in which the two men moved. A close reading of Dream of Yangzhou would have revealed to Yi Junzuo that the provincial little town he visited in 1932 had less than a century earlier been a thriving centre of social life and literary activity. It was also a place where much store was set by what people wore, and where the resources for wear were constantly being renewed by imports from other places, near and far; and in this sense at least it had long been a fashionable city, well before the same could be said of Shanghai.

\section{NOTES}

1 Yi Junzuo 1934: 4-6. The controversy is discussed in Finnane 1994: 150-74.

2 Translation adapted. Li Gan's comment is also quoted in WeI Minghua I998: I43.

3 On male dress in the Republican era, see Harrist 2005. On the qipao, much has been written. See Finnane 2007.

4 See e.g. Wu Youru, 'Shizhuang nüshi' 時裝女士 [Fashionable Women], in Wu Youru huabao 1983.

5 Efrat Tseëlson, 1992. Fashion and the Signification of Social Order. Semiotica 9I: I-I4, cited in ENTWHISTLE 2000: 44.

6 See Lin Sumen i808. These items are discussed in Finnane 2003: 405-7.

7 All quotations from Jiaodong Zhou Sheng 1978 were translated by A. Finnane. 


\title{
4
}

\section{The Culture of Yangzhou}

Residential Gardens

\section{Věna Hrdličková}

Hangzhou is famous for its lakes and mountains, Suzhou is famous for its city and shops and Yangzhou for its gardens.

(Li Dou 李斗, Yangzhou huafang lu 揚州畫舫

錄 [Pleasure Boats of Yangzhou] 1795)

\begin{abstract}
G eographically, Chinese gardens can be divided into three major types, each with local characteristics: the gardens of the north, Beifang yuanlin 北方園林, the gardens 'south of the river,' Jiangnan yuanlin 江南園林, and the gardens 'south of the pass,' Lingnan yuanlin 嶺南園林. As Yangzhou is located on the dividing line between the north and the south of China, i.e. the river Changjiang 長江, in its gardens northern manliness xiong 雄 and the Jiangnan elegance xiu 秀 are combined, which enhances the pleasant atmosphere of the city. They are therefore aptly compared to the poems of Jiang Kui 姜熟 of the Song dynasty, 'who employed a strong and powerful pen in depicting tender feelings' (CHEN Congzhou 1988: 96).

The Yangzhou residential gardens represent an important genre in Chinese garden culture. At present those gardens which have miraculously survived the vicissitudes of time are much admired historical treasures. In the past they provided a cultivated space for everyday living, studying, receiving guests and other activities. Their characteristic is 'the integration of natural and man-made beauty, blending into one state the artistic conception and reality of life with the goal of creating in the limited confines of a garden the illusion of endless space' (Feng Zhongping 1994: 19) (Fig. 4.I).

The Yangzhou gardens developed in accordance with the historical and economic circumstances of the region and of the city. Their existence was early connected with the natural conditions of abundant water resources and a mild climate, which attracted scholars, poets, painters and officials wishing to retire; and later on with the prosperity of salt merchants, who were willing to invest a substantial part of their wealth in houses surrounded by elegant gardens to enhance their social prestige. According to written sources, the Yangzhou garden traditions go back to AD 447,
\end{abstract}


when the local district commander Xu Zhanzhi 徐湛之 of the Liu Song 劉宋 dynasty built in the northeast part of his palace a garden with a lake, a pavilion, a music terrace and other garden features. ${ }^{1}$

\section{HISTORY}

During the Sui dynasty (589-618) the emperor Yangdi 煬帝 established Yangzhou as his southern capital, and built palaces with beautiful gardens there. After the fall of the dynasty the place was deserted and fell into ruins. The Tang poet Bao Rong 鲍溶 (fl. ca 820), who visited the site, described the lost glory of the once beautiful buildings in his 'Two Poems about the Palace of the Sui Emperor Yangdi', Sui Yangdi gong ershou 隋煬帝宫二首. This however did not mean the end of the garden tradition in Yangzhou. Quite apart from the gardens in the official quarters, there existed at that time in Yangzhou a number of other gardens, and the fact that the names of some of them included a family or clan name indicates that they were privately owned. They were mentioned in the poems of Yao He 姚合 (fl. ca 83I) and others who gave their impressions of this charming and lively city which attracted many prominent visitors (ZHU Jiang 2002: 76).

In the Song period (tenth to thirteenth century), when the Chinese sense of beauty reached a level of unprecedented elegance, a number of such private gardens were built in Yangzhou. They were quite often named after one of their architectural forms, such as ting 亭 [pavilion], lou 樓 [tower ${ }^{2}$ ], tang 堂 [main hall, principal building] and others, which were found in them. The gardens of the officials extended beyond the city borders, as for example Ouyang Xiu’s 歐陽修 Pingshan tang 平山堂 [Level Mountain Hall]. ${ }^{3}$ In I257, the prefect Jia Sidao 贾似道 established east of his office a spacious junpu 郡戋 section. ${ }^{4}$ It was a kind of park separated from the official quarters with a gate leading to a garden where there were pavilions, artificial hills, a lake deep enough for sailing, and other places of interest. In the spring the common people were allowed to enter it and admire the blossoming trees and the lovely flowers. This was a novelty compared to the past, when the public was excluded from such places (ZHU Jiang 2002: 77).

The following period of Mongol rule did not contribute in any considerable degree to the development of garden art, but the Ming dynasty was a turning point in Yangzhou garden design. Scenic gardens built inside the city, mostly by private scholars, became a common feature. The names of famous gardens such as the Jie chun tang 皆春堂 [Hall of Entire Spring], Xiu yuan 休園 [The Garden of Rest], Xiao dong yuan 小東園 [Small Eastern Garden] and others are recorded. These yuanlin, often only a few $m u$ 畧 in area, had sceneries, jing 景, with man-made mountains and rockeries, jiashan 假山, streams and lakes, and flowers and trees representing the seasons of the year. The gardens were made into a harmonious whole by wind- 
ing paths, bridges and other means, rather as in a scroll painting. ${ }^{5}$ Such landscape gardens were characteristically designed after long deliberation and with great care by their owners, with the help and advice of professionals. Zheng Yuanxun 鄭元勳 (1603-1644) of Yangzhou, the author of A Personal Record of the Garden of Reflection, Yingyuan ziji 影園自記, wrote:

After having acquired this plot of land some seven or eight years previously and having spent these seven or eight years assembling the materials for its construction, with everything now in readiness and with the conception of the

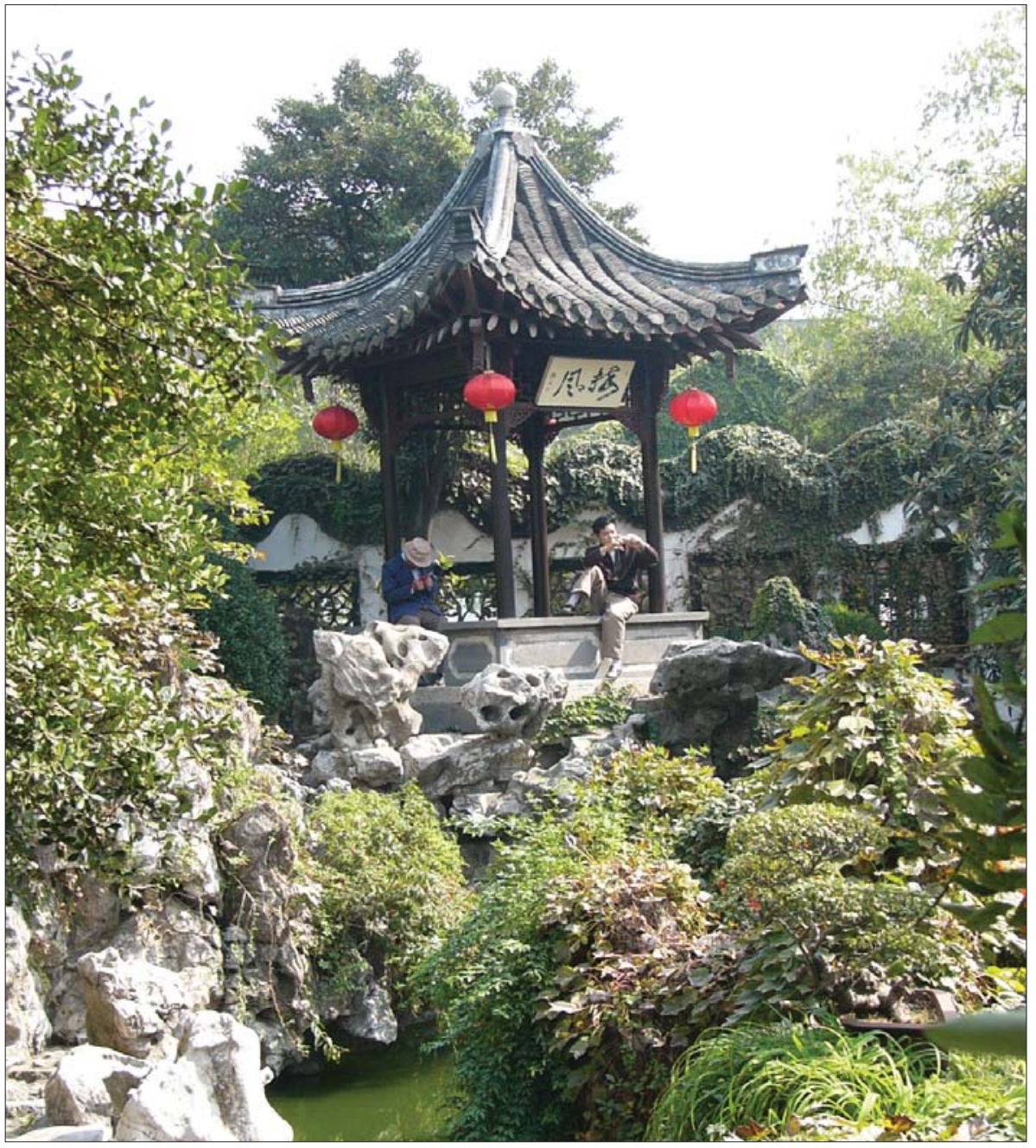

Figure 4.1 The Wind Pavilion, Feng ting 風亭, He yuan. Photo by Lucie B. Olivová. 
garden fully formed in my mind, my garden began to take rough shape within the space of eight months.

(ZHeng Yuanxun 2004: 9-10)

\section{THE AESTHETIC GROUNDS}

The art of investing the small space of a garden with the dimension of the infinite - expressed in Chinese as 'the world in a teapot,' huzhung tiandi 壸中天地 - was the fruit both of philosophical reasoning and of traditional experience. The result of this careful planning was that 'from entering and leaving a garden one actually walks only a mile and half, but you would think that we have collected together in this small space all the famous sights south of the river.' (Ji Cheng 1988: 35)

Ji Cheng 計成, the author of Yuanye 園冶 [The Craft of Gardens], a native of Jiangsu and a prominent garden designer of the late Ming dynasty, who was also active in Yangzhou, expressed the attitude toward planning and building a garden on a limited area of five $m u$ in this way:

To make a garden here one should not only pile up the rocks to emphasize the height, but excavate the earth to increase the depth, in proportion with the tall trees scattered on the hillside here ... Following the course of the stream we should construct pavilions and terraces, whose reflections will be scattered on the surface, with winding gullies and flying galleries leading on from them, so that people will be taken beyond anything they could have imagined.

(Ji Cheng 1988: 35)

Shen Fu 沈復, a writer, scholar and aesthete of the latter part of the I8th century, while visiting Pingshan tang in the spring of 1783 , made this comment:

The way a pavilion or a terrace is placed, a wall or a rock is situated, and bamboos or trees are planted - all things neither completely hidden nor fully exposed - are so skilfully executed that they do not encroach upon the sight of the touring visitors. Such can only be the work of an architect of the mind.

(Fusheng liuji 浮生六記; quoted from KwoK 1997: 52-53)

The means to this end were perfected mainly because the craftsmen were capable of carrying out the ideas of the landscape gardeners, both amateurs and professionals.

The construction of private gardens in Yangzhou reached its peak during the eighteenth century. It was stimulated by the southern tours of the Qing emperors Kangxi and Qianlong, who were impressed by the beauty of Yangzhou scenery and the refined charm of the Jiangnan gardens to such a degree that after their return to Beijing they incorporated some of the most attractive scenes into their imperial parks, and even brought rocks from Jiangnan back with them to adorn their gardens. Reciprocally, the imperial visits had an important impact on the style 
of Yangzhou residential gardens. Built at this time mostly by the rich salt merchants, they became more elaborate and more ostentatious, with multi-storey mansions and gazebos reflecting northern, imperial influence (FInNANE 2004: 197). However, they lacked the simplicity and closeness to nature of the original retreats of the wenren 文 人, who delighted in 'a small grass hut, a square courtyard, a few stalks of bamboo, a pile of stones a few feet high,' as Zheng Banqiao 鄭板橋 (I693-I765), a painter and poet, one of the famous 'eight eccentrics of Yangzhou,' Yangzhou baguai 揚州八怪, expressed it (Hu Dongchu I991: 33).

By the mid eighteenth century there were more gardens inside and outside Yangzhou than in Suzhou. They could be divided according to their location and disposition into chengshi shan yuanlin 城市山園林 [urban mountain gardens] and hu shang yuanlin 湖上園林 [gardens along the lake] (ZHU Jiang 2002: 72). The Yangzhou gardens contributed to the charm of Yangzhou, but they also were an important part of the city culture. Various activities and social events took place in their pleasant surroundings, as is described on different occasions by Li Dou 李斗 in his Yangzhou huafang lu 揚州畫舫錄 [Pleasure Boats of Yangzhou], where the theme of gardens is prominent.

\section{ROCKS AND YANGZHOU GARDENS}

Generally speaking, the Yangzhou garden tradition is typified by artificial rockeries and elevated places from which even a small garden with a lake as a central point could be viewed and fully appreciated (Fig. 4.2). Stones in Chinese gardens symbolize mountains and hills, and are therefore an important part of their composition. The saying is that Yangzhou is famous for its gardens, and its gardens are famous for their rockeries. The craftsmen, shijiang 石匠, who created them joined up into guilds, which were known for their high level of artistry. They co-operated with the owners of the gardens and the architects as 'the hidden significance of the mountains and forests needs a deep study . . . and only when you have the real thing within you ... the imitation that you make will become real' (Ji Cheng 1988: 197).

The Yangzhou style of working with stones was known as the Northern Jiangsu style and was different from the Southern Jiangsu style, typical especially of the Taihu region. Contrary to the famous garden city Suzhou, located close to the Taihu lake with its boulders sculpted by water, there were no stone resources in the vicinity of Yangzhou. There were no mountains in sight and the terrain of the city was rather flat. No wonder Zheng Yuanxun, a typical wenren and a garden enthusiast noted: 'Born, as I was, in River North and thus beyond the sight of a handful of stones [meaning mountains], throughout my youth it was only in paintings that I came to see tall mountains with lofty peaks' (ZHeng Yuanxun 2004: 8). Stones had mostly to be transported to Yangzhou by boats from distant places and different locations, 


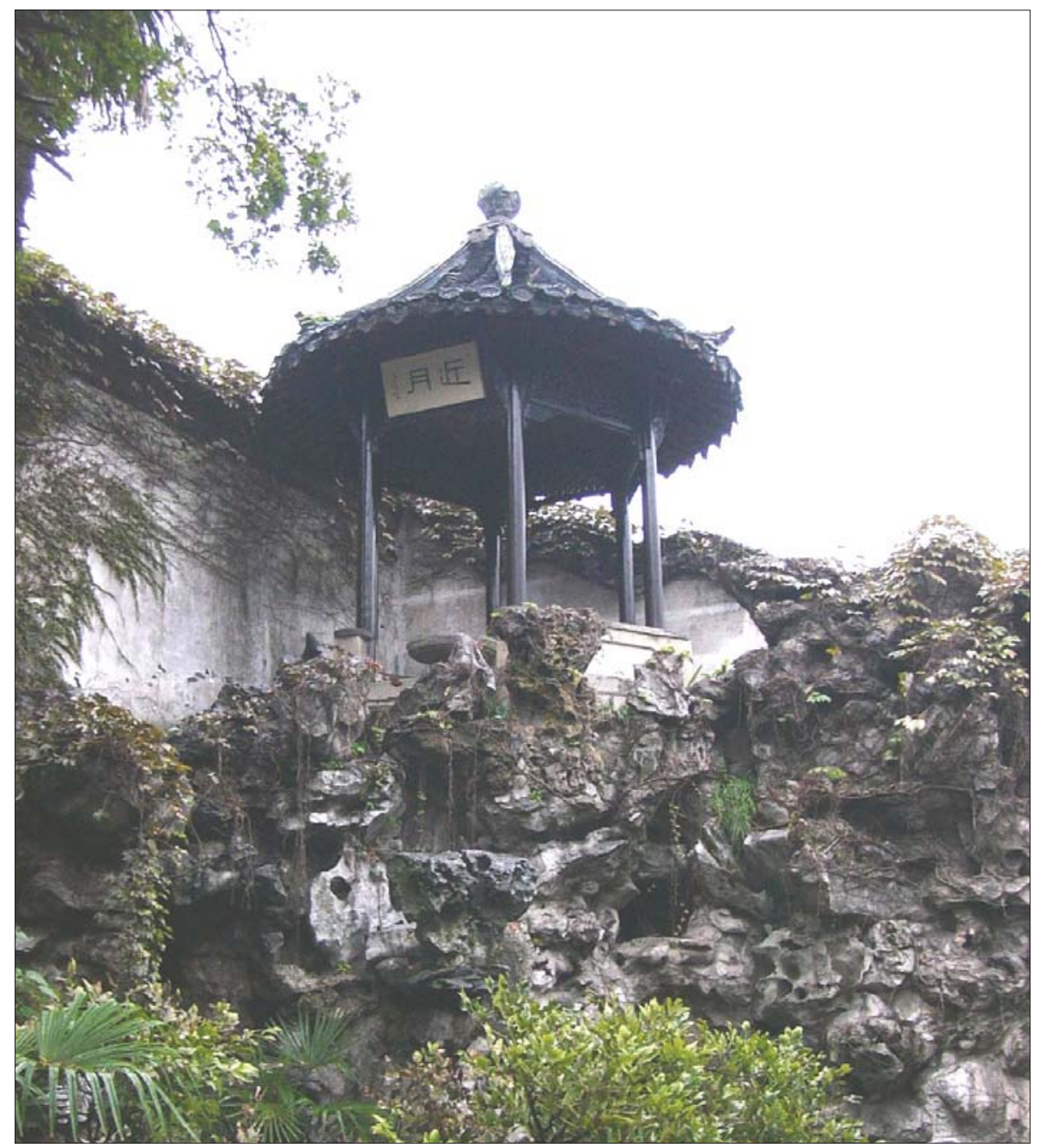

Figure 4.2 Rockery stuck onto the wall, with the Moon Pavilion, Tiebi shan yue ting 貼壁 山月亭, He yuan. Photo by Lucie B. Olivová.

but usually from Anhui, Jiangxi and the southern parts of Jiangsu. The result was that there was a bigger selection of stones in Yangzhou than in Suzhou or Hangzhou (Chen Congzhou i983: 3).

Yangzhou became especially famous for its rockeries piled up from smaller stones, so called dieshan 叠山, which were more common in the local gardens than massive individual boulders. Different kinds of stones were used for the construction of jiashan 假山 ['imitated' or 'man-made' hills and rockeries]. The commonest were greyish stones, Taihu shi 太湖石, yellow stones, huang shi 黄石, and white stones, 
xuan shi 宣石 (ZHU Jiang 2002: I36). The greyish lime stones, Taihu shi, had pits and hollows all over the surface formed by wind and waves, and they expressed a feeling both of stability and motion. The Song painter Mi Fu 米蒂 admired them for their 'wrinkles' and Su Shi 蘇軾 6 praised them for their inspiring 'ugliness' (Hu Dongchu I99I: 79). As there was a great demand for them, they were not easy to get, and garden enthusiasts were willing to pay enormous sums of money for them. Contrary to these, the huang shi, a form of sandstone, were quite common and were 'all over the place.' Ji Cheng, a great lover and connoisseur of rocks and stones, wrote

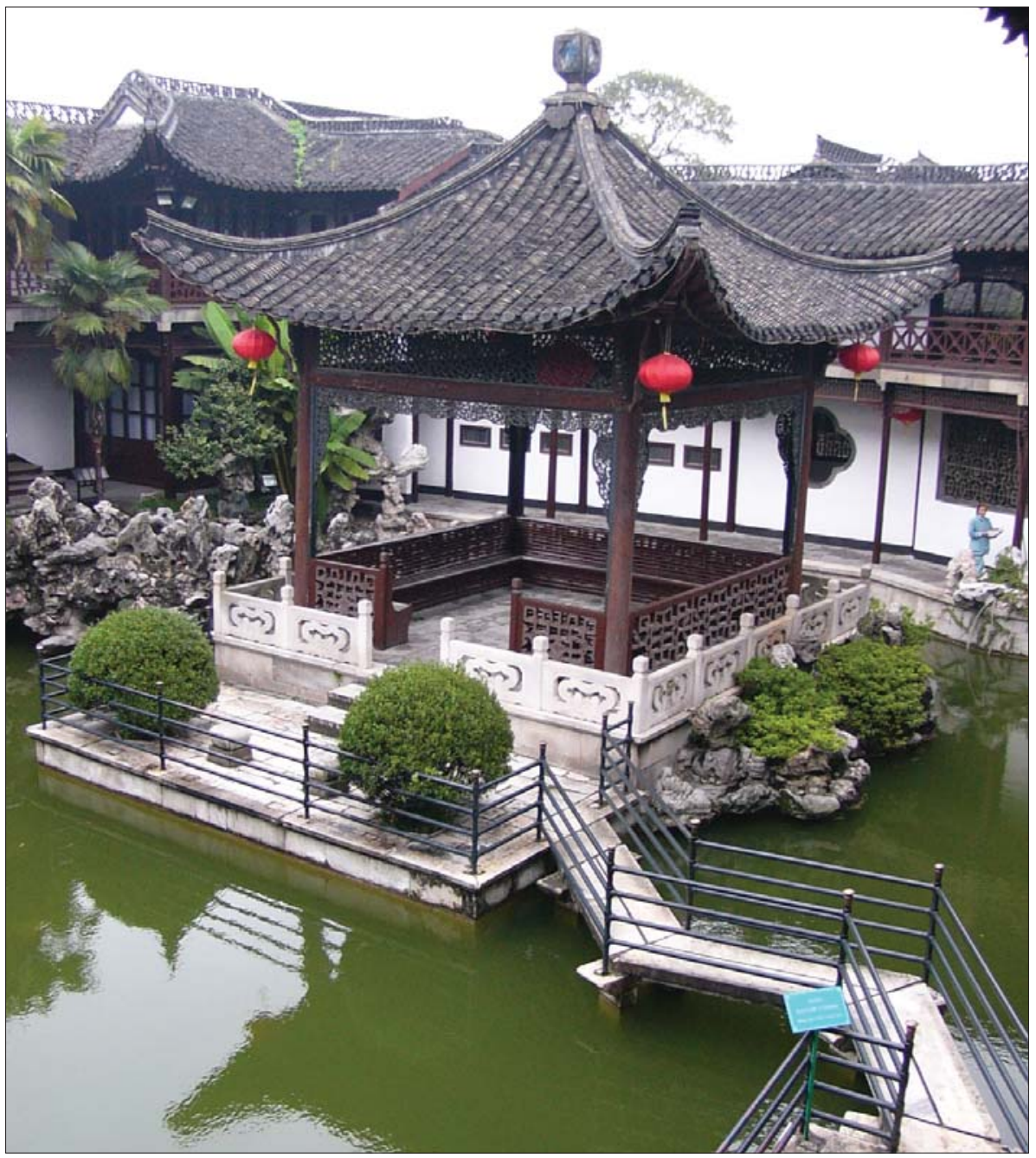

Figure 4.3 The Pavilion in the Heart of the Pond, Shuixin ting 水心亭, with a zig-zagging bridge, He yuan. Photo by Lucie B. Olivová.. 
about them: 'Vulgar people are aware only of their hefty appearance and not of their subtle attraction' (JI Cheng I988:II6). They were especially suitable for building caves. The xuan rocks came from the Ningguo county in Anhui. They were white as snow and were often called 'snow rocks.' The older they were, the whiter they got. For Yangzhou it became a fashion to use different stones within one garden as in Ge yuan 个園, where the famous four hills, symbolic of the seasons of the year, were created from four different types of stone respectively. Very much admired were the artificial mountain caves, with water flowing into them, as is the case of the Summer Hill, Xiashan 夏山, in the same garden.

\section{OTHER FEATURES OF YANGZHOU GARDENS}

Together with rock, water is an important element in the Yangzhou gardens. It brought liveliness and coolness during the hot summer days, when the rich owners would entertain their guests in pavilions, located often in the middle of an artificial lake. The Chinese admired water for its adaptability and ability to take over the shape of its precincts, to mirror the sky, the trees and the moon. Ponds, brooks and streams represented this element in the gardens, with all the changes they underwent during the course of the year. The He yuan 何園 garden in Yangzhou is famous for its oblong pond with the Shuixin ting 水心亭 pavilion in the middle of it, which was used as a stage for theatrical performances (Fig. 4.3). The gardeners also practiced a way of arranging stones in dry garden settings (han yuan 旱園) so as to create the sense of water 'without a drop of it,' as for example in front of the Two-Thirds of Bright Moon Hall, Erfen mingyue lou二分明月樓, in Yangzhou (CHen Congzhou 1988: 36).

The Yangzhou gardens are also admired for their ancient trees, $g u m u$ 古木, and famous flowers, ming hua 明花, and rightly so, because as Su Shi once said: 'Terraces and pavilions, like wealth and power, will be achieved in time, while plants and woods, like fame and integrity, will be attained after a long time' (Li Yande 1994: 340). In Yangzhou gardens old pines, songshu 松樹, cypresses, baishu 柏樹, willows, liush $u$ 柳樹, Sterculia platanifolia, wutong shu 梧桐 樹, Sophora Japonica, huaishu 槐 樹, magnolias, mulan 木蘭, wisterias, teng 籐, Prunus mume, mei 梅, apricot, xing 杏, and peach trees, taosh $u$ 桃樹, are much treasured and are considered living cultural relics. The petals of the flowering Prunus mume, covering the ground in early spring, are compared to the beauty of snow, which is rare in this region. Pavilions and other architectural features which during the Qing dynasty were influenced by the loftier architecture of the North are of importance as well, but it is the trees which give the gardens the patina of age. Trees were selected to represent the seasons of the year and every one of them has its special position and meaning to the effect that 'each has been examined and deliberated upon time after time, to be discarded when it did not prove appropriate, regardless of how beautiful it might have been on its own' 
(ZHeng Yuanxun 2004: I6, n6). During the long history of the Yangzhou gardens, quite a number of pavilions, halls and rockeries were named after trees.

From among green plants and grasses, bamboo was considered to be the essence of elegance: a junzi 君子 [gentleman] among plants. As the saying went 'not one

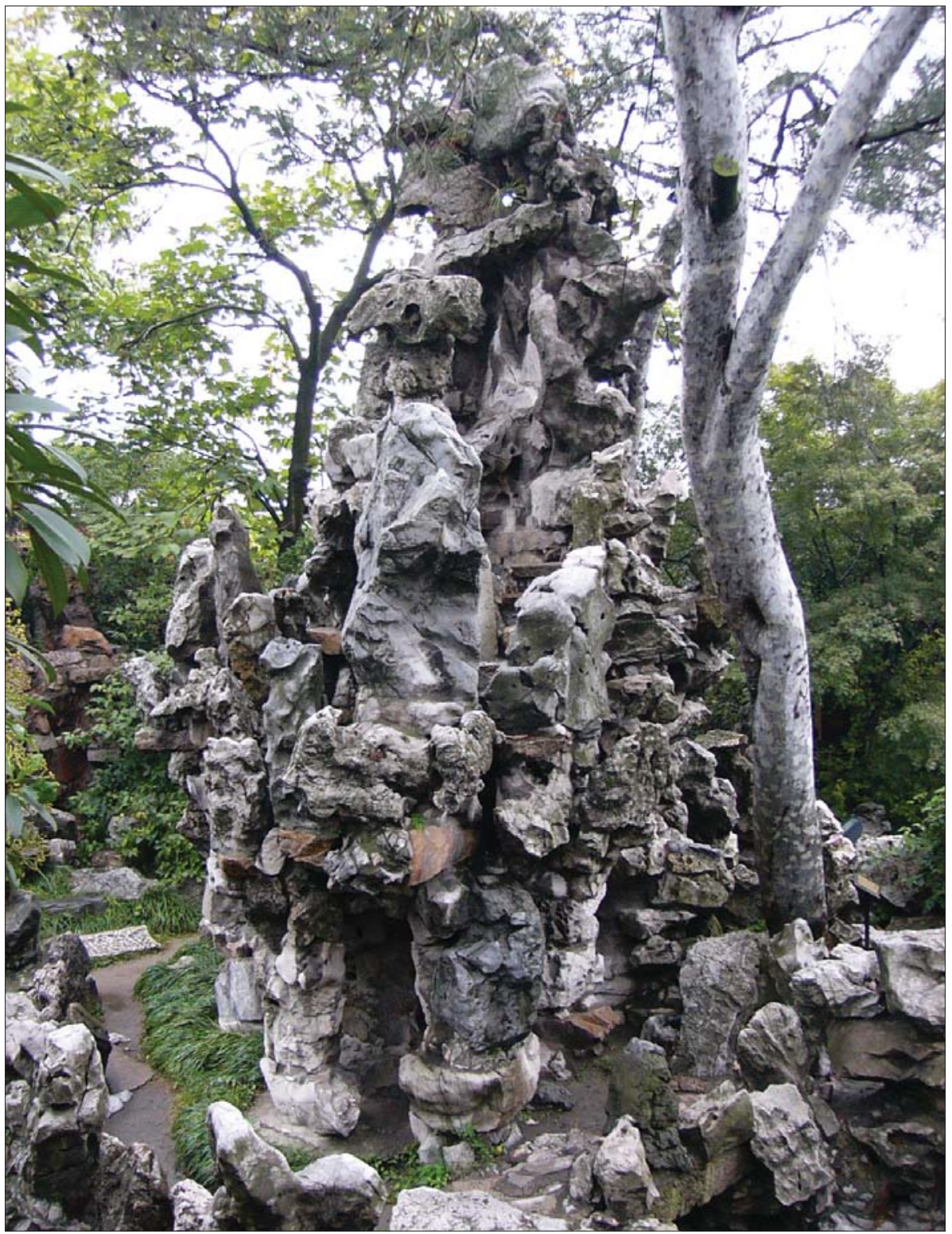

Figure 4.4 A solitaire stone, He yuan. Photo by Lucie B. Olivová. 
single day without this gentleman,' and according to Su Shi, 'One can manage without eating meat, but one cannot manage without bamboo' (EBERHARD 1986: 29); in other words, without meat, one becomes thin, but without bamboo, he becomes vulgar. There were many species of bamboo in the Yangzhou gardens, no less than

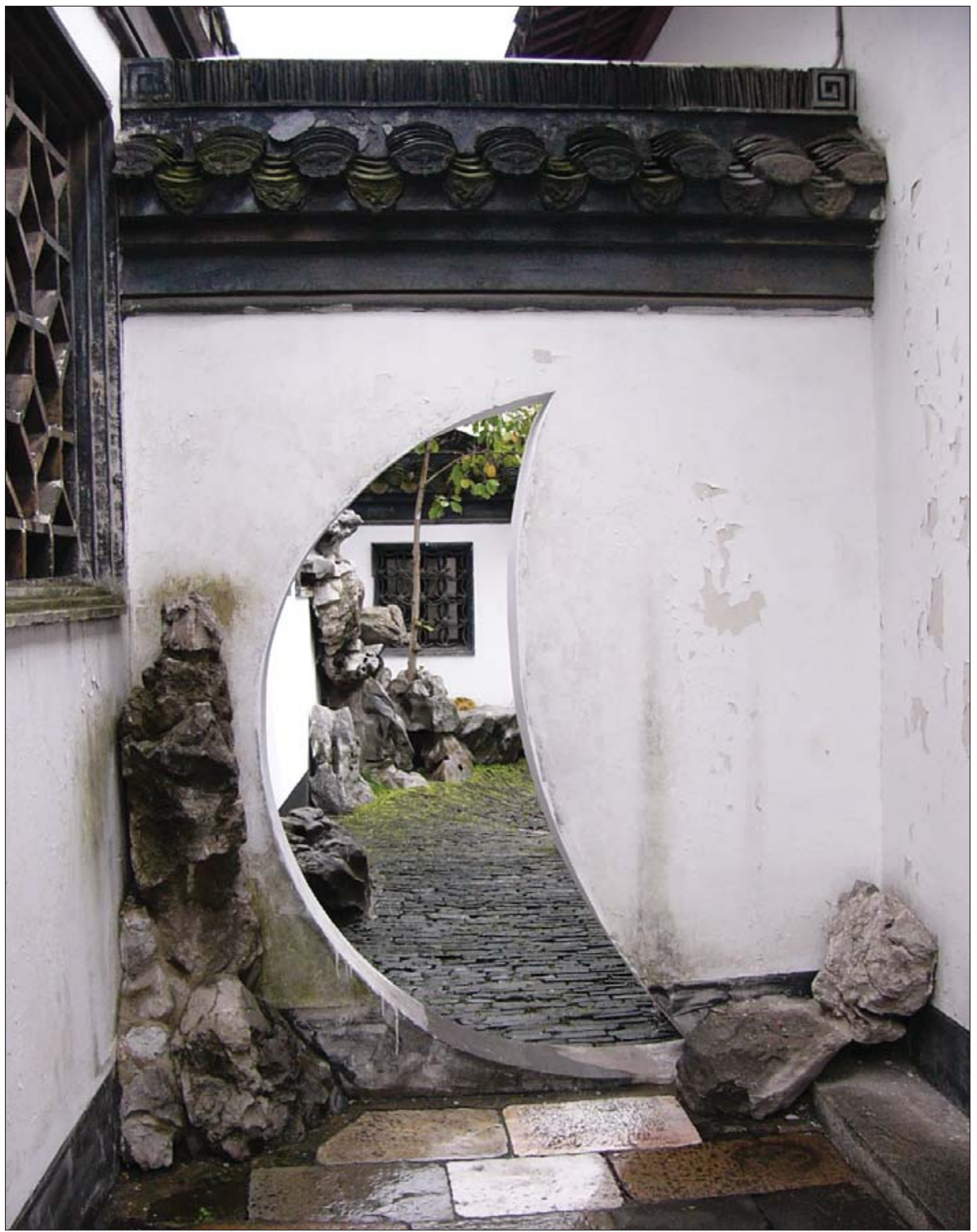

Figure 4.5 Door opening in the shape of a crescent-moon, He yuan. Photo by Lucie B. Olivová. 
one hundred, and they were selected according to the type of the yuanlin. The names of sceneries and garden buildings often include the character for bamboo.

A typical Yangzhou plant was the peony Paeonia lactiflora, shaoyao 药藥, with lanceolar or oval leaves, large splendid purple, pink or white blossoms and roots used for medical purposes. Shaoyao adorned the memorial ancestral hall gardens and contributed to the fame of Yangzhou in the same way as the peony, mudan 牡丹, did to Luoyang. Already in the year I079 shaoyao were classified and described in Wang Guan's 王觀 Shaoyao pu 药藥譜 [A Treatise on Shaoyao]. According to this book, a family named Zhu 朱 was famous for their plantations containing over 50,000 examples of these peonies. When they were in bloom, the owner let the public come in to enjoy the sight of them (Fig. 4.4). ${ }^{7}$

An important part of the Yangzhou gardens were miniature plants in pots, pencai 盆菜, and miniature sceneries, penjing 盆景, arranged on square or oblong ceramic trays. The term penjing is now used for miniature trees in pots, and the miniature settings are known as shanshui penjing 山水盆景. In Yangzhou their traditions reach back to the Sui and Tang dynasties, becoming popular in the Ming and Qing periods (ZHU Jiang 2002: 153). In the gardens penjing and shanshui penjing were used to adorn yards, halls, studies, gazebos, pavilions and other garden structures. The penjing are divided into flower and grass sceneries, huacao penjing 花草盆景, and bamboo and tree sceneries, zhumu penjing 竹木盆景. There are two kinds of shanshui penjing: shu shi penjing 树石盆景 [tree with stone penjing] and shui shi penjing 水石盆 景 [water and stones penjing]. The Yangzhou miniature trees belong to the Northern school of Jiangsu Province, Subei pai 蘇北派. The charm of the miniature trees, known outside China as bonsai, is that though they should not grow more than 60 to $I I 0 \mathrm{~cm}$, they possess all the attributes of trees growing in nature and are a living realization of the idea yi da guan xiao, xiao zhong jian da 以大觀小, 小中見大 [through the small see the large, and in the big observe the small] - so close to the hearts of the Chinese (WANG Zhiying, PAN Chuanrui I986: II-I2). In Yangzhou many enthusiasts and professionals have specialised in this art. Li Dou mentions in the fourth chapter of his Yangzhou huafang lu a certain xiucai 秀才 [holder of the lower examination degree] from the Zhang 張 family, nicknamed 'fencer' Zhang, who was known for his talent for growing potted Prunus mume, meihua penjing 梅 花盆景:

On the Day of Flowers (the I5th day of the 8th month), a Hundred Flowers Fair is held at the gate of licentiate Zhang's house. Celebrated species from all the suburban villages are gathered here. The licentiate's name is Sui 繸, and his $z i$ is Yinyuan 飲源. He excels in the sword dance, therefore he is nicknamed fencer Zhang. He is also good at trimming flowers. His plum bonsais are equal to those of licentiate Yao Zhitong 姚志同, and department-magistrate Geng Tianbao 耿天保. They are called 'the three plum blossom trimmers.' Zhang 
Qiren 張其仁, bearded Liu Shisan 劉式三, and the daoist Wu Songshan 吳松山, who learned the art from them, follow. ${ }^{8} \quad$ (Li Dou I963 [I795]: 8I-82)

In the Yangzhou school of penjing, Yangzhou penjing pai 揚州盆景派, different kinds of trees are used, such as the five-needle pine, wuzhen song 五針松, or the cypress, bai 柏. It is typical of this school that the Chinese juniper, gui bai 檜柏, would have its branches carefully shaped by palm fibres into flat roundish layers, called 'terrace,' 台 tai, when they have less than three layers, and 'clouds,' yun 雲, when they have more layers. The trunks of the miniature trees are also skillfully shaped and it is said that not a branch was untouched by the human hand. The shanshui penjing connect with the Chinese theory of painting, for while creating them it is necessary to arouse the heart and create a space for the poetic imagination, yijing 意景(WANG Zhiying, PAN Chuanrui 1986: 28) (Fig. 4.5).

The private, residential Yangzhou gardens, designed as a rule by painters and scholars and built by experienced craftsmen, have their own 'language,' which, when understood, can become an inspiration for garden enthusiasts, not only in China but throughout the world.

\section{NOTES}

1 The garden was described in Taiping Huanyu ji 太平寰宇記 [Notes on Huanyu District from the Taiping Reign], juan I20. See Borotová 1997: I8.

2 Precisely, lou is a building of more than one storey, often used for observing scenery. Guo Qinghua 2002: 56.

3 See the account of its history in Meyer-Fong 2003: I28-29.

$4 P u$ 戋 meaning originally 'orchard.'

5 Professor Zhu Jiang speaks of 'gardens reminiscent of a landscape painting,' shanshui huayi de yuanlin 山水畫義的園林 (ZHU Jiang 2002: 80).

6 Su Shi, hao Dongpo 東坡 (IO37-IIOI), essayist, poet and calligrapher. An eminent figure of the Northern Song dynasty officialdom.

7 For more detailed information see ZHU Jiang 2002: 144-58.

8 Translated by Lucie B. Olivová. 


\section{5}

\section{A Traveler's Tale of Two Cities Yangzhou, Shanghai}

\section{Malcolm McKinnon}

\section{AS EVERYONE KNOWS}

$\mathrm{H}$ u Hong 胡紅 wrote out the characters swiftly, without hesitating, and then translated: 'If you divide the moonlight in three, two parts will be in Yangzhou.' 'It's a poem everyone knows,' he explained apologetically, an apology for excluding you from that charmed category, 'everyone.' 'Oh, and one other,' and he wrote more and then translated again, 'Bind yourself with a lot of money to ride the crane to Yangzhou.'2 Then, he looked up questioningly, as if to ask, 'How much does someone want to find out how little they know?', but I nodded and he bent to writing again, four lines this time. 'And this', he said pointing to the new-written characters, 'is the most famous poem in Chinese, and it's also about Yangzhou, by Li Bai 李白, another Tang dynasty poet.'3

I asked of course. I asked pretty much any Chinese person I met whether they knew of Yangzhou, had they been to Yangzhou, what did they know about Yangzhou. The answers were always 'yes,' 'no, but I would like to,' and 'a beautiful place, Tang dynasty poetry, gardens, lakes, pleasure ...' Answers like this came from Japanese too, thus far does the fame of Yangzhou reach. Answers like this found on the printed page too:

Ever since Emperor Yang of the Sui dynasty visited Yangzhou, the city has been a renowned place amongst poets and literati: renowned by many, renowned for a long time. Ordinary people follow suit. Even today, if you mention the name of Yangzhou to people, they will nod and shake their head, saying: 'An excellent place! An excellent place!' Especially for those who have never been to Yangzhou but have read some Tang poetry, Yangzhou will always have an image as beautiful as a mirage seen from afar.

(ZHU Ziqing 1989 [1929]: 78). ${ }^{4}$

'And why are you going there?' Hu asked. 'Well it's an old city with a lot of history, and I'm interested in ...' What was I interested in? I was not a Sinologist, I 
was studying cities, non-Western cities. I wanted a story from China which would demonstrate, as many historians had long argued, that modernity did not come solely from the West, but also drew on the country's own internal dynamic:

The internal dynamics and logic of a non-Western nation have come to be seen as more powerful than a strong but external impact. Applying this outlook to modern Chinese history, scholars have convincingly demonstrated that in some dimensions of Chinese life traditional social and institutional practices continued into the modern era, that modernity in some respects had Chinese roots and was not something entirely transplanted from outside, that some social and political aspects of late imperial China were comparable to those of 'early modern' Europe...

(Lu Hanchao I999: 17-18)

Could an old provincial city, like Yangzhou, have been 'modern'? Could it have a 'modern' commerce and public life, individuality in its creative life, before the West appeared on the scene? Maybe, but by the time I set off for Yangzhou, I was not so sure. From all the talk of poetry, of cranes and plum blossoms (which I was later to learn were not on plum trees), ${ }^{5}$ it seemed Yangzhou was exactly the wrong place to look for anything modern. But the hotel reservation was made, the introduction to the university arranged, and Wang, who had suggested Yangzhou as the perfect city for my purposes, would be disappointed (he worked for Hewlett Packard; modernity before the 1990s? what could I mean?). So two days after the 'poetry lesson' with Hu Hong, and one week after arriving in Beijing from Fukuoka, I was on the overnight train from Beijing to Nanjing, sharing a compartment with a physics professor and his research assistant, both of whom had much better English than I had physics, and at least as good poetry. 'Ah Yangzhou,' said the professor. 'Bond yourself with a lot of money to ride the crane to Yangzhou.' 'Ah yes,' I replied knowingly, 'but perhaps "bind" not "bond". Though we did bond, on the strength of that. And on arrival in Nanjing the two helped me, in pouring rain, to a taxi that took me across town to the bus station, for the one-hour trip to Yangzhou. ${ }^{6}$

\section{YANGZHOU THEN}

Ma was a professor from Yangzhou University, who had the misfortune not so much to have the best spoken English in the department but to be studying European history and therefore expected to be particularly skilled in dealing with a foreigner like me. Or maybe he was just too junior to say 'no.' Since I didn't have my search clear in my head, he naturally decided that I must have come to Yangzhou to see the sights famous in its history - so famous places we duly saw, first the Ge yuan 个園.

It would be easy to miss the Ge yuan because it's part of a large merchant house and typically is closed from, not open to, the world. You pay 30 yuan - a lot in China, 
where you can get a meal for is yuan - for a ticket. It's designated one of the 'four famous gardens' in the whole country, so maybe that accounts for the high price. Inside, lots of rocks, built up to resemble mountains, walls, with big circular 'windows' breaking into them, and a sequence of four gardens within the gardens that echo the seasons. Bridges across water courses, pavilions, and in one pavilion singing is under way - it's Beijing opera, Ma explains; it started in Yangzhou. That sounded odd, but later I read about it in two works that became increasingly indispensable as I pursued the Yangzhou modernity hunt: Antonia Finnane's Speaking of Yangzhou and Ginger Hsü's Bushel of Pearls (FInNAne 2004; Hsü 200I). The Kunshan 昆山 or Kun opera, Kunqu 昆曲, I learnt, flourished under the patronage of Yangzhou's salt merchants; when the Qianlong 乾隆 Emperor visited the south, including Yangzhou, in I75I, the first of six such tours, he decided to import southern performers to Beijing.?

Gardens, opera, merchants, salt: they recurred as we visited other sights of Yangzhou. Salt? 'Salt and civilization,' a New Zealand historian of China titled one work, and in Yangzhou you can't escape the connection (ADshead 1992). The imperial government licensed salt traders. They bought cheap and sold dear. Economists call it rent-seeking: once you had the license you couldn't lose - well nearly couldn't. In late Ming and early and mid Qing times (ca I550-I850) the salt administration for a big swath of central China was located in Yangzhou. The merchants followed them. One calculation reckons that the Yangzhou salt merchants controlled the salt supply to a quarter of the empire's population (that is, to perhaps 75 million people in I80o), which in turn led to them accumulating more wealth than any other merchants, until the rise of the port towns that traded with the West, the treaty ports. ${ }^{8}$ Neither officials nor merchants were local. The officials would be at least from a neighboring, if not a more distant province: the merchants were mostly from the impoverished Shanxi and Shaanxi provinces or from Huizhou 徽州, just upriver from Nanjing, a district from which merchant networks had spread out and flourished in the lower Yangzi over at least two centuries (Ho Ping-ti I954: I43-44). So Yangzhou in the eighteenth century, when the system was at its peak - or most lucrative - was an official/merchant version of the universities at Oxford or Cambridge: in but not of its surroundings.?

Am I closer to something modern? It doesn't seem like it. One account in Speaking of Yangzhou of Li Dou's 李斗 Yangzhou huafang lu 揚州畫舫錄 [Pleasure Boats of Yangzhou], written I764-I795, tells of occasions in which desks 'were set out in the garden with calligraphic tools ready to hand; tea and fruit available for refreshment; brushes flying till poems were written ... wine and delicacies rewarding each poet for his labors; and the day ending with musical performances' (FInNANE 2004: 199). ${ }^{10}$ These merchants with their gardens, trees laden with blossom then fruit, libraries, poetry readings, literary games, musical theatre performances; the restaurants, teahouses and bathhouses, in which they meet each other, and conduct 
CHINA. No.2.(1869.)

CORRESPONDENCE

RESPECTING THE

ATTACK

ON

BRITISH PROTESTANT MISSIONARIES

AT

YANG-CHOW-FOO, AUGUST 1868

Presented to both Houses of Parliament by Command of Her Majesty. 1869

\section{LONDON: \\ PRINTED BY HARRISON AND SONS}

Figure 5.1 'Missionaries attacked at Yangzhou.' Reproduction of the front page of a report to the British parliament of an attack on British missionaries at Yangzhou in August 1868.

liaisons, with women, with youths; all this seems saturated in a timeless, traditional China. It's 'willow-pattern' recognition: as if you'd walked not into a park or garden but into a picture, or into the image on a piece of 'china' . . the arched bridges over water, graceful willows, it's spring and they're just leafing, making gently falling draperies of pale apple green.

The distance from modernity is only underlined by the latter-day visitors to Shou $X i b u$ 瘦西湖 [Slender West Lake], who in strolling around, taking photographs, hiring craft that they then paddle up and down the lake itself, often with a great deal of mirth, or boarding much larger vessels which do the same thing, seem as remote as me from eighteenth century Yangzhou. ${ }^{11}$

And satisfyingly, as befitted an oriental city, Yangzhou then declined. At the end of the century culture and wealth drained from Yangzhou. The reach of government faltered, and paradoxically - or maybe not - a heavier tax burden fell on the salt traders. Who were losing business to salt smugglers. If people bought cheap from smugglers why buy dear from traders? Salt merchants left Yangzhou, for other places, for other profits. The town lost its 'superstructure,' turned in on itself, the 
great gardens outside the walls fell into disrepair. It was Oxford without a university, Antwerp without ships. The nadir came in the I850s, during the Taiping 太平 Rebellion against the Qing dynasty. ${ }^{12}$ Making their headquarters in Nanjing, Taiping and Qing imperial forces battled over Yangzhou three times. Its great Treasury Library, Siku quanshu 四庫全書, one of only four in the Empire, was sacked (FInNANE 2004: 299-309). The 'angel of extermination,' wrote a Jesuit missionary in I854, 'hovers over this recently rich, voluptuous city, striking repeatedly, never pausing to sheath his sword.' 'Serves them right,' you can almost hear him add. And more misery, I856 saw a plague of locusts, and drought impoverished the country districts.

In I868-1869 Yangzhou is in 'head-lines.' Recall the 1966 film, The Sand Pebbles? With a laconic Steve McQueen cruising up and down the Yangzi rescuing missionaries in war-torn I920s China, a story of Western protagonists and Chinese spectators, a storyline echoing others such as the Inn of the Seventh Happiness, Pearl Buck's The Good Earth and a whole welter of images of China at war, China poor, China mysterious, China hostile. ${ }^{14}$ That was how it happened, wasn't it, how China first met the modern world, how the East was won?

Well it was seemingly that same story fifty years earlier. In August I868 a 'mob' attacked the mission station in Yangzhou of the China Inland Mission. British ambassador (and former consul at Shanghai) Rutherford Alcock's report to London (Fig. 5.I) of 'the outrage by which a party of missionaries with their families were victims at Yang-chow, and narrowly escaped with their lives from the fanatic mob led on apparently by the literary and educated classes' certainly does not suggest that modernity was alive and well in Yangzhou. Alcock was in fact questioning the practicability of missionary endeavor in the interior of China, far from centers of British power and influence, but that only makes the point more powerfully. ${ }^{15}$

Two months later Medhurst, the consul at Shanghai, reported to Alcock that after having brought his 'negotiations at Nanking in respect of redress for the Yangchow outrage to satisfactory termination' he had taken a flotilla of vessels and forces up the Grand Canal to Yangzhou. Save the indignity of repeated groundings of HMS Dove the journey proceeded smoothly and 'by $2 \mathrm{pm}$ on the 15 th [November I868] the flotilla steamed successfully past the city to the anchorage assigned to it ... the naval and marine battalion, which had been marched from the bivouac of the previous night . . . reached the ferry opposite the gate at the same moment, and the effect of the simultaneous arrivals upon the thousands of native spectators must have been as useful as it was no doubt interesting. '16 Without a doubt. Regrettably, Medhurst doesn't describe the city, but 'native spectators' does not suggest, any more than Alcock's 'outrage' and 'fanatic,' an outlook shaped by any notion of a modern Yangzhou.

Medhurst returned to Shanghai, mission completed; the missionaries stayed on in the city. For them 'modern,' if it were anything, was Christianity, and they 
determined on bringing the Christian message to the Chinese, with a confidence and a determination which seems impossibly remote, not just from today's Chinese, but from one's own self, despite their being but three generations and hardly any DNA removed from the present. Was it truly possible? That Geraldine Guinness (aka Mrs Howard Taylor) would write of her arrival in Yangzhou, less than I2O years ago, that 'Our hearts were wonderfully drawn together in those last days, and drawn nearer to the Master also, as, in the midst of this great heathen city with its 300,000 inhabitants, we realized the shortness of time, the magnitude of the work, and His gracious presence and power that so abundantly outweighs our weakness ... I got down the map of China from its place on the wall to trace out quite clearly the long journey of each [missionary sister]. Oh, what a scattering of lights amidst this heathen darkness! . . . Dear Miss Ramsay from Doric Lodge and Miss Hooke will be two months traveling steadily up the great Yang-tsi before they reach Chingking in Sz-chuen, the place of their future labors. ${ }^{17}$

It's amusing that the Dove kept grounding and I know that for all Geraldine Guinness's enthusiasm the missionaries made few converts, but my own quest is not in much better shape. I jump forward, another half century; the empire is no more, Yangzhou, disliked by the new republic, has lost its reputation as well as its prosperity. Antonia Finnane reports visitor Emily Hahn describing Yangzhou as a 'very old moss-grown city, dank and green ...' (FInNAne 2004: 313). She also records a 1932 Chinese visitor observing no department stores, no cars, the great houses in disrepair, the ordinary houses 'antiquated,' poor drainage and sanitation, streets full of rubble and a people wedded to superstition, eating, drinking, decadence and idleness. Wherever modern was, it was emphatically not Yangzhou. ${ }^{18}$

\section{YANGZHOU NOW}

That was seventy years ago. Today, you are likely to approach Yangzhou from Nanjing, arriving on the western side. You don't have warning. No sweeping descent from mountains into city outskirts, no crossing of a harbor bridge or round a foreshore to see it all of a piece. Just mile after mile of highway through farm land, and then, leaving the bus station, the first built up area. Ten years ago that was also farmland, I was told by $\mathrm{Xu} \mathrm{Yu}$ 許玉, a city official, but is now spotted with ten to twelve-level apartment buildings, office buildings, shopping centers and wide roads of the kind that bring non-words like 'thoroughfare' or 'dual carriageway' to mind. The apartment buildings have recurrent Western motifs, Grecian columns and porticos for instance; they're mostly red painted or red brick, with yellow and white details. In Communist times, housing in cities in China was yoked to work places. ${ }^{19}$ Now there's a housing market, a housing boom, a housing bubble, depending on whom you ask. You can buy one of these 'upscale' apartments for 300,000 yuan $\left(\mathrm{US}_{\$ 40,000}\right.$ ) and, 
a fairly recent change, you can borrow to buy, although most people will have paid cash. The road gets busier; there are fewer gaps between the buildings. It seems very modern, very up to the minute, rather like a Japanese city, although a closer look shows that most cars are taxis, that there are many, many cyclists and equally many people riding buses.

The hotel is close to the center of the town. ${ }^{20}$ Nearby Siwang ting 四望亭 Road is lined with restaurants, and in the lanes off it, markets with a great array of vegetables, fruit and cooked food. Siwang ting Road meets the main street, Wenhe 汶河 Road, and at the junction, and along Wenhe Road, both left and right, there's neon everywhere. On the further side of Wenhe Road I find the 'old town' - the squareshaped Yangzhou that features on maps or drawings of the city, the Yangzhou that was the city until the I950s, when the city walls were demolished (FInNANE 2004: I3). Have I jumped back in time? Men are wheeling around the streets calling for repair work, little shops are barely visible in the doorways of houses, public toilets and bath houses are marked, and busy, every few blocks; turn a corner and you come across a canal, or another lane of one-storey housing. You feel remote from those you pass. 'Isn't it funny?' my walking companion translates the words of some passers by. 'We don't know what they're saying, and they don't know what we're saying!'

But later I see I980s or earlier photographs of these areas. The canals are full of rubbish, the buildings, which are now white-washed, are drab, even the trees look more miserable. The old city may seem remote, 'old,' but in fact it is well on the way to becoming a history theme park. We exit abruptly back into hustle bustle and razzle dazzle - it's Wenchang lu 文昌路 this time, another wide street sliced through the old city in the early I980s, flashing neon lights at night, lined with music stores, bookstores and five-floor department stores, a McDonald's and a 'Kentucky' - as it is always called - streams of car and cycle traffic.

Over the next weeks and on subsequent visits I walk through most of Yangzhou, with the help of a few bus rides and occasional advice from concerned fellow travellers. One day I head east on the number 2 bus. If 'West' was a version of the capitalist modern world, 'East' seems more like once-communist Russia or Ukraine; two to three floor concrete, un-white-washed (grey-looking) apartment buildings, one after another on both sides of the street, with trees only partially softening the effect. We turn right and are almost out of town, and when the bus makes another left turn it is onto a rough road lined with shops and stalls. Had it once been a village center, was it still? The number 2 bus reaches the end of its route and indeed pretty much the end of the road. I am 'nowhere' - that is nowhere near west side or downtown Yangzhou's gardens or its glitz, but surrounded by pile after pile of steel rods, of screws, nuts and bolts, of motors and boat hulls. It turns out to be a trading place for used metal goods. I gaze at two giant cooling towers not too far away. I walk desultorily eastwards towards a waterway and watch two fellows coming toward me 
in a row boat. Is it a ferry, I wonder? They signal me to get on. I look back to the number 2 bus: it's turned and is heading back into town. So why not? It is only a couple of minutes of rowing, even with the passenger. They won't take payment and I realize that whatever they're doing it's not running a timetabled service and maybe not even a service at all (Fig. 5.2).

I walk up the other side, finding myself in a boat building yard or certainly a boat parts building-yard; most the materials being worked with are plastic or fiberglass rather than timber or metal. I am accosted by one of the workers. I don't know how many years of Chinese lessons will be needed to explain quite how I've reached the boatyard but it was more than I have or he will want to wait for, so I decide best to keep on walking and find myself out on the street facing another shipyard: Yangzhou Dayan 揚州大燕. I keep walking, following a sign to the Zhuyu wan 茱英灣 Park, past the 'Jiangsu Guoli Forging Machine Co Ltd' 江蘇國立鍛壓機床有限公司, a public welfare home and a defunct needle and sewing factory.

It's all a reminder that Yangzhou, like the rest of China, has a modern twentieth century history from well before 1990 - that the I9II revolution that overthrew the Qing dynasty, and the 1949 one that brought the Communists to power, were both about making China modern. And if the former ignored Yangzhou, the latter did not, and what I'm encountering is some of its inheritance. No surprise then that the streets looked like once-Communist Moscow or Kiev.

It's now late on a spring afternoon and the sun is shining benignly over the park from behind the cooling towers, now to my west, and the big power station of which they are clearly a part. The park is on a promontory separating two water courses and there is a 'street sign' right where the two stretches of water join. Later I discover that one of those stretches of water is the Grand Canal, the Grand Canal. This very place, with its cooling towers, metal traders, boatyards, was where emperors once disembarked. How could the two be connected? If I'm going to find a connection, I will have to leave Yangzhou. Which means, I decide, that I have to engage with the city that lies just four hours down the highway, that stands pre-eminent in any account of modernity in China.

\section{TRY SHANGHAI}

That's Shanghai, of course. But here's the rub. I'm looking for a modern way of doing things that has Chinese characteristics, Chinese roots. And while Shanghai is in China, it's not clear through the later nineteenth and early twentieth centuries that it's of China. Isn't it the pre-eminent artifact of the impact of the West on China? Where enterprise, innovation, efficiency, orderliness, technology make a first appearance?

The Shanghai, not the Yangzhou, that got banks in I848, Western-style streets and gaslight in 1865 , telephones, electricity and running water in the early I880s, cars 


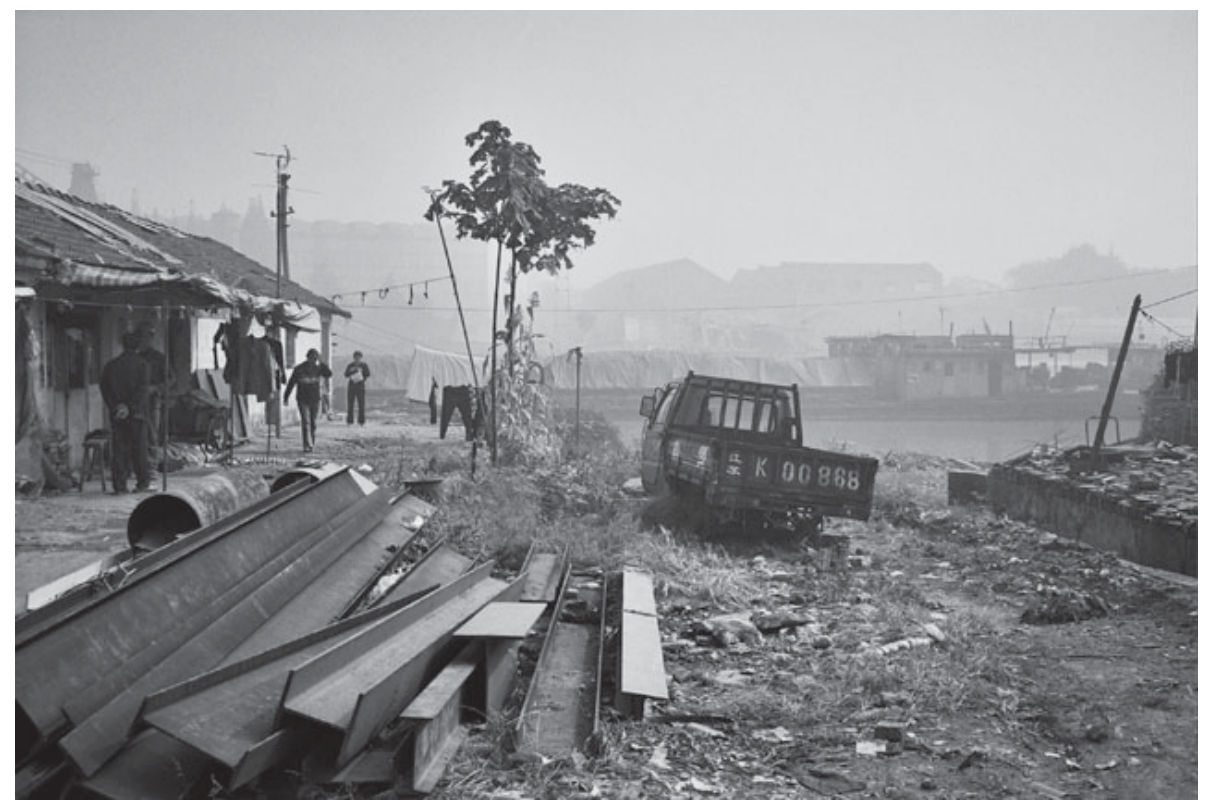

Figure 5.2 Metal trading area and the Grand Canal. Metal traders operating at the eastern end of Taiping Road, Yangzhou. The Grand Canal, in the background, has a very different appearance than it did in the eighteenth century. Photo by Avenal McKinnon, October 2005.

in I90I and trams a few years later. ${ }^{21}$ The Shanghai whose waterfront was rebuilt in the late I920s and early I930s with New York-influenced 'skyscrapers'; in which the Wing On and Sincere department stores opened their doors on Nanking Road; to which Westerners came and went, in and out of offices, clubs, golf courses, along the Bund, and in massive suburban houses (LeE 1999: IO-I5). The Shanghai of 'White' Russians and proper Britons, of Margot Fonteyn and W. H. Auden, of memory makers and movie magic. The Shanghai whose 'shining moment' in those same years defined 'modern,' the Shanghai which provides the setting for a 2Ist century film about a former American diplomat and a Russian countess. ${ }^{22}$

Seemingly even the Chinese themselves knew this was where their modern world had originated:

The sun had just sunk below the horizon and a gentle breeze caressed one's face ... under a sunset-mottled sky, the towering framework of Garden Bridge was mantled in a gathering mist. Whenever a tram passed over the bridge, the overhead cable suspended below the top of the steel frame threw off bright greenish sparks. Looking east, one could see the warehouses of foreign firms on the waterfront of Pootung like huge monsters crouching in the gloom, their lights twinkling like countless tiny eyes. To the west, one saw with a shock 
of wonder on the roof of a building a gigantic neon sign in flaming red and phosphorescent green: LIGHT, HEAT, POWER! ${ }^{23}$

So? For all that sense of demonic Western machine power driving modernization, it doesn't take too much investigation to learn that there are Chinese stories of modernity in Shanghai just as compelling as those Western ones. Which is hardly surprising, given the numbers. As one guide book explained in the 1920s, there were in Shanghai '. . . one million Chinese to fewer than 15,000 western foreigners ... the [newcomer] hardly ever meets [another] foreigner. ${ }^{24}$ By the 1933 census the number of foreigners had increased to perhaps 70,000, but not all would have been Westerners (the numbers would have included Japanese, for instance) and the total Chinese population was over three million. ${ }^{25}$

It was many of those Chinese who took to modern life and made it their own. Read about the Shanghai orchestra, which started off with Filipinos and Westerners but became mostly Chinese. Think of the nineteenth century artists in Shanghai who studied, and then responded to, Western art. Of the writers of new kinds of fiction, the initiators of new journals like Xiaoshuo yuebao 小說月報 [Short Story Monthly] (Hsü 200I: 5, I3; Melvin and CaI 2005: 89-9I; Gimpel 200I: 24-29). Think of the women who, some time in I920s Shanghai, started to wear the qipao 旗袍. Better known in the West through its Cantonese pronunciation as cheong sam, this 'archetypical' Chinese dress, in fact a hybrid of Chinese, Manchu and Western elements, derived its significance 'not from the numbers of women who wore it' but because the women who did were 'the female face of a progressive China.'26

I gaze at the photographs of a family whose story mirrors such changes and adaptations. Look at the picture of the Chi Zhi 持志 University cross-country team with young male family members looking frankly at the camera along with their fellow students. Look at the school song: a western musical score with Chinese words. A son in jersey and trousers posed self-consciously against a tree. ${ }^{27} \mathrm{~A}$ graduation photograph from about 1935, an engagement announcement from the Xindu 新都 [New Capital] Hotel in Shanghai, on II June 1943: the fiancée must be about 22. And the wedding photograph with her 43-year-old husband from 25 July 1943, she in white, Western bridal wear, he dressed to complement her in Western morning suit, and it's ... Shanghai in 1943 , in wartime. Another story, another set of questions there, which I don't pursue for the moment. A traditional Chinese 'wedding basket' but also glass and china in 1940s style including squarish art deco style cups, another basket of embroidered cottons, some in Western, some in Chinese style. So it's a family, this family, which displays the Chinese face of modernity, the Chinese face of modern Shanghai, even to that wedding during the years of Japanese occupation. And where have I found this family? Or rather, where have I found their pictures? In Yangzhou. 
To find them, or rather, to come across them I'd visited, with Professor Ma, the He yuan 何園 - which tells a quite different story from its near-namesake. Though when you enter its grounds, it does seem very much like the Ge yuan. If I'm honest, I admit I'd probably fail a 'Which garden is this in?' Yangzhou photo quiz. Arched bridges over water courses, ponds with lilies, heaped mounds of rocks, some with passages underneath them, platforms linking one 'island' with another. Old magnolia and other trees shading the courtyards, smaller bushes. I've walked back into that timeless, but 'old,' China and I'm a bit - well maybe jaded is the word. Repetitions on themes, repetitions that won't disclose any new experience.

But a first surprise. The house and grounds were constructed by a He Ruchi 何 汝持, the son of the founder of the family fortunes, not in I683, or I783, but in 1883 . And a second surprise, whatever I might think of the grounds, the house seemed far from 'old-fashioned.' It takes a while for me to 'see' this. The traditional courtyards, the approaches to the rooms along open balconies, the generally dark toning of the timber: it all looks 'old.' But then I looked into a study. It had both bookshelves and a desk along Western lines and even an easy chair, a kind of rocking chair, an item of furniture new to China at the time. The rooms of two of the daughters had Western-style beds, 'open' at the sides, unlike the box beds characteristic of 'traditional' Chinese houses. And then I reached the photograph display. Each successive generation of the family took on a different style, maybe even a different persona, as decade followed decade. Photographs are of course new themselves as an aid to family recollection and identity. The family founder always appears in the photographs in 'traditional' Chinese dress, but his sons appear in both Chinese and western dress. If I knew more I could probably detect refinements in the pattern of change that don't fit the crude categories of 'traditional' and 'Western. ${ }^{28}$ But it is clear that these changes, these new departures, were taking place not just in Shanghai, but in Yangzhou, in a city saturated in the past. ${ }^{29}$

So the energy of Shanghai had roots in Yangzhou? It's not just a modernizing Shanghai family that proves to have Yangzhou antecedents, it is also a Shanghai garden. I don't get to see the Zhang garden in Shanghai but I read about it. It was built in the grounds of a house that had been foreign-owned but was bought by Zhang Shuhe 張叔和, who made the garden in the late nineteenth century. 'Apart from ponds and rockeries, weeping willows and bamboo groves, the garden featured a modern building called Ankaidi 安塏第 ('Arcadia') and a theater called Haitian shengchu 海天勝 處 ('sea-horizon beauty'). Western restaurants, novel electric appliances and recreational installations were added. ${ }^{30}$ Very 'Shanghai modern.' But in her study of this garden, Meng Yue explores 'echoes and variations' between Yangzhou and Shanghai, arguing that, 'As the urban interiors of eighteenth-century Yangzhou make clear . . . features that are conventionally thought of as uniquely 'modern' and 'Western' . . . may be related to the formation of an upper-class urban culture.' ${ }^{31}$ 
And then there's writing. Around 1900 a 'courtesan novel' was published in Shanghai. It's a kind of fiction reckoned to have developed in the nineteenth century but with roots in earlier forms, one of which was the cautionary novel - what happened to men - and women - who got embroiled in decadence and sybaritic living. And this particular novel turns out be a reworking and republishing of a Yangzhou novel, Fengyue meng 風月夢 [Illusion of Romance], in which, Patrick Hanan explains, 'All of its place names were changed to Shanghai place names, while its courtesans were transmogrified into the most famous prostitutes of the contemporary Shanghai scene. ${ }^{32}$ Fengyue meng itself had been published in Shanghai in I883, and influenced the first Shanghai city novel, Haishang hua liezhuan 海上花列傳 [Lives of Shanghai Flowers] which was first serialized in 1892, and appeared in book form in 1894. But its preface was written in 1848 , and Hanan reckons it to be the 'first Chinese "city novel" in any meaningful sense, and Yangzhou the first city to be so treated' (HANAN I998: 349).

Yangzhou in the I840s then, if its decline was unmistakable, nonetheless had the cultural energy to produce new departures in fiction and to convey a sense of the vitality of daily life. 'No novel is better than Fengyue meng at giving us the sense of crowded public places. Masses of people flow over the bridge, entering or leaving the city; bearers of vegetables, fish, water and firewood . . . all jostle their way forward. There are also the swift sedan chairs of the salt merchants, as well as . . women offering to mend or patch clothes, friars beating their wooden fish, boys dressed up as girls' (HANAN 1998: 352). Indeed even in I863, with the struggle between the Taiping and the dynasty still continuing, local notable Jin Changfu 金長福 kept a diary in which the weather, parties, gatherings and comings and goings - he had at least eleven sons - loom larger than 'current events' as he calls them. ${ }^{33}$

So Yangzhou was not then the half-alive city it appeared to be in 1868 , let alone that 'city of heathen' which Geraldine Guinness encountered in the I88os, but more like its nineteenth-century European counterparts. And we can turn from the world of the novel and private life to accounts of the cities themselves, for instance those of Robert Fortune, who traveled through parts of China in the I84Os, immediately after the Anglo-Chinese wars of the I840s which saw selected ports in addition to Guangzhou (Canton) first opened to foreigners. Fortune is a 'bad boy' in the nationalist narrative of nineteenth-century China, because he got himself clandestinely into the tea plant region to uplift plants that would be used to start tea plantations in British India. And he's second to none in observing the failings of Chinese life, the opium addiction most notably but also more generally:

Doubtless the Chinese were in that half-civilized state in which they are now, at a very early period ... it is long since they discovered the art of making the beautiful porcelain, lacquer ware, and silks . . . but these very facts - their 
civilized condition, their advancement in the arts . . instead of telling in their favor as an active and intelligent people, do the very reverse when we consider what they might have been now and what they really are.

(ForTune I979: 5). ${ }^{34}$

But even Fortune's journal conveys the vigor of urban life and people as he travels around, disguised as a northern mandarin. Fortune did not cross north of the Yangzi but visited, for instance, Shaou-hing-foo (Shaoxing 紹興) which 'probably contains nearly as many inhabitants as Shanghai (270,000), with canals circling, moat-style, three to four miles of walls.' Fortune got the boatman to take a side canal through an arch in the ramparts into the city, observing that 'On the sides of the canal the houses have a somewhat mean and poor appearance, but they are better in other parts of the town. A great trade seems to be carried on in all the necessaries of life ... I saw many ornamental gates in the town, erected to the memory of virtuous women ... but its chief fame results from the number of literary men which it has produced . . . wherever you meet them it is their pride and boast to have received their education in the city of Shaou-hing. '35 That reference in passing to Shanghai is itself revealing; no humble fishing village but a city of a quarter of a million, a population the equal of any European capital save London and Paris, and with a longstanding and vigorous domestic trade as well as a more recent and volatile export one. ${ }^{36}$

We are nearly back in the eighteenth century. The founder of the He family fortunes, He Jun 何俊 (b. I797), lived through the Taiping wars, kept his wealth and fathered a dynamic, outward-looking family. Like the salt merchants, He Jun had come to Yangzhou from Anhui, Wangjiang 望江 county in his case. ${ }^{37}$ The I840s novels also had links to narrative traditions in Yangzhou; and Shanghai painters had Yangzhou antecedents (Hanan 1998: 355). So while people from Yangzhou were merged into the stubborn, rustic, naïve category of Subei 蘇北, in booming modern Shanghai, Yangzhou culture nurtured that of the new metropolis (HonIG I992).

\section{AT THE BA GUAI MEMORIAL HALL}

I'm on the brink of that 'timeless' eighteenth-century world with which I started, heading for a memorial hall, a kind of museum. I reach it by turning into a side street, really not much more than an alley. Off the glamorous Wenhe Road, beneath an arch that leads into the alley, and after a couple of hundred meters or so to a big pair of wooden doors, through which I can see a ticket office. The operatives in the office look up languidly but sell me and my companions tickets. At is yuan there won't be too many visitors, but it does not look as if income from the visitors has been lavished on the museum, for that is what we have come to, a museum, not a house or garden. It's known as the Ba Guai Memorial Hall, and that doesn't help much either, 
unless you know that ba guai 八怪, which means 'eight eccentrics,' refers to a group of artists who flourished in late seventeenth- and eighteenth-century Yangzhou (Fig. 5.3)..$^{38}$

The interior that I've now reached, formerly the Buddhist monastery Xifang si 西 方寺, has the familiar feel of all such interior Chinese spaces: a disposition of buildings and open areas that face inward, not outward, and relate with each other not the world beyond. The buildings are given over both to accounts of the lives of the artists and also to displaying their works, of which only some are originals. I know the $b a$ guai are significant, but I'm new to them and their art. Will they become significant after I'm educated by the art? The first room provides the context: the ba guai, it seems, did not come from Yangzhou. A map shows the various towns they came from, all within a manageable distance from the town, most from Jiangsu or Anhui provinces. I read the dates and discover that most of them were quite long lived. The map showing their origins is paired with one that explains the salt trade and its importance to Yangzhou. I get the picture, I've seen it elsewhere by now - trade, wealth, patronage, art - and you don't have to be a Marxist to accept the sequence in its generality.

This monastery, as it turns out to be, provided one of the artists a place to live, at least for a time. His rooms have been presented as they were in his time. This brings me closer to the still amorphous individuals. I can look into a bedroom from an outside window and then at it again from its doorway. It's on a very human scale, though I wonder what it was like when it was very, very cold. It looks as if it would cope much better with heat: a cool, dark, quiet interior, away from the heat and bustle of the day. Today it's cold though and I wonder. I move on to look at the paintings and a fair few are what I expect: landscape scenes with mountains in the distance, strips of cloud, figures crossing bridges, that kind of thing. And also lush flower arrangements, women whose garb is arranged in gracious folds, and wise-looking old scholars.

There's not much interpretation, even in Chinese. The attendants pay little attention to us. The women, with short cut hair, are garbed in the jacket and trouser outfits in either blue or brown which are far commoner at this time in China than news stories on hyper-modern Shanghai would make you think. And they are working women, something I see all over urban China. They are not rude but nor are they courteous or gracious, they're very matter of fact. It's pleasing once I get used to it, a democratic survival of the communist revolution perhaps. It's a reminder that 'modern' has more than one plot and that not all the past is traditional, far from it. I think that the garb and manner of these women, testimony to a revolution now ambivalently remembered, marks them as more not less modern. ${ }^{39}$

And then I see something equally novel. Here are some ducks; a fish, by Li Fangying 李方膺; a melon and crab, by Luo Pin 羅聘. And people: a man leading 


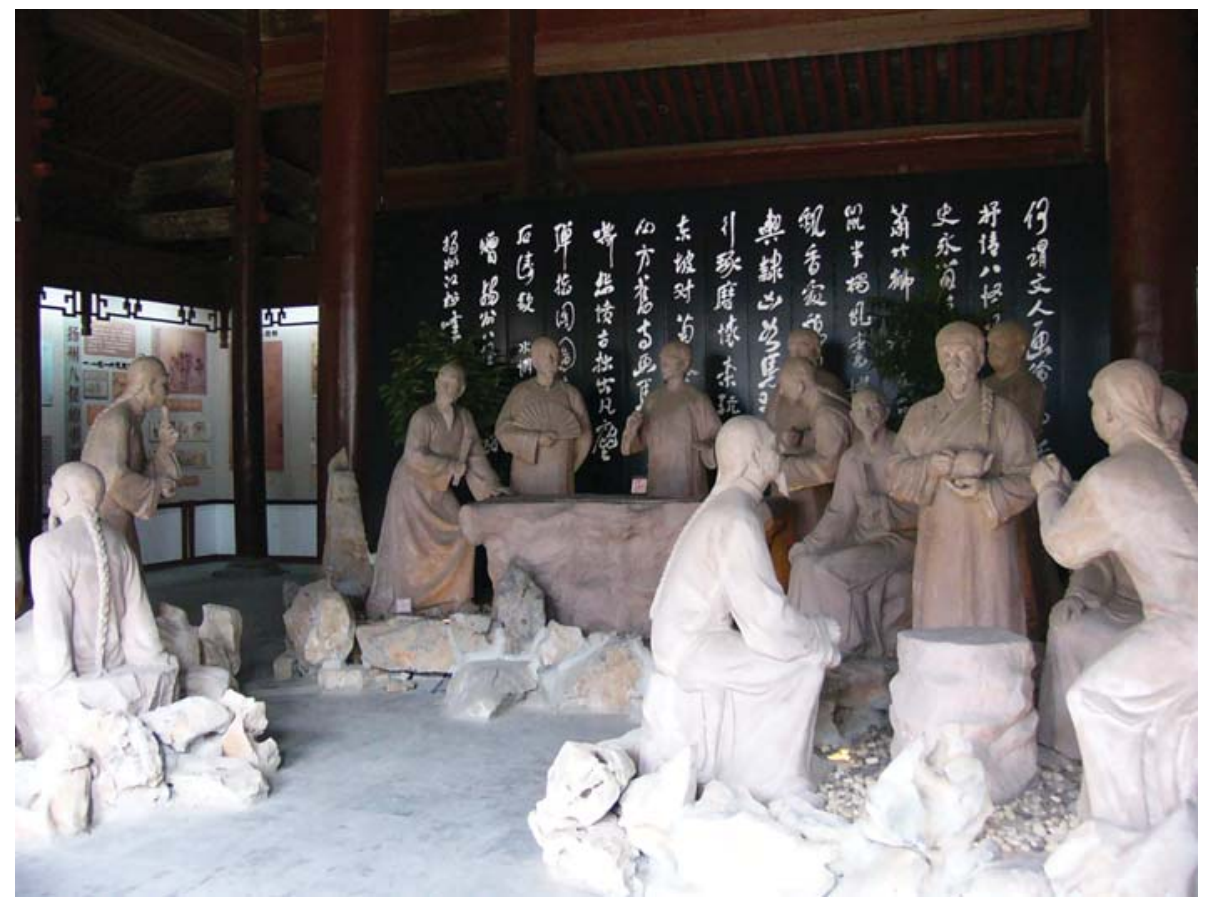

Figure 5.3 Ba Guai memorial hall. The central building with lifesize clay figurines. The museum occupies the complex of Xifang si, where Jin Nong lived in his late years. Photo by Lucie B. Olivová, October 2005.

a horse; two men and a boy, a group of children clustered around . . . something, possibly lanterns - but we can't see the 'action' of the picture, we see mostly backs and/or bent-over faces, it is almost cartoon style, with no attempt to locate it in a landscape, yet expressive and engaging (Fig. 5.4).

Ordinary things drawn boldly, made lively and expressive, in a way I had not expected. A camel and a man by Hua Yan 華孷, the camel occupies the foreground, its head at ground level. It's grazing at something with what seems like a quite content expression, which contrasts with that on the face of a mustached, darkhaired - and that's about all that's visible - man, holding back the entrance flap of a round roofed tent (rather like a yurt, you think) right by the camel. Maybe the man is accompanied by the camel, but even if so, it rather looks as if he's startled to see it so close to his night's accommodation - we know it is night because there's a crescent moon in the sky, away at the top of the panel, the bottom of which is occupied by the camel and the man. ${ }^{40}$

This eighteenth century looks different. If these artists were painting and drawing in such fresh, such seemingly modern ways, does this tell me something about the 
society in which they worked? Scholarship provides answers. In A Bushel of Pearls Ginger Hsü explores the shifting world in which painters moved in this city of the sybaritic wealthy, and discusses the dissolution of old bonds and ties that were brought about by the increase in wealth and spending (and possibly by the spread in education?), and the advent of new patrons, especially moneyed city dwellers, and new needs. Many artists, she writes, 'by involving themselves directly in the sale of their products and demanding straight cash transactions . . conducted themselves like professional craftsmen-painters who regularly engaged in this form of exchange' (Hsü 200I: 2I2). Jin Nong 金農 was one such painter. He was probably a commoner, but from a landowning family well-off enough to have him educated privately. He taught at times and was 'the central figure in several prestigious poetry societies but he was also involved in inkstone and lantern production and antique dealing' (Hsü 200I: I64). Jin Nong's break with long-established representations in, for example, portraying the demon-slaying hero Zhong Kui 鍾道 as a drunkard, was a satirical comment on the officialdom of his day, but the image could still function as a demon-slayer if that's what the buyer wanted (Hsü 200I: 59-60, 192-98). And Jin Nong needed buyers to live. Those buyers were not themselves always literati. They might have, like Jin Nong's correspondent Fang Fu 方輔, average amounts of cash, but also the wish to 'add some literary or artistic flavour to their lives' (Hsü 200I: 204). In Jin Nong's own memorable analogy, 'orchids become mixed with garlic and shallots': worthy gentlemen, making a living from art, lost their distinction among other social groups. ${ }^{41}$

In his Shitao: painting and modernity in early Qing China, Jonathan Hay makes similar points about Yangzhou in prefatory comments to his account of the artist Shitao's 石濤 life and work. 'Beneath its unfamiliar surface,' Hay argues, 'Yangzhou was in many ways a modern city. It was linked to large parts of China . . . by a mail service, a transportation network . . a banking system . . a and a network of interregional trade ... all of this was underpinned by the use of silver as a standard nationwide currency.' Citing Anthony Giddens' 'modernity checklist,' Hay instances the existence in Yangzhou of systems of banking, interregional trade, a trust in abstract systems and a dissociation of time and space, all characteristic attributes of modernity. ${ }^{42}$ Kenneth Pomeranz presents similar arguments for the lower Yangzi in his comparative historical study of society and economic growth in Europe and East Asia (Pomeranz 2000). Another historian observes that 'heightened sensibility and reflexivity in self-writing actually declined from the seventeenth to the nineteenth century' (STRUve 2004: 45, 'Introduction'). So it's no simple matter, but some evidence of a modern infrastructure, of a modern sensibility, in the 'willow-pattern' city is enough for the moment.

Perhaps now I could loop back and explore the recent modern history of Yangzhou, go back to those metal working yards, those determined women. Another project, another year. For the moment I store an older picture. Zhu Ziqing 朱自清, writing in 


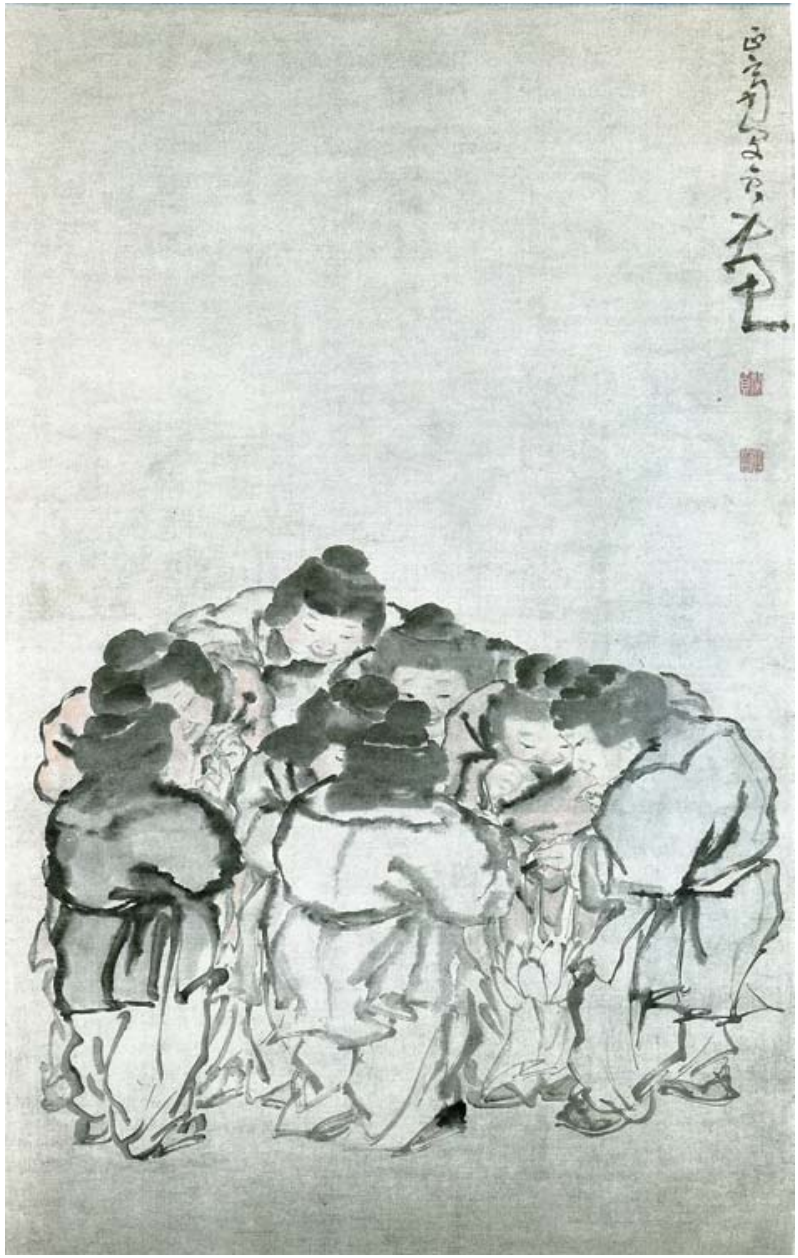

Figure 5.4 Min Zhen 閔貞 (1730-1788), Eight children playing / Ba zi xixi tu八子嬉 戲圖. Yangzhou Museum.

I929, remembered from perhaps twenty years before 'foreign records from the Modeli company' being played on the boats that plied the Slender West Lake, Shou Xihu. Can you hear that music? From a craft on the lake, a descendant of the celebrated 'decorated barges' - melodies from a phonograph. ${ }^{43}$

\section{NOTES}

1 By Xu Ning 徐凝, flourished early ninth century. See also Owen 1996: 630.

2 Also cited in Hsü 20oI: 4, 'Carrying thousands of strings of silver around my waist, I ride on a crane leaving for Yangchow,' attributed to Tang dynasty poet Bai Juyi 白居易.

3 'At Yellow Crane tower in the West/ My old friend says farewell/ In the mist and flowers of spring/ He goes down to Yangzhou' (www.cctv.com/program/civilization/2007062I/I07256.shtml). 
4 Translated by John McKinnon.

5 On the flowering plum, or meihua 梅花, see BICKFORD 1996.

6 This before the opening of the rail line to Yangzhou in April 2004.

7 Finnane 2004: 286-87, citing Mackerras, Colin. 1972: 6-7; see also Hsü 200I: 62, including comment about merchant patronage of huabu 花布 (popular theatre).

8 Hsü 200I: 4-5, citing Ho Ping-ti r954.

9 In fact Ho Ping-ti 1954: I44 quotes one ca I600 source which says that immigrants outnumbered locals by twenty to one.

10 See further on 'dream' fostered by Li Dou et al., Finnane 2004: 4, 204-08, 296; Hay 200I: 8; Hsü 200I: 62-63 (including numbers of boats).

11 For further on Shou Xihu see Finnane 2004: 5, II5; Hsü 200I: 28; HaY 200I: I3.

12 More generally, see discussion in Olivová's chapter of this book.

13 Finnane 2004: 308, citing Stanislaus Clavelin, cited in Le R. P. Brouillon, Mémoire sur l'état actuel de la mission du Kiang-nan, suivi de lettres relatives a l'insurrection, I85I-I855. Paris: Julien, Lanier et cie, I855.

14 Engineer Jake Holman (Steve McQueen) arrives aboard the gunboat U.S.S. San Pablo, assigned to patrol a tributary of the Yangzi in the middle of exploited and revolution-torn 1926 China. His iconoclasm and cynical nature soon clash with the 'rice-bowl' system which runs the ship and the uneasy symbiosis between Chinese and foreigner on the river. Hostility towards the gunboat's presence reaches a climax when the boat must crash through a river-boom and rescue missionaries upriver at China Light Mission, ex www.imdb.com/title/ttoo60934/plotsummary; adapted from Richard McKenna's novel (McKenna I962).

15 Sir Rutherford Alcock to the Secretary of State for Foreign Affairs, Peking, II Sept. I868. In Great Britain. Parliament. China No. 2 (I869), number 5; see also Cambridge History of China vol. II, Late Ching I800-I9II part 2. 1980: 78.

16 Acting Consul Forrest to Lord Stanley, Shanghai, 24 Nov. 1868 enclosing Consul Medhurst to Sir R. Alcock, Yang-chow, 20 Nov. I868. In Great Britain. Parliament. China No. 2 (1869), number 17 .

17 Mrs. Howard Taylor. In the Far East (China illustrated): Letters from Geraldine Guinness in China (I888-I889) Edited by Her Sister. London: Morgan and Scott [I889], p. 35; referred to in FinNANe 2004: 5 .

18 Quote and report of controversy in Finnane 2004: 314.

19 See further Bray 2005.

20 And earlier? See Meyer-Fong 2003: 5. Hay 200I: I3.

21 Lee 1999: 6; see also Finnane 2004: 3I2: 'Shanghai, with its foreign settlements, great buildings, paved roads, running water, electricity, motor cars and trolley buses, provided the general context for a new twentieth-century apprehension of Yangzhou.'

22 International Herald Tribune 27-28 Nov. 2004; the film, The White Countess, was released in December 2005.

23 Quoting the first lines of Mao Dun's 茅盾 novel Ziye 子夜; translated by S. Shapiro, cited in LEE 1999: 3. See also Jones 200I.

24 Shanghai: a Handbook for Travelers and Residents 1973 [1920], reprinted Taibei, pp. IO-I2; cited in LEE I999: I5. 
25 Johnson 1995, provides context.

26 Steele and Major i999: 47-48, quoting Finnane 1996. For a broader focus see Hershatter 2007: 85-88.

27 Polumbaum 2002 is relevant here

28 As discussed in FinNane 1996, especially discussion of photographs, p. I26.

29 Chen Congzhou 1983, which discusses the revival in Yangzhou after 1860, including in the operations of the salt administration; this coincides with the He family construction of the house.

30 www.shme.com/old_shanghai/note_r.htm, downloaded 30 Aug. 2005

31 Meng Yue. 2002: 38; for the idea of 'colonial modernity' see for example BARLOW 1997.

32 Hanan 1998: 349. I am indebted to Finnane 2004, for this reference.

33 See Meyer-Fong's chapter of this book.

34 For opium see ForTune 1987: 50-51. Both books by Robert Fortune were first published by John Murray, London.

35 Fortune 1987: IIO-II3; Shaoxing lies between Hangzhou and Ningbo; see also the description of Hangzhou, pp. 35-37.

36 JoHNSON 1995, passim, but including especially the introductory discussion on the 'myth of the fishing village', pp. 8-IO; early nineteenth century population estimates, p. II9; scale of home market trade, pp. 165-66; trade collapse, p. 175; n.b. also that Johnson relates her study of Shanghai to a response to a sense of contrast between the fates of Suzhou and Shanghai which parallels the Yangzhou-Shanghai contrast.

37 Note that he is described as a scholar official, not a merchant. See comment in Cambridge History of China vol. II, Late Ching I800-I9II part 2. 1980, in particular the discussion, p. I7, on the control of merchants through licensing and the salt merchants of Yangzhou as an example.

38 Robert E. Harrist, Journal of the American Oriental Society, Oct. 2002, describes the label, invented in the nineteenth century as 'one of the most useless in the number-happy history of Chinese critical writing on art' (in review of Hsü, Bushel of Pearls, www.findarticles.com/p/articles/ mi_go208I/is_200210/ai_n9207879.

39 See further on this Rofel 1999, and special issue of China Review 5/2 (Fall 2005), 'Collective memories of the Cultural Revolution.'

40 See reproduction in Figs I6.I and I6.2 in Chapter I6; in the Ba Guai Memorial Hall but Hua Yan 華品 not conventionally one of the ' 8 .'

41 Hsü 20OI: 2I2; see also p. 227, 'These paintings have qualities that are distinctively modern, even while they remain within the larger context of traditional Chinese painting.'

42 HaY 200I: 22; point about accounting and finance is also made by POMERANZ 2000: 167-68; see also review on H-Net, Aug. 2000. For Giddens, see Giddens I990: especially 4-45.

43 ZHU Ziqing 1989 [1929]: 79. The original version of Zhu Ziqing's 'Yangzhou summer days' was first published in Baihua xunkan 白話旬刊 vol. II, December I929, no. 4. 



\section{Part II}

Books and Literature 



\section{6}

\section{Yangzhou Printing and Book}

Culture in the Qing Period

\section{J. S. Edgren}

Y angzhou has been a Chinese cultural center for many centuries, and I already knew something of its reputation for printing, but I had never looked closely at the details of its publishing history. I was familiar with the names of famous books and the personalities and events related to them in Qing dynasty (1644-1911) Yangzhou, and superficially they seemed at one with the book culture in southern China as a whole. Nevertheless, I sensed that something about book production and consumption in Yangzhou was different from that of the other renowned book centers in the greater Jiangnan region, namely Nanjing, Suzhou, and Hangzhou. This paradox was perplexing at first, and then I discovered that Yangzhou apparently had not produced the sort of vibrant commercial sector that characterizes the development of traditional Chinese publishing, but it was not clear why. The overview of Yangzhou printing history that follows, with emphasis on its outstanding eighteenth century, has been approached with such questions in mind, and an attempt to answer them has been reserved for the conclusion.

This chapter about Yangzhou printing and book culture in the Qing period is concerned with the rather expansive administrative area of Yangzhou prefecture, rather than just metropolitan Yangzhou proper. Based on current administrative divisions, one account divides the entire region into eleven towns and counties: Yangzhou 揚州, Jiangdu 江都 (including 甘泉 Ganquan), Hanjiang 邗江, Yizheng 儀 徵, Gaoyou 高郵, Xinghua 興化, Baoying 寶應, Taizhou 泰州, Taixian 泰縣, Taixing 泰興, Jingjiang 靖江. ${ }^{1}$ Not only do these jurisdictions correspond well to the area that produced the Yangzhou imprints, but the historical place names are virtually unchanged. This survey will include simple case studies of representative Yangzhou publishing enterprises and their outstanding publications, and a few works will be featured by describing them in a book historical or a bibliographical context.

Traditional Chinese bibliography divides publishers into three general categories: official publishing, guanke 官刻; private publishing, sike 私刻 or jiake 家刻; and commercial publishing, fangke 坊刻. Other forms of institutional publishing, such as that by the principalities, fanfu 藩府, or by the academies, shuyuan 書院, are usually 
regarded as official publishing. On the other hand, the institutional publishing of religious bodies can be taken as a form of private publishing.

\section{EARLY PRINTING}

In addition to scattered textual references about local printing from Tang (6I8-907) and Five Dynasties (907-960) sources, there are several specimens of Yangzhou regional printing from the Song (960-I279) and Yuan (I279-I368) periods. The extant Song and Yuan imprints are all of the highest quality. An example of this is the II73 edition of the collected writings of Qin Guan 秦觀 (IO49-IIOO), Huaihai ji 淮海集 [Huaihai Collection], published at the local academy of Gaoyoujun, Gaoyoujunxue 高郵軍學 (Fig. 6.I $)^{2}$. The main work is in forty juan 卷, ${ }^{3}$ followed by Huaihai houji 淮 海後集 [Sequel to Huaihai Collection], six juan, and Huaihai jushi changduan ju 淮 海居士長短句 [Long and Short Lines (ci-poems) by Huaihai Jushi], three juan. Qin Guan, a much admired poet and official of the Northern Song, was a native of

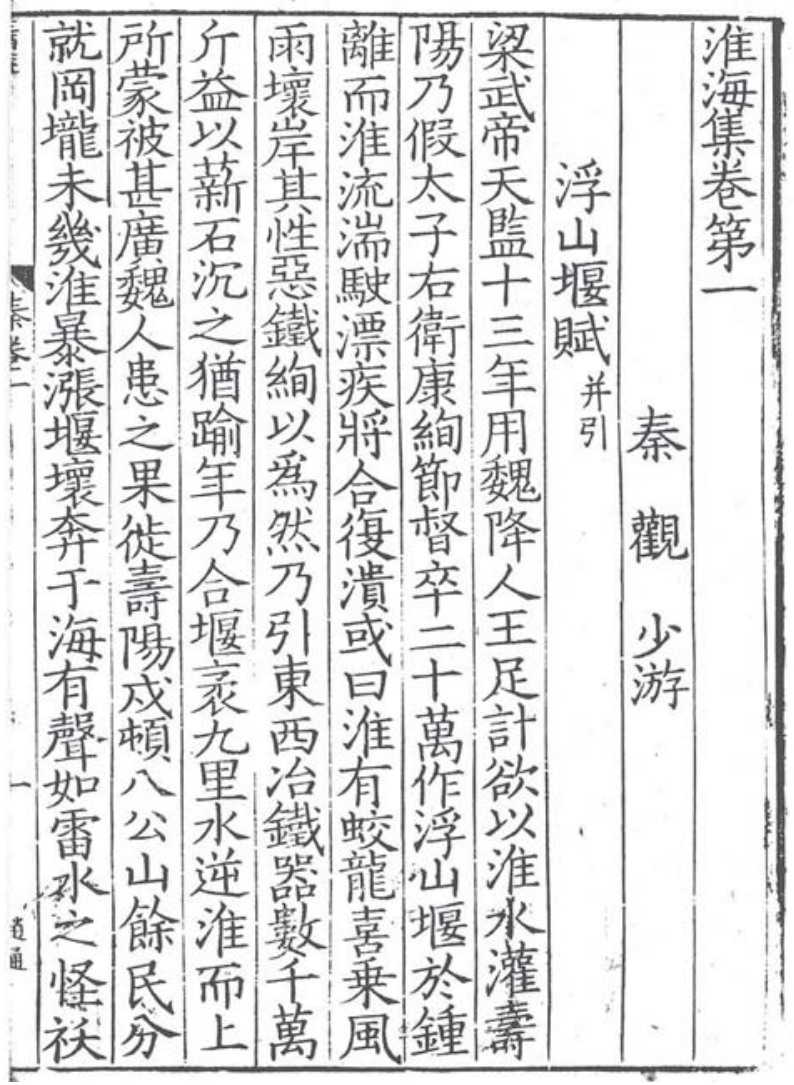

Figure 6.1 Huaihai ji

[Huaihai Collection], 1173. Source : Naikaku Bunko sōhon shoei 1984, pl. 36. 
Gaoyou, which partly explains the book's publication there. Several copies of this edition are extant, but they are later impressions from the Yuan and Ming periods. This copy represents one of the best and earliest impressions.

The Naikaku Bunko copy of Huaihai ji not only is a very early impression, but it is uncommonly complete. Immediately after Lin Ji’s 林機 preface, dated II73, there is an interesting table containing information about the costs for bound volumes of the edition. Since this kind of economic information is scarcely mentioned in early printing history, it seems worth recording here. 'The Gaoyoujunxue edition of Huaihai wenji (i.e. Huaihai ji) accounts for 449 woodblocks, which together with blank leaves and endpapers etc. uses altogether 500 sheets of paper (per copy). Sansheng 三省 paper at 20 cash per sheet is Io strings of cash; xinguan 新管 paper at Io cash per sheet is 5 strings of cash; zhuxia 竹下 paper at 5 cash per sheet is 2 strings and 500 cash; ink at I cash per woodblock is 500 cash; the binding of Io volumes, $c e$ m, with dark blue paper at 70 cash per volume is 700 cash; and the fee for labor and materials, gongliao 工料, is 500 cash (per copy).' The three grades of paper imply

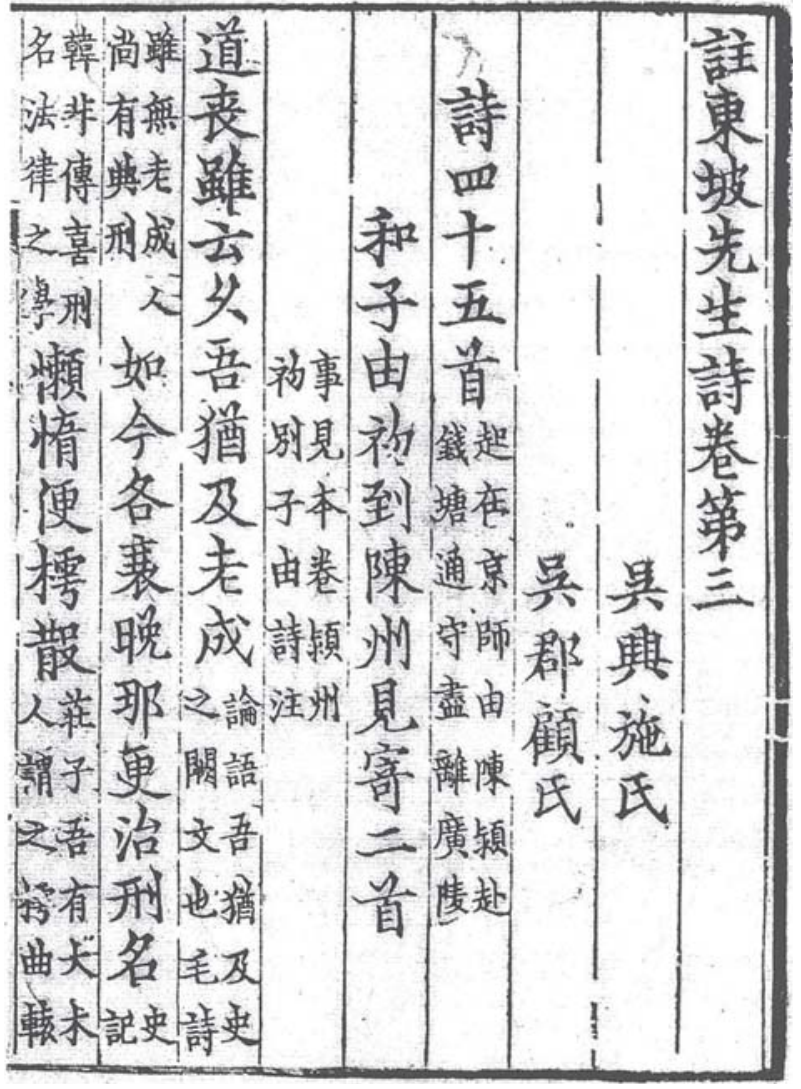

Figure 6.2 Zhu Dongpo xiansheng shi $[\mathrm{Mr}$ Dongpo's Poems with Annotation], 1213. Source : Changshu Weng shi cangshu tulu 2000, pl. 56-1. 
levels of status: sansheng refers to the three most important agencies of the central government, xinguan refers to paper for official use, and zhuxia may simply mean low-grade bamboo paper. The currency cited is qian 錢, and the unit is wen 文, the familiar Chinese round coin with a square hole in the center, commonly called 'cash'. I,Ooo coins can be strung together as a 'string of cash', guan 貫. I assume that the labor fee is for printing and collating; materials may refer to the simple tools used by the printers.

The name of Zhao Tong 趙通, one of the kegong 刻工 [block-cutters] for the book, is printed at the bottom of the banxin 版心 ['block-heart'] (the place where the printed pages were folded) on the first leaf (see Fig. 6.I). Zhao Tong is a well-known itinerant artisan who contributed to important books published in Hangzhou, Shaoxing, and Jinhua in the Eastern and Western Liang-Zhe circuit in the second half of the twelfth century (WANG Zhaowen 1990: 218. EDGREN 1989: 166). His participation both reflects the superior quality of this edition of Huaihai ji and how Yangzhou was connected to the influential world of Liang-Zhe printing and publishing of the twelfth century.

In I213, one of the most important collections of Su Shi's 蘇軾 (IO37-IIOI) poetry, $Z h u$ Dongpo xiansheng shi 註東坡先生詩 [Mr Dongpo's Poems with Annotation], was published by the Jiangsu Bureau of Tea and Salt, Huaidong cangsi 潅東倉司, located at Taizhou (Fig. 6.2). This edition was reissued from the original set of blocks in 1262 by Zheng Yu 鄭羽 at the same bureau. From Zheng Yu's colophon at the end of the work we know that 179 replacement woodblocks were used. We also learn that a calligrapher named Fu Zhi 傅穉 had transcribed the text, which is an elegant version of Ouyang Xun's 歐陽詢 (557-64I) style of writing, very popular in printing circles at the time. This work is important because it contains commentary by the poet's near contemporaries Shi Yuanzhi 施元之 and Gu Xi 顧禧. This edition is very rare. There are three defective copies, two of which together make a nearly complete copy. The Shanghai Library copy, formerly in the collection of Weng Tonghe 翁同穌 (I830-1904) (EDGREN 1984: 74-75; EdGREN 1994: 79-82, II3-II4, I3I), is most complete, lacking ten juan of forty-two. The copy in the National Central Library (Taibei), contains twenty juan, including four not in the Shanghai copy. Seven juan held by the National Library of China (Beijing) are already present in the two other copies. ${ }^{4}$

The National Central Library copy of Zhu Dongpo xiansheng shi has a history of its own. In 1699, while it was in his possession, the Qing official Song Luo 宋恽 (1634-1713) published a new edition (retitled Shi zhu Su shi 施註蘇詩 [Shi (Yuanzhi's) Annotated Edition of the Poems of Su (Dongpo)] based on this copy, which at the time was only seventy-five per cent complete. By the time the National Central Library copy passed into the hands of the scholar Weng Fanggang 翁方綱 (1733-18I8) in I773 it was widely known in China. Weng Fanggang (no relation to Weng Tonghe) chose to name a room in his library after this Song edition, and he used it to publish 
a critical commentary on Su Shi's poetry. While still in his collection dozens of scholars and artists visited and viewed the rare book and left behind colophons and drawings that he had bound in. In the early twentieth century a fire in the library of the then owner, Yuan Siliang 袁思亮 (I879-I940), resulted in the loss of ten volumes and damage to others. Even in its current state in the National Central Library, the copy contains more than seventy handwritten colophons praising the book. Several of the colophons note that this illustrious work was published at Yangzhou by the Bureau of Tea and Salt.

The work Shitian xiansheng wenji 石田先生文集 [Mr Shitian's Collected Writings] by Ma Zuchang 馬祖常 (I279-I338, sobriquet Shitian), in fifteen juan, published in I339 by the Confucian School of the Yangzhou Circuit, Yangzhoulu ruxue 揚州路儒 學, is an extremely refined Yuan edition. ${ }^{5}$ Unlike the commonly encountered works of Yuan commercial publishers, especially from Fujian, the Shitian xiansheng wenji displays generously spaced characters, printed from expertly cut blocks, and printed on large sheets of good quality paper. The above three examples are all impressive but isolated, official publications from Yangzhou of the Song and Yuan. In fact, it is not until the relative stability of the Ming (I368-I644) and the extreme prosperity of the Qing that a varied Yangzhou print culture can begin to be imagined.

A recent study of xylographic printing in Yangzhou by Wang Cheng 王澄, Yangzhou keshu kao 揚州刻書考 [Examination of Xylographic Publishing in Yangzhou], 6 clearly demonstrates the uneven nature of the development of book publishing in Yangzhou in the imperial period. In this comprehensive bibliography, pages I-II are enough to cover the combined Song and Yuan dynasties; pages II-52 are sufficient to cover the Ming period; but pages 53-3IO are needed for the Qing dynasty. Wang Cheng estimates that eighty per cent of Yangzhou's known book production took place in the Qing. The accelerated growth of publishing in Yangzhou beginning in the late seventeenth century certainly was due to the new wealth created by the salt industry, but it also was stimulated by the imperial favor bestowed on Yangzhou through the southern tours of the Kangxi (r. I662-I722) emperor, and later of the Qianlong (r. I736-I795) emperor. In the remaining space available, I will discuss some of the methodological challenges of compiling regional histories of publishing and introduce some interesting examples of Ming and Qing Yangzhou imprints, focusing particularly on the eighteenth century.

It is generally accepted that the first half of the Ming dynasty represents a rather low point in the history of printing and publishing in China. The unprecedented flourishing of publishing that took place in China at the end of the Ming began at the turn of the sixteenth century and first matured in the Jiajing period (I522-1566). The Jiajing era saw a sharp increase in official publishing, particularly expressed in the case of Yangzhou in the publication of local gazetteers by the prefectural government in Yangzhou and in the counties and districts that made up the prefecture. 


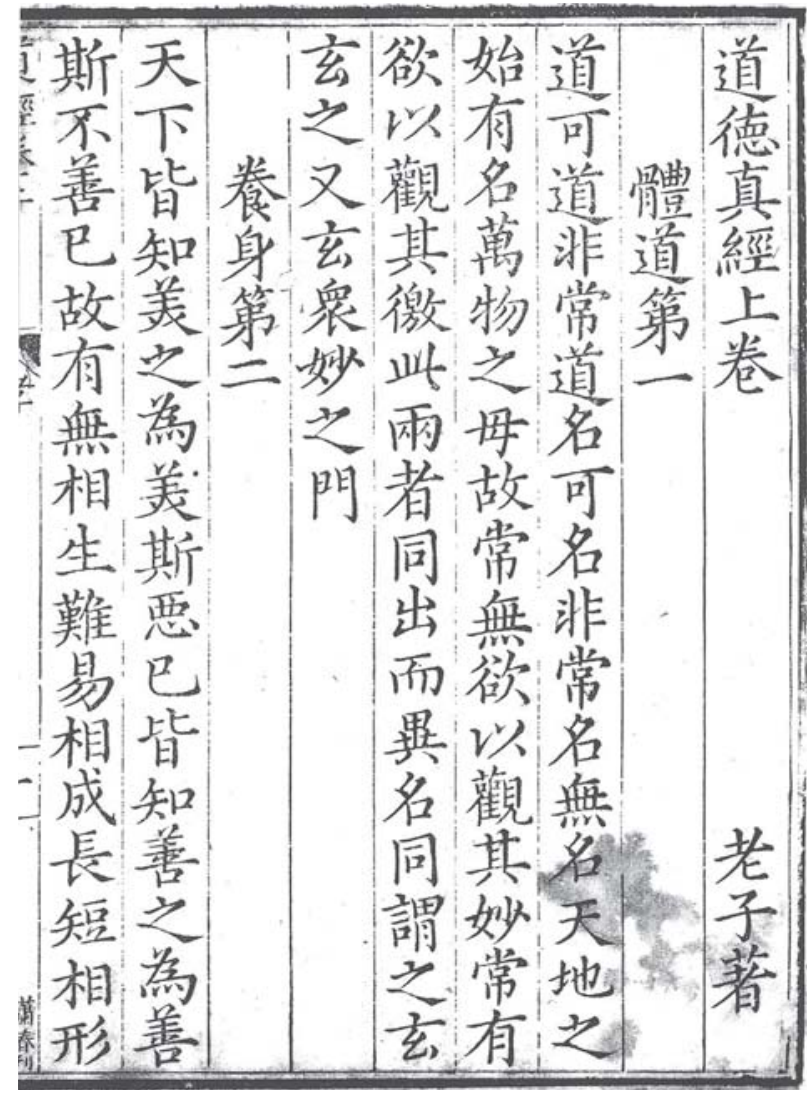

Figure 6.3 Daode jing [Classic of the Way and the Virtue] or Laozi, 1581. Private collection of the author.

As early as I5OI, Tieya wenji 鐵崖文集 [Tieya's Collected Writings] by Yang Weizhen 楊維楨 (I296-I370, sobriquet Tieya) was published by the Yangzhou Zhengyi Academy, Zhengyi shuyuan 正誼書院. The format of this edition is rather typical of books from the first half of the Ming. Their manner of printing continued to be very conservative in that elements prominent since the early Ming also featured strongly in them. These elements included the use of sizhou shuangbian 四周隻邊 [double-borders on all four sides of the leaves], a thick heikou Zhao Mengfu 趙孟煩 (I254-I322) style of calligraphy, Zhao- $t i$ 趙體.

A Yangzhou edition of the early Wanli period (1573-1620) can be used to illustrate some of the problems in identifying regional publications and their publishers. In I58I, an official named Chen Nan 陳楠 (jinshi I562) compiled and published a fine edition of the four Daoist classics known collectively as Si zi 四子 [The Four (Daoist) Philosophers]: the Daode jing 道德經 (also known as Laozi 老子), Guanyinzi 關尹子, Liezi 列子, and Zhuangzi 莊子 (Fig. 6.3). ${ }^{8}$ Some of the twenty-five kegong whose names are recorded in the work are from Nanjing, but it would be a mistake to attribute 
the place of publication of this work to Nanjing solely because of that. Instead, we should keep in mind the itinerant nature of the block-cutting profession.

Fortunately, some copies of this work possess a detailed colophon by Chen Nan printed on the final page. The colophon clearly states that Chen Nan, who was serving as Commissioner of Salt Distribution, Du zhuanyunyan shi 都轉運鹽使, for the Liang-Huai region, published the book at the Shende Academy, Shende shuyuan 慎德書院, in I58I. This firmly identifies the place of publication as Yangzhou. The Yangzhou Prefectural Gazetteer simply lists him as the third commissioner of the Wanli reign and states: 'Chen Nan, from Fenghua (Zhejiang), a jinshi graduate' (YAO Wentian I8IO: 37:I2a). What remains unclear, however, is whether Si zi should be considered a private or official publication. On one hand, Chen Nan, who edited and probably paid for the publication, could be regarded as the publisher. This would make the work itself a private publication. On the other, either the Salt Commission or the Shende Academy could be thought of as the publisher and the work classified as an example of official publishing. Nevertheless, from the wording of the colophon it seems that the Shende Academy was the place where the woodblocks for the edition were kept, and this could be taken as evidence that the Academy was the publisher. In the colophon, Chen further states that this publication was based on a Guangzhou edition [of I577] published by Shi Yaochen 施克臣 (jinshi I550).

The place of publication and the name of the publisher of official editions and commercial editions are usually fairly easy to identify. In the case of private publications this is not so easy. One problem is that the publisher's place of family registry (jiguan 籍貫) can be mistakenly taken as indicating the place of publication. In fact, scholars and literati often lived for extended periods of time away from their places of family registry, and published books in places where they had moved to or where they were sojourning, or in places they were visiting or posted to on official business. Accurately determining when, where, and by whom an early edition was published is rightly viewed as very important by modern bibliographers and book historians, but this was not always the case with traditional bibliographers in China. This is compounded by the fact that many older books include no clear indication of the date or place of publication.

We can see how these factors can become problems in a recent publication with a very promising title: Quan Ming fensheng fenxian keshu kao 全明分省分縣刻書考 [Examination of Ming Xylographic Editions Arranged According to Province and District of Publication]. ${ }^{9}$ Although the guanke and fangke entries are listed according to the locations of the official institutions and commercial enterprises, which in most cases are valid, private publications, which make up the majority of examples, are nevertheless recorded under the individual's jiguan. As a result, Shi Yaochen's edition of Sizi is found under Anhui, Qingyang xian 青陽縣, instead of Guangzhou, and Chen Nan's edition of the same title is recorded under Zhejiang, Shangyu xian 
上虞縣, instead of Yangzhou. This designation distorts the problem further, because the Chen Nan (same characters in his name) from Shangyu was a jinshi of 1526, and he did not compile the i58I edition of Sizi.

Despite its shortcomings, Quan Ming fensheng fenxian keshu kao contains listings of 8,260 editions of books published in the Ming, together with the names of 4,670 Ming publishers, and it can be used to advantage, if consulted with care. Based on this compilation and other sources, one is left with the conclusion, as already suggested, that there is very little evidence of commercial publishing in Ming Yangzhou. Given the facts of its early development and the fundamental significance of commercial publishing in China's overall book history, it is this anomaly that probably distinguishes Yangzhou most and underlies its relative lack of prominence. Indeed, there are comparatively few commercial publishers recorded by Wang Cheng $(2003)^{10}$ for the Qing period, to which we now turn.

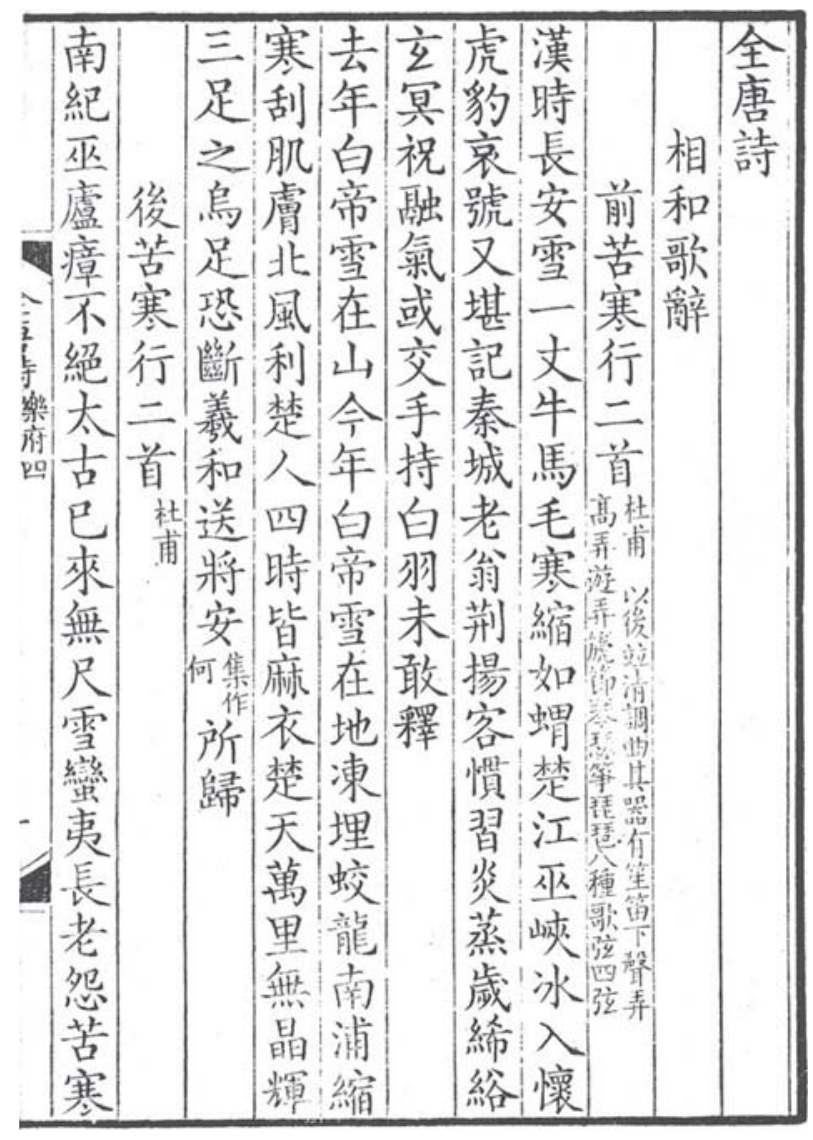

Figure 6.4 Quan Tang shi [Complete Tang Poetry], 1707. Source : Zhongguo banke tulu 1961, pl. 493. 


\section{QING PRINTING}

The new dynasty began tragically for Yangzhou and its inhabitants: The physical destruction and chilling bloodletting of 1645 after the Manchus took the city ${ }^{11}$ certainly devastated whatever level of print culture had existed there at the time. Further depredations took place in Yangzhou during the Taiping Rebellion of the mid-nineteenth century. ${ }^{12}$ As one might expect, Yangzhou printing flourished most in the two centuries between the two tragedies.

It has already been stated that the spectacular rise of printing in Yangzhou was related to the development of the salt industry in the Qing and the prosperity that followed. Many important and lavish publishing projects were funded by the wealth it produced. The famous bureaucrat Cao Yin 曹寅 (I658-I7I2) was appointed salt censor or head of the salt monopoly at Yangzhou in 1704 by the Kangxi emperor and held that office in alternation with his in-law Li Xu 李煦 (I655-I729) until I7I2, the year of his death. Cao is best known, of course, as the grandfather of Cao Zhan 曹露 (Cao Xueqin 曹雪芹, d. I763), author of the great novel, Honglou meng 紅樓夢 [Dream of the Red Chamber]. Cao Yin's main home was in Nanjing, where he had first been appointed textile commissioner in 1690 and maintained a lavish villa. However, because the distance between the two domains was not great, it was convenient for him to manage affairs in both places. Probably the single most important event in the Yangzhou publishing world of this period was the emperor's order in 1705 for Cao Yin to print the Quan Tang shi 全唐詩 [Complete Tang Poetry] in 900 juan plus a table of contents in I2 juan (Fig. 6.4). It took two years to complete the entire publication, which entailed careful textual collation. For the purpose of publishing this monumental poetry collection, Cao Yin established the Yangzhou shiju 揚州詩局 [Yangzhou poetry office] within the Tianning si 天寧寺 Buddhist temple compound north of the city wall.

There are several reasons why Cao Yin was chosen for this task. For one thing, he was willing to use his accumulated wealth for producing the publication, despite the fact that it was for the benefit of the court. Not only was Cao Yin well suited by experience to supervise the editorial staff, but the responsibility actually enhanced his literary reputation. Throughout his career as an official holding important posts in the empire, Cao Yin had distinguished himself as an active member of the literati and, indeed, he was regarded as an eminent book collector at the time. His library was called Lianting 楝亭 [Lian-tree pavilion], named after a type of flowering tree planted outside the library in the Cao family garden (Spence 1966: 58.). The National Library of China possesses two manuscript copies of the library's catalogue Lianting shumu 楝亭書目. ${ }^{13}$ The contents, numbering over 3,000 titles, were reprinted in a series of articles in the National Library's journal. ${ }^{14}$

The Yangzhou shiju published several more unusually large works on behalf of the palace in the following years. The best known titles include the Peiwen zhai 
yongwushi xuan 佩文齊詠物詩選 [Anthology of Classified Poetry from the Peiwen Studio] of 1707; the Peiwen zhai shuhua pu 佩文齋書畫譜 [Compilation of Quotations from Literature on Painting and Calligraphy from the Peiwen Studio] of I708; the Yuanjian leihan 淵鋻類函 [Classified Encyclopaedia] of I7IO; and the Peiwen yunfu 佩文韻府 [Peiwen Phrase-Dictionary Arranged According to Rhymes] of I7II. ${ }^{15}$ The disposition of woodblocks after an initial printing is an important question in publishing history, and in the case of the Quan Tang shi it is known that the blocks were delivered to Beijing and later impressions were carried out at the Wuying Hall, Wuying dian 武英殿. The Wuying dian is the palace hall that became the center for all activities related to imperial publications from around 1680 until the end of the Qing. Its peak of activity was reached during the Qianlong emperor's reign. The chief result of the establishment of Cao Yin's Yangzhou shiju, nevertheless, was that large numbers of craftsmen, from block-cutters to printers and book binders, were attracted to Yangzhou, thereby stimulating the publishing trade in general.

\section{$\sqrt{\text { 東 }}$}

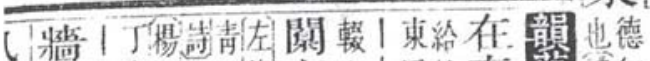

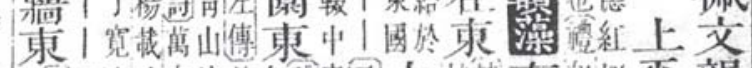

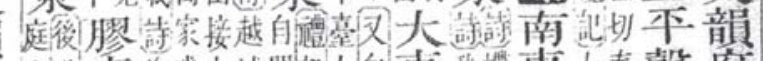

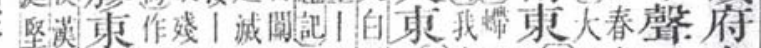

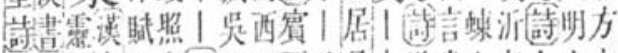

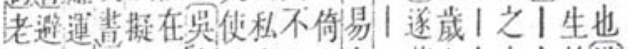

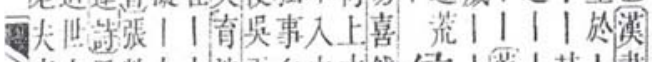

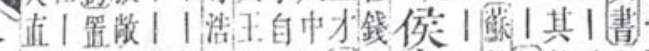

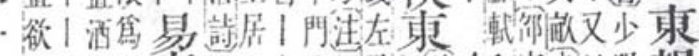

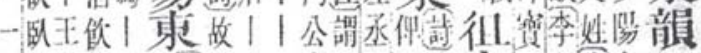

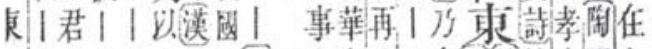

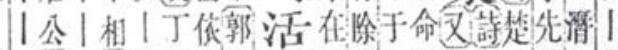

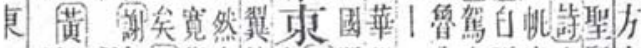

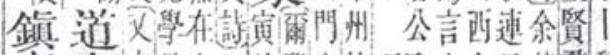

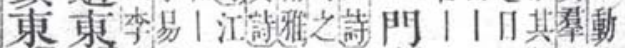

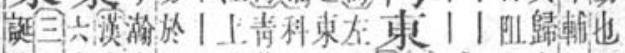

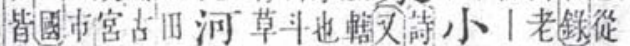

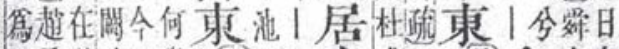

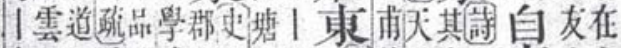

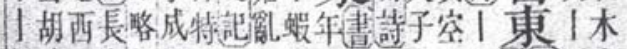

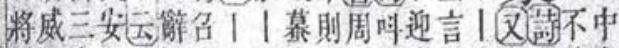
軍薜市立楊歸君｜｜也罪公怒寞大火自我些會 葛在九震何耳吾唐人 | 索在小東䣷來 意

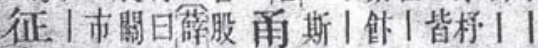

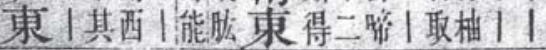

Figure 6.5 Peiwen yunfu [Peiwen Phrase-Dictionary Arranged According to Rhymes], 1711. Source : Qingdai neifu keshu tulu 2004, pl. 35. 
The style of printing in Yangzhou poetry office editions, often referred to as 'soft, manuscript style', ruanti xieke 軟體寫刻, is quite distinctive and very different from the 'artisan style', jiangti 匠體, usually associated with commercial publishing. The manuscript style itself implies that the strokes in characters have lines of varying thickness with rounded edges similar to those written by brush and ink. The artisan style is characterized by uniformly thick vertical and thin horizontal strokes that have sharp edges and present a dense and compact appearance. The fact that the cramped jiangti style is used in the Peiwen yunfu (Fig. 6.5) may be due to its specific purpose as a reference work. A comparison of figures 6.4 and 6.5 clearly shows the distinction between the two styles. The ruanti style favored by Cao Yin possibly was influenced by Lin Ji 林佶 (b. 1660), who wrote out the text to be cut on woodblocks for several private editions, such as the work of his teacher Wang Shizhen 王士禛 (I634-I7II) entitled Yuyang shanren jinghua lu 漁洋山人精華 錄 [Recorded Writings of Wang Shizhen (sobriquet Yuyang shanren)], published in Yangzhou around 1700, and who was later employed as a calligrapher in the Wuying dian from 1706 to I7I2.

It is currently believed that as many as ten titles were published as palace editions by Cao Yin in Yangzhou. What is more significant is that they totaled over 2,500 juan, which testifies to a great economic investment and the need for a large work force. During the same relatively brief period that Cao Yin was involved in the administration of the salt monopoly in Yangzhou, he privately published some twenty titles, often based on his own writings or on rare books in his own Lianting collection. These editions came out under two Yangzhou hallmarks: Yangzhou shiju and Yangzhou shiyuan 揚州使院 [Yangzhou courier office]. It is worth noting that the 'written' style, xieke 寫刻, of printing has dominated the examples of Yangzhou printing I have introduced thus far.

According to Wang Cheng, Yangzhou shuju 揚州書局 [Yangzhou book office] as another hallmark used by Cao Yin. From the early nineteenth century Yangzhou shuju was also used in Yangzhou for guanke purposes. In imitation of precedent, the Jiaqing emperor (r. 1796-I820) in I808 ordered publication of the Qinding Quan Tang wen 欽定全唐文 [Imperially Authorized Complete Prose of the Tang Dynasty] (WANG Cheng 2003: 59-6I. Weng Lianxi 2004: pl. 139). The cutting of the blocks is reported to have been completed in I8I4, but actual publication and distribution of the enormous work (I,000 juan and more than 500 volumes) did not take place until I8r8. Much like Cao Yin's publication of Quan Tang shi a century earlier, the Yangzhou commissioner of salt distribution Zeng Yu 曾燠 (I759-1830) was responsible for this publication. Like Cao, Zeng also published books privately during his tenure as salt commissioner. The most notable is the lavishly illustrated, large-format edition of the ancient Erya, the Erya yintu 爾雅音圖 [Erya Lexicon with Illustrations], published at Yangzhou in I80I. In I869, after the Taiping Rebellion, the Yangzhou 
shuju was succeeded as an official publishing house by the Huainan shuju 淮南書局 [Huainan book office].

In the eighteenth century the Qianlong emperor expanded the palace book collections, and he is best known for having created the Siku quanshu 四庫全書 [Complete Library of the Four Treasuries]. This enormous manuscript repository comprises about 3,500 individual titles, totaling nearly 80,000 juan, and was bound as 36,000 physical volumes, which were stored in exquisite boxes made of nanmu 楠木 wood. It was edited and transcribed between 1773 and 1782 by a board of more than 350 eminent scholars and countless court scribes. Rare printed works and manuscripts were solicited from all over the country, and more than I0,000 works were reviewed for consideration. The resulting bibliographical descriptions for I0,254 titles were published in 1782 as the Qinding siku quanshu zongmu 欽定四庫全書總目 [Imperially Authorized Annotated Catalogue of the Complete Library of the Four Treasuries], which still remains the most comprehensive Chinese descriptive bibliography. The project was also designed to weed out works thought to be politically subversive at the same time that it accomplished its more public goal of preserving an extensive body of writing of all sorts.

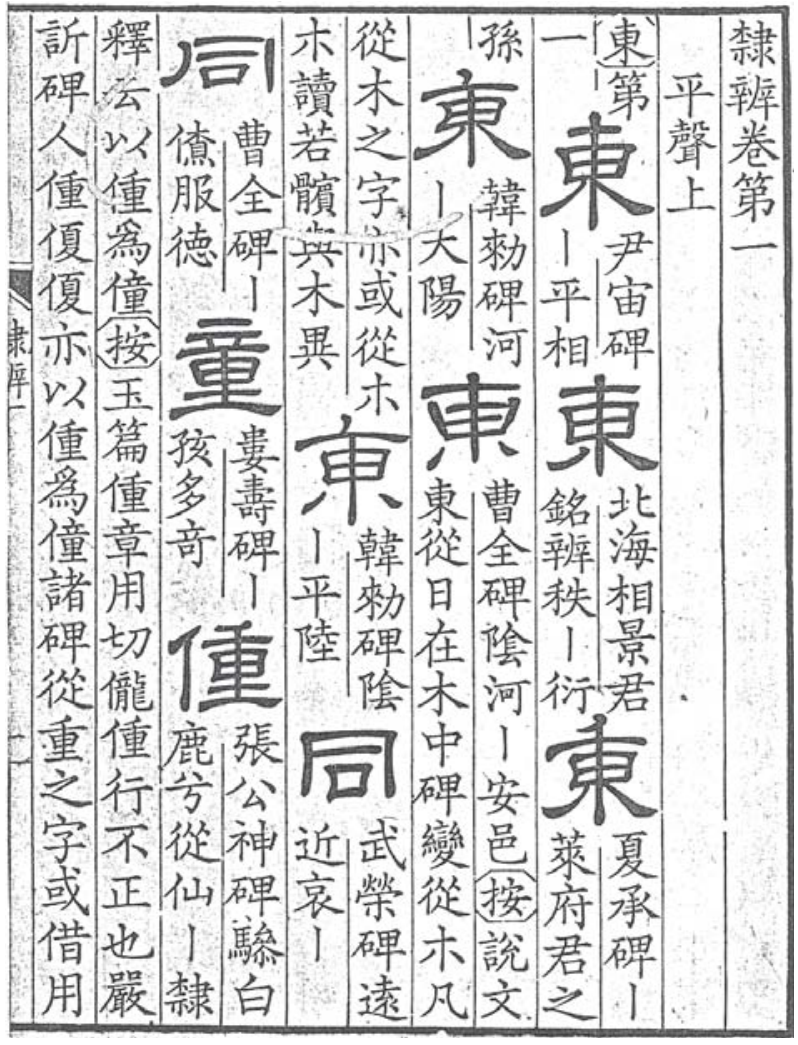

Figure 6.6 Libian

[Dictionary of Clerical Script], 1718. Private collection of the author. 
For this project many rare books were donated by Yangzhou collectors. For instance, the Ma family of Yangzhou (originally from Anhui province) made a fortune in the salt trade and became famous as bibliophiles and patrons of the arts. ${ }^{16} \mathrm{Ma} \mathrm{Yu}$ 馬裕, second generation owner of their library, was the largest single contributor to the Siku quanshu project. He contributed, in three separate batches, a total of 776 titles of rare books and received a reward from the Qianlong emperor. Only three other famous book collectors, all from Zhejiang province, were equally honored. Ma Yu's father Ma Yuelu 馬曰璐 (I7OI-I76I) and his uncle Ma Yueguan 馬 日琯 (I688-1755) were renowned as poets and as publishers of elegant editions, and the family was prominent within the book culture of Yangzhou. Their library named Xiao linglong shanguan 小玲瓏山館 and its garden were a focal point for literati of the time. Ma Yueguan compiled and published several handsome editions there, including chronological biographies of Han Yu 韓愈 (768-824) and Liu Zongyuan 柳宗元 (773-819), which were printed in Song style in 1729 and 1730. The Mas' hospitality extended to offering lodging to favored guests. In 1746 , for example, Li E 厲鶚 (1692-1752) from Hangzhou published his voluminous Songshi jishi 宋詩紀事 [Recorded Events about Song Poems] after a long residence there, and he signaled his close relationship by crediting Ma Yueguan as co-compiler. Chen Zhang 陳章 (b. 1696) states in a preface to his edition of Yuxiang yigao 于湘遺稿 [Posthumous Writings of Lou Qi ( $z i$ Yuxiang)], published in 1755 , that it was written while he was a guest at the Xiao linglong shanguan.

Between 1782 and 1787 , seven identical sets of the Four Treasuries collection were produced in manuscript on the emperor's orders to be deposited in seven library buildings erected between 1775 and 1784 . The first four sets were designated for the imperial palace and three detached palaces in the north; the remaining three were to be placed in Yangzhou, Zhenjiang and Hangzhou in the south. The building of one of the library buildings (the Wenhui ge 文匯閣) in Yangzhou and the depositing of a copy of the collection there was a further sign of imperial favor and an added boost to the literary reputation of Yangzhou.

Besides the Ma family, there were a number of other prominent book collectors and high end publishers in the eighteenth century. Space permits only a brief look at three of them: the first representing the dilettantism of the age, the second and third displaying its sound scholarship. Jiang Chun 江春 (I72I-I789), a wealthy merchant who moved from Shexian 舒縣 in Anhui province to Yangzhou, collected books on a large scale. He also published several sumptuous books as status symbols. The best known is the voluminous (Ioo juan) work on jades entitled Guyu tupu 古玉圖譜 [Illustrated Catalogue of Ancient Jades], which he published under the hallmark of Kangshan caotang 康山草堂 in I779. Guyu tupu purports to be a catalogue of the Song imperial collections of the twelfth century, but it is not considered to be authentic (WILSON 2006: I05-II4). Jiang Chun claimed that the edition he published was based 
on a rare manuscript in his own possession, and it is not clear whether Jiang Chun had been deceived himself or had contributed to the deception. Despite the fact that the Siku quanshu editors had rejected it as a clumsy forgery in their bibliographical notice (Ji Yun 1997: 1548-I549), the work continued to enjoy enormous popularity throughout the Qing period.

Xiang Yin 項絪, a retired official, also originally from Shexian, published several books of high quality in the late-Kangxi and Yongzheng (1723-1735) reigns. His fine editions have been praised for their scholarly content. They include an edition of the famous historical and geographical study of ancient waterways, Shuijing $z h u$ 水經 注 [Classic of Waterways with Annotations], published in 1715 under the hallmark Qunyu shutang 群玉書堂. Libian 隷辨 [Dictionary of Clerical Script], a lexicon of clerical style characters as found in early inscriptions (Fig. 6.6), was compiled by Gu Aiji 顧藹吉 and published in I7I8 under Xiang's other hallmark, Yuyuan tang 玉㪄 堂. These two publications were greatly admired and both were reprinted by Huang Sheng 黃晟 and others more than once in the eighteenth century in editions that tried to reproduce their original style.

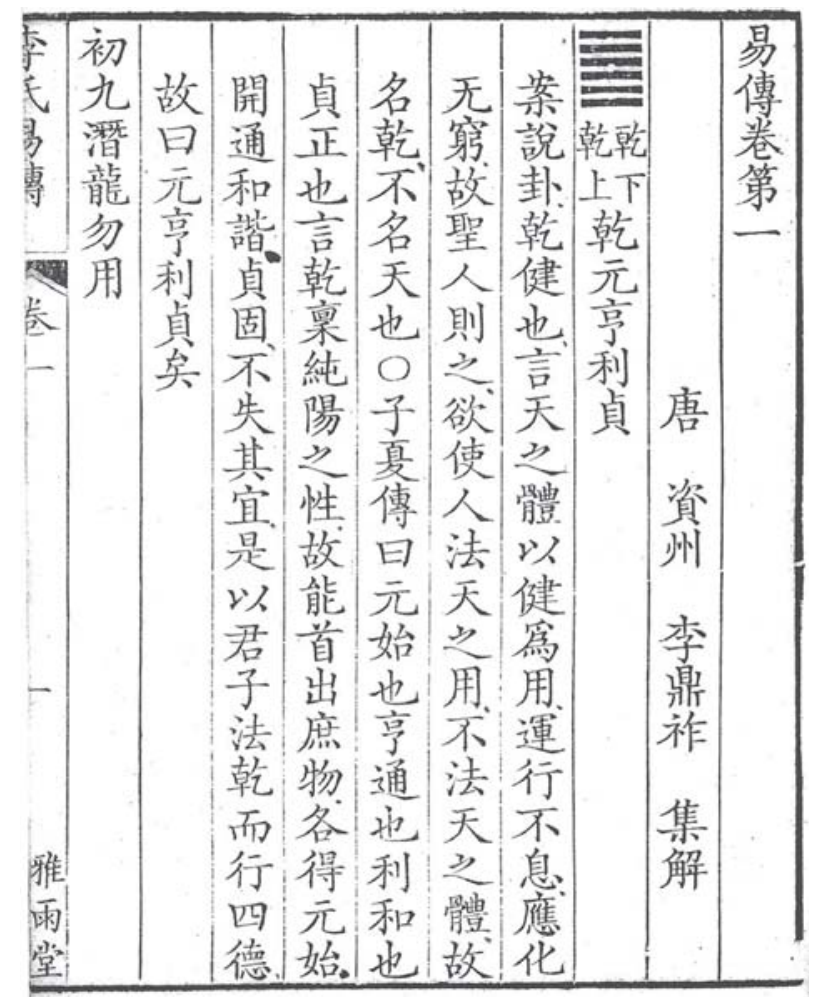

Figure 6.7 Yizhuan [Tang Commentary on the Yijing], 1756. Private collection of the author. 


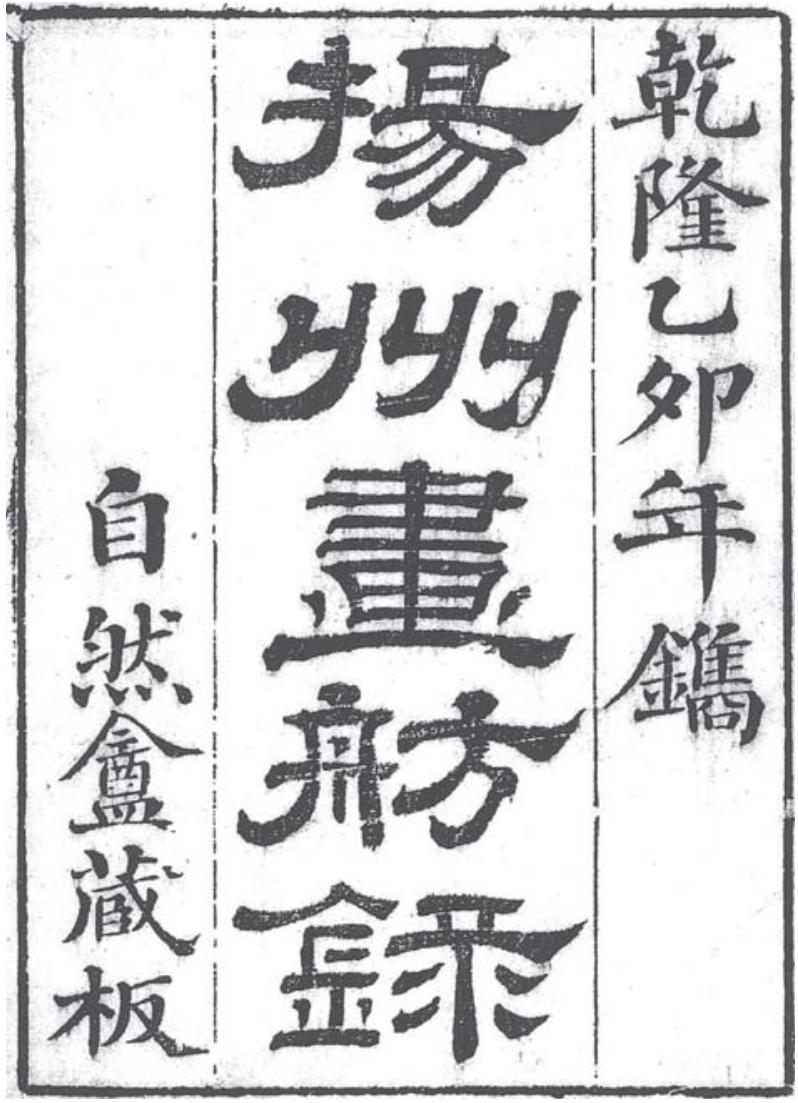

Figure 6.8 Yangzhou huafang lu [Pleasure Boats of Yangzhou], 1795. Private collection of the author.

Lu Jianzeng 盧見曾 (I690-I768), from Dezhou in Shandong province, published many scholarly works and reprints during his second tenure as salt commissioner of Yangzhou from I753 to I762. Through his close association with Ma Yueguan, Lu Jianzeng also managed to complete the printing of Zhu Yizun's 朱彞尊 (I629-I709) monumental bibliography of classical texts, Jingyi kao 經義考 [Examination of the Classics], in I755. Only I67 of 297 juan had been printed previously, and Lu's successful completion of the work gained him praise from scholars. Yizhuan 易傳 [(Tang) Commentary on the Yijing], is the first in a collection of fourteen pre-Song works published by Lu under the collective title Yayu tang congshu 雅雨堂叢書 [Yayu tang Collectanea] from I756-I760 (Fig. 6.7). The Beijing scholar Fashishan 法式善 (I753-I8I3) later praised Yayu tang congshu for the rarity of the editions included and the high quality of the publication.

The publications of these three men and numerous others of similar type were works of the highest aesthetic standards that used skilled craftsmen and depended on the best quality paper and ink. They were aimed at a rather exclusive audience, 
but this did not hinder their wide circulation and fame. Although they were not originally produced for profit, that did not prevent them from being traded commercially. They were, of course, also distributed informally by means of intellectual networks and given as presents, one of the prime motivations for private publishing of this kind.

It is not surprising that the famous artists, especially painters and calligraphers, associated with Yangzhou's colorful eighteenth century contributed to book culture in Yangzhou. Books by the likes of Jin Nong 金農 (1687-1763), Luo Pin 羅䀻 (I733-I799), Zheng Xie 鄭敩 (I693-1765), and Wang Shishen 汪士慎 (I686-1759) were published in Yangzhou in their lifetimes. An exquisitely printed collection of Jin Nong's poetic works, entitled Dongxin xiansheng ji 冬心先生集 [Collected Writings of Mr Dongxin (sobriquet of Jin Nong)], was published in Yangzhou in 1733 (Meng Xianjun 2006: 67-69). Xylographic printing made it possible to produce facsimiles of the authors' actual style of writing. Jin Nong's calligraphic inscription was used for the title on the cover page of a 1744 edition of poetry. The entire text of Banqiao shichao 板橋詩鈔 [Selected Poetry of Zheng Xie], published by Zheng Xie in Yangzhou in 1743 , was carved in imitation of his own distinctive handwriting. Books containing specimens of the calligraphy of celebrities had great aesthetic appeal and xylographic facsimile editions of famous texts had reproduced texts close to photoreprint quality in China long before the invention of photography.

The famous Yangzhou 'guidebook', Yangzhou huafang lu 揚州畫舫錄 [Pleasure Boats of Yangzhou], was published by its author, Li Dou 李斗, in $1795,{ }^{17}$ and immediately gained wide popularity (Fig. 6.8). Although the guidebook is reported to have been reprinted in new editions more than once, Li's own edition, published under the hallmark of his own studio, Ziran an 自然鿖, in Yangzhou was, in fact, reissued using the original woodblocks on several occasions. The presence in some copies of new prefaces and colophons from the Jiaqing (I796-I820) and Daoguang (I82I-I850) periods contributed to a false assumption that these are really new editions, but actually they should be considered new impressions from the original blocks. ${ }^{18}$ But they certainly attest to the great demand for this publication. The cover page reproduced in Fig. 6.8, with its date of 1795 , comes from a copy actually printed as late as I872, albeit with some replacement woodblocks, which demonstrates that the bulk of the original blocks survived the Taiping Rebellion.

Finally, we must remember the many eighteenth-century scholars who infused the book world of Yangzhou with distinction through their published writings. Ruan Yuan 阮元 (1764-I849) was an enormously esteemed and productive author. Although he published and printed many major works while away from Yangzhou on official postings, he still managed to publish over fifty titles in Yangzhou, and for bigger projects he was known to commission teams of block-cutters, sometimes invited from neighboring provinces. Among Ruan Yuan's many interests was epig- 


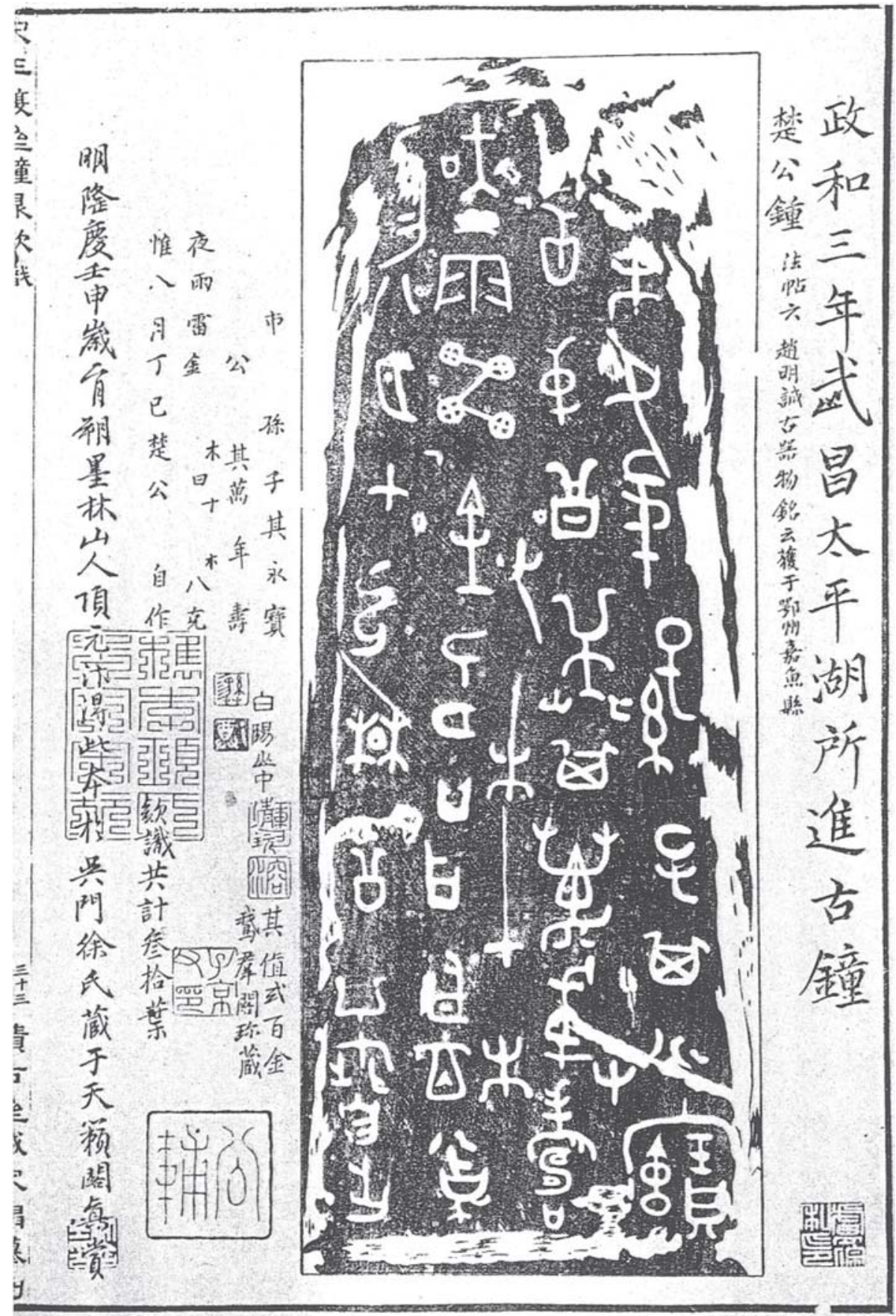

Figure 6.9 Zhongding kuanzhi [Inscriptions on Bronze Vessels], 1802. Source : Zhongguo banke tulu 1961, pl. 544. 
raphy and early inscriptions. In 1802 he published the spectacular Zhongding kuanzhi 鐘鼎款識 [Inscriptions on Bronze Vessels], which included elaborate xylographic reproductions of rubbings from bronzes (Fig. 6.9). ${ }^{19}$

Wang Niansun 王念孫 (I744-I832) and his son Wang Yinzhi 王引之 (I766-I834) were philologists from Gaoyou who published extensively. Jiao Xun 焦循 (I763-I820) was a classicist and mathematician from Ganquan who published in many fields. He wrote works on Yangzhou history and geography and also contributed to the compilation of the Yangzhou fuzhi 揚州府志 [Yangzhou Prefectural Gazetteer], published in I8ro. Book collectors in Yangzhou continued in this period to be patrons of the arts and scholarship. The library of Qin Enfu 秦恩復 (176I-I844), called Shiyan zhai 石研齋, was a meeting place for many of the scholars from throughout the Jiangnan area. Furthermore, Qin Enfu published many superb editions under the Shiyan zhai hallmark.

Indeed, for the first few decades of the nineteenth century Yangzhou's elite publishing continued to flourish. The cosmopolitanism demonstrated by the Mas remained a feature of Yangzhou book culture. For example, the Mongol scholar Fashishan, from Beijing, was a close acquaintance of Ruan Yuan. In the first decade of the nineteenth century Fashishan spent time in Yangzhou as an editor on the Qinding Quan Tang wen project. At the time he also compiled Li Wenzheng gong nianpu 李文正公年譜 [Chronological Biography of Li Dongyang 李東陽 (I447-1516)], which was published in Yangzhou by his friend Wang Qisun 王芑孫 (I755-I818), a native of Suzhou. The Yangzhou native Cheng Bangrui 程邦瑞 published Cunsu tang wenji 存素堂文集 [Collected Prose Writings of Cunsu tang (sobriquet of Fashishan)] in I807, followed by a sequel in I8II. Such were some of the interwoven relationships among the literati and publishers in Yangzhou.

During the Jiaqing and early Daoguang periods, the activities of bibliographers and book collectors throughout China stimulated the publication of important textual criticism as well as facsimiles of rare editions and ancient classics, and Yangzhou was no exception. In I808 Ruan Yuan privately published his famous Shisan jing zhushu jiaokanji 十三經注疏校勘記 [Text-critical Notes to the Thirteen Classics with Commentary] in Yangzhou. In I825 he published a Yangzhou facsimile edition of Gu Lienüzhuan 古列女傳 [Biographies of Exemplary Women of the Past], said to be based on a Song edition in the possession of the Ruan family. Many others in Yangzhou produced valuable private editions at the same time.

As far as can been learned from relevant bibliographies and catalogues, a decline in the quantity and quality of Yangzhou publications, which probably began in the middle of the I830s, ran its course in the early I850s, when Yangzhou was threatened, attacked, and occupied multiple times for nearly a decade. The earlier decline, no doubt, was caused by complex economic conditions that affected other areas of southern China as well. The violent incursions by the Taiping armies, beginning in 
1853, not only inhibited printing and publishing, but led to the wholesale destruction of books and manuscripts left unprotected. Needless to say, Yangzhou was not able to regain its former glory after the middle of the nineteenth century, but it has been able to obtain a new identity as a center for traditional xylographic printing.

After the period of recovery from the Taiping destruction it is possible to recognize an increase in establishments for Buddhist printing and commercial publishing in Yangzhou, which may be the result of changed demographics in the region. One of the most remarkable of the new businesses was the Chen Henghe shulin 陳恒和書林 [Chen Henghe bookshop], set up in Yangzhou in 1923 by Chen Henghe (1883-1937). Chen came from a background in xylographic printing near Yangzhou, and after serving an apprenticeship in a bookshop in Shanghai, he returned home to start his business. He specialized in xylographic printing and publishing, and he acquired existing sets of woodblocks as well as engraving new ones. After his death he was succeeded by his son, Chen Lüheng 陳履恒. The Chen Henghe shulin provided the foundation for the antiquarian book trade in Yangzhou after 1949 .

Guangling shushe 廣陵書社 [Guangling publishing company], named after the ancient name for the region, deserves a special status among publishers in China today. Founded as the Yangzhoushi Guangling guji keyinshe 揚州市廣陵古籍刻印社 [Guangling ancient books publisher of Yangzhou] in 1960, the organization was created to deal with the large collection of woodblocks accumulated by Chen Henghe and others. From the start they reprinted many important works from original woodblocks, cutting replacement blocks as needed, and publishing them as thread-bound editions. The name was changed to Guangling shushe in 1999 to cope with the new challenges and opportunities facing publishers in China. Since 2003 Guangling shushe has been affiliated with the newly founded China Block Printing Museum at Yangzhou, Yangzhou Zhongguo diaoban yinshua bowuguan 揚州中國雕版 印刷博物館, and a large part of its woodblock collection is stored there.

In 200I, Guangling shushe published Litang daoting lu 里堂道㯖錄 [Litang's Scholarly Notes] by Jiao Xun ( $z i$ Litang) in forty thread-bound volumes. The work in forty juan, never previously published, is based on Jiao's own manuscript held by the National Library of China. Two scribes (Liu Yueting 劉躍庭 and Rui Mingyang 荫名 揚) collaborated with more than ten block-cutters for twenty years to complete this monumental work. It is their crowning achievement as a xylographic publisher and one not likely to be repeated.

\section{CONCLUSION}

I will try to draw some conclusions from this admittedly simple survey of printing and book culture in Yangzhou. From the start I noted a certain lack of continuity 
and comprehensiveness in the development of publishing in Yangzhou, especially measured from the sixteenth century and compared to the other cultural centers of the south. It appears that book publishing in Yangzhou was dominated by official publishing and private publishing, with a relatively small proportion of commercial publishing, especially when compared with the likes of Nanjing, Suzhou, and Hangzhou. Until the nineteenth century there are few examples of truly commercial editions in Yangzhou, and some of those are merely attributed. To be sure, there were print shops that provided the necessary labor for all the steps of book production that served the needs of the private publishers. It is likely that some of these shops engaged in the printing and publishing of popular literature, chapbooks, and primers that were provided to hawkers for sale, but there is little evidence of such artisans rising to the level of major commercial publishers, who mingled with literati authors and editors as we find in other places.

There is one possible exception, but it may be an important one. According to a mid-nineteenth-century Suzhou edition of Rulin waishi 儒林外史 [Unofficial History of the Literati], the great eighteenth-century novel by Wu Jingzi 吳敬梓 (I70I-I754) was first published privately in Yangzhou by Jin Zhaoyan 金兆燕 (b. 1719) between I768 and I779. The source goes on to say that it was followed by more than one Yangzhou commercial edition. In fact, the second oldest extant edition of Rulin waishi was published in 1816 by a Yangzhou bookshop named Yigu tang 藝古 堂 (WANG Cheng 2003: 295, 30I). I do not know the name of the proprietor of this shop, but it might be worth investigating. In any case, this one example cannot tip the balance of Yangzhou's singularity.

Perhaps Yangzhou's geographical position on the north side of the Yangzi River, separating it from Nanjing and the other nearby Jiangnan centers, was an isolating factor. One also wonders whether the so-called Jiangnan-Jiangbei dichotomy might not have contributed to social differences. The dichotomy was compounded by the fact that 'the naming of Jiangnan and Jiangbei was informed by a mix of sometimes contradictory geographical, cultural, and administrative factors. ${ }^{.20}$ Perhaps the prevalence of sojourners among the population of Yangzhou was destabilizing in some way, or perhaps the disproportionate influence of the salt trade influenced the level of commercial publishing. Sojourning and the extreme wealth and power of the salt merchants certainly contributed to social and economic imbalances in the society (FInNANe 2004: 144). Among the sojourners were many natives of Shexian in Anhui province, where printing was well developed, who became salt merchants at Yangzhou. Perhaps these connections were exceptionally influential.

I must leave the subject here with many puzzling questions unsolved. However, it is my sincere hope that this essay may stimulate future research into Yangzhou printing and book culture that will help us to gain further insight into these problems. 


\section{NOTES}

1 Jiangsu yiwenzhi: Yangzhou juan 1995: (prefaces) I5-20. Finnane 2004: Appendix A, lists seven counties and their market towns as of the early eighteenth century.

2 Zhongguo guji shanben shumu 1985-96 (vol. 6): 460. Naikaku Bunko sōhon shoei 1984: pls. 35-38.

3 Juan is the chapter-like division of traditional Chinese books. It is an essential detail of Chinese bibliographical description.

4 As recently as 2004, the National Library of China added another juan by acquiring juan 42 from the former library of Chen Qinghua 陳清華 (1894-I978). It is from the famous defective copy held by the National Central Library. Juan 42 is already part of the Shanghai Library holdings.

5 Zhongguo guji shanben shumu I985-96 (vol. 6): 27I-272. Zhongguo banke tulu I96I (vol. I): 56, pl. 30I.

6 WANG Cheng 2003 is an important contribution to the growing body of research on printing, publishing, and book history in China.

7 Illustrated in WANG Cheng 2003: I2.

8 Zhongguo guji shanben shumu 1985-96 (vol. 5): 997, records five copies in mainland Chinese libraries. There are two more copies in the National Central Library, Taiwan.

9 See Du Xinfu and Du Tongshu 20or. This work is largely based on Du Xinfu's Mingdai banke zongmu 明代版刻綜目 [A Comprehensive Bibliography of Ming Printed Editions], Yangzhou, Guangling shushe, 1983 .

10 WANG Cheng 2003 makes the valid point that his meager list (pp. 296-3IO) of Qing commercial publishers cannot be considered fully representative, since it mostly leaves out the lower echelon of commercial publishers who served popular tastes with the likes of vulgar fiction, songbooks, primers, and various handbooks. Such publications were either ephemeral in nature or poor in quality in terms of material used and workmanship and less likely to be preserved. However, the same can be said of every regional book market in China.

11 The best known first-hand account is the diary of ten consecutive days by Wang Xiuchu 王 秀楚, Yangzhou shiri ji 揚州十日記 [Ten-Day Diary of Yangzhou], Yangzhou: Guangling shushe, 2004. Meyer-Fong 2003 analyzes the cultural recovery of Yangzhou up to the beginning of the eighteenth century.

12 An interesting record of events is contained in the anonymous manuscript divided into two juan and covering the period from the seventh month of 1853 until the ninth month of 1856 found in Luo Ergang 2004.

13 Zhongguo guji shanben shumu 1985-96 (vol. 3): 1399.

14 Guoli Beiping tushuguan guankan 國立北平圖書館館刊 [Bulletin of the National Library of Peiping] 4:6 (I930): 8I-IO6; 5:I (I93I): 77-IO2; 5:2 (I93I): 87-96; 5:3 (I93I): 9I-IIO; 5:4 (I93I): 99-II2.

15 Peiwen zhai was the name of the Kangxi emperor's private study in the palace, and its use in book titles, or merely Peiwen, implied an association with the emperor and his love of learning.

16 Hsü Ginger Cheng-chi 200I: 17-63, discusses the Mas' roles as patrons of artists and as friends and hosts of the cultural elite of Yangzhou in the eighteenth century. Their relationships included scholars, famous writers, and even members of the Qing court.

17 Olivoví 200I: I42-I43, points out that there is reason to believe that the actual date of publication was 1797 , based on the date of Ruan Yuan's foreword and an internal reference to it. 
However, due to the nature of xylography, prefaces often pre-date, and can even post-date, the actual date of publication, if that is taken to be the date of completion of cutting of the set of woodblocks used for the main text. In the context of traditional publishing practices, the date of Qianlong yimao (1795) has an authoritative position on the cover page of the book (see Fig. 6.8). Nevertheless, Olivová's observation that the yimao year extends into early 1796 and her notice of the 1797 dates are significant.

18 Olivová 200I: I43-I44. I believe that Olivová's description of different pre-twentieth-century 'editions' of Yangzhou huafang lu are all of later printings and reissues.

19 Zhongguo banke tulu 196r: pl. 544. As can be seen in this figure, in addition to the standard kaishu 楷書 text used for the annotations and transcription of the inscription, this page also contains a reproduction of an ink-squeeze rubbing of the inscription, a reproduction of a colophon in more calligraphic style, and seal impressions.

20 FinnANe 2004: 30; the history and implications of the names are discussed pp. 27-34. 


\section{Pleasures of a Man of Letters}

\section{Wang Shizhen in Yangzhou, 1660-1665}

Li Hsiao-t'i

W ang Shizhen 王士禎 (I634-I7II) was the leading personage of the early Qing literary scene. His followers and biographers regarded him as the 'doyen of contemporary poetry, whose elegant style prevailed for decades' (Sun Yancheng I992: II2). Such was the general opinion at that time. Recent research also stresses Wang Shizhen's leading role in early Qing poetry, and has brought into focus his impact on the Guangling $c i$ 廣陵詞 school (Li Kanghua 200I: I87-20I). ${ }^{1}$ Since Wang Shizhen is a well-known author, it is only natural that the major studies about him have been written by literary historians, using the methods of literary criticism. They concentrate on Wang Shizhen's literary successes, his influence, and his important theory of literary creation, or creativity: the so called shenyun shuo 神韻說.

But Wang Shizhen's poems and tales also provide excellent material for cultural historians, as proven by the recent research of Tobie Meyer-Fong. She has examined in detail how Wang Shizhen built up his prestigious position through activities such as the gatherings at the Red Bridge, or trips to various places in Jiangnan. By the same token, the reputation of Yangzhou and of the Red Bridge grew, as a consequence of Wang Shizhen's poetry and social position (Meyer-Fong I999: 49-84).

This chapter follows in the steps of the cultural historians, and scrutinizes in detail the five years when Wang Shizhen served as an official in Yangzhou. I have focused on Wang Shizhen's everyday life, touching upon a variety of situations: the apprehensions he felt before taking the office, his official duties and the mistakes he made, his dual role as poet and official, the reception of guests who were passing through Yangzhou in a never-ending stream, and finally his enjoyment of poetry and wine, his bond to the Yangzhou and Jiangnan landscape, and the gatherings with his literati friends. I believe that many otherwise excellent studies tend to overlook the trifles and the minute details in the lives of people who played an essential role in officialdom. Consequently, only the austere and cool facets of elite culture emerge. The setting, be it the town, gardens or land, is left out, as are non-standard religious beliefs, or the taste for poetry and wine. When reconstructing the 'literati culture,' the original colors, smells, taste, and feel are forgotten. Not long ago, I sought to incorporate such elements in writing about Zheng Banqiao 鄭板橋 (Li Xiaoti 2005: 
213-34). Through the analysis of his Yangzhou memories, I could trace his frustrations. Wang Shizhen, notably, surpassed many others by talent, spiritual force, and fame. He was able to establish a novel style of living in half-forgotten Yangzhou. For this, he is also worthy of new evaluation.

\section{LEAVING FOR YANGZHOU IN TEARS}

In 1658 , the fifteenth year of Shunzhi, Wang Shizhen, then only twenty-five years old, passed the palace examination and received the jinshi 進士 degree. One year earlier, he had gained a name in the literary circles thanks to his set of four poems titled 'Autumn willows,' Qiu liu shi 秋柳詩, which had been composed in reply to poems by other well-known personages on the banks of lake Minghu 明湖 in the city of Jinan. And now, still so young, he was fortunate to be ranked among the first three in the palace examination. He must have felt satisfied and have harboured hope for a great career, since the top graduates of the palace examinations were normally placed in official positions in the capital. But the rule had been changed from 1658 onward, and graduates were sent to provinces. In 1659 Wang Shizhen learned with disappointment that he had been assigned as a prefect to Yangzhou.

Although disappointed, Wang Shizhen accepted his lot without protest. It happened that a few months before this assignment was publicly announced, he had visited the temple of Guandi 関帝 on Qianmen Street, in order to ask Heaven about his future. He received the following prophecy:

\section{今君庚申未亨通, 且向江頭作釣翁, 玉兔重生應發跡, 萬人頭上迬英雄。}

You will not be successful before the year gengshen; until then, you will be a fisherman by the river. When the Jade Rabbit is reborn, that is where you start from, becoming a hero, superior to ten thousand men.

(Sun Yancheng I992: 15).

Wang Shizhen did not understand the meaning at first, but when later notified about his assignment, he guessed that 'being a fisherman by the river' alluded to Yangzhou, which lies close to the river Yangzi. Still later, looking back, he analyzed the prophecy with even more clarity. He spent five years in Yangzhou, and then, in October 1665, he became a secretary at the Bureau of Receptions of the Ministry of Rites, Libu zhukesi zhushi $i$ 禮部主客司主事. The Jade Rabbit is reborn in the year gengshen 庚申, i.e. 1680, when he was nominated chancellor at the Directorate of Education, Guozijian jijiu 國子監祭酒. Wang Shizhen was born in 1634, and he was reborn, through his promotion, in 1680. So finally, each line of the prophecy was borne out.

Wang Shizhen obviously did not doubt this supernatural advice. He not only recalled it in his Random talks at the north of the pond, Chibei outan 池北偶談, which 
basically is a book of narratives and tales, but also recorded it, with all seriousness, in his biography, nianpu 年譜. ${ }^{2}$ Evidently, he paid a lot of attention to strange and unusual omens. A weakness for stories about supernatural phenomena is characteristic of Chinese men of letters, after all, and was a frequent topic of random anecdotes, biji xiaoshuo 筆記小説. Yuan Mei 袁枚 (I7I6-I798), the poet whose status can compare, for his time, to Wang Shizhen's, is another good example of such attitudes. In his collection of stories titled What Confucius would not have talked about, $Z i$ buyu 子 不語, and in the Sequel, Xu Zi buyu 續子不語, Yuan Mei wrote about contemporary bureaucrats and their encounters with ghosts, merging the real with the fantastic, so that the reader almost believes it. The style of Wang Shizhen's Chibei outan is somewhat different: it is closer in manner to historiography, but tales about supernatural beings were not avoided. Wang Shizhen not only included the topic of the supernatural in historical passages, but used quite an official 'tone.' For example, in the opening chapter of his biography he described and explained the supernatural events accompanying his family's origin and rise (SUN Yancheng 1992: I). Even in writings from his later years supernatural elements remained an integral part of his view of life (WANG Shizhen 1983 [I709]: 55I).

And so, at the beginning of 1660 , Wang Shizhen started off for Yangzhou. His mother, née Sun 孫, was worried about him, because he was still so young. It was true that Yangzhou was the place where his grandfather used to stay, so he had an example to follow. ${ }^{3}$ But the poems which Wang Shizhen wrote about parting with his mother are very emotional; it was a tearful scene. Madame Sun was worried that her son was not yet competent to fulfill the duties of the highest regional official, being still too young and impulsive. Wang Shizhen, on the contrary, was apprehensive that he might not be able to carry on composing poetry, for which he had already gained some reputation. His fears were recorded by his friend Wang Wan 汪琬 (I624-I690), who discussed the question with Wang Shizhen when the latter had already been recommended for the post. Wang Wan did not believe that Wang Shizhen would abandon poetry, and therefore advised him to 'live quietly and let matters of government take their course,' qingjing wuwei zhi zhi 清靜無爲之治 (WANG Wan 1997: vol. 2:614). Wang Shizhen's worries were excessive, even though he did not comply with Wang Wan's advice. During his five years in office in Yangzhou, Wang Shizhen not only composed a lot of poetry, he also secured a leading position in the literary world of early Qing China. The many poems, the endless stream of guests, literary gatherings, and trips persuade one that Wang Shizhen basically remained a man of literature. However, his biographer, Sun Yancheng 孫言誠, holds the opinion that Wang Shizhen's literary gains are exaggerated, while his political merits in that period are underestimated (Sun Yancheng I992: II4). He claims that Wang Shizhen gained the respect and esteem of worthies because he could balance the roles of official and poet. Before we plunge into this important question, let us 
turn to the concrete political problems Wang Shizhen faced when entering office. In that way, we shall gain an informed view of his situation.

\section{THE INTERTWINED ROLE OF A POET AND AN OFFICIAL}

In the sixteenth year of Shunzhi 順治 (1659), one year before Wang Shizhen took office, the army led by Zheng Chenggong 鄭成功 ${ }^{4}$ occupied the southern bank of the Yangzi: it entered the town of Zhenjiang, encircled Nanjing, and got the support of the local gentry. Once Zheng Chenggong was defeated, however, the Qing court began to investigate officials at all levels, and their relatives, to find out who had welcomed or supported Zheng Chenggong. In I66I, the Qing court sent inspectors from the Ministry of Revenue, Hubu 戶部, and the Ministry of Justice, Xingbu 刑部, to Nanjing (then called Jiangning 江寧), to conduct the trials. By that time Wang Shizhen had set free those officials against whom there was insufficient evidence, or who had been imprisoned on the basis of false accusations. Thus, many individuals were liberated (Sun Yancheng 1992: 17-I8).

Wang Shizhen surely tried to be just and not to favour anyone. His actions were very courageous, and he was not afraid to challenge his superiors. In the event, there were no explicit negative reactions from them, yet in the second year of his service, Wang Shizhen was demoted in rank as a result. In his biography, he neutrally recorded Madame Sun's remark concerning this matter: 'Life is not easy, if you decide to be honest, you cannot avoid upheavals' (Sun Yancheng 1992: 20). Wang Shizhen quietly took the advice, and throughout his life resolved many further unjust cases.

From Wang Shizhen's correspondence with his friend the poet Mao Pijiang 冒辟 疆, ${ }^{5}$ nevertheless, one can guess that he felt extremely low-spirited and disappointed about his demotion. He wrote, for example, that he was penalized 'last year because of quite a trivial matter, based on hearsay' (MAO Xiang 1997 [I673]: vol. 4: 170). After the demotion, Wang Shizhen lost all interest in life: 'My brush cannot describe one ten-thousandth of how awful the situation had been,' he wrote in a letter to Mao Pijiang in I662 (ibid.: I7I). In addition, he felt low-spirited and even angry because of the imprisonment of his elder brother Wang Shilu 王士祿 (1626-1673; jinshi 1652), who had been accused of wrongdoing when acting as an examination official in the Henan provincial examination. A short remark in Wang Shizhen's correspondence, 'The recent matters are so disastrous, and there is no one to turn to. In the words of Shaoling 少陵 (i.e. the Tang poet $\mathrm{Du}$ Fu 杜甫), “I feel so gloomy, and no one cares any more", probably refers to that (Wang Shilu zhuan 1928: 132).

In the fifth month of the year 1662, Wang Shizhen, his wife, and his brother Wang Shihu 王土祜 started a long fast and practiced Buddhist rites (MAO Xiang 1997 
[1673]: vol. 4: 170). Although the source does not specifically state what prompted such actions, it is nevertheless quite possible that it also related to the setbacks which Wang Shizhen had encountered in his career. Fasting and praying became a standard practice for all the Wang brothers whenever they had career problems, for example when Wang Shihu did not pass the examination in Beijing in I664, or when Wang Shilu was dismissed from the office. On that latter occasion the whole Wang family felt very unhappy; Wang Shilu copied sutras every day, meditated, and ordered an embroidered image of Buddha; he also wrote a lengthy poem about fasting, explicitly stating that he fasted whenever he met with life difficulties (SUN Yancheng 1992: 76-77).

Although his official career seems to have been relatively straightforward and uncomplicated when compared to the problems which famous personalities of Yangzhou, be it his elders or his peers, or even historical figures, had encountered, Wang Shizhen's frustrations were real and substantial. And while in public, as we learn from descriptions by his contemporaries, he always behaved in an agreeable and dignified manner, ${ }^{6}$ his melancholy sometimes broke out in personal letters. He preferred to conceal from most people the stresses of his official life. His social persona did not reveal any displeasure or disappointment. Most of his poems have a happy tone, he gave parties and celebrations, he traveled for pleasure. Many of Wang Shizhen's admirers want to ensure that this tone of his poetry does not give rise to misunderstanding about Wang Shizhen himself so they stress, when writing about his cultural activities in Yangzhou, the numerous problems he encountered in the administration and the excellent way he handled them.

Take for example Wang Shizhen's effort to clear Yangzhou's tax liability, owed to the Qing court. In the period 1645 to I660 the debt had accumulated to more than twenty thousand liang, and many officials and their relatives had been imprisoned - in addition to those imprisoned in 1659, when Zheng Chenggong had attacked the lower Yangzi region. ${ }^{7}$ Wang Shizhen found this situation unacceptable, and wrote letters to both his superiors and subordinates urging them to make up the deficit, and help ensure the prisoners' release. He finally managed to have the debt paid off, thereby rescuing many from imprisonment (Sun Yancheng 1992: 17-I8). The first person to write about this episode was Hui Dong 惠棟 (1698-1758), a renowned scholar from Suzhou. He recorded it as an example of the difficulties Wang Shizhen had to overcome when in authority in Yangzhou (Liv Zhengyun 1993: 176, 178).

At the same time that he was carrying out his official duties, Wang Shizhen was capable of developing into an eminent poet, under the sobriquet Yuyang shanren 漁 洋山人. In the three years 1662-1664 Wang Shizhen wrote more than three hundred poems, an astonishing amount. Lu Qi 陸折, who wrote the introduction to the collection of these poems, repeatedly emphasized Wang Shizhen's simultaneous role as politician and poet. Wang Shizhen described his own situation in these verses: 
流水聲中視公事, 寒山影裏見人家

I notice public duty in the sound of a stream, I can see my home in the haze of cold hills.

(Yuyang shanren ji qizhong I: ra,b).

It was precisely because of his dual role that Wang Shizhen's poetry became a success, and that he could surpass other poets.

\section{PLEASURE OF A MAN OF LETTERS}

Wang Shizhen's major leisure activity, apart from traveling to the well-known sights and old monasteries of Jiangnan, was to arrange parties and elegant gatherings for literati and friends. The two important events of his five-year official term which deserve most to be remembered are the gatherings in the Shuihui 水繪 Garden in I664, and at the Red Bridge, Hong qiao 紅橋, in 1665 . They were, unlike other gatherings, conceived as 'purification ceremonies', xiuxi 修裙, - a kind of libation ritual. They were understood in a very special way and the number of participants was higher than usual. ${ }^{8}$ Both events were cultural highlights, and were recorded in writing by many of the guests present.

The Shuihui gathering was held in the splendid garden residence of Mao Pijiang, in Rugao 如皇. It stood on land bought by Mao Pijiang's grandfather, who had had a house built there. When his grandson returned home and settled there in 1645 he had the old house rebuilt into a spacious garden retreat named 'embroidered with creeks,' shui hui, since the place was surrounded by hills, and creeks from all directions met there. The reputation of the garden and its owner spread widely. Eminent men from all over the country befriended and visited Mao Pijiang, staying on in his garden seemingly without any inclination to leave. He entertained people of humble as well as prestigious origin; he served good wine and the best selection of teas; he organized poetry readings, and viewings of bronzes with inscriptions and samplings of calligraphy and paintings. The Shuihui Garden was also known for its theatrical performances. It seems that neither north nor south of the Yangzi had anyone entertained as many guests as did Mao Pijiang over some forty years.

The purification ceremony held in this garden in spring I664 lasted four nights. It was an outstanding cultural event. According to Wang Shizhen, who composed a series of poems about it (WANG Shizhen 1999 [I700]: 478-85), the ceremony was characterized by sumptuous revelry. Good wine, delicious food, musical performances, and natural scenery enhanced by pavilions made the spring gathering a perfect display of earthly pleasures, and brought the glamour of the refined literati culture of the Ming-Qing transition to its zenith. Richly informed with classical allusions, Wang Shizhen's poems doubtless contributed a great deal to the making of the legend of the Shuihui garden. 
By comparison, the purification ceremony - or rather ceremonies, for there were two - at the Red Bridge took place in the city. In I662 Wang Shizhen organized a ceremony together with the poet Chen Weisong 陳維崧 (zi Qinian其年, I625-1682), and they published a collection of poems to commemorate it: Hongqiao changhe ji 紅 橋唱和集. The second ceremony, held in I665, was described in Wang Shizhen's twenty poems titled Yechun shi 冶春詩.' In one of these poems, Wang Shizhen described the spring scenery in the third month, and concluded:

\section{青無不見隋宮殿, 一種垂楊萬古情}

One can see green bushes, overgrowing the Sui palace, Willow branches have covered ten thousand memories.

(Wang Shizhen 1999 [I700]: 387)

Unlike Zheng Banqiao, who filled his verses with images of ruins, Wang Shizhen described the ancient town against the background of eternal spring. The Red Bridge, set between hilly banks with gardens and pavilions, had become a destination for travellers in its own right, because of the enchanting scenery. ${ }^{10}$ Wang Shilu later compared the second gathering at the Red Bridge to 'a dream, attended by Ouyang Xiu 歐陽修 and Su Dongpo 蘇東坡, ' the leading cultural figures of the Song dynasty (Sun Yancheng 1992: 23). The guests composed poems, drank excellent tea, there were paintings to look at and music to listen to.

Thus did Wang Shizhen originate in Yangzhou a mode of socializing, which over the next forty years the gentry of the region tried to emulate.

\section{THE RECOGNITION OF SU DONGPO}

Although the verses 'What certainly makes a man happy are the pleasures of rivers and hills,' shi jun zhi le, jiangshan zhi xing ye 使君之樂, 江山之幸也, by You Tong 尤侗 (I6I8-I704), can be accepted as merely a general agreeable statement, it also has a more profound meaning. Several places in Yangzhou and its vicinity gained significance thanks to Wang Shizhen's delight in traveling, his cultural activity, and his writing. One such place was Shangfang si 上方寺, a Buddhist monastery, which became well known once Wang Shizhen had visited it, and praised it.

When writing of Yangzhou, Qing writers most often mention the Red Bridge, the monuments of the Sui empire, and Ouyang Xiu's Level Mountain Hall, Pingshang tang 平山堂. They became the cultural reminders of Yangzhou's glorious past. Transcending space and time, writers selected the most brilliant moments of Yangzhou's thousand years of history and created a shared memory of them. There are also some poets and officials who attached themselves, due to their personal inclinations and sentiments, to a special site or historical person. For example, the frustrated Zheng 


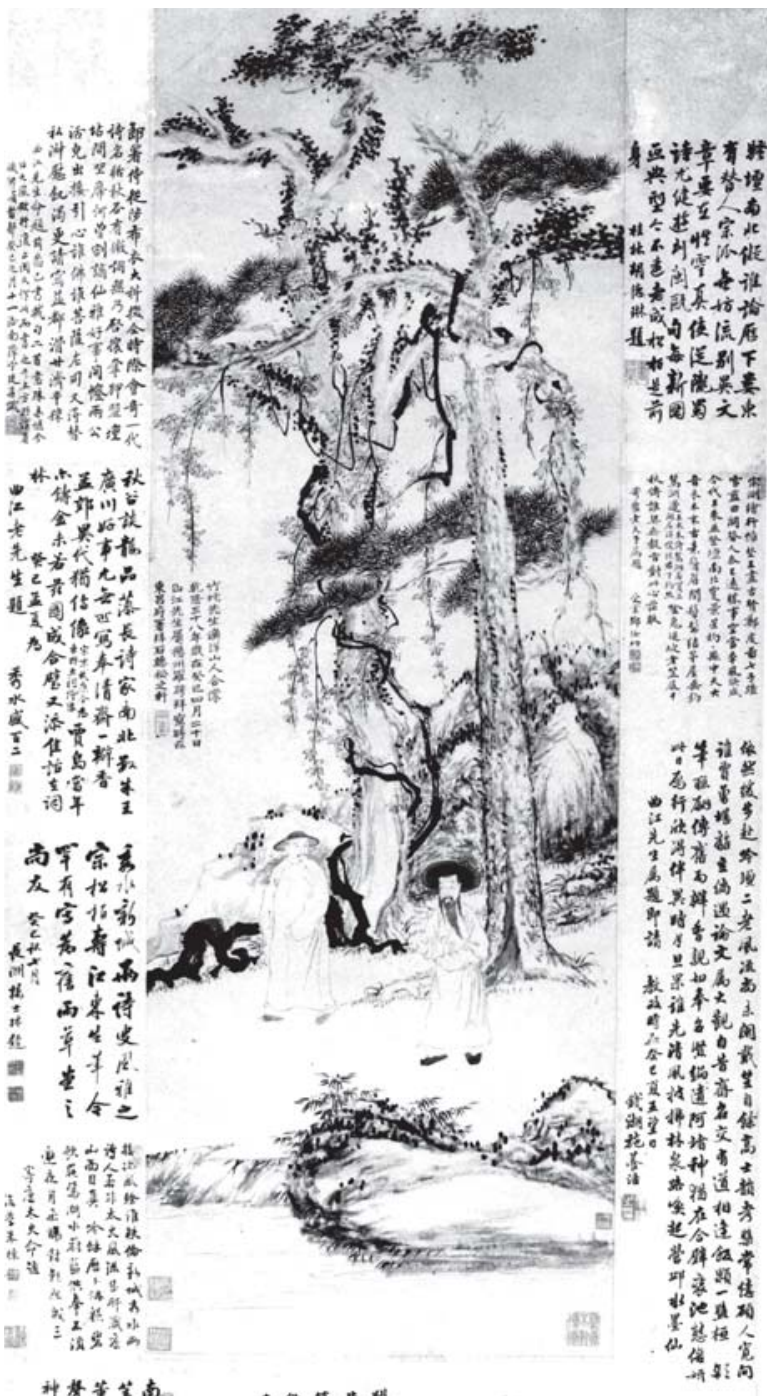

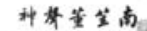

详电克样宝

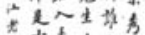

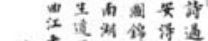

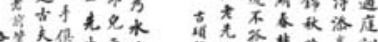

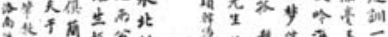

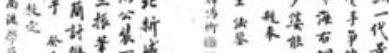

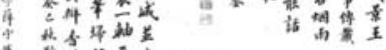

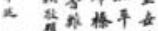

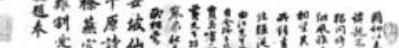

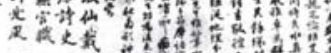

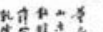

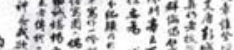

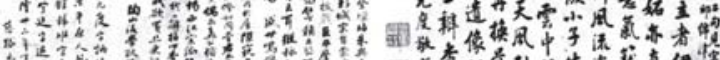

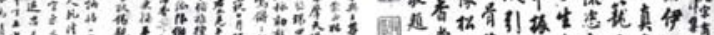

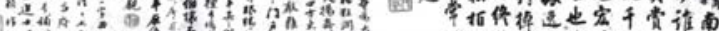

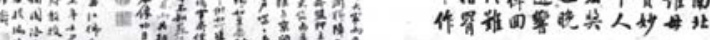

1)

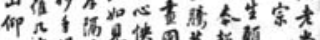

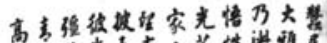

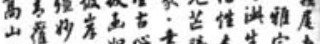

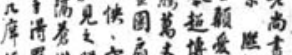

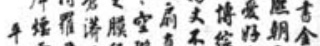

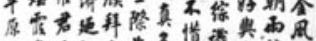

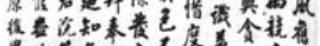

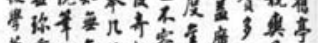

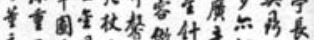

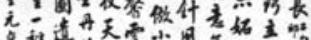
Yangzhou. Luo Pin painted century later. Courtesy The British Museum, London. this idealized portrait one

Figure 7.1 Luo Pin (17331799). A joint portrait of Wang Shizhen and Zhu Yizun. Ink on paper, 101.7 $\times 35.5 \mathrm{~cm}$. Dated 1773 . British Museum, London. The two celebrated poets met three times, but never in 
Banqiao was fond of the ruined tombs of Sui dynasty. They confirmed the disappointment he felt with his own life, and his rejection of the luxurious lifestyle of the Yangzhou of his own time. Wang Shizhen, too, chose a specific symbol to express his attachment to Yangzhou's past. It was the poet, essayist, and calligrapher Su Dongpo (IO37-IIOI), with whom he tried to identify and through whom he expressed his own ideas and feelings. And thus he introduced Su Dongpo into the rewritten cultural history of Yangzhou.

At the Spring Festival of I66I, his second year in Yangzhou, Wang Shizhen and his friends made a trip to Pingshang tang, and then continued to the Shangfang monastery in the north-east Shugang 蜀崗 hills. The Shangfang Chan 禪 monastery, popularly known as the Western Bamboo monastery, Zhuxi si 竹西寺, was founded by the emperor Sui Yangdi 隋煬帝 (605-6I7). When Su Dongpo served as a magistrate in Yangzhou, in I092, he traveled to Shugang on a certain occasion, and then wrote a poem. ${ }^{11}$ The poem, in his calligraphy, was copied onto the stele in the monastery.

Wang Shizhen had begun to search in monasteries for old steles with poetry shortly after taking up his post in Yangzhou, and his friend Wang Wan praised him for this (Wang Wan 1997: vol. 3:462). When Wang Shizhen visited Shangfang, he composed a poem, matching the one by Su Dongpo, to be carved on the same stele. On this first and only visit to the Shangfang monastery, the place was dilapidated, pigeons were flying through the interior, and the broken stele was covered with spider webs. But the desolate setting did not dent Wang Shizhen's admiration for Su Dongpo and his literary genius. Sweeping away dust and exclaiming over the decay, the master of the early Qing poetic world readily stepped back into the times of Su Dongpo, making an imaginary toast and praising him in vivid verses.

Wang never was to return to the Shanfang monastery, but he remembered the broken stele at the moment of leaving Yangzhou. Assigned to the Ministry of Rites in 1665 , in the spring of the following year he ordered his student Zong Yuanding 宗元鼎 to have the stele with Su Dongpo’s calligraphy repaired and placed into the wall of the monastery (JIANG Yin 200I: 59). This is a further proof of Wang Shizhen's affinity with $\mathrm{Su}$ Dongpo. This story of the broken stele came to sit at the head of Yangzhou's cultural genealogy. On the Qingming 清明 festival just after the stele was repaired, the Wang brothers, Mao Pijiang, Chen Qinian, and others composed poems to commemorate the event. Among the writers was the abbot of the monastery at the time, whose pen-name was Shuokui shangren 碩揆上人 and who came to Yangzhou from Lingyin si 靈隱寺 in Hangzhou. The poetic dialogue between the abbot and Wang Shizhen is analogous to the story of Su Dongpo and the monk Liaoyuan 了元. ${ }^{12}$

The Wang brothers could find in Su Dongpo's writings even more parallels to and affinities with the frustrations of their careers. On the eve of I663, Wang Shizhen recalled the events of the past year, I662, in a set of poems. In the introduction, he 
mentioned how at home he and his brothers used to read Su Dongpo together, and how moved they were by his writing. They had not yet experienced parting, he wrote, and 'had not yet known the sorrow which the word implied.' But once they matured, 'they ran off in four directions, and could only remember the joyful moments at home, which were now beyond their reach; so now they better understood the pain of the two Su brothers' (WANG Shizhen I997b: vol. 3: 21a-b). Thus did the parting with his brothers remind Wang Shizhen of the parting between Su Shi 蘇軾 and Su Zhe 蘇敫.

When Wang Shilu was imprisoned in I664, the poems written by Su Dongpo in Huzhou 湖州 immediately came to Wang Shizhen's mind, and he was unhappy that he could not go to Beijing on behalf of his brother to defend him, as Su Zhe once had done for his brother. Wang Shilu also recorded that Wang Shizhen alluded to Su Dongpo on that occasion (Jiang Yin 200I: II4).

Wang Shizhen's official position in Yangzhou, the respect he gained on the contemporary literary scene, as well as his affinity to $\mathrm{Su}$ Dongpo did not go unnoticed. ${ }^{13}$ A contemporary who wrote an introductory caption to one of his poems regarded the two poets as equal (Yuyang shanren ji qizhong 6: Ib); and Shuokui shangren in a matching poem, changhe shi 唱和詩, pointed out several parallels between $\mathrm{Su}$ Dongpo and Wang Shizhen. They both initiated a school of poetry, both took office in Yangzhou, both befriended a monk: Liaoyuan and Shuokui respectively. The monastery and the stele were dilapidated when Wang Shizhen first came there, so what else would have brought him to such a place, if not the spiritual link with Su Dongpo? Was he not Su Dongpo's reincarnation, after all (Yuyang shanren ji qizhong 6: 8b-9a)? Shuokui composed the poem at the Qingming festival of I666, just after Wang Shizhen had returned to Beijing, leaving behind a new cultural mood.

\section{TRAVELING}

In I645, when Wang Shizhen was twelve years old, the Qing army had bombarded Yangzhou from the north-west, then ransacked the whole town, massacring the inhabitants. The wealth which Yangzhou had enjoyed since the Wanli 萬曆 reign (I573-I6I9) was suddenly destroyed (WANG Zhenzhong 1996: 77). Wang Shizhen took up office in Yangzhou fifteen years later. The social order had been restored by then, but the city was still a long way from being as it would be in the times of Zheng Banqiao, who would sell his paintings to rich salt merchants.

However, because of Yangzhou's location at the intersection of transport routes, and because of the reputation of Wang Shizhen's literary circle, loyalists, men of letters, and officials, high and low, often gathered there. Some were passing through Yangzhou when traveling to Beijing in search of office, some had retired from office and were returning to the South, some had come to sweep their parents' graves, some were simply traveling around. Except for a very few, for instance Zhu Yizun 朱䕨尊, 
who arrived when Wang Shizhen was away in Nanjing, ${ }^{14}$ they all met Wang Shizhen on various occasions (Fig. 7.I).

One visitor was his old friend Wang Wan, who traveled through Yangzhou after being released from the Ministry of Punishment in the autumn of I661. When he arrived he was not considered a habitual visitor, meriting only a routine reception. Wang Shizhen greeted him in front of the city gate and, as we know from the poems they exchanged, Wang Shizhen ordered a feast for numerous guests in his honor (Jiang Yin 200I: 76). On the third day of the feast, Wang Shizhen wanted to donate to his guest two of the ten cranes he kept, but Wang Wan politely declined. It was not until Mao Pijiang and Chen Qinian put pressure on him that he accepted the cranes with pleasure (WANG Wan 1997: vol. 3: 462).

Wang Wan finally returned to his hometown Suzhou, but shortly afterwards, in the spring of the following year, he returned to Beijing to accept a new official post. On his way back, after the Qingming festival, he passed through Yangzhou and briefly stayed. Wang Shizhen, who had to inspect the Huaiyin region, took him along to Shaobo 邵伯 lake for sailing, and then each continued on his way (JIANG Yin 200I: 83-84). This event took place before Wang Shizhen was demoted in response to his handling of the forthcoming trials of loyalists, but in his poems dedicated to Wang Wan his anxiety over his official position was clearly expressed. ${ }^{15}$

Wang Shizhen never neglected his visitors, even when they were not as close as Wang Wan. For example, when Li Jing 李敬, the former vice-minister, shilang 侍郎, whom he knew from Beijing, passed through Yangzhou in 1661, Wang Shizhen paid him a visit on his boat as soon as he arrived (WANG Shizhen 1997a [I691]: vol. 2: 317). In 1662, Wang Shizhen entertained Qiu Xiangsheng 丘象升 at Pingshan tang. Qiu Xiangsheng was Wang Wan's 'schoolmate', he had passed the jinshi examination in the same year as Wang Wan, and was passing through Yangzhou on his way to Qiongzhou 瓊州, where he had been assigned the office of sub-prefect, tongpan 通 判. Fifteen years later, Qiu Xiangsheng still remembered Wang Shizhen's hospitality (JIANG Yin 200I: 77).

\section{LITERARY FRIENDSHIPS}

Wang Shizhen's career proceeded smoothly. But although he was very conscientious during his five years in Yangzhou he did not allow his official duties to limit where he went or whom he met. He never succumbed to the restrictions of tanxiao you hongru, wanglai wu baiding 談笑有鴻儒, 往來無白丁 [talking and joking with scholars, but encountering no commoners]. To the contrary, he often helped poets of lower social standing, even those who lived in poverty. While visiting scenic places, he always invited the literati who lived near Yangzhou to visit him in the city. Some of those he befriended are discussed in the next few paragraphs. 
Ding Yin 丁㑷, an old friend of the poet and scholar Qian Qianyi 錢謙益 (I582I664), was outstanding among the literati without an official post with whom Wang Shizhen kept in contact. When young, Ding Yin had learnt opera singing, and was an accomplished performer of Southern songs, nanqu 南曲. He lived in Nanjing, in the fabled quarter on the bank of the Qinhuai 秦淮 river, and was well acquainted with the culture of pleasure houses. When Wang Shizhen came to Nanjing in I66I, he stayed in Ding Yin's house. Ding Yin guided him through Qinhuai, and the stories from dramas he told became material for Wang Shizhen's 'Various poems about Qinhuai,' Qinhuai zashi 秦淮雜詩 (Sun Yancheng 1992: 18). Ding Yin and Wang Shizhen shared literary interests and Wang's interest in the famous locality fostered their literary ties, too.

Shao Qian 邵潛 had a personality and way of life that was in marked contrast to the elegant and refined Ding Yin, and he is likely to satisfy our expectation of what a commoner was like. A retired official from Tongzhou 通州, he was 'arrogant, and cursed people, so that nobody liked him.' As a fifty-year-old, he took a second wife but 'turned her out, because she despised his poverty and age; his maid was lured away by a rich man, and so he lived alone near the Western gate at Rugao' (WAng Shizhen 1997a [I69I]: vol. 2: 434). Yet this poor and sour scholar, with a peculiar and arrogant character, who could not even keep a wife, gained Wang Shizhen's friendship. In 1665, Wang Shizhen paid him a visit in Rugao. The street was too narrow for a sedan chair to pass, so Wang Shizhen had to get down and walk to the shabby doorway. The house was simple and small, dark inside, but the study was full of woodblocks. Shao Qian went to the market to get some wine, to offer to his distinguished guest, then Wang Shizhen helped him pour the wine, they drank and had an excellent time. When the prefect of Rugao heard about this, he immediately exempted Shao Qian from labour duties (WANG Shizhen I997a [I69I]: vol. 2: 434). Wang Shizhen, who was young and sociable, did not adopt Shao Qian's arrogance and conceit toward others, but they apparently found a mutual empathy, and later Wang Shizhen invited Shao Qian to join the purification ceremony in Mao Pijiang's garden (Sun Yancheng 1992: 14).

Lin Gudu 林古度 (1580-1666) was a famous Ming loyalist poet who had a close relation with Ding Yin. During the Wanli reign, in Beijing, he came to know Wang Shizhen's grandfather, with whom he used to discuss and write poems. In I66I, when Ding Yin showed Wang Shizhen around Nanjing, the eighty-year-old accompanied them, so as to meet the offspring of a former friend. Wang Shizhen showed his poems to Lin Gudu, and was rewarded with a positive appraisal (Yuyang shanren ji qizhong 5: $\mathrm{b}$ ). Although more than half a century separated them in age, they quickly established a sound relationship, because they admired each other's poems. Lin Gudu went to Yangzhou several times to see Wang Shizhen, and took part in the gatherings at the Red Bridge, and at the Pingshan Hall. In I664, Lin Gudu took 
his poems to Yangzhou, poems which had been written over sixty years, since 1604 . Wang Shizhen selected 156 poems in the style of the Six dynasties and of early Tang. When Yangzhou friends heard about this, they were envious. Lin Gudu had lost his sight by the next year, when Wang Shizhen returned to Nanjing, and 'they parted in tears.' Not long afterwards, Lin Gudu died (WANG Shizhen I997a [I69I]: vol. 2: 295). Thanks to Wang Shizhen's critical insight, the work of this aged and forgotten poet won recognition at the very end of his life.

Given Wang Shizhen's position on the literary scene, 'one word of praise from him was more valuable than receiving an imperial robe,' as the saying goes. ${ }^{16}$ The case of a certain Wu Jiaji 吳嘉紀, a commoner from Taizhou 泰州, is a good example. This man lived in seclusion and relative poverty. Accidentally, his poems caught the attention of Zhou Lianggong 周亮工 from the Ministry of Revenue, who had them published. But nobody took notice until I663, when Zhou Lianggong traveled through Yangzhou and presented the book to Wang Shizhen. After reading the poems, Wang Shizhen sent Wu Jiaji a complimentary letter. Wu Jiaji replied, expressing great joy.

Wang Shizhen's contacts with Wu Jiaji and other authors of lower social strata led to the creation of a new kind of literary network in the Yangzhou region. Needless to say, he established and maintained contacts with authors from officialdom, and from the local gentry as well. Still, he did not become very close to Qian Qianyi or Wu Meicun 吳梅村 (Wu Weiye 吳偉業, I609-I672), who were well-established poets, perhaps because of the gap in age; the two nevertheless respected and praised his successes. This was particularly the case with Qian Qianyi, whose poetry not only influenced Wang Shizhen, but whose positive attitude toward him played a key role in the social circles. However, the relation between them developed unevenly. When Wang Shizhen came to Yangzhou, he began to meet several Ming loyalists, but he dreaded Qian Qianyi's reputation for hostility to the Qing regime. At last, induced by Ding Yin, he sent his respects to Qian Qianyi, on the occasion of his eightieth birthday in 166I. That was the beginning of their friendship. Qian Qianyi first wrote the introduction for Yuyang shanren ji 漁洋山人集, and then wrote a poem in old style on a fan, which he asked Ding Yin to present to Wang Shizhen together with a complimentary letter (Jiang Yin 200I: 2-6; SUN Yancheng I992: I9). Because of this praise and approval, whenever anybody subsequently attacked Qian Qianyi, Wang Shizhen defended him. But later on, with Wang Shizhen in office in Beijing, and advancing in his career, he began once more to fear associating with such a prominent Ming loyalist. He set limits to the connection, and became more critical of Qian Qianyi's literary work (JIANG Yin 200I: 7-2I).

Perhaps this was an exception. The fact that Wang Shizhen maintained a close friendship with Mao Pijiang, who was one of 'the four gentlemen of the late Ming,' shows that he was not afraid to befriend loyalists, and could be tolerant of political 
dissent. In I66I, Mao Pijiang came to Yangzhou together with the poet Zhu Kesheng 朱克生, and they visited Wang Shizhen. They drank together in the prefectural house, and composed poems (Jiang Yin 200I: 78). Mao Pijiang thereafter sent Wang Shizhen a present on every duanwu 端午 festival or on Wang Shizhen's birthday (JiANG Yin 200I: 84, 88, I09, II6). In 1665, as we know, Wang Shizhen held a grand purification ceremony in Mao Pijiang's garden. It is apparent that Wang Shizhen was very fond of his host the loyalist.

Wang Shizhen not only befriended famous literati linked to the Ming dynasty, he also extolled the martyrs who had fought against the Qing. For example, he wrote a short biography of Shi Kefa 史可法, the loyal general who had sacrificed his life for the Ming (WANG Shizhen 1997b: 139). Later, in about 1685, Wang Shizhen wrote about the life of a certain hermit Zhang Linzhe 張霖者 from Xincheng 新 城 (now Ji'nan 濟南), who had become well known in his home town as a poet. After the fall of the Ming dynasty, Zhang Linzhe turned his back on officialdom and lived with his family in the countryside, composing poetry and enjoying wine. His transgression of social norms must have made an impact on Wang Shizhen. In his biography of Zhang Linzhe, Wang Shizhen also disclosed Zhang's anti-Qing sentiments (WANG Shizhen 1997b: 147).

The two examples above show that Wang Shizhen's political stand was liberal. He was born in the Ming, but was only twelve years old when the dynasty fell. His adult life and official career belong to the Qing dynasty. He was a loyal servant of the Qing dynasty, yet he wrote about Ming loyalists, and maintained cordial relations with several important Ming officials, as long as it did not create problems for him. To what extent this was an expression of his longing for late Ming conditions and culture needs to be further scrutinized. For the time being, it needs to be stressed that the literati who lived through political upheaval or transformation, including Wang Shizhen, gained an enriching experience from that difficult period.

Wang Shizhen was aware of the depth of Ming loyalist feeling. After all, the whole family of his uncle Wang Yuyun 王與允 had hanged themselves in 1644, in protest at the Qing enthronement. Moreover, in I657 Wang Shizhen composed 'Autumn willows,' mentioned already, which are sometimes interpreted as a lament for the Ming (YAN Dichang 1998: 420-23). But there is no clear evidence to prove that Wang Shizhen, who was a child when the Ming dynasty fell, struggled over his recognition of the Qing conquest, as did the loyalists he later befriended. He was not afraid to meet them but he understood the 'rules' for an official like himself: at literary gatherings he discussed their poetry, and quoted well-known lines, but avoided poems with clear political overtones (ZHANG Yusheng 1996: 52).

It is obvious that Wang Shizhen kept away from sensitive political issues. He never compromised his standing as an official; he moved between his two distinct worlds. One world represented the friendly network made up of his peers from the 
metropolitan examinations, many of whom became officials in various regions, and of other bureaucrats serving the new dynasty. His other world consisted of some well-known literati and commoners who would not serve the Qing, but whom he nevertheless befriended. The fact that their pessimistic, desolate poems were so different from his did not impede mutual intercourse. It should be understood that Wang Shizhen discussed with them their origin, background, and political opinion; he dealt with them tactfully. It is therefore a distortion to maintain that his poetic and social contacts were based on schemes to protect his political power (ZHANG Yusheng 1996: 52-53; YAN Dichang, 1998: 430).

Being a leading figure of early Qing poetry as well as the head of the Guangling ci group, Wang Shizhen naturally attracted literati who were interested in drama, or gained recognition as playwrights. Li Yu 李漁, You Tong and others came to Yangzhou and paid their respects (JIANG Yin 200I: 97, I3I). Most interesting, however, were his contacts with Chen Qinian, the famous composer of $c i$ 詞. Chen Qinian's father Chen Zhenhui 陳貞慧 was one of 'the four gentlemen of the late Ming,' as was Mao Pijiang. Because of that old relationship, Mao Pijiang introduced, in Shuihui garden, his beloved male actor Xu Ziyun 徐紫雲 to Chen Qinian, and the two fell ardently in love. When Mao Pijiang learned about their love, he unselfishly presented Chen Qinian with Xu Ziyun, and received Chen Qinian's 'Hundred Poems about Plum Flower,' Yibaishou yong meihua jueju一百首詠梅絕句 in exchange. The love of Chen Qinian and Xu Ziyun was a well-publicized romantic affairs in the cultural circles throughout Jiangnan. More than ten years later, Xu Ziyun abandoned Chen Qinian, and married and raised a family. He died shortly after (YuAn Shufei 2002: 29I-93). Their relationship, from beginning to end, was retold in the poems of literati, and later collected into two slim collections: Jiuqing tu yong 九青圖詠 ${ }^{17}$ and Yunlang $x i a o s h i$ 雲郎小史 which were circulated at that time.

As has been said, Mao Pijiang presented Chen Qinian with the actor he himself adored, in exchange for Chen's 'Hundred Poems'. Other literati and officials constantly praised and played up Chen Qinian's amorous affairs with actors and singsong-boys, just to keep up good relations with the famous poet (YUAN Shufei 2002: 293). In this respect, Wang Shizhen was no exception. Chen Qinian became Wang Shizhen's good friend a year or two after the latter came to Yangzhou (Jiang Yin 200I: 53). Chen Qinian kept moving between Yangzhou, Rugao and Yangxian 陽 羡. He helped Mao Pijiang with the party given on the duanwu festival, he congratulated Wang Shizhen on his birthday, and he also composed poems at the gathering of the Yechun 冶春 poetry club, founded by Wang Shizhen. The poems Chen Qinian wrote on that occasion disclose both his respect and his affection for Wang Shizhen (Sun Yancheng 1992: 23).

Not only did Wang Shizhen know of the homosexual affair between Chen Qinian and Xu Ziyun (Sun Yancheng 1992: 25), it can also be noted that the sentiments 
between Wang Shizhen and Chen Qinian were stronger and deeper than Chen Qinian's relations with other literati. The language they used to describe their mutual feelings was unusually expressive. In a poem, Chen Qinian recalled his presence at Wang Shizhen's twenty-ninth birthday party in 1662; another poem by Wang Shizhen discloses his yearning for Chen Qinian in the winter of that year (MAO Xiang 1997 [1673]: vol. 4: 170, 172). On the next visit of Chen Qinian to Yangzhou, in summer 1664, they met every day (ibid.: 173). Wang Shizhen rarely displayed such a strong attachment to his other acquaintances of that time.

After the purification ceremony at the Shuihui garden in 1665, Wang Shizhen's five-year term in Yangzhou ended and he returned to the North. Mao Pijiang, Chen Qinian and others bade him a ceremonial farewell, and composed poems for the occasion. Although Chen Qinian's poem is not devoid of clichés, strong feeling and true sadness are evident (MAO Xiang 1997 [1673]: vol. 4: I7I). Obviously the two were in love, and together passed some intense times in Yangzhou. Wang Shizhen did not, it is true, satisfy his friend in the manner Chen Qinian would have hoped for, but that was not an obstacle to their attachment. ${ }^{18}$ After all, it was more natural for Wang Shizhen to develop an attachment to Chen Qinian, who was only ten years older, than to Mao Pijiang, who belonged to his father's generation, or to septuagenarians like Qian Qianyi, Wu Meicun, Shao Qian or Lin Gudu.

\section{CONCLUSION}

Regarded as an official Wang Shizhen comes across as a strong, just and rigorous man. But in his private life, we find a romantic poet. He loved poetry and singing, parties and sight-seeing, and through those activities overcame the boundaries imposed by his official duties. He disregarded differences in dynastic allegiance, social strata, personal age, place of birth, or official rank, and established a dense social network in Yangzhou. Yangzhou owed to Wang Shizhen the revival of its reputation as a city of cultural significance, as writings by scholars of the Qianlong (I736-I795) and Jiaqing (1796-I820) eras attest.

Wang Shizhen was talented and rich, well known throughout the empire, the most celebrated poet of his day. In addition, he bridged the worlds of the Ming and Qing literati. To use E. M. Forster's phrase, he was a typical 'round' character, one whose character was capable of surprise, contradiction, and change. ${ }^{19}$ We cannot reconstruct his personal character on the basis of his poetry and official actions alone; that would produce a 'flat characterization.' But with the details of his everyday life to hand, I have aimed to provide a fresh perspective on both Wang Shizhen and on the elite culture of the period (as I have also done in analogous studies of Mao Pijiang, Yuan Mei, and Zheng Banqiao). In the cultural environment of those days, a young and enthusiastic poet was, on the one hand, able to act as a Confucian 
scholar-official, but on the other hand, through his sensual poetry, cross boundaries and create a life - a capability which gained the admiration of his contemporaries.

When approaching works written by a person with a 'round' character, the analyses and methods provided by traditional historiography, i.e. by intellectual, political, or literary history, do not suffice. These methods make the gentry literati flat, a mere compound of the so-called 'literati culture.' But if we study the person's way of life, and are able to uncover subtle private details, we gain a more complex understanding of the cultural context. I have tried to describe the details of the life of Wang Shizhen in order to reconstruct the historicity of the culture to which he belonged, thereby hopefully shedding new light on this important field of research.

\section{ACKNOWLEGEMENTS}

This article is an abbreviated English rendition of Li Xiaoti 2005a. I am deeply grateful to Lucie B. Olivová, with Malcolm McKinnon, for turning the original article into its present shape in English.

\section{NOTES}

1 Guangling ci, a group of poets from Suzhou, Wuxi, and Changzhou, gathered and unified around Wang Shizhen.

2 See Wang Shizhen 1997a [I69I]: 528; and Sun Yancheng 1992: 15-I6.

3 His grandfather Wang Xiangjin 王象晉 served there as a military official in the Chongzhen 崇禎 reign (I628-I644). Sun Yancheng I992: 4, I6.

4 Zheng Chenggong (1624-1662), also known in the West as Koxinga, fought for the restoration of the Ming dynasty. In 1659, he and Zhang Huangyan 張煌言 invaded Jiangsu province, but were defeated by Nanjing and retreated to Xiamen. The next year, Zheng Chenggong withdrew to Taiwan.

5 Mao Pijiang, or Mao Xiang 冒襄 (I6II-I693), poet and scholar from Jiangsu, who declined any official post under the Qing.

6 In Wang Shilu's words, 'His spirit was penetrating; he was like a jade tree, and he talked brilliantly' (Sun Yancheng 1992: 23).

7 See note 4.

8 The number of participants at the xiuxi ceremony, given in 1757 at the Red Bridge by the salt commissioner Lu Jianzeng 盧見曾, was more than 7000. Li Dou I960 [I795]: 229-30.

9 Wang Shizhen included the twenty poems in Yuyang shiji 漁洋詩集 (WANG Shizhen 1997c). For the collection Yuyang shanren jinghua lu, compiled around I700, which became his most popular collection, he only selected twelve. They are now habitually known as the Yechun juejue shi'er shou 冶春絕句十二首.

10 Wang Shizhen left a record in his 'Trip to the Red Bridge,' Hongqiao youji 紅橋遊記, included in Sun Yancheng 1992: 21 . 
11 Specifically, Su Dongpo saw off a friend called Li Xiaochuan 李孝傳, who departed on official duty for Lingnan 嶺南. The poem is titled Shugang Chanzhisi changhe shi 蜀崗禪智寺唱和詩, and collected in Yuyang shanren ji qizhong 6:Ia.

12 The Chan 禪 master Foyin Liaoyuan 佛印了元 (I032-IO98), of the Yunmen 雲門 school, was a friend and spiritual mentor of Su Dongpo. WeIDNer 200I: 66 n58 reads: 'He promoted the shuilu 水陸 cult among nationally prominent clergy, officials and merchants who visited merchants who visited Jinshan 金山 during his tenure as an abbot there.' For Su Dongpo's connections with Liaoyuan, see Grant I994: IOI-03, 220-2I nI4.

13 Wang Shizhen's poetry written in Yangzhou is rather based on Tang examples, but in his middle years, he 'moves over from the three Tang poets and begins to create after the two Song poets' (Yan Dichang 1998: 449-450).

14 In the second half of the sixth month of I664 (Jiang Yin 200I: II3). Zhu Yizun (I629-I709) is considered one of the best writers of $c i$ 詞 in early Qing.

15 See the two poems titled 'Seeing off Tiaowen on his way to the capital,' Song Tiaowen zhi Jing er shou 送苕文之京二首 (WANG Shizhen I997c: 652).

16 Yi zi zhibao, rong yu huakun一字之糔, 榮於華衰.

17 Jiuqing was Xu Ziyun's sobriquet.

18 See Chen Qinian's poem 'Parting with Wang Ruanting 阮亭’ (CHen Weisong 1965, vol. 2: 254-255).

19 I am using the E. M. Foster's theory and terms, from Aspects of the Novel, as published in Chinese translation, see Fusite I973: 92-94. 


\section{8}

\section{Early Qing Yangzhou}

in Shi Chengjin's

\section{Vernacular Vignettes}

\section{Roland Altenburger}

$\mathrm{T}$ his chapter introduces the narrative oeuvre of a Yangzhou writer of the early Qing period, named Shi Chengjin 石成金 (or Shi Tianji 天基), who has been scarcely studied so far and therefore is hardly known even to literary historians of China. Shi's stories are of considerable interest, first of all, to the research of Yangzhou's cultural history, for this author realized a rare project in Chinese literary history: a sizeable body of fifty-two short stories or vignettes, all of which are focused on his home town, in one way or another, as the project's general title Yangzhou jinshi 揚州近事 [Recent Events in Yangzhou] indicates. The aim will be to discuss the significance of this local as well as temporal circumscription, and to explore the nature of these texts and to assess their value as a source on the social and cultural history of the city of Yangzhou from an angle different from that of the standard sources.

Shi Chengjin, while quite unknown to literary historians nowadays, nevertheless has made a modest name as a prolific author of morality tracts and instructions on how to attain a happier and longer life. An important matter of concern of this study will be to understand how the vignettes were embedded in the author's larger textual production. While it will be argued that, in a certain sense, the vignettes were indeed a consistent part of this author's life-long project of moral didactics, it is equally important, however, to note that there is sufficient evidence to show that Shi conceived his stories also as a literary project, and these short narrative texts deserve to be compared to the classic vernacular story, the aesthetics of which the author appears to have consciously assimilated to some degree. But rather than devaluating Shi's vernacular vignettes as deficient later examples of the genre of the short story, huaben 話本, they shall be appreciated here for their hybrid character. Shi Chengjin was neither a literati author, nor a storyteller in the marketplace. As a writer who on the one hand was lacking the credentials of either official position or examination degree, but who on the other hand nevertheless shared the ethos and life-style of the literati class, he may be regarded as an important representative of the hitherto poorly understood 'middlebrow' zone of 
writing, publishing and reading. The notion of cultural hybridization can serve as a key to the understanding of this author's in-between position, both socially and culturally, and of his highly unconventional textual production, which was written mostly in the vernacular and included a wide range of popular types of text clearly geared to a sub-elite readership. The study of this author and his vernacular vignettes offers insights into this understudied field of middlebrow textual culture in the late imperial period (cf. Hsiung Ping-chen 1999).

\section{SHI CHENGJIN: THE MAN AND HIS WRITINGS}

Shi Chengjin (b. 1660, studio-name Xingzhai 惺齊, sobriquets Juedaoren 覺道人 et al.) was a native of Yangzhou's Jiangdu 江都 district and lived in this city for most of his life, throughout much of the early Qing period. His course of life has

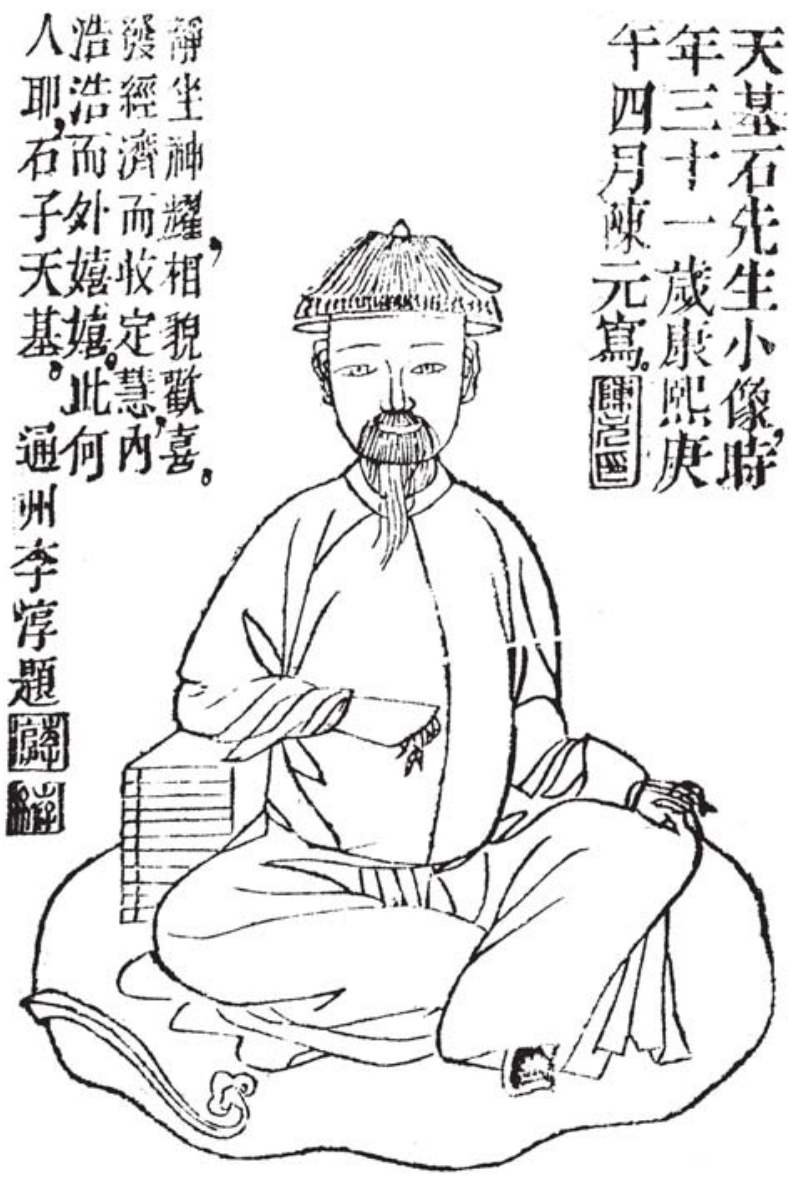

Figure 8.1 Idealized portrait of Shi Chengjin, from Chuan jia bao (1739 edition). 
scarcely been documented. Even the few biographical sketches that we have are full of gaps and leave many questions open. ${ }^{1}$ Based on the available materials, it may be concluded that Shi Chengjin was born in 1660 and died sometime after 1739. As a young student he was known for his precociousness, and he remained an active scholar throughout his life. However, he apparently never gained any degree in the civil service examinations, and probably never even participated in them. ${ }^{2}$ Therefore it is hardly surprising that neither the local gazetteers nor any other local-historical document include any biographical entry on him. The Shi family owned several plots of land outside the city of Yangzhou. Like his father and grandfather before him, Shi Chengjin supported his studying through income from agricultural work done by tenants on their land, termed as gengdu 耕讀 [tilling and studying]. Shi himself is likely to have been a city resident, at least for the larger part of his life, and he seems to have come into touch with the harsher realities of peasants' lives only during his summer visits to the countryside (e.g., TTL 8.42).

Despite his lack of examination degrees and hence also of official appointments, Shi Chengjin definitely considered himself a member of the lower gentry. The only portrait of him that we have depicts him at the age of thirty years as a private scholar wearing an official's cap (see Fig. 8.I). This idealized representation may have included a strong element of self-fancying. Nevertheless, he appears to have been on good terms with several administrative officials serving in Yangzhou as well as with members of the local elite. At the celebration of his seventieth birthday, several representatives of the local elite as well as officials paid their tribute, because he enjoyed a certain local fame and was well respected for both his deeds and his writings. He was noted as a model of filial piety and lauded for his acts of charity. As for his writings, for decades he was a prolific author in a stunning variety of genres, including scholarly studies on the Confucian canon, commentaries on Buddhist sutras, practical guides to essay writing, collections of proverbs, songs and antithetical couplets, and numerous guides to ethical behaviour for all walks of life, inside as well as outside the home, for merchants as well as officials. ${ }^{3}$ The collection of jokes, titled Xiao de hao 笑得好 [Achieving Goodness Through Laughing; or, Having a Good Laugh] (mentioned in YHX 19.89) has perhaps become his bestknown work. This book, which ranks among the outstanding collections of jokes (YIN Kuiyou and Jin Yong 200I: 319-320), indicates that Shi Chengjin was not the stern moralist we might expect, but rather a merry person who loved laughing.

Already during his lifetime selections from his writings were compiled into various 'collected works' editions, ${ }^{4}$ published under the general title Chuan jia bao 傳 家寶 [Family Treasure]. 5 The title, the miscellaneous contents, and the pragmatic approach of most of the texts included suggest that the author conceived it as a reference book for a general readership, somewhat similar to a 'household encyclopaedia', riyong leishu 日用類書. This compilation indeed includes some practically-oriented 
items such as a 'Manual of Many Abilities' ('Duo neng ji' 多能集, $C J B Q$ I: I27-I45), which offers guidance for all kinds of everyday techniques, whereas a major number of his texts clearly have an ethical-didactic, edifying, even proselytizing tendency. Therefore, from a different angle, Chuan jia bao has been considered a 'morality book', shanshu 善書 (You Zi'an 2005: I3I-I42; Lufrano 1997: 40, I38, I48). While none of its items is concerned with moral accounting ('ledgers of merit and demerit'), a lot of them convey simple messages concerning behaviour that would be conducive to social harmony, such as 'don't quarrel!', or 'accept your lot!'.

Perhaps the most striking feature of Shi Chengjin's textual production is its language register, for the author wrote the large majority of his texts in the vernacular, and only a minor number in a simple 'semi-classical' style. Therefore, the vernacular stories that were at least partly included also in Chuan jia bao did not stick out as exceptional in terms of language. In the 'Author's Preface' to Chuan jia bao, Shi Chengjin argued for his unconventional choice of the vernacular by the modernsounding argument that, after all, the vast majority of the population, the 'common man', changren 常人, was illiterate, or semiliterate at best, therefore, it would be useless to address him in a profound classical style (CJBQ I: 2). This indicates that the target readership Shi Chengjin had in mind was less the educated elite, but the subelite. This authorial attitude reflected the self-positioning of a member of the lower stratum of the local elite who tended to define his social status and function based on his superiority of education as compared to the common folk, toward whom he could assume the role of moral instructor and adviser in everyday matters. Thus, Shi Chengjin became a mediator, even a 'translator', of values and concerns between the elite and the common folk. Although he himself had never served on any official post, he also gave bold advice to officials, particularly to newcomers in office, as well as to the local gentry, from the point of view of the local common folk. ${ }^{6}$ Siding with the common people, he did not refrain from castigating the misbehaviour of those in powerful positions.

Shi Chengjin wrote his own preface to Chuan jia bao, dated 1739, for a new edition of this compilation. ${ }^{7}$ Another preface to probably an earlier edition of Chuan jia bao is dated as early as 1707 and signed by Zuo Bifan 左必蕃 (juren I68I), who served as Prefect of Yangzhou in 1702-1707. The I739 edition appears to have been the most comprehensive one, for it included 'I2O items old and new' in 32 juan ['scrolls' or sections of a book]. It also featured a list of unprinted works by the same author, amounting to over 300 additional juan, which attests to the stunning productivity of this author. Chuan jia bao became Shi Chengjin's true legacy to posterity. The I739 edition was carved and printed by his two sons, Shi Shennian 石莘年 and Shi Songnian 石嵩年, assisted by two grandsons, in the Shi family's own printing workshop, which specialized in the publication of the patriarch's profuse textual production (WANG Cheng 2003: I26). It is likely that, to the sons and grandsons of 
Shi Chengjin, the carving and printing of the patriarch's legacy meant more than just an act of filial piety, but rather the internalization of the patriarch's numerous lessons. Shi Chengjin himself claimed that his writings were being 'circulated all over the empire', liuchuan tianxia 流傳天下 (YHX 27.130). Based on this claim, which was echoed in several prefaces and biographical sketches, some modern scholars consider him an influential writer of his time (Jiangsu etc. I990: 474; XıAo Xiangkai and ZHANG Hong 1994: 245). Editions of Chuan jia bao appear to have gained a rather wide distribution, particularly during the nineteenth century. ${ }^{8}$ In fact, the compilation is being reissued even nowadays: since the I990s, at least five new editions have been published in Mainland China alone.

\section{SHI CHENGJIN AS AN AUTHOR OF VERNACULAR VIGNETTES}

Shi Chengjin was also the author of a set of vernacular vignettes comprising a body of fifty-two individual items. ${ }^{9}$ They were originally published in two separate volumes. The main collection, published in I726, titled Yuhua xiang 雨花香 [Rain-Flower Scent] (Fig. 8.2), comprised forty items, and a supplementary volume, by the title Tongtian le 通天樂 [Heaven-Reaching Joy], with another twelve items, followed in I729. Shi's sons were also responsible for the printing of the earliest known editions of these stories. ${ }^{10}$ These have been dated 1726, based on the preface by Yuan Zaixi 袁載錫, Shi Chengjin's brother-in-law, who then served as an Instructor at the Confucian school of Jiangdu district (YHX: I75). The 1739 edition of Chuan jia bao included a preface to Yuhua xiang by the author himself, which was also dated $1726 .{ }^{11}$ The author's preface to Tongtian le, however, is dated $1729,{ }^{12}$ supporting the assumption that this second volume was conceived as a later supplement to Yuhua xiang. ${ }^{13}$ The titles of the earliest known editions of both story collections carry the term xinke 新刻 [newly carved], which leaves open the possibility of earlier printings.

Seven of the forty stories in Yuhua xiang include an appendix with either a moral tract or some other piece of edifying writing. In some cases, though, the appended texts seem hardly related to the preceding stories and might have been chosen at random from the author's varied repertoire. It would seem likely that the appendices were not conceived as an integral part of the collection, but were later additions to a revised edition working from modified printing blocks. The appendices to three Yuhua xiang stories hold dating clues that are clearly later than $1726,{ }^{14}$ whereas the latest year mentioned in the stories themselves is 1725 (YHX 37.159). In fact, the earliest known edition of Yuhua xiang shows obvious marks of excisions and modifications to the printing blocks, such as emended pagination. In the supplement collection Tongtian le, quite differently, each of the twelve tales has an appendix, and evidently these texts were written especially as commentaries to the stories. Parts, though not 
the complete sets, of both story collections were also included in the 1739 edition of Chuan jia bao. ${ }^{15}$ It is notable that the textual nature of the stories is not radically different from that of other parts of the compilation (cf. DAI Jian 2006: 39), since the stories also include moral preaching (particularly in the appendices), while the moral tracts occasionally also include exemplifying story material (e.g., CJBQ 2: 5I, 3: 15).

In his preface to Yubua xiang, the author explained that, by the title, he meant to allude to the Buddhist Master Yunguang (Yunguang Fashi 雲光法師, who lived at the time of the reign of emperor Wu 武 of the Liang dynasty, AD 502-549), who erected an altar on a hill south of the city of Jiangning 江寧 (later Nanjing), where he preached and explained the sutras to a large audience. Heaven responded by miraculously bestowing 'rain-flowers', yuhua 雨花 (i.e. colourful pebbles) that gave up an 'otherworldly fragrance', yixiang 異香. The place was henceforth called Yuhuatan 雨花壇, or Yuhuatai 雨花臺 [Rain-Flower Altar, or Terrace]. ${ }^{16}$ The author adopted the allusive title Yuhua xiang for his collection of stories in order to suggest a slight similarity between his book and Master Yunguang's preaching. The title of the supplement volume, Tongtian le, at a first glance would seem like a close parallel to Yuhua xiang, for it suggests itself as an implied reference to Tongtiantai 通天 臺 [The Terrace of Communicating with Heaven], a ritual platform established by emperor Wu 武 of the Han dynasty (r. I4I-87 BC) on Ganquan 甘泉 mountain, near the capital Chang'an. However, the author, in his preface to this volume, pointed out that, by the title, he meant to express his belief in men's ability 'to attain heavenly joy anytime and anyplace' (SHI Chengjin I990c: 2), hence my tentative rendition as 'Heaven-Reaching Joy.' ${ }^{17}$

According to his preface to Yuhua xiang, Shi Chengjin hoped that his stories would alert and edify, in order 'to awaken people's confused consciousness and to restore their original goodness' (YHX: 176). He did not refer to them as 'stories', even less as 'fiction', but as 'records', jilu 紀錄, about 'facts', shishi 實事 (YHX: I76). Moreover, his moral tracts include repeated warnings against reading 'miscellaneous divertive writings', xianza 閑雜, and 'fiction', xiaoshuo 小說 (CJBQ I: 66, 69). Apparently, Shi Chengjin himself did not consider his stories as belonging to either category. He had his personal name or his style (or both) printed as the statement of authorship on most of his writings, most notably on his two volumes of vernacular stories. $\mathrm{He}$ was perhaps the first literati author in Chinese literary history to claim credit, by his personal name, for the authorship of a volume of vernacular narrative. ${ }^{18}$ At first, this might be considered an indicator of the rising status of vernacular narrative at the time, but above all, it 'says much about the nature of his fiction', as Patrick Hanan pointed out (198I: 209). It remains more than doubtful that the author himself conceived his stories as fictional narrative, even though, as I will argue in a seeming paradox, it is more than likely that he based them on the model of the vernacular story in the tradition of Feng Menglong 馮夢龍 (1574-1646), Ling Mengchu 凌濛初 
(I580-I644) and Li Yu 李漁 (I6II-I680). The vernacular story has been defined as 'an undivided piece of written, fictional narrative in a colloquial (or vulgarized) style' (Nienhauser i986: 443).

Chinese literary historians, starting with Hu Shiying 胡士瑩 (I9OI-I979) (I980: 623), have been quick to identify Shi Chengjin's tales as belonging to the genre of the vernacular story that they termed as nibuaben 擬話本 [imitative storyteller's script], a problematic label, which however shall not be discussed here any further. Feng Menglong's three collections, starting with Gujin xiaoshuo 古今小說 [Stories Old and New] (I620), as well as Ling Mengchu's two volumes of vernacular stories all comprised the quasi-canonical number of forty items. The fact that Yuhua xiang, too, was edited to the even number of forty items already signals that its author was well aware of the genre tradition, although he refrained from claiming any relationship to it. ${ }^{19}$

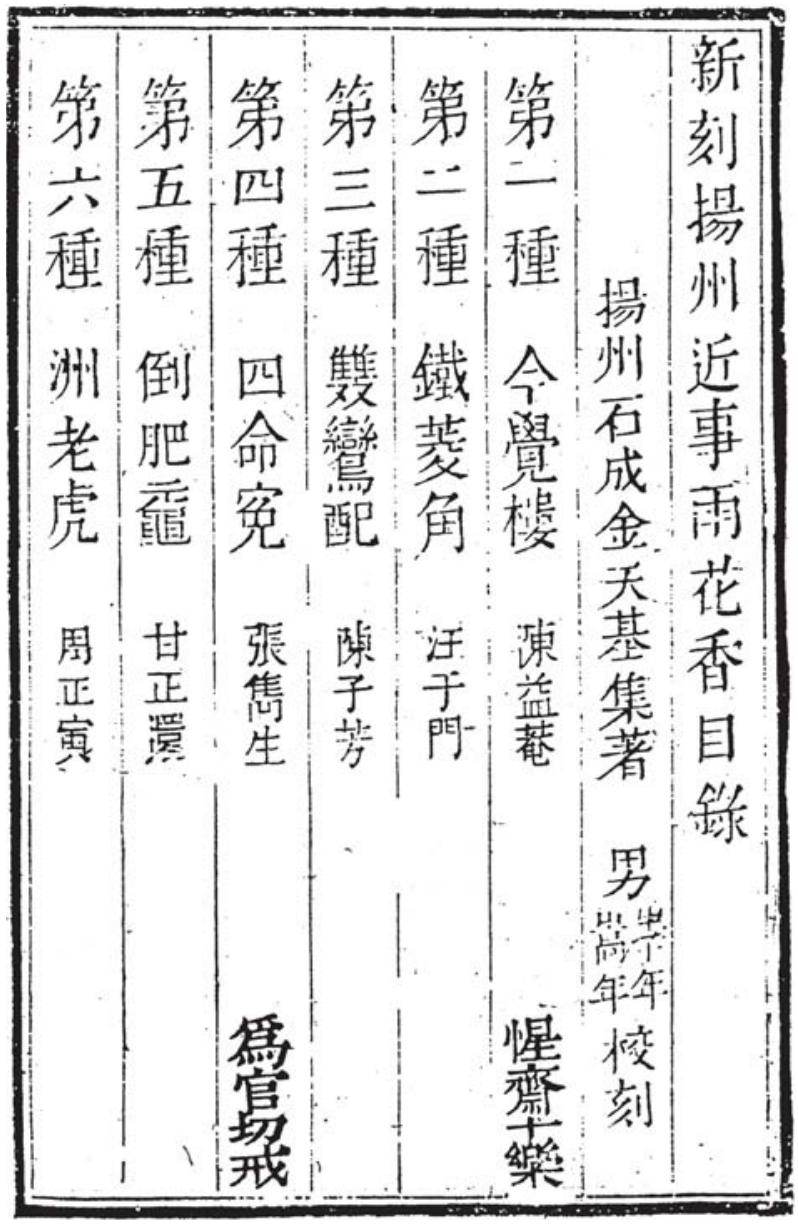

Figure 8.2 Table of contents for Yuhua xiang (1726 edition). 
The number of twelve stories in the supplementary volume Tongtian le, too, seems to follow the model of Li Yu's collection Shi'er lou 十二樓 [Twelve Storey-Buildings] (1658). The 'allegorical' three-character titles Shi chose for his two collections, as well as for each item, is yet another feature reminiscent of Shi'er lou. ${ }^{20}$

Nevertheless, several other features of Shi's stories put them at an obvious distance from the genre of the vernacular short story. Most notably, the 'storyteller's manner' that is generally considered a hallmark of the genre (YANG Shuhui i998: 42-44) is not imitated in his stories, and the author's narrative rhetoric does not employ any storyteller's formulae such as hua shuo 話說 [The story goes that ... .] or any introductory poems, and the stories betray hardly any trace of the craft of oral storytelling. ${ }^{21}$ The length of the individual tales in the two collections is very unequal, but even the longest item is considerably shorter than the average vernacular story. Therefore I choose to refer to them as vernacular short stories (or vignettes). The table of contents for Yuhua xiang also indicates the protagonists' names. Each item has an introductory section, which highlights in advance the main moral issues of the subsequent story. However, this introductory passage may not be considered an actual ruhua 入話 [introductory tale] as is typical for the classic vernacular story, for Shi's introductions include hardly any narration. ${ }^{22}$ Each 'item', zhong 種, in Shi's collections regularly contains one story, but two items ( $\mathrm{YHX}_{7}$ and 23 ) have two stories, and one ( $Y H X \mathrm{I} 8)$ even comprises four short accounts.

As a characteristic structural feature of the collections of vernacular stories by the three masters, the pieces are often arranged in contrasting pairs, thus suggesting a 'parallelism' that gently pushes the reader to read the paired stories antithetically (YANG Shuhui 1998: 79). Shi Chengjin apparently applied this device quite consistently throughout his two collections. As a rule, we find a tertium comparationis for each pair of tales. For instance, the first and the second story in Yubua xiang are about a hermit who is completely detached from worldly cravings ( $Y H X \mathrm{I})$ versus a wealthy salt merchant who is morbidly obsessed with the idea of protecting his wealth $\left(Y H X_{2}\right)$. Thus, the juxtaposition of the two stories signals the contrasting of two contrary attitudes to material wealth. In some cases, the juxtaposition of paired stories is additionally indicated by an obvious parallelism in the titles, such as in ' $\mathrm{Zi}$ hai zi' 自害自 [Harming Oneself] $\left(Y H X_{7}\right)$ and 'Ren tai ren' 人抬人 [Promoting Each Other] (YHX 8). Occasionally, paired stories are further linked by an overlap also of the protagonists, such as in the second story of Yubua xiang $\left(Y H_{2}\right.$ 2), where the hermit-painter from the first story $\left(Y H X_{\mathrm{I}}\right)$ intervenes in order to 'awaken' the miser. In some other cases, too, there are explicit cross-references between paired stories. ${ }^{23}$ Cross-references are also employed to link disparate stories in order to remind the reader of textual reiterations that usually might escape his attention. ${ }^{24}$

The author has some characters appear in more than one story. Two particularly meritorious local officials, Prefect Shi Shilun 施世綸 (YHX $38, T T L$ Io) and Magistrate 
Xiong Kaichu 熊開楚 $(Y H X 8,38)$, are honoured by more than one appearance. Some religious characters also appear in more than one tale: Hu Si Guniang 胡四姑娘, a lay Buddhist turned female saint $(Y H X$ 35, 36), and Jubo Shi E渤師 [Master Vast Sea] from Tianning si 天寧寺 [Heavenly Peace Monastery] $(Y H X 28,40)$. The structurally most significant reappearance of a character, though, is that of Lai Heshang 懶和尚 [Monk Indolence], a monk from Xilai an 西來庵 [Western Coming Temple] who only cares about praying to Buddha. He has a first appearance as a side character visiting the hermit-painter in the first story of Yuhua xiang (YHX I.3-4) and reappears, now an eminent monk, as the protagonist in the last story of Tongtian le (TTL I2). Thus, this character discreetly brackets the entire cycle of stories.

In one tale, the narrator at first frankly admits that the story he recounts actually was a 'legend', qiwen 奇聞, that had been 'passed around', hongchuan 鬥傳, in the city, but then restores his credibility by the claim that he himself had been an eyewitness to the event ( $Y H X$ I4.70-7I). At two occasions, the author-narrator remembers that he had been among the crowd watching a delinquent being paraded through the streets on the way to execution (YHX 24.II4, 38.162). ${ }^{25}$ Despite the author's occasional claims to the status of an eyewitness, it is a gross overstatement to say that personal experience was Shi Chengjin's primary or even only source (cf. DAI Bufan I980: I88). Local lore and hearsay must have provided for much of Shi Chengjin's story material.

The various structural devices support the idea that Shi Chengjin's collections of vernacular vignettes were definitely more than careless compilations of local anecdotes and hearsay. Both the thoughtful arrangement of the items as well as the densely woven net of intra-textual references are evident signs of conscious artifice, and hence also of fictionalization. If the authorial narrator nevertheless repeatedly defended the nature of his stories as factual and non-fictional (YHX I2.64, 29.138), he sought to prevent his readers from believing that he had made things up, and thus to save the didactic lessons in the text. However, it is obvious that Shi Chengjin, like any other storywriter, submitted his story material to certain procedures of fictionalization. This process may be tentatively reconstructed for one story $\left(Y H X{ }_{27}\right)$ about a character Juedaoren 覺道人 [Man Awakened to the Way]. While sightseeing at a temple on Huqiu shan 虎丘山 [Tiger Hill], near the city of Suzhou, he manages to obtain a personal communication via spirit-writing on the planchette, $j i$ 乩, from the Daoist saint Chunyangzi 純陽子 (i.e. Lü Dongbin 呂洞賓). ${ }^{26}$ In Chuan jia bao we find a corresponding entry that reveals the 'autobiographical' basis of this story (SHI Chengjin 2002, 2: 459-460). The transformation from personal account to vernacular fiction was accomplished in part by switching from the first to the third person and to a conventional Daoist persona, whose description actually permitted the author to include a self-portrait in disguise ( $Y H X$ 27.126). Whatever the actual motivation for this revision may have been, it reminds us of the basically fictional nature of these stories, despite the author's recurrent protestations to the contrary. 
Generally speaking, the level of narrative art in Shi Chengjin's stories is rather modest. Some items even have hardly any narration, but instead emphasize characterization and description (e.g., $Y H X$ I). Some critics (e.g., JIA Jia 2003) have pointed out the general weaknesses with regard to narrative development and complexity of plot as the most serious flaw of Shi's stories. The third item in Yuhua xiang $\left(Y H_{3}\right)$ stands out as the most ambitious individual tale (perhaps besides $Y H X_{4}$ ) in Shi's two collections, but for this story we find an earlier version by another author. ${ }^{27}$ Due to one passage that corresponds almost literally, a direct source relationship would seem very likely (XIAO Xiangkai and Zhang Hong 1994: 250). As for a different example, the ninth item in Yubua xiang (YHX 9 ) is on the same subject matter as the introductory story to chapter 33 in the collection Erke paian jingqi 二刻拍案驚 奇 [Slapping the Table in Amazement, Second Collection] (1632) by Ling Mengchu (Ling Mengchu I960 [1632]: 33.482-484), an episode about Preceptor of State Yao Guangxiao 姚廣孝 (I335-I4I8; GoodRICH and FANG Chaoying 1976: I56I-I565). However, in this case, there is no evidence whatsoever for any direct textual relationship between the two stories.

Some critics have compared Shi Chengjin's vernacular stories very unfavourably to those of the previous masters and have considered it representative for the huaben genre's 'first stage of decline' (XIAO Xinqiao and Liv Fuyuan 2003: 426-427; cf. Hu Shiying 1980: 398). While it is beyond discussion that Shi's texts are no match to the predecessors' in terms of narrative art, it should be taken into due regard that this set of fifty-two stories, while indeed sharing some typical features of the genre, nevertheless exhibit a very distinct format and a conception of their own. Therefore we should not forcefully assimilate it to the genre tradition of the vernacular story, but rather consider it a hybrid side-branch to it, related but at the same time significantly distanced from it.

\section{EARLY QING YANGZHOU IN SHI CHENGJIN'S STORIES}

The phrase Recent Events in Yangzhou in the two collections' full titles indicates that the stories were conceived as some sort of chronicle of the recent past with a regional focus on Yangzhou. The spatial circumscription was actually meant to refer to Yangzhou Prefecture rather than the city as such, since several stories are set in villages and market-towns far outside the city. In some cases, the local linkage to Yangzhou is even looser, as the protagonists merely hail from Yangzhou, whereas the actual events take place elsewhere (e.g., YHX 6, 9, I2). Despite this explicit regional focus, Yuhua xiang and Tongtian le cannot be considered truly 'regionalist' collections of stories, for they fail to, or rather, were never meant to, convey any full sense of the city of Yangzhou, its topography, history and tradition, the local culture and mentality of its inhabitants, or to celebrate its cultural pride, its uniqueness, and the 
grandeur of a special place in the empire. In this regard, Shi Chengjin's stories are no comparison to the rich body of vernacular stories set in the Song dynasty capital Dongjing 東京 (later Kaifeng), and particularly the Southern Song capital Lin'an 臨 安 (Hangzhou) (cf. LiU Yongqiang 200I, 2002). Nevertheless, most of Shi Chengjin's fifty-two tales are 'rich with local flavour' (Hu Shiying 1980: 623) and contain a wealth of information that will be of particular interest to cultural historians of early Qing Yangzhou (DAI Bufan I980: I88). Moreover, most tales have a stereotypical opening, as derived from the historical-biographical tradition, introducing the characters by first giving their 'coordinates': the era or year in which they lived or in which the related events occurred, and the protagonists' name, place of residence, profession and status. These data permit us to map most characters temporally, locally and socially. Lacking identification, on the other hand, may generally be considered the result of intentional suppression or even 'self-censorship', and is therefore significant as such.

\section{Historical Setting}

As for the temporal setting, among the fifty-two tales, only eleven items do not include any relevant data defining at least a reign era or a clue that allows us to assign the events to a certain period. For several items, the implied temporal setting can be supplemented due to the involvement of some local official whose office terms were noted in the prefectural gazetteer (Chongxiu Yangzhou fuzhi 1974 [18Io]). According to my findings (Tab. I), only eight items are set in the Ming, five among them in the late Ming. It would not seem incidental that the stories set in the late Ming were placed at the beginning of the main collection $\left(Y H X_{\mathrm{I}-4}, 7\right)$. However, apart from this concentration of 'early' stories, there is no evident chronological order in the two collections. The large majority of narratives, namely thirty-five items, are explicitly set in the early Qing: nine stories have a Shunzhi era (I644-I66I) background, eighteen are set in the Kangxi era (1662-I722), whereas only one story $\left(Y H X_{37}\right)$ is set in the Yongzheng era (I723-I735). Seven stories are clearly contemporary, but lack any temporal definition. About twenty out of the fifty-two narratives refer to events that took place during the author's adult lifetime, that is, after about 1675 . This survey indicates that the 'recent' period, in the author's conception, spanned about I50 years, for the larger part preceding his own lifetime.

A traumatic rupture in the history of Yangzhou was the city's brutal rape in the course of its conquest by Qing troops in May I645 (MEYer-Fong 2003: I4-20; Finnane 2004: 69-89). Throughout the Qing dynasty, the historical truth about the unimaginable violence of this massacre was considered politically sensitive. Shi Chengjin, who was born some fifteen years after the massacre, knew about it from word of mouth. In I7I9, he noted in his 'Zhen fu pu' 真福譜 [Guide to True Happiness] that he was fortunate to live in a 'prospering era', shengshi 盛世: 
I have heard the older generation talk about the destruction of the city of Yangzhou at the end of the Ming. Back then a bloody massacre occurred; families were torn apart or ruined. The cries of the miserable were shaking heaven and earth; the cruelties were too unbearable even to listen to [when recounted]. How happy I am that nowadays, fortunately, there are no such atrocities due to warfare.

(CJBQ 3: 167)

Three of his Yangzhou tales (YHX 2, 5, TTL 9) have the 1645 massacre as a historical backdrop. The tale 'Tie lingjiao' 鐵菱角 [Iron Caltrop] $\left(Y H X_{2}\right)^{28}$ is about a wealthy salt merchant originating from Huizhou, named Wang Ren 汪人, who was extremely stingy. He had accumulated one million liang of silver which he kept in four different storehouses. In 1645, when (as the formula goes) 'the troops of the Great Qing destroyed the city of Yangzhou', Da-Qing bing po le Yangzhou cheng 大清兵破了揚州 城 ( $Y H X$ 2.13), they sent an envoy to Wang Ren's home in order to confiscate all his silver for the support of the troops. He could not bear to lose his entire fortune in one day and died from a heart attack. Quite unlike what is otherwise known about the rape of Yangzhou, in this story the Qing military men appear with civilized manners, formally demanding a military tax, rather than just pillaging this huge treasure of silver. Moreover, they even represent a higher force of just retribution, for the salt merchant, due to his heartless stinginess, deserved to lose all his wealth.

The story 'Dao fei yuan' 倒肥唒 [Hanging Upside Down a Fat Water-Turtle] ( $Y H_{X}$ ) opens on exactly the same formula concerning the city's 'destruction' as in the above account, but it adds the following, more explicit statement:

Only because Grand Secretary Shi [Kefa 史可法 (I604-I645)] refused to surrender, he provoked the anger of the military commanders who authorized their troops to massacre. Those of the common people who could run fast, stayed alive; those who moved forward too slowly, were mown down like grass.

$(Y H X 5.35)$

Despite these rather frank words in the introduction, the story itself does not focus on the atrocities committed by the Qing troops, but instead on the outrageous behaviour of some local ruffians who try to take advantage of the emergency situation of the local population, to whom only the escape route northward, to Shaobo 邵伯, at the city's outskirts, has remained open. The bandits block a bridge where they demand a high toll from the fugitives who desperately seek to pass. They kill numerous people, rob piles of treasures and rape several women. The situation is eventually resolved by six 'stalwart men' who chase away the gang, capture the two gang leaders and bury them alive, feet up in the air, so as to serve as a warning example. The authorial narrator lauds this courageous intervention as perfectly justified under the given circumstances. Nevertheless, the description of the hooligans' outrageous behaviour 
Table 8.1 Dating of the Yuhua xiang and Tongtian le stories.

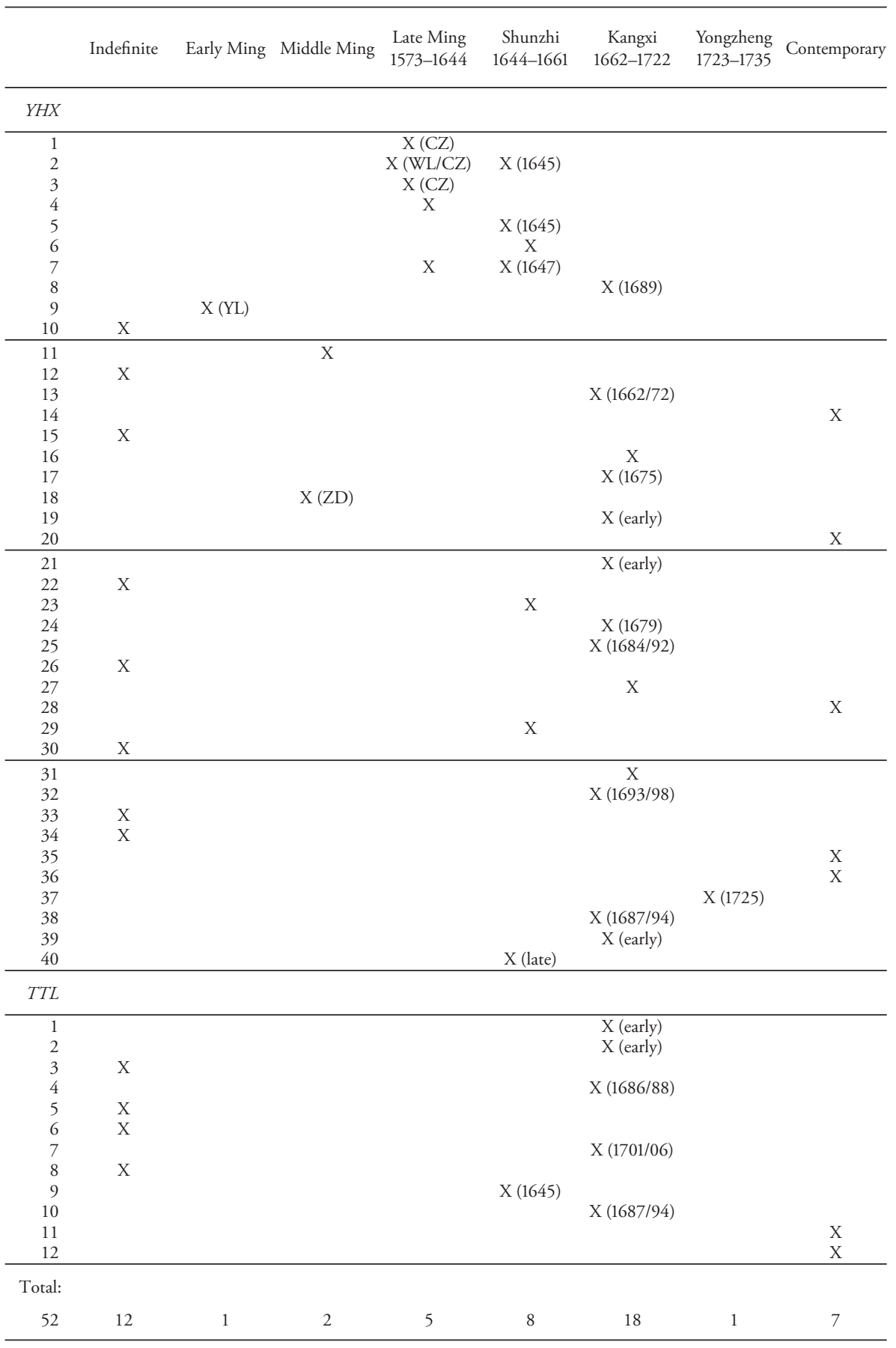


which after all occurs only as a minor side episode to the large-scale atrocities committed by the Qing troops, seems a case of displaced representation. ${ }^{29}$

The story 'Xia wei shang' 下為上 [Topsy-Turvey] (TTL 9) is about a widow who severely mistreats her slave girl. The arrival of the Qing troops inverts the power relation between the two, turning the slave into the mistress and vice versa, since a Qing general chooses the slave girl as his spouse, and the former mistress as her servant. This story, besides quoting the standard formula concerning the 'destruction' of the city, also includes a description which at least implies the mass rape of local women by Qing troops:

There was a general who gave orders to a large group of soldiers to open all the wardrobes and drag out all the ladies and female servants. They were led [out into the streets], the soldiers following behind with drawn swords. Those who were moving too slowly, were cut down.

(TTL 9.45)

The slave girl escapes because she tries to commit suicide by throwing herself into a pond. By this action she apparently attracts the general's attention, for it is implied that he chooses her due to her high principles as demonstrated by the suicide attempt, and despite her rather unattractive appearance. Thus, in all three stories representing the massacre of 1645 there is a tendency toward displacing the atrocities, and at the same time rehabilitating the role of the Qing troops who tend to be recast as a power of 'higher' justice. Between the lines, the choice of this mode of representation tells us something about the political sensitivity of early Qing local-historical memory.

As my survey of the temporal settings (Table 8.I) indicates, the large majority of stories were set in the Shunzhi and Kangxi eras, the period in which Yangzhou recovered from the Qing conquest and the city was reconstructed in both the material as well as the symbolical sense. This process of recovery, however, cannot be perceived in the stories. Shi himself did not participate in this process in any recognizable way, although his collection of stories, at a first glance, might appear as just such a project to promote the city. The Kangxi emperor's six visits to Yangzhou, between 1684 and 1707, go entirely unmentioned in the stories, although they were events of enormous significance for the local elite. Shi's apparent detachment from these larger processes is yet another indicator of his marginality vis-à-vis the city's top elite, for he definitely was not part of that network of literary luminaries and talented officials whose poetry sessions 'gave the city its aura of importance in the later seventeenth century' (Meyer-Fong 2003: 3I). Shi Chengjin remained an outsider to their 'world of pose and pretensions acted out through poetry and leisure excursions' (Meyer-Fong 2003: II3). In the stories, there is one single reference to such highbrow entertainment activities $\left(Y H X_{25}\right)$, but, significantly, it is undercut by irony. When a corrupt Salt Commissioner invites the local celebrities for a boating party at Rainbow Bridge, Hongqiao 虹橋, considered the place for such an event, the 
party is disrupted by an eccentric monk collecting donations, who tosses a precious golden cup into the lake, in order to demonstrate his disregard for worldly riches.

\section{Local and Spatial Setting}

Although the opening of a story usually provides information on the protagonist's place of residence, or the site of a particular event, we rarely get any precise address, such as a street or lane. A person or an event is more commonly located in relation to one of the city gates, to a bridge, to either of the administrative offices of Yangzhou Prefecture and Jiangdu District, or to a major religious institution. ${ }^{30}$ If we map all the relevant places that are mentioned in the stories (see Table 8.2), we discover that the great majority of sites are concentrated inside the Old City, jiucheng 舊 城, whereas only a few locations refer to the New City, xincheng 新城 (Table 8.2, Fig. 8.3). The spatial, social and functional differentiation of the city's two halves, the Old City in the west and the New City in the east, has variously been stated (Meyer-Fong 2003: 9-IO; Finnane 2004: I72-I76). The Old City was the domain of civil administration, since all the important administrative offices, except for the salt administration, were concentrated there. By contrast, the New City, which had become a part of the walled city in the mid-sixteenth century, was the home of wealthy salt merchant families. Yet, during the second half of the seventeenth century, the salt merchants were far less affluent than they would later become in the course of the eighteenth century, and therefore 'played a relatively minor role in the late seventeenth century' (MEyer-Fong 2003: 23). The relative importance of the city's two parts changed dramatically, from the early eighteenth century on, as the salt merchants prospered and the New City eclipsed the Old City. Thus, the focus on the Old City in Shi's stories quite faithfully mirrors the distribution of cultural and political importance in the perception of contemporary inhabitants of Yangzhou.

Salt merchants nevertheless get their share of attention in the stories. Wang Ren $\left(Y H X_{2}\right)$, as a young man, came to Yangzhou from Huizhou to make a fortune in the monopoly salt trade. It is perhaps significant that the place of residence of this clearly negatively portrayed character is not mentioned in the text, but it definitely would have been in the New City. The same is true for Chen Youde 陳友德 ( $Y H X$ I3), another salt merchant about whom an event is noted in the Old City, but whose residence we would rather expect to be in the New City. For two early Qing salt merchants who distinguished themselves as benefactors in charity (cf. You Zi'an I999: 65-66), Min Shizhang 閔世璋 (b. I607) and Cheng Yourong 程有容 (both of whom appear in $Y H X$ I8), no place of residence is indicated either. The dwelling place of yet another rich salt merchant family is located 'within Toll Station Gate', Chaoguan men nei 鈔關門內 ( $Y H X$ 23.IIO), in the New City's south-western corner. The two sons of this family sue each other over a triviality and eventually both die in 


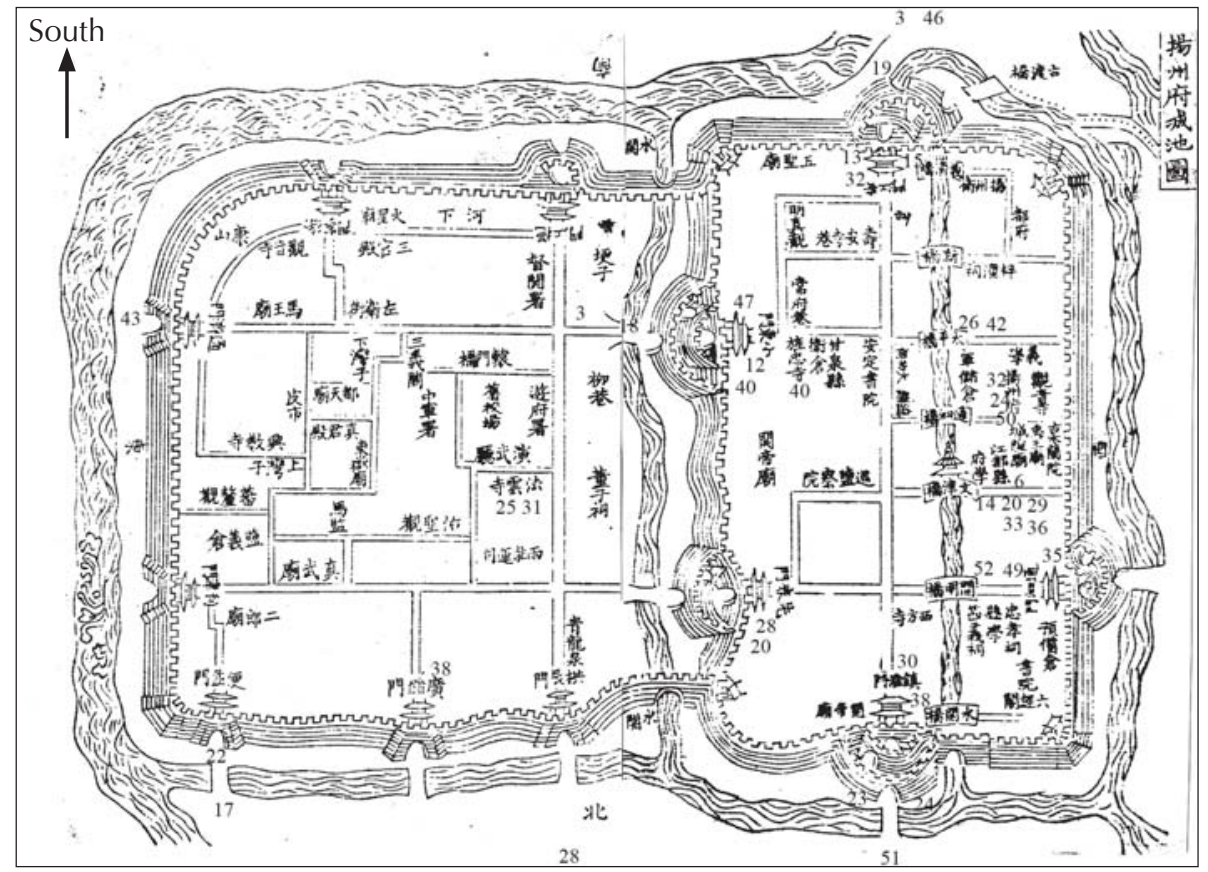

Figure 8.3 Map of the city of Yangzhou, based on Yangzhou fu zhi 1810, with indicated sites as mentioned in Yuhua xiang and Tongtian le stories (see Table 8.2).

prison. The foolishness of their self-destruction might be the reason why the family's name is not mentioned.

Shi Chengjin, by his stories, apparently did not intend to convey any social or cultural panorama of the city of Yangzhou. While pieces of information about city life are scattered all over the text, they are never moved to the primary focus of attention. For instance, the quarter 'outside Toll Station Gate' is repeatedly referred to as the city's 'red light district' (YHX 20.99, TTL 6.3I). The city's execution ground, outside North Gate, is also mentioned several times ( $Y H X$ 23.III, 24.II4, 38.126). The city's most popular sightseeing itinerary, between Fahai si 法海寺 [Ocean of the Law Monastery] and Pingshan tang 平山堂 [Level Mountain Hall], is mentioned only in connection with an exemplary woman, née Cheng (Cheng shi 程氏), who had committed suicide after her husband, a merchant, had died on a business trip just one month after marriage. She received a memorial arch at the most prestigious burial site near Pingshan tang (Meyer-Fong 2003: 133). A visit there soon became a compulsory stop on any sightseeing tour, the author claims (YHX 37.I59).

The author's family residence was called 'the villa at Yan Bridge', Yanqiao shu 衍 橋墅. Although its exact location has remained unidentified, it must have been in the Old City, for, in an autobiographical story, the author relates that once he attended 
Table 8.2 Sites mentioned in the Yuhua xiang and Tongtian le stories.

\begin{tabular}{|c|c|c|}
\hline Sign & Story & Main Locations \\
\hline \multicolumn{3}{|c|}{$Y H X$} \\
\hline \multirow[t]{2}{*}{1} & 1 & 西門外, 西山裡, 西崗一帶 \\
\hline & 2 & \\
\hline \multirow[t]{2}{*}{3} & 3 & 小東門外 / 南門外驢子行 \\
\hline & 4 & \\
\hline 5 & 5 & 邵伯, 艾陵湖 \\
\hline \multirow[t]{2}{*}{6} & 6 & 江都縣, 江營 \\
\hline & 7 & \\
\hline \multirow[t]{3}{*}{8} & 8 & 東關外 \\
\hline & 9 & \\
\hline & 10 & \\
\hline 11 & 11 & 萬頭東鄉 \\
\hline 12 & 12 & 小東門內 \\
\hline 13 & 13 & 南門, 小東門 \\
\hline 14 & 14 & 府學, 江都縣衙門 \\
\hline 15 & 15 & 南門裡 / 西鄉, 陳家莊 \\
\hline 16 & 16 & 東岳廟前 (舊城) \\
\hline 17 & 17 & 便益門外黃金壩 \\
\hline 18 & 18 & 小東門/敗閘 \\
\hline 19 & 19 & 南門外 \\
\hline 20 & 20 & 鈔關門外堂巷 / 江都縣門前 / 大東門 \\
\hline 21 & 21 & 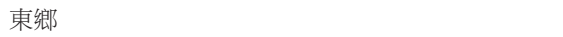 \\
\hline 22 & 22 & 便益門外 \\
\hline 23 & 23 & 鈔關門內 / 北門外 \\
\hline 24 & 24 & 北門外 / 府大門外 \\
\hline 25 & 25 & 北郊虹橋 / 北門外 / 法雲寺 \\
\hline \multirow[t]{2}{*}{26} & 26 & 府東太平橋 / 太平街 \\
\hline & 27 & \\
\hline 28 & 28 & 大東門 / 天寧寺 \\
\hline 29 & 29 & 江都縣衙門 \\
\hline 30 & 30 & 北門內 \\
\hline 31 & 31 & 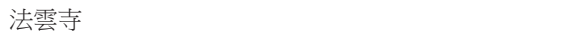 \\
\hline 32 & 32 & 西鄉 / 南門內 / 府大門外 \\
\hline 33 & 33 & 東鄉邵伯湖邊楊家莊 / 江都縣 \\
\hline 34 & 34 & 鈔關城外 \\
\hline 35 & 35 & 西門裡 \\
\hline 36 & 36 & 江都縣 \\
\hline 37 & 37 & 平山堂 / 法海 \\
\hline 38 & 38 & 廣儲門城內 / 北門外 \\
\hline 39 & 39 & 東關過渡 \\
\hline \multirow[t]{3}{*}{40} & 40 & 小東門 / 府東権忠寺 \\
\hline & $T T L$ & \\
\hline & 1 & (城外一里多遠) \\
\hline 42 & 2 & 太平橋 \\
\hline 43 & 3 & 缺口門外 \\
\hline \multirow[t]{2}{*}{44} & 4 & 鈔關門外約二里遠 / 鈔關至南門寶塔灣一帶河堤綷路 \\
\hline & 5 & \\
\hline 46 & 6 & 南門驢行 / 鈔關門外 \\
\hline 47 & 7 & 小東門內 / 江都縣衙門 \\
\hline 48 & 8 & 東鄉 \\
\hline 49 & 9 & 西門裡薛家汪 \\
\hline 50 & 10 & 府衙門 / 淮道衙門 \\
\hline 51 & 11 & 北門城外 \\
\hline 52 & 12 & 西來庵 / 西門二舖街 \\
\hline
\end{tabular}


a party outside the city wall, and when he wanted to go home, late at night, the North Gate (leading into the Old City) was already closed, so he had to spend the night at a relative's home (TTL II.5I). In his 1739 preface to Chuan jia bao (CJBQ I: 2), written in old age, Shi Chengjin however mentioned that he was living in the Dongsheng 東聖 quarter at Shaobo, about twenty-five kilometers northwest of Yangzhou. It remains unclear whether, in old age, he had permanently moved away from the city.

The selection of a proper place to live, buju 卜居 (cf. Ho Wai-kam 1987: 33), emerges as an important theme in the stories, particularly in the opening stories to both Yuhua xiang as well as the supplement volume Tongtian le. In the introductory remark to the first story, the authorial narrator contradicts the late Ming obsession with finding the perfect place to live, claiming that a happy life does not depend on one's 'realm', jingjie 境界, but only on one's personal attitude to life. If one does not know how to live a merry life, one cannot become happy even in the islands of the immortals. The late Ming painter portrayed in this programmatic story, Chen Zheng 陳正 ( $z i$ Yi'an 益庵), lives the life of a hermit in the hills west of the city, 'out in the suburban wilderness', zai huangjiao yewai 在荒郊野外 (YHX I.4), in a modest residence with a large garden that permits him a self-subsistent mode of existence. He is described as 'a contemporary lofty recluse', dangdai zhi gaoren 當代之高人, who seemingly 'transcended the secular world' (YHX I.5). All through the year, in the afternoons, he can hear the sounds of flute-playing and singing from the pleasure boats at Rainbow Bridge, ${ }^{31}$ but it is implied that Painter Chen does not long for that world of fancy entertainment, since he has seen through the vain desires of alcohol, sex and wealth. Despite his argument that 'joy does not depend on place', qu bu zai jing 趣不在境 ( $Y H X$ I.3), Chen Zheng's choice, outside yet not too far away from the city, would nevertheless seem crucial to the harmony he had found.

A closely related case is that of the protagonist Old Tian (Tian laozhe 田老者) in the first story of Tongtian le, 'Chang huanyue' 長懽悅 [Everlasting Merriness] (TTL I). He lives 'about one $l i$ outside the city wall' and 'does not like to enter the city' (TTL I.2). He spends his days 'in joyful leisure', xiaoyao kuaile 逍遥快樂, in his large bamboo garden. He is considered 'an otherworldly person of our time', dangjin zhi yiren 當今之異人. Unlike Painter Chen, who only had a rudimentary education, Old Tian served one term as a District Magistrate, but he was caught in the dilemma that an incorruptible 'pure magistrate', qingguan 清官, necessarily had to become impoverished. Therefore he quit his post after a few months, giving health problems as a pretext. Tian was already an old man when the author, who was still very young in the early Kangxi era, allegedly visited him. By placing the portraits of Painter Chen and Old Tian at the respective beginnings of the two collections of vignettes, the author evidently meant to establish them as lifestyle models. ${ }^{32}$ 


\section{Social Setting and Personality}

Among the people drawn in Shi Chengjin's stories, we find rather few public persons, and hardly any trace of local celebrities on the social and cultural scene of early Qing Yangzhou. Apparently the main criterion for the selection of characters and stories was their exemplarity with regard to ethical issues. In Shi Chengjin's evaluation, even a person from the lowest social background could emerge as a paragon of virtue. For instance, in the story 'San ding ku' 三錠窟 [The Hole with Three Ingots] ( $Y H X$ 3I), a lowly pole-carrier, jiaofu 腳夫, excels in the practice of filial piety. There is no fixed relation whatsoever between social status and moral performance.

Shi Chengjin, in some of his stories, preferred not to reveal the names of certain characters of status who were involved in shameful activities. Sometimes he tacitly did so, but in two cases he frankly stated that he had intentionally suppressed the protagonists' names. In one case, he refused to identify a number-one champion in the civil examinations, zhuangyuan 狀元, of whom he claimed that, in a previous existence, he had been a dog. He also left open the historical time at which the events allegedly took place, so as not to render him identifiable ( $Y H X$ I2.64). The other case for which he explicitly preserved the anonymity of the story's protagonist is a story about a wantonly corrupt Magistrate of Jiangdu District on duty during the Shunzhi era. The author-narrator refers to him only by the nickname 'Skinner', Bopi 剝皮, and suppresses his real name 'out of consideration for his descendants and family' ( $Y H X$ 29.138), but the local readers would definitely have known whom he meant. In yet another case $\left(Y H X_{7}\right)$, a local official serving during the first years of the new Qing dynasty seeks to promote his official career by having falsely executed as 'bandits' some harmless villagers who fail to wear the required pigtail. The official's name is given as Xu Xuan 許宣, but no such name appears in the gazetteers. In yet another quite embarrassing case about a magistrate who is beaten up by ang of local hooligans (TTL 8), the author was tactful enough to give only the man's surname Liu 劉, which renders him virtually unidentifiable, since in the early Qing, no fewer than four men of this surname served as magistrates of Jiangdu District.

The social composition of the 'world' of Shi Chengjin's stories is very diverse, for it includes people from virtually all social layers and groups. Starting from the bottom of the social hierarchy, there are several 'asocial' elements of urban society, such as beggars ( $\left.Y H X{ }_{2} 28\right)$, a thief ( $Y H X{ }_{24}$ ) and other petty criminals ( $\left.Y H X{ }_{2} 20\right)$. Local hooligans and 'rootless rascals', guanggun 光棍, 33 especially in the villages, are frequently described as a major threat to social harmony $\left(Y H X_{4}, 5,17,32,33\right.$, TTL 4). The consequent suppression of such bullies and hooligans by local officials is repeatedly lauded. The urban 'middle classes' are rather prominently represented by various kinds of shop owners, small merchants and craftsmen (YHX I5, 20, 22, 28, $34,37,38,40, T T L 2,7)$. The salt merchants appear as a rather distinct group, but 
certainly not as the all-dominating socio-economic force they became later on, in the Qianlong era. The lower elite, Shi Chengjin's own social group, comprising holders of minor examination degrees and downwardly-mobile descendants of elite families, is represented by a 'half-educated' teacher $\left(Y H X_{4}\right)$, talented young scholars ( $Y H X$ IO, TTL 5), and scribes, the latter being shown in a remarkably negative light (YHX 26, 30). In two stories (YHX 6, TTL 8), holders of Academy Student, jiansheng 監生, degrees are described as local bullies who are terrorizing their communities.

The sphere of the administrative seat, yamen 衙門, is represented by lowly runners $\left(Y H X_{\mathrm{I} 4}, 35,36\right)$ on the one hand, and powerful administrative officials on the other. The various magistrates and prefects certainly are the most prominent and most recognizable personalities in these stories. In fact, the author included in his stories an evaluative rating of several local officials' performance, pointing out both outstandingly positive as well as negative cases. The few drastically negative examples regularly include the officials' punishment for the misdeeds committed, such as in the case of Wu Zuanxu 吳纘緒, a subaltern official in charge of punishments, xingting 刑廳, who is portrayed as a wantonly cruel man whose life inevitably has a violent end $(Y H X$ 23). The author's heroes in the administrative sphere were Shi Shilun (d. 1722), who served as Prefect of Yangzhou from 1689 to 1693 (Chongxiu Yangzhou fuzhi 1974 [18ro]: 35.Iob, 38.4b; Hummel 1943: 653-654; Meyer-Fong 2003: 2I), and Xiong Kaichu 熊開楚 who was Magistrate of Jiangdu District around the same time, between 1687 and 1694 (YHX 8.47; cf. Chongxiu Yangzhou fuzhi 1974 [I8Io]: 35.IO, 38.I2b). The author lauded Shi Shilun as an incorruptible and extremely capable official, an opinion widely shared among the population; Xiong Kaichu he praised as being the best magistrate he had ever seen. One story about Shi Shilun shows his treatment of an arrogant fellow official (TTL Io), while another demonstrates his superior skill in solving a murder case $\left(Y H_{3} 8\right)$. Xiong Kaichu is also involved in the investigation of this criminal case, but has to pass it on to Shi for it is too 'big' for his administrative level $(Y H X$ 38). In another story, Xiong explains his administrative philosophy of laissez faire, arguing that a district magistrate eagerly 'looking for trouble' is a mere plague to his district $(Y H X$ 8.48). Decent performance in office is summarized by the principle of 'benefiting the people', limin 利民 ( $Y H X \mathrm{I} 8.88$ ).

Another official to receive high praise is Prefect Fu Zehong 傅澤洪 (in office 1693-1698; Chongxiu Yangzhou fuzhi 1974 [I810]: 35.IIa-b, 38.4b) who is presented as a model of 'good governance', shanzheng 善政. The story about him (YHX 32$)$ serves to illustrate his capability as an administrative official in two cases. When this prefect leaves office after a five-year term, a large crowd of people bid him farewell. The local population even collect money for two commemorative steles to be erected in front of the prefectural yamen. Thus they seek 'to make a little repayment for Heaven's grace' of having sent such a good official ( $Y H X$ 32.I48). Several other prefects also receive praise, though in milder tones, for their performance in office, such as a 
Prefect Gao 高 (most probably referring to Gao Degui 高得貴, a bannerman, in office I678-1679; Chongxiu Yangzhou fuzhi I974 [1810]: 38.4a) who is lauded as a wise official and a man of integrity ( $Y H X$ Io), and Prefect Jin 金 (referring to Jin Zhen 金鎮, in office 1673-1675; Chongxiu Yangzhou fuzhi 1974 [I8Io]: 38.4a) who is applauded for his cleverness in uncovering a fraud $\left.\left(Y X_{\mathrm{I}}\right)\right)$. An ambiguous case is that of Cui Hua 崔華, who first served as Prefect of Yangzhou (I680-I684) and was then promoted to the lucrative and notoriously corrupt post of Salt Commissioner of the Liang Huai (1684-1692; Chongxiu Yangzhou fuzhi I974 [18Io]: 38.4a, 3a). Due to an encounter with a Buddhist monk, Cui Hua is 'converted' from a common corrupt official to a model administrator who is perfectly immune to bribery. When he ends his term as salt commissioner, the local salt merchants are so grateful for his decent performance in office that they erect a shrine for him $\left(Y H X{ }_{25}\right) .{ }^{34}$

Shi Chengjin's commemoration of good officials in his vignettes may in fact be similarly viewed as a symbolic act of enshrinement. The district magistrates and the local gentry, xiangshen 鄉紳, also play a crucial role in the official recognition and public appraisal of ethically desirable and beneficial acts and meritorious persons from the common folk. The ritual visit paid by regional officials and representatives of the local elite, at the occasion of a high birthday or a funeral, repeatedly serves as the ultimate marker of ennoblement ( $Y H X_{4}$.3I, 5.37, 37.159, 40.172), just as with Shi Chengjin's own seventieth birthday.

\section{THE MORAL MISSION}

The narrator's favourite stance appears to have been that of a paternal advisor. This may be demonstrated by reference to the story 'Shao zhi fei' 少知非 [A Youngster Recognizes his Mistakes] (YHX 20), about a young man who lost his father during childhood and, as an adolescent, is being misled by 'inferior folk', xiaoren 小人, into self-destructive behaviour such as aria-singing, gambling and whoring, but eventually manages to return to the right path thanks to his own cleverness as well as to the advice and the warning voice of a friend of his father's, who is of course no one else but the author himself. The young man is 'merely from a merchant background', buguo shengyiren chushen 不過生意人出身, and therefore lacks the proper education and is in particular need of moral guidance ( $Y H X$ 20.99). The author writes four educative songs, gec $i$ 歌詞, to persuade the young man. The first of these songs he has circulated as a pamphlet on single sheets of paper, doufang 斗方 [flyers], as a form of public criticism trying to shame the young man into betterment. ${ }^{35}$ After the songs have failed to have any effect upon the young man, the first-person narrator hands him a copy of his counselling book Ren shi tong 人事通 [Comprehending Human Affairs], ${ }^{36}$ which he recommends to him for daily readings. Three years later, indeed, the young man has overcome his youthful errors and now expresses his gratitude to 
the author for his insistent guidance. In this story speaks the author's firm and naive belief in the persuasive power and educative effect of the types of edifying writing he himself produced en masse. ${ }^{37}$ The story also highlights the simple concept of literary didactics that the author had in mind, and demonstrates how seamlessly the stories fitted into the author's larger project of ethical didactics.

Shi Chengjin was also a deeply religious man. His syncretistic system of beliefs is expressed on numerous occasions throughout the stories (cf. XIAO Xiangkai 1994: III-II2). It included the basics of Confucian social ethics as well as the belief in the existence of Daoist and Buddhist saints and, on top of everything, a deep concern with certain folk-Buddhist ideas, which the author hoped to diffuse through his writings. It is notable that Shi Chengjin was not in any perceivable way inspired by any 'sectarian' movement, as was often the case with authors of morality books. Yuhua xiang even includes an unmasking story about a sectarian religious movement which fabricates a cult around a fake reincarnation of Dutian 都天 Boddhisatva ${ }^{38}$ in order to cheat the population of a village ( $\left.Y H X_{\mathrm{I}}\right)$.

While we cannot go into the details of the varied, complex and partly selfcontradictory system of religious beliefs and ethical concepts underpinning Shi's stories, we shall highlight here only the notion of retribution, baoying 報應, which the author in his own preface to Yubua xiang singled out as being central to the ethics of his stories:

Thus, every good deed is repaid by a likewise reward, and every evil deed by a likewise punishment. This is perfectly evident from the examples provided; the failures of the past may serve as lessons.

(YHX: 177)

The concept of retribution played a remarkably peripheral role in Shi Chengjin's ethical tracts, which mostly provide positive advice, descriptions of socially harmful behaviour and its negative consequences not being given much space. The fictional discourse of the vernacular story, on the other hand, often takes transgressive behaviour as its point of departure in order to show its negative consequences and to suggest possible ways to remedy the disrupted harmony. In the stories by Feng Menglong and Ling Mengchu, the rule of retribution operates as the predominant logic of narrative causality that explains why things inevitably happened the way they did. Based on an ethical concept of 'Heaven' as an impersonal agent of universal justice, they show the contingency of the human world (cf. LAUwAERT I990; IDEMA 1974: 52-53).

Shi Chengjin's stories, too, are rich with representations of transgressions and indeed read like a catalogue of misbehaviour and crime such as corruption, fraud, blackmail, gambling, theft, harassment, adultery and murder. The concept of retribution governs the ethical evaluation in Shi's stories, too. ${ }^{39} \mathrm{In}$ its most radical version, there is a perfect symmetry of fates: Heaven inflicts upon the culprit as punishment 
exactly the same harm as the victim had to suffer from the culprit. Consider the case of the district magistrate who executed fourteen innocent villagers as 'bandits', so as to promote his official career. On the journey to his next post, real bandits raid his caravan and kill fourteen members of his family $\left(Y H X_{7}\right)$. This instance of exact numerical justice was considered by the narrator a case of 'retribution in the present age', xianbao 現報 or xianshibao 現世報, as opposed to 'retribution in a future life', laisheng bao 來生報 ( $Y H X$ 36.155), which could require sons to suffer for the sins of their fathers (e.g., in $Y H X_{21}$ ). Shi, in his stories, also repeatedly refers to the idea of Heaven 'watching very closely', guaranteeing that no oversight due to carelessness could occur ( $Y H X$ 3.21, 7.45, 30.143). Despite the narrator's claim that 'retribution is frighteningly evident' (TTL 8.40), in Shi Chengjin's stories, too, it works as a narrative principle of causality, which however decreases rather than increases the stories' verisimilitude and credibility. Quite contrary to the author's intention, it is perhaps the most obvious mark of fictionalization, ${ }^{40}$ and it is yet another feature that links Shi Chengjin's stories to the genre of the vernacular story.

\section{CONCLUSION}

Hanan characterized Shi Chengin very aptly as 'a tireless pedagogue, a man of simple aesthetic pleasures and deep moral and religious convictions' (I98I: 209). Moreover, Shi Chengjin was a versatile author who tried his hand in numerous different types of text, while single-mindedly pursuing a larger project as represented by the collected works edition Chuan jia bao, which also included the larger part of the body of vernacular vignettes that have been discussed here. These short pieces, the definitive edition of which was the collection Yubua xiang with the supplement Tongtian le, may be characterized as generically hybrid texts. Hitherto, they have usually been described and judged only in relation to the genre of the vernacular story, which in several respects must indeed have served as an important point of reference. Some features of the texts as well as of the collections, such as the parallel arrangement of items, or the emphasis on the concept of retribution, are clearly reminiscent of this narrative genre, whereas other features are not. Therefore, rather than critiquing these texts as deficient later examples of a certain genre model, they should be contextualized in the larger oeuvre of the author, as represented by the widely read collection Chuan jia bao, which was also the primary channel by which a part of the texts was being circulated. In this wider context, the vignettes tend to be perceived as morality book items rather than as vernacular fiction (cf. DAI Jian 2006). The embedding of the texts in the author's larger project of ethical didactics is also underscored by the fact that the author-narrator in the narratives linked them up to other writings in his oeuvre Chuan jia bao by frequent cross-references (cf. note 6), whereas other references, e.g. to popular literature, ${ }^{41}$ are rare. Therefore, the 
vignettes may be viewed as just one facet of a life-long project of proselytizing via all available genres of writing and channels of communication, including a format similar to the vernacular short story.

The author's original intention, however, does not need to prevent us from reading these vignettes also as a textual body of popular literature, and even as a private project of local and social history. These short stories, all of which are related to Yangzhou in one way or another, indeed provide a rich and virtually untapped source of this city's local and social history. Based on a survey of the historical, local and social settings of the individual items, we find that the distribution of both local setting and social representation convey an image that is largely in line with insights gained from local-historical research. The fact that Shi Chengjin's multi-layered image of Yangzhou society includes virtually all social classes and professional groups further increases its relevance as a socio-historical source providing information on social groups and aspects of everyday life that are scarcely represented in official history. The general heading Recent Events in Yangzhou refers to a historical time-span of about 150 years, for the larger part in the early Qing, and for more than half of the texts preceding the author's adult lifetime. In terms of regional distribution it encompasses Yangzhou Prefecture rather than the city as such, although numerous pieces are indeed set within the city. These 'Yangzhou stories', in the narrower sense, however, may not be considered a 'regionalist' project, for their declared purpose was not the celebration and glorification of the city's local tradition and culture, and they were not meant to contribute to the symbolic rebuilding of Yangzhou in the early Qing, either. Shi Chengjin was detached from these elite concerns. Rather he was writing from an intermediary position between the common folk and the local elite, from where he was able to address both social groups. Due to this ambiguous self-positioning and the self-claimed duty as a mediator, his vignettes as well as the extensive body of his other writings, as an interesting case of middlebrow texts, also deserve further study from the point of view of the sociology of writing and publishing in late imperial China.

\section{PRIMARY SOURCES WITH ABBREVIATED REFERENCES}

CJBQ [SHI Chengjin]. 1936. Chuan jia bao quanji 傳家寶全集. Zhou Weili 周惟立, ed. 4 vols. Shanghai: Guangyi shuju.

TTL Shi Chengjin. I990a. Tongtian le 通天樂. Zhang Bing 張兵, Chu Lingzhen 儲玲珍, eds. In Shi Changyu 石昌渝 et al., eds. Xiong Longfeng kanxing xiaoshuo si zhong deng si zhong 熊龍峰刊行小說四種等四種. In Zhongguo huaben daxi 中國話本大系. Nanjing: Jiangsu guji chubanshe.

YHX SHI Chengjin. 1990b. Yuhua xiang 雨花香. Zhang Bing 張兵, Chu Lingzhen 儲玲珍, eds. In Shi Changyu 石昌渝 et al., eds. Xiong Longfeng kanxing xiaoshuo si zhong deng si zhong 熊龍峰刊行小說四種等四種. In Zhongguo huaben daxi 中國話本大系. Nanjing: Jiangsu guji chubanshe. 


\section{NOTES}

1 The main sources regarding Shi Chengjin's biography are the following: (I) 'Tianji xiansheng zhuan' 天基先生傳 [Biography of Mister (Shi) Tianji], by Wei Yuanyi 魏元疑 et al., CJBQ I: 5-6; (2) the laudatio by Tang Shaozu 唐紹祖 (1668-1749) held on the occasion of Shi's seventieth birthday, $C J B Q$ r: 3-4, as 'Zeng yan' 贈言 [Words of Encouragement]; and (3) 'Wang sheng qi shi zhuan' 往生奇逝傳 [Biography (of my Wife's) Past Life and Remarkable Death], being the obituary Shi Chengjin wrote for his wife, née Zhou (Zhou shi 周氏), YHX 27.I29-130. Moreover, a self-description in disguise is included in $Y H X$ 27.I26. Cf. List of Primary Sources with Abbreviated References at the end of this chapter.

2 Erroneous biographical information on Shi Chengjin, claiming that he gained a jinshi degree and once served as a district magistrate, was at first published by XIAO Xiangkai (I988: II) and later resumed by Zhang Bing (I99I: I49-I5I). Xiao Xiangkai later denied the accuracy of the information he had spread (I994: I09-IIO), but unfortunately it continues to be circulated in some reference books, e.g., Liu Shide i998: 47I.

3 Already in the 1940s, Zhao Jingshen 趙景深 (1902-1985) pointed out that the author of Chuan jia bao had experimented with all kinds of 'low literature', su wenxue 俗文學 (ZHAO Jingshen I980: 404).

4 A ‘complete works' edition, Shi Tianji quanji 石天基全集, in IO4 fascicles, appeared in 1726. The library of The University of Tokyo holds the only copy I know of, but which I have not seen. Based on its table of contents, this edition is likely to have been closely related to the Chuan jia bao editions that were alternatively titled Jia bao quanji 家寶全集.

5 In his 'Author's Preface', 'Zi xu' 自敘, Shi explained that he had derived the title from a book of 'instructions', xun 訓, entrusted to him by his father as 'a personal family treasure' (CJBQ I: 2 ). The family instructions the author referred to are likely to be those included in $C J B Q$ 2: 77-80.

6 See 'Guan nianzhu' 官念珠 [The Official's Rosary], in CJBQ 2: I25-135, also mentioned in $Y H X$ 32.I46; 'Sheng tang qiejie' 陸堂切戒 [Avoidances When Ascending to Office] and 'Yu men zhong' 于門種 [The Seed at the Door], in CJBQ 2: 135-138 and 173-176, respectively; both are also quoted in $Y H X$ 4.26. Moreover, see 'Guanzhang yue' 官長約 [Agreement with Officials] and 'Xiangshen yue’ 鄉紳約 [Agreement with the Gentry], CJBQ 3: II-I6, I6-22; cf. You Zi'an 1999: 194-197.

7 The introductory remark to the last story in Yubua xiang (YHX 40.168) mentions the title Jia bao ming quan ji 家寶命銓集 [Collection of Important Selections from the Family Treasure], which could have referred to an otherwise unknown edition of Shi's 'essential' works.

8 The scholar Ping Buqing 平步青 (I832-I895) commented on it as follows: 'The headings of the various items are extremely ridiculous. However, if one got rid of the redundancies and compiled them into one volume, it could well be of some help in regulating people's conduct and social affairs, and it would be of particular use in primary education.' (PING Buqing 1982: 387) As one sign of the relatively wide distribution of Chuan jia bao, some Chinese textbooks for foreigners, compiled by missionaries during the nineteenth century, carried excerpts from it. See Song Lihua 2006: 130 .

9 These texts have been studied only preliminarily by Chinese scholars and hardly at all by Western scholars of Chinese fiction. The most relevant Chinese contributions are XIaO Xiangkai 1994 (for a fuller version see XiaO Xiangkai and Zhang Hong 1994: 236-252) and Jia Jia 2003. The brief but substantial remarks by HanAN (198r: 209-210) have been the hitherto only major reference in English. To my knowledge, the only item $(Y H X 26)$ ever translated into any Western 
language (in this case, German) appeared in Rudelsberger (1926: 200-204). It was based on a Chuan jia bao edition.

10 A copy of this edition is kept in the Shanghai Library. It has been reproduced in the series Guben xiaoshuo jicheng (SHI Chengjin 1990c). The Nanjing Library holds a fragment of a joint edition, hekeben 合刻本, of both parts. See Jiangsu sheng etc. 1990: 474.

11 'Yuhua xiang zixu' 雨花香自敘, in SHI Tianji 4: 8.44a-b, reproduced in YHX: i76; not included in the otherwise complete Shanghai Library copy. The edition Shi Tianji quanji (cf. note 4), equally printed in 1726 , included in its first 42 juan a complete set of the forty Yuhua xiang tales, but not yet by the title Yuhua xiang. Moreover, two items that later came to be included as appendices to Yuhua xiang stories, were treated on the same level with the stories.

12 'Tongtian le zixu’ 通天樂自敘, in SHI Tianji 4: 8.45a-b, reproduced in SHI Chengjin I990c.

13 The table of contents for Yuhua xiang includes the note: 'The twelve [stories] of HeavenReaching Joy have been newly added.' (SHI Chengjin I990c: 6) But the titles of the individual items are not listed.

14 In the introduction to $Y H X 8.47$, the authorial narrator mentions that he is about to reach his seventieth birthday. $Y H X_{1.5}-7$ indicates that the author had already passed the age of 70 sui, which would point to 1729 or later. In $Y H X 27.130$, it is mentioned that Shi's wife died in 1732.

1534 of the 40 items from Yuhua xiang, and Io out of the I2 items from Tongtian le, were included as a consistent set in part three, san ji 三集, juan 27-30. The edition CJBQ that I consulted features only 20 items from Yuhua xiang and 2 from Tongtian le. Moreover, in this edition, they are not presented as one textual set, but as separate items scattered over various parts of the compilation. For instance, $Y H X_{\mathrm{I} 7}$ and $\mathrm{I} 8$, being two items with religious contents, were grouped with other religious texts.

16 For a relatively early (I2th c.) source that mentions this legend, see ZHang Dunyi 1967: I.42b.

17 Cf. Hanan: 'Understanding Heavenly Pleasures' (I98I: 209).

18 Non-elite authors, such as professional storytellers, had no scruples in disclosing their authorship of vernacular fiction. See Dong Guoyan and Yang Fang 2005: II.

19 Hanan (I98I: 210, 244n9) discovered in Shi Chengjin's oeuvre one reference to a narrative by Li Yu.

20 The title of the first story in Yubua xiang, 'Jin jue lou' 今覺樓 [The Storey-building of Immediate Awakening] (YHX I), in particular, echoes Li Yu's Shi er lou, where each of the twelve stories is named after a storey-building $(l o u)$. Moreover, in terms of topic, 'Jin jue lou' seems particularly close to the final story in Shi'er lou, 'Wen guo lou' 聞過樓 [Corrigibility House] (Li Yu i986: I2.262-284); see Wu 200I: 617.

21 The only element I found to be reminiscent of the storyteller's craft in Shi Chengjin's vernacular stories is a humorous set piece, quoting a list of illnesses contracted by an old man who indulged in excessive sexual activity ( $Y H X$ I9.9I).

22 The exception to the rule is TTL 9.44-45, where a brief story is included as part of the introduction.

23 For instance, the introductory remark in $Y H X_{11.62}$ that foreshadows $Y H X_{\text {I2 }}$; or the introduction to $Y H X 38.160$ that counterpoises the story's highly literate but 'shameless' female protagonist with the illiterate but perfectly virtuous female protagonist in the preceding story, $Y H X_{37}$ 
24 For instance, in the introductory remark to $T T L$ 12.55, the narrator refers the reader back to $Y H X$ 27, where he had already stated the principle that praying to Buddha had the greatest merit. In $Y H X$ 28.13I, the introduction of an excessively miserly character includes a cross-reference to the miser in $Y H X_{2}$.

25 Rather gruesome is the description of how a thief who had relapsed repeatedly was taken through the streets in a closed coffin in which he was going to be buried alive, as an unofficial method of execution. The author-narrator remembers how he, squeezed by the crowd, 'could still hear the cries from within the coffin' ( $Y H X$ 24.II4).

26 On spirit-writing cults in the early Qing, see ZeITLIN I998: IO2-IO9; on a cult related to Lü Dongbin, see MORI 2002: 167-I68.

27 See the third story in the early Qing collection of vernacular novellas Yun xian xiao 雲仙笑 [Laughter of Immortals in the Clouds] (Tianhua Zhuren 1983: 3.37-53). This slim volume of five novellas is attributed to Tianhua Zhuren 天花主人, who around 1650 was the leading author of 'scholar-beauty', caizi jiaren 才子佳人, romances.

28 The heading of this item refers to a military device with four spikes (hence similar in shape to a water caltrop) that was strewn on the ground to hurt the enemy. The protagonist in this story uses such traps to protect his wealth from thieves, thereby causing many accidents. Eventually, 'Iron Caltrop' became a nickname for the man himself, hinting at his miserly and misanthropic character.

29 A similar case of displaced representation of the Yangzhou massacre may be seen in $Y H X_{3}$, which includes a description of the devastation of the city of Jingzhou 荊州 and the atrocities committed by the troops of the 'rebels' Li Zicheng 李自成 (d. I645) and Zhang Xianzhong 張 獻忠 (I605-I647). The story's protagonist survives the massacre and returns to his hometown Yangzhou, where everything is still 'in perfect peace', taiping 太平 ( $Y H X_{3.19-20}$. This may be read as a foreshadowing of the catastrophe that hit Yangzhou soon after.

30 This would not reconfirm Xu Yinong's finding (2000: 74) regarding the localization of urban artifacts in Ming-Qing texts about the city of Suzhou.

31 In the preface to the compendium 'Ren shi tong' 人事通 [Conversant with All Human Matters], Shi Chengjin mentioned that he built a thatched hut next to Rainbow Bridge, from where he could watch the fleeting and vain world of entertainment, from which he learned a lot about the workings of the human world. For this preface (not included in $C J B Q$ ), see Shi Chengjin 2002, 2: $28 \mathrm{I}$.

32 Here there is a striking parallel to Wu Jingzi’s 吳敬梓 (I7OI-I754) novel Rulin waishi 儒林外 史 [Unofficial History of the Scholars] (earliest extant edition I803), written about one to two decades after the first publication of Shi Chengjin's stories. Hanan (I98I: 210) previously pointed out a 'distinct similarity' between $Y H X$ I and the prologue, chapter I, of Rulin waishi. TTL I further emphasizes the link as indicated by Hanan, and the correspondences of both stories, $Y H X$ I and $T T L$ I, to the concluding chapter 55 of Rulin waish $i$ are all the more striking.

33 For the rendering of the term guanggun as 'rootless rascals', see Sommer 200o: II and passim.

34 For a mentioning of the factual shrine, Cuigong ci 崔公祠, see Chongxiu Yangzhou fuzhi 1974 [I8IO]: $25.3 \mathrm{ob}$.

35 See $Y H X 6.39$ for another case in which doufang are being used as a 'mass medium' to circulate satiric verses as a way of public criticism. In $Y H X 27.129$ the author claims that two of his instructional texts of a more religious kind were printed on doufang and distributed all over the 
city as well as in the near-by villages, in several hundred thousand copies! For a discussion of the contemporarily widespread practice of gluing doufang onto walls, as a way of influencing public morals by short pieces of literary writing, see Shi Chengjin 2002, I: I84. The author makes the point that sometimes one has to resort to lowly media of expression in order to reach the common people.

36 This book, written in vernacular script, offers practical advice on numerous aspects of life, from education to food and medicine. It was included, along with a sequel, in $C J B Q$ 2: I-49.

37 In $Y H X_{40}$, a book written by the author plays a crucial role in the spiritual transformation of a character. Shi Chengjin's lay-Buddhist scripture 'San shen chou' 三神咒 [Incantations for the Three Deities] is advertised by Monk Jubo as 'the most simple and quick as well as the most

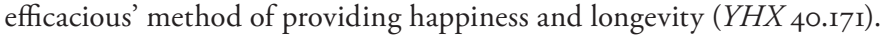

38 Dutian was the canonization and deification of the Tang-dynasty loyalist official Zhang Xun 張巡 (d. 757), who during a siege had killed his concubines to feed the starving soldiers. Dutian was primarily considered a rain-god. Cf. WERnER 1932: 527. In the city of Yangzhou there was also a temple for this popular deity.

39 This is particularly evident in $Y H X 26$, where the concept of retribution is construed as a narrative of close parallel between the fates of the two protagonists.

40 PING Buqing considered Shi Chengjin's stories being 'exaggerated displays of retribution half of which must have been the product of fabrication and cannot be verified' (1982: 387).

41 See the literary allusions to Xixiang ji 西廂記 [The Story of the Western Wing] as well as to other dramas in $Y H X$ I9.92-93. 


\section{9}

\section{Local Fiction of the Yangzhou}

\section{Region: Qingfengzha}

\section{Margaret B. Wan}

The Qianlong (1736-1796) and Jiaqing (1796-1821) periods saw an increasing 1 consciousness of local identity among men of letters in Yangzhou, who began to document local history, customs, dialects, and entertainment. An early example of this sentiment, Li Dou’s 李斗 famous guidebook Yangzhou huafang lu 揚州畫舫錄 [The Pleasure-boats of Yangzhou] (1797), extensively recounts the entertainment arts of Yangzhou. In his account Li Dou lists ten local storytellers as the masters of their art and names the most famous tale told by each. Three of the titles listed correspond to extant novels published within a couple of decades in Yangzhou: Qingfengzha 清風 閘 [Qingfeng Sluice] (1819), Shan'e tu 善惡圖 [Chart of Good and Evil] (n.d.), and Fei Tuo quan zhuan 飛跎全傳 [The Braggart's Tale] (1817). ${ }^{1}$ Besides this intriguing connection to local storytelling, the publication and narrative technique of Qingfengzha mark it as a product of Yangzhou, as we will see below.

Generally the term 'Yangzhou novel' calls to mind the courtesan novel Fengyue meng 風月夢 [Illusion of Romance] (I848), the first 'city novel' in China (HanAN 2004: 34). Qingfengzha forms an interesting counterpart to it. Qingfengzha and Fengyue meng both show close ties to Yangzhou in their origins, and both give detailed descriptions of the region and daily life. The two diverge in most other respects, however. Fengyue meng comprises a true city novel, never leaving Yangzhou, while Qingfengzha is set in a town in a prefecture bordering Yangzhou. The sense of local identity, while strongly present in each work, differs in both substance and expression. Thus each work embodies the interest in local identity in its own way.

Understanding the relationship of these novels to the Yangzhou region requires us to examine the social context of fiction in the Qing. Cynthia Brokaw's model is helpful to determine where these narratives fall on the spectrum in late imperial China. In Commerce in Culture, Brokaw argues that commercial printing in the Qing allowed book culture to spread into even the hinterlands and across all social and educational strata. She proceeds to differentiate between a 'select' strata of specialized texts aimed at the small segment of highly educated men throughout the empire; a 'core' of 'bestselling' reading material which extended socially across all literate levels 
and geographically across the Chinese empire; and texts largely of 'local' interest. Her model considers factors such as print quality, geographic distribution, and how accessible the language of the imprints was. By considering the production and distribution of texts as material objects, Brokaw's model provides a realistic way to hypothesize who the audience for particular texts might have been. In this scheme, most novels would be 'bestsellers' appealing to a national audience, while cheap chantefables printed in dialect epitomize the 'local' (BROKaw 2007: 8, 557-58).

Like most successful novels published in the Qing dynasty, Fengyue meng spread from its local origins to be published for a national readership, in this case by the Shenbaoguan in Shanghai. ${ }^{2}$ The 'bestsellers' in general crossed social boundaries and were read by all literate segments of society throughout the Chinese empire. Fengyue meng even attracted the attention of famous literati and intellectuals like Han Bangqing (Hanan 2004: 35). But what of the other, less studied category of 'local' texts? Qingfengzha's publishing history places it in that group. Its publication during the Qing was almost exclusively limited to Yangzhou. ${ }^{3}$ Why would it be a success locally but not find publication elsewhere? Does it target local audiences? How does the narrative portray the local?

Before attempting to answer these questions, we must explore what 'local' might mean in Qing Yangzhou. As Antonia Finnane points out, because of Yangzhou's special position as the center of the Salt Monopoly, 'sojourners' from other parts of China, especially Huizhou merchants, dominated Yangzhou society. It was mostly the little people who were from Yangzhou and the surrounding area. In her discussion of the construction of identity in Qing Yangzhou, Finnane notes three sets of social distinctions (city versus towns and rural areas; moneyed elite versus common people; and sojourner salt merchants versus natives of Yangzhou), which she argues 'can with some license be collapsed into one' (Finnane 2004: 288). These distinctions played themselves out in cultural practices so that, for example, in drama the Huizhou merchants sponsored Kunqu 芘曲, while the locals enjoyed performances of luantan 亂彈 in Yangzhou dialect. ${ }^{4}$

These three sets of distinctions provide a way to discuss how Qingfengzha was marketed, the implications of its narrative techniques, and the view of Yangzhou regional identity it presents. Since Qingfengzha has received little scholarly attention, I will also discuss its two main sources: the oral storytelling tradition of $\mathrm{Pu}$ Lin 浦 琳 (Qianlong era) and his disciples on the one hand, and a short story on the other. I will introduce what is known of the storyteller who created the oral repertoire QINGFENGZHA, ${ }^{5}$ and the novel's relationship to the short story it draws upon.

\section{PU LIN AND HIS STORYTELLING}

As mentioned above, Li Dou recognized Pu Lin as one of the greatest Yangzhou storytellers of his era based on his telling of QingfengzHa. Elsewhere in Yangzhou huafang $l u$, Li Dou 
states that the character Pi Wu 皮五 (Pi Fengshan) in the oral repertoire QINGFENGZHA is autobiographical, based on the storyteller Pu Lin's own experiences (Li Dou [I797] I963: 455-6, 56I). He gives a brief biography: orphaned in his youth, Pu Lin was a beggar until a townswoman took pity on him and found him a bride. He made a living by sweeping the streets, then gambling, then taught himself the art of storytelling.

The neighbor woman had a nephew who told stories, pinghua 評話, for a living. Every day he would practice in the woman's home. When Pizi (Pu Lin) had heard it a long time, he thought storytelling was not hard to learn. But all the tales, shuobu 說部, were too familiar to people, so he took his own experiences, under the fictional name Pi Wu, and created the story Qingrengzha.

(Li Dou [I797] I963: 455-6)

Here we seem to have the nucleus of the novel Qingfengzha: its subject and main character. Another biography by Jin Zhaoyan 金兆燕 from Anhui gives a somewhat different account of Pu Lin's initiation into storytelling.

Pu Lin, styled Tianyu, was from Jiangdu in Yangzhou ... Pu Lin did not read ... One day when he was passing by the marketplace, he heard someone telling stories, pinghua, and liked it ... In the days that followed he got some books by novelists, xiaoshuo jia 小說家, about deeds and consequences, yin'guo 因果, and had people read them aloud so he could listen; after hearing them one time, he would never forget. Thereupon he embellished the language and described the forms, and told them back to people. There was no one who heard it who was not moved and startled, and some even cried. ${ }^{6}$

This biography gives us two important pieces of information: the storyteller Pu Lin was a native of Yangzhou, and he was illiterate. Apparently he also drew on written popular culture, mediated through others' reading. Elsewhere in the biography Jin Zhaoyan mentions another story Pu Lin told, rather than QIngfengzha. We have no way of knowing what written fiction Pu Lin might have drawn on in his storytelling. One might speculate that the text Qingfengzha could plausibly represent a double interchange of written and oral: from written story to oral telling, and from oral telling to written novel. Each step would involve adaptation to the medium and genre. We have the texts from the first step and third step, but of Pu Lin's actual performance we have of course only anecdotes. ' Even if we posited that the text of the novel Qingfengzha was written based (however distantly) on the oral repertoire, we would have to account for the anonymous person who wrote it down. Recent research on storytellers' scripts shows that even when the storyteller himself writes down a story from his repertoire, his own notation varies considerably from the tale as he tells it (BøRDAHL 2005). This discrepancy between oral and written is inevitable, and would probably be exacerbated when another person records the tale. 


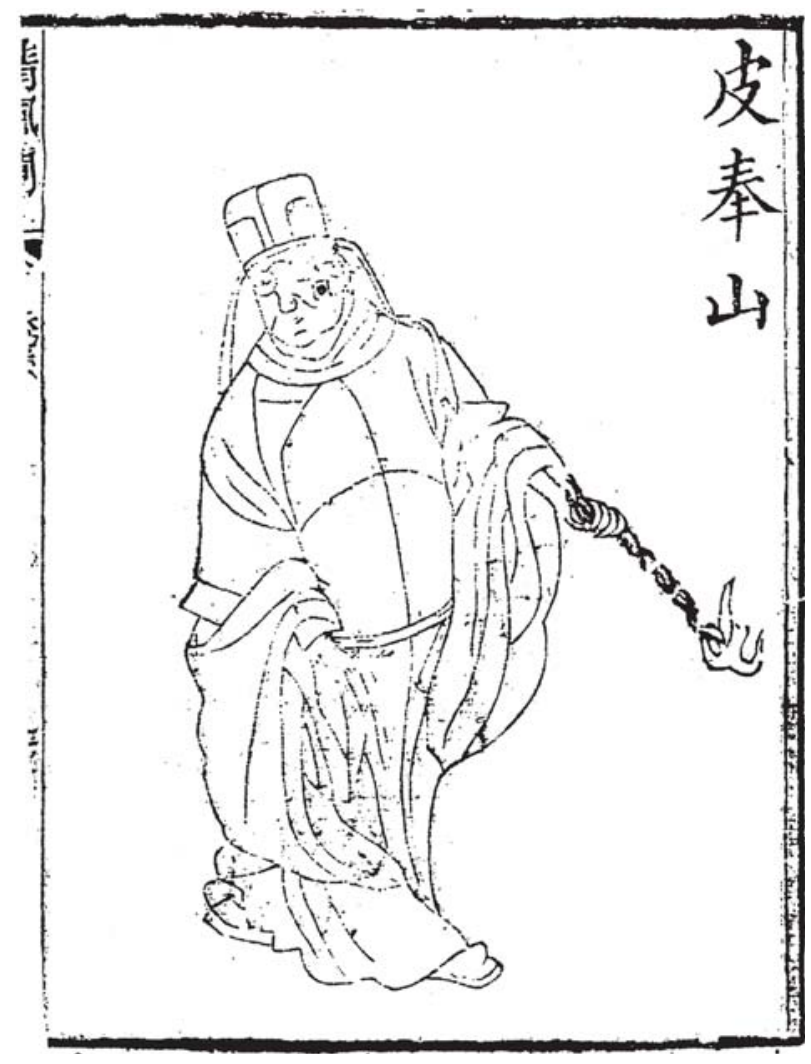

Figure 9.1 The scoundrel, Pi Fengshan or Pi Wulaizi, Qingfengzha (1819).

$\mathrm{Pu}$ Lin did more than capture the attention of his biographers. Jin Zhaoyan writes that $\mathrm{Pu}$ Lin performed before the ladies and gentlemen, shi nü 士女, of Yangzhou, and recounts an incident where his storytelling moved the rich ladies and even their maids and cooks to charity. As a native of Yangzhou living in the Qianlong period, $\mathrm{Pu}$ Lin's ability to appeal to rich and poor alike also suggests a transcendence of the boundaries between Huizhou sojourners and Yangzhou area locals. Pu Lin seems to have become affluent later in life, though whether he made his fortune through storytelling or gambling depends on the account. Jin's biography notes his refusal to wear fine clothes or eat delicacies, and his initiative to provide warm coats for the poor and to fix the roads of Yangzhou (TAN Zhengbi 1985: 78). By doing such good works, Pu Lin acted in an 'elite' manner.

\section{JUDGING A BOOK BY ITS COVER}

Let us now turn to the novel. As we have it, Qingfengzha consists of two intertwined strands: a court-case frame story revolving around a murder, and the central story 
of Pi Wu the Rogue, Pi Wu Laizi 皮五癩子, a notorious swindler (Fig. 9.I). ${ }^{8}$ It starts out with Sun Dali, a timber merchant from Taizhou, Zhejiang Province, who gets stranded in Dingyuan County 定遠縣 with his wife and daughter, Xiaogu (Fig. 9.2). He settles down there and becomes a clerk. His wife soon dies, and he remarries. Meanwhile, Sun Dali takes pity on Sun Xiaoxu, a literate orphan beggar; he sets him up as a clerk, trains him, and adopts him as a nephew. His new wife, Qiang Shi, starts an affair with the adopted 'nephew,' which leads her to murder Sun Dali. She covers the crime by making it look like suicide; the neighbors see 'Sun' jump into Qingfeng Sluice. She then marries Sun Xiaoxu and rids herself of the daughter by marrying her off to the ne'er-do-well Pi Wu the Rogue.

$\mathrm{Pi}$ Wu continues to gamble, paying almost no attention to his bride, who relies on the matchmaker Zhang Mama to survive. When Xiaogu is on the point of committing suicide one night, her father's ghost appears. It gives her a verse to help solve the crime, helps her borrow money from Sun Xiaoxu, and tells Pi to treat his daughter better or else. Pi continues drinking, gambling, and swindling. On New Year's Day, when Pi has gambled all their possessions away, he begins winning. After a few days,

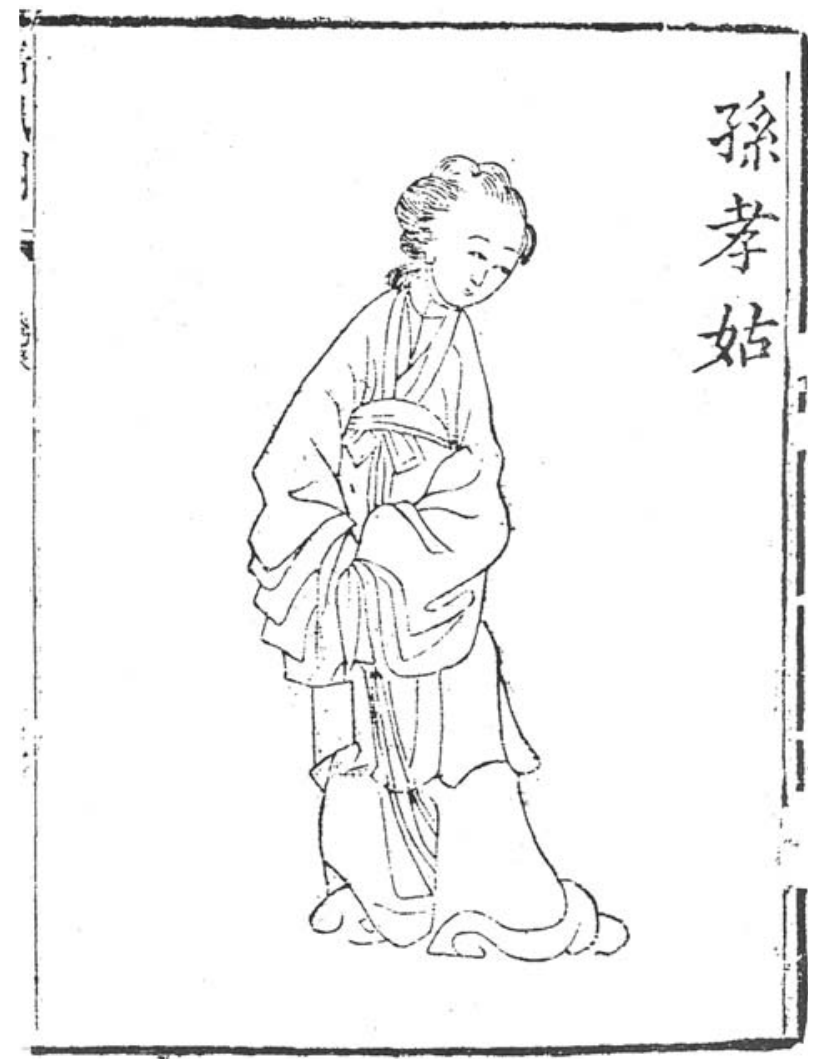

Figure 9.2 The virtuous girl, Sun Xiaogu, Qingfengzha (1819). 
dressed respectably, he is invited by the shop owners to a gambling party. He wins a huge fortune over two days. He buys a grand house, hires servants, and invites Zhang Mama to live with them. He gives up drinking and becomes a pawnbroker, then buys status as a Vice Director, yuanwailang 院外郎. He and Xiaogu have a son. Later, when Judge Bao is sent to the area, Xiaogu gets Pi Wu to air her father's grievance. Judge Bao solves the case, and Qiang Shi and Sun Xiaoxu are executed. $\mathrm{Pi}$ Wu and his family live happily ever after.

The text Qingfengzha presents a puzzle. It appeared in the Jiaqing era, well after the oral storytelling repertoire by the same name became famous. Aside from the title, however, it never explicitly makes the connection. Instead, the preface and physical format package it as a novel. But Qingfengzha only superficially fits the category. While it apparently failed as a 'novel,' and never became a national bestseller in the Qing, it succeeded in appealing to local audiences, perhaps in part due to its evocation of local storytelling practices. Thus the text attests to two possible 'genres' through which it could be understood, each with a different implied audience.

The preface to the novel Qingfengzha by Master of Plum Spring, 梅溪主人, dated I8I9 specifies its purpose and reading public in some detail.

Fiction, xiaoshuo 小說, began with Yu Chu 虞初. ' Later, some creating popular elaborations, yanyi 演義, took one person and event then broadened it out, often producing several tens of thousands of words, such as Investiture of the Gods and The Water Margin, which have been around a long time. Others were written out of thin air, concealing the people and hiding the events, like Jin Ping $M e i$ and Story of the Stone. After a while no one knows who they really refer to, and readers just tell each other it is so and so. Only with the book Qingfengzha, not only did the events truly occur, but the people also really existed. It's about a Song Dynasty injustice, and borrows Pi Fengshan to right the wrong. Fengshan was a town idler. The poorer he got the more despicable he became; not only did his family refuse to speak to him, but the people of the area were full of hatred and enmity. He was nearly driven to his death before he was reborn ... After he realized his ambition, this was Heaven sending him to right the wrong, and not allowing him to die of poverty.

(Ding Xigen 1996: 1624-65)

The first section of the preface places Qingfengzha in its literary context, invoking bestselling novels and arguing that this novel outdoes them. The claim that Qingfengzha excels by depicting real people and events revolves around someone called Pi Fengshan. However, giving credence to the Song Dynasty setting obfuscates any connection with reality the work might otherwise claim. The preface never mentions Pi Fengshan's origins or connections with the storyteller. Furthermore, no author appears on this edition. The preface goes on to discuss how the work came to be published. 
Everyone who sees, lan 覽, this book says wow in admiration . . Because this book is widely praised, and can reverse the trend toward decadence, I regretted that there had never been a printed edition, so it could not be passed down or go far. Today, with no regard to the cost, I sent it to be carved [on printing blocks], hoping to make it so in poor areas and remote places, seashores and mountainsides, there is no one who cannot buy a copy.

The publisher imagines this book will reach a rural, geographically diverse, and not necessarily affluent audience. ${ }^{10}$ The remark that the work was 'widely praised' before it was printed is also suggestive. We might surmise that it circulated in manuscript before being published. Since we know from Yangzhou huafang lu that the story was performed by the Yangzhou storyteller Pu Lin, ${ }^{11}$ it is tempting to speculate that it may have gained popularity through oral storytelling and been recorded from memory. However, the preface makes no reference to storytelling. When the preface speaks of the book circulating before it was published, the verb for 'sees', lan, is appropriate for a text but would not be used for watching oral performance. Finally, the publisher justifies the work as exerting a positive moral influence, one of the most common apologies for fiction. Despite the phrase 'no regard for the cost,' the book is an ordinary or even crude edition. The publisher's aspirations came true only in part. Although Qingfengzha was 'passed down' and reprinted, it never seems to have 'gone far' and was reprinted only in Yangzhou through the Qing dynasty. ${ }^{12}$

Qingfengzha makes a strange novel. Although its preface, title, and physical format (chapter divisions and headings) fall within the conventions of the novel, the narrative does not. Anomalies in its narrative technique point to a close relationship with storytelling. It evokes the storytelling milieu for its readers in quite specific ways. For example, while the traditional Chinese novel uses markers like 'he said' and 'she thought' to set off dialogue and monologue, in Yangzhou pinghua 揚州評話 dialogue without markers abounds. In oral performance the storyteller's manner of speaking would mark the change from one character to another, making tags like 'he said' or 'she asked' unnecessary (BøRDAHL 2005: 255, 269). This break with the conventions of the novel occurs frequently in Qingfengzha. ${ }^{13}$

Yangzhou dialect appears throughout the novel Qingfengzha. Distinctive usages such as zaikuai 在快 [there] /zae kuae/, ba 把/ba/ as main verb 'give', and meide 没得 [does not have] /me' de'/ are too many to list (Fig. 9.3). ${ }^{14}$ Significantly, they occur in the narration as well as in dialogue. While traditional Chinese novels do make use of dialect to allow characters to speak in role, extensive and consistent use of dialect was rare before the nineteenth century. Even then, dialect generally appears in dialogue rather than narrative. To the extent that Qingfengzha diverges from the conventions of the novel, it evokes Yangzhou pinghua's distinctive manner of speaking rather than transcribing it in standard Mandarin. While Yangzhou storytelling often plays 
with linguistic registers, it is performed in Yangzhou dialect. Thus language also marks the text of Qingfengzha as local. ${ }^{15}$

For the purposes of this chapter, I define the 'local' Yangzhou region primarily by shared dialect features. Dialect in the novel Qingfengzha appears on the page as grammatical divergences from standard Mandarin such as the examples listed above, as well as particular idioms. ${ }^{16}$ Some grammatical features of Yangzhou dialect are shared with Jianghuai Mandarin. ${ }^{17}$ Others may be of more limited usage but are used in Dingyuan County (the setting of Qingfengzha), which belongs to the same subgroup of Jianghuai Mandarin as Yangzhou. ${ }^{18}$ This definition of the region by dialect coincides with the practice of Yangzhou storytellers, who operated in a large area around the Grand Canal and the lower Yangzi. On the other hand, it preserves the distinction Finnane notes between 'locals' and 'sojourners' in the Yangzhou region. It is worth noting that some linguists consider Huizhou speech an independent dialect (Li Huimin 2004). In the Language Atlas of China, Huizhou dialect is considered a major dialect on a par with Jianghuai Mandarin or Wu dialect, and is clearly distinguished from the dialect common to Yangzhou and Dingyuan County (Wurm et al. I988: B3, Bio). Thus in either Dingyuan County or Yangzhou, the Huizhou 'sojourners' would stand out, as would speakers of Wu dialect. Evidence suggests that a similar social dynamic was at work as well in both Yangzhou and Dingyuan County, Anhui. Huizhou sojourners, as merchants and pawnbrokers, exerted a considerable influence over the towns in which they lived. A saying current in the region went, 'Without Huizhou merchants, there would be no town', wu Hui bu cheng zhen 無徽不成鎮 (WANG Zhenzhong 2002). The lines between 'locals' and 'sojourners' are best understood as linguistic and social rather than administrative boundaries. ${ }^{19}$

Dialect must have been important to identity in Qing Yangzhou. The 'sojourning' merchant population would speak differently from the locals. 'In Yangzhou, the marketplaces must have echoed with the sound of various languages and accents, with buyers and sellers sometimes struggling to reach understanding' (FInNANE 2004: 289). What purpose does the use of dialect serve in this novel? On the simplest level, dialect serves to distinguish between sojourner and native. Qingfengzha begins with a stranger who gets stuck in Dingyuan County on his travels. This opening - a stranger coming in from outside - bears a striking similarity to the beginning of the plot proper in Fengyue meng, but the way the trope develops diverges sharply. Unlike Fengyue meng, which effectively introduces the city of Yangzhou to the stranger, Qingfengzha presents its setting in Dingyuan County as familiar. In Fengyue meng, Lu Shu's position as an 'outsider' from Changshu means the novel often makes a point of him not understanding local speech or customs, which must be explained to him. ${ }^{20}$ Fengyue meng emphasizes Lu Shu's status as a stranger when he appears on the streets of Yangzhou: as he wonders about what he sees, the narrator states, 'It 
was Lu Shu's first time in Yangzhou, so he didn't know why and there was no one he could conveniently ask.' (28) Later he is puzzled by the others' teasing, and they have to explain 'a Yangzhou saying of ours', women Yangzhou de suyu 我們揚州的俗語 (49).

While Fengyue meng carefully points out and explains certain Yangzhou usages, in Qingfengzha Yangzhou dialect simply serves as the unmarked medium of communication. Shan'e tu makes this even clearer by explicit labeling when characters speak standard Mandarin, Jinghua 京話 (II5). More subtly, in Qingfengzha the speech of sojourners calls attention to their origins, but scenes of misunderstanding, so common in Fengyue meng, are absent here. A key moment in Qingfengzha turns on one character taking an interest in another due to his accent. Early in the novel, Sun Dali, a timber merchant from Taizhou 台州 in Zhejiang Province, gets stranded in Dingyuan County and is making his living as a tavern keeper (25). A worker from the yamen deduces from his accent that he is not a local and offers him a job as a clerk. But promotion based on accent or native place works for both good and ill; it makes Sun Dali and it destroys him. It is his decision to adopt his 'fellow countryman,' tongxiang 同鄉, Sun Xiaoxu and give him a job in the yamen that eventually

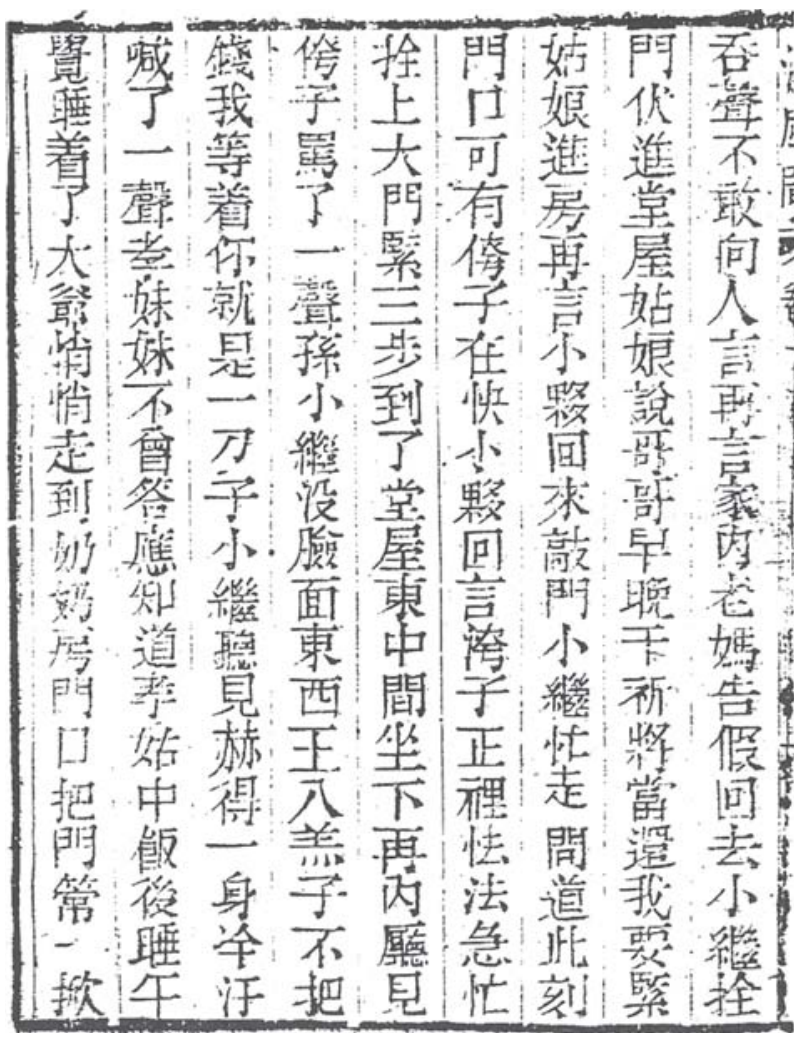

Figure 9.3 A sample page from Qingfengzha (1819) with examples of Yangzhou dialect, such as zai kuai [there], 4th column; ba [with, take] as a main verb, 6th column. 
leads to his own murder. ${ }^{21}$ Still, even the stereotyped rough-and-ready types from Shanxi, who are marked by a derogatory Yangzhou nickname for 'northerner' as well as their distinctive speech, seem well integrated into society in Qingfengzha. ${ }^{22}$

While the unavoidable gap between oral and written makes any attempt to see the extent to which this novel reflects actual practices of Yangzhou pinghua 揚州評話 misguided, narrative anomalies suggest that the text of Qingfengzha evoked local storytelling conventions for its readers, as did Shan'e tu and Fei Tuo quan zhuan. Why, then, would they be published as 'novels'? Part of the answer lies in the conventions of Yangzhou storytelling. Yangzhou pinghua primarily employs prose, so a record evoking it might easily take this format, unlike the translation that would be necessary from prosimetric storysinging forms like lute ballads, tanci 彈詞, or drum ballads, guci 鼓詞. ${ }^{23}$ Indeed, Yu Yue's 俞樾 comments about the novel Qingfengzha show that he was reading it as a record of storytelling, hoping to find in it the brilliance that inspired Li Dou's comments. Yu Yue found the work disappointing, noting, 'I have read this book, and it is without any great merit ... Could it be that the wonder of his speech is not captured by the pen? ${ }^{24}$

\section{QINGFENGZHA AND ITS WRITTEN SOURCE}

Besides the issues raised by Qingfengzha's evocation of storytelling practices, the novel also draws on a Ming short story. The novel Qingfengzha borrows the material for its framework from the early vernacular story 'The Ghost Appears Three Times,' Jingshi tongyan 驚世通言 (\#13), a court-case story (MA 1979: 252). Within that framework, about half of the novel depicts the antics and reform of the goodfor-nothing Pi Wu the Rogue (Pi Wu Laizi). While Qingfengzha borrows from an earlier short story, it is not textual borrowing. It takes some ideas for dialogue, and retains most incidents. Still, while preserving the basic story line, it radically changes its presentation and interpretation. The structure of Qingfengzha differs considerably from that of the short story. Whereas 'The Ghost Appears Three Times' proceeds as a court-case mystery, only revealing the nature of the crime at the end, Qingfengzha discloses the crime and its perpetrators early on. The short story relies on suspense, as the reader figures out what happened. Even with the final solution of the crime, the short story provides only a cursory explanation, leaving some of the details in the dark. As with many court-case stories, it pays little attention to character development, instead tending to use stock types in service of the plot.

Qingfengzha, on the other hand, gives the reader superior knowledge, allowing one to see everything as it happens. The interest in Qingfengzha does not rely on suspense; it almost becomes character-driven rather than plot-driven. While still based 
on stock types, Qingfengzha works at revealing the psychology of its characters and why they make particular decisions. These differences in narrative technique make the frame story of Qingfengzha read more like a 'folly and consequences' story. ${ }^{25}$ Heavy use of foreshadowing combines with narrator's comments to point out the moments of bad judgment that lead to ruin. Sun Dali's undoing is clearly shown to be a result of his own weakness. Though he is aware of the dangers of remarrying, and tries to resist, his desires overcome his judgment.

Every day he went out and entered the yamen, working very diligently. It was just when he came back at night that he felt the bitterness of being alone. Even though he could talk with his daughter, father and daughter slept in separate rooms. So when the old father went to his room he couldn't help that half the bed was ice cold, and in his heart wanted to take another wife. Tossing back and forth, it was hard to sleep at night.

(Qingfengzha: 1.28)

In order to present the crime as a mystery, the short story does not specify anything about his wife, so Sun, as well as the reader, is taken completely by surprise. In contrast, in Qingfengzha his virtuous first wife dies, and all sorts of dire foreshadowing appears when he takes another wife. Moreover, when Sun Dali hears he can marry Qiang Shi without paying a bride-price, his love of a bargain makes him take her without looking into her background. The narrator opines, 'A bargain is the backdoor to being taken advantage of,' pianyi shi chikui de houmen 便宜是吃虧的後 門 (2.32).

In the frame story, the characters are ruined by their own folly. Just as Sun Dali's fatal decision to remarry leads to his death, young Sun Xiaoxu's dalliance with prostitutes begins his downfall. Stinginess is a factor in both cases. Because Sun Xiaoxu keeps most of the clerk business for himself and shows off his earnings without sharing them with his colleagues, his jealous peers plot his ruin and send someone to take him to the pleasure quarters. The prostitutes in Qingfengzha are simply stereotypes, not individualized characters as they are in Fengyue meng. While Qingfengzha portrays the effect living in the brothels had on the young man - he felt like an immortal, shenxian 神仙 - it is not glamorous, nor anything he sought out himself. Instead he resembles the son led astray in vernacular short stories. Sun Dali's reaction is also like that of the fathers in those stories: he is irate, because the brothels are a slap in the face of everything he has worked for (4.46). Sun Xiaoxu then sees through the schemes of the brothel and delivers a first-person lecture to the readers warning them against visiting prostitutes.

I urge all you young brothers, zhuwei shaonian zidi 諸位少年子弟, you absolutely cannot fall for mist and willows [prostitutes]. I, Sun Xiaoxu, used to have money in hand, and the madam and girls used a hundred tricks to get close 
to me and a thousand ways to flatter me. But now when my hands are empty they use all kinds of language to hurt me without considering old times. Isn't it awful?

(Qingfengzha: 4.48)

Besides the striking way the character breaks through the frame of fiction to converse directly with his readers, this lecture also suggests that the implied readership for Qingfengzha included young men who might benefit from the lesson. ${ }^{26}$

If the prostitutes are primarily faulted for their heartless greed, the wanton woman's appetite for sex also poses grave danger. Indeed, the attitudes toward sex in Qingfengzha bear a striking resemblance to those in many early and middle period vernacular short stories. ${ }^{27}$ The poem that opens Chapter 8 expresses this danger in well-worn images.

A sixteen-year-old beauty, her body seems weak.

That sword beneath her waist will do foolish men in.

Even though you never see a human head fall,

Secretly she'll make your body wither.

(Qingfengzha: 8.65)

In keeping with this type, Qingfengzha portrays Sun Dali's second wife, Qiang Shi, as a siren or succubus who exhausted her first husband, murders Old Sun, and comes close to exhausting her lover, the young Sun Xiaoxu. (8.68)

Still, few of the characters in Qingfengzha are simply black and white. Even the adulterers Qiang Shi and young Sun Xiaoxu perform the proper rites for Sun Dali after his death, and the narrator attributes it to their conscience (8.64) or good intentions (9.72). Indeed, Qingfengzha portrays Qiang Shi's decision to kill her husband as almost a case of possession. 'As the missus was walking to her room, a strange wind arose and a black ball rushed at her and struck her. Suddenly her willow eyebrows stood on end and her beautiful eyes bulged out with a killing air; as she walked out how fierce she looked!' (7.62). Implicitly the possession partially exonerates Qiang Shi, making her slightly less culpable than she would be for the premeditated murder of her husband. Thus the least sympathetic characters are still portrayed as human rather than as purely evil. The only unambiguous characters in the novel are the paragons, Judge Bao and the virtuous daughter Xiaogu.

The novel Qingfengzha can be divided into two main story lines. Within the court-case frame story, the tale of $\mathrm{Pi}$ Wu functions almost as an independent narrative. The central position of this inserted tale comprises a further difference between the structure of the novel Qingfengzha and that of the short story. However, it develops a possibility present in the original short story in the role of the gambler Wang Xing, also known as 'Wino' Wang, Wang Jiujiu 王酒酒.

This other line of Qingfengzha treats Pi Wu's outrageously idle existence as humorous, rather than as a serious folly story. The difference between the two lines 
of the narrative amounts almost to a shift of genre when he appears. Unlike the folly story's emphasis on the consequences of a lapse in judgment, we are never shown how $\mathrm{Pi}$ Wu came to be the inveterate drunkard and gambler he is. There is one indication that he had seen better days - Zhang Mama says he had owned a pawnshop - but the rest of his background is left in the dark. Although his behavior and attitude are often totally incorrigible, he still comes across as a fascinating, slightly larger than life character.

\section{THE VIEW FROM BELOW}

The court-case framework allows a low mimetic level. On the surface, the social world of Qingfengzha is similar to that of the short story on which it draws. Old Sun is a Headquarters Clerk, yasi 押司, in the short story and a Clerk, shuli 書吏, in the novel. For most of the tale he represents the highest rung on the social ladder. Qingfengzha, however, dwells more on the social world of Pi Wu and his cronies. Thus much of the novel revolves around beggars, ne'er-do-wells, peddlers, and pawnbrokers.

While the social level of the novel may resemble that of the middle period short story (ca I450 to I550), Qingfengzha's world view is not the simple utilitarian morality Hanan observes in 'Hangzhou realism' (Hanan 1981: 60-6I). Pi Wu wins at gambling, and is unrepentant even after taking a bride. Most of Pi Wu's antics are related in the light-hearted spirit of the early vernacular short story 'Song Four Causes Trouble for Mister Zhang,' which also has indirect ties to Judge Bao and most likely has roots in oral storytelling (HANAN 1981: 50-5I). Just as in the story of the master thief, in Qingfengzha we are not outraged by Pi Wu's stealing, but wonder how he will trick people and get away with it. Although Pi Wu's only assets are his quick mind and utter brazenness, his self-aggrandizing speech and manner remind one of the 'good fellow', haohan 好漢, tradition in literature (although it may be simply funny or rude). One extreme example comes when his new bride asks Pi about his trade when he finally returns home after eight days of absence. He replies,

Missus, you really are clueless! You didn't inquire into my background before you married me? Missus, wait for me to tell you, listen now, let me tell you my official station, listen well. I'm the court's rebellious son, a die-hard trickster, the crow-devil, a leech. I'm the Warm Wine Star in heaven come to earth, the reigning Emperor of the Con Men. Name's Pi Fengshan, nicknamed Wu the Rogue, don't you know?

(Qingfengzha: I4.I06)

In keeping with his self-styled title of Emperor, Pi Wu also uses the imperial 'we' (I5.III). Naturally the contrast between the imperial 'we' and the penniless drunkard uttering it makes it funny. Although Pi Wu's sometimes endearing irreverence may call to mind heroes of Shuibu zhuan like Lu Da, it goes far beyond them. Pi Wu's 
actions also are less justified. He is neither standing up for others nor opposing hypocrisy. He is simply looking out for himself. The loyalty and brotherhood that are central to the haohan have little relevance in Qingfengzha. The low social status and provincial setting make loyalty to the emperor seem irrelevant, while Pi Wu's treatment of his former cronies shows almost no sense of obligation. Once he becomes wealthy, the Confucian proverb about choosing friends who will benefit you justifies his farcical banquet as an acceptable way to break with them.

The scene is quite humorous. In keeping with his new status, Pi Wu's manner of speaking also undergoes a transformation. 'Master Wu as an honorable man was of few words,' guiren shaoyu 貴人少語 (26.166). Thus the servant sent out with the invitations has no idea where to find these men, who have only nicknames like 'Scabby' or 'Wanderer,' until a gatekeeper clues him in. In preparation for the hoodlums' arrival Pi clears the good furniture out of a room in his mansion and puts in old broken stuff, locking up the rest of the house. As they drink he declares that he does not owe them anything, then threatens them with his new friend Chen Buya, a yamen runner, whereupon the ruffians bolt. (27.170) The oxymoron of a beggar's banquet underlies the scene. However, this scene forms a sharp contrast to the true beggar's banquet at Pi's wedding. There Pi and his guests made merry with cast-offs and food wangled from neighbors. Now, in his new role as a wealthy and respectable man, $\mathrm{Pi}$ is putting his former cronies in their place. The very idea of the dregs of society dining at Pi's new mansion is comic, and the scene plays on the contrast. The staged nature of this 'banquet' - using furniture appropriate to beggars instead of his fine new things - shows Pi's understanding of the other men's desperate nature and his desire to protect himself from them, but it also serves to show how far he has come. He is no longer one of them, nor does he wish to be.

Much of Qingfengzha revolves around the largely comic flouting of social conventions, either in the unthinkable acts of the adulterous wife or the merry tricks of the protagonist Pi Wu. In this respect, the novel Qingfengzha parallels Pu Lin's storytelling, which as Li Dou noted satirized rules and prohibitions, fengci guijie 諷 刺規戒 (Li Dou [I797] 1963: 455-6). Still, in the novel customs and rituals provide the implicit norms against which to measure the characters, both socially and morally.

Qiang Shi's insistence on marrying her lover Sun Xiaoxu uses the contrast with the ideal to portray her utter shamelessness. In the short story 'The Ghost Appears Three Times' the widow seems to set impossible conditions for remarriage, which the matchmaker manages to meet, thereby preserving her reputation and deepening the mystery. In Qingfengzha, however, the scene becomes comic by flying in the face of norms. The wedding goes against propriety on several counts. First, despite the fact that they are not blood relatives, they are in name 'aunt' and 'nephew,' or effectively mother and son. Secondly, the narrator notes that she marries before the hundred days of mourning are over. Even Sun Xiaoxu is shocked when she suggests 
the wedding; he suggests they should keep things as they are since marrying would be against propriety (9.7I). She insists, and he gives in. They buy fashionable cloth, hang lanterns and decorations, buy red candles, and are busy preparing for three days. Sun Xiaoxu waits in trepidation before the banquet, wishing it would pour rain so no one could come. Even after the guests arrive Sun Xiaoxu is too embarrassed to say why they have been invited. His roundabout explanations keep the guests guessing until Qiang Shi forces him to start the ceremony. When the guests realize Sun Xiaoxu intends to marry his 'aunt,' they curse him, slap him, and leave outraged. Qiang Shi curses back, and says if she was not afraid of scaring off the spirit of felicity, xishen 喜神, on her wedding day, she would fight them (9.74-75).

Thus everything about the wedding inverts the ideal. As the verse that opens the chapter states, here marriage, instead of fulfilling one's fate, goes against proper relations, and in so doing brings early death rather than longevity and good fortune. Similarly, instead of the harmony prescribed for a wedding day, here all chaos breaks loose. Even the cooks they hired call them beasts and leave. Xiaoxu and Qiang Shi then go through the ceremony all alone (I0.77). The wedding scene depicts Qiang Shi as lascivious and shrewish.

In contrast, the narrator is much more sympathetic to Pi Wu, despite his faults. The narrator's stance appears most clearly in the verse commentary, especially at the beginnings of chapters. Pi Wu's match to Xiaogu is treated positively:

The great event of marriage does not occur by chance, of course it is the moonbeams that secretly bind.

The husband sings, the wife follows, harmony' til old age,

in years to come longevity and good fortune will both be theirs.

(Qingfengzha: II.85)

This idyllic vision of marriage is by no means realized immediately in Pi Wu's case, but it does come true by the end of the novel. Still, the ceremony itself is another parody of matchmaking and wedding preparations. Whereas Qiang Shi had all the outer trappings for a wedding that was a moral farce, Pi Wu's utter poverty creates a farcical ceremony but a true bond. Qiang Shi decides to get rid of her stepdaughter Sun Xiaogu by marrying her off and charges the matchmaker, Zhang Mama,

'Help me find someone without a tile above his head or an inch of ground below, who will curse every time he opens his mouth and hit every time he moves his hand, a real good-for-nothing ... I don't care if he's scabby or pockmarked, ragged or crippled or blind. First I don't want anyone outstanding, second I don't want anyone well dressed, third I don't want any bride-price, fourth I don't want anyone rich or powerful, fifth I don't want anyone wellconnected, sixth I don't want to choose a good family, seventh I don't want a family on the rise, eighth I don't want an established tradesman, ninth I want 
someone who fights and tenth I want a drunkard.' When Zhang Mama heard this she was upset, but since there was the gleaming silver she couldn't return, she had to agree.

(Qingfengzha: Io.82)

She finds exactly what Qiang Shi wanted in the ne'er-do-well Pi Wu the Rogue, and proposes the match to him that evening. Even he cannot take it seriously:

Mama, any other family might do, but if you say Master Sun's family, Mama, [how could it be] they don't want anyone on earth but have decided on me, $\mathrm{Pi}$ Wu the Rogue? It wouldn't hurt [to tell me]: is it my good character? My eloquence? My family background? My appearance? Mama, just tell me what they see in me, there's no harm, right? If you want to discuss character, mine is tops. If you want to know about me, my $\mathrm{Pi}$ Wu the Rogue pointy head and jowls are extra extra special. Fine baliao 罷了! If you're going to be my matchmaker, there's something I want to say at the outset: if you expect me to provide for her, that will never be. In good weather we'll each provide for ourselves, and in bad she'll have to give me a meal. Mama, if you can make this match, you can invite me to drink a pint to celebrate; if it doesn't happen, you can give me a pint to comfort me.

(Qingfengzha: II.87)

Both speeches invert the usual criteria for matchmaking to comic effect. In addition, Pi Fengshan's disbelief finds a parallel in Li Dou's biography of the storyteller Pu Lin. When a neighbor woman told him she had found a bride for him, he thought it was a joke. On the appointed day, she had to search him out and force him to come to the wedding ceremony. ${ }^{28}$

\section{EVOKING THE LOCAL}

If the courtesan novels can be read as a kind of handbook to the pleasure quarters, Qingfengzha's depiction of the details of daily life, such as shopping, ritual occasions, and festivals, gives a sense of the norms of day-to-day existence. It is tempting to see the documenting of social customs in Qingfengzha as a popular equivalent of the Yangzhou local histories that emerged around this time. A similar impulse animates Fengyue meng, but again it is carried out differently. Fengyue meng spends whole pages describing local practices step by step, seemingly introducing them to the neophyte and consequently making the novel more accessible to outsiders. Qingfengzha, on the other hand, apparently assumes knowledge of the rituals it merely refers to.

Take, for example, the New Year's celebration that occupies Chapters I6-I8. Most of these three chapters revolve around Pi Wu's tricks putting together the customary feast. As the New Year approaches Pi Wu and his wife Xiaogu have neither firewood 
nor rice. Pi wangles sticky rice, dregs, fodder beans, and taffy for the kitchen god out of different vendors 'on account.' They send off the kitchen god, and Xiaogu is pleased that $\mathrm{Pi}$ is reforming (I6.II9). Pi Wu makes a hole in the mat roof for the kitchen god to exit through, and addresses him,

Your disciple Pi Wu the Rogue this year has only plain candles and incense, with no offerings of the three sacrificial meats. If you protect your disciple and help me get rich next year, I will certainly buy the three sacrificial meats and offer them in full ceremony. This year we hope your spirit will forgive us. Eat up, old man, no one is going to keep you company!

(Qingfengzha: I7.I2I)

Besides showing their utter poverty and Pi Wu's new-found concern for his wife, the scene also refers to local customs of the Yangzhou area in the use of sticky rice to send off the kitchen god (Finnane 2004: 29I). However, it does not describe the kitchen god dinner they make from the materials Pi Wu brings home. Perhaps the list of ingredients is sufficient to bring to mind familiar customs, like turkey and mistletoe for Americans. In this way Qingfengzha evokes rather than describes, forcing the reader to fill in the gaps. The way in which this is done suggests that the narrator and implied reader belong to the same community. Similar techniques are common in oral storytelling, for instance, in which the storyteller assumes that the audience has a general knowledge of the tale he is telling, and can simply refer to other parts rather than needing to explain (BøRDAHL 1996: 184, I86).

Another clear difference between Fengyue meng and Qingfengzha is the setting and how it is experienced. The action in Fengyue meng never leaves Yangzhou, and its carefully visualized trajectories give a sense of the sights of the city (HANAN 2004: 38-39). Fengyue meng appeals primarily to the eye with its page-long descriptions of dress and scenes. Qingfengzha, on the other hand, takes place in a town in the hinterland of Jiangbei. While much of the novel occurs on the streets, Qingfengzha appeals primarily to the ear. ${ }^{29}$ Long visual descriptions are rare in Qingfengzha, and one such passage actually rhymes throughout, thereby appealing to the ear as well as the eye (Io.83). The aural approach achieves particularly good effect in the scene where Xiaogu is married off to Pi Wu the Rogue. From the time she goes into the bridal sedan until the morning after the wedding, it is clear that she knows only what she hears. At first she cries out for someone to save her from being sold off, and two young men start a fight with the sedan-bearers.

They slapped the bearers' mouths. 'Where are you carrying her off to?' We won't speak of the bearers being beaten, but will turn to Zhang Mama who saw from far off - why was the sedan stopped? She heard the two say, 'You old so-and-so, I'll take you to the county office and report you to the official for selling people!' Zhang Mama said, 'Gentlemen, do you know who the girl 
is going to marry? I'm sure you've heard of his reputation, it's that Pi Wu the Rogue! Today he's getting married, who did you think it was?' When the two heard that, they were so scared they pissed their pants and ran off . . . Now when Xiaogu in the sedan heard Zhang Mama's words, and understood that the two were so scared that they ran like the wind, she wondered if it really was as Zhang Mama said, that he had a great reputation.

(Qingfengzha: I3.IOI-I4.IO2)

Thus the scene plays with dramatic irony. Based on what she hears, Xiaogu deduces that her husband must be a man of some reputation, who had a big wedding banquet, and is up early to go to work. The reader already knows that, conversely, he has nothing to his name, the 'banquet' is laid for his beggar friends on the ground on rush mats in borrowed broken crockery, and he goes off first thing in the morning to gamble. Only when Xiaogu opens her eyes in the morning does she realize her plight.

Now, Xiaogu saw Pi Wu go out, he must be going to do business. An early riser gets thrice glory, the late riser thrice famine. He's not back yet, he must be relieving himself. After another quarter of an hour when he still didn't come back, she said, 'Someone must have dragged him to the teahouse. Yesterday I heard there must have been quite a few tables at the banquet, so he must not be just an empty name. What's there to worry about him having some tea!' Then she opened her eyes, got down from the bed and looked outside. She couldn't help feeling a wave of pain, and silently shed tears. How bitter my fate! Who could have known Zhang Mama would act as a go-between to marry me to a husband like this! So we live in a thatched hut with a reed door? She shut the door, and sat on the edge of the bed in a stupor for a while.

(Qingfengzha: I4.I05)

Similary, a sound often heralds the transition between one scene and the next: the door creaks to announce Zhang Mama's arrival (I4.IO5), or the sound of firecrackers indicates the opening of a new shop (I4.IO7). ${ }^{30}$ In addition, conversations overheard on the street or in public areas like teahouses play an important role in Qingfengzha.

The depiction of a particular region demands that one look at oneself from the outside (FoOTE 200I: 47). This requires a process of estrangement. ${ }^{31}$ Fengyue meng presents this double perspective through the frame story, modeled on Hong lou meng (A Dream of Red Chambers, also translated by the title Shitou ji 石頭記, Story of the Stone), which presents the text as the experience of a roué who regrets his ways and hopes others can learn from his mistakes. In the cautionary exposition in the opening chapter of Fengyue meng, the narrator states, 'I in my ignorant youth spent thirty years addicted to the brothel scene ... so I learned the dangers of that path' (8). He 
happens upon Guo Lairen, from Recognize Error Prefecture and Regrets the Past County, who wrote his experiences up into the book Fengyue meng. Guo Lairen's claim for the provenance of his tale also emphasizes first-hand experience: 'Mine is true events of a few people I witnessed with my own eyes' (I2). Thus the narrator of Fengyue meng, in the double guise of himself and Guo Lairen, can be both native and stranger, and from his new perspective present his experiences in a manner accessible to outsiders. The frame story makes Fengyue meng the product of a sojourner, and within the body of the novel the implied reader is an outsider. The figure of Lu Shu allows the narrative to constantly point out and explain customs and language particular to Yangzhou. The access this provides to those curious about Yangzhou or its famous courtesan culture might be another reason the novel attained national publication. The form of Fengyue meng mirrors its content: it draws on and advances conventions of 'literati' fiction that were steady sellers nationally. Hanan notes that the pseudonym and location indicated in the preface suggest that the author was a 'Yangzhou literatus working the lighter side of literature' (HANAN 2004: 34). Thus it is no surprise that the narrative techniques of Fengyue meng display an awareness of traditional fiction commentary as well as a debt to Honglou meng (HanAN 2004: $43,45)$.

Qingfengzha, in contrast, implicitly restricts the narrative situation to members of the local community around Yangzhou. It assumes, rather than explains. While distinctions are still made between strangers and natives, the implied reader is a native. In contrast to the moral change experienced by the narrator in Fengyue meng, who has realized the error of his ways, the change experienced by Pi Wu in Qingfengzha is primarily economic, although it engenders a change in behavior and attitude. ${ }^{32}$ As we will see below, the change of identity that forms the turning point of Qingfengzha does not result in a new perspective on the stranger/native dichotomy, even if it plays upon those terms. The narrator appears as implicitly tied to the region. In addition, the unusual narrative form lies somewhere between the conventions of the novel and the practices of local Yangzhou storytelling as they can still be observed.

Fengyue meng sets up boundaries and largely preserves them. Lu Shu is a stranger in Yangzhou in the beginning, and his dalliance in Yangzhou only forces him to go back where he came from. He never crosses over to become a local. In contrast, the central story in Qingfengzha turns on a change of identity. A local hoodlum becomes a well-respected member of his local society. The moment of transition is interesting. While Pi Wu actually obtains his money by gambling, he invents other accounts of its provenance. First he gives 'Smiling Tiger' Pan Caichen a story about how he got his fortune from his uncle in Huizhou on the condition that he reform (I9.I33). This implicitly gives him wealthy Huizhou connections, although nothing in the novel corroborates his lie. Then in Chapters 19 and 20, Pi dresses up as a sojourner merchant from Guangdong in order to gain entrée to gamble in respectable society. 
The scene plays upon or literalizes a local expression, 'seeking a Cantonese fortune,' xiang fa Guangdong cai 想發廣東財, for a family that had lost its wealth (FInNAne 2004: 292). To complete the disguise Pan's servant invents reports on his movements, endowing him in the other merchants' imaginations with an opulent residence, extravagant habits, and elite connections. No matter that the disguise does not work; $\mathrm{Pi}$ is still allowed in since he has money to gamble. He wins enough to loan money to his new-found fellows. In fact, he soon buys the pawn shop he used to frequent, thereby taking the place of the Huizhou merchant who retires from it, and he buys a mansion from a Huizhou man. ${ }^{33}$ While Pi Wu's failure to perform the identity of the Guangdong merchant shows the boundaries between local and sojourner are not exactly permeable, he attempts to invent several new identities for himself on the way to respectability. They are not given credence by themselves, but in combination with his new-found wealth they allow Pi Wu to start a new life.

Indeed, one might see a trace of local pride opposed to sojourners in Qingfengzha. The chapter title 'Eight barbarians meet to gamble, one person gets rich' (20.137) suggests that all the wealthy merchants are sojourners. The Yangzhou fangyan cidian defines the term 'barbarian', manzi 蠻子, as a southerner, usually someone from the Wu dialect region (220-2I). In Qingfengzha the merchants are not all from the Wu region, but they might well all be outsiders. The sojourner mentality is evident in two cases in Qingfengzha. In one, the pawn shop owner decides to sell his shop and move back home to Huizhou. Even though he has lived away for decades, Huizhou is still home to him. In the other the Shanxi merchant borrows money to go home and replenish his stock-in-trade. It is tempting to see Pi Wu's win as the victory of the disenfranchised local man against the sojourner merchants that dominated the Yangzhou region. ${ }^{34}$

More significant, however, is the frequent crossing of these lines. In Qingfengzha, heroes and villains come from both sojourners and locals. A glance at the central characters confirms this: foolish Sun Dali and his virtuous daughter Xiaogu hail from Taizhou, Zhejiang; the adulterer Sun Xiaoxu from Sizhou, Anhui; the vicious wife Qiang Shi from Yangzhou. They almost form exemplary pairs: the filial Xiaogu and unfilial Sun Xiaoxu, the chaste Xiaogu and unchaste Qiang Shi. When we recall that Sizhou was in the same prefecture as Dingyuan County, the pairs may seem to support the binary local/outsider, inverting it to favor the outsiders. However, two of the three marriages that occur within the novel wed local and sojourner, suggesting the possibility of crossing those boundaries. Pi Wu's own identity is fluid, as we have seen, but he is implicitly a local son of the streets. Despite his unsavory past, even the rich sojourner merchants are fair to Pi Wu when he gambles with them.

Once prosperous, Pi Wu performs the cultural identity of the wealthy merchant, acquiring a mansion, building a garden, and eventually participating in philanthropy. ${ }^{35} \mathrm{He}$ literally buys his way into respectable society. He acquires both home 
and shop from Huizhou men, thereby taking their place, and even purchases office as a final marker of his status. The rags-to-riches narrative also allows Qingfengzha to return the narrative in the last few chapters to normative status, portraying at least some of the rituals as they should be practiced - or through hyperbolic opulence and abundance.

Here again, the way custom is observed gives us insight into Pi Wu's position and how he views his place in society. Upon the birth of his son, custom decrees that he have eggs delivered to his kin. As an orphan, he has no relatives of his own, so he orders that the customary eggs be delivered to friends, workers, servants, neighbours, and their relatives, saying, 'Give them out! You are all relatives, so give them out!' In so doing, he treats the whole town as his family, and a million eggs are duly handed out (27.I7I). The novel explicitly lists one of the 'eight barbarians,' Pan Caichen, among the recipients.

The striking fluidity of Pi Wu's regional and economic identity calls to mind Bakhtin's rogue, who can play roles at will and whose outrageous deceptions are justified as a lie to liars (BAKHTIN I98I: 404). It is true that the viewpoint in Qingfengzha is largely cynical, and society as a whole does not come out well. Whenever general opinion is sought, the advice is usually expedient and wrong-headed. Sun Dali discusses everything with his colleagues, who always advocate the path of least resistance. For instance, they were enthusiastic about him remarrying, and one of them even arranged the match with Qiang Shi. Sun's colleagues, far from representing some wisdom of community, are clearly not to be trusted. Still, most of the ordinary shopkeepers and local merchants who become Pi Wu's victims do not do anything to deserve his tricks; they are simply caught off guard. Similarly, while the narrative censures Pi Wu's shenanigans, their outrageousness makes them entertaining. ${ }^{36}$

Though Pi Wu's reform brings a sigh of relief from his wife, it is almost comic, since wealth makes him not merely cautious but fearful. 'He didn't even go out the reed door, afraid that if he went out he would invite calamity' (I9.132). He tells his wife not to sleep too soundly, in case someone tries to dig their way into the house. He gives up drinking as well, saying, 'Alcohol is no good, it wreaks havoc on your temper' (2I.I44). When Zhang Mama hears of this, she says, 'A wastrel reformed is better than gold.' The situation is also made comic through a neighbor woman's reaction. Upon hearing that Pi Wu has come up in the world, she cries, 'My demon husband will never in his life get rich! Oh, why didn't I marry him [Pi]!' (22.I47). Morals constantly link to money.

It is tempting to read Qingfengzha as suggesting that morality is only relevant to those who have enough to live on, and that money creates identity. However, the long-suffering Xiaogu counters this materialistic reading; she is unchanged by poverty or wealth and continues to uphold her principles throughout. Still, 
in both the short story and more obviously in Qingfengzha, the ghost's gift of wealth is what allows the good-for-nothing husband to reform and take the case to court. In contrast to most Judge Bao tales, here justice is the privilege of the respectable.

The jingle that concludes Qingfengzha takes the part of the poor in counseling those who are better off:

Advise people not to be coercive.

Being coercive will certainly bring bad consequences.

Just be a little patient, it doesn't matter,

One day retribution will cut them off.

Advise people not to be obsessed.

Obsession longs for beautiful poses.

You love her and she loves you,

But one day she will turn on you and it will be too late for regret.

Advise people not to be evil.

Prosperity, difficulty or advancement, each has surplus or lack.

How many were once rich but now are poor?

You can't laugh at, deride, and cheat them.

Advise people not to be idiotic.

Don't take the poor to be idiots.

One day when the spirits' power comes to protect,

Prosperity and glory will come together. (Qingfengzha: 32.196-97)

Although this appears at first glance to repeat the old notion that riches or poverty are fated, on closer inspection it proves to be a striking departure. It warns against coercion, qiang 強, and advises against evil, $e$ 惡, or condescending toward the poor, since many of the wealthy do sink into poverty, and conversely the poor can achieve wealth and glory (32.196). Instead of the sense of social stability implicit in the old chestnut about being satisfied with your station in life, this points to an unusual awareness of social mobility.

\section{CONCLUSIONS}

'Local' must always be defined in relation to somewhere else, through negotiation with the outside. Qingfengzha provides a case in point. The work was not created simply from scratch, but took inspiration from both written fiction and oral storytelling. The frame story to the novel as we have it draws on a short story from a nationally circulated collection. However, in the process of appropriation from the written and oral sources and translation to a new medium Qingfengzha resulted in a new interpretation. 
Both the narrative of the novel Qingfengzha and the biographies of Pu Lin portray someone adept at negotiating the boundaries of local society, appealing to rich and poor, sojourners and natives alike. Pu Lin's two biographies show he was appreciated by both the Yangzhou local Li Dou and the Anhui man, Jin Zhaoyan. The biographers' own positions might also point to the social status of his most ardent admirers. Both Li Dou and Jin Zhaoyan served as functionaries in Yangzhou. Jin was a clerk and then a schoolteacher (REN Qian 198I: 333), while Li Dou probably served as an editor in the Theatre Office (Olivoví 2002: III). Thus it seems that the highest social stratum Qingfengzha focuses on, that of the clerks, was quite active in creating a distinct Yangzhou identity in the Qianlong period. On the other hand, in contrast to the rural audience imagined in the preface to Qingfengzha, the narrative elides the agrarian entirely. The rogue may be poor, but he is unquestionably urban.

The novel Qingfengzha presents a more 'inclusive' view of society than Fengyue meng. Unlike the latter, it does not clearly privilege locals or condescend toward sojourners. Of course, the historical backdrop for each work differs dramatically. As a tale told in the Qianlong, then recreated and published as a novel in the Jiaqing period, Qingfengzha appeared in the last moments of Yangzhou's golden age, while the Huizhou merchants still dominated society. A few generations later Fengyue meng portrays a Yangzhou where the locals had regained the position of the elite and the crumbling Salt Monopoly meant fewer wealthy Huizhou families in the city (Finnane 2004: 300).

In what sense should we understand the novel Qingfengzha as 'local fiction of the Yangzhou region'? Its publication in the Qing ties it exclusively to Yangzhou, a fact which becomes especially significant when one considers that most successful novels of the period soon reached national readerships. More indirectly, the core story of $\mathrm{Pi}$ Wu was invented by a Yangzhou storyteller, and in the ongoing oral storytelling tradition (QIngfengzha or PI Wu Lazi) it came to be one of the quintessential representatives of that art. However, both the practice of oral storytelling and the hinterland setting of the novel Qingfengzha remind us of the linguistic and cultural ties between the city of Yangzhou and the surrounding region. Yangzhou and a swath of Jiangbei stretching north and west to Dingyuan County, Anhui, shared dialect features in grammar and usage, storytelling traditions, and to some degree the dominance of sojourners. If we choose to take the setting of the novel Qingfengzha seriously, it meshes with the publisher's preface to appeal to a readership extending to the poorer areas beyond Yangzhou. As a small city, Dingyuan might be closer to the everyday experience of many of the 'locals' or common people of the region than the metropolis Yangzhou itself. Thus one might argue that the novel Qingfengzha points to a sense of regional identity, including but not exclusive to Yangzhou, as opposed to city identity or national identity. 
If Fengyue meng displays Yangzhou's uniqueness within the narrative by preserving the boundary between local and sojourner, the practices of Yangzhou pinghua evoked by Qingfengzha thirty years earlier serve as an assertion of local distinction in another sense. The appearance in the Qianlong-Jiaqing period of narratives evoking Yangzhou storytelling practices and repertoires (including Shan'e tu and Fei Tuo quan zhuan) parallels the emergence in quantity of local ballad texts that evoked performance genres in other regions (such as tanci, guci, and muyushu 木魚書). The quantity and variety of cheap, locally produced texts that evoked local performance traditions suggests that each form reached its own avid readership. This might point to a new importance of local identity and local dialect. Instead of writing serving the 'centripetal' role it always had - as classical and standard Mandarin - in unifying China, in these 'local' texts writing is more closely aligned with regional oral culture through the use of dialect and the familiar formulae of local storytelling forms. They may also have encouraged a more aural reading or even served as libretti for amateur performance. Indeed, it seems that the use of language itself was one of the central attractions of quite a few local Yangzhou narratives. If we read the preface to Qingfengzha against the grain, in the context of the social divides of the Yangzhou region, we might see it as offering the narrative as an alternative to national bestsellers for the less affluent, rural, and small-city 'natives.' The wide use of dialect in ephemeral entertainment genres may have provided a local alternative to the national bestselling novel. Certainly much of the written corpus in each tradition renders the stories of well-known novels like Shuibu zhuan (Water Margin) or Honglou meng in forms evoking local storytelling. This phenomenon undoubtedly has implications for the construction of local identity. As Finnane notes, 'The early nineteenth century deserves consideration as a time when throughout China, communities may have been in the process of being redefined in more locally and historically specific terms' (Finnane 2004: 292). The availability of local entertainment narratives must have been both a product of and a participant in that redefinition.

\section{NOTES}

1 Qingfengzha, Shan'e tu, and Fei Tuo quan zhuan show signs of adaptation from storytelling, though the exact relationship to the oral is beyond recovery. For editions, see Отsuka 1987: 169, I66, and 151-52. On the Yangzhou location of these printing houses see WANG Cheng 2003: 300-302. For the preface to Fei Tuo quan zhuan see Ding Xigen 1996: I439-40.

The title Fei Tuo quan zhuan comes from a local Yangzhou expression. 'To cheat someone with falsehoods is called a hopping hunchback; if it is very skilled and very false, it is called a flying hunchback', Jiao Xun 焦循, quoted in Ding Xigen 1996: I439. While tuozi 跎子 comes to mean 'braggart' or idler, the narrative of Fei Tuo quan zhuan literalizes the expression by making the central character become a hunchback after seeing a quack doctor for a minor ailment. 'On his back imperceptibly one spot grew higher, and became a lump of useless flesh. His left leg also ... 
shortened three inches. Because of this, people called him the hopping hunchback' (Fei Tuo quan zhuan: 217). Later he grows wings, completing the expression and giving the work its title.

2 Most editions of Fengyue meng were published in Shanghai; the earliest known edition of 1883 was published by Shenbaoguan, which certainly had a national reach. OTsuka 1987: 106-IO7.

3 Local Yangzhou printing houses reprinted Qingfengzha and Fei Tuo quan zhuan during the nineteenth century. Only around the turn of the twentieth century were they reprinted in Shanghai with the new lithographic technology. Even then, Fei Tuo quan zhuan kept its local Yangzhou associations with the title Sanjiao sanman Weiyang jiahua chuanqi 三教三蠻維揚佳話傳奇 [The three teachings and three barbarians, a fine tale from Weiyang (Yangzhou)] (Shanghai shuju lithographic edition, Shanghai 1895), listed in Liu Cunren 1982: 255.

Qingfengzha was reprinted in Shanghai and Hong Kong in the Republican era. The Shanghai editions sell it as pornography under the title Xiuxiang ruyi jun zhuan Qingfengzha 繡像如意君傳清 風閘 [Qingfeng Sluice, an Illustrated Tale of Master Ruyi] (Zhuji shuju, Shanghai r9ı6; and Tianhua shuju, Shanghai I920), using the title to link it to the notorious work of pornography Ruyi jun zhuan. The Hong Kong reprint takes the opposite tack by selling it as court-case fiction, gong'an, expurgating the explicit sections, and saying so in the preface. See Song dai qi an Qingfengzha 代奇案清風閘 (Hong Kong: Wugui tang shuju, [1930?]), title page.

4 For the theatrical genres of Kunqu and luantan, cf. Chapters Io and II in the present volume.

5 To distinguish the novel from the storyteller's oral repertoire, I will refer to the printed novel in italics as Qingfengzha and follow Vibeke Børdahl in writing the oral repertoire in capital letters as Qingfengzha.

6 From Zongting guwen chao, juan 4; quoted from ZHU Yixuan 1989: 431.

7 The repertoire Qingfengzha continued to be performed in Yangzhou storytelling through the twentieth century. For an edited text based on an eighth-generation storyteller of Pu Lin's school, see Pi Wu lazi by Yu Youchun et al. 1985. Cassette recordings of this repertoire from the I980s also exist.

8 In the tradition of Yangzhou storytelling, he is called Pi Wu lazi 皮五辣子. While close in pronunciation, the two orthographies emphasize different aspects of his character. His name in the novel reveals him to be an idle rascal, while that in the modern storytelling tradition emphasizes his sharp tongue and aggressiveness.

9 A Han Dynasty author, whose work is listed in the bibliography section of Ban Gu's Han Shu under the category 'xiaoshuo.' This name later became synonymous with the term xiaoshuo, 'small talk' or later, fiction.

10 At first glance the less affluent audience imagined by the publisher of Qingfengzha seems to correlate to the experience of the storyteller Pu Lin. However, the parallels are not quite so neat. As we have seen above, not only did Pu Lin transcend his earlier penury, but his audience cut across status boundaries as well. In contrast, the preface to Fei Tuo quan zhuan explicitly states that the work originated as oral banter, though it contrasts it to the themes of performers of tales, yan xiaoshuo zhe 演小說者. It imagines the readership for this book as Yangzhou gentlemen of leisure and refinement (Ding Xigen 1996: I439-40).

11 Li Dou 1963 [I795]: 258.

12 While Qingfengzha's inclusion on Ding Richang's I868 list of prohibited books could suggest that the novel circulated beyond the Yangzhou region, I suspect he got the title from the 1844 local proscription by the Prefect of neighboring Huzhou in Zhejiang. 
13 E.g. Qingfengzha: 5.50-5I, 10.79-8I, II.87, I6.II8. It also appears in Shan'e tu. Fei Tuo quan zhuan flouts narrative conventions even further by foregrounding verbal play (puns and reified idioms) to the point that plot serves merely as an excuse for such wordplay. It reads almost like comic dialogue, xiangsheng 相聲, rather than a novel.

14 E.g. Qingfengzha: 2.31, 4.4I, 5.49, 5.50, 6.56, 7.62, 7.63, 8.66, 9.74, II.85, II.87, II.89, I3.97, I3.99, I4.I07, I5.109, 17.124, 19.133, 20.138, 25.164, 26.169, 28.178, 31.188. For the distinctive usage of these patterns in Yangzhou dialect, see BøRDaHL 1996: IO6-7, II3-I5, II7. Yangzhou dialect pronunciation in phonemic transcription is given within / /, cf. BøRDAHL 1996: 72-76. The unusual orthography of zai kuai 在塊, which Qingfengzha renders as 在快, suggests that the sound took precedence over the meaning when it was written down.

15 On the play with registers in Yangzhou storytelling and the use of 'round mouth' versus 'square mouth' styles therein, see BøRDAHL 1996: 83-98. She notes that 'square mouth' often serves to characterize heroes or important personages; it is closely related to 'the formal "official's language,” guanhua 官話.' In contrast, 'round mouth' generally portrays the speech of 'small persons, xiao renwu 小人物;' it is 'associated with smooth everyday Yangzhou vernacular' and includes 'low-style patois, tuyu 土語.' Up through the twentieth century, QINGFENGzHA was still being performed in Yangzhou storytelling under the title PI Wu LazI 皮五辣子. Its eschewal of historical subjects allowed $\mathrm{Pu}$ Lin to draw freely on his own experience, and the language of performance in present-day Yangzhou pinghua is primarily 'round mouth.' Pu Lin's biography in Yangzhou huafang lu leads one to conclude that he created at least the core story of Pi Wu out of whole cloth. This stands in sharp contrast to most repertoires of Yangzhou storytelling, which are created on the basis of well-known stories. It is impossible to know whether or not the court-case frame story (borrowed from the Ming short story) was part of Pu Lin's telling of QIngfengzha. For a comparison of Qingfengzha and the published Pi Wu Lazi, see Xu Duanrong 2002.

16 One article lists particular words in Qingfengzha that are characteristic of Yangzhou dialect. Only three of the examples are noted as being used in other cities or regions. CAO Xiaoyun 2003: 3I-34.

The representation of dialect in the novel Qingfengzha largely obscures any distinctive pronunciation. We cannot 'hear' the words on the page. Since the dialect differences between one town and the next within the Yangzhou region were primarily phonological, the written text could transcend those distinctions. For an example of the kind of phonological information that is lost in written text from storytelling, see BøRDAHL 2004.

$17 \mathrm{Ba}$ as 'give' is characteristic of Jianghuai Mandarin as a whole. See Li Huimin 2004: 602.

18 The Yangzhou usage 'zaikuai' (there) is also typical of present-day dialect in Dingyuan County. See Dingyuan xian zhi 1995: 831. Both Yangzhou and Dingyuan belong to the Hongchao subgroup of Jianghuai Mandarin; see Wurm et al. 1988: B3.

19 Dingyuan County belonged to Fengyang Prefecture, which bordered Yangzhou Prefecture to the west. While we now recognize Yangzhou and Dingyuan County as belonging to two different provinces, in the early Qing both were part of the province 'Jiangnan.' Only in I667 was it divided into Jiangsu and Anhui. (Finnane 2004: 29)

20 See, for example, the reference in Fengyue meng to the big-footed maid in the brothel as a 'sturgeon,' complete with a bamboo-branch poem, zhuzhici 竹枝詞, to back up the usage (49).

21 Sun Dali repeats the act of charity that made him a clerk when he discovers Sun Xiaoxu. He notices him reading aloud from a poster, although dialect is not explicitly mentioned. $\mathrm{He}$ explains his decision to adopt Sun Xiaoxu by saying that they are from the same native place, 
tongxiang. However, the novel states that Sun Dali is from Taizhou, Zhejiang, while Sun Xiaoxu is from Sizhou 泗州 in Anhui. Sizhou, which defined the Western border to Yangzhou Prefecture, belonged to Fengyang Prefecture.

22 The speech of the Shanxi merchants is generally marked by their use of the northern vulgar pronoun zajia 咱家. At one point in the novel the Shanxi merchant Yao Xianggong uses Yangzhou dialect 'zaikuai' (20.138). The use of Yangzhou dialect by sojourners again demonstrates that Yangzhou dialect is the general mode of communication in the novel.

23 For examples of the process of translation, see WAN 2004.

24 Yu Yue, Chaxiang shi congchao, quoted from ZHU Yixuan 1989: 433. Modern scholars including Tan Zhengbi refer to Qingfengzha as a pinghua xiaoshuo 評話小說, implicitly recognizing its differences from the conventional novel. However, they use the same term for modern, edited records of storytelling. It is of course impossible to know what relationship the novel Qingfengzha bore to contemporary Qianlong-Jiaqing era storytelling.

25 On the folly story see Hanan I98I: 59-68.

26 Elsewhere the narrator delivers a short comment advising men to avoid remarriage and taking concubines (Qingfengzha: 9.72). Again the implied audience is male.

27 In many of the early short stories (before I450) and the middle stories (ca I400 to I575), sex forms the main theme of interest. With the exception of the subgroup Hanan calls the romance, most of the stories dealing with sex portray it as dangerous. See Hanan I981: 45, 58, 60.

28 Zhu Yixuan: 432.

29 For an extensive study of how late Qing martial arts novels use sound to evoke the storyteller, see Keulemans 2004.

30 In most cases the text of Qingfengzha simply notes that the character heard the sound of a door, the sound of firecrackers, and so forth, without using onomatopoeia to imitate it directly. This stands in contrast to the frequent use of onomatopoeia in Shan'e tu and late Qing martial arts novels.

31 In this respect, the representation of a region parallels the representation of the self in autobiography. 'To be autobiographical . . . is not to record or recall a past self as it was but to reconstruct or reinvent that past self according to the perceptions of the present self' (HUANG I995: 147). The 'truth claims' of both Fengyue meng and Qingfengzha turn on assertions that they represent lived experience. The preface and prologue to Fengyue meng both declare that the work tells of events the author experienced. Li Dou's biography states that Pu Lin created the oral repetoire Qingfengzha based on his own experience, and that Pi Wu is a pseudonym for Pu Lin. Even the preface to the novel Qingfengzha insists the events and characters are real. The real name of the author of either novel is unknown, since for Fengyue meng we have only a pseudonym and with Qingfengzha we do not know who wrote the text of the novel. However, the similar approach to reading each text makes the contrast between them even more instructive.

32 The narrator does give advice to $\mathrm{Pi} \mathrm{Wu}$, often invoking a later temporal perspective. This appears most clearly in the poems, such as 'After wine doing evil instead of peacefully sleeping;/ ridiculous, spouting opera as you beat the walls./ I urge you from now on you must show restraint,/ not con money like you did in those days' (Qingfengzha: I2.9I). References looking back on Pi Wu's life in poverty recur in at least three of the introductory poems. The instance quoted above is most striking, since Pi Wu's situation has not yet changed significantly; it reveals 
the narrator commenting from a distance as he looks back over Pi Wu's life. The other two poems point to the great change in fortune Pi Wu experiences (25.I6I, 27.I7I).

33 Although Qingfengzha does not specifically identify Zheng Erye's origins, Zheng is a common Huizhou surname. See Finnane 2004: 239.

34 The Shanxi merchant's heavy gambling losses serve to punish his brother's ill-gotten gains; it was his brother's loan-sharking that pushed Sun Xiaoxu into Qiang Shi's arms.

35 While the mansion is apparently in Dingyuan, when Pi Wu renovates it and builds a garden he sends servants to specific places in and around Yangzhou to buy wood, tiles, and lacquer. They go by boat and return within a day. (24.156) Some of these sites are verifiable in the I8Io gazetteer of Yangzhou, including Xiannü miao 仙女廟 where they bought lumber. See Yangzhou fuzhi 1963 [I8Io]: 96, II6-I7. Finnane notes that gardens were not built by locals in Yangzhou, but by salt merchants, mostly from Huizhou. Finnane 2004: I89. For the 'patterns of cultural activity' of salt merchants in Yangzhou, see ibid.: 64 .

36 Roger Chartier notes a similar moral ambiguity in some of the literature of roguery in the popular Bibliothèque bleu, in which the text 'both lauds and censures its hero, . . . sympathizes with his tribulations yet celebrates his punishment, and . . humorously presents his 'subtle' robbing techniques but then holds them as culpable behavior.' He attributes this 'unevenness' to material from oral tradition being refashioned under the strict morality required by the genre and era (Chartier 1987: 331). 


\section{Part III}

\section{Performance and Entertainment}





\section{Yangzhou Local Theatre}

\section{in the Second Half of the Qing}

\section{Colin Mackerras}

7 his chapter treats local theatre in Yangzhou and its environs in the second half 1 of the Qing dynasty, meaning mainly from the late eighteenth century to 1911, but will include occasional references to earlier and later dates. It will show the role of Yangzhou in China's overall theatre, and specifically its local theatre, at that time. It will draw attention to several men who contributed to Yangzhou's local theatre or commented on it in unusual ways, as well as discussing the role of the masses in theatre. Finally, it will attempt to evaluate and explain the vibrancy of theatre in Yangzhou during its heyday, which was late in the eighteenth century, as well as pointing to reasons for the decline.

Yangzhou was 'one of the great cities of late imperial China, a place well known to historians because of the enormous wealth accumulated within its walls during the eighteenth century' (FINNANE 2004: 1). ${ }^{1}$ Its location just to the north of the confluence between the Yangzi River and the Grand Canal has always been of enormous advantage, and was especially so when water transport was pre-eminent. We know of Yangzhou's distinction in culture and lifestyle, which is why most of the papers in this volume deal with the late imperial era. It is also very important to note that in the eighteenth century Yangzhou was a major economic hub as well. During the Qianlong era (I736-I796) it was the centre of the Lianghuai 两淮 Salt Administration, which was the largest of the empire's eleven salt administrations and affected most of east central China. At their height in the eighteenth century, the salt merchants included some of the richest people in China. ${ }^{2}$ However, for various reasons, which included changes in government policy and their own extravagance as well as a severe crisis in hydraulic management that involved the collapse of the waterway system, Yangzhou's salt merchants began to decline in the early decades of the nineteenth century. Most importantly, the conquest of the region by the Taipings in I853 occasioned total destruction in the city of Yangzhou, as it did in most of the lower Yangzi Valley.

The chapter is based on a range of Chinese- and English-language sources. The two most important individual sources, in ascending order, are Jiao Xun's 焦循 Huabu 
nongtan 花部農譚 [Peasant Chats on Popular Theatre], which is prefaced the sixth lunar month of I8I9 and will be considered in greater detail later on. The other is $\mathrm{Li}$ Dou's 李斗 Yangzhou huafang lu 揚州畫舫錄 [Pleasure Boats of Yangzhou]. Written over thirty years, it was first published in 1795 , but with a preface by eighteenthcentury China's most famous poet Yuan Mei 哀枚 (I716-I798) dated the equivalent of early 1794. Li Dou was himself a playwright and theatre-lover, and his work, an extraordinarily detailed compendium on Yangzhou and its lifestyle and entertainment late in the eighteenth century, has a whole juan 卷 ['scroll', i.e. section of a book] on the theatre, including detailed and invaluable references to local theatre. An important general source is the long-term experience and memories of old artists and others involved in the Yangzhou theatre.

\section{THE THEATRICAL CONTEXT}

Drama was very class divided in late imperial China. In essence, the educated elite loved the 'elegant' drama, yabu 雅部, while the masses preferred the various styles of popular theatre which Li Dou and others term 'flower drama', huabu 花部. Historians nowadays mostly call the 'elegant' drama Kunqu 崑曲, because it was in the Kunshan 崑山 area near Suzhou 蘇州 that it was developed in the mid-sixteenth century. Actors were in general very low in social status, especially those of the huabu.

The rise of the various regional systems and styles of theatre is a fascinating subject but the details are beyond the scope of this paper. ${ }^{3}$ The earliest of three systems was Yiyang qiang 陽腔, which, based on village dialects, spread from Yiyang in Jiangxi Province through most of South China and also to Beijing, where it was called Jingqiang 京腔. Slightly later, bangzi qiang 梆子腔 (sometimes translated as 'clapper opera') developed in the north, spreading to the south. In the eighteenth century, a third system emerged, termed pihuang 皮黄. It is a combination of two styles, namely xipi 西皮 and erhuang 二黄, the former initially a bangzi qiang variant, the latter of southern origin, probably coming from Yihuang 宜黄 in Jiangxi. From the eighteenth century the two spread as a unity to various parts of the country, especially Beijing, where in I790 a company from Anhui called Sanqing 三慶 went to celebrate Qianlong's eightieth birthday. Jingju 京劇 (literally 'capital drama' but sometimes translated as 'Peking Opera') resulted from this combination of xipi and erhuang. To this day some people regard 1790 as the 'birth' of Jingju, and celebrations for the 20oth anniversary took place in 1990.

One contemporary history of Chinese traditional theatre (LiU Yanjun 200I: 159-160) expresses the late eighteenth and early nineteenth centuries in terms of a 'struggle between huabu and yabu' with the former gaining the victory, despite the opposition of the imperial court. Already in the early eighteenth century the Kunqu playwright Tang Ying 唐英 (1682-1756) had gained inspiration from regional theatre, 
despite the prevailing contempt the literary elite still held for popular mass drama. By the late eighteenth century, Kunqu was in decline, while popular drama had moved to centre stage.

Yangzhou contributed significantly to the rise of popular theatre. Li Dou (I795: 5, 26a; 200I: I30) certainly confirms the presence of the various systems of huabu within Yangzhou. It is possible that the Sanqing Company performed in Yangzhou before going to Beijing in $1790 .{ }^{4}$ Like other cities, Yangzhou had its own wandering local theatre companies, which contributed significantly to special occasions in the city, such as festivals, both national and local.

Li Dou also claims that 'the huabu within the city belongs purely to the locals', in contrast to the more elevated Kunqu, 'and they call it "the confused plucking", luantan 亂彈, of the local region'. He goes on to observe that the plays the local actors perform come from the zaju of the Yuan dynasty and that because their singing, rhythms and costumes are extremely crude, they get the name 'straw stage theatre', caotai xi 草臺戲 (Li Dou I795, 5: 25b; 200I: I30).

One of the most authoritative contemporary histories of Chinese theatre gives a very important place to these small-scale local styles of theatre, listing Yangzhou's luantan first among a range of such regional theatres. The authors place a very high evaluation on these forms of theatre, both from an artistic and social point of view. They observe that among these many forms of local theatre, 'there was none that did not meet the needs and demands of the popular masses of the locality, being thus produced and developed within a certain time under favourable artistic conditions and social material circumstances' (ZHANG Geng and Guo Hancheng 198I, Vol. 3: 33). Another specialist notes that Yangzhou's luantan was 'an independent and perfect kind of drama' a 'Yangzhou drama performed by Yangzhou people' (WEI Ren I999: 9).

Li Dou has quite a bit to say about the role types in the popular Yangzhou theatre (Li Dou I795, 5: 27b; 200I: I32, as translated FEI 1999: 95):

Of all lines of business in huabu the young female roles and clowns, especially the acrobatic clowns, are the most prominent. The roles of young warriors and painted faces are next in the hierarchy. In contrast, the roles of elderly and middle-aged men do not even have separate categories, simply designated as male parts. Likewise, the roles of elderly and proper women are jointly labelled female parts.

The clowns specialize in generating comical gags, both verbal and physical. The characters they create range from wily tricksters to vulgar philistines, from bumblers to slow-wits, from cunning merchants to shameless rascals, all spouting some hilarious mixture of regional dialects that just keeps the audience in stitches. The limitation of local colors and dialects, however, also contributes to each individual regional folk theater's not having influence as widespread as 
that of Kunqu. The Beijing school is an exception, since mandarin is used in delivering comic speeches, thus making its clowns the most favored.

What is interesting here is that the old male roles were to predominate in importance with the rise of the Jingju in the nineteenth century. The importance of younger female roles and clowns accentuates the fact that the folk dramas were generally small in scale and comic. However, this was certainly not entirely the case, as is obvious from the importance of Yuan dramas as a basis for luantan items.

Among the huabu styles, the most important were 'incense fire drama', xianghuo $x i$ 香火戲, and 'flower drum plays', huagu $x i$ 花鼓戲, some items of which still exist to this day under the name Yangju 揚劇 [Yangzhou drama] (Wei Ren and Chen Depu I995: 404).

Xianghuo drama takes its origins from religious activities. The xianghuo were Buddhist monks, shamans and other clerics, as well as ordinary peasants and fishermen, who could sing such songs (Song Ci I955: 34). The function of these performances was to honour the gods, or to make requests or offer repentance to them and to thank them for favours received. For instance, somebody who fell ill might pay for a simple play to ask the gods for recovery and then have another play performed to give thanks if he did indeed get better (Wei Ren and Chen Depu i995: 405). Although shamans had been both male and female in earlier times, they were all male by the mid-Qing and certainly there were no women in the xianghuo xi troupes.

Accompaniment for the singing of the xianghuo xi came from cymbals and percussion only, with no string or wind instruments. The lyrics were mainly in seven- or ten-character poetic lines (WeI Ren and Chen Depu 1995: 407). The content 'had a thick religious colouring, but also included folk legends and mythical stories' (SoNG Ci I955: 40). Mostly these plays were orally transmitted, but that this was by no means a universal pattern is evident from the discovery in 1957 of a hand-written play script dated 1784 and called a xianghuo xi (see Wu Baitao I983: 528). It seems as though the xianghuo xi had developed into full-scale drama by the late Qianlong period. (WEI Ren I999: 4I).

Huagu $x i$, on the other hand, was always very small in scale, usually just one male comic character, chou \#丑, and one female character, dan 트, singing and dancing together, for which reason they were sometimes called caishuang 踩雙 or 'treading double'. This is the style to which Li Dou is referring in the passage cited above when he talks of the clowns and young female roles. Over time, the number of characters expanded to seven, although the two-character plays remained prevalent. The stories mostly reflected actual life and one contemporary writer claims that among the themes of these plays were to 'sing the praises of the joys of labour and reveal the irrationalities of feudal society' (Song Ci I955: 4I). Many were essentially love-stories, such as Shuang xiashan 雙下山 [Two Going Down a Mountain], which is about a monk 
and nun who escape from their religious life and decide to form a pair. However, it is clear from Li Dou's comments above that stories of battles were also popular and that the plays could include acrobatics. It is also clear from what Li Dou says that comedy had a major place in these plays. The people who performed were often amateurs, such as young handicraftsmen or peasants (Wei Ren and Chen Depu 1995: 405).

The music, as transmitted to the present, has a strong rhythm and clear and humorous style. Many of the tunes derive from a third style, termed Yangzhou qingqu 揚州清曲 [Yangzhou ballad singing]. This is actually a shuochang 說唱 style [telling and singing arts], probably of Yuan-dynasty origin. In addition to popular and folk tunes sung in the entertainment quarters of Yangzhou, such as teahouses, brothels, wine-houses and pleasure-boats, Yangzhou qingqu has many tunes in common with the aristocratic Kunqu. (See Song Ci 1955: 38; Wei Ren and Chen Depu 1995: 407; Wei Ren and WeI Minghua 1983: 529).

There was certainly a theatrical tradition in Yangzhou by the early Qing period (Strassberg 1983: I28). According to Zhou Yibai (1953, 3: 668), Qianlong's decision to include in his palace theatre actors from outside the court was a direct result of his I75I southern visit, when he had been greatly impressed by the acting standards he had seen in Suzhou and Yangzhou. What this tells us is that Yangzhou's tradition was already strong by then, but it almost certainly gained greatly from the fact of the Emperor's approval, reaching its apogee in the second half of the eighteenth century. Poet Lin Sumen 林蘇門 (1759-after 1809) published a collection of poems and commentaries on Yangzhou in I808. He ranks Beijing and Suzhou first and second for the drama. By the time the poems were published, Yangzhou had begun 'producing pale imitations of Beijing styles', having sunk from the earlier days of the mid- to late-eighteenth century (FInNANE 2004: 286 citing Lin Sumen).

\section{Women in the Yangzhou Theatre}

By the eighteenth century, mixed male-female troupes had become an extreme rarity. In the early Qing there were prostitutes termed yuehu 樂户 in Yangzhou, one of whose roles was to perform at a ceremony on the day before the Spring Festival to welcome in the New Year. During the reign of Kangxi the yuehu were abolished, as a result of which it was men who took all roles for such ceremonies, including those of women (Li Dou I795, 9: I2a; 200I: I98).

For women, acting has a long association with the sex industry in China. Yangzhou has a long-standing reputation for the beauty of its prostitutes, dating back at least to the Tang dynasty. In the eighteenth century Yangzhou still had female troupes in the brothel quarters. Li Dou (I795, 9: I7b-I8b; 200I: 203-4) gives us a description of one of them. Called Shuangqing 雙清, its manager was a woman and it had nineteen girls, one of whom was the manager's daughter. Some of them were very young, one 
only ten years old at the time Li Dou wrote. In addition to the actresses, there were two managers and teachers, a few instrumentalists, and some caretakers who looked after the costumes and such matters. Curiously enough, there was one male actor in the troupe, who performed female roles. Strictly speaking, then, it was not really an all-female troupe. Yet the predominance of women, the fact that its location was in a brothel and the fact that its leader was a woman perhaps permit us to call it a female troupe.

In addition to the brothels, there were also some female troupes in private mansions, who like the Shuangqing Troupe performed Kunqu. However, the great majority of troupes, both inside private mansions and outside, were male. This applied both to Kunqu and popular theatre and throughout almost everywhere in China. Other than those in the Shuangqing Troupe, all actors mentioned in this chapter were male.

\section{THE ROLE OF THE SALT MERCHANTS}

It was fashionable for elite men to own their own drama troupes. The salt merchants so important for Yangzhou's economy in the eighteenth century were great patrons of the arts, and in particular of the theatre. It is true that they declined in the nineteenth century, their fondness for drama performances possibly even being part of the extravagance that undermined them, and the abolition of the Lianghuai Salt Administration's merchant monopoly in I83I dealt them a major blow. However, Li Dou (I795, 5: Ia; 200I: I07) lists seven salt merchants who founded their own companies in their heyday, and there were no doubt others.

Kunqu was the preferred drama style for the merchants, among whom some enjoyed considerable social status, despite the Confucian contempt for their class. According to Li Dou (I795, 5: Ia; 200I: I07), 'the predominance of kunqiang (Kunqu) began with the merchant Xu Shangzhi 徐佾志, who summoned famous actors from Suzhou and formed the Old Xu Company'. Suzhou was the main home of the Kunqu and of its best actors. Li Dou's claim is very interesting, because in fact most of the men in China at the time who sponsored private companies trained their own house-slaves in theatre. Although Xu was not unique in getting already famous actors from outside, that was not the norm.

From the point of view of theatre in general and of local theatre in particular, the most important of the salt merchants was most certainly Jiang Chun 江春. The reason for his eminence was that he patronized two troupes, one for the elegant and aristocratic Kunqu, the other for the popular local huabu, and was the only one of the salt merchants to do so. He deserves a bit more attention here.

According to Li Dou (I795, I2, 6b; 200I: 274), Jiang Chun (I72I-I789) was a 'Shexian 歌縣 man' but may not actually have been born in what was then the capital 
of Huizhou 徽州. He was the most distinguished of the Huizhou merchants, whose rise from the sixteenth century in Yangzhou and Yizheng 儀徵 County outside the city has been discussed by Antonia Finnane (2004: 56-68). Having become a zhusheng 諸生 (first degree) graduate in Yizheng County, he rose so high on the financial and social scale as to be on good terms with the Qianlong Emperor, whom he entertained several times, also attending an imperial banquet. He contributed money to Qianlong's military campaigns and the emperor helped him out when he fell into financial difficulties in I77I. ${ }^{5}$ He owned two of Yangzhou's gardens, for which the city was so famous. The more important was the already old Kangshan Caotang 康山 草堂, which was located just within the city walls in the southeast corner of the New City. Jiang Chun had it restored and developed, and Qianlong stayed there during his 1780 journey to the south. ${ }^{6}$

Jiang's Kunqu troupe was called Deyin 徳音 [Virtuous Sounds] or the Inner Jiang, Nei Jiang 内江, Company. The huabu company had the name Chuntai 春臺 [Spring Stage] or Outer Jiang, Wai Jiang 外江. After Jiang Chun died, both troupes devolved on other patrons, the Chuntai Company being taken over by Luo Rongtai 羅榮泰 (LI Dou I795, 5: Ia; 200I: I07).

Jiang Chun was unable to train actors from his own household in regional theatre arts, so he got well-known actors from outside to form the Chuntai Troupe. They included famous dan like Wei Changsheng 魏長生 (Wei San 魏三), to be considered in the next section, as well as Yang Baguan 楊八官 from Suzhou and Hao Tianxiu 郝 天秀 from Anqing 安慶. All the main actors of that time appear to have been dan.

The fact that a man who enjoyed good personal relations with the emperor himself should spend money and effort on founding a regional theatre company shows something about the shifting social status of at least certain forms of local theatre, as compared with Kunqu. Not only did Jiang Chun win the services of several very distinguished actors, but the Chuntai was the first known privately sponsored company since the sixteenth century that did not devote itself entirely to Kunqu.

Chuntai is the name of a company that plays a very important role in the history of Jingju. To celebrate Qianlong's eightieth birthday in I790 the Sanqing Company from Anhui went to Beijing and was soon followed by various others, of which three, together with the Sanqing, became known as the 'four great Anhui companies', Sida Huiban 四大徽 班. Among these companies was one called the Chuntai. Surviving the longest of the 'four great Anhui companies', it did not disband until the Boxer disaster of 1900 and included among its members the famous laosheng Yu Sansheng 余三勝 (I802-I866), himself a major contributor to the development of Jingju.

So the question arises whether Jiang Chun's Chuntai Company is the same as the Chuntai Company that contributed so much to nineteenth-century Jingju. For a discussion of local theatre in Yangzhou, this is not a trivial question, because a posi- 
tive answer would make Yangzhou's importance for the history of Chinese theatre as a whole significantly greater than a negative one.

Until 2005 the historical museum in Yangzhou claimed that the city's Chuntai Company was indeed the same one that later became so famous in Beijing, although the new museum set up that year was much less certain. Li Dou's claim that it was taken over by Luo Rongtai after Jiang Chun's death suggests that it was still in Yangzhou when he completed his work early in I794. We do not know precisely when the famous Jingju Chuntai Company first went to Beijing, but it could easily have been after that. We only know that the Sanqing Company went there in 1790 and that others, including the Chuntai, went there after that, but almost certainly before the end of the eighteenth century. ${ }^{7}$

On the other hand, one source implies strongly that it was the Zhejiang Salt Administration that had arranged for the various companies, including both the Sanqing and the Chuntai, to go to Beijing, which would suggest that neither was from Yangzhou. ${ }^{8}$ Moreover, there were several quite well known companies called Chuntai [Spring Stage] at the time, ${ }^{9}$ which would mean that identity of companies does not necessarily follow from having the same name. I believe that the question of whether Jiang Chun's Chuntai Company was the same troupe as the Chuntai Company that did so well in nineteenth-century Beijing must remain open until further evidence is available.

\section{ACTOR WEI CHANGSHENG}

Another major contributor to Yangzhou's local theatre in the late eighteenth century was the Sichuanese dan Wei Changsheng (1744-1802). Although from Chengdu, the style of drama he is recorded as performing was Qinqiang 秦腔, which is actually a variant of clapper theatre, bangzi qiang, originating in Shaanxi Province.

The authors of the aforementioned history of Chinese theatre, Zhang Geng and Guo Hancheng (198I, 3: 20-2I) have the following to say:

The bangzi qiang of Shanxi and Shaanxi originated in the folk songs and storytelling, shuochang, of the Shanxi-Shaanxi regions. It first evolved into small-scale folk drama. Afterwards, on the basis of folk theatre, it adopted the artistic attainments of ancient dramas, and gradually developed into largescale theatre.

The precise time of origin of this clapper theatre is unclear - it may be as early as the sixteenth century - but by the eighteenth century there were several notable urban traditions throughout China. By the I770s there was a flourishing Qinqiang theatre scene in Xi'an, about which some records survive. ${ }^{10}$ And it appears that this drama style had at about the same time spread to Sichuan, the place of origin of the most 
notable of the Qinqiang actors, and indeed of eighteenth-century China as a whole, namely Wei Changsheng.

With stage name of Wei Three (Wei San or San'er 三兒), Wei Changsheng went to Beijing in 1779 , taking the capital by storm with his artistry and virtuosity. Though he himself did not stay very long in Beijing, the music he introduced remained and later came to be part of the Jingju. In that sense he deserves a prominent place in the history of Jingju and of Chinese theatre as a whole.

Wei Changsheng's most famous item there was Gunlou 滾樓 [Rolling Tower], a flirtatious and bawdy play about the marriage of two women Zhang Jinding 張 金定 and Gao Jinding 高金定 to Wang Ziying 王子英 (Qi Senhua, et al. 1997: 573). According to Xiao Tiedi Daoren (1965: 266), writing in I803, 'the whole country went crazy' about this item and its main performer Wei Changsheng. He adds, 'I was the only one who didn't like it', a sarcastic comment perhaps emphasizing the general enthusiasm he found around him. Wu Changyuan (1965, I: I65), a writer contemporary with Wei's first visit to Beijing, claimed that an old family member had seen Wei act the part of a woman chaste till death: 'his voice and facial expressions were so vivid as to bring tears to the eyes'.

Despite his moving presentations of such characters, Wei soon gained the reputation for being immoral, and his salacious acting got him banned from the Beijing stage in 1782 and 1785 . He apparently evaded the first ban through a homosexual relationship with the scurrilous Manchu courtier Heshen 和珅 (I750-I799), who by this time had gained significant influence over the Qianlong Emperor, ${ }^{11}$ but was forced to obey the second. He acted in Yangzhou and Suzhou in the late I780s and returned to Sichuan in 1792 . He died in Beijing during a brief return visit there. ${ }^{12}$

Why Wei Changsheng deserves space in this chapter is because of his visit to Yangzhou. In 1788 he lived in the city and was for a while a member of Jiang Chun's Chuntai Company. Li Dou (I795. 5: 27a; 200I: I32) says that Jiang Chun gave him I,OOo cash for performing one scene, an enormous sum. It was largely due to Wei Changsheng's influence that the Chuntai Company became so distinctive in Yangzhou's theatre history. According to Li Dou (I795, 5: 26a-b; 200I: I3I-I32), actors like Yang Baguan and Hao Tianxiu took over items Wei performed, such as Gunlou. In addition, they integrated various major styles of regional theatre together as they performed in the Chuntai Company, including Qinqiang, which they adopted directly from Wei, and the Beijing variant of Yiyang qiang, called Jingqiang. Li Dou also notes that Hao Tianxiu 'took over the spirit of Wei San'er'.

Apart from his membership of the Chuntai Company, Wei Changsheng gained great fame, even notoriety, in the environs of Yangzhou. Jiao Xun, to whom we return in some detail in the next section, was not impressed with the ethical value of Wei's performances, He refers to Wei's 'lewd and salacious songs and low and ridiculous words'. A generation of actors, including Fan Da 樊大 ${ }^{13}$ and Hao Tianxiu, 
had copied this brilliant but disreputable actor and taken his bad influence right to the townships in the countryside. Fortunately, Jiao Xun (1960, 8: 225) felt able to report in I819 that, 'in recent years, there has been a gradual return to the old ways', meaning the much less bawdy situation that had prevailed before Wei Changsheng cast his unwelcome spell.

\section{JIAO XUN AND YANGZHOU'S LOCAL THEATRE}

We now look in a bit more detail at Jiao Xun (I763-1820), one of Yangzhou's most distinguished scholarly figures of the mid-Qing. Spending most of his life in Yangzhou or in a nearby rural area, he became a noted philologist, but with broad interests, ranging from mathematics to history, and including theatre. He was also a main compiler of the I8Io edition of the Yangzhou fuzhi 揚州府志 [Gazetteer of Yangzhou.$^{14}$

Jiao's initial successes in the official examinations, for instance becoming a xiucai 秀才 in Yangzhou in 1799, seemed to prepare him for an official career. However, he gave up all such ambitions after I8oI, when he failed to compete successfully in the metropolitan examinations in Beijing. He spent the rest of his life in scholarly pursuits, living the last decade or so of his life in a country house near Yangzhou.

Jiao Xun was very fond of theatre. He wrote two works on the subject. The first is $J u$ shuo [On Theatre] (I805), which is a set of critical writings about theatre in Chinese history in six juan. Though much shorter, the second is the more interesting for this chapter, as it shows Jiao Xun in a much more unusual light for men of his class at the time. It is Huabu nongtan [Peasant Chats on Flower Theatre], which discusses experiences he has had as a theatre-goer and performances he has attended, especially of the huabu or popular theatre. In the preface he writes (Jiao Xun 1960, 8: 225, as translated FeI 1999: 92):

It has been a long tradition that in the second and the eighth month of the year the villages outside the city [of Yangzhou] would host performances, one after another. Old peasants and fishers all come to enjoy themselves on these occasions.... I often take my old wife and young grandchildren with me on a little boat, rowing along the lake to catch various performances.

Jiao Xun's son, Jiao Tinghu 焦廷琥, also wrote of festivities in the lake villages in the second and eighth months, at which 'drama was performed during processions in thanks to the gods, amid a clamour of cymbals and drums' (quoted from Wei Ren I999: 8). Yet we know from other sources that at least in some parts of Yangzhou and its environs it was not only in the second and eighth lunar months that performances took place. The feast-days of the gods and corresponding festivals were, where possible, times for making merry and asking the gods for good luck as well as being 
occasions for popular theatre performances. Although such days were mostly in the second or eighth months, those that were not could also be an excuse for a drama performance. For instance, the 23rd day of the sixth lunar month was the feast-day of the 'fire-star' (Mars). People would put up temporary or 'straw' stages and platforms for the audience. In a work on Yizheng County just outside Yangzhou, Li Xiufang (I794-I867) observes that 'everybody takes the opportunity of the feast-day to make merry. Worshipping the god is just the excuse' (Li Xiufang I985 [I897] 6: 6b).

\section{A Famous Popular Play}

Another area where Jiao Xun commented on matters relevant to the local theatre in Yangzhou and its environs is a critique he made of a local huabu play called Sai pipa 賽琵琶 [Competing with the Lute). This item takes its name from the fact that it is on a theme similar to the famous Pipa ji 琵琶紀 [Story of the Lute] by Gao Ming 高 明 (ca I306-I359) and so appears to regard that play as a rival. Sai pipa probably dates from the eighteenth century and belongs to the category of xianghuo xi, discussed above [Wei Ren I999: I99).

The story, set in the Song Dynasty (960-I279), is about the evil Chen Shimei 陳 世美, who abandons his wife Qin Xianglian 秦香蓮 and their children for the hand of the emperor's daughter. He even tries to kill them when they turn up and embarrass him in his new home. The Prime Minister, surnamed Wang, takes the deserted family's side and brings charges against Chen for concealing their existence from the emperor and his murder attempt, but initially without effect. Qin Xianglian and her children undergo many sufferings. However, though she hangs herself in the Temple of the Three Warrior Gods, the gods save her and teach her and her children military arts. Both mother and children win military honours and victories against the Western Xia. Qin Xianglian eventually becomes the judge in the case brought by Prime Minister Wang against Chen and has him executed.

Jiao Xun says that, of all huabu plays, this is the one he likes the best. His reason is because it is extremely satisfying dramatically to see the female judge condemn her husband to death after he has abandoned her, tried to murder her and put her through so many sufferings. 'It is like instant recovery from a long illness; it is like having the ultimate scratch of an unbearable itch; no words can describe this kind of pleasure and satisfaction.' Jiao (I960: 23I, as translated FEI 1999: 94) considers it superior to Pipa ji, which does not provide the same sense of satisfaction. He also rates it much higher than the famous Xixiang ji 西廂紀 [The Story of the Western Wing], which he considers of a 'salacious sexual nature' and 'not to the taste of the respectable'.

Four comments are apposite. One is that Jiao Xun's view is strikingly condemnatory of unfaithful husbands, for what gave him most satisfaction was not the punish- 
ment of a man who had deceived the emperor but the abandoned wife's presiding over the execution of her unfaithful and murderous husband. His work consists of 'peasant chats' and no doubt reflects a view he found to be widespread in Yangzhou. Audiences included women, as Jiao Xun makes clear from the fact that he took his wife and his phrase for 'young grandchildren', yousun 幼孫, makes no distinction of sons or daughters. Considering that already women were banned from the theatre in Beijing by this time, the presence of women in the audience may not be obvious.

Secondly, Sai pipa includes the phenomenon of a female military leader and female judge, in both cases defeating men. Although this tradition has been given a good deal of focus in recent times, it is not new in China. It is a striking sidelight on the Chinese tradition, which was generally very oppressive against women. ${ }^{15}$

Thirdly, it has been suggested that two significant seventeenth-century editions of Xixiang $j i$ aimed to take out the obscenities from the play, ${ }^{16}$ making it less 'of a salacious sexual nature', specifically for 'respectable' audiences, as Jiao Xun puts it. As a writer on theatre, Jiao Xun obviously knew various versions of the play, certainly both those for elite and educated audiences and the more popular ones. It is possible that he is referring above to the popular versions he had seen outside Yangzhou, in which case he distinguishes his own 'respectable' taste from the more earthy one prevalent among the peasants.

Finally, we may note that this story is quite secular. It does not seem to accord with the idea of the xianghuo $x i$ as being religious. The impetus of the occasion that gave rise to the performance of drama may have been something like giving thanks to the gods, but that does not seem to have affected the content.

Popular items such as Sai pipa were rarely written down, even though the story of the wicked Chen Shimei has for centuries been very famous among all classes of people in China. In 1962 two old xianghuo xi actors, Pan Xiyun 潘喜云 and Zhou Ronggen 周榮根, gave an oral transmission of Sai pipa, and the resultant text has been published. Pan's grandfather had performed the role of Qin Xianglian possibly a generation or so after Jiao Xun had seen and been so impressed with the play. It has a story very similar to the one Jiao Xun described in $1819 .{ }^{17}$

\section{The Development of Yangzhou's Popular Theatre after Jiao Xun's Time}

The decline of the salt merchants brought with it a weakening of the theatre they patronized, while the Taiping Rebellion devastated the garden culture of Yangzhou. The result was that the Kunqu theatre once so prosperous there almost vanished and has never revived to a position even remotely like what it had been in its heyday of the eighteenth century.

However, the popular theatre was not nearly as badly affected by this economic decline as the Kunqu. We know that the Taiping leaders used some forms of drama for 
propaganda purposes (MackerRas I976). On the other hand, the Qing government and its provincial dependents were never very keen on popular theatre, and came down hard on actors who had anything to do with the Taipings. Moreover, the devastation of war inevitably affected the frequency of theatre performances and the livelihood of actors. However, in sharp contrast to the Kunqu, the popular theatre was able to revive and by the end of the century was regaining at least a part of its audience.

Jiao Xun's comments on the xianghuo xi he saw are not the only ones showing how popular these performances were in the early decades of the nineteenth century. Ding Changshan 丁長山, a descendant of the Ding family prominent in xianghuo xi circles in the early nineteenth century, reports big gatherings of people at Liuhe 六合 near Yangzhou called taiping shenghui 太平盛會 [grand gatherings of great peace] or qingmiao shenghui 青苗盛會 [grand crop-shoots gatherings]. The leaders of the gatherings would select dramatic items, which the troupe of his ancestors performed. They were quite extended plays, much more than simple skits. Both men and women took part, all wearing clothing appropriate to the occasion (WEI Ren I999: 4I).

According to a story told by the two old artists Pan Xiyun and Zhou Ronggen in their 1962 article 'Yangzhou xianghuo xi 揚州香火戲' (and quoted directly in WEI Ren 1999: 3I-32), xianghuo xi was involved in the Taiping Rebellion. When the Taiping leader Chen Yucheng 陳玉成 led a campaign to the east, a xianghuo xi actor surnamed Wang 汪 accompanied him with several tens of actors and performed a play at one of the gates of the city of Liuhe as a decoy. When the rebels were able to shell the gate and take the town late at night, the county magistrate committed suicide. After the rebellion was suppressed the Qing government wanted to punish the actors. They succeeded in having Wang killed, whereupon the other actors fled. They became farmers and set up a temple, which they called after the Taiping leader Hong Xiuquan 洪秀全. The story cannot be confirmed, but is quite credible. It suggests that the xianghuo xi came out of the Taiping Rebellion weaker than it went in, and that the Qing government hated this form of local theatre.

However, in the late years of the nineteenth century, xianghuo xi revived, being performed on stages not only inside temples but outside them. According to oral transmissions by old artists (cited by SoNG Ci 1955: 34), 'after midday when there was nothing to do, they would beat gongs and drums and begin singing'. Song $\mathrm{Ci}$ (I955: 34) continues that the content may not have escaped the influence of religions such as Buddhism entirely, 'but its essential spirit was not to honour the gods but to entertain people'. Song is probably right, but the two aims of honouring the gods and entertaining people are not actually in opposition with one another.

By the end of the Qing period, a few xianghuo xi artists had gone to perform in Zhejiang and the outskirts of Shanghai. In 1919, for the first time, a professional xianghuo xi company went to central Shanghai to give performances. It was followed 


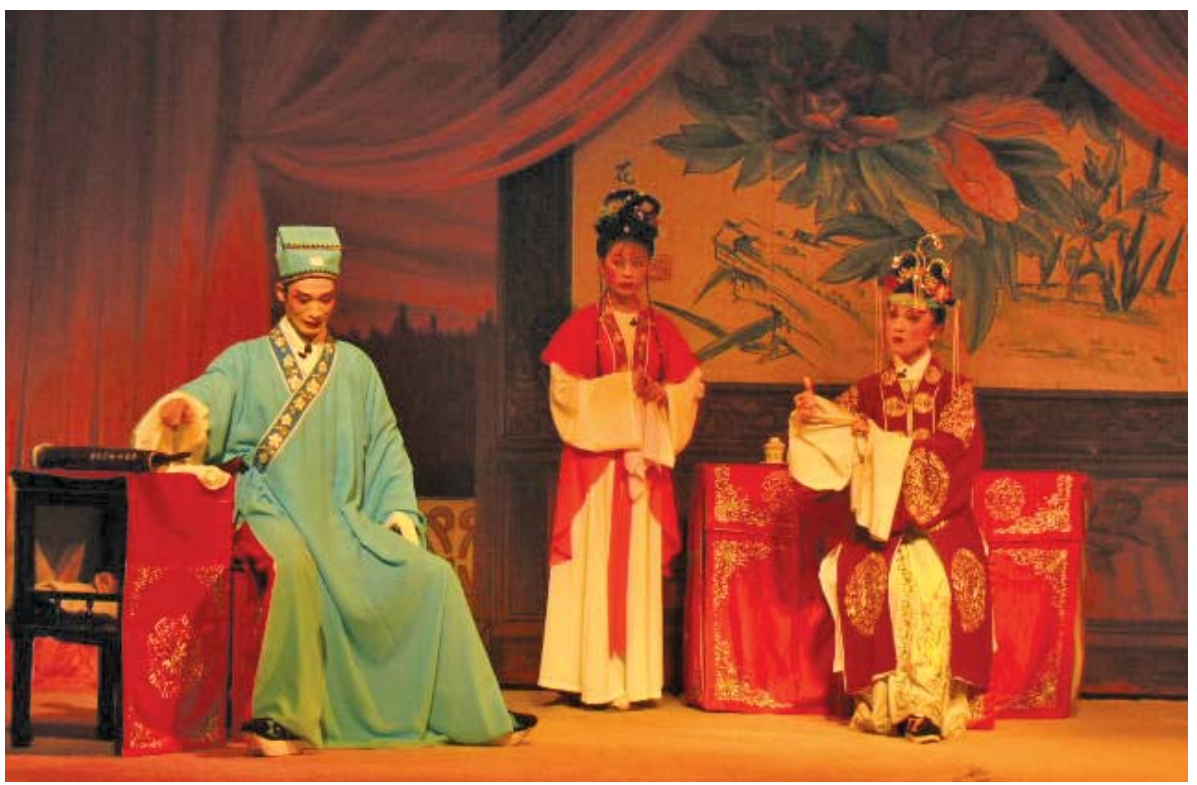

Figure 10.1 A scene from the traditional Yangzhou drama, Yangju, Zhenzhu ta 珍珠塔 [Pearl Pagoda]. The performance, by the Yangzhou Municipal Yangju Troupe, 揚州市揚劇 團, took place in October 2005 in the small town of Ganquanzhen outside Yangzhou, and was part of Ganquan's Second Special-Topic Report Meeting of Advanced Education Activities, Ganquan zhen di'er pi xianjinxing jiaoyu huodong zhuanti baogao hui 甘泉鎭第二批先進性教育活動專题报告會. The costumes and stage properties are traditional but nevertheless very characteristic of a modern professional company. The performance shows the continuing activity of the local Yangzhou theatre, with young performers being trained and part of an educational festival. Photo by Colin Mackerras, October 2005.

soon after by another one, which included the actor Pan Xiyun, whom I have quoted a couple of times in this article as an oral authority. By 1926, there were thirteen companies performing Yangzhou's xianghuo xi in Shanghai (WEI Ren and CHeN Depu I995: 405).

Turning next to look at the huagu xi, we find that this most local and folksy of Yangzhou drama styles was less affected by the political and economic conditions of the time than the xianghuo xi. The Taipings no doubt had some impact, but it was much more restricted than on Kunqu or xianghuo xi, and the government noticed it less.

The development of huagu $x i$ to a larger scale of drama style was very slow. There were several reasons for this. Wei Ren (1999: 48) comments as follows:

One of the reasons was that for a long period there were no professional troupes or professional artists. Performance activities were limited to the song and fun of the flower lantern festivals. There were of course quite a few huagu artists, 
with fathers handing on their art to their sons, sons to their grandsons, from generation to generation. But because the members of each generation had uneven innate talents, interests and love for their art, the skills and artistry of their ancestors tended to depreciate. This circumstance persisted to the late Qing and early Republic.

It was not until the early twentieth century that anybody really took seriously the idea of founding a professional huagu xi company. The year I9I5 saw the establishment of the Mingfengshe 鳴鳳社, which shortly after went on tour, visiting Hangzhou, Shanghai, Nanjing, Zhenjiang and Hankou. After that more professional companies were established in Shanghai, which took on the job of training a new generation of actors, including both male and female. (Wei Ren, Chen Depu I995: 405.)

From the I930s, Yangzhou's xianghuo xi and huagu xi were performed together as a single style. Although they certainly retained their individual features and music, attempts were made to integrate them. As a single drama style they were called Weiyang xi 维揚戲. After the People's Republic was established, further integration work was done, incorporating also Yangzhou qingqu. The style was renamed Yangju and professional Yangju companies were set up with members of the surviving Weiyang $x i$ and other troupes. Training schools were also established to train a new generation of performers. (See Lu Yingkun 1999: 694) (Fig. IO.I).

Covering the last two centuries or so, recorded titles of plays belonging to any of these styles making up the Yangju total I,I43. Among these, 2I4 are xianghuo xi, 89 are huagu xi, 79I are Weiyang xi, the rest belonging to other styles. (WEI Ren I999: I64-I65, for lists see WEI Ren I999: 859-933.) Most plays were handed down orally from generation to generation, but hand-written and printed texts survive for some. Under the People's Republic, a few old actors, including Pan Xiyun, Wang Zaiguo 王在國, Shi Yufang 石玉芳 and Pan Yulan 潘玉蘭, were asked to write down or dictate the texts of some items, after which these were edited and published. In some cases, scholars and theatre enthusiasts have resuscitated the plays by memory of having seen them and adapting available texts of the story. Old hand-written scripts and printed versions form the basis for some revived plays. One major work preserving or reviving old Yangju plays is Wei Ren's Yangzhou xi kao, published in 1999. This volume has the texts of 29 plays, commentary on each item and notes on the sources used to develop the texts. They include all the transmission methods cited above, such as the memory of old actors or others, play-scripts and printed texts (Fig. IO.2). (See Wei Ren I999: 195-856.)

Traditional Yangju are still performed and young people still recruited to become actors and singers of this style. The dialect used in the Yangju is mainly that of Yangzhou, and a good deal of the music is based on local folk songs. However, very few of the stories of the dramas are exclusive to Yangzhou, and the costumes and performance style are similar to those found in other regions. (See Fig. IO.I.) 


\section{CONCLUSION}

Apart from Beijing, Yangzhou was probably the main centre in China for the local theatre in the late eighteenth century, certainly among the foremost centres. The last century and more of the Qing dynasty saw Yangzhou's place in the overall scheme of Chinese theatre decline to one of relative unimportance.

Jiang Chun's patronage of the local theatre helped enormously and in ways more or less unprecedented in China at the time. Great actors and artists from other parts of China thought it worth their while to visit Yangzhou and influenced what happened there and in the city's environs. The most spectacular example is of course Wei Changsheng, whose role in Chinese theatre history is highly significant, but he was not the only one. Local folk theatre flourished both inside and outside the city and although there was nothing unique about that, especially in the Jiangnan region, the sources do present a picture of unusual vibrancy.

Yangzhou contributed to the growth of the Chinese theatre in general by being a melting pot for a range of regional styles. In this way it appears to have contributed to China's overall theatre development. This would be the case even if Jiang Chun's Chuntai Company were different from the one of the same name that became so prominent in the rise of the Jingju in the nineteenth century. And if the two companies called Chuntai are indeed the same one, then Yangzhou's contribution to overall Chinese theatre development would be much enhanced, because Beijing's Chuntai Company was enormously significant for nineteenthcentury Jingju history.

The nineteenth and early twentieth centuries saw the continuation of popular theatre styles in Yangzhou and surroundings, even though the Taiping Rebellion caused major interruption. But the drama of the aristocracy and the wealthy suffered enormous decline in virtually all respects. The salt merchants were no longer significant patrons of the arts or of theatre. In Yangzhou's overall history, the drama of the nineteenth century reflected that of the economy and society as a whole: it was a period of significant decline.

What does stand out is that eighteenth-century Yangzhou demonstrates the role of patronage in the history of regional drama in China with greater clarity probably than any other city of the time. It raises the more general question of the role of patronage in the non-elite arts. Given that folk theatre was doing so well, did it really make any difference that a salt merchant like Jiang Chun would wish to patronize regional styles of theatre? My answer is that Jiang Chun was contributing to a trend towards regional theatre that was in process at the time and would have persisted even without him. But his patronage did make a difference to the development of local theatre all the same, certainly in Yangzhou and quite likely in China as a whole. 


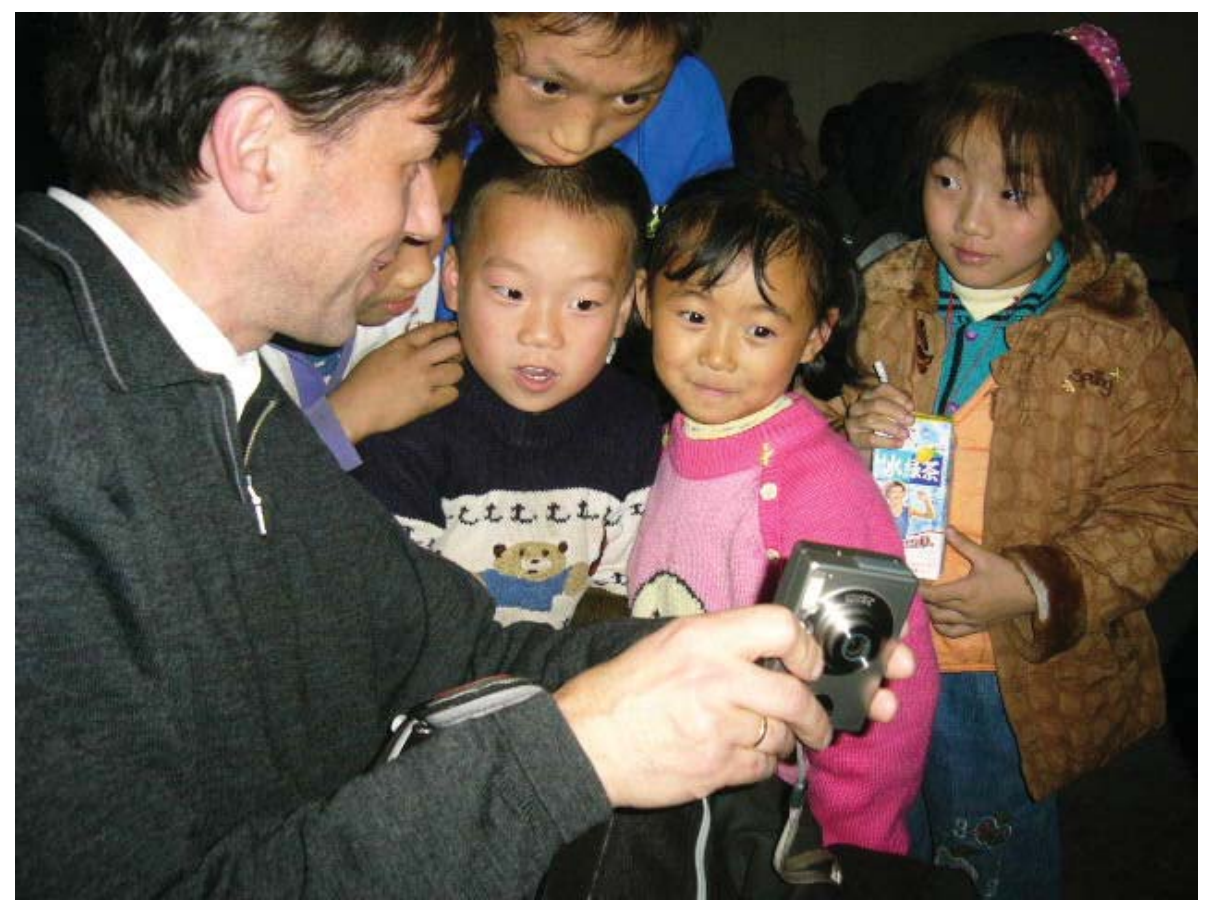

Figure 10.2 Young members of the audience at the performance of the Yangju Zhenzhu ta being shown a camera by a foreigner. The theatre was fairly small holding only a few hundred people, but was nevertheless full. The audience included quite a few children. Dress was very informal. Photo by Colin Mackerras, October 2005.

\section{NOTES}

1 See also Finnane 1993.

2 See the seminal study of Ho Ping-ti 1954: especially pp. I50-I54.

3 See Mackerras i97I. According to a major encyclopedia, there are 335 regional styles of theatre in modern China. See Tian Yirong et al. 1995: 'fanli' 凡例.

4 See Liu Yanjun 200I: I59. Liu Yanjun (200I: I69) actually calls the company 'the Yangzhou Sanqing Company', but I doubt this very much. It is true that Li Dou (I795, 5: 26a; 200I: I3I) mentions the Sanqing Company, but gives no suggestion that it was local to Yangzhou.

5 See the brief biography of Jiang Chun in MaCKerRas 1972: 78-80.

6 On the history of the Kangshan Caotang see ZHU Jiang 2002: 198-199.

7 The Rixia kanhua ji [Records of Looking at Beijing's Flowers], prefaced 1803 by a man writing under a pen-name (because the 'flowers' of the title are boy-actors, some of them probably lovers), has notes on sixty-three still performing actors, spread over eleven companies. The Chuntai Company has twenty, which is much the largest number among the eleven, suggesting it was already among the most prominent, possibly the most prominent company in Beijing by then (Xiao Tiedi Daoren i965). 
8 This is a note by the son of the Manchu Wulana 伍拉納 quoted by ZHou Yibai 1953, vol. 3: 607.

9 There was also a famous Chuntai Company in Anhui. This is attested by steles dated 1780 and I791, which are quoted by OuYang Yuqian 1957: III-II2.

10 See some discussion of the Xi'an actors of the I770s in MaCKerras I972: 8I-86.

11 Knight Biggerstaff writes that Heshen 'held the emperor's complete confidence from the end of I775 until the emperor's death (I799)' (Hummel 1967 [1943]: 288).

12 On Wei Changsheng, his acting career and his contribution to Jingju and Chinese theatre in general see MACKERRAS 1972: 9I-98.

13 Fan Da had originally gained his reputation for Kunqu performance, but had later taken up various regional styles, like Qinqiang, Yiyang qiang and Erhuang, excelling in all of them. So good did his reputation become that people called him the 'theatre wizard', xiyao 戲妖 (Li Dou I795, 5: 26b; 200I: 13I).

14 For a brief rundown on Jiao Xun's life see Hummel 1967 [1943]: I44-45. Also see the much more detailed account of Jiao Xun and his son Jiao Tinghu 焦廷琥 (b. 1782) by the distinguished scholar ZHANG Shunhui 張舜徽 (I9II-I992) (2004: II3-I50).

15 On this topic see especially the chapter on woman warriors in Li Siu Leung 2003: 83-IO7.

16 See Sieber 2003: I23-I6I, which is a chapter on editions of the Xixiang ji, 'the book-market, and the discourse on obscenity'.

17 For the text of the play see WeI Ren 1999: 20I-222, and for commentary on it see 199-200. 


\section{Kunqu in Yangzhou}

\section{Then and Now}

\section{Lindy Li Mark}

F rom the mid seventeenth until the nineteenth century, a literary drama genre known as chuanqi 傳奇, set to the musical style known at that time as Kunqiang 崑腔 (Kunqu 崑曲 or Kunju 崑劇 today), spread beyond its place of origin in the Wu dialect region of the coastal Yangzi delta, to other parts of China - north to Beijing, south to Wenzhou, even west to Sichuan. It was the most sophisticated and popular performing art of the empire. During that time, Yangzhou was a commercial and cultural centre of central China. Situated at the confluence of the Grand Canal and the Yangzi River, it was the major entrepôt for commodities from fertile 'rice-fish' central China to the less fertile north China. In addition, as the administrative centre of the salt monopoly and silk trade, a burgeoning upper and middle class of wealthy salt merchants, silk commissioners, and officials congregated there. With their demands for luxury goods, cultural accoutrements, and entertainment, Yangzhou attracted people of talent from all the artistic occupations. These artisans, painters, calligraphers, singers, writers, actors, courtesans, and their less reputable counterparts fed into a flourishing urban high culture.

Moreover, as a headquarters for Emperor Qianlong on his six inspection tours to central China, Yangzhou received the kind of economic and cultural stimulus conferred on a city today by the Olympic Games or world expositions. Emperor Qianlong loved the theatre, and Kunqu was the entertainment of choice. Unfortunately, Kunqu almost disappeared from Yangzhou after the city was sacked during the Taiping Rebellion of the mid nineteenth century. Even today, there is no professional Kunqu troupe in Yangzhou, only several amateur singing clubs.

Before going into the history of Kunqu in Yangzhou, let me first give a brief reprise of the genre. Kunqu theatre was, historically, the staple of elite entertainment, referred to in the literature as yabu 雅部 [elegant division] (or 'classical division'). Its 'elegance' stems from the sophisticated poetry that makes up its libretti, written by renowned men of letters. Its counterpart, known as huabu 花部 ['flowery' or variety division] (or 'popular division'), refers to various regional vernacular theatres such as Peking opera, Yiyang opera, and others. The appellation Kunqu [song of Kun] is derived from the name of Kunshan City 崑山, located between Shanghai and 
Suzhou. It was in Kunshan, and in nearby Suzhou 蘇州 and Taicang 太倉, that a regional musical style was combined with refined, dramatic poetry, and perfected by a group of literati musicians and poets, to become known as Kunqu. ${ }^{1}$

Kunqu is the musical setting of chuanqi, a genre of literary drama that flourished during the late Yuan and throughout the Ming and Qing dynasties. ${ }^{2}$ Chuanqi plays are made up of numerous episodic scenes, comprising singing, dialogue, and dance movement. The plays are also unusually long, comprising as they do scores of scenes; plays of thirty to fifty scenes are common. For example, the well-known Ming dynasty drama The Peony Pavilion, by Tang Xianzu (I550-16I6), has fifty-five scenes, comprising over 400 poetic arias. It would have taken several days to perform it in its entirety.

A play usually begins with a short prologue setting forth the central theme and outline of the plot. Each scene, chu䕬 (or 出), thereafter is composed of spoken dialogue interspersed in a suite of lyric poems set to music. Because of the length of the plays, by the nineteenth century a typical performance was made up of excerpted scenes, frequently from different plays. Most of the members of the audience would be well acquainted with the full-length narrative from which each scene was drawn, and would not need to sit through a whole play to enjoy the singing and acting of one scene. On festive occasions, such as New Year celebrations, or the birthday celebration of an important person, a complete play might still be performed, over several days.

Drama historians have noted that from the seventeenth to the nineteenth centuries the standing of Kunqu in Yangzhou surpassed that in its cities of origin. The fame and reputation of Kunqu performers rested on the recognition and fees they commanded in Yangzhou. An extensive discussion of theatres and actors in Yangzhou is found in History of the Development of Kunju (Hu Ji, Liu Zhizhong I989: 45I-464), and I shall not repeat it here. However, that book is about the development and spread of Kunqu, therefore the narration sometimes does not, and perhaps cannot, always separate the discussion of Kunqu from that of other regional theatres that preceded the crystallization of the Kunqu style, such as Yiyangqiang $七$ 陽腔, Gaoqiang 高腔, Pihuang 皮黃 (another name for today's Beijing opera), and so forth. These regional dramas also flourished in Yangzhou, causing a profusion and confusion of names in the literature.

The good times in Yangzhou did not last. The sacking of the city by the Taiping rebels in 1853 dealt the cultural life of the city a serious blow. When transportation in the second half of the nineteenth century began shifting eastward to land rails and coastal shipping, and import tariffs from foreign goods replaced salt-silk revenues, Yangzhou fell into economic decline. After the quelling of the Taiping Rebellion, performers and theatrical troupes dispersed to more prosperous commercial centres on the coast such as Nantong 南通, Hangzhou 杭州, and Shanghai 上海. In addition, 
Kunqu faced competition from a local vernacular genre of Yangzhou theatre, which eventually also spread to coastal cities.

The twentieth century also saw troubled times. The Japanese massacre of Nanjing in 1937 extended to Yangzhou (ZHANG Nan 2002: 95-96, 99-IOI), whilst in the turmoil of the Liberation (I949) and Cultural Revolution (I966-I976) more blows were dealt to traditional theatre in Yangzhou's cultural life. Unlike major cities such as Beijing, Shanghai, Nanjing, Suzhou, and Changsha, all of which have governmentsupported Kunqu troupes, Yangzhou today has no professional troupe. In Yangzhou, Kunqu was and still is kept alive by non-professional literati associations, called qushe 曲社 [song society].

In researching this chapter, I found that historical sources are uneven and incomplete, while sources on Kunqu in Yangzhou after the nineteenth century are particularly sparse. This situation is surprising in view of the fact that Yangzhou was such a centre of Kunqu in the eighteenth and early nineteenth centuries. Happily there is now a group of local scholars researching the cultural history of Yangzhou, including Kunqu in Yangzhou (Geng Jianting 2005, WeI Minghua 2004, Wu Runsheng 2003, ZHANG Nan 2002), and several new sources have been discovered, or rather, rediscovered.

In view of the nature of the sources, this chapter is arranged under four headings: sources on Kunqu in Yangzhou; Kunqu troupes in Yangzhou; Kunqu performance practice in Yangzhou; and Yangzhou speech in Kunqu. Why these four? In the first place, although some early sources on Kunqu in Yangzhou have been cited by historians, a few recently rediscovered ones are not so well known, and it seems worthwhile to introduce them to an English-language readership. Secondly, while information on performance practices is sparse, information on the numbers and nature of historic Kunqu troupes in Yangzhou may help shed light on the rise and fall of the genre. Moreover, one of the troupes, the Quanfu troupe, is the single thread connecting present day Kunqu in Yangzhou to its predecessors. Thirdly, while there are no professional performances in Yangzhou today, the nature and structure of some Kunqu plays can be gleaned from a recently discovered manuscript. Discussion of two Yangzhou plays is therefore included. Finally, another way in which Yangzhou has influenced Kunqu is through the use of Yangzhou speech in some Kunqu plays. I discuss this aspect briefly.

\section{SOURCES ON KUNQU IN YANGZHOU}

There are three important sources on Kunqu in Yangzhou. The most oft-quoted source is undoubtedly Yangzhou huafanglu 揚州畫舫錄 [The Pleasure-boats of Yangzhou] (I795) by Li Dou 李斗. This travelogue-style work describes the scenic locations and historic sites in and around Yangzhou, and includes an account of the entertainment 
industry, including Kunqiang (the older designation of Kunqu). A later work in a similar vein is Zhuxi huashi xiaolu 竹西花事小錄 [Jottings on the Flowers of Zhuxi] (c.I868) by an anonymous writer self-styled 'Mendicant Fenlituo' 芬利它行者. This journal contains personal memoirs and essays dealing with the decades following the Taiping Rebellion, and describes the revival of the pleasure quarters. ('Flowers' is a euphemism for opera performers during the Qing dynasty, especially men performing female roles) (WEI Minghua 2003). Third, and perhaps most importantly, is the Yicun qupu 佚存曲譜 [Music Scores Lost and Found] (I736-I86I). This manuscript anthology was formerly privately held and comprises a collection of thirty scenes actually performed in Yangzhou, with musical notation, dialogue, stage props, makeup, and movement notes all included. In addition, there are choreographic scores, shenduan pu 身段譜, for two scenes; musical scores for instrumental interludes chuida qupai 吹打曲牌; and musical notations for a genre of instrumental music known as shi fan 十番 (LIN Xin 2000). Overall Yicun qupu is the most valuable source for the history of Kunqu performance practice. It has been partially reprinted, in a version edited and hand-copied by the late Wang Zhenglai 王正來. The remainder was being edited in preparation for re-publication when Wang Zhenglai died. In addition to these major sources, there are a few personal memoirs - biji journals 筆記 - that contain scattered information (e.g. GENG Jianting 2005; LIN Xin 2000; WEI Minghua 2003; Wu Runsheng 2003).

\section{KUNQU TROUPES IN YANGZHOU SINCE THE LATE QING PERIOD}

\section{Professional Kunqu Theatrical Traditions}

During the reign of Emperor Qianlong, Yangzhou was an important place of sojourn for the emperor and his entourage on his six 'southern inspection tours.' Aside from providing opulent quarters and lavish repast, an important part of Yangzhou's hospitality to the emperor was theatrical entertainment, and this prompted the organization of acting troupes. According to Li Dou's Yangzhou Huafanglu, there were three types of troupes:

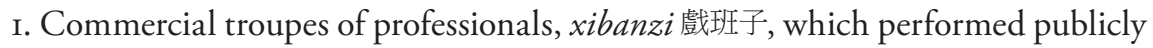
for pay in the city. These all-male troupes were relatively large, comprising several scores of performers specializing in many roles, along with musicians, prop men, and such.

2. Private family troupes, jiaban 家班, kept by wealthy individuals and performing at the pleasure of their patrons. Jiaban would also be called upon to perform for the emperor when he visited the city. Jiaban were usually small, comprising a dozen to twenty members. However, some of the semi-official jiaban troupes maintained 
by wealthy salt merchants for the entertainment of the emperor numbered well over a hundred (Li Dou 200I [I795]: 84). Note that all-female troupes tended to be private family troupes (WU Runsheng 2003: 202-03). All-female performances were known as maor $x i$ 貓兒戲 [cat plays] (WU Runsheng 2003: 200).

3. Pleasure boat troupes, huafang xiban 畫舫戲班, i.e. small commercial pleasure boat troupes. These troupes were the smallest, from four-to-five to seven-to-eight performers, often family members. They lived and performed on special boats equipped with stage and supporting prop vessels. These boat troupes would ply the waters of the Grand Canal and lakes and entertain viewers who might be either on the shore or in other pleasure boats.

Yangzhou huafanglu is the most extensively quoted source on theatre life in Yangzhou. A summary of its contents is included in Kunju fazhanshi (Hu Ji, LiU Zhizhong 1989: 652-64) and only some of the salient points will be commented on here. Li Dou makes a clear distinction between the 'elegant division,' yabu, i.e. troupes that perform primarily Kunqiang, and the 'popular division,' huabu. Li points out that wealthy merchants often maintained both types, and some troupes performed both kinds of plays. However, the troupes that exclusively performed Kunqu were considered more prestigious.

Li Dou's descriptions of theatrical troupes are uneven but he does include some important details. For example, he lists the instruments played by the ensembles and precisely indicates their placement on the stage. He also lists some of the famous actors, their roles, their teachers, their apprentices, and some of the plays in which each excelled. The teachers were primarily from nearby Suzhou, as were most of the 'good' actors. This may account for the lack of development of local Yangzhou troupes, Suzhou being so close that it was easy to bring in performers. Moreover, the Yangzhou dialect belongs to the south-eastern branch of Mandarin or Jiangnan guanhua 江南官話, and is closer in pronunciation to Beijing Mandarin than to the Wu dialects of the coastal Yangzi delta. Since Kunqiang was (and is) sung and spoken in a stage language closer to Wu dialect, Yangzhou singers were ridiculed for their rustic diction, rather as if a performer were criticized for singing Italian opera with a strong Texan accent (I will return to this discussion below, cf. the section on 'Yangzhou Speech in Kunqu').

Although Li Dou's coverage of the troupes is uneven, the sheer number of Kunqu troupes mentioned in his account attests to the popularity of the art. He names seven wealthy salt merchants who maintained family Kunqiang troupes (Li Dou 200I [I795]:79).

Xu Shangzhi: Lao Xu Troupe

Wang Qiyuan: Wang Troupe Hong Chongshi: Da Hong Troupe
徐尚志: 老徐班

汪啟原: 汪班

洪充實: 大洪班 
Cheng Qiande: Cheng Troupe

Jiang Chun: Deyin Troupe

Zhang Da'an: Zhang Troupe.

Huang Yuande: Huang Troupe
程謙德: 程班

江春: 德音班

張大安: 張班

黃元德: 黃班

The last-named salt merchant, Huang Yuande, apparently organized several additional troupes in succession: the Xiao Zhang Troupe 小張班, the Xiao Cheng Troupe 小程班, the Xiao Hong Troupe 小洪班, and the Baifu Troupe 百福班. An all-female Shuangqing Troupe 雙清班 is described in great detail and was a very popular independent troupe that was also headed by a woman. It is likely that there were other wealthy individuals who maintained less well-known family troupes. In addition to Li Dou's account, recent scholarship on the history of Kunqu has uncovered several more troupes. Kunqu Cidian (Hong Weizhu 2002, hereafter KC) names the following, all active during the Qianlong-Jiajing period:

$\begin{array}{ll}\text { Jiqing Troupe } & \text { 集慶班 (KC: 915) } \\ \text { Ruyi Troupe } & \text { 如意班 (KC: 938) } \\ \text { Jixiu Troupe } & \text { 集秀班 (KC: 916-I7) } \\ \text { Quanfu Troupe } & \text { 全福班 (KC: 917) } \\ \text { Jixiu Yangbu } & \text { 集秀揚部 (KC: 917) }\end{array}$

It is apparent therefore that at least fifteen Kunqiang troupes were active in Yangzhou in the seventy-three years between the I780s and I853. The last-named troupe listed, Jixiu Yangbu, was apparently the only troupe made up of Yangzhou natives, and they performed 'popular division,' huabu, operas as well. It is said that this troupe was first laughed at because their diction was too rustic, that is, with a Yangzhou dialect influence.

From Li Dou's biographies of some of the actors, it appears that there was some movement of performers between the troupes. Further, not all of the troupes were active at the same time and some of the troupes were not very long lived. Nevertheless, the numbers testify to the popularity of the genre into the mid nineteenth century despite competition from the 'popular division.'

The Quanfu Troupe 全福班 was organized during the Daoguang era 道光 (I82II850). Its members were originally from Suzhou, and became famous in Yangzhou. It was disbanded during the Taiping Rebellion but eventually regrouped as a touring troupe, jianghu ban 江湖班 [troupe of the rivers and lakes], up to the early twentieth century (Zhang Yunhe 1982). ${ }^{3}$ This troupe made annual tours by boat to sixty-six cities of the Yangzi delta and lake regions. Yangzhou was most likely visited, but probably less frequently than in the past. Its economic and political decline, coupled with the language difference, contributed to the waning and eventual disappearance of Kunqu troupes from Yangzhou. It is worth mentioning here that Kunqu as we now 
know it is largely a legacy of the Quanfu troupe. In 1920, the last group of masters of the Quanfu troupe became the teachers of the now famous Chuanzibei 傳字輩 [Chuan generation of actors], who in turn were the teachers of many well-known senior performers of today.

In the course of describing the specialties of specific actors, Li Dou mentions scores of plays, and excerpted scenes by name:

Play titles:

Mudan ting 牡丹亭 [Peony Pavilion]

Xiaoguang jian 宵光劍 [The Night-shining Sword]

Zui puti 醉菩提 [Drunken Boddhi]

Shuihu ji 水潡記 [Water Margin]

Pipa ji 琵琶記 [The Lute]

Qianjin ji 千金記 [A Thousand Golden Coins]

Xixiang ji 西廂記 [The Western Wing]

\section{Scene titles:}

Xun meng 尋夢 ['Dream Search' from Peony Pavilion]

Chi su, Dian xiang 痴訴, 點香 ['Crazy Accusation', 'Offering of Incense' from Snow pavilion 艷雪亭]

Xiangyue, Xiangma 相約, 相罵 ['The Appointment,' 'The Quarrel', source unknown]

Shuang si fan 雙思凡 ['Double Carnal Longing', a popular single scene]

Nanpu, Zhu bie 南浦, 囑別 ['Southern Shore', 'Farewell Bidding' from The Lute]

You dian 游殿 ['Tour of the Temple Hall' from The Western Wing],

Nao zhuang 閙莊 ['Disturbance in the Estate', source unknown]

Jiu Qing 救青 ['Rescue of Qing'er']

Hetao 河套: ['River Works'?]

Canxiang 參相 ['Audience with the Minister'?]

Yi jian 議劍 ['Appraising the Sword'?].

The plays and individual scenes, except the last three, are still in the Kunqu repertoire today. Some of them are no longer performed on stage, but the lyrics are sung by members of Kunqu clubs. In the following section I shall discuss the non-professional singing tradition.

\section{The Qingchang Tradition}

In addition to theatrical performances, Li Dou goes to some length to describe the non-theatrical, amateur singing tradition known, then as now, as qingchang 清 唱 [pure song] (Li Dou 200I [1795]: 208-2I0). When doing qingchang, make-up, 
costumes, and movements were not used. The singers were largely literati amateurs who had studied with each other, or retired professional actors. They met at informal gatherings and performed for each other. At festivals, small ensembles of singers and musicians would set up in the open and compete for an audience. The winner was the singer or singing group that attracted the largest audience, as shown, for example, by the greatest number of pleasure boats moored in front of it. Money did not change hands: earning a living was clearly not a goal for these performances:

\section{每一市會, 爭相鬥曲. 以畫舫停筒就聽者多少為勝, 多以熙春台, 關帝廟為清唱之地.}

At every festival, there are singing competitions. The winner is determined by how many pleasure boats are moored in [front of the performers] to listen. Pure song takes place mostly at the Temple of Guan Di or Xichun Terrace.' (Li Dou 200I [I795]: 210)

Another writer of the nineteenth century, Dong Yushu, mentioned above, describes several amateur musicians in the following manner:

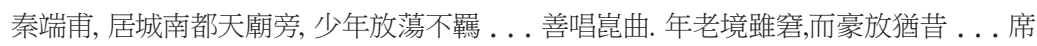
次高歌入雲, 有關西大漢撥鐵板銅琶, 唱 ‘大江東去’之概. 又有周某, 人稱‘周鵝頭’, 善吹 笛,抑揚高下, 與度曲之聲相應

Qin Duanpu lived in the southern quarter by the Dutian Temple. When he was young he was carefree and uninhibited . . very good at singing Kunqu. Although poor in his old age, he was as unrestrained as ever . . . at banquets his singing voice reached into the sky. There was a big fellow from the west who played the lute with an iron plectrum and sang 'East Flows the Great River'. There was another man surnamed Zhou whom everyone called Goose Head Zhou. He played the flute well and accompanied the rise and fall of the singing melody. (Dong Yushu 2002 [I878]: 22)

Singing Kunqiang was also very fashionable among women. Ladies of well-to-do families studied Kunqiang as a matter of personal cultivation; they never performed in public. Daughters of poorer families studied to become courtesans and to perform for hire at parties. Yangzhou was famous for beautiful courtesans, known as Yangzhou shouma 瘦馬 [thin horses of Yangzhou] ${ }^{5}$ (WEI Minghua 1998). They excelled in the arts of singing and acting, including Kunqiang. Some of them may also have been recruited to all-female troupes. The qingchang tradition continues today, not only in Yangzhou, but in major cities of China, as well as in several cities in the United States.

Another way in which Kunqu had an influence on local genres is seen in Yangzhou xiaochang 揚州小唱 [Yangzhou ditties]. This type of singing became known later as qingqu 清曲 [pure song]. Yangzhou xiaochang groups sang local popular songs that 
were considered secondary to Kunqu (Li Dou 200I [I795]: 2I5). But singers sometimes rearranged lyrics from the Peony Pavilion and Winning the Champion of Flowers 佔花 魁 in the qingqu style. From these historical sources emerges a picture of Kunqu as the elite performance genre in Yangzhou. But it influenced the huabu or the 'popular division,' which in turn gave Kunqu healthy competition.

After the Taiping Rebellion was suppressed, Yangzhou revived, but never recovered its former glory. Pleasure quarters reopened, but there is no information as to whether professional Kunqu troupes regrouped. Zhuxi huashi xiaolu 竹西花事小錄 [Jottings on Flowers of Zhuxi] (ca I868) is a description of the singing-girls of Yangzhou. The real name of the author is not known. This self-styled Buddhist mendicant was obviously familiar with the eight pleasure quarters of Yangzhou. Names of the favourite courtesans are given and the Kunqu pieces in which each excelled. These girls did not sing Kunqu only, they also sang other popular pieces.

Among recently discovered sources is the memoir of a Yangzhou physician Geng Jianting 耿鑒庭, who traces Kunqu activity in his family back four generations (GENG Jianting 2005). We learn that he has not sung himself, but his forebears, also local physicians, were well-known amateur participants. According to his memoir, Kunqiang was performed on ritual occasions such as on the birthday of the deified hero Guan Gong, Daoist festivals, and funerals. On these occasions scenes from plays with supernatural themes were performed. For example, at a funeral, Saohua 掃花 [The Flower Sweeper] and Sanzui 三醉 [Thrice Tipsy] - two scenes from Tang Xianzu's play Handan meng 邯鄲夢 [Dream of Handan] - might be sung. In Saohua, the immortal Lü Dongbin 呂洞賓 arrives somewhere in the celestial realm and informs the flowersweeping fairy He Xiangu 何仙姑 that she has been promoted, and that he has to find a replacement for her. She warns him not to get drunk again and cause her to miss the divine peach festival 仙桃會. In the subsequent scene Sanzui, Lü Dongbin flies on a cloud to Yangzhou, to seek a worthy replacement as a divine flower sweeper. He feigns intoxication and is laughed off by merrymakers who do not recognize his supernatural identity. The symbolic function of this part of the story is to alleviate the grief of mourners by reminding them that there is a higher immortal realm.

In 2005, I attended the annual mid-autumn Kunqu singing festival in Suzhou and met Professor Lin Xin 林金金 of Yangzhou. We had a long conversation about Kunqu associations in Yangzhou. He offered to introduce me to some of them. Unfortunately I was not able to accept his kind offer at the time. Evidently, there is lively competition among Kunqu qingchang associations in Yangzhou today.

\section{KUNQU PERFORMANCE PRACTICE IN YANGZHOU}

As for how the music of Kunqiang was performed in Yangzhou, there is little information except for what can be gleaned from the earlier mentioned Yicun qupu 
佚存曲譜 [Music Scores Lost and Found] (1992 Neibu 內部 [internal publication]). Thirty scenes in this manuscript anthology date from I736-I86I, including musical notation, rudimentary stage directions, notes on costumes, and dialogue. A handcopied, edited, and annotated lithograph reproduction of the original manuscript was printed in 1992. Since it was neibu, i.e. not for general circulation, only a few libraries have it. ${ }^{6}$ This anthology may well be the only surviving source of Yangzhou performance practice of Kunqu, and I discuss it in the following paragraphs.

According to the epilogue by the original owner Yu Nianchun 郁念純 (I9II-), a devotee of Kunqu, he acquired thirty pieces of handwritten Kunqu musical scores dating from the Qing dynasty from a second-hand bookstore in Yangzhou in the I950s. These pieces are rare manuscripts comprising two categories of scores: actors' stage scripts which include lyrics, musical notation, dialogue, percussion patterns, and rudimentary stage directions; and qingchang scores with lyrics and musical notation. In 1965, Professor Zhao Jingshen, then at Fudan University, visited Yangzhou and examined the collection. Zhao immediately recognized its value and recommended that the manuscripts be published. But the Cultural Revolution intervened and tragically over half of the collection was destroyed by Red Guards. In I988, Xu Qinjun 徐沁君 of Yangzhou Normal College and Wang Zhenglai 王正來 (d. 2003) of the Nanjing Provincial Drama School edited and annotated the remaining manuscripts in two volumes. These were finally printed in 1992 and distributed as neibu materials (only for certain selected groups). Only a few copies were given to libraries and scholars outside China. According to the epilogue by Wang Zhenglai, the original manuscripts were donated to Jiangsu Provincial Cultural Arts Research Institute 江蘇省文化藝術研究所. However, there is a great deal of controversy about Wang Zhenglai's role in obtaining the manuscripts and where they are at present. Wang Zhenglai died in an accident in 2003, and it is rumoured that the location of the manuscripts is unknown.

The extracts from plays and the individual scenes in Yicun qupu suggest that the items of the collection were primarily intended for performance at celebratory and ritual occasions. There are four individual scenes that do not belong to longer chuanqi plays, but to the category of ritual opening scenes, kaichangxi 開場戲, for performance at celebrations. They are short, musically simple, but full of colourful pageantry and auspicious supernatural characters. For example, one of these plays is titled Cifu 賜 福 [Bestowing Blessing]. The Yicun version is different from scenes of the same title in other anthologies. For example, the Yicun version of Cifu consists of a song suite composed of the following seven titled songs, with lyrics and musical notation:?

$\begin{array}{lll}\text { Dianjiangchun } & \text { 點絳唇 } & \text { [Dotting Crimson Lips] } \\ \text { Hunjianglong } & \text { 混江龍 } & \text { [Dragon in Turbid Waters] } \\ \text { Youhulu } & \text { 油葫蘆 } & \text { [Greasy Gourd] }\end{array}$




$\begin{array}{lll}\text { Tianxiale } & \text { 天下樂 } & \text { [Joy under Heaven] } \\ \text { Jishengcao } & \text { 寄生草 } & \text { [Herb of Long Life] } \\ \text { Nuozhaling } & \text { 哪吃令 } & \text { [Song of Nuozha] } \\ \text { Shawei } & \text { 繁尾 } & \text { [Coda] }\end{array}$

The song suite of Cifu found in other widely distributed anthologies, such as Yuzhong $q u p u$ 與眾曲譜 (1977 [1907]), and Liuye qupu 六也曲譜 (1970 [1940]), has a different suite of songs as follows:

$\begin{array}{lll}\text { Zuibuayin } & \text { 醉花陰 } & \text { [Drunk in the Shade of the Flower] } \\ \text { Xiqianying } & \text { 喜遷鶯 } & \text { [Joyful Oriole] } \\ \text { Guadifeng } & \text { 刮地風 } & \text { [Ground Wind] } \\ \text { Shuixianzi } & \text { 水仙子 } & \text { [Narcissus] } \\ \text { Shawei } & \text { 鴊尾 } & \text { [Coda] }\end{array}$

Comparing these song suites it can be seen that the Yangzhou Cifu is different from other versions of the same scene.

Two multiple-scene plays in the anthology are very likely those performed on ritual occasions. Musical dramas are often performed as offerings to deities (evidently Chinese gods love the theatre as much as humans) and as entertainment at temple festivals, and on birthday celebrations of honoured elders, or at weddings. The plays have a religious theme, or include stories dealing with supernatural events, but they are also very entertaining and even humorous. I summarize two of them below.

\section{Two Plays from the Yicun Qupu}

\section{1. 'Pink Tigress' Yanzhi hu 胭脂虎}

Volume I of the Yicun qupu contains four scenes from the play Yanzhi hu 胭脂虎 [Pink Tigress] (also known as Fubu tao 伏虎鞱 [Subduing the Tigress] in the anthology Jicheng qupu 集成曲譜 Volume I: Io). It has religious meaning, pageantry, and humour.

The play opens with a parade of Buddhist deities: Pink Tigress enters as a female Yaksha 羅刹女 wielding double swords. She is followed by the guardian deity Weituo 韋陀, also carrying a sword, and the four Jingang 金岡, temple-gate guardians. The four Jingang exit, then re-enter with eight Zen masters, eighteen Arhats, Weituo, and four nuns. Finally, the Benevolent Page Shancai 善才 and Dragon Maid Longnü 龍女 and the major deity Bodhisattva Guanyin 觀音 enter. This parade of supernatural beings comprises over thirty actors on stage at the same time, so it was clearly scripted for a large troupe.

With the assemblage now on stage, Guanyin tells the audience the origin of suffering in the mortal world. She explains that much suffering among humans 
stems from jealousy on the part of women, and lechery on the part of men. Therefore, she is releasing Pink Tigress and her nemesis, Jiaye 迦耶, to be reincarnated on earth as husband and wife, to teach people about the pain of carnal desire. She also dispatches a powerful Arhat, the Venerable Tiger Tamer 伏虎尊者, to the secular world, to subdue the tigress. In the following scenes we find that Pink Tigress is reincarnated as a domineering shrew who builds a hall with a large sign reading: 'Hall of the Great Shrew' Daci baodian 大雌寶殿. This title is a parody of the main prayer hall in Buddhist temples in which the statue of Buddha is enthroned, and which is always named 'Hall of the Great Power,' Daxiong baodian 大雄寶殿. In this play, Pink Tigress holds court in the Great Shrew Hall to give advice on how to control men, and mete out punishment to wayward husbands. For example one woman complains that her husband has taken a concubine and neglects her. Pink Tigress condemns the man to empty out his wife's chamber pot every morning. The Yicun qupu has only the first four scenes from this drama, but clearly, entertainment is combined herein with Buddhist teachings. It is not difficult to imagine this play performed as part of wedding celebrations.

\section{2. 'Flame Mountain' Huoyanshan 火焰山}

Another drama titled Huoyanshan 火焰山 [Flame Mountain] is a complete play and consists of fifteen scenes from the legend of Journey to the West. In this play, Tripitaka and his four disciples, on their journey in quest of Buddhist sutras, are obstructed by a range of fiery mountains. Tripitaka's most powerful guardian, Monkey, tries to steal the magic fan of Princess Iron Fan 鐵扇公主 to cool the Flame Mountain. The princess refuses and defeats him in every fight. Monkey finally succeeds after the third try by disguising himself as her husband King Demon Bull 牛魔王. After escorting his mortal master, the saintly priest Tripitaka, across the mountain, he returns the fan. Needless to say this play entails a great many acrobatic fighting scenes, and also humour when Monkey tries to conceal his real identity. Infuriated by the deceit, the Princess and the Demon Bull pursue Monkey, and more fight scenes ensue. At the end, Guanyin subdues the ill-tempered Princess Iron Fan and her husband, and converts them to Buddhism.

In other versions of this play under the more widely known title Xiyou ji 西遊記 [Journey to the West], Monkey changes himself into a fly and enters the Princess' stomach by way of her drink. He tortures her from within, until she yields the fan. Unlike the Yicun version, however, Guanyin does not appear at the end of the play and there is no explicit religious message.

Without analyzing the music of each scene in the Yicun anthology and comparing it with its counterpart in other collections, it is not possible to say what musical characteristics are unique to the Yangzhou style of Kunqu. Unfortunately, 
there is also nothing to indicate for which troupes these manuscripts might have been devised. Wang Zhenglai states in his epilogue that some of the scenes are the only examples in existence; but he does not point out which ones. It is well known, however, that play scripts were closely guarded trade secrets and transmitted only from master to specially-favoured disciples or family members, who were expected to continue in the profession. That these scripts eventually surfaced in old book stalls is evidence of the decline of theatre in Yangzhou.

\section{YANGZHOU SPEECH IN KUNQU}

Another significant way, albeit limited, that Yangzhou has left its imprint on Kunqu, is in the use of Yangzhou dialect in the spoken part of some plays. Spoken parts in Chinese opera are called bai 白 [Speech]. Dialogue in Kunqu, as in Peking opera, is spoken in an artificial stage language called yunbai 韻白 [rhyme speech] (rhyme, yun, is here a short form of Zhongzhou yun, cf. below). Yunbai is delivered in heightened tonal contours and used by all role types except comic roles. Yunbai has no prescribed pitch levels, but there are complicated pitch contours and tone Sandhi rules based on the rhyme-tone system called Zhongzhou yun 中州韻 [Rhymes of the Central Plains]. The problem with Zhongzhou yun is that there were never any standard pronunciation guidelines. ${ }^{8}$ Although it is understood that certain words rhyme (according to the standard of the rhyme dictionary), they are nevertheless spoken in dialect, where the rhyming may only partly concur with that of the Zhongzhou yun ideal.

The other stage language is subai 俗白 [vernacular speech], and this is spoken only by comic characters, especially when telling jokes. The most commonly used vernaculars are Jingbai 京白 [capital (or Beijing) speech], the vernacular spoken in and around Beijing, and Subai 蘇白 [Suzhou speech], the vernacular of Suzhou. These dialects add color, humor, and liveliness to the action, not only because they are more easily understood by the local audience, but also because dialect itself is considered funny. Dramatic plays make use of misunderstandings based on dialectal differences for comic effect. In any given scene, the serious characters will speak in yunbai while the comic characters will speak in the local dialect. Normally the speech style is not specified in drama anthologies; dialogues are written with the syntax of a semi-formal guanhua 官話 [Mandarin, or language of officials], something between colloquial and classical Chinese. However, Hu Shi 胡適 has already in the I930s pointed out that in performer's scripts, the dialogues of comic characters are sometimes rewritten to reflect the local dialect (Hu Shi 1967 [1937]:9). In the case of Jingbai such revision would involve very little change, except perhaps for the insertion of some slang expressions. In the case of Suzhou vernacular, Subai, the most commonly used comic speech, as this is the home region of Kunqu the written dialect using homonym substitute characters can be difficult for non-Suzhou speakers to read and understand. But in 
theatrical performance Subai is used even when the scene is performed elsewhere, e.g. in Beijing, regardless of whether the audience understands it or not. Conversely, in certain plays in the 'Northern' style music, the Beijing vernacular is spoken by comic characters regardless of where it is performed.

In a small number of plays, interestingly, Yangzhou dialect is specified in the script. For example, in one of the scenes, Jiaoge 教歌 [Teaching Singing], that were performed in Nanjing in October 2005 for the participants of the workshop Lifestyle and Entertainment in Yangzhou, the stage direction reads:

此粷丑用蘇白, 淨用揚州白.

... in this scene, the chou [clown] uses Suzhou speech; the jing [painted face] uses Yangzhou speech.

Such dialect notation is likewise found in the Zhuibaiqiu 綴白蕓, an anthology of popularly performed play scripts compiled at various times between I688 and 1774 . This notation indicates that the use of Yangzhou and Suzhou dialect is a long standing tradition.

In the scene Shiseng 勢僧 [The Bully Priest], the stage direction reads:

付踱上作揚州話白介

$F u$ (role-type designation) saunters on stage speaking Yangzhou dialect.

(Zhuibaiqiu vol. 5: 44).

Dialect is not always explicitly tagged in all drama compendia, but the dialogue may contain dialect expressions. For example in the Liuye qupu 六也曲譜, we find no dialect directions for the above scene Shiseng, but the following underlined expressions reflect Yangzhou dialect usage:

Ex. I:

… 昨兒徐太夫人拉塊, 佈施的上白米一千擔 ...

... yesterday at old Madame Xu's (place), one thousand dan of white rice was donated...

(Liuye qupu Vol. I: 394)

Ex. 2:

… 那次女, 阿一哇, 就庽害拉 ....

... the second daughter, ayiwa [Dear me]!, she is quite something ...

(Liuye qupu Vol. I: 394)

Ex. 3:

$\ldots$ 闐唬死人拉 ....
$\ldots$ loud to scare one to death ....

(Liuye qupu Vol. I: 396)

Figure 11.1 (next three pages). The scene Shiseng 勢僧 [The Bully Priest] from the Liuye qupu 六也曲譜 [Liuye Kunqu scores] collection. 


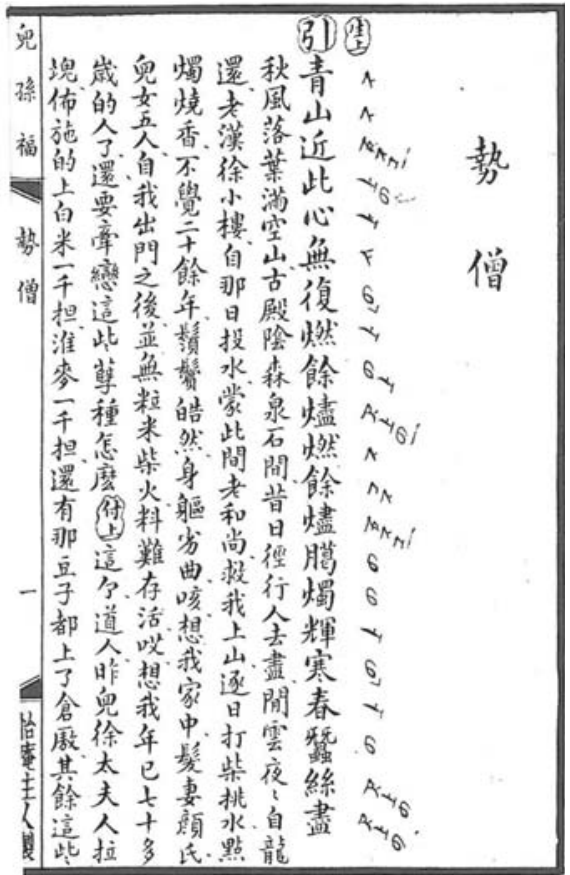

免

孡如泰时年就何面候高萃百

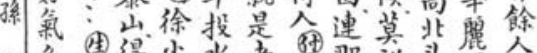

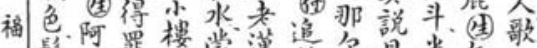

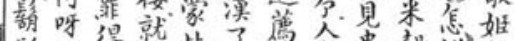

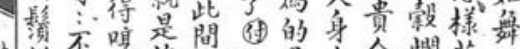
势璔敢太你老阿, 是多合烟葉隊

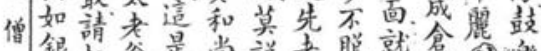
银起畐是尚説考脱就侌过祭

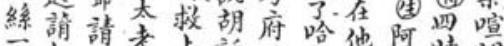

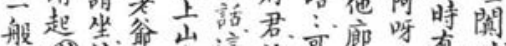

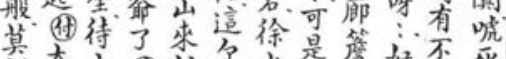

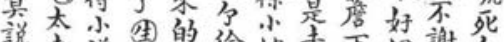

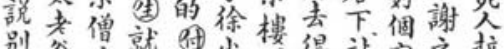
的谷. 這是听. 㮴进得站富之拉

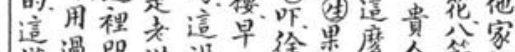

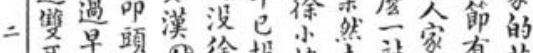
耳早国徐投㮴去站家有花

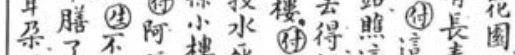
眼四聂呀楼死馀但嗃运春阿 目睛吃不示有了的少不度老之呀 畐過取僧死掼知的景:

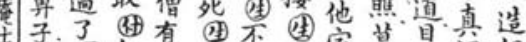

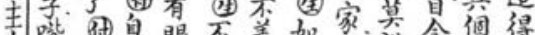
人就哪然不曾我此追請的黄咕

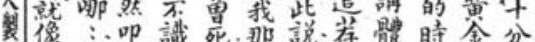

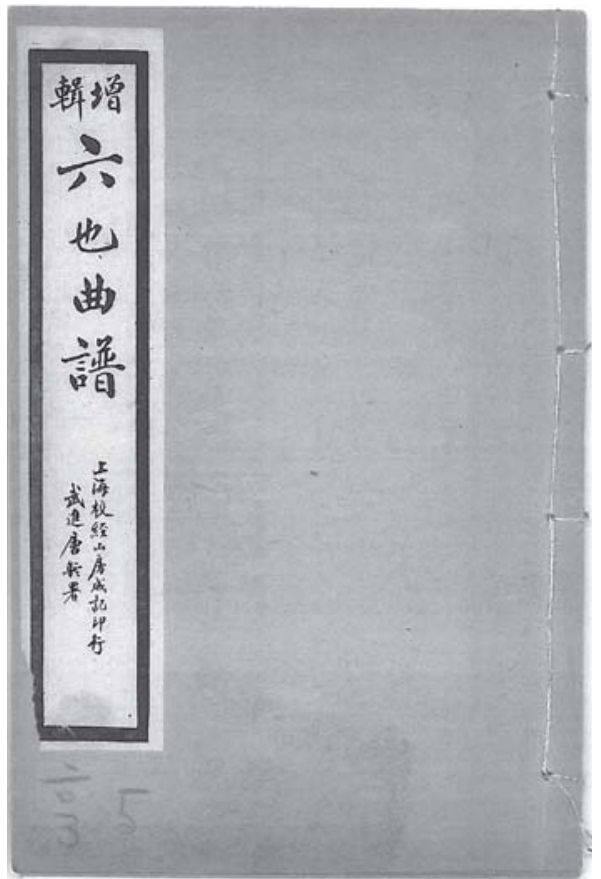

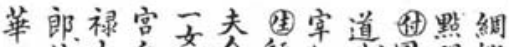
屋你大皇長就師相, 我回明犌 车道年后子是是阿在素不布

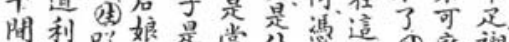

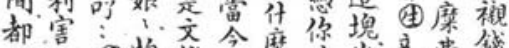

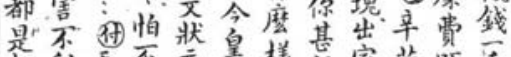
朝吾不元量㥞基家苦吓平 朝害子怕拜的家官拉了哈两

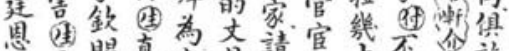
里賜真東敦臣十不企放 香整翰個果娘説家年辛别放

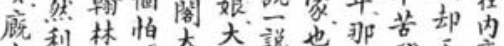

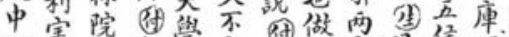
肥害供三学大我渴京是侯瀑 鳥師奉子声闻我法士何府, 有

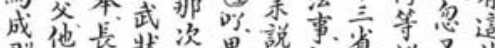

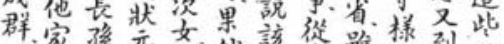

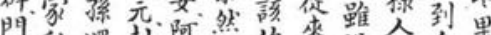
外私還封阿大㷛来没家名盟

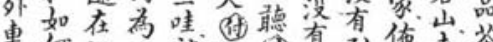

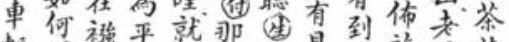

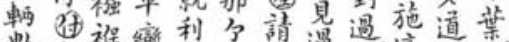

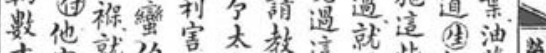
十. 家就伯. 拉夫教這是紫師盟榮

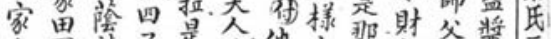

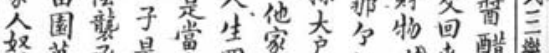

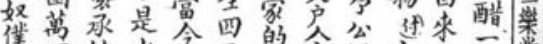


鬼

書遇狀磨這請僧是徐姆敦哈

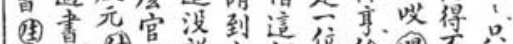

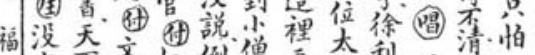
㤫南文好倒僧再老徐徐 $\mathrm{F}^{\mathrm{V}}$

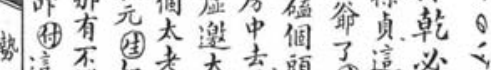
这不如老太去顽四追必必

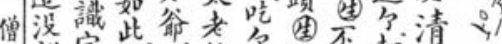

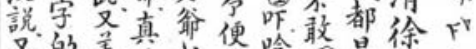
不的差昰拉點哈过是高。

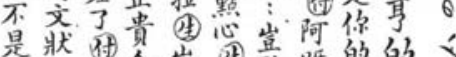

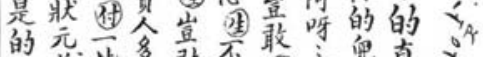
了差此多聂甭坶兒真义

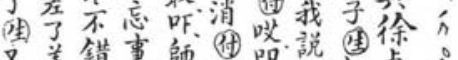

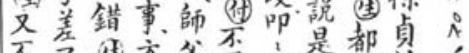

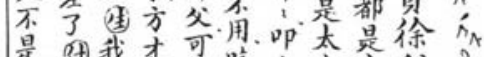

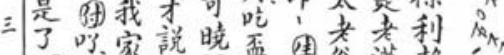

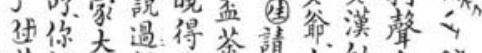
呚的孩的他罷起太的名

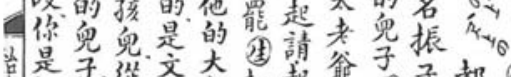

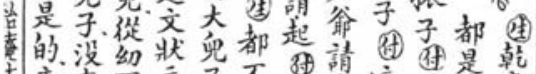
竟有不元子不太坐、這吸. 我高 説念曾㗇是消老待没徐的制

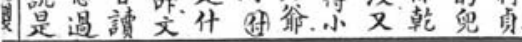

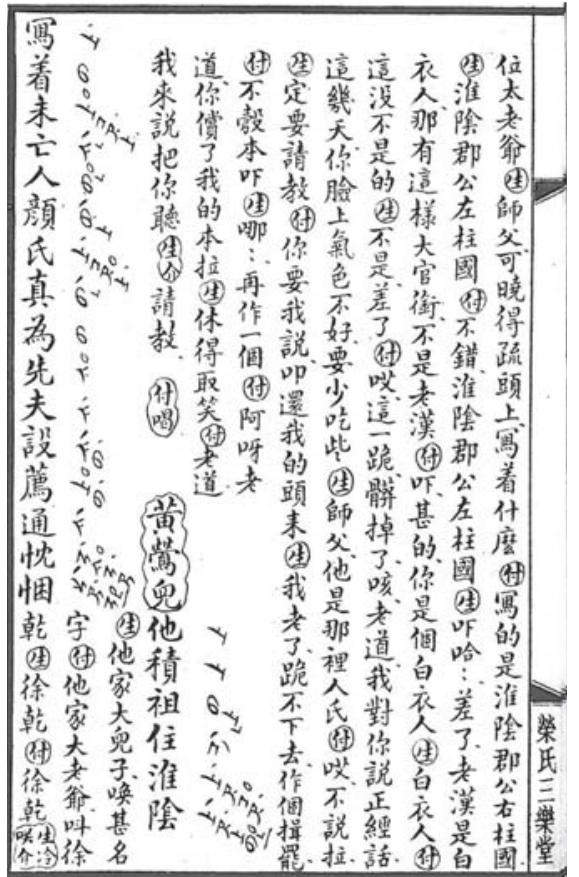

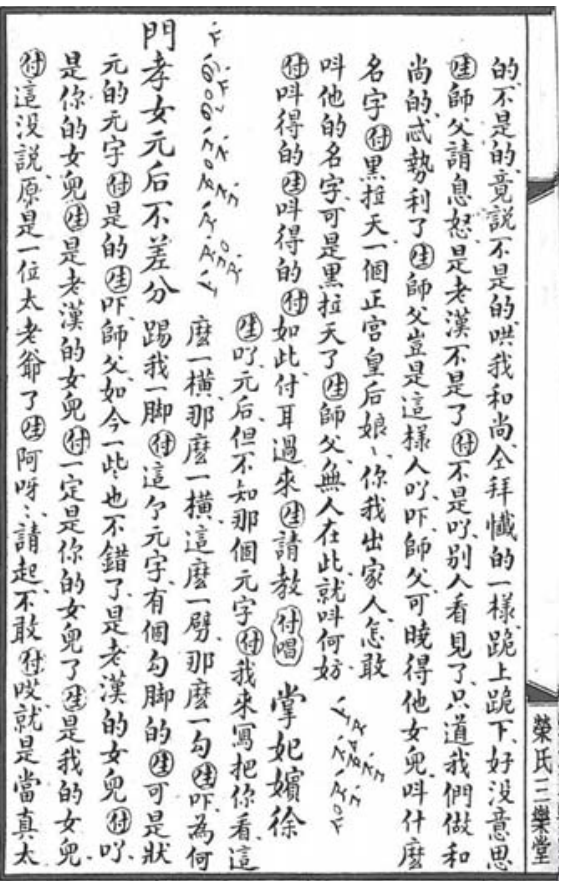

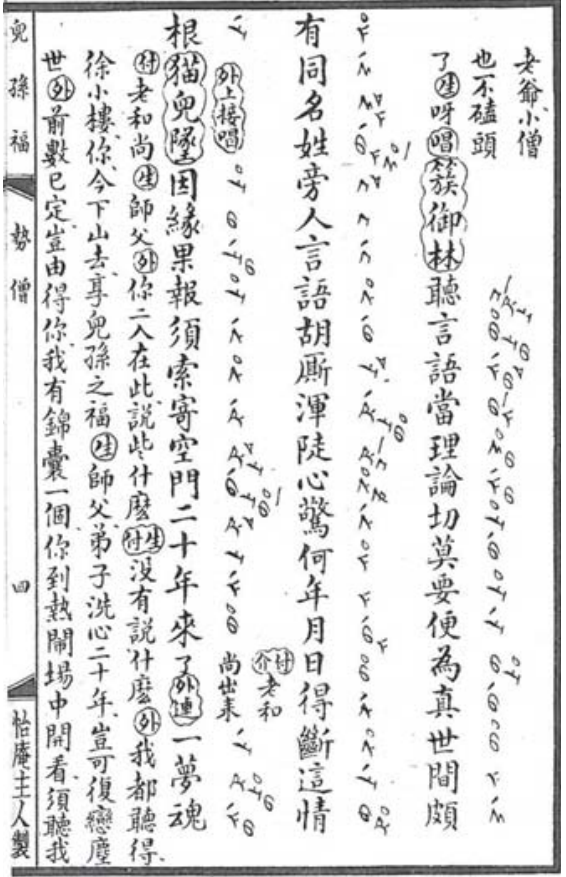



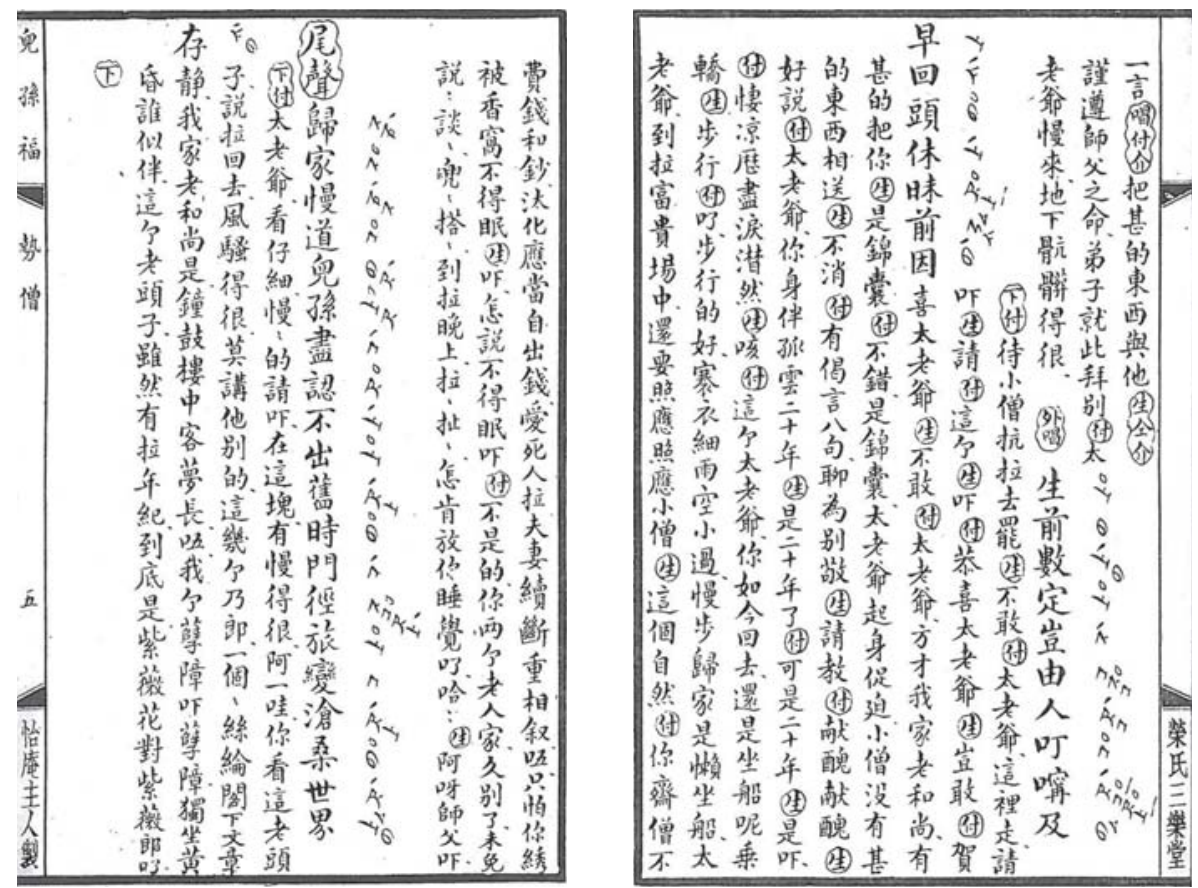

Ex. 4:

…他女兒, 阿一喂, 要諕死人拉 ...

... his daughter, ayiwei [good grief], scares one to death . . .

(Jicheng qupu Vol. 6: 939)

Not all readers of such scripts (Fig. II.I) will know how to pronounce these lines, and the speaker, the priest, is not labeled as chou 丑, but $f u$ 付. But he is a comic character in this hilarious satire about a greedy, bullying, and fawning Buddhist priest. In example I, the Yangzhou dialect 'there' or 'that place', lakuai (pronounced /la-kuae/ in Yangzhou dialect), ${ }^{9}$ is written instead of Standard Chinese zheli or zher. In Suzhou dialect it would have been geda. In examples 2 and 4: the exclamations ayiwa, ayiwei, are also typical Yangzhou exclamatory expressions. In examples 3 and 4 the expression 'to scare or be scared', tianxia 闐唬 and xia 諕, with glottal stop, rushing 入 聲 [entering tone], in the word xia 諕 (pronounced /he'/ in Yangzhou dialect), are also Yangzhou expressions for Standard Chinese 'scare' xia 嚇. Thus these passages from the Liuye and Jicheng anthologies contain unmistakable Yangzhou dialect markers, even though dialect is not specified in the stage directions.

On the other hand, the well known play Leifengta 雷峰塔 [Thunder Peak Pagoda] about Lady White Snake, is said to be a Yangzhou product, or heavily edited by a Yangzhou native. But there are no explicit traces of Yangzhou dialect in the entire 

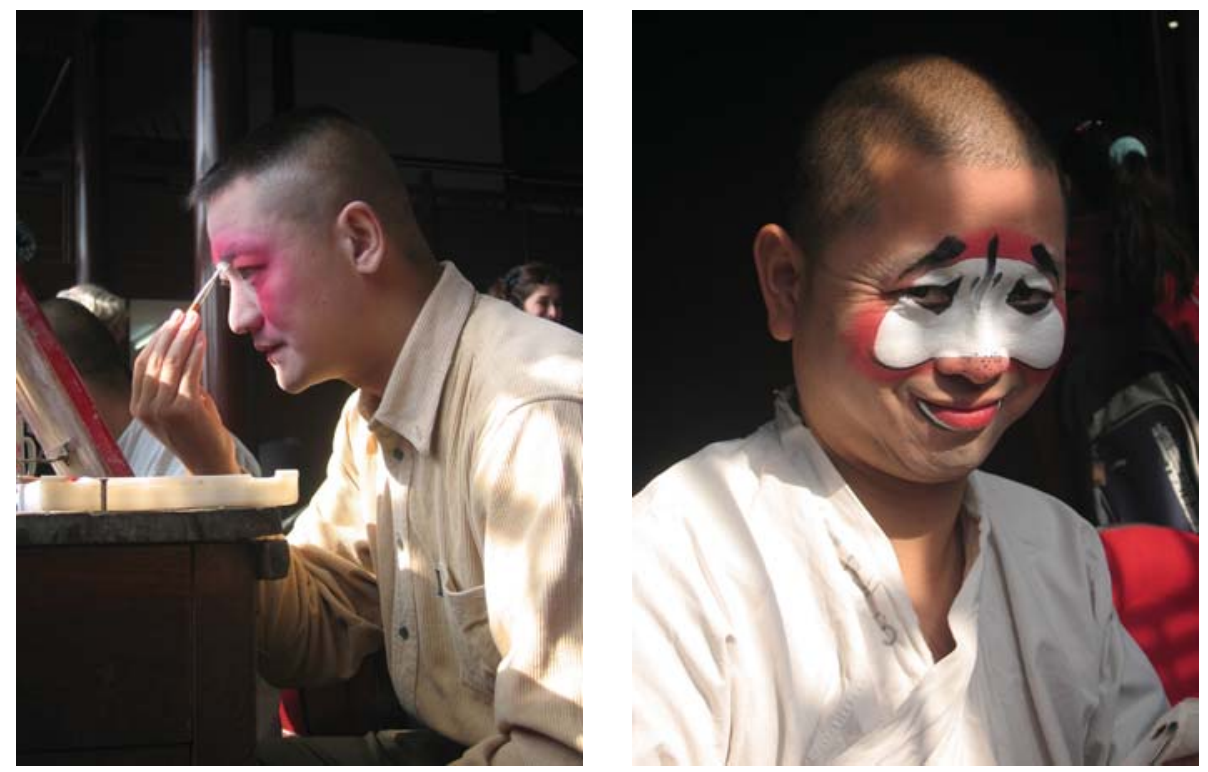

Figure 11.2a-b An actor from the Nanjing Kunqu Troupe is painting his face for the performance of a comic role. Nanjing, 23 October 2005. Photos by Linda Pearson.

play. A play reputedly by Cao Yin 曹寅, commissioner of silks and trusted servant of the Kangxi Emperor, later revised and renamed Tiekuan tu 鐵冠圖 [The Crown of Steel], was supposedly composed when Cao was resident in Yangzhou as silk commissioner. But this play, as well as Kunqu plays in general, have come down to us today with very little Yangzhou linguistic imprint.

The fact that Yangzhou dialect is sometimes specified is unusual in that no other dialects are ever explicitly stipulated in stage directions, even though Kunqu spread to many other dialect areas, for example, Kunming. Since Kunqu originated in the Suzhou/Taicang region, Suzhou dialect would be the usual vernacular for comic characters. One would have expected Yangzhou dialect to be used more widely in the past, but there is no evidence of that today. In the Yicun qupu Yangzhou dialect is never mentioned. Perhaps it was not necessary to do so. It is difficult for me to speculate on why Yangzhou dialect was not more widely used in Kunqu in the past, or why it was specifically notated in these particular plays, and assigned to rather disreputable characters in the plays. Could it be a sign of $\mathrm{Wu}$ region chauvinism after the decline of Yangzhou?

\section{CONCLUSION}

From what I have been able to find, Kunqu seems to have been extremely resilient through the last three hundred years in terms of its music and performance practice, 
insofar as we can see from surviving musical scores and stage scripts. Yangzhou was well known as the centre of Kunqu dramatic performance during the Ming and Qing dynasties, from historical sources such as the Yangzhou huafanglu. That it was the gathering place of elites from all over China, who might there have first become acquainted with the genre, certainly played a role in its spread to the rest of the empire. But historical circumstances caused its virtual disappearance from that city. Now it has only a thriving amateur Kunqu tradition. In the past, Yangzhou undoubtedly contributed to the creativity of chuanqi drama through the work of literati playwrights who were either Yangzhou natives or temporary residents of Yangzhou. Being largely in a literary form, the work of the Yangzhou literati probably did not differ materially from that of playwrights elsewhere.

Kunqu has been on the decline since the nineteenth century and may be on the verge of extinction today. There have been many speculations on the reasons for this situation. The Yangzhou example suggests that economic affluence, political influence, and an educated elite clientele all played a part in the flourishing of this art. Whether Kunqu will be revived in the Yangzhou of tomorrow may well depend on the same factors.

\section{APPENDIX: ANTHOLOGIES OF PLAYS WITH MUSICAL SCORES}

Jicheng qupu 集成曲譜 [Jicheng Kunqu Scores] (1969 [1925]), edited and annotated by Wang Jilie 王季烈. Taibei: Jinxue shuju, 6 vols. (Includes libretti, musical notation, dialog; minimal stage directions.)

Liuye qupu 六也曲譜 [Liuye Kunqu Scores] (1977 [1907]), compiled by Yi’an zhuren 怡安主人. Taibei: Zhonghua shuju, 2 vols. (Includes libretti, musical notation, percussion indication, and dialog.)

Yicun qupu 佚存曲譜 [Kunqu Scores Lost and Found] (I990-I99I [I736-I86I]), edited by Xu Qinjun 徐沁君 and Wang Zhenglai 王正來. (Based on a manuscript in the collection of Yu Nianchun of Yangzhou - Yangzhou Yu Nianchun cangpu 揚州郁念純藏譜 [Old Scores in the Collection of Yu Nianchun of Yangzhou], 2 vols. (incomplete).

Zhui baiqiu 経白装[The Patched White Fur Cloak] (1967 [1763-1774]), compiled by Qian Decang 錢德蒼. Taibei: Zhonghua shuju, Io vols. (Based on editions dating to I688. Includes libretto, dialog, stage directions; no musical notation.)

\section{NOTES}

$\mathbf{1}$ 'Kun' is pronounced in Modern Standard Chinese like quin in 'quintuplets'; 'qu' is pronounced like 'chew', or the German 'tschü.'

2 All pre-modern Chinese drama had singing parts. Spoken drama was introduced in the twentieth century. 
3 Zhang Yunhe's 張允和 article 'Yi kunqu Quanfuban' 憶芘曲全福班 [Remembering Quanfu Kunqu Troupe] is published in English translation in CHINOPERL Papers, 1986, No.I4: 77-95.

4 This is the opening line from the play Dao hui 刀會 [Meeting with a Single Halberd], in which Guan Yu 關羽 enters enemy territory single-handed.

5 'Thin horses' refer to courtesans. See also Chapter I4 in the present book.

6 I am grateful to Professor Hong Wei-Chu for permission to copy the work held in the Drama Research Institute at National Central University, Zhongli, Taiwan.

7 The song titles are unrelated to the textual contents; they designate only the poetic form and melodic motifs that are associated with the poem.

8 The controversial nature of this stage speech can be gleaned from the fact that many regional dramas, including Peking opera, Cantonese opera, and Shaoxing drama, all claim to use Zhongzhou yun as their stage language. Yet it does not take an expert to recognize that the stage speech of the local drama genres resembles the respective regional dialects.

9 The pronunciation of the Yangzhou dialect is rendered according to the phonemic system in BøRDAHL I996: 72-76; see also Chapter I2 in the present book.

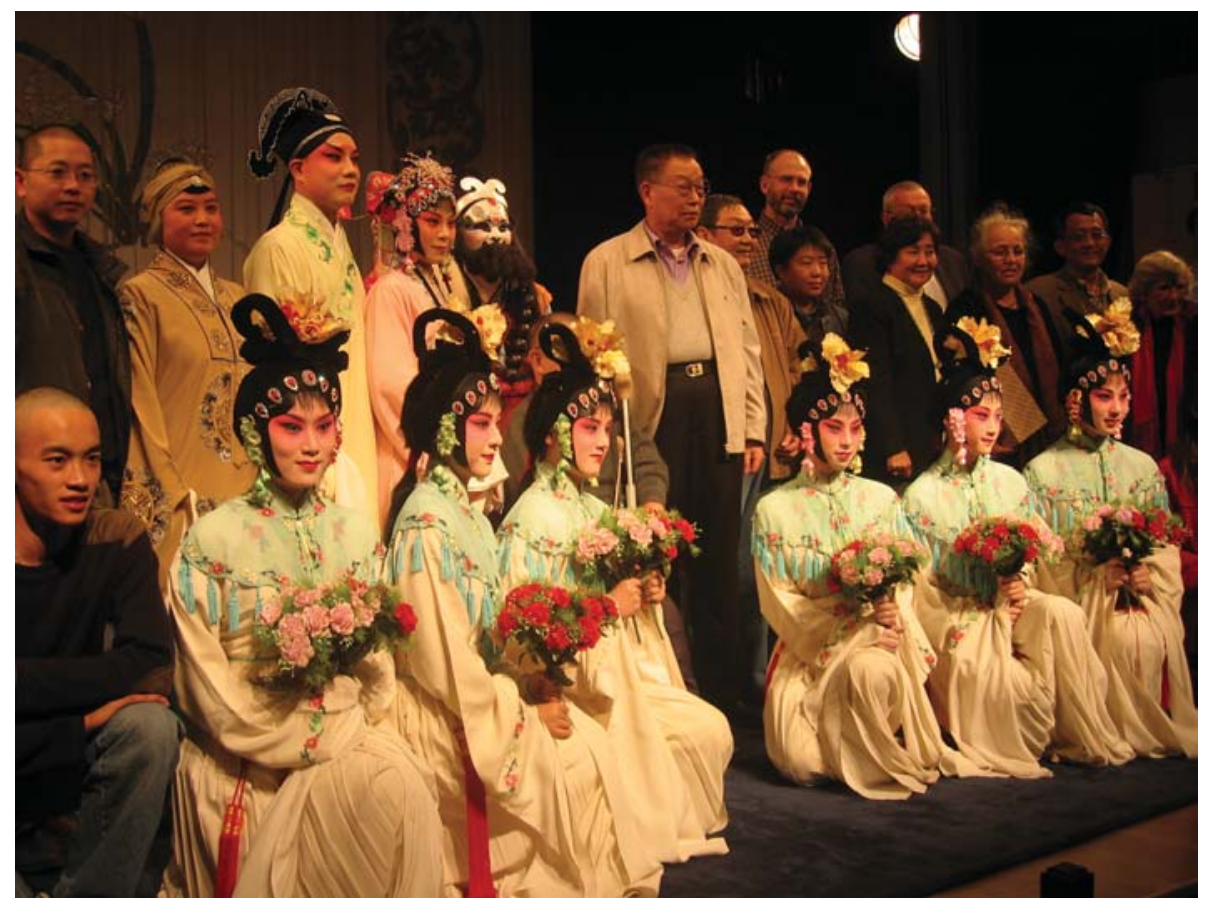

Figure 11.3 Nanjing Kunqu Troupe poses with participants of the 'Workshop on Lifestyle and Entertainment in Yangzhou'. Nanjing, 23 October 2005. Photo by Linda Pearson. 


\section{Written Scripts in the Oral}

\section{Tradition of Yangzhou}

\section{Storytelling}

\section{Vibeke Børdahl}

T Yangzhou traditional lifestyle and entertainment, professional storytelling, pinghua 評話 [commented tales], has played an important role since late Ming times. It seems to be no mere coincidence that the famous storyteller Liu Jingting 柳 敬亭 (1587- ca 1670), honoured as the forefather of Chinese storytellers, both north and south of the Yangzi, came from a township in the Yangzhou Prefecture (Zhongguo dabaike quanshu - Xiqu quyi 1983: 222). Yangzhou pinghua 揚州評話 was for about four hundred years widespread in the large area between Shanghai and Nanjing, along the Yangzi River and the Grand Canal. The great tales of the tradition have been transmitted orally through the twentieth century. ${ }^{1}$ During the last decade, under the influence of modernization and the media revolution, the number of active storytellers has, however, diminished drastically, and their traditional audiences have dwindled. ${ }^{2}$

Here we are concerned with the role of storytellers' scripts ${ }^{3}$ for the generation who were born in the first decades of the twentieth century and had their careers during that century. We mainly discuss two scripts from the late Qing and early Republican period. Until recently scripts, jiaoben 腳本, as aides-mémoire were seldom mentioned by the storytellers of Yangzhou, who often claimed pure oral transmission for their art (CHen Wulou (SI Su) 1962: 44-45) and in fact only a minority of the storyteller families owned handed-down scripts for their performances. In the following we discuss the currency and nature of scripts, their usage, linguistic form and relationship to the oral sagas as performed.

Some of the earliest vernacular short stories, huaben 話本, and plain tales, pinghua 平話, dating from late Song to early Ming, are sometimes claimed to be printed versions copied or adapted from storytellers' 'prompt-books' or scripts. ${ }^{4}$ While the question of the relationship between early huaben literature and storytelling has been thoroughly treated from many aspects, the handed-down storytellers' own scripts that are accessible in our time have so far received but little scholarly interest. 
I hope this chapter may serve as a point of departure for more extensive studies along these lines.

\section{SCRIPTS AND PROMPT BOOKS IN CHINESE PERFORMANCE}

Several categories of texts can be subsumed under the idea of 'script'. Chinese terms for 'storytellers' script', huaben 話本, jiaoben 腳本, diben 底本, were formerly regularly translated into English as 'prompt book', a term taken from Western drama, where a prompter sits below the stage in a so-called prompt box, whispering to the performers in case they forget their next line. But a script, in the sense of a prompt book used by a prompter who has no role in the performance apart from this assisting function, is foreign to traditional Chinese theatre, and even more so in the setting of Chinese storytelling.

The stage of traditional Chinese theatre has no prompt box or similar equipment, and prompting, if ever it existed, is left unmentioned. In the nuo drama tradition, nuoxi 侣戲, which survived in Anhui province into the last decades of the twentieth century and is by some researchers considered a kind of living 'fossil', reflecting ritual and drama from a thousand years earlier, a special use of script is recorded. The actors in the play are farmers who carry masks and play the various roles as pantomime (not uttering a word); the Master of Ceremonies sits at the rear of the play arena and directs the performance, while reciting from a play script the whole text of the drama, both narrative portions and the dialogue of the protagonists. This function is, however, very different from that of a prompter in Western drama (McLaren 1998: 87). In Chinese shadow theatre from the recent period, a script is sometimes used as libretto during performance. Because the puppeteers are invisible behind the screen, they can glance at the script while handling the figures and doing their parts. Even though no prompter is involved, this seems to be the closest in function to a prompt-book in the Western sense. However, most performances in this genre are based on memorized and improvised acting, like the other dramatic genres (Chen Fan Pen 2004: 15). Lindy Li Mark informs us that among amateur performers of Kunqu 崑曲 drama in the I930s and 1940s scripts were sometimes used during performances in private gatherings, and to look at the script while performing was called 'to spread out the bed roll', tan pugai 攤鋪蓋. But those who were dependent on their scripts were chided (MARK I990: IOO). Mark is describing a special case where amateur performers gathered informally. We can see from her reminiscences that scripts were not supposed to be ready to hand for professional artists during a performance.

Among Chinese storytellers the general attitude has been to treat such documents, when they did exist, as a professional secret, and research on this aspect of storytelling has accordingly been scant. Chen Wulou was probably the first Chinese 
scholar who made a first hand investigation of those storytellers' scripts that he was personally able to see in Yangzhou during the 1950s (Chen Wulou (Si Su) I962, 1994, 1999). The question of the existence, usage and form of storytellers' scripts was again treated in detail by Věna Hrdličková, who found that for the various genres that she personally was able to investigate in North China during the 1950 s and 196os, or for which she had secondary sources (including sources on Yangzhou storytelling), written scripts of continuous text 'were unnecessary and actually undesirable' (HrdličKová 1965: 227, 234). However, in her study of Beijing drum song, Jingyun dagu 京韻大鼓, in the first half of the twentieth century, Kate Stevens mentions the importance of written scripts for the creation of new pieces (whereas the transmission from master to student as well as preparations for performances seemed primarily based on oral/aural imitation and practice (STEvens 1973: 77-78, I04, I23). And for the recent period, Mark Bender describes Suzhou storysinging, also called chantefable, Suzhou tanci 蘇州彈詞, as heavily dependent on scripts for the preparation of performances, the teaching of new generations and the creation of new stories (BENDER 2003: 34, 7I, 75, 80)..$^{5}$ Other genres, such as Laoting drum song, Laoting dagu 樂亭大鼓, from rural areas in Hebei province, described by Junko Iguchi, seem far less dependent on written sources and scripts (IGUCHI 2003: 69-94; 2007).

The only time I have seen a 'Chinese storyteller' with a script in hand during performance was during a stay in Tianjin in 200I. Tianjin is famous for making small clay dolls representing all the trades, and I found a storyteller doll. He is sitting at a table with a book or script in front of him. I saw many performances of storytelling in Tianjin at the time, but never a 'living' storyteller with a script or book in hand, nor have I seen any in Yangzhou, the Lower Yangzi area, or elsewhere in China. So why did this little clay storyteller have a script in front of him? I tend to interpret this as a sign that storytelling is now becoming an obsolete occupation and the artisans who make the dolls do not know what storytelling really is about. They apparently think it is 'telling books', shuoshu 說書, in a literal sense and make the dolls accordingly. However, to be prudent, one should keep the little doll with the book in mind, when exploring the situation of scripts in Chinese storytelling.

The variations between the various performance genres of China with respect to the diffusion, form and usage of scripts should remind us that the concept of 'orality' in the study of oral literature must constantly be scrutinized and redefined as the interdependence between written and oral elements in a given performance genre is explored. ${ }^{6}$ We are studying oral performance in a society where writing has an immensely long history and strong penetration. The circumstances under which oral-related documents are created are often highly obscure, and their purpose and function may change over time (HANAN 1973: 182; Ge Liangyan 200I: 60). 


\section{HABITS AND RULES OF PUBLIC PERFORMANCES}

The storytellers of Yangzhou pinghua traditionally tell long sagas, shu 書 [text, repertoire, 'book'], divided into sessions of two to three hours at a time, called 'a day of storytelling', yi tian shu 一天書, or 'a session of storytelling', yi chang shu一場書. A saga is performed during engagements of two to three months.

There is normally only one performer, and in contrast to other genres of storytelling in Yangzhou, such as Yangzhou xianci 揚州弦詞 [Yangzhou string tales or storysinging] and Yangzhou qingqu 揚州清曲 [Yangzhou pure song or ballad singing], Yangzhou pinghua has no musical accompaniment. Even though a certain amount of metric verse, both rhymed and non-rhymed, occurs at irregular intervals, the genre is not prosimetric in the sense of featuring a balanced shifting between prose and verse (MAIR I997: 367; BøRDAHL 2003: 68, 70-7I, 83).7 Some performances are entirely in prose, and all performances are predominantly in prose. Passages learnt by heart, whether in verse or in prose, alternate with passages of improvisation and re-creation in a more free style.

The usual circumstances of Yangzhou pinghua as performed in the story house, shuchang 書場, are well defined and the storytellers have a rich technical vocabulary describing the habits and demands of performance on stage, as well as the pedagogical principles for transmission of the art from generation to generation. It is significant that written materials or scripts are not mentioned as a requirement for performance or teaching.

In fact, the storyteller often performs scenes where he as the narrator is 'reading from a document' to the audience. However, in such cases he always recites the text of the document by heart and uses his requisites, the fan and the handkerchief, to allude to the document mentioned, such as a letter, book, proclamation, etc. He is never reading aloud from a text where the words of the performance are written, and he never consults such texts during public performances in the traditional setting.

\section{TRANSMITTING BY MOUTH}

As young disciples, storytellers learned their repertoires by listening to and imitating their masters, a practice called 'transmitting by mouth and teaching from the heart', kou chuan xin shou 口傳心授. Some storytellers were illiterate or semi-illiterate. Others had some school education. But such differences were not important when it came to learning the art of storytelling. The art was transmitted solely by oral-aural and visual methods. Gesture and mime were essential ingredients and probably important for memory. Blind children were not infrequently trained as storytellers, and their inability to read was never mentioned as a setback. 
The youngster would study with his father/master every day, being taught at first only one or two sentences a day. The disciple would imitate the master's words, tone, gestures and facial expressions, and then spend time alone trying to remember and act out the day's instruction. He was also supposed to follow his master to the storytelling house daily to observe the performance and wait on his master. The following day he would rehearse in front of his master; this was called 'to return the story', huan shu 還書. Much of the teaching was 'reinforced' by spanking. Little by little the passages to be remembered would be extended until the student was expected to be able to 'return' a whole 'day of storytelling' (that is, 2-3 hours, as previously mentioned) at a time (WANG Shaotang 1979: 289; WANG Xiaotang 1992: 30-34).

Remembering by heart was only the first step in learning storytelling. The novice was soon taught to recreate in a living language, which would reflect the style and narrative technique of his master. Only certain passages were supposed to be memorized by rote, such as poems and set pieces.

The education of storytellers by the method of 'transmitting by mouth and teaching from the heart' prevailed until the ig6os, and the storytellers who in the late I990s belonged to the mature and older generation had been through that experience. A sceptical and almost hostile attitude to writing and reading, considered dangerous to memory, was widespread (Børdahl 2005: 235-242). Some 'fake' storytellers, who apparently had learned by heart from books and had not received education from a professional master, were looked down upon. The fact that there are a couple of terms for such a practice - 'telling empty storytelling', shuo kong shu 說空書, or 'telling dead storytelling', shuo si shu 說死書 - shows that even though this way of learning the art was not accepted, it obviously did occur (Yangzhou quyi zhi 1993: 246; BøRDAHL 1999: 246-247, 250).

New repertoires were in many cases created by applying the skills acquired as a storyteller to oral 'embroidering' on themes from popular literature. Such activity did not primarily involve the writing of a script or any other writing, and how far it required the active reading of the work used as a model is an open question, since knowledge of the themes, plots and protagonists of the popular written culture was so widely disseminated in the population through many other channels than book reading.

Scripts had a function as ritual objects, as revered inheritance, and they were conceived as a family property that needed protection against 'stealing' (copying). Silence about scripts was inborn in the milieu, and several of the storytellers whom I have interviewed said that they wouldn't as novices have dared to ask their master if there was a script for their repertoire, so do not know to this day if he might have had a script. They were never taught with the aid of scripts (BøRDAHL and Ross 2002: I38, I49, I6I-I62). During the I950s the government supported the transcription of 
storytellers' spoken repertoires into edited book versions. Government organizations also collected materials for folklore research but this was not always welcome. For example, the storyteller might be expected to hand over his interesting documents to the archives of the province, after which he might never have a chance to see them again. This was another reason to keep silent (CHEN Wulou (SI Su) 1962).

The publication of storytellers' repertoires in notational versions, taken down from oral performances, shortened, rearranged and polished, resulted in a new genre, so-called 'new tale books', xin huaben 新話本. The repertoires of the most famous Yangzhou masters were published in anthologies and novel-size editions, with a break during the Cultural Revolution (1966-1976). Besides the appeal of these books as entertainment for a general readership the editors also envisaged that these works could serve as scripts (WANG Shaotang [1959] 1984: IIII [editors' postscript]).

Although there is a general consensus that oral education was the basic training, some storytellers are now open about the fact that their forefathers wrote scripts, kept them as a kind of guarantee and bequeathed them to later generations. Since, however, Yangzhou storytellers generally were not particularly concerned about scripts and seldom had scripts in their possession, why would a minority of the storytellers own scripts, and what kind of function would they serve?

In the following we discuss two scripts that have both been in active use for storytelling during the first half of the twentieth century. One of them can roughly be dated to late Qing, ca I880-I9IO; the other is from the early Republic, the year 1923.

\section{A SCRIPT IN THE TRADITION OF WESTERN HAN}

This late Qing script belonged to Dai Buzhang 戴步章 (1925-2003), a highly esteemed master and the most prominent performer of Journey to the West ${ }^{8}$ from the Dai school, Daimen Xiyou ji 戴門西游記 (Fig. I2.I). Dai Buzhang's father, Dai Shanzhang

Table 12.1 School of Western HaN

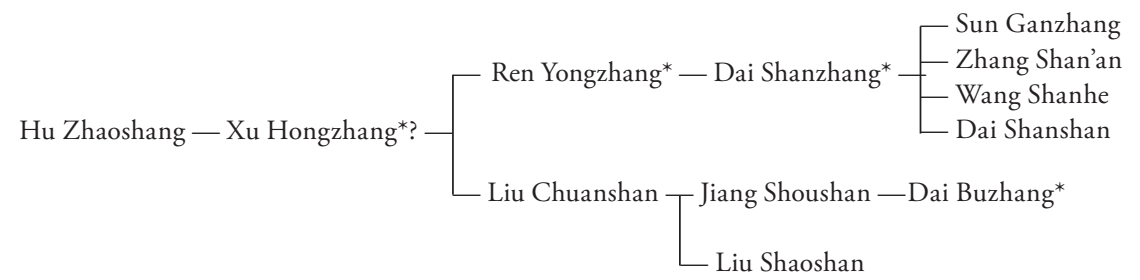

Storytellers who have owned the script on Western Han, according to the memory of the Dai family, are marked with an asterisk. The table is according to Yangzhou quyi $z h i$ 1993: 350. Information about the storytellers, ibid. pp. 283, 292, 288, 321; cf. also BøRDAHL and Ross 2002, Life stories. 

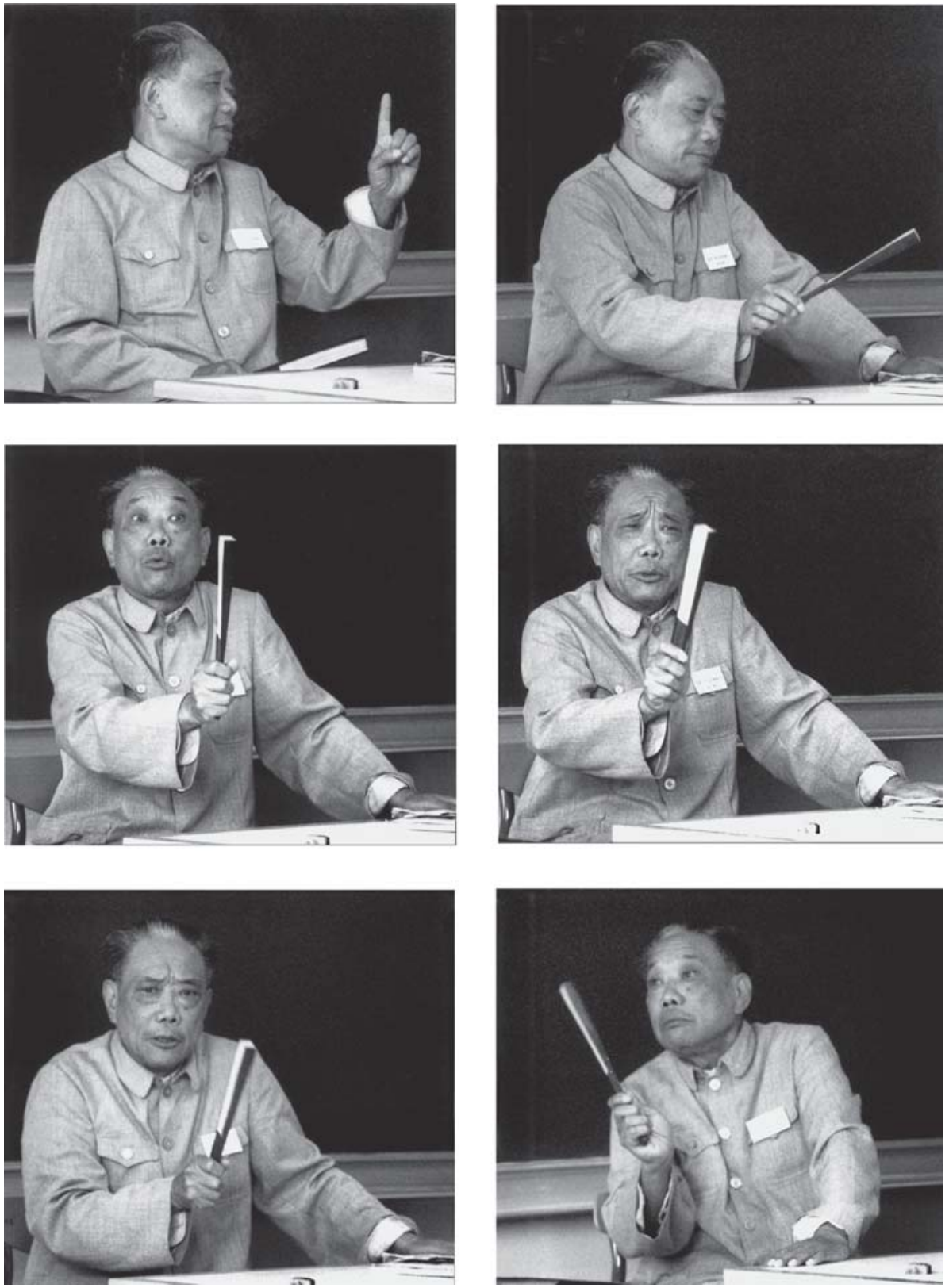

Figure 12.1 Dai Buzhang 戴步章 (1925-2003) performs in Copenhagen 1996. He was a transmitter of the sagas of Western Han and Journey to the West. Photo by Jette Ross. 


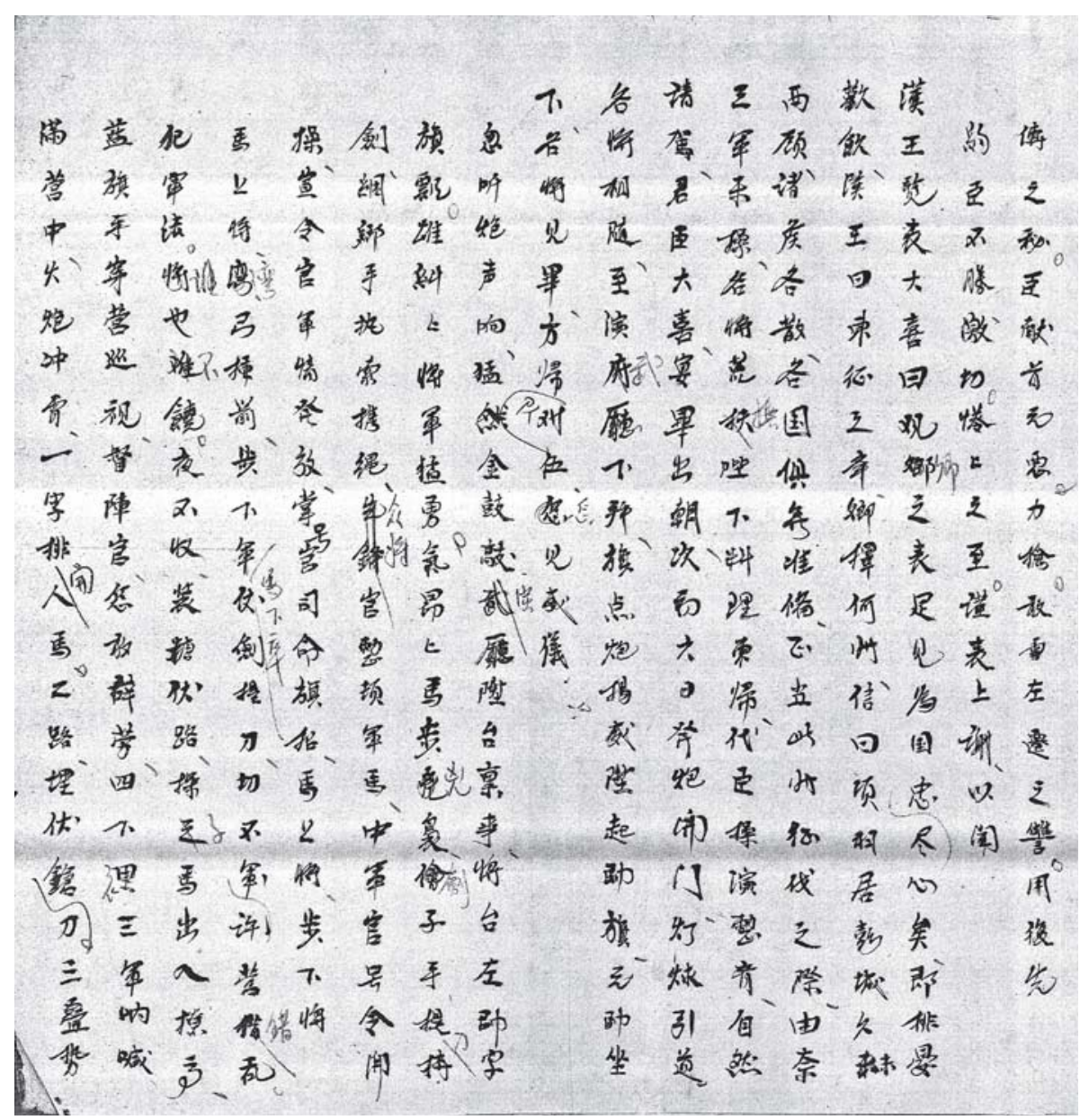

Figure 12.2 A page from the script of WESTERN HAN, including the passage analysed below.

戴善章 (1880-1938), and most of his uncles and brothers were all storytellers, and they specialized in several of the large traditional repertoires. The script contained the handwritten version of the repertoire of Western HAN, Xi Han 西漢, one of the semi-historical repertoires with a long history of oral transmission. The manuscript is attributed variously to his father's teacher, the storyteller Ren Yongzhang 任永 章 (Late Qing-Republic, fl.), and to the teacher of this teacher, Xu Hongzhang 許鴻章 (I847-1905), who belonged to the second generation after the founder $\mathrm{Hu}$ Zhaozhang 胡兆章 (ca I850, fl.) (Table I2.I).?

In his childhood Dai Buzhang often listened to his father's performances of this saga. After his father's death in 1938, Dai Buzhang studied Western Han with 
another master of this repertoire, Jiang Shoushan 江壽山 (I888-I96I), and at the time read through the script as preparation. He used the script for memorization of the poems, he said; otherwise he had little use for it. He only performed this saga periodically in the I940s and early I950s. Performing episodes from the Western HAN repertoire in more recent times, he was no longer able to remember the poems. On 24 October 2003, a month before he passed away, Dai Buzhang gave a performance for me to tape-record from the part of the repertoire that corresponds to the passage selected from the script (Fig. I2.2). ${ }^{10}$

\title{
Narrative and Linguistic Structure of the Script
}

The worn pages of the script were covered with characters in handsome calligraphy. The passage under study is written in a style reminiscent of the Shi Ji 史記 [Records of the Historian], as seen in the biography of Han Xin 韓信. It is not copied from this work, however; no full sentences are exactly the same, only a few expressions. The particular episode is not mentioned in Shi ji, but there are very similar episodes. ${ }^{11}$

\section{Transcription of a prose passage from the script}

\begin{abstract}
漢王览表大喜曰观卿之表足见爲国忠尽心矣、即排晏歡飲漢王曰東征之举卿擇何時、信 日項羽居彭城久未西顾诸侯各散各国俱無准備、正当此時征伐之際、由奈三軍未操各將 荒扶陛下料理東歸、代臣操演整齊、自然請駕君臣大喜宴畢出朝、次初六日發炮開门、灯 球引道、各將相随至演府廳下拜旗点炮揚威陸起帥旗・元帥坐下各將见畢方歸对伍、怎见 威儀 12
\end{abstract}

\section{Translation of the extract}

When the King of Han had read the memorial, he was greatly pleased and said:

'My Lord, a glance at your memorial is sufficient proof of your deep loyalty towards our country, indeed!'

Then a banquet with wine was served, and the King of Han said:

'When do you suggest that we should undertake the eastern expedition?'

(Han) Xin said:

Xiang Yu has settled in the town of Peng. For a long time he has not cared about the western lands. The feudal lords are dispersed in all directions. The various states are totally unprepared for war. This is the right opportunity for launching a punitive expedition. However, our whole army is untrained and our commanders need practice. If Your Majesty plans to return to the east, your servant is surely willing to take on the duty of training and drilling the army.'

They were all, sovereign and subjects, happy with this answer, and thus the banquet was finished and they left the court. On the following day, the sixth 
of the first month, canons were fired, the gate was opened and lanterns were carried at the head of the procession. General after general marched forward until they arrived at the place in front of the martial arts mansion, where they flourished their flags, fired cannons and showed their military prowess. When the flag of the commander-in-chief was hoisted, he took his seat. Only then did all the generals take up their position with their troops. What a spectacle, this military ceremony:

[Here follows a long poem in rhymed verses of unequal length]

From the narrative aspect, the passage contains short third-person summaries of action and description (covered narrator) and dialogue in direct speech. The dialogue passages take up more than half of the space. The passage ends with a poem (not translated here), describing the scenery of the military ceremony. The poem is longer than the previous prose section. Poems and other set pieces such as memorandums, letters, etc., are indented in the manuscript, taking up about half the space of the whole script. The narrative prose sections (with dialogue) are generally shorter than the sections of poems and set pieces.

The fact that prose and poetry alternate, as well as the stock phrase before the poem, 'what a spectacle', zen jian 怎见, are features reminiscent of the 'storyteller's manner' as seen in vernacular fiction since the Ming period, but otherwise the passage is devoid of any such explicit features. ${ }^{13}$

The language of this passage is characterized by a terse literary style, including a number of grammatical markers, pronouns and other vocabulary typical of literary Chinese, wenyan, (such as: zhi 之, $y i$ 矣, $b i$ 畢, wei 未, he 何, $w u$ 無, nai 奈). The language imitates the style of early historical works, not only in the selection of tag word for 'he said' (yue 日), and in pronouns of address between the king and his generals (qing 卿, bixia 陛下, jun 君, chen 臣), but also in the monosyllabic staccato rhythm of most phrases and sentences. Four- and six-syllable expressions are dominant. Even if some of the sentences are also possible in MSC and some compounds (zhunbei 準備, duiwu 隊伍) are from modern usage, there are exceedingly few features of modern vernacular, and there is no trace whatsoever of Yangzhou dialect grammar.

The handwriting features a number of characters differing from the authorized dictionary forms, i.e. 'fire a cannon', fapao 發炮, written with an alternative element in the character $f a .{ }^{14}$ In a few cases a homonym character is used instead of the usual character for the word, i.e. 'troops', duiwu 隊伍, written with the common character for 'correct, facing', dui 對 (对), instead of 'team', dui 隊, and 'general', shuai 帥, written with an alternative character for 'falling', shuai 摔 (two occurrences).

The unauthorized forms of characters in the script passage are indicators of the general habit of simplification of characters in handwriting at the time. These forms were acceptable, but not completely standardized. Only a few of the characters in the script could be considered 'errors', because they reflect only the sound of the 
word correctly, but not the content, i.e. a different morpheme is used to represent a homonym morpheme. Such cases represent modern loan characters, and they are symptoms of writing based on oral performance rather than on written works (GE Liangyan 200I:II2).

\section{Script and Performance: WESTERN HAN}

Next, we consider the narrative and linguistic form of a performed version of the same passage. The most conspicuous difference between the script version and the performance is length: The performance covers the same stretch of 'storyline', shuluzi 書路子, and the same space of 'story time' as the script version, but it is about twelve times as long.

Dai Buzhang starts this performance with a couplet, not found in the script. Prologue poems were sometimes, particularly in former times, used to begin the day's performance, called 'head of performance', shutouzi 書頭子. Dai Buzhang may choose to begin this way because he knows that he will not be reciting any of the poems that traditionally belonged to this performance, and therefore he is substituting with a more general poem.

The story proper opens with a relatively terse sentence in wenyan-coloured style, giving some background information to the episode. Already in the second period the language switches into the sentence structure of modern Chinese vernacular: There is a constant shifting of style, with wenyan-like structures imitating the awesome style of the king and his generals, occurring mainly in part of the dialogue:

觀卿家之表, 足見卿家之忠心爲國, 於民有利, 於國有利, 於朕躬有利, 於文武官員有利, 卿家是一大功勞。

My Lordship, a glance at your memorial is sufficient proof of My Lordship's loyalty towards our country! This is good for the people! Good for the country! Good for us, the King! And good for the civil and military officials! Your Lordship has made a great contribution! ${ }^{15}$

This wenyan-like style is characterized by the use of certain grammatical markers (zhi 之, $b i$ 畢, $w u$ 無, wei 未, ye 也), and certain old-fashioned pronouns and other vocabulary (he 何, $w u$ 吾, yan 言), including terms of address, the same as those of the script or very similar (qingjia 卿家, instead of qing 卿). Four- and six-syllable expressions are frequent in these passages.

Most of the performance is, however, in modern Chinese, as clearly marked by pronouns, measures, suffixes and sentence markers ( $w o$ 我, $n i$ 你, ta 他, women 我們, shenme 什麼, zhege 這個, nage 那個, ge 個, naxie 那些, de 的, le 了, ne 呢, $m a$ 嗎, $a$ 啊): 
什麼地方於我們漢有利, 什麼地方於楚有害, 什麼地方楚國有優先的地方, 有特長的地 方, 什麼地方是我們的缺陷、缺點的地方, 把這個形勢呃完全都寫到了。

Where were conditions favourable to our state of Han? Where were conditions harmful to the state of Chu? Where were the advantages and strong points of the state of $\mathrm{Chu}$, and where were our own disadvantages and defects? All of this was treated in the memorial.

These portions are characterized as ordinary spoken language, with more repetitions and rewordings of phrases than is normal in a written/printed text of MSC.

When we only observe the oral text as transcribed into Chinese characters, without regard for the pronunciation, we may note that the better part of the text is unmarked for dialect features on the level of morphology, syntax and lexicon. On the phonological level of analysis this is completely different, since every syllable of the performance is clearly pronounced in Yangzhou dialect, also the portions with wenyan-like structure. The storyteller does, however, shift between so-called 'square mouth', fangkou 方 $\square$, and 'round mouth', yuankou 圓 $\square$, pronunciation, corresponding to stylistic registers. While the pronunciation is dialectal throughout, there is a shifting between different sub-dialectal pronunciation variants, some of which are closer to standard pronunciation. The grammatical usage also changes in correlation with these stylistic registers (BøRDAHL 1996: 83-85).

In the first half of the performance I did not find any structures reflecting Yangzhou dialect grammar, i.e. structures that are not found in MSC or are highly marginal in MSC, but are common in Yangzhou dialect. However, in the latter part such structures appear not infrequently, such as the following: ${ }^{16} \mathrm{Y} . / \mathrm{me}$ ' de'/ 沒得 or /be' de'/ 不得 (MSC: meiyou 沒有 or bu neng 不能); Y. /zw/ 走 (MSC: cong 從); Y. suffixation with /zr/ 子 and /tw/ 頭 in certain nouns, i.e. /suo'-fa'-zr/ 說法子, /uon-ie'tw/ 玩意頭, (MSC: no suffixation with $z i$ or tou, or this suffixation marginal); Y.: / $\mathrm{kw} /$ 可 as marker of alternative question (MSC: alternative question form $\mathrm{V} b u \mathrm{~V}$ ?); Y. /ha-zr/ 下子 as verbal measure (MSC: verbal measure xia or no verbal measure, xiazi highly infrequent); Y. special usage of co-verbal sentences with /ba/ 把 and double /ba/, i.e. /ba/ N V /ba/ N V (MSC: co-verbal sentences with $b a$ are used in a more restricted way and sentences with double $b a$ constructions are marginal); Y. I guae-guae/ 乘乘 (MSC: infrequent interjection, highly frequent in Y.)

Phrases and expressions, specific for Yangzhou dialect, become more and more frequent as the performance proceeds and the storyteller gets 'into the story' and avails himself more freely of the 'round mouth' register, used primarily for narration (informal), storyteller's comment and inner monologue (thoughts of characters), i.e. the non-dialogue portions, called 'private talk', sibai 私白, in the storytellers' terminology. In this register the flavour of daily colloquial Yangzhou dialect is particularly strong. ${ }^{17}$ 
In direct speech (and occasionally also in some portions of formal narrative) we find sentences and phrases from the script incorporated, as indicated by italics. These wenyan-coloured phrases, most of them coined in four- and six-syllable expressions, are explained at great length in the performance, often with a humorous touch. The explanations are part of the informal narration, storyteller's comment, or the many passages of inner monologue that we find in this fragment.

\section{Script and Performance - Discussion}

The owners of the script are convinced that it is written by one of the old masters from the School of WeSTERn Han, i.e. by a storyteller who was able to perform the repertoire. Apart from the poems that were undoubtedly meant to be quoted by heart as written in the script, was the language of the script close to the language of performance that the storyteller had in mind? Certain dialogue and narrative passages are performed by Dai Buzhang in phrases identical (or near identical) with the script version. When prose sentences in the stern and terse style of the script are spoken intermittently during performance, commentary and explanation in ordinary daily language are added profusely. Bits and pieces of 'historical chronicle' are thus framed by 'translations' into colloquial language.

The old-fashioned and laconic utterances, identical with those of the script, may function, in this case, not only as a reminder of the plot development, but also as a reservoir of a special language, lending the performance the style and 'air' of Han dynasty military conversation. This ingredient adds colour and atmosphere to the performance, otherwise conducted in present-day Yangzhou dialect. Square mouth pronunciation is typically found in the passages of quoted military conversation and in the more concise narrative passages.

The storyteller who wrote the script might have copied from some former history book for the prose passages, just as the poems might quite possibly have been copied from verse books. However, being able to bring a text such as this script into written form, the 'scripter' might also have been able to create a literary, shumian 書 面, condensed text from oral performance. Dai Buzhang said: 'In my lifetime there has never been any storyteller who would perform the text in this way. And I do not think it would have been performed like this in former times, either.' It seems likely that the storyteller-scripter wrote in a far more concentrated style than the performance he had in mind, and that he applied a style of written language that he found appropriate - not a word by word notation of the language of performance. Were his words taken over directly from other sources or were they only created in the style of former histories and novels? From these alternatives I cannot so far eliminate any. Further, I do not think that we can rule out the possibility that the storyteller-scripter actually wrote down the essential wording of the performance 
Table 12.2 Wu School of THReE KINGDOMS

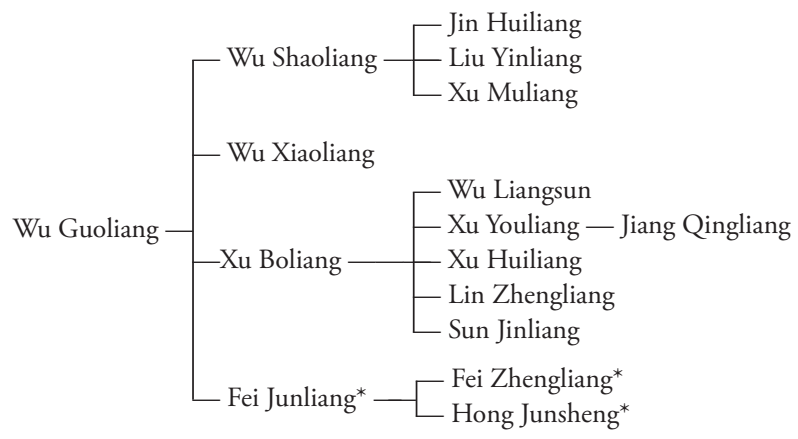

Storytellers who have owned or used the script of Three Kingdoms are marked with an asterisk. The table is according to Yangzhou quyi zhi 1993: 345. Information about the storytellers, cf. ibid. pp. 273, 276, 79, 28I, 333; cf. also BøRDAHL and Ross 2002, Life Stories.

as he knew it from oral tradition. When we observe how Dai Buzhang in 2003 during his performance actualized the important utterances in their old-fashioned garb but enveloped them in 'storyteller's comment' of the modern storytelling style, it is tempting to see this as a demonstration of the meaning of the genre-name: 'commented tale', pinghua 評話.

Was the style of the script part of the oral tradition, a striving to preserve essential and memorable sentences to pass on, utterances to be incorporated into future performances to give a stamp of place and time to the contemporary dialectal prose? Or were the sentences of the script coined in a literary idiom with little connection to the actual oral style of the performers, purely as a resumé of the plot? In the present case, the comparison between script and performance seems to suggest rather the first alternative, but both usages are plausible.

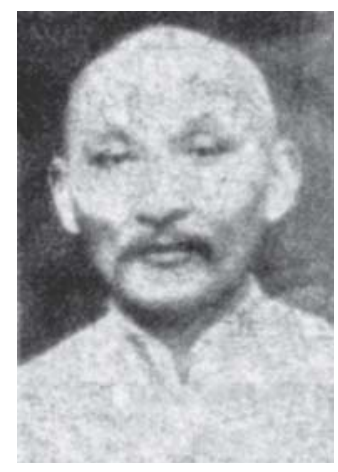

Figure 12.3 Fei Junliang 費駿良 (1891-1952). Photo anonymous, Yangzhou quyi zhi 1993. 


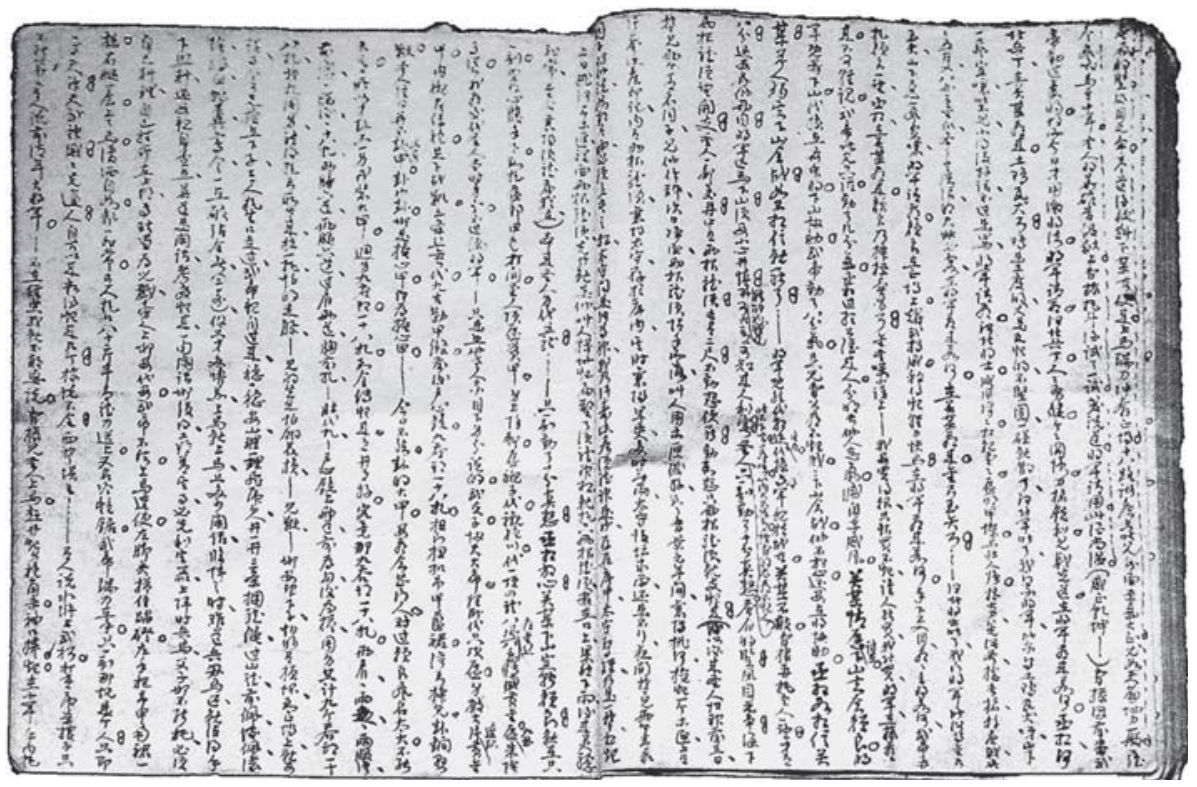

Figure 12.4 A double page from the script of THREE KINGDOMS, written by Fei Junliang, including the passage analysed below.

\section{A SCRIPT IN THE TRADITION OF THREE KINGDOMS}

Our second example is from a script written by Fei Junliang 費駿良 (I89I-I952), father of Fei Li (artist name: Fei Zhengliang 費正良) (b. I93I), the present owner of the script. Fei Junliang was a disciple of Wu Guoliang 吳國良 (I872-I944) from the Wu School of Three Kingdoms (Wupai San guo 吳派三國) (Table I2.2, Fig. I2.3).

Fei Junliang had better education than most storytellers of his time, and he organized and ran a private school for many years, besides his activities as a professional storyteller. He was an aficionado of storytelling who at the age of thirty-two was accepted as a disciple of Wu Guoliang. During his apprenticeship in I923 he listened every day, as was the custom, to his master's performance and - something that was rare - developed the habit of writing every night a summary of the day's episode as he remembered it.

According to Fei Li, his father wrote as fast as possible, with no concern for anything but his own ability to learn and remember. He used a kind of stenographic writing with lots of simple substituting characters, since his notebook was only meant for his private use (Fig. I2.4). Much later in life Fei Junliang let his sons see these notes at some point in their education, but that was not the original purpose. Publishing was out of the question during those days, and as Fei Li emphasized: his father had absolutely no thought of writing for such a purpose. ${ }^{18}$ 
After the death of his father, Fei Li became engaged in the work that has been undertaken in China on a large scale since the I950s to preserve the storytellers' traditions in book form. Fei Li used on the one hand his father's scripts, on the other hand his own education as an oral storyteller, to create book versions of the oral repertoire. The purpose was neither to preserve the original form of the scripts, nor to preserve the authentic form of the oral performance, but to rewrite the material into romances for a reader. The published work was intended to retain as much of the oral style as was considered artistically successful for a written work, but dialectal wording that was not easily understood elsewhere in the country was to be left out or changed into MSC. Also in many other respects the work was to be adapted to the genre conventions of the xin huaben and organized according to principles of logic, coherence and modern stylistics, as well as to the political and moral climate of the time (FEI Junliang and FEI Li 1986, Preface: 4-5).

\section{Narrative and Linguistic Structure of the Script}

A passage from the script, written in a notebook with the title 'Brocade heart and embroidered mouth', Jin xin xiu kou 錦心繡 $\square$, 'Former Volume', Qian ce 前冊, i.e. 'Former Three Kingdoms', is rendered below: ${ }^{19}$

\section{Transcription of a prose passage}

分付摆酒、武帝入席、曹操陪坐、当在巡酒上看、手下飽忝战飯、有人上來禀丞相、罔下颜 良索战、知道了、退、又來了、颜良正場罵战、知道了、退、接連五六次、曹操不動身色、武帝 一望、奇怪、敵人正場索战、理所当然、点將開兵、不能在塊陪我闲谈、工工谈不在只一刻, 等到——既把我请得来。何方老实些同我说明。再一想。明白・我才到的。他请我开兵。未 免不近人情 $\infty$ 他不好意思開 $\square \infty$ 我何不体贴他 $\infty$ 向他讨令下山去会颜良 $\infty$ 再一想不能 $\infty$ 设 恐他不是请我動手 $\infty$ 回我一句不敢勞駕 $\infty$ 那一來才下不去 $\infty$ 有了、等我來用句话引他下 子。丞相到此・開兵几次。只有一次、颜良刀伤操兩元降将、宋现、未续、後來张许徐夏、四 将下山传战颜良、亦復未能取圣、只匹夫勇不可当、(五) 矢某亦復早已闻名。一—虽闻其 名,未見其人。20

\section{Translation of the extract}

[He] ordered:

'Feasting!'

God of War (Guan Yu ${ }^{21}$ took his seat. Cao Cao entertained him. The orderlies sent round the wine and served the dishes. The soldiers ate to their heart's content. Somebody came up to report to the Prime Minister:

'Yan Liang stands at the foot of the hill and challenges us!'

'[I] know! Withdraw!'

[He]came again:

'Yan Liang stands in the middle of the ring and swears at us!' 


\section{'[I] know! Withdraw!'}

[This happened] five or six times. Cao Cao did not change his mien. When God of War saw it, [he thought]: 'Strange! His enemy stands in the ring and swears [at him.] As a matter of course [he should] order [one of his] generals [to get] into battle. $[\mathrm{He}]$ cannot sit here and chat with me! Chatting is not suitable at this moment! Let's wait and see. - Since he has invited me over, why doesn't he behave more sincerely and explain [the situation] to me?' [He] thought again. 'Oh, I see! I have just arrived. He wants to ask me to go into battle. [Therefore he] must rely on friendship, and so he is embarrassed to [take the initiative and] open his mouth. Why should I not show him consideration? [I can] ask him for the order to go down the hill and meet Yan Liang.' [But then he] thought about it again: 'No, it does not work! Probably he will not ask me to get into action, but he will just answer me: '[I do] not dare to oblige [you]!' And then [I] cannot go down. [I] know! Let me try to lure him a bit!':

'Prime Minister! [Since you] came here, how many times have you gone into battle?'

'There was a time, when Yan Liang beheaded two of my lower generals, Song Xian and Wei Xu. Later [I] entrusted the four generals, Zhang, Xu, Xu and $\mathrm{Xia}$, to go down the hill and engage Yan Liang. Again and again they have failed to come out victorious! That fellow is too valiant for any to face.'

'[I], a certain person called Guan, have heard of his fame again and again. - Although [I] have heard his name, [I] have never seen him in person.'

The passage contains mainly dialogue and monologue (with inserted dialogue), with a few phrases of third person summaries of action (covered narrator). Dialogue and monologue are not marked in any way; there are no tags or punctuation markers for this purpose. It can only be deduced from the use of pronouns and the content of each sentence.

Only prose passages are taken down in the notebook, while poems are kept in another notebook. There are no stock phrases, taoyu, to indicate the places where poems should be inserted, but at certain points of division of the tale, couplets, duilian 對聯, are inserted. This latter feature seems to be the only reminiscence of a 'storyteller's manner', otherwise the script is devoid of any of the usual components of the 'manner'.

Apart from a few words of decidedly wenyan flavour (wei 未, yifu亦復, $q i$ 其), and a number of four- or six-character expressions (chengxiang dao ci, kai bing ji ci 丞相 到此, 開兵几次; yifu wei neng qu sheng 亦復未能取圣; yong bu ke dang 勇不可當; ${ }^{22}$ sui wen qi ming, wei jian qi ren 虽闻其名, 未見其人), the passage is entirely in vernacular Chinese, as is marked by the use of the pronouns wo 我, ta 他, the determinatives zhe 這 (written 只), na 那, the measures $j u$ 句, yuan 員 (written 元), the verbal suffix le 了, as well as modern phrase structure and lexicon. A few phrases are formed according to markedly Yangzhou dialect patterns (/zae kuae/ 在塊, /ze' ie' ke'/ 只一刻, /haze/ 下子). 


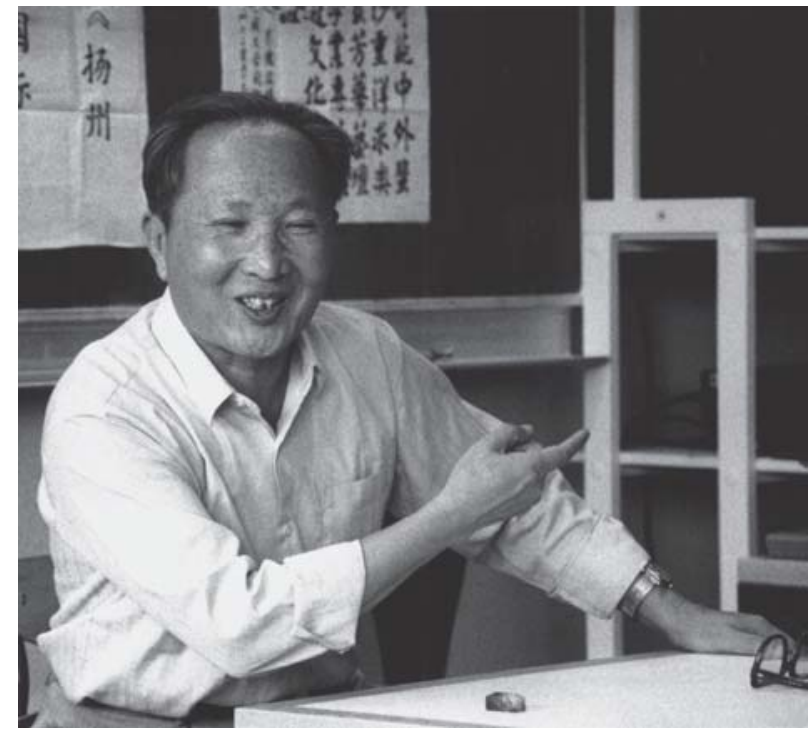

Figure 12.5 Fei Zhengliang 費正良 (b. 1931) (artist name of Fei Li) performs the episode 'Beheading Yan Liang' from THREE KINGDOms. Copenhagen 1996. Photo by Jette Ross.

The style is compressed, a staccato sequence of verbal predicates, frequently lacking an explicit subject and/or object, as shown by the square parentheses in the translation. In both classical and modern Chinese such sentence structure is possible, but in classical literary Chinese sentences without subjects are more frequent. The compressed nature of most sentences may reflect the wish to condense the notation of the performance, furnishing only the barest linguistic message by which to aid recall for a future performance of the same episode. However, this way of writing also furnishes the passage with a certain old-fashioned and imposing style, natural to a tale about the wars of old.

The handwriting uses predominantly su $z i$ form of characters, similar to the later simplified forms, but also many 'authorized' forms, corresponding to the later fanti, apparently without any precise system. A large number of characters are written with homonym (or almost homonym) characters instead of the usual characters for the word, i.e. fenfu 吩咐 'order', written fenfu 分付; dangchai 當差 'orderly', written 当在; 23 can 餐 'meal', written tian 忝; ${ }^{24}$ zhengchang 征場 'battle ring', written 正場; bu dong shengse 不動聲色 'without changing his mien', written bu dong shense 不動身色; zheyike 這一刻 'this moment', written 只一刻; 25 he fang 何 妨 'why not', written 何方; yuan 员 'measure word for general', written 元; proper names Song Xian 宋憲, written 宋现, Wei Xu 魏續, written 未续; qu sheng 取勝 'win a victory', written 取圣; interjection 唔 'Ahem', written 五. Many of the loan characters are obviously based on pronunciation in Yangzhou dialect, where they are true homonyms or at least close in sound, while this is sometimes not so obvious in MSC. 
The scripter wrote rapidly, for personal use. The loan characters can hardly be considered 'errors', because this type of shorthand was used throughout the passage. They obviously came from listening, because they are based on Yangzhou pronunciation. It is improbable that the storyteller did not know the correct characters, since he was a school teacher of considerable education. He was rather saving himself time and trouble by writing substitute characters, which were used solely to assist his memory of what had been said.

\section{Script and Performance: FORMER THREE KINGDOMS}

In this example, the relationship between script and performance is the opposite to that of the first script, where the storyteller was asked to perform the passage which had been selected from the script. In the case of the Three Kingdoms, I had had since 1996 a recording of a performance by Fei Zhengliang (Fei Li), and only much later did I see the corresponding passage in his father's script. Not unexpectedly, the performance is considerably longer than the version in the script, in this case four times longer (Fig. I2.5).

The performance as well as the script are devoid of stock-phrases, and poems or other set pieces are lacking. In my collection of Fei Zhengliang's performances, poems are comparatively rare, and as we have noticed there are no poems inserted in the script.

The part of the performance that we are considering, just like the script, consists mainly of dialogue and inner monologue linked by a few sentences of summary and storyteller's comment. 'Square mouth' register is used only sparingly, namely in the most formal parts of the conversation between the two high-status characters, Cao Cao and Guan Yu, as well as in their inner reproduction of former conversations. Otherwise the performance is conducted in the 'round mouth' register of modern Yangzhou vernacular, and this is also the mode of speech used for rendering the inner thought of the protagonists.

At the beginning of the passage Cao Cao's attendant repeatedly reports the actions of the great general Yan Liang, while Cao Cao only utters the shortest possible orders:

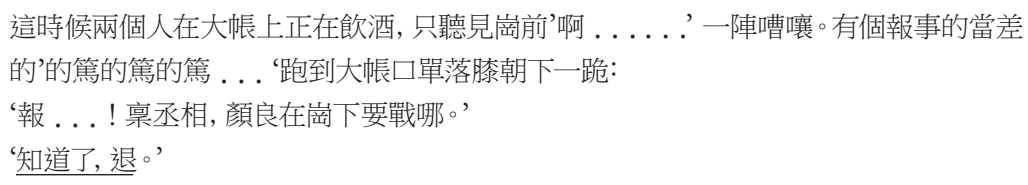

Now the two of them were sitting in the big tent and drinking, when they heard a great noise in front of the mountain: 'A-a-a-a-a-a-a-h!' An attendant rushed into the big tent: 'Diddleli-diddleli-diddleli . . .' and knelt down on one knee: 
'Report . . .! Our Prime Minister is informed that Yan Liang is standing at the foot of the mountain and urging for battle.'

'I know! Withdraw!'

Dialogue is indicated by modulation of voice, by use of pronouns and sentence particles, as well as the contents of the utterance, not by tags such as 'he said', 'he thought', etc. Here we notice that the script is similar to the oral tradition in providing no explicit frame for dialogue or monologue versus narration.

The conversation between Cao Cao and Guan Yu is sometimes coloured by markedly wenyan style, spoken in 'square mouth' register:

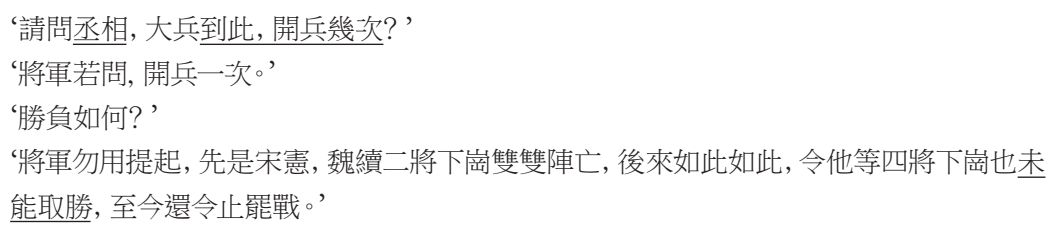

'I should like to ask the Prime Minister, after your men arrived here, how many times have they engaged in combat?'

'Since you ask this question, my general, they have engaged in combat once.'

'How was the outcome?'

'Don't mention it, my general. First my two generals Song Xian and Wei $\mathrm{Xu}$ went down the mountain and both of them fell in battle. After that things have been only so-so. Now four other generals have gone down, but none of them have been able to win a battle. Up to now we are in a cease-fire.'

In such passages we find a few typical grammatical markers of wenyan style, such as: $z h i 之, w e i$ 末, $w u$ 勿, $q i$ 其.

Sentences containing grammatical features specific to the Yangzhou dialect occur not infrequently throughout the performance in the 'round mouth' passages, i.e.: Y. /me' de'/ 沒得 or /be' de'/ 不得; Y. / kw/ 可 as marker of alternative question; Y. /haze/ 下子 as verbal measure; Y./caa/ 朝 as high frequency preposition; Y. Ize'-kuae/ 這 塊 and /la-kuae/ 那塊; Y. /zo sr/ 做事 'why'; Y./-te'/ 掉 as high-frequency resultative complement; Y. /i-ue/ 咦喂 as high-frequency exclamation; Y. /la-ie'-gw/ 哪一個 as pronoun in the form of DM compound. Some of these same dialectal structures were found in the script (underlined).

\section{Script and Performance - Discussion}

The analysis accords well with the information we have about the script: that it was written in stenographic fashion in an attempt to grasp as much of the recent 
performance as would be necessary for the scriptwriter (novice storyteller) to reproduce/recreate the episode in his following rehearsal (or for his own future public performance). In the novel, the entire episode of Guan Yu and Yan Liang is told in less than 400 characters, while it is more than ten times longer as told by Fei Zhengliang in 1996. In Three Kingdoms there is no passage with the same content as that found in the extract from the script or the performance. In the script there is, however, a single phrase, i.e. 'too valiant for any to face', which is identical with the text in the novel. This expression is not used in the performance. Both script and performance testify to the high degree of textual independence of the Yangzhou pinghua tradition vis-à-vis the written heritage of the novel.

The telegraphic style of the script, where subjects and objects are mostly implicit, seldom explicit, is not a general characteristic of the spoken performance, which is far more explicit in this regard. But in the dialogue of the two main characters we find a tendency towards the same short and abrupt utterances as in the script. Therefore this feature of the script is not necessarily only a kind of shorthand; it may also function as a marker of spoken style in imitation of the military leaders. Some of the short commands and concise exchanges of Cao Cao and Guan Yu are precisely those that are identical in script and performance.

Significantly, dialect features peep through here and there, a strong indication of the closeness between the script and the oral tradition from which it was drawn. It is also a sign of the scriptwriter's willingness to write 'from the ear', instead of basing himself on the norms of written expression. His use of substitute characters, reflecting homonyms of his dialect rather than homonyms of MSC, is further evidence in this direction. The text of the script does not necessarily depend only on what was said by his master on the day of performance. It may just as well represent what Fei Junliang, the disciple and scriptwriter, had incorporated into his memory along with his acquired competence in the art. What is found in the script may be more recreation than reproduction, which is also true of the traces of dialect grammar: whether they came from the original performer (the master) or from the writer of the script (the disciple) cannot be verified. All we can say is that the same dialect features were found in the performance given three-quarters of a century later by the son of the disciple/scriptwriter.

The linguistic flexibility of prose narration in Yangzhou pinghua is demonstrated once again in this small sample of script and performance. Apart from poetry and set pieces, memorization by heart is foreign to this tradition, where prose constitutes by far the larger portion of each performance. The Three Kingdoms script obviously does not invite learning by rote. Written as a personal aide-mémoire, it appears as a truly transient genre, elusively mediating the oral and written modes of language. 


\section{CLOSING REMARKS}

The two scripts we have examined are both narrative texts, not mere lists of topics. Both are extremely brief, not only with a view to the corresponding performances, but also considered as independent texts. The Western Han script is written in a succinct, almost telescopic style, offering so little 'filling' that it would seem indigestible for any uninitiated reader. It would be difficult to imagine a person who would enjoy reading the script for its own sake. The same holds true in the case of the Three Kingdoms script, but for different reasons. Its abrupt jottings of performed words may have served their purpose as memory triggers for the scripter-performer. But for a person who was not orally trained in the repertoire, the text would give little help. In sum, both scripts seem only suited for recall of their corresponding oral versions by persons who were already well schooled.

In their linguistic form the two scripts are clearly different from each other. The older script is written in a wenyan-like style, with no dialectal features. The more recent is written in a much more vernacular style, including structures of typical Yangzhou dialect grammar, in spite of the fact that it mirrors military conversations conducted in imposing and commanding high style. The difference in written style might be an early testimony to the growing influence of vernacular Chinese, baibua, resulting in the language reform of the early decades of twentieth century China, where literary Chinese, wenyan, was superseded by the vernacular as the new normative written medium. The new norm did not, however, encourage the writing of dialect. It seems plausible that the two scripts were conceived through different mechanisms: the scriptwriter of the older script condenses into literary style the main contents of the repertoire, while the scripter of the younger was reflecting in rapid succession his immediate recollections of spoken words and sentences.

The use of 'vulgar characters', suzi (non-authoritative forms or 'loans'), is often explained as a sign of the 'lack of culture', meiyou wenhua 沒有文化, (low education) of the storytellers who made such 'errors' based on the sound of the words they tried to commit to paper. From the sample texts under study, the loan characters (homonyms or close homonyms) can be plausibly explained as intentional shorthand, rather than misunderstanding or unintentional miswriting of the oral performance they reflect. At the same time, such a writing habit attests to the close connection between the written specimen and an oral source, in particular when the homonyms reflect dialect pronunciation.

We saw how the text of the script from Western Han was to a certain degree preserved in the performance and how the latter functioned as a kind of exposition and exegesis of fixed phrases handed down from 'history'. The Three Kingdoms script, on the other hand, represents a drastically shortened summary of spoken/ heard words. It recorded in writing not the exact memorable words of former times, 
but rather bits and pieces of the master's actually performed words as remembered, with memorable and less memorable utterances both jotted down.

None of the two samples can be envisaged as 'notational scripts' in the sense of careful and complete registrations (notations) of oral performances as spoken (HANAN 198I: 5). The written version was not intended to be published for a reading audience, but to help stabilize the oral tradition and prevent extinction. This kind of script was not actually used for educating the next generation of storytellers, but might occasionally be consulted by storytellers who already had the basic training, or as handbooks where the mature storyteller could look up passages and lines of plot when his memory failed him. However, we must emphasize that such usage is little talked about by the storytellers and they have no terms for it, though they have a rich technical vocabulary for their art. They do not regularly use scripts when preparing the day's performance, but rely on mental concentration and meditation, for which they do have a special term, 'to warm up the story', wushu 焐書 (Yangzhou quyi zhi 1993: 249, BøRDAHL 1996: 229).

As mentioned at the outset, both the existence and the use of storyteller's scripts offer a way to gain a deeper understanding of the role of writing and written influence in the oral traditions of storytelling, from a contemporary as well as a historical perspective. Written scripts play a different and much more extensive role in some other present-day orally performed genres. Apparently the reliance on written scripts is growing as the general educational level is raised. Yangzhou storytellers, as we have seen, are sceptical about this development. 'Oral transmission and teaching from the heart' is still seen as the backbone of the art, the absolute precondition for its continuation.

The narrative forms of both extracts from the scripts are almost completely devoid of the characteristics of the 'storyteller's manner'. Apart from the expression 'what a spectacle' zen jian, introducing a poem in the Western HAN script, and the fact that this script contains both prose and poetry in alternation, the prominent features of the 'manner' are missing. Neither of the two scriptwriters apparently had any interest in meeting a reader's requirements or in writing more than the absolute minimum deemed necessary for the preservation of the repertoire, not for future readers, but for future performers. Comparing these extracts from scripts with their corresponding performances, their function as a precarious lifeline for the oral tradition, a true aide-mémoire, emerges in high relief.

Finally, it is tempting to speculate once more on the old 'prompt-book theory' about a connection between early vernacular fiction and storytellers' scripts. On the basis of the case study of two scripts of Yangzhou storytelling from ca 1880-1923, considering their extremely laconic style - cut to the bone - one would wonder if any 
of the early pieces of pinghua or huaben fiction that have been considered candidates as storyteller's scripts would really qualify as such. The short-winded and completely unadorned style of the Yangzhou scripts, bordering on the incoherent and sketchy, and the almost total absence of 'storyteller style' of narrative markers or simulated communication with the audience are pertinent features in perfect harmony with the actual use of the scripts.

Our findings would fit better with the view that the early huaben fiction as transmitted to our time has gone through considerable literary rewriting and layout adaptation before being printed, a format that would seem unnecessary and superfluous in scripts for a living performance tradition. The literary rewriting might, on the other hand, be closer in many aspects than any eventual scripts to the actual oral performance of the time.

\section{ACKNOWLEDGEMENTS}

The scripts under study here were photographed in May 2000 by my friend, the late Danish photographer Jette Ross (1936-200I), with whom I worked closely and co-authored several books on Yangzhou storytelling. I wish to thank the storytellers, the late Dai Buzhang 戴步章 (1925-2003) and his family, and Fei Li 費力 who gave us access to their inherited family treasure for research purposes. I am also indebted to Huang Ying 黃瑛, Yangzhou, who transcribed a performance by Dai Buzhang, corresponding to a passage in the family script, into characters from the tape recording. The full transcription with translation is published in BøRDAHL 2005: 283-29I. A performance by Fei Li (Fei Zhengliang 費正良), corresponding to a passage in his father's script, is published in BøRDAHL and Ross 2002: 315-336. This chapter is based, with permission, on my previously published article, 'Storytellers' Scripts in the Yangzhou pinghua Tradition', Acta Orientalia, Oslo, No. 66, 2005, pp. 227-296. The present shortened and rewritten version is further based on papers of the same topic presented during the workshop 'Lifestyle and Entertainment in Yangzhou', which took place in Yangzhou in October 2005, and during the annual meeting of CHINOPERL Association in San Francisco, April 2006. I wish to thank the participants in these two meetings for lending me a patient ear and suggesting improvements. The study is part of the project 'Traditional Oral Culture in the Modern Media World of Asia - The Case of Chinese Storytelling', financed by the Program for Cultural Studies, The Norwegian Research Council, Oslo.

\section{NOTES}

1 Yangzhou storytelling is treated in detail in several book-length studies, cf. WEI Ren and WeI Minghua 1985, BøRdahl 1996/2006, BøRDAHL and Ross 2002.

2 A video project was undertaken, comprising the full repertoires of four masters of Yangzhou storytelling, recorded during live performances 2002-2003, cf. BøRDAHL, Fei Li and HuAnG Ying 2004 .

3 In the present article the word 'script' is used in the sense of a text that may serve as aide-mémoire, libretto, or other related purposes vis-à-vis oral performance. In order to avoid confusion, 'writing system' or 'calligraphic style' is called 'writing' or 'transcription', not 'script'. 
4 Throughout the twentieth century the understanding of the storytelling style in vernacular fiction, and its origin, development and function, have been continuously debated and the theories refined, see Lu Xun (Lu Hsun) [1923] 1964, Cheng Yizhong [1964] I980, LÉvy 1965, I97I, I98I, 1999, Hanan 1967, 1973, 198i, Průšex 1967, 1968, Riftin [1970] 1997, Idema 1974, Hu Shiying i980, Porter 1991, Zhou Zhaoxin 1994, McLaren 1998, Meng Zhaolian 1998, Ge Liangyan 200I. See also the more detailed treatment of this issue in connection with Yangzhou storytelling in BøRDAHL 2003 and 2005.

5 See also Margaret B. Wan's recent study of performance-related tanci texts from the mid and late Qing period and their counterparts in the genre of the novel, WAN 2004, pp. 370-37I, 374, 377-380, 389-39I.

6 For a discussion of the interpretations of 'oral' verbal art, cf. Finnegan 1977 [1992]: 16-24 and I992, chapters I, 2 and 6.

7 In contrast, Yangzhou xianci 揚州弦詞, just like Suzhou tanci 蘇州彈詞, features a regular prosimetric shifting, called 'seven parts telling and three parts singing', qifen shuo,sanfen chang 七分 說, 三分唱.

8 Titles of oral repertoires are written in capital letters (majuscules) in order to distinguish them from book titles. Books are written in italics.

9 Details of the transmission are found in BøRDAHL 2005: 245-246.

10 The whole script was photographed in 2000, cf. Acknowledgements at the end of the chapter. A passage of prose text was chosen at random for study, primarily based on the clarity and readability of the photo of that page.

11 Cf. Sima Qian (edition undated): Shi ji, juan 92, Huaiyin Hou liezhuan 淮陰候列傳 3I.

12 The transcription into computer characters strives to render the characters in the form of the manuscript, i.e. jianti and fanti forms alternate as they do in the handwritten version. However, some characters are written in non-standard forms that do not exist in computer writing. In these cases I have chosen the form that seems closest to the manuscript form.

13 The script in a few rare places uses the standard stock phrase before poems, 'there is a poem to testify to this', you shi wei zheng 有詩為證, but otherwise there are none of the usual sets of fixed phrases of introduction, connection and conclusion, and no modern equivalents. In Yangzhou pinghua these stock phrases (as well as modern equivalents) are likewise absent, with only rare exceptions, cf. BøRDAHL 1996: 239-24I.

14 The non-authorized forms were at the time called 'vulgar characters', su $z i$ 俗字, and 'wrong characters', cuo zi 錯字; some of the su zi cuo zi correspond to the modern 'simplified characters'; in some cases a part of the character - radical or phonetic - is written with an alternative element, which is not among the current dictionary forms of this character.

15 Passages in the performance that correspond word by word (or nearly word by word) with passages in the script are underlined in the character version and written in italics in the English translation

16 Y. = Yangzhou dialect. MSC = Modern Standard Chinese. The examples of Yangzhou dialect grammatical structures are listed in their order of first occurrence in the performed text. All of these structures are described in more detail in BøRDAHL 1996, Chapter 4, where references to linguistic studies of Yangzhou dialect grammar are given. See also Yangzhou fangyan cidian 1996, and BørDAHL 2005: 254-255. 
17 Dialogue of ordinary characters, xiao renwu 小人物 [small persons], is also in round mouth register, but in the present passage the speaking characters all belong to the high status group, $d a$ renwu 大人物 [great persons], who speak in square mouth register.

18 Personal communication during visit to the home of Fei Li, October 2003.

19 In the Yangzhou storytellers' inside jargon, the Three Kingdoms repertoire, consisting of the 'former', 'middle' and 'later' Three Kingdoms, is called: 'Former Volume', Qian ce, 'Fire Volume', Yan ce 炎冊 (great fires play a major role in this part of Three Kingdoms), and 'Later Volume', Hou ce 後冊, communication from Fei Li, November 2003.

20 The passage is rendered in jianti and fanti forms according to the usage of the manuscript. Irregular forms are given in the form closest to the manuscript form. The symbol $\infty$ reflects the habit of Fei Junliang to write double circles in the margin to emphasize the important passages. Personal communication from Fei Li, October 2003.

21 According to Fei Li, storytellers of his father's generation had a taboo against speaking the name of Guan Yu, because he was a god. So they called him God of War.

22 The phrase 'too valiant for any to face', yong bu ke dang 勇不可當, is found in the Yan Liang episode of San guo yanyi. This is the only expression in common between the script and the novel. As we shall see later, the phrase is not used in the matching oral performance.

23 The character 在 Y/zae/ is not a perfect homonym for 差 Y/cae/, but closer in sound than the corresponding pronunciations in MSC: zai versus chai. In the following we register several such examples of 'loan characters' that are not perfect homonyms.

24 餐 Y./caen/, 忝 Y/taen/.

25 這 Y. /ze'/, 只 Y. /ze'/. 


\title{
The Traditional Style of
}

\section{Storyhouses in Yangzhou}

\author{
Fei Li \\ Translated by Huang Ying
}

Y

angzhou storytelling, Yangzhou pinghua 揚州評話, has a long history, and the storytellers' house or 'storyhouse', shuchang 書場, has a long history, too. The poem, 'A hundred tunes while enjoying the view of the Jiangnan', Bai diao wang Jiangnan 百調望江南, was written by monk Xing'an 惺庵居士 in the Qing Dynasty:

揚州好,
書場破愁魔。
說到飛跎回味美,
聽來皮瘌發科多,
四座笑呵呵。
Yangzhou is wonderful!
In the storyhouse you will be cheered up.
The tale of The Braggart has a rich aftertaste,
The story of Pi Wu the Idler is full of jesting.
The audience sitting all around is breaking out in laughter!

It shows that the storyhouse used to be a popular place for entertainment and enjoyment, as well as for increasing one's knowledge.

The wine shops and teahouses of Yangzhou also used to combine their business with storytelling, and further there were special storyhouses, called storytellers' societies, shushe 書社. These more prestigious establishments, such as Willow Village Storytellers' Society, Liucun Shushe 柳村書社, Awaken the People Storytellers' Society, Xingming Shushe 醒民書社, and Cry of the Dear Storytellers' Society, Lu ming Shushe 鹿鳴書社, were mostly in the Jiaochang area, 教場. Their owners and tea-masters, chafang 茶房, smart and capable as they were, managed these establishments well, and so were famed far and near. The customs and etiquette, the rules and conventions of these storyhouses have much inherent interest. 


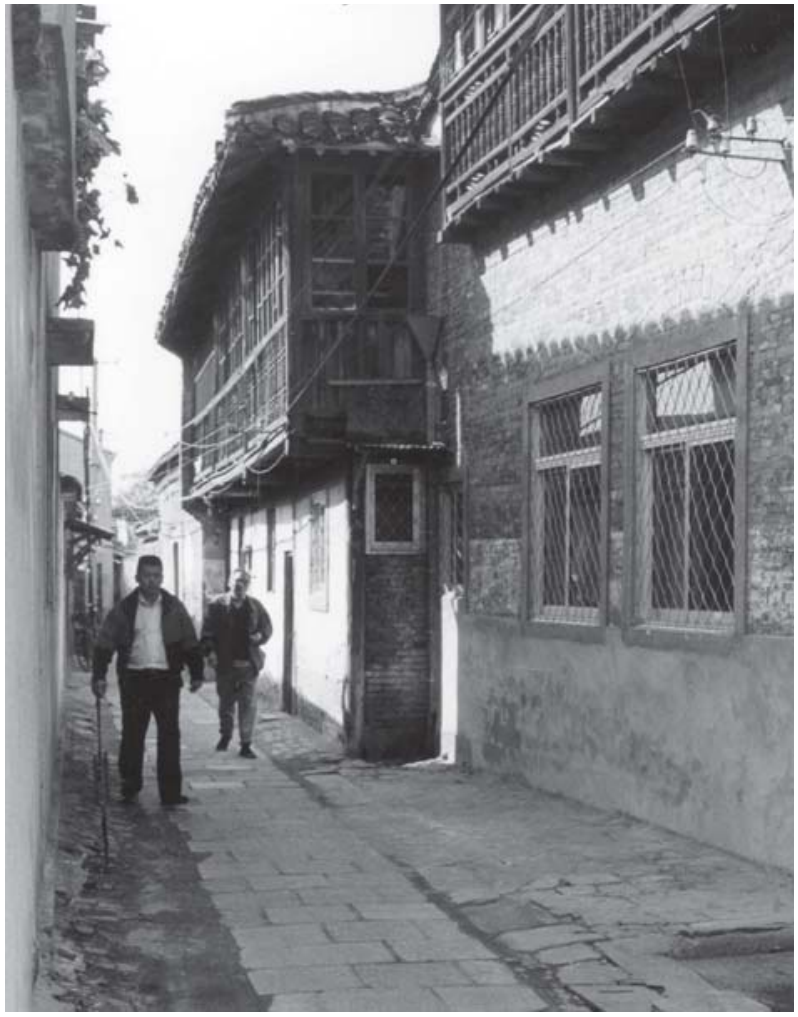

Figure 13.1 A street in the Jiaochang area of Yangzhou, 1997. Photo by Jette Ross.

\section{STORYTELLERS AND REPERTOIRES}

In order to manage a storyhouse with success, the most important thing was to engage compelling storytellers. First of all, the artist had to be able to perform storytelling at the highest artistic level. Secondly, the repertoire had to be attractive to the audience. Repertoire was traditionally divided into the major texts, da shu 大 書, and the minor texts, xiaosh $u$ 小書. By major texts was meant the historical texts of Yangzhou storytelling, such as Three Kingdoms, San guo 三國, Water Margin, Shuibu 水滸, Western Han, Xi Han 西漢, The Tale of Yue Fei, Yue zhuan 岳傳, etc. By minor texts was meant the other texts of Yangzhou storytelling, martial knights-errant tales, such as The Five Knights-errant's Adventure, Xiao wu yi 小五義, detective stories, such The Cases of Lord Shi, Shi gong'an 施公案, supernatural stories, such as Journey to the West, Xiyou ji 西游记, stories about social life, such as Qingfeng Sluice, Qingfengzha 清 風閘, Piwu the Idler, Piwu Lazi 皮五瘌子, and Yangzhou storysinging, Yangzhou tanci 揚州彈詞, formerly called Yangzhou xianci 揚州弦詞 [Yangzhou string tales].

There used to be so many famous masters, both for the major texts and the minor texts, that they were named after their repertoires, such as 'The Kang Masters of 
Three Kingdoms', Kang San guo 康三國, 'The Wu Masters of Three Kingdoms', Wu San guo 吳三國, 'The Wang Masters of Water Margin', Wang Shuihu 王水滸, 'The Ma Masters of Water Margin', Ma Shuihu 馬水滸. Among the famous masters were also Zhong Songyan 仲松岩, who told Qingfeng Sluice; Dai Shanzhang 戴善章, who told Journey to the West; Fan Zizhang 樊紫章, who told Cases of Lord Shi; and the Zhang family of storysingers, Zhang shi tanci 張氏彈詞, and many others.

\section{SEASONS AND ENGAGEMENTS}

All the storytellers attracted large audiences and were eagerly sought for by the owners of the storyhouses, changfang 場方. When these owners wanted to engage a storyteller, they would send a letter or make a visit. At this time the conditions of the engagement would be negotiated. For instance, would the owner of the house be responsible for the storyteller's meals and accommodation? Or would the storyteller and his family take care of such matters themselves and the owner only provide compensation for the performances?

For all such cases there were conventions. The first/most important thing was to decide the date of the opening performance and the length of the engagement. Usually an engagement would last two to three months, certainly no less than forty days, and a few storytellers were able to perform continuously for more than half a year.

An engagement was called 'a job', yidang 一檔 or yiju一局, and the jobs were named according to the season: the job beginning on the first of the first month according to the lunar calendar was called New Year job, niandang 年檔; the job coming right after this one was called 'second job', erdang 二檔; it usually began in the third or fourth month. Then came 'summer job', xiadang 夏檔, 'autumn job', qiudang 秋檔, and 'winter job', dongdang 冬檔. The period between winter and New Year was called 'winter's end heading for New Year', weidong dai nian 尾冬帶年.

When the arrangements were settled, the owner of the house would send a gift of money to the storyteller to confirm the contract, pinjin 聘金, called 'the small gift', xiaoli 小禮. The gift could also be calligraphic works, paintings or other items, depending on the special interests of the storyteller. Taking receipt of the small gift indicated that the storyteller accepted the job. The agreement could not be altered without special reasons. In the rare case when a storyteller was not able to begin his job as scheduled, he might ask a colleague to take his place for some time, diangong 熱工, with the permission of the owner. The income from that period would then belong to the colleague.

A few days before the storyteller took the stage, the owner of the storyhouse was supposed to 'bring out the red', chuhong 出紅, also called 'show the red', lianghong 亮紅, namely put up advertisements in the streets and lanes of the neighborhood. 
The advertisements used to be written on red paper, simply called 'red', hong 紅, symbolizing good luck. On such advertisements the name of the storyteller was written in bold characters, with the name of the repertoire, the date and hour of the first performance, and the name and address of the storyhouse written in smaller characters. Sometimes it was also indicated that there would be storytelling 'during bad weather', fengyu wuzu 風雨無阻.

There were some special rules for 'showing the red'. If one advertisement was already fixed to the wall, a new red advertisement could not be posted on its left side, the superior position. Otherwise, there would be criticisms from colleagues. However, after three days, such a restriction lapsed. A particular big red poster called 'gate red', menhong 門紅, was put up at the entrance of the storyhouse. If the 'red' was already fixed on the wall, but the storyteller failed to perform as scheduled with no one taking his place, it was called 'missing the red', huanghong 黃紅, and the audience could complain. From the first day of storytelling, a small wooden board covered with red paper was hung outside the storyhouse; on one side of the board was written 'Good words to enlighten the world', xing shi liang yan 醒世良言, and on the other, 'Telling about the past and discussing the present', tan gu lun jin 談古論今. The board thus informed the passers-by that there was storytelling available that day. If there were evening performances, a lantern was hung at dusk. If storytelling was cancelled on a certain evening, the owner would ask the tea-master to 'fork down

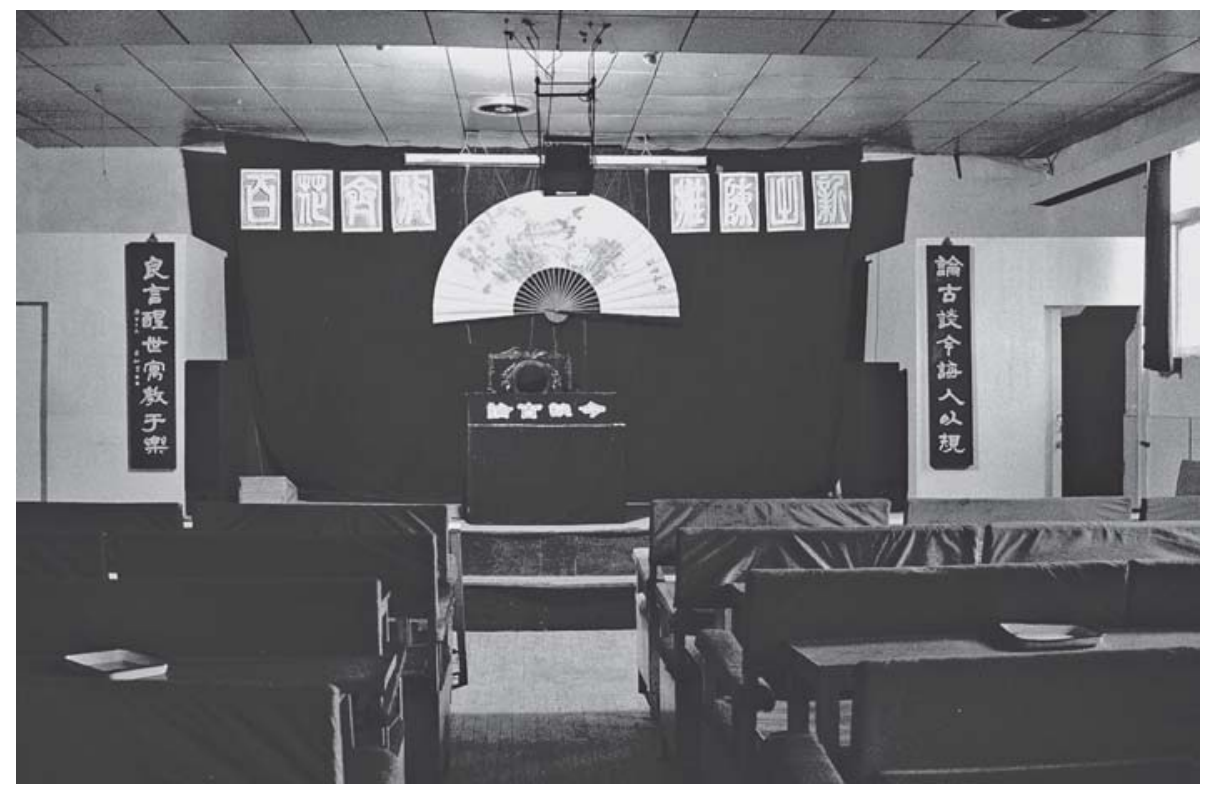

Figure 13.2 The stage of the Great Enlightenment Storytellers' House, Daguangming shuchang 大光明書塲, in the Jiaochang area, 1997. Photo by Jette Ross. 

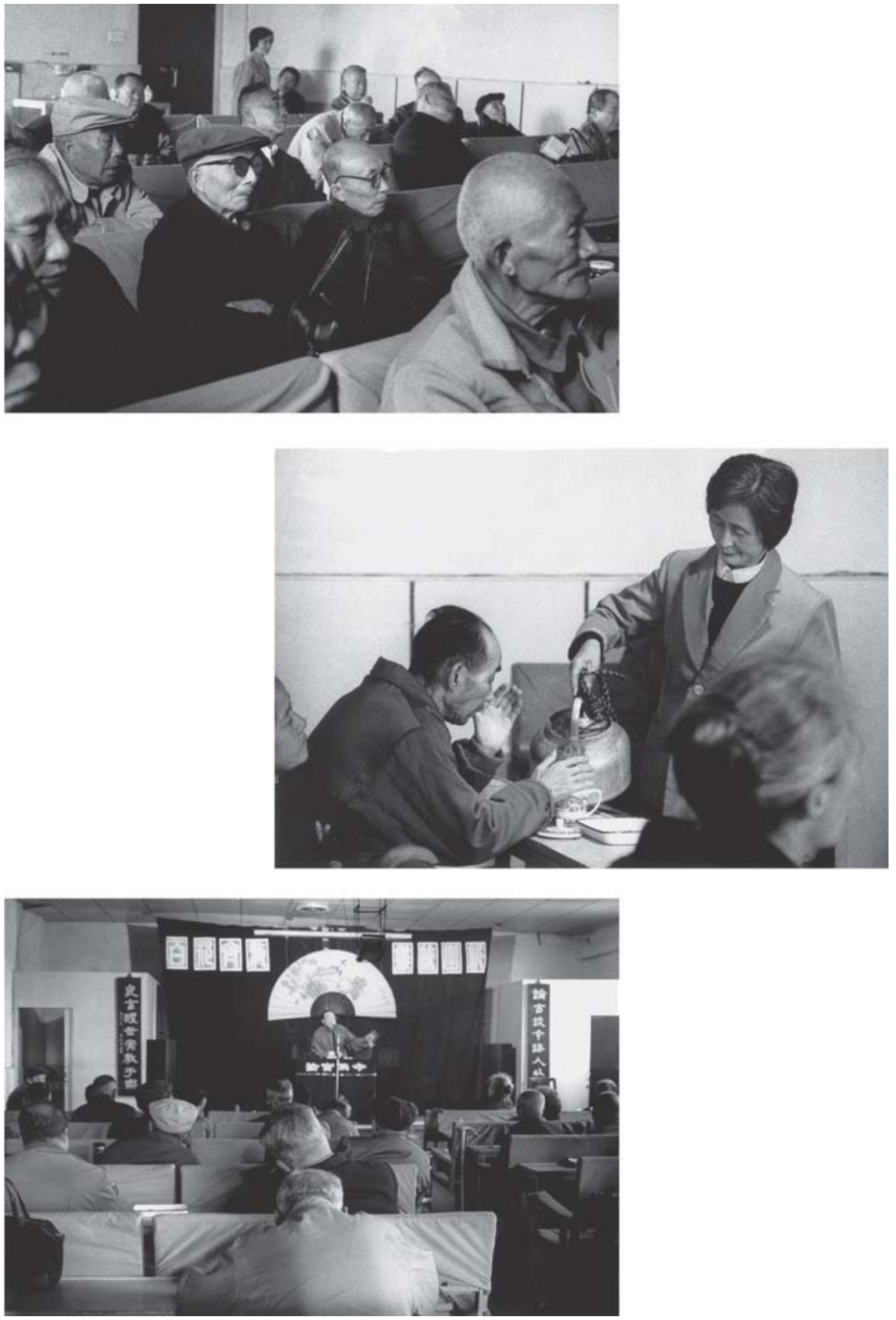

Figure 13.3 Storytelling and tea in the Great Enlightenment Storyhouse, 1997. Photo by Jette Ross. 
the signboard', cha xiaopai 叉小牌, and 'fork down the lantern', cha denglong 叉燈籠, so that people should not come in vain.

\section{THE STORYHOUSE AND THE STAGE}

Most of the storyhouses were rectangular or square and could accommodate about two hundred to five hundred people. The storytelling stage, shutai $i$ 書台, was placed in the middle against one of the walls. A table and a chair were placed on the stage. The storytelling table, shuzhuo 書桌, was covered with a large piece of red tablecloth, on which the name of the storyhouse was embroidered. The chair was furnished with a mat and a cover, and it was higher than an ordinary chair. This was in order to allow for the storyteller's breathing and gesticulation. The table cloth was said originally to be there to hide the storyteller's patchy trousers, because storytellers were often poor. When two artists performed storysinging, the table would be turned round and a chair placed on each side.

On both sides of the stage, there was a pillar. A black board with white characters written on it was hung from each pillar. On the board to the left was written the name of the storyteller and the repertoire; on the board to the right was written the title of the session for that day, huimu 回目. Once the storyteller changed or the session was finished, the words would be changed accordingly. On the pillars was also posted red paper notifying the fees for storytelling and tea. The storyhouse audience would usually sit on long benches with narrow tables. There were also some long tables fixed between the pillars on both sides. Teapots, teacups, peanuts, melon seeds and other snacks could comfortably be placed on the tables. Tables and benches were placed in rows, a simple but comfortable arrangement that the audience felt at home with.

\section{THE ENJOYMENT OF STORYTELLING AND TEA}

Apart from the solo performance of storytelling, pinghua, and the duo of storysinging, tanci, there was also another form of performance called 'common job', gongdang 公檔, where three to five storytellers would all participate, taking turns

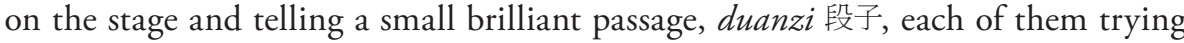
to do his best, a real treat for the audience. For storytellers a 'common job' was also a chance to meet and discuss professional questions and exchange views about artistic technique. In former times 'common jobs' were usually intended for charity or to help a colleague in difficulty. When Japan invaded Shanghai on I3 August 1937, Yangzhou storytellers arranged a 'common job' in Zhenjiang to raise money in support of the soldiers fighting against Japan in Shanghai. Later they held other 'common jobs' in Zhenjiang and Yangzhou to support the resistance against Japan 
and the campaign against opium. Well-known masters like Wang Shaotang 王少堂, Dai Shanzhang 戴善章, Zhu Dechun 朱德春, Fei Junliang 費駿良, Zhong Songyan 仲 松岩 and others often participated in 'common jobs'. This was an honorable contribution to the history of Yangzhou storytelling. However, as such arrangements required the presence of several famous storytellers, who also had ordinary jobs, 'common jobs' were seldom held.

A day-time session, richang 日場, was performed in the afternoon, in former times most often from $3 \mathrm{pm}$ to $5 \mathrm{pm}$. Tea-masters usually prepared boiled water in advance, put the tea in the empty teapots, and arranged hot towels for the audience, with some empty teapots reserved for those who preferred to make tea using their own leaves. When the customers arrived, the owner would stand at the entrance to greet them and usher them to their seats. Whenever old customers came along, he would chat for a while with them. When people had taken their seats, the tea-master would first serve each guest a hot towel to wipe his face, then a pot of tea and a teacup. Two or more guests might share a large pot. The tea-masters, who were well

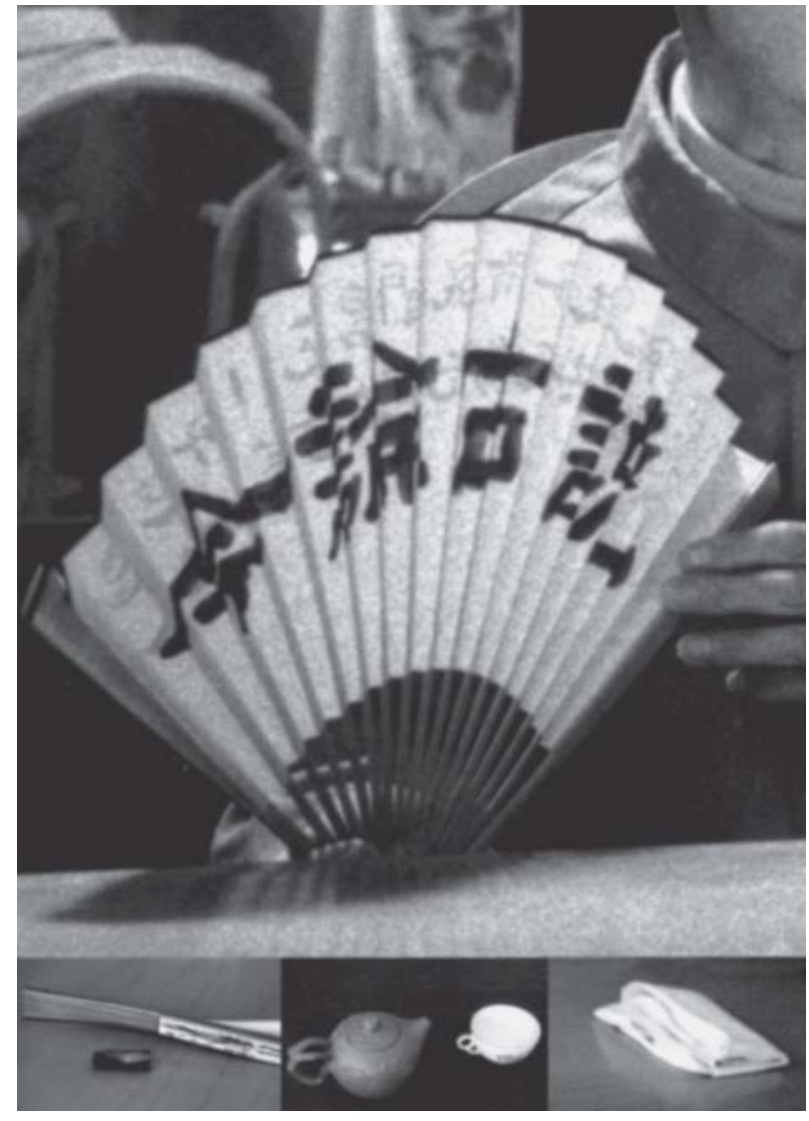

Figure 13.4 Props of Yangzhou storytelling, 2000. Photo by Jette Ross. 
acquainted with the habits of the aficionados, changke 常客, would place a teapot on the table closest to the seat that these guests preferred, which meant that the seats were reserved. Such guests were offered meticulous service. At $3 \mathrm{pm}$ most of the audience would have arrived. If it was a famous storyteller, all seats would be taken by then. The audience would be from all walks of life, some would be dignified men of letters; some shop owners and managers, who greeted each other whenever they saw a familiar face; and some were workers, noisily talking and laughing. All of them came to enjoy the tea and the chatting, and now they awaited the storytellers.

At such times vendors would be busy carrying baskets on their arms filled with cigarettes and fried snacks. They would walk around the room to sell their wares, but they did not make their street cries. There was one vendor from the north of China, nicknamed The Northerner, Beifang kuazi 北方侉子, who spent the whole year selling fried snacks in the storyhouses in the center of the old town, the area called the Parade Ground, Jiaochang 教塲. He sold a rich variety of snacks: in his big bamboo basket there were many small sacks, one for each type, such as big peanuts, small peanuts, watermelon seeds, pumpkin seeds, sunflower seeds, horsebeans, fried horsebeans and so on. He was always smiling and had a pleasant temper, and was very popular with the audience. In addition, he could measure the weight of the food by hand instead of using the scales. If someone bought his peanuts, he would place them in a beautiful pile on the table, and to show his generosity he would add some more peanuts, with a smile.

Rainy days would sometimes present a problem. If the red advertisement did not indicate that the performance would go on in spite of bad weather, and only a few guests had arrived, should the storyteller take the stage or not? The usual practice was to observe the raindrops from the eaves, yankoudieshui 簷口滴水. If raindrops were dripping from the eaves at the moment for beginning the performance, the storyteller had the right to cancel, and the guests would have come in vain. But if they weren't dripping, the storyteller would have to take the stage despite the lack of guests. Heaven decided! ting tian jueduan 聽天決断.

\section{PROPS AND STAGE BEHAVIOUR}

Usually the storyteller would step onto the stage fifteen minutes ahead of time, seating himself and then smiling or nodding to friends and acquaintances, putting the handkerchief, shoupa 手帕, the folding fan, zheshan 折扇, his watch, shibiao 時錶, and the talk-stopper, zhiyu 止語 (also called wakening-rod, xingmu 醒木), on a suitable place on the table. The tea-master would have already prepared a pot of strong tea for him, and now he would serve him a hot towel. The storyteller would wipe his face, take a gulp of the tea to clear his throat and then sit peacefully, restoring his energy or silently recalling, $w u$ 悟, the key points in his coming performance. 
This was considered correct stage behaviour, tai pin 台品. Some storytellers, however, were lacking in this respect and might sit on the stage and pick their noses and ears, meitaipin 沒台品.

At 3 pm sharp, the storyteller would lift up the talk-stopper with his right forefinger, middle finger and ring finger to knock the table - 'Bah!' - as if saying, 'Please, everybody, stop talking and listen to me!' Storytelling called for the storyteller's full concentration; if distracted, he would not be able to focus on the performance and then could not perform well. His glance might start to wander uneasily around, zoushen 走神, and he might miss the thread of his story. So at the tapping of the talk-stopper people would stop talking, and at this very moment the tea-master would also shout in a loud voice 'He opens the mouth!', kaikou 開 $\square$, signaling to the audience to keep silent.

After knocking the table with the talk-stopper, some storytellers began to tell the real story, zheng shu 正書, directly, but others started the daily performance with an 'opening of performance', shutouzi 書頭子, which had no direct connection with the main story. The 'opening of performance' was meant to silence the audience, attract its attention and instil a listening mood, as well as to allow time for latecomers. There were two types of 'opening'. Storytellers who recounted the minor texts would crack a couple of jokes to make people laugh and relax the atmosphere; storytellers who recounted the major texts would begin by reciting a poem to set the tone for their high-style repertoire. Performers of storysinging began with singing an 'opening piece', kaipian 開篇, with an instrument. The 'opening' was supposed be different from day to day; storytellers who liked to tell jokes had therefore to learn by heart one or two hundred different jokes, and those who preferred to recite poems had to memorize a large number of poems. Poem reciting had a long history and some storytellers even composed poems by themselves. Men of letters among the audience especially appreciated the poems and often brought brush and paper to write them down.

After the 'opening' there was a small pause, and then the performer would lightly knock the table again. Then the real story would begin. The audience would listen carefully and soon lose themselves in the plot of the story and the fate of its characters.

\section{AUDIENCE AND AFICIONADOS}

The storytellers preferred to obtain a so-called 'single job', dudang 獨檔, i.e. a job in a locality, where there was storytelling in only one storyhouse, so that the audience had no choice. If storytelling was performed at the same time in the same neighborhood by two performers in different storyhouses, that was called a 'double job', duidang 對 檔. Competition might arise between the two storytellers, each trying to attract the audience with his art, and this was called to 'beat the opponent in a double job', da 

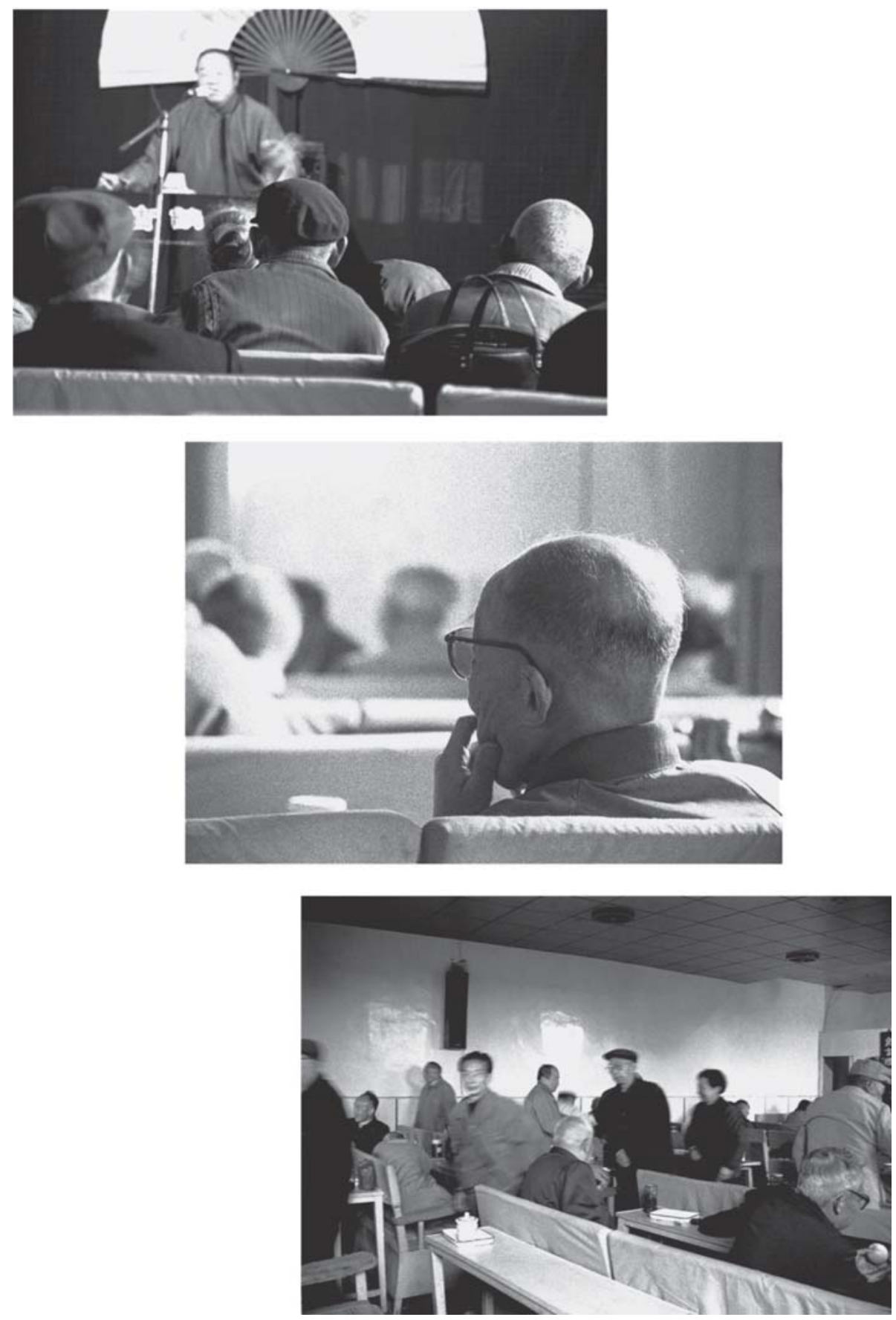

Figure 13.5 The audience in the Great Enlightenment Storyteller's House, 1997. Photo by Jette Ross. 
duidang 打對檔. If both were able, they would match each other, and there would not occur any 'beating'. Both storyhouses might even hang out a wooden board with the words 'full house', ke man 客滿. However, if one storyteller was able to attract the audience from the other house, this was known as 'turning over the pagoda', dao baota 倒寶塔, or 'carrying along the audience', ba ren lingguo laile 把人拎過來了. If the other storyteller had to give up before finishing his job, because his audience had dwindled away, that was called to 'carry along the audience of the other side so that his job goes adrift', ba duifang ling piaodiaole 把對方拎漂掉了. As the old saying goes: 'Two of a trade are natural opponents', tonghang shi yuanjia 同行是冤家. However, this kind of thing would only happen when there was a great gap between the two storytellers' skill.

A 'single job' also demanded a certain level of storytelling skill. When a skilled storyteller took the stage for the first time at a certain place, the listeners might at first be scarce. But he would patiently continue his performances, and his audience might grow from day to day. In that way he would get his 'business going', ling 領. Less gifted artists would not be able to attract audience, and so might have to give up.

Among the audience there would be some aficionados. These elderly fans of storytelling, shu mi 書迷, would choose the seats close to the stage, where they could hear the voice clearly, but not see the performer's facial expression. Most people among the audience did not like these seats, but the elderly aficionados preferred them because they were real insiders and wanted to 'listen to storytelling', tingsh $u$ 聽 書. They wanted only to listen, not to look. They knew the contents very well, and they came to judge the artistic level of the story-telling. When these people listened, they would cock their ears and listen quietly, smoking a pipe the while. They would nod their heads at the highlights, but if the storyteller made an occasional mistake, they would tap the side of the stage with their pipes 'tap-tap'. Apparently they were emptying the pipe of ashes, but in fact they meant: 'Mr Storyteller, you made a mistake right there!' Most storytellers knew the meaning of 'pipe tapping', qiao yandai 敲煙袋. Experienced ones would go on with the story as if nothing had happened, asking for criticism only after the session was over. Inexperienced storytellers might try to correct the mistake immediately and make an unnatural break in the stream of telling. This was called 'to eat a spiral shell', chi luosi 吃螺螄. If they continued to make mistakes, and even made unnecessary blunders, they would be criticized by the audience, this was called to 'turn a somersault', die gentou 跌跟頭. Sometimes they would feel so embarrassed that they could not go on stage again.

\section{A SESSION OF STORYTELLING}

It is said that one session of storytelling, yichangshu 一場書, used to be divided into six sections, duanzi 段子, lasting three hours. Later a session was divided into four sections, lasting two hours (in recent years, the four sections have been reduced to 
three sections and then to two sections). Four sections were called 'four rounds', si zhuan 四轉. The 'first round', touzhuan 頭轉, was the longest; the 'final round', mozhuan 末轉, was the shortest. A short break between two rounds was called 'resting between the rounds', xie zhuan 歇轉. When the storyteller finished the first section, that was called 'cutting mouth', jiankou 剪 $\square$. When the first round had just started, some people would gather at the entrance of the storyhouse, listening for free. Since they didn't pay, they were not given seats, but would stand in the passage near the gate. They might be listening for free, but they were very eager. They did not come or go in time for the beginning or the ending of the session, because they were afraid to be in the way of the regular audience and of being expelled by the owner. Besides, the 'opening of performance' was unrelated to the real story, and the ending would be repeated the next day. For they knew well that the storytellers always used to create suspension or 'sell the crisis', mai guanzi 賣關子, to make the listeners return the next day to hear the outcome. The owner could do nothing about such 'customers', and in fact, as they didn't disturb anyone, the owner did not really mind. After all, they helped to create the bustling atmosphere around the event.

In the storyhouse, the storytellers had the hardest work, but the tea-masters came next, and their contribution was also highly valued. A big house usually had two tea-masters, and they would cooperate with great skill. Before the ending of the first section of storytelling, they would begin to serve tea for the audience. They carried the big kettle with the right hand, walked over to the guests, picked up the teapot with the thumb, ring finger and little finger and opened the cover of the teapot with the middle finger and forefinger of the left hand. The right hand poured the boiling water into the teapot exactly to the brim without any water overflowing or splashing outside, then they would loosen the forefinger and middle finger and the cover would land exactly on the teapot. Their actions were fast, precise and beautiful; it was quite a sight. After the tea was served, they brought out hot towels out for members of the audience to wipe their faces. They could wet ten towels at a time; one tea-master would pass the fresh towels to guests and collect used towels on his left arm. Meanwhile, the other tea-master would have got ready another ten towels, in order to save time. He would send the first a knowing glance and throw the clean towels to him, while the used ones were thrown back. Throwing the towels back and forth, they never lost a single one on the floor, truly a spectacle! The audience was so familiar with this that they weren't startled by it.

Money-collecting was usually arranged at the beginning of the second section, and the owner himself would take care of this. In former times, it was complicated to collect money, for the storytelling fee, shujin 書金, and the tea fee, chajin 茶金, were collected separately, and the tea-masters got a additional tip, xiaozhang 小 帳. Later on these various fees were collected together and divided afterwards, so that money was collected only once, to save time. There was also another kind of 
contract, called a 'guaranteed job', baodang 包擋: No matter whether the audience was big or small, the storyteller's wages remained the same and were guaranteed by the owner. But this was not very common. At the time when copper cash and coins were current, a big bowl, dawan 大碗, was carried around to collect money. If the big bowl was full to the brim, a washing basin, mianpen 面盆, would be used. The bowl with the money was placed on the storytelling table and divided after the session. When paper currency came into use, canvas bags replaced the bowl. There were three layers in the bag, the layer at the bottom for big banknotes, the middle layer for small notes and the outside pocket for coins, this latter very convenient for collecting and returning small change. If two guests were competing to pay the fee for each other, the owner would pretend to be in a dilemma and then quickly accept payment from the one who offered small notes, so that he wouldn't bother about giving change. Then the owner would smile to the other: 'Please, accept his offer today! Tomorrow you'll be the host!' This was smart of him, since he saved time and was also luring them back. When the money-collecting was over, the owner tied the mouth of the bag to stop the money slipping out and then put the bag under the storytelling table, where nobody could touch it. That looked better than placing the bag on top of the table.

\section{SELLING THE CRISIS}

At the end of the session the storyteller used to 'sell a crisis' and end his performance in the 'closing mouth' register, shoukou 收 $\square$. Then he would stand up, smile and take leave of the audience. At this moment the tea-master would shout: 'Please, come early tomorrow!' ming'er qing zao 明兒請早. The audience, though still kept in suspense and with a strong desire to know the outcome, would get up and promptly leave the storyhouse. Some guests had already decided to come back the next day, this was called 'to be enticed by storytelling', ting shu tingshangyin 聽書聽上㒣. The storyteller would be standing at first and sit down again after a while. Out of politeness, he would leave the stage only after the audience had left.

Sometimes, when the 'crisis', guanzi 關子, just before the 'closing mouth', was very exciting, the audience couldn't help asking for more and might shout out loudly: 'One more round!' (Encore!) dazhuan 打轉. Then the storyteller would sit down again to resume the story, and the owner would use another bag to collect money from the audience. Collecting for this round would not be so formal as before, and people short of money would not be pressed. This income belonged entirely to the storyteller. It sometimes happened that the suspense of the 'crisis' was so compelling that people demanded still another round, and again money was collected. Usually there could not be more than three rounds, after which the owner would come out saying: 'The master is getting a sore throat, please come tomorrow!' 
Fei Li

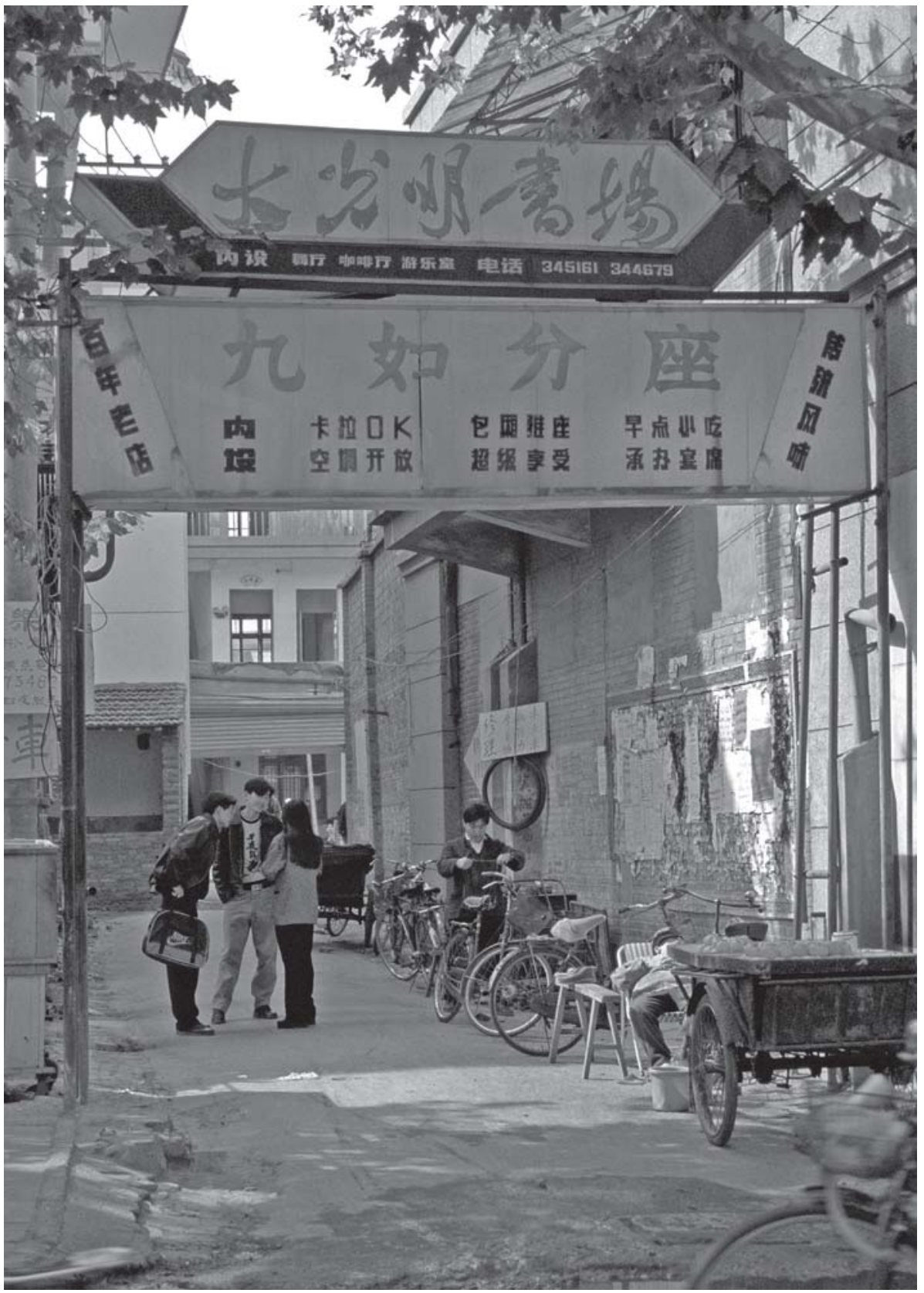

Figure 13.6 Entrance to the Great Enlightenment Storytellers' House from the main street, 1997. Photo by Jette Ross. 
Finally the storyteller would get down off the stage and sit opposite the owner to divide the income. The owner would take out all the money from the bag and turn it upside down to show that no money was hidden. The storyteller and the owner would count the money, putting aside one tenth for the tea-masters and dividing the rest evenly. That would be the end of the storytelling session and the storyteller would then stroll back to his living quarters to rest. However, the tea-masters would still have to clean the floor, the desks and chairs, collect the pots and cups and wash the dishes.

\section{MODERN TIMES}

In the I980s great changes took place in the storytellers' houses. Money-collecting was replaced by selling tickets; tea was prepared in cups by members of the audience; customs and guild regulations were also simplified. The rebuilt Great Enlightenment Storytellers' House, Daguangming shuchang 大光明書塲 was refurbished with soft-cushioned chairs, electric light, microphone, etc. On each side of the drapery behind the stage there were wooden tablets, both with the couplet written by a famous calligrapher and painter Li Yaru 李亞如:

談古論今, 誨人以規;

良言醒世, 寓教於樂。

Discussing the past and telling about the present, teaching so as to advise;

Good words to enlighten the world, instruction infused in amusement.

Between the couplets was placed a plaque transversely hung up with four characters on it:

\section{益智怡情}

Increase your wisdom and be well amused!

These inscriptions precisely indicated the traditional social function of the storytellers' house. The place is clean and elegant, equipped with the necessary modern entertainment facilities. In this respect there has been an improvement compared to the storyhouses of former times.

\section{ACKNOWLEDGEMENT}

The original was published as Fei Li 費力: 'Shuchang fengqing' 書場風情, in Yangzhou fengqing 揚 州風情, [The Flavour of Yangzhou]. Jiangsu wenyi chubanshe, Nanjing 199I: II4-I23. The present translation by Huang Ying 黄满 is a slightly shortened version. 


\section{4}

\section{Life in the Green Lofts of the}

\section{Lower Yangzi Region}

\section{Stefan Kuzay}

$\mathrm{D}$ uring the declining years of the Qing period traditional teahouses, pleasure districts and bordellos played a significant part in the everyday life and popular culture of the Lower Yangzi region. Today this world has largely disappeared and historical sources on this facet of Chinese social history are rare. To gain an insight into the life, habits and self-expressions of the men and women who frequented this world, working, performing or just spending their evenings and nights as guests and customers, I have investigated a collection of late nineteenthcentury texts for songs performed by 'singsong girls' in the great cities of Shanghai, Suzhou and Yangzhou. Sometimes between the lines, but more often explicitly and with amazing frankness, the anonymous authors of the songs express the often dire circumstances of these lives.

The songs that form the basis for this study are not related exclusively to Yangzhou, but to the larger region of the Lower Yangzi, where both North Chinese dialects (including Yangzhou dialect) and Wu dialect (comprising Suzhou and Shanghai dialects) play significant roles. The songbooks of the Lower Yangzi nonetheless have a few points of connection with Yangzhou that we take up in the following pages.

Among the other literary works in China that focus on brothel life is the novel Fengyue meng 風月夢 [Illusion of Romance] (Preface 1848). ${ }^{1}$ It provides a detailed view of Yangzhou brothels in the mid-nineteenth century. The songbooks under investigation in this chapter are of roughly the same period and may thus serve as an additional 'insider's' source on the courtesan culture of the region.

\section{SONGBOOKS AND GREEN LOFTS}

This investigation is based on a corpus of IO3 songbooks collected in the area of Jiangnan, Jiangbei and Shanghai between the years 1898 and I90I by the young Finnish scholar Hugo Lund (hereafter HLC). ${ }^{2}$ These books include titles from storysinging, tanci 彈詞 [plucked tales] and other prosimetric genres, but most of their 
contents comprise short folk songs or erotic verses of the genres 'mountain songs', shan'ge 山歌, and 'current popular songs', shidiao xiaoqu 時調小曲. ${ }^{3}$ These two song genres both address matters of work and love, but show distinctly different metric features. While the shan'ge of the HLC have lines of seven syllables throughout, the shidiao songs show a varying line length of three to ten syllables. A typical example of the former is Siqing shan'ge 私情山歌 [Mountain Song of a Secret Affair] and of the latter Jinü tan wugeng 妓女嘆五更 [Lament of a Prostitute (in the style of) the Five Double-hours]. ${ }^{4}$ The collection also contains songbooks with themes from traditional legends, such as Baishe zhuan 白蛇傳 [The Tale of White Snake], Wu Song 武松, Meng Jiangnü 孟姜女, and several song variations of a story known as Wopao zhuan 倭袍傳) [The Japanese Robe]. ${ }^{5}$ The majority of the textbooks of the HLC, however, contain just one or a few short song texts.

This chapter deals predominantly with songbooks of the shidiao genre. One particular feature of these 'current popular songs' is their ability to adapt to local traditions and performance features, combining the popular folk melodies and topics of a certain district with the traditional repertoire of storytelling artists and folk singers. It is typical for the Yangzhou ditties, Yangzhou xiaoqu 揚州小曲, variant of this genre that several songs could be linked to one larger cycle. The six booklets of the HLC from 'The Japanese Robe' do form such a cycle. ${ }^{6}$ Shidiao uses predominantly the Wu dialect. Some texts are, however, not particularly marked with a view to dialect, and as a whole the collection of songs seems connected to the Jiangnan culture, Jiangnan wenhua 江南文化, of the Lower Yangzi region in a broad sense.

In the following pages nine HLC songbook texts will be discussed because of their special relevance for teahouse and 'green loft' entertainment. They all belong to the genre of shidiao xiaoqu or just shidiao, and the genre name is mostly part of the title. The song tradition shidiao by and large disappeared from the Chinese performance culture of the late Republic and the People's Republic. As the places where they were most frequently performed belonged to an 'underworld' that both the Guomindang and the Communists were eager to suppress, the songs also went out of use. While teahouses and storyteller houses could still exist and provide people with a certain range of entertainment, the establishments that were connected with prostitution and opium were effectively eradicated during the first half of the twentieth century, leaving only the flowery names of the brothels and streets of prostitutes, such as 'green lofts', qinglou 青樓, 'loquat lanes', pipa menxiang 枇杷門巷, 'flower streets', huajie 花街, and 'willow lanes', liuxiang 柳巷.

The term qinglou ['green lofts' or 'green mansions'], referring to brothels or houses where pleasure girls worked, has a long history ${ }^{7}$ and has been associated particularly with Yangzhou since at least the Tang period, when Du Mu 杜牧 (803-853) composed the famous lines: 


\section{十年一覺揚州夢,}

贏得青樓薄辛名

After ten years I awoke from my Yangzhou dream, with nothing to my name but bad luck in the green lofts. ${ }^{8}$

Yangzhou thereafter retained a reputation for its pleasure districts, as is evident from the lyrics of Yangzhou man 揚州慢 [Slow Tune of Yangzhou] by Jiang Kui 姜熟. (II55-I22I), which says:

\section{青樓好夢, 䧼賦深情}

The sweet dream of the green lofts

Will hardly yield deep love.

The expression 'loquat lanes' likewise can be traced to the Tang period and refers to the brothel or singsong house quarters of the city. It occurs in a shi-poem Ji Shu zhong Xue Tao jiaoshu 寄蜀中薛涛校书 [Conveyed to Xue Tao in Shu] by Wang Jian 王建 (766-830). ' Other terms also used in the HLC songbooks to mean pleasure quarters are 'flower streets' and 'willow lanes' (Appendix: 8):

\section{終日煙館走, \\ 花街柳巷眠 \\ Every day [they] visit the opium-dens, sleep in the flower streets and the willow lanes. ${ }^{10}$}

In Yangzhou, other current names for brothels included 'mansions of Qin and lodges of Chu', Qinlou Chuguan 秦樓楚館 (WEI Minghua 2004: 202). ${ }^{11}$

\section{THE HISTORY OF SHIDIAO}

Shidiao xiaoqu originated during the Ming period. They took inspiration from popular folk songs and were especially sung at times of leisure. Despite their popularity the oral tradition of these songs suffered in the chaos and warfare of the final period of the Ming (I368-I644) and the formative years of the Qing (I644-I9II). Only during the reign of Qing Qianlong (I735-I796) was the tradition revived. Several textbooks in block print method are preserved from that time (Ni Zhongzhi I99I: 362).

Later this song tradition developed into semi-professional and professional singing. In such contexts the songs were performed as simple entertainment for people of all classes, just like performances of prose storytelling, pinghua 評話, and chantefable, tanci 彈詞. Wherever the public met, celebrated or relaxed these songs could be heard. 
The main venues were market squares and itinerant stages, teahouses and pleasure boats, as well as the many middle- or high-class brothels. ${ }^{12}$

The most characteristic subjects of the shidiao xiaoqu genre were courting, love and romance. But despite what is implied by the term romance, the language and style of the songbooks are far from romantic. Matters of love and passion are expressed in rather straightforward, uncouth and slang-like language, reflecting the taboo-free and apparently unrestrained lifestyle of both performers and audience. Not a few of the songs give a voice to young girls who ended up suffering a drab fate in shady establishments. Other texts describe the harsh living conditions of the labouring people who worked for rich landlords, or in the factories or port of Shanghai.

\section{THE ORIGIN, TIME OF PRINTING, CONDITION AND TYPOGRAPHICAL FEATURES OF THE HLC SONGBOOKS}

It is difficult to establish the geographical origin of the songbooks contained in the HLC. Apart from the names of some print houses, which I have not been able to locate, they seldom contain explicit information about the place of printing. ${ }^{13}$ Only four songbooks in the collection of IO3 name the city of the printing shop, in those instances Suzhou and Dangkou. ${ }^{14}$ One songbook is designated as printed in Jiangbei 江北, the area between the Yangzi and the Huai River, with Yangzhou as its cultural and economical centre. ${ }^{15}$ Further evidence that the Lower Yangzi area (including Jiangnan and Jiangbei) is the place of origin can be found by looking at tune titles, the use of certain melodies and tune titles being regionally determined. As described below the songbooks contain dialect expressions, which also hint in this direction. Future comparison of dialect differences between the I03 individual songbooks might determine the geographical origin of each text more precisely. Several of the tune titles of the HLC suggest that the tunes originate from the area around Suzhou or Yangzhou. ${ }^{16}$

The earliest of the songbooks is dated I866, the fifth year of the Qing Tongzhi reign (I86I-I875), while the last one is from I894, the ninth year of the Guang$\mathrm{xu}$ reign (1875-1908). The condition of the textbooks, including the front covers, fengmian 封面, is very good, giving the impression that they have not been opened during the more than one hundred years that they have been in the Finnish archives. The booklets actually show no visible trace of being used, let alone over-used. They might well have been purchased shortly after being produced. The reference to the year I866 does therefore not necessarily relate to the actual printing date, but to the year the wood blocks were carved. The songbooks could have been produced later, although some may be reprints of earlier editions. Hugo Lund left Jiangsu in I9OI, so that is the latest possible date of publication. ${ }^{17}$ 
The booklets are IO $\times 15 / 16 \mathrm{~cm}$ in size, and contain from 6 to $\mathrm{I} 4$ pages recto/ verso. They are printed on fragile paper of low quality, with glue binding. All of the IO3 songbooks are printed without punctuation, and line breaks are absent from all booklets apart from those of the genre 'Mountain Song of the I2 Months', shier yue shan'ge 十二月山歌, which are clearly structured in verses.

The majority of the books contain no stage directions such as chang 唱 [sing] or bai 白 [tell], as would be given in Ming period texts of the chantefable genre shuochang cihua, 說唱詞話. The sole exception is a booklet of drama, xiwen 戲文, with the title Wang daniang bugang 王大娘补缸 [Lady Wang Gets Her Jar Mended], which does use stage directions. This text also contains directions for two role types of traditional Chinese opera: the female role dan 且 and the clown chou \#. $^{18}$

The texts are full of 'incorrect' (phonetic loan) characters, such as bang 邦 for 幫, or lailin 來林 for 來臨, and dialect characters, such as nai 奈 frequently used for $n i$ 你,

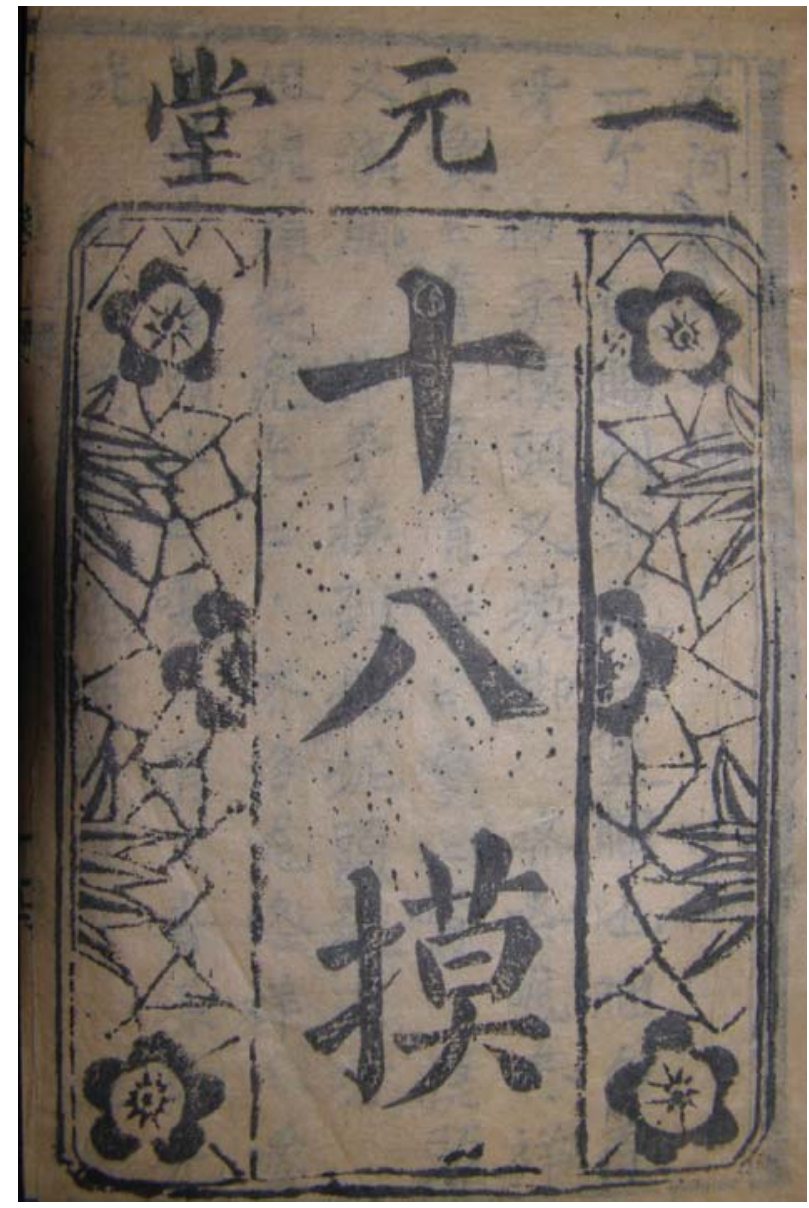

Figure 14.1 Front page of Shiba mo 十八摸 [The Eighteen Ways of Massage]. ${ }^{19}$ 
or qime 其麼 for sheme 什麼. None of the songbooks contains illustrations, but seven booklets feature a stylized border with bamboo, flowers or book scrolls on the front page (Fig. I4.I).

\section{LIFE AND ENTERTAINMENT IN THE TEAHOUSES AND GREEN LOFTS}

The population of China had risen from less than 200 million at the beginning of the Qing period to over 400 million at the turn of the twentieth century. Towards the last quarter of the nineteenth century many landless peasants migrated to the prosperous cities in search of work. Many educated members of the gentry also moved to the cities, as administrative bodies and offices, their usual sources of employment, had not expanded as fast as the population. This migration created a vast pool of cheap labour, and also a demand for entertainment. Young women with a talent, however modest, for singing or playing a musical instrument looked for employment in the pleasure districts. Young girls of poor families were sold to contractors. Already in I8Io the local Gazetteer of Yangzhou Prefecture had the following entry:

In this locality there are rascals who seek to make a profit from buying up young girls from poor families with few moral principles. Their aim is to dress them up, train them in the various arts of singing, dancing, writing, painting, and sell them at a profit to matchmakers [. . .] Poor families, observing the profits, do not hesitate to thrust their own daughters into the business. [. . . ] Of all degraded customs, none is as bad as this. ${ }^{20}$

A tradition of employing and educating courtesans in the various performance arts such as singing, dancing, acting, storytelling, pinghua, and playing musical instruments, is evident from various entries in the Yangzhou huafang lu 揚州畫舫錄 [Pleasure Boats of Yangzhou], published in 1795. The chronicle reports the names of women that have been bought in Yangzhou and Suzhou, to be brought up and educated either as prostitutes, courtesans, concubines or actresses (Li Dou 李斗 200I: 20I.45-46 and 48). ${ }^{21}$

In cities like Shanghai, Suzhou, Nanjing and Yangzhou the districts that were assigned for teahouses, music halls and storyhouses, shuchang 書場, were also the districts for brothels. Often they were even located in the very same house, as will become evident when we look at the songbook texts. Performances of storytelling, pinghua, and prosimetric storysinging, tanci, in teahouses and storytellers' houses have a particular lengthy and strong tradition in Yangzhou and Suzhou. The history of courtesans and prostitutes in nineteenth- and twentieth-century China has, however, mostly been 
studied from sources pertaining to the Shanghai area, and one can only with some reserve apply the findings of these studies to the wider area of the Lower Yangzi. In the absence of local Yangzhou evidence I have, however, chosen to rely to some extent on these Shanghai studies (cf. Dougherty 2006, Henriot 1996, Hershatter 1999, McMahon 2002, Scherer 1983, Vance Yeh 1998, Xue Yongli 1996).

Prior to the Guangxu reign (1875-1908) of the late Qing, women performing pinghua and tanci enjoyed a position superior to those women employed by teahouses merely as singsong girls to entertain the guests. Though of low social status in comparison to married women, the pinghua and tanci performers still had a reputation as artists. To distinguish them from the average prostitute or high-class courtesan they were given the title 'storytelling residence', shuyu 書寓, directly referring to their performance talents and indicating that they were women who made their living by narrating and singing stories. ${ }^{22}$ Initially therefore the profession of shuyu meant only the duty to sing and tell stories An old saying defines a shuyu as 'only selling [their] art, not [their] bodies', zhi mai yi, bu mai shen 只賣藝不買身. ${ }^{23}$

There was, however, one way a committed admirer could get better acquainted with a shuyu-performer. If he declared a serious and respectable interest in a performer, and presumably with the stipulation that he had sufficient income, the two could formally marry for a period (Hershatter 1999: 42). During that time the client would be the performer's patron and she would, at least publicly, entertain him exclusively (but would still be allowed to perform at banquets and at other official or private occasions). Shuyu were thus first class entertainers, professionally educated women, but with a possible commitment to one individual customer (DOUGHERTY 2006: 9-II).

The decline of the Qing Empire and the socio-economic development of the foreign concessions in the large cities were accompanied by an influx of impoverished women and men from the countryside to the cities. During the Taiping uprising of the I850s and I860s refugees poured into the cities, in particular into the larger commercial centres or to port cities like Shanghai and its foreign settlements. Many of them came from neighbouring Suzhou, which the Taiping had made one of their strongholds in the region. Suzhou's strong tradition in storytelling and singing meant that many of the Suzhou residents that fled belonged to artist families and were now in search of stages or teahouses in which to perform.

Consistent with these social developments, from the I870s onwards more and more storytelling houses opened up in Shanghai and the other major cities of the Lower Yangzi region (VANCE YeH 1998: II, I4). They very often had female storytellers and singers and subsequently the status of male storytellers declined. But the influx of female performers produced fierce competition amongst them for the male clients. In increasing numbers female storytellers and singers found themselves pressed into prostitution. ${ }^{24}$ In novels like Haishang hua liezhuan [Flowers of Shanghai] (I892) ${ }^{25}$ brothel customers complain about the low level of education and refinement of the 
women. Accordingly shuyu female artists turned into high-class courtesans, although still not to be confused with common prostitutes: ${ }^{26}$ the mansions they lived in were called shuyu too, while the houses of lower courtesans were labelled 'hall', tang 堂, or 'court', yuan 院. But however described, by the fin de siècle years the talented and literary courtesan of old was but a pale memory. ${ }^{27}$

The songs in the repertoire, as reflected in the HCL collection, contain two kinds of content: on the one hand, traditional themes and legends, such as Meng Jiangnü or Wu Song, and on the other hand, descriptions of the life in the green lofts as experienced during the last years of the nineteenth century. The latter type allowed the artist to depict and criticize the reality of the day without having to refer to stories from the past, as was traditional: they used a language of direct realistic expression. The majority of the HLC song texts belong to this group, and only songs of this type are treated here, since they are most relevant for this chapter. Nine of the songbooks are selected for specific analysis in the following discussion. Their subject matter deals with the daily or nightly life in the community of those people that frequented the pleasure districts: clients, idlers and opium addicts; employees, courtesans and singsong girls.

\section{THE PERFORMERS OF SHIDIAO}

Any interested person could have bought songbooks at a bookstall in the road or in teahouses and started singing. But a public performance of short and unsophisticated items would not have qualified an individual for the large stages of regular storytelling houses nor for him or her to be regarded as one of the professionals who excelled in performing countless verses of ballads and song cycles. But such a performance would certainly have fitted into the repertoire of small-scale entertainment in teahouses and in particular in the green lofts. The term 'singsong girl' was coined by the foreigners of the legation quarter of Shanghai in the nineteenth century and derived from a sound translation of the honorific term for 'storyteller master', xiansheng 先 生, (used for both male and female storytellers) of the Suzhou and Yangzhou area: heard by foreigners and 'misunderstood' as 'singsong'. In Yangzhou another term for a courtesan, whether culturally trained or not, was current, 'thin horse', shouma 瘦 馬, a name with quite different associations, as we shall see. ${ }^{28}$

Singers, actors, performers and prostitutes all ranked at the bottom of the social ladder, with that of prostitutes perhaps at times occupying a slightly higher social position than the other groups. A traditional saying, still current (ironically) in drama circles, is:

\section{一妓二乞三戲子}

First the prostitutes, then the beggars, last the opera singers 
These lowest ranks of society were, as mentioned, the subject of several novels that appeared in the later half of the Qing Guangxu era, just as did the songbooks of the HLC. However, being works of the literati the novels tended to look at the pleasure districts from an idealized outsider perspective. Moreover they claimed literary qualities and were printed in great quantities throughout China. In contrast, the humble songs of the HLC contain countless spelling mistakes, topolectic expressions and character variations, which show beyond doubt that they have not been created by highly educated authors or aimed at such a readership. The nine texts chosen for this investigation were mainly written in the first person singular, implying thereby that the songs represented the voice of the performers themselves. Whether this feature was a sign of authentic autobiographical expression, or a genre-immanent characteristic or perhaps a combination of the two, is open to speculation.

From the late Ming period a number of generic conventions for the form and contents of this type of song existed. These included the transmission of longestablished expressions and tunes. Because of that, any part of a song text or any expression of a protagonist in a song could be either an authentic statement of a late nineteenth-century author or a convention repeated from earlier periods.

In the case of the texts of the HLC, standardized elements can be detected in particular in the first lines of each verse. Songs in the structure of the 'five night watches' or the 'twelve months' use conventional lines as a start-up. However these repetitive elements serve mainly as a framework and do not convey the actual contents of the texts, which follow in each verse from line two to line four. These latter parts of the songs appear to carry individual authentic statements, of a kind that I have not found in other collections. ${ }^{29}$ As such they provide rare evidence about socially taboo areas, revealing intimate information on a range of topics, for example:

1. Who were the people who visited and worked in the teahouses?

2. What was the social standing of the male visitors and in which way did their attachment to the pleasure districts influence their private life and their families?

3. What expectations or hopes did the girls/women have in regard to the customers?

4. What did a typical evening entertainment look like?

5. What kinds of refreshments were served? On which occasions?

6. What role did opium, alcohol and gambling play during the entertainment?

7. How far was opium addiction a subject in the songs?

A closer look into the content of the HLC songbooks will reveal some answers to these questions. 


\section{A NIGHT IN A TEAHOUSE}

Most probably the shidiao that were written in erotic or slightly lewd style were performed for small groups of customers who had booked the company of just one or two singsong girls. Many of the texts deal with dining and gambling, flirting and seduction, describing all aspects of the nightly proceedings in teahouses and brothels. The working environment of the girls is fully described. We see them performing as singers, as escorts during drinking and dining parties, and as bedfellows for small groups of customers in the upstairs private rooms. The protagonists in these texts are clients, prostitutes, high-status courtesans, and the madams of brothels.

Among the most revealing of the song-texts is Da chahui 打茶會 [A Visit to the Teahouse] (Appendix I). ${ }^{30}$ It tells with amazing detail and frankness what happens when guests arrive in the upper storeys of a teahouse (Fig. I4.2).

This shidiao text is structured as a dialogue between the guests and a hostess, intersected and followed by her private thoughts, kept in the first person singular. The main protagonists are two young men and two young women - the hostesses. The madam of the house, an elderly lady, also features.

Two young men are on a night out. They start rather late; when they arrive at the teahouse it is already the time of the first night watch. They appear at the steps of the establishment and instantly start shouting for the girls:

\section{打茶會, \\ 走上扶梯, 客人來}

Let's pay a visit to the teahouse.

Let's get upstairs, guests have arrived!

Obviously the visit is meant to be to a private room, as the customers are rushing upstairs. From there they call for a 'service-girl', xiangbang 相邦, to bring hot towels. Here, in the upper rooms, the young women greet the guests courteously, offer them tea and inquire about their 'honourable names and addresses', zunxing guifu 尊姓 貴府, presumably in order to estimate how much they can pay. We learn that the gentlemen's names are Yang 楊 and Qian 錢, two shopkeepers from the area near the East Gate.

Similar parties of well-to-do young men and prostitutes, with the customers staying overnight in the brothels, are described in detail in the Yangzhou courtesan novel Fengyue meng (HanAN I998: 350). The same novel tells in chapter eight about a different and much dreaded sort of 'tea party guest', chahui ke 茶會客. Apart from its innocent literary meaning this term could in late Qing times denote local hooligans who appeared uninvited at the gate and forced their way into a brothel during evening entertainments. They constituted a constant threat to the courtesan houses, 
kidnapping courtesans and extorting money from both them and the madam (VANCE Yeh 1998: 8).

The song is structured along the double-hours of the 'five night watches'. Each verse first announces in standardized phrases the actual double-hour and then tells of a new stage of delight the customer and (at least as far as the text suggests) the young women have reached. In the first double hour the tea party begins with the starters, which are, as the waitress explains in detail, 'oilyautumn-plums, large silk-oranges, sunflower seeds and peanuts'. The second night watch introduces the range of games and entertainments available. The song proceeds:

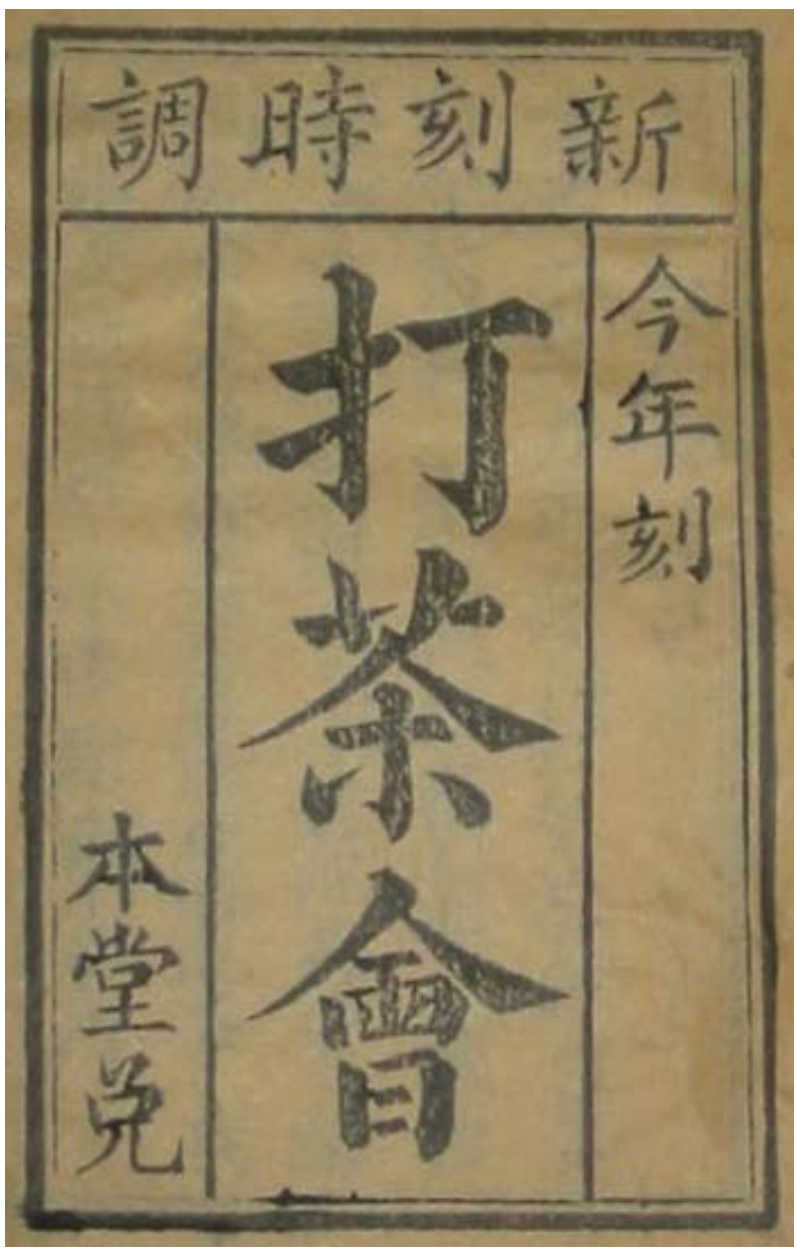

Figure 14.2 Front page of Da chahui 打茶會 [A visit to the teahouse]. 


\section{二更二點月正明}

點只煙燈 (阿得會)

點只煙燈

要想碰和三三心

骨牌精（阿）

In the second night watch, the second double-hour, the moon is bright,

Let's light some opium! (Hey, hey)

Let's light some opium!

Would you like to gamble and relax?

Hey, domino wizard!

This is consistent with Fengyue meng. Chapter one of that book devotes considerable space to opium consumption in brothels. It describes opium as 'a staple brothel item' and warns of the dangers of addiction not only to the clients but also to young prostitutes. As it was their daily and nightly task to offer opium to the customers they ran a high risk of being urged to join in smoking and of becoming addicted while acting as solicitors of the drug.

In the song Da chahui it is interesting to note that it is not the girls who accompany the guests at the gambling table. For this purpose a 'domino wizard' or 'spirit', gupaijing 骨牌精, is called up to the private room. The gupaijing is the professional gambler of the house. It was his task to cheat the customer and accumulate some additional revenue for the house. As with every other new stage of the evening's proceedings, the domino game is followed by a snack. This time it consists of a 'soup of lotus seeds', 'bright almonds' and a 'white flour paste of lotus roots'. ${ }^{31}$

\section{三更三點白白洋 \\ 天氣清涼 (阿得會) 天氣清涼}

In the third night watch, the third double-hour, the moon is bright white,

The morning air is fresh and cool. (Hey, hey)

The morning air is fresh and cool.

By now the young female entertainers are afraid the customers might get bored, so they lure the guests to a different sort of gambling:

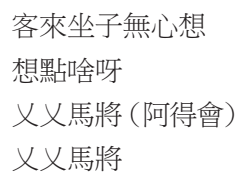


When you come here to sit, you needn't have any worries on your mind!

What are you thinking about?

Let's play Mahjong (Hey, hey)!

Let's play Mahjong!

On this occasion too, pleasant words conceal a special secret of the house. In the next line the girl 'confides' to the audience how Mahjong is played there: she arranges the seats in artful ways and generally seeks to cheat the customers.
巧手段,
奈輸我贏
費精神,
贏者開心
One clever move [of me]
And you lose - I win.
[You might] rack your brains,
But the winner will rejoice!

In the fourth night watch one of the young men finally takes the initiative, saying:

\section{床上去, 做戲}

Let's go to bed and make love!

Now the names of the two young women are revealed: Wang Guilin 王桂林 and Zhu Aiqing 朱愛卿. While 'flying [rolling] all over the bed', manchuang fei 滿床飛, one of them has a confession to make: she whispers to Yang that she would like to marry him, only the madam of the house will not allow it. She does not want to lose her investment and urges the young woman rather to 'enjoy' her best years with the customers:
輕年紀,
浮骨體,
做好戲
While you are young, with such frivolous bones as yours, You had better enjoy it and make love.

In the fifth night watch, as the moon is about to wane, the two parties are entangled in each other's arms. The language passionately and graphically depicts the 'battlefield' of the sexes: 


\section{大家要好 \\ 倷用鎗来我双刀 \\ 大戰一場真討好 \\ 实在討好}

Everybody is perfectly happy,

You move in your spear, I'll [match you with my] double blades,

Fighting in this battleground - it's really so very pleasing,

Just so satisfying.

The end of the fifth night watch sees all 'combatants' exhausted. Wang Guilin says:

$$
\begin{aligned}
& \text { 做完戲, } \\
& \text { 來下床了 } \\
& \text { After making love, } \\
& \text { let's get off the bed. }
\end{aligned}
$$

Yang tries to keep her there for just a bit longer, using all the charm at his disposal: he praises the delightful beauty of women when they are at their most exhausted and sleepy. But Wang Guilin, far from being impressed, hands him a towel to wash his face, serves some tea and a final dessert; an early morning treat of fruits, nuts, dates and sugar-coated chestnuts, and politely shows him to the door, although not without inviting him back for the very same evening:

\section{楊大少, 夜裡請早}

Honourable Yang, please, come early tonight!

In this song one finds a rather positive and even cheerful outlook on the profession and duties of young women working in a teahouse-type of brothel. They are described as charming, witty and seductive, while also slightly exploitative. All in all it is the picture of carefree young girls, not worrying too much about the future. Only towards the end of the song, in the fifth hour, does one of the girls speak more openly. Up to that point she seems ready enough to accept the rather intimate propositions of the client, but she then remarks in a melancholic and bitter voice that she secretly hopes that he will marry her. Maybe she is so desperate that she proposes this to every client.

The two customers are depicted as good-natured, though simple-minded, easy to cheat and not really concerned with the fate of the girls. Yang shows no commitment whatsoever. He does not deign to answer her proposal. But irrespective of his outlook, the madam would not let the girl leave anyway, which she rationalizes by arguing that the job is more pleasure than anything else and that she wants her employees to 'enjoy their youth'. 
This song, in particular its optimistic outlook in the last verse, was obviously written to depict pleasurable working conditions for young courtesans such as Wang Guilin and Zhu Aiqing. Performed probably for customers like Mr. Yang and Mr. Qian it would have created a cheerful atmosphere and a sense of anticipation of pleasures in store. When it comes to the girls' sorrows the author takes great care to allay any concerns male listeners might have: the dominant message is that these courtesans surely earn their money in a playful manner and enjoy what they are doing.

\section{SONGS OF PLEASURE AND DANGER, ROMANCE AND HARDSHIP}

A slightly different perspective on the pleasure districts is shown in the song Nanfenghua quan 男風花勸 [Advice on Men's Love Affairs] (Appendix 4). ${ }^{32}$ This text consists of a dialogue between two friends, who call each other 'younger brother' and 'elder brother'. The senior of the two urges the younger to curtail his carefree and lighthearted behaviour, to stop visiting 'houses of the prostitutes', jinü renjia menhu 妓 女人家門戶, and those 'women of the willows and flowers, with a character as fickle and unruly as water' shuixing yang hua nü 水性楊花女. He quotes a long list of literary works in which characters like him have lost property or health, or suffered divine punishment and destruction. He cites many examples of famous figures from the field of Chinese history who have suffered a disastrous fate on account of immoral behaviour in their youth. But his preaching is unsuccessful: obviously the younger of the two friends is equally versed in history and literature. Far from giving in, he has no shortage of examples that would, at least to his understanding, prove just the opposite. Therefore he not only easily refutes all reprimands and good intentions, but now it is he who urges his elder brother to come along to the pleasure districts, asking:

\section{家花那比野花鮮}

How could the flower in your home be as fresh as that in the wild?

In the end neither of the two is able to convince the other and they go in opposite directions.

The text Yuanmiao guan jingchu 元妙觀景處 [The Sights of the Yuanmiao Temple] describes yet another area of pleasure and diversion (Appendix 9). It depicts the neighbourhood of a Suzhou temple, including a fair, food stalls and teahouses, and all kinds of entertainments, including opera performances of Southern plays, nanxi 南戲. But though the long list of locales and distractions dazzles the mind, the author/singer distinguishes them strictly from places such as brothels or gambling 
and opium dens. She shows herself, at least in the first verse, as a pious believer and claims that for those who only come to enjoy cheap pleasures:

\section{空來白相圓廟觀}

It is no use at all to come looking at the Yuanmiao-temple.

It seems, however, as if the sole purpose of this remark is to reassure those who secretly long to give in to temptation. Having made her point she vigorously starts relating in detail all the things a visitor might see around the temple and claims:

\section{觀里事務說弗完}

The daily events of this temple are so many; one couldn't list them all.

She then proceeds to talk about the teahouses around the temple grounds:

兩邊棚子紅欄杆,

來個茶客才坐滿

The awnings on both sides have red railings.

Guests are coming, lay out the table!

The entertainments in these surroundings are many:

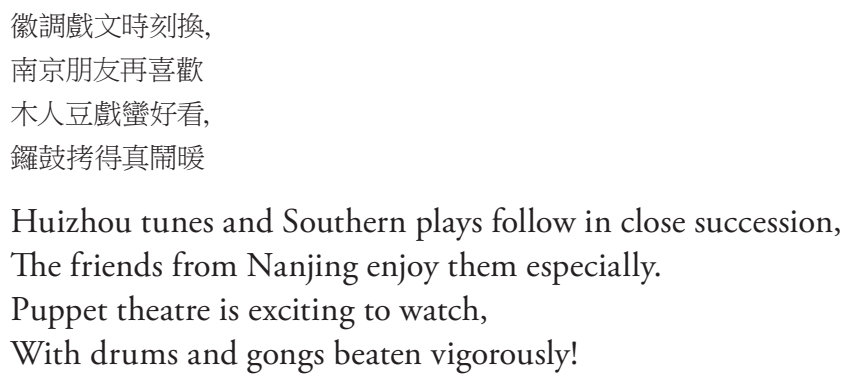

While watching the performance the audience has a choice of various small tasty dishes, like dried bean curd, rice cakes, dimsum and sweet broth with large dumplings.

Apart from performances and food specialities the text also reports on the clientele frequenting the teahouses. There are actors and singers, and customers of all ages and walks of life. Firstly elderly men are introduced, who spend a lot of money at the teahouse. They come to enjoy the music and to relax. Among them are also rich but foolish men, easy to cheat. When playing dominoes their partners know cunning tricks, like the 'move of the immortals', Xianren yaosuan hao shouduan 仙人要算好 手断, and fool them as best they can. Apart from rich and elderly gentlemen, other characters frequent the teahouse, as the song goes on: 


\section{娘姨大姐坐茶館}

Sister niangyi pays a visit to the teahouse.

Originally the term niangyi stood simply for maidservant. Phrases from this and the following songbook make clear that the connotations of niangyi by the late Qing period had changed considerably in Jiangnan and Jiangbei. By then the term denoted a locally famous beauty, often an entertainer or higher-class prostitute, slightly older than her colleagues. She enjoys the full attention of all young male customers, as

\section{年輕後生去去轉}

All the young men follow her everywhere.

\section{鄉下伯伯才來看, \\ 野貓想喫咸魚干}

Even the old 'uncle' from the countryside comes to look [at her, like] the wild cat that once also longs to taste a salty dried fish.

The country bumpkin ventures a trip to the city, to behold for once such an urban beauty, at least from a distance. Amusingly rustic and naive characters are a stereotype of Chinese operas and novels. Fengyue meng for instance gives a vivid portrait of $\mathrm{Mu}$ Zhu, a cousin of an elegant Yangzhou rake, who has arrived from his village and marvels at the beauties of the city (HANshang Mengren 邗上夢人 I988: 32.227).

The wealthy elderly men and idle young men who can afford to hang around the leisure quarters are amply described, in all their weaknesses, in those songs, to be discussed next, which lament the abuse of opium. We also see in these songs the women of the flower streets and willow lanes. The elegant and slightly more adult beauties, like 'sister niangyi', are too famous and popular to need to prostitute themselves, unlike the girls in songs like $D a$ chahui who, despite their musical abilities, are confined to their rooms and are allowed to come forward only when the madam calls them out to let a male customer choose amongst them. Much less are they forced to linger in the streets to attract customers, as do the lowest and unregistered prostitutes, the 'chicken of the wild [suburbs]', yeji 野雞.

The setting depicted for these characters is grand and stately. The teahouse stage is situated on the ground floor, where also the rich elderly men sit and enjoy music (Appendix 9):

\section{羅臺丁丁石闌杆 [ . . . ]}

The silken terrace [of the stage] is most beautiful, with railings of stone, [...]. 
The song Da chahui speaks of the two customers climbing to the upper floors, where the private rooms for smaller groups are found, but also the apartments of those courtesans who enjoyed a higher reputation and status than those residing on the noisy ground floor. The song Yuanmiao guan jingchu mentions a tower with several storeys and beautiful balconies:

\section{三層樓上頂好看 \\ 堅到大湖也不遠}

On the third floor of the mansion the roof ridges look grand, With a view over the entire lake, not far in the distance.

The main role in the text that follows is played by a niangyi. The song Dajiao niangyi tantou 搭腳娘姨灘頭 [Liaisons of a Niangyi (in the tune of) Tantou] describes her duties in her profession (Appendix 2). She is the right hand of the madam and it is her task to accompany the younger singsong girls and courtesans to banquets and feasts. It turns out that she works in this trade to support her husband. She lives in the brothel but the madam, nainai 奶奶, does not allow him to enter the house and spend the night with her. Romantic attachment by a courtesan to a husband or a client was always the cause of a conflict with the nainai. Yet liaisons between actors and courtesans were very common. Almost inevitably such romantic affairs lost the brothel money, especially if the lover was treated for free by the courtesan and took the status of a 'graciously subsidized guest', enke 恩客. Such cases would usually end either in the dismissal of the young courtesan or in the ending of the affair. This particular niangyi much prefers living in the brothel, however sordid such an existence must have been, to doing fieldwork in the countryside. When her husband urges her to return home with him to the village and start a new life there, she bluntly replies:

\section{挑盤扛橋無吾分}

Carrying the pole and doing hard labour is not for me.

She has tasted urban life, and what she desires is a proper house and good food.

\section{主末主子好常化,}

喫末喫子時鮮貨

[You've got] no place to live, [but I want] to live in a nice place,

[You've got] nothing to eat, [but my] food should always be seasonal and fresh.

She also confides to the audience that once a customer had even offered to marry her: 
許我一位二夫人,

如吾肚氣養子

He would take me as his concubine, if I could bear him a son.

This evidently was the highest, if the most unlikely of hopes for any singsong girl and prostitute, whether young or beyond her youthful days like sister niangyi.

\section{OPIUM ADDICTION, INFIDELITY, POVERTY AND BROKEN HEARTS}

A number of shidiao-songs report on the darker side of life in the entertainment quarters. They tell about the wrecked lives of opium addicts, and of the sorrows of those young girls who came to the city with high hopes only to end up in shady establishments and opium dens. Among the protagonists of these songs are the young lovers and wives of those men who spend their nights in the pleasure districts. While the husbands waste the family fortune on gambling and opium, their spouses wait for them at home. While all the songs up to now have focused exclusively on the lives of the singsong girls and their customers, the following texts throw light on the home background of the clients.

In the song Jie yangyan 戒洋煙 [Giving Up Opium] (Appendix 3) a young woman urges her lover to stop using opium and scolds him for wasting his money on drugs or in brothels and opium dens. As he also seems less affectionate than before she is suspicious that he might be distracted by other women. But it is not so much jealousy that makes her anxious, as seeing him getting sicker and thinner day by day, exhausted as he is from his nightlife. In fact she compares his wrecked body to that of a poor emaciated scholar.

Reading this text one cannot help but think of Mr. Yang from the song 'A Visit to the Teahouse' and the way he was invited by Wang Guilin to smoke opium and play Mahjong. He might well have been the object of affection of this concerned young lady in 'Giving Up Opium'. It is easy to imagine that he, his friend Qian or for instance the young light-hearted man of the song 'Advice on Men's Love Affairs' could one day end up as impoverished drug addicts.

Jie Yangyan describes the effect of opium addiction on a formerly healthy person. But the compassionate attitude of the addict's fiancée and her urging him to see a doctor who would help him to give up the drug provides the text with a modestly optimistic outlook. In the course of the late Qing enlightenment movement, qimeng yundong 啟蒙運動, colloquial songs such as this one were used to urge the uneducated urban public to give up consuming opium. (Li Xiaoti 
200I: 207-208). But in fact all other songs with similar content lack even this small element of domestic comfort.

The song Shibei jiu 十杯酒 [Ten Cups of Wine] tells starkly of real misery (Appendix 5). All the protagonists in this text are brutal alcoholics, drug addicts in the last stage of decay, or prostitutes. In the first verse a young man goes out to organize some opium. On his way he calls on a prostitute, who serves him as long as his money lasts. When his last piece of copper is spent she tries to kick him out, whereupon he abuses and attacks her. As she is a 'yellow fish', huangyu 黄魚, an illegal prostitute who has no one to turn to, she is an easy victim for both the manager and brutal customers. To add to her miseries in the last verse it is revealed that her husband is probably an opium addict and a pimp. With not only her relatives in the countryside but also her parents-in-law and her husband relying on her income she has finally ended up in this brothel.

The Yangzhou courtesan Fenglin of the novel Fengyue meng suffered a similar fate. There is a vivid account on how she has been trained in the trade of the courtesans and, when she came of age, was forced by her mother-in-law and her husband to work in an ordinary brothel to support them. In the course of the novel she turns into an opium addict herself (Hanshang Mengren 1988: 7: 50).

According to Honig a division between women from Jiangnan and Jiangbei could be observed in Shanghai. The second-class prostitutes, yao'er 幺二, were primarily from Yangzhou and areas further north, while the first-class prostitutes, changsan 長三, who lived in lavishly furnished brothels, came from Jiangnan (HoNig I992: 28I).

While the last song described the pitiful existence of an illegal prostitute, the next song, Wugeng xiangsi 五更相思 [Longing All Through the Night], tells of the lot of an elderly prostitute who has herself become an opium addict (Appendix 6). She has already pawned all her summer and winter clothes and the little money she got for them is long gone. Once she was an artist of some ability:

\section{人人吓, 說我本事高, 彈唱有我分 \\ Oh, everybody [once] said my talents were great. \\ In singing and playing the lute I can do my share.}

But though the customers enjoy her tunes, she cannot live off music and songs alone; she has had to sell her body:

客人吓, 進門叫我唱一套,

口里說我心里想着少

最可恨, 出局還把別人來叫 
$\mathrm{Oh}$, and the customers, they come in and ask me to sing a tune, [But] what my mouth says is hardly what I feel inside.

What I resent most of all: When [one] leaves the room, I still have to ask another to come in.

The woman of the song, like many of the poor girls who came to the city, had probably received some sort of education to become a singer and entertainer, but had ended up in one of the flower houses. That this was the fate of large numbers of girls and young women from poor conditions in the Lower Yangzi area is well documented. As for the Yangzhou area in particular, the sources for this go back to the early Qing period. ${ }^{33}$ From the late Qing the custom is also reported:

\section{揚州人多買貧家小女子, 教以筆札歌舞, 長即賣為人婢妾, 多至千金, 名曰瘦馬}

People in Yangzhou often buy young girls from poor families, teach them to read and write, sing and dance, and when they are older they are sold off as slave girls for prices of up to a thousand taels. They are called 'thin horses. ${ }^{34}$

The woman of the shidiao calls herself a guanren, 官人, a prostitute or courtesan. ${ }^{35}$ She deplores the fact that she has fallen so low and reminisces about the good times she has seen, how many clients she had when she was young and how easy life had been. She must have been well off at one point of her career, as she goes on to say 'The clothes that [I] wore even had buttons from foreign countries. ${ }^{36}$ It was not unusual for well-to-do young ladies to add fashionable Western-style elements to their garments. The use of outlandish dress, textiles and other trendy accessories was also a fashion among the dandies and ladies of the pleasure quarters of early nineteenth century Yangzhou, as is described in some detail in Fengyue meng (Finnane 2003: 4II). The pitiful woman of this song is just one example of a once smart and successful woman of the pleasure districts. At night she rests, lonely, on her pillow. She longs to go back home, but is afraid to see her family and to look into the eyes of her father and her brothers. The song then finishes rather abruptly with the exclamation:

悔當初,
不該應把喫鴉片煙
Oh I regret how it all began:
I should never have started to smoke opium! ${ }^{137}$

The six pages of detailed descriptions on how she grew older, how younger women are more attractive, how customers stay away or bully her and how she is now so destitute that she hardly has even a dress fit to leave the house in, come down to this last line: 'I should never have started to smoke opium!' 
Opium was without doubt among the greatest threats to both well-being and livelihood for young men and women of the late Qing. This is forcefully expressed in the shidiao of Yangyan zitan 洋煙自嘆 [Lament of the Opium Smoker], which is also structured in the pattern of the five night watches (Appendix 7). In this song the voice of a young man carries the message. Full of self-pity, he admits to having taken up the habit of smoking opium. What follows this initial confession is a whole litany of miseries:

\section{有豪杰因, 煙床思前想後,}

皆因是承祖業無福消受

Originally I was quite a brave man! Lying on the opium couch I think of the past and imagine the future,

It is all just because though I inherited my forefathers' business I did not enjoy any good luck.

Others will have to take the blame for his addiction. Bad company has driven him into the arms of the drug:

\section{成人安鴉片煙把我來勾, \\ 誰知道上了㒣時刻難丟}

When I grew up [some people] secretly gave opium to me and got me hooked.

Who would have thought I would become addicted and could not stop it any more?

From then on his life is under a bad star:

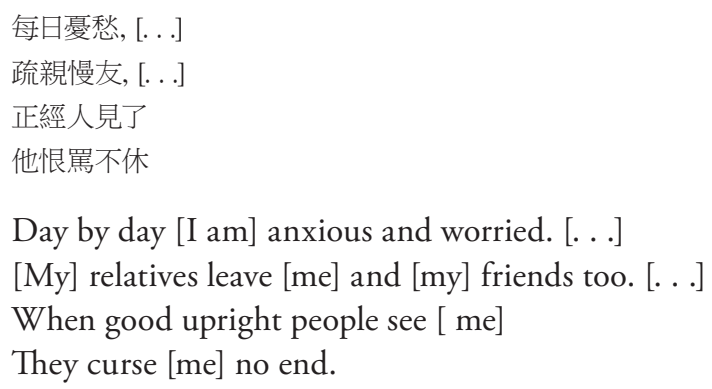

At the end he is left destitute and hungry, his wife and his son have long left him, his mind is numb, his brain confused, he does not even have any shoe laces. But at this point the text takes a sudden turn. As if finally the moment has come to start a new life, he sings out in particular to warn other young men and to urge them to learn from his example. The 
rich ones should not think that 'smoking opium would not harm their good name', while the lower addicts should not 'do anything to get a smoke'. He confesses that he himself has committed 'crimes' against many good friends and even sold all his parents' property. He has sunk so low that he cannot even visit any public places or walk in broader lanes, for fear of meeting some of the many people who had once lent money to him. But:

\section{從今後積金銀結交朋友, \\ 到茶坊談一談又添茶酒, \\ 發幾拳行機令歡容笑 $\square$, 要將我從前事一筆消勾}

From now on I will save money and look for better friends, I will go to the teahouse, chat and have a cup of tea or wine,

Do some finger guessing and drinking games, with a friendly face and a smile.

It will be as if I had severed myself from the past, as with a stroke of the brush.

His mind rambles on and he imagines how things will look up once has destroyed his opium utensils. He will get rich and people will soon start liking him again. But if he goes on as before he might turn into a thief or even become like those who have made themselves laughing stocks:

\section{也有的將妻子包干朋友, \\ 做鳥龜只洛個大煙長久, 忍作氣吞作聲提壷打酒}

Selling their wives to their friends,

They do the cuckold just to get a pipe full of opium and to go on [smoking] every day.

[They] even endure quietly the shame of bringing the jug and serving wine [to them].

The second text of the same songbook, called Yapian wugeng 鴉片五更 [The Opium (smoker), (in the style of) the Five Double-hours] follows the same pattern (Appendix 8). It presents more detailed information on how customers of teahouses become addicted to opium:

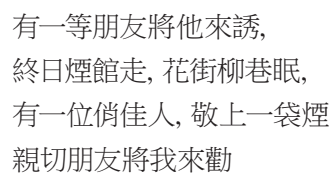


There is one kind of person who tries to lure others to come along with him,

Every day he visits the opium-dens, sleeps in the flower streets and the willow lanes.

There is this charming beauty who offers [you] a dose of opium, [or] close friends urge [you] to join them.

This song is the only one to describe the pleasure and hallucinations that the opium smokers experience at the initial stage of addiction, i.e.:

\section{煙槍拿在手, 將煙火上烘, \\ 一口口往下送, \\ 昏昏沉沉好比雲端中, \\ 八洞神仙難比我受用}

The opium pipe in hand, about to light it with the opium lamp,

One mouthful after the other is sent down,

Dizzily submerging [into the fumes], like drifting on a cloud.

The eight grottoes of the immortals would not be as enjoyable to me!

But now the morning comes, the moon settles in the west, the effect of the smoke vanishes and the addict sobers up. The turning point is reached, when euphoria switches to despair:

\section{眼淚不住往下滴, \\ 這位尊容畫匠難下筆}

Tears stream from my watery eyes;

With such an [ugly] face, even a painter could not draw a picture of me.

The very last phase of addiction finds him lying on the opium bed. He looks down at his ragged clothes and in a fit of self-pity he exclaims

\section{一條庫褲子有福又無腰, 晒太陽, 捉虫子}

My trousers still have a bottom but no waist, Under the bright sunlight I catch the lice [that crawl all over me].

This detailed description of the final stages of drug abuse constitutes the most gruesome document on opium addiction in the HLC. That this aspect of the life in the brothels should be a theme for the songs of the singsong girls in the Lower Yangzi area is another 
indication of the amazing frankness and stark realism that the shidiao of the period bear witness to, even though a flavour of sentimentality pervades the texts in places.

\section{CONCLUSION}

The nine shidiao songs chosen from the HLC songbooks for analysis here reflect the world of the teahouses and bordellos in which they were performed and sung. They display a vivid picture of this facet of urban life of the late Qing, yet they are a source that has not been given much attention. In honest and frank words the anonymous authors reflect on the lot of singsong girls, courtesans, clients and opium addicts. Ample material on the proceedings in teahouses and other places of nightly entertainment is provided, as the narrators or the characters depicted in the songs report on food, drinks, games and performances available.

In some songs, even negative elements in some of the shidiao are shown in a friendly light, as if not to spoil the enthusiasm of a potential customer. Life in the pleasure districts appears tempting and full of excitement. But other songs draw a bleak image of a life of shame. In their self-accusations and desperate self-pity no difference can be detected between the voices of the various protagonists. Each speaker has reason to feel ashamed and degraded: the singsong girl for her status as a semi-prostitute; the gambler or the opium addict for wasting the family heritage. It is true that several authors of or characters in the songs describe their miserable lot in order to warn others. At least in theory, these texts could have been written not only to entertain but as cautionary tales.

The nine songs from the Hugo Lund Collection that are analysed in this chapter seem to convey a naive half-sentimental half-realistic tone from the past. The shidiao songs let us glimpse the individuals who peopled the green lofts of the late nineteenth century. A part of the teahouse and brothel milieu, these songs bring us particularly close to the atmosphere and circumstances of low life in cities such as Yangzhou, Suzhou and Shanghai, and as such they represent a valuable source for the social history of the Lower Yangzi area.

\section{APPENDIX: MANUSCRIPTS OF SONGBOOKS}

I. Da chahui, ben tang dui, xinnian ke, xinke shidiao, da chahui wu geng 打茶會, 本堂兌, 新年刻, 新 刻時調, 打茶會五更 [A Visit to the Teahouse; from our printing firm; edition of the new year; a new imprint of a popular tune; A Visit to the Teahouse, (in the style of) the Five Double-hours]. Oriental Library, University of Helsinki.

2. Dajiao niangyi tantou, fuqiao niseng tantou, Wenyetang, xinke chaoben, xiashan jianjianhua 搭 腳娘姨灘頭, 附俏僧尼灘頭, 文業堂, 新刻抄本, 下山剪剪花 [The Liaisons of a Niangyi (in the tune of) Tantou; attached A Tantou Tune of the Pretty Nun and the Monk; new imprint, textbook by the 
Wenye print firm; (attached) Escape from the Monastery, (to the tune) Jianjianhua]. Oriental Library, University of Helsinki.

3. Jie yangyan, wuyan jianjianhua 戒洋煙, 烏煙剪剪花 [Giving Up Opium; Black Opium, (to the tune) Jianjianhua]. Oriental Library, University of Helsinki.

4. Nan fenghua quan, xinke shidiao 男風花勸, 新刻時調 [Advice on Men's Love Affairs, a new imprint of a popular tune]. Oriental Library, University of Helsinki.

5. Shibei jiu, xiaodazi, bentang dui, xinke shidiao, xinbian huayandeng shibei jiu 十杯酒, 小大子, 本堂 兌, 新刻時調, 新遍花煙燈十杯酒 [The Ten Cups of Wine, (to the tune) xiaodazi; from our print firm; a new imprint of a popular tune; newly edited: The Opium Pipe in the Flower House and Ten Cups of Wine]. Oriental Library, University of Helsinki.

6. Wugeng xiangsi, xiaodiao chaoben, bentang fadui 五更思想, 小調抄本, 本堂發兌 [Longing All Through the Night; manuscript (in the style of a) minor tune; from our print firm]. Oriental Library, University of Helsinki.

7. Yangyan zitan changben, Sanyuantang dui, xinke Caodiao 洋煙自嘆唱本, 三元堂兌, 新刻曹調 [Songbook: Lament of the Opium Smoker; by the print firm Sanyuantang; new imprint (in the style of a) cao-tune]. Oriental Library, University of Helsinki.

8. Yapian wugeng, Shangyang Sanyuantang dui, yapianyan tan wugeng Yinniusi 鴉片五更, 上洋三元 堂梓, 鴉片煙嘆五更銀銈絲 [The Opium (smoker), (in the style of) the Five Double-hours; by the print firm Sanyuantang, Shangyang (Shanghai); Lament of the Opium Smoker, (in the style of) the Five Double-hours; (to the tune of) yinniusi (attached to Yangyan zitan changben)]. Oriental Library, University of Helsinki.

9. Yuanmiao guan jingchu, Sugu, Jingde tang zi xing 元妙觀景處. 蘇姑, 敬德堂梓行 [The Sights of the Yuanmiao Temple; Suzhou; engraving of the year Xinmao (I89I) by the print firm Jingde Tang]. Oriental Library, University of Helsinki.

\section{NOTES}

1 Hanshang mengren 邗上夢人 [Fool of Hanshang, i.e. Yangzhou] is the pseudonym for the author of the preface. See Hanshang Mengren (I988 [1848]). This novel is treated in detail in Hanan 1998.

2 Manuscripts of songbooks and their sources are listed in the Appendix. In the following I will refer to the songbook collection purchased by Hugo Lund as HLC. An annotated edition and translation into English is in progress. Lund had been sent out to purchase Chinese texts and books for the University of Helsinki for the founding of a Department of Chinese Studies. As he lost his first collection during the Boxer Uprising he collected in his remaining time in China whatever he could lay his hands on. Among the 2,565 books Lund finally sent back to Europe was a wide range of printed materials of all sort of genres, among them the IO3 songbooks referred to in this paper; see also KuZAY 2007.

3 The Toyo Bunka Kenkyujo, Peking University and Capital Libraries as well as Academia Sinica, Taipei, all have extensive collections of songbooks. The collection 'colloquial literature', suwenxue 俗文学, of the Academia Sinica contains songbooks of shidiao, shan'ge and other 'miscellaneous tunes', $z a q u$ 雜曲, though of a later date.

4 Siqing shan'ge, shier ge yue 私情山歌, 十二個月, 新刻 [Mountain Song of a Secret Affair; (in the style of) Twelve Months; a new imprint]; Jinü tan wugeng, bentang dui, xinke shidiao 妓女嘆五更, 本堂 
兌, 新刻時調 [Lament of a Prostitute (in the style of) the Five Double-hours; from our print firm; a new imprint of a popular tune].

5 (a) Baishe zhuan shan'ge, bentang dui, Tangshi changju 白蛇傳山歌, 本堂兑, 唐詩唱句 [Mountain Song on the Story of the White Snake, by our printing firm, Tang poetry lyrics for singing], Wu xianhuadiao, Pan Jinlian xi shu, Jiangbei Qingxiage zi 武鮮花調. 潘金聯戲叔. 江北青霞阁梓 [Fresh Flower Tune of Wu. Pan Jinlian Tries to Seduce Her Brother-in-law. From the print firm Blue Mist Pavilion, Jiangbei], Meng Jiangnü cai cha 孟姜女採茶, 本堂梓, 新刻時調 [Meng Jiangnü. (A song from the genre) Tea Picking. From our printing firm, a new imprint of a popular song], Wopao, songfu fudu 倭袍, 送符服毒 [The Japanese Robe. Sending a Note and a Dose of Poison].

(b) For a complete account of the textual history of the Wu Song legend, see BørDaHL 2004b: Is ff.

(c) On the Wopao zhuan-songbooks of the HLC and their position in literary history see KuzAY 2007.

6 On the relation between Yangzhou tanci and Yangzhou shidiao xiaoqu see LuAn Guijuan 1998: I2 ff; concerning the performance techniques of shidiao, see Ni Zhongzhi I99I: 369.

7 Probably the first mention of qinglou with the meaning of brothel goes back to the poem Wanshan jian caisang ren shi 萬山見採桑人詩 [Poem on Seeing a Girl Picking Mulberries at Wanshan Mountain] by Liu Miao 劉选 of the Southern Liang Dynasty (397-4I4). It is part of the anthology Yutai xinyong 玉臺新詠 [New Songs of the Jade Terrace] (Xu Ling 徐陵 (507-583) 200I: 8.I4). The continuing use of qinglou to mean bordello up to late Qing times is also evident from the novel Qinglou meng 青樓夢 [Dream of the Green Mansion] by Yu Da 俞達, banned for its erotic content; cf. TAO Muning 1993: 22I.

$8 \mathrm{Du} \mathrm{Mu}$ 杜牧: Qianhuai 遣懷 [Confession], in Zhonghua (ed.), Quan Tangshi 全唐詩 [Complete Collection of Tang Poems], vol. 524:52: 5998. Translated by the author.

9 Wang Jian 王建: Ji Shu zhong Xue Tao jiaoshu 寄蜀中薛涛校书 (Conveyed to the Collator Xue Tao 薛涛 in Shu), in Zhonghua (ed.), Quan Tangshi 全唐詩, vol. 307.97: 3434. The poem refers to the former courtesan Xue Tao (768-831).

10 Cf. Yapian wugeng 鴉片五更 (Appendix 8), verse I.

11 WeI Minghua 2004: 202. For a translation of his 'Yangzhou shouma 揚洲廋馬' [The Thin Horses of Yangzhou], see Finnane i995: 47-66.

12 For shidiao xiaoqu, one of the smallest branches of the quyi tradition, the term minjian xiaodiao 民間小調 [minor popular tunes] was also coined; cf. LuAN Guijuan I998: 2I. The textbooks of the HLC use exclusively the term shidiao.

13 On the front page most songbooks show the phrase 'produced by our print shop', bentang zi 本堂梓. Variations with similar meaning: bentang kan 本堂刊, bentang dui 本堂兌, benzhai dui 本 宅兌.

14 The names of the print shops are: Yiyuan tang一元堂, Sanyuan tang 三元堂, Yuande tang 元 德堂, Yousan tang 酉三堂, Baoshan tang 寶善堂, Jifu tang 集福堂, Shanxiu tang 山秀堂 and Jingde tang 敬德堂 in Gusu 姑蘇 (Suzhou 蘇州), Caixia tang 采霞堂 in Dangkou 蕩 $\square$ and Qingxia tang 青霞堂 in Jiangbei 江北. I am much indebted to Dr. J. S. Edgren, Editorial Director of the Chinese Rare Books Project of Princeton University, who advised me on my search for the location of print shops in the Yangzhou region. He referred to the generic nature of print shop names of popular booklets and pointed out that the same name could occur in multiple 
locations. Collections like the HLC were to be considered as references on this matter in their own right.

15 a) Wu xianhuadiao, Pan Jinlian xi shu, Jiangbei Qingxiage zi 武鮮花調. 潘金聯戲叔. 江北青霞阁 样 [Fresh Flower Tune of Wu. Pan Jinlian tries to seduce her brother-in-law. From the print firm Blue Mist Pavilion, Jiangbei]. b) According to Zhu Ziqing 朱自清 (I898-I948) Shanghai residents referred to Yangzhou people, and in particular Yangzhou migrants, as Jiangbei lao 江北老 [old (hands from) Jiangbei]; cf. Finnane 1994: II52.

16 Among others jiandianhua 剪靛花, huadiao 花调, manjianghong 满江红, nüxiangsi 女相思. Various Qing period texts give evidence of the origin of jiandianhua, huadiao from the Yangzhou region, cf. Ni Zhongzhi 倪钟之 I991: 372 and Wu Zongxi 1996: I36.

17 For details on the dating of these texts, see KuZAY 2003: I3Iff.

18 Wang daniang bugang, mingban xiwen, Sanyuan tang $z i$ 王大娘补缸. 名班戲文. 三元堂梓 [Lady Wang Gets Her Jar Mended; play text of a famous troupe; printed by the Sanyuan printing firm]. Considering the formal and structural differences from the IO2 other songbooks, this text might belong to another category, namely drama. However, all the I03 titles share the same format and topical character. Though this is the only text using stage directions such as bai [tell] and chang [sing], it is by no means sure that it is a drama text, but it might well belong to a prosimetric genre, with two performers reciting and singing.

19 Shiba mo, Yiyuan tang 十八摸, 一元堂 [Eighteen Ways of Massage, Yiyuan printing firm].

20 See Chongxiu Yangzhou fuzhi 重修揚洲府志 [Gazetteer of Yangzhou Prefecture] I8Io, Vol. 6o: i2a, cf. Finnane i995: 65 and Wei Minghua 2004: 213.

21 For a translation of excerpts of the Yangzhou huafang lu see BOROTA I996: 58ff.

22 The term shuyu initially referred to the place where stories were recited or read. The term was applied subsequently to the women performing there. Shuyu did not wish to fall in the same rank as for example the changsan (long-three) or the yao'er (one-two), who did offer sexual services; cf. HenRiot 1996: I35. On the development of the term and profession of shuyu in Jiangnan see XUE Yongli 1996: 165.

23 Scherer has a slightly different version: zhi mai kou, bu mai shen 只賣口不買身 [only sell the mouth, not the body], cf. SCHerer i983: I27.

24 Henriot observes for the last quarter of the nineteenth century a greater 'sexualization' of and a merging of the once distinct various groups of the courtesans and entertainers; cf. Henriot 1996: 137 .

25 The most prominent example of such literature might be Han Bangqing's novel Haishang hua liezhuan 海上華列傳 [Flowers of Shanghai] from I892, the first of the many Wu dialect novels to appear in print; cf. MCMAHON 2002: 7.

26 On the social development of the shuyu profession see McMaHON 2002: 8.

27 The main topic of ridicule is the poet courtesan Wen Junyu 文君玉.

28 For the etymology of this term, cf. WeI Minghua 2004: 202-204. See also below.

29 The Fu Ssu-nien Library of the Academia Sinica, Taipei, contains various songbooks of shidiao, shan'ge, and so-called 'miscellaneous tunes', zaqu 雜曲, collected by Li Jiarui 李家瑞 in Beijing (Beiping), which are very similar to those of the HLC. They are however neither in scope nor in range identical with those. 
30 The text examples I quote display the characters used in the songbooks. Therefore they contain also homonyms of those characters that the authors presumably originally intended to use.

31 In a similar text of the HLC the customers get served at this occasion with 'four meat dishes, four times vegetarian and four times dessert'; cf. Appendix 6.

32 Nanfeng is also another expression for love between men. For this information I am indebted to the peer reviewer of this paper. Nevertheless the text in question here does not refer in any way to homosexual love. Nor does another songbook with the title Nüfenghua quan, xinke shidiao 女 風花勸, 新刻時調 [Advice on Women's Love Affairs; a new imprint of a popular tune] deal with homosexual love between women. Both songbooks discuss the pro and cons of matrimonial fidelity.

33 For a description of the courtesan market see Zhang Dai's 張岱 (I597-I685) essay collections Ershisi qiao fengyue 二十四橋風月 [Romance on the Twenty-Four Bridge] and Tao'an mengyi 陶 庵夢憶 [Dream Memories of Tao'an] with the essay Yangzhou shouma 揚州瘦馬 [Thin Horses of Yangzhou], I60-162; Pollard and Soh Yong Kian provide a translation of Tao'an mengyi essays concerning courtesans, cf. Pollard and SoH Yong Kian 1990: 157-162.

34 Zhang Dalai 章大來: Hou jia ji 後甲集 (WEI Minghua 2004: 203).

35 The term guanren in the context of Yangzhou, Shanghai and Jiangnan pleasure districts refers to a courtesan or a prostitute; cf. Li Dou 200I: 202, and VANCE YeH 1998: 8. This is confirmed by the text of the HLC. The confusion concerning the term guanren is not reduced by the fact that it could also refer to the male customer in brothels and to adolescent male prostitutes.

36 On the acceptance, availability and usage of foreign textiles and accessories in Chinese society of the nineteenth century, see Finnane 2003: 395-425 and Rowe 1984: 79.

37 On the social connotations of female opium consumption, see McMaHon 2000: I29-I79. 


\section{Part IV}

\section{The Yangzhou School of Painting}





\section{5}

\section{The Study of Forgeries of Paintings}

by the Yangzhou Eccentrics

\section{Zhuang Sue}

$\mathrm{I}$ $\mathrm{n}$ the field of Chinese art, forgeries of paintings, as well as of calligraphy, jade, terracotta, sculpture and other objects, are commonplace. The phenomenon is encountered more often than in Western art. Forgeries cause severe problems in Chinese art history research and in the art market, and must always be taken into account by museum collectors. Accordingly, research into the authenticity of Chinese art works is extremely important. Most studies of forgeries of Chinese paintings have focused on a particular piece of work. This chapter takes on a complex task, the study of the paintings of a group of artists, the Eight Eccentrics of Yangzhou.

The term 'Eight Eccentrics of Yangzhou', Yangzhou ba guai 揚州八怪, ${ }^{1}$ refers to a group of idiosyncratic artists who were active in Yangzhou. The earliest extant book that mentions the term is Yangzhou huayuan lu 揚州畫苑錄, published in I883, by Wang Yun 汪鍂, a famous Qing art critic. Since then no fewer than fifteen different artists have been identified as one of the Eight Eccentrics, in various sources. For this reason, art historians nowadays prefer the term Yangzhou school, Yangzhou huapai 揚州畫派。

During the seventeenth and eighteenth centuries, the city of Yangzhou was a very prosperous cultural and economic center in China, on account of its control of a large part of the empire's salt trade. It was said that because of the splendour of the city and the patronage offered by its salt merchants, these artists of Yangzhou, only a few of whom actually came from Yangzhou, congregated there in search of opportunities and income. Although some of these artists also did landscape and figure paintings very well, they were more skilled in flower and bird painting in the xieyi 寫意 (depicting the idea) style. Most of them painted using very loose, vigorous and even coarse strokes and the style of their paintings is accordingly very expressive, energetic and rough. Their compositions, unlike the rigid format of classical flower and bird paintings, were usually arranged very freely and creatively. These qualities were considered odd, hence eccentric, by more conventional contemporary artists. Nevertheless, their special styles were liked and also easy to imitate, contemporary and later artists replicated and even forged the works of the Yangzhou school. As a result, a large amount of forgeries are now in existence. 
The paintings of the relatively famous artists among the Yangzhou Eccentrics, for example Jin Nong 金農 (I687-I763), Li Shan 李鱓 (I686-ca I756), Zheng Xie 鄭 圝 (I693-I765) or Gao Fenghan 高鳳翰 (I683-1749), have generated a large number of forgeries and copies. Marshall Wu, the expert on Jin Nong, reckoned that onethird of the paintings attributed to Jin Nong were forgeries. ${ }^{2}$ My own study of these masters has uncovered large numbers of forgeries amongst paintings attributed to $\mathrm{Li}$ Shan, Li Fangying 李方膺 (I695-ca I755), and Gao Fenghan. How come such large numbers of forgeries were created?

Literary sources tell us that forging the works of the Yangzhou Eccentrics have been taking place since those artists' lifetimes. In 'Twenty-three Quatrains' (Jueju ershisan shou 絕句二十三首), Zheng Xie wrote a poem about Gao Fenghan:

西園左筆壽門書,
海内朋交索向余,
短札長箋都去盡,
老夫贋作亦無餘。

Friends from far and wide ask me for

Xiyuan's left hand and Shoumen's pen.

Short notes and long letters all long gone

Nothing left of my forgeries either

(Zheng Xie 1985: 98). ${ }^{3}$

This poem confirms that Zheng Xie had forged works by Gao Fenghan (i.e. Xiyuan) and Jin Nong (i.e. Shoumen) and that he was very proud of his forging skill. The paintings of Zheng Xie were also forged by his admirers. Tan Yunlong 譚雲龍, a carpenter from Shandong, could reproduce Zheng Xie's paintings with such fidelity that even connoisseurs could not identify them. When Zheng Xie was too busy, he would ask Tan Yunlong to paint for him. Inscriptions signed by Yuanpu 源普 and Hengqing 恒慶 on Tan Yunlong's Bamboo, held by the Qingdao Museum, tell us that he forged Zheng Xie's paintings every day at home, and he even borrowed Zheng Xie's seals for such paintings (Zheng Xie 1985: 827). Another foremost Yangzhou Eccentric, Jin Nong, mentioned in his books and letters that his two favourite students, Xiang Jun 項均 (dates unknown) and Luo Pin 羅䀻 (I733-1799), painted for him so that he could meet the demands of buyers. He nonetheless knowingly signed the paintings. Jin Nong also praised Xiang Jun and Luo Pin, saying that they painted much better than he $\mathrm{did} .{ }^{4}$ It seems that both Zheng Xie and Jin Nong did not mind others copying their paintings. In contrast, Li Shan was so worried about it that he wrote a colophon on Twelve Hanging Scrolls of Flowers (Huahui shi'er pingfu 花卉十二屏幅, dated I753, Shanghai Museum collection), saying:

My paintings are not good, although I have been famous for a long time. Lots of women are more beautiful than Wang Zhaojun 王昭君 and Xi Shi 西施, 


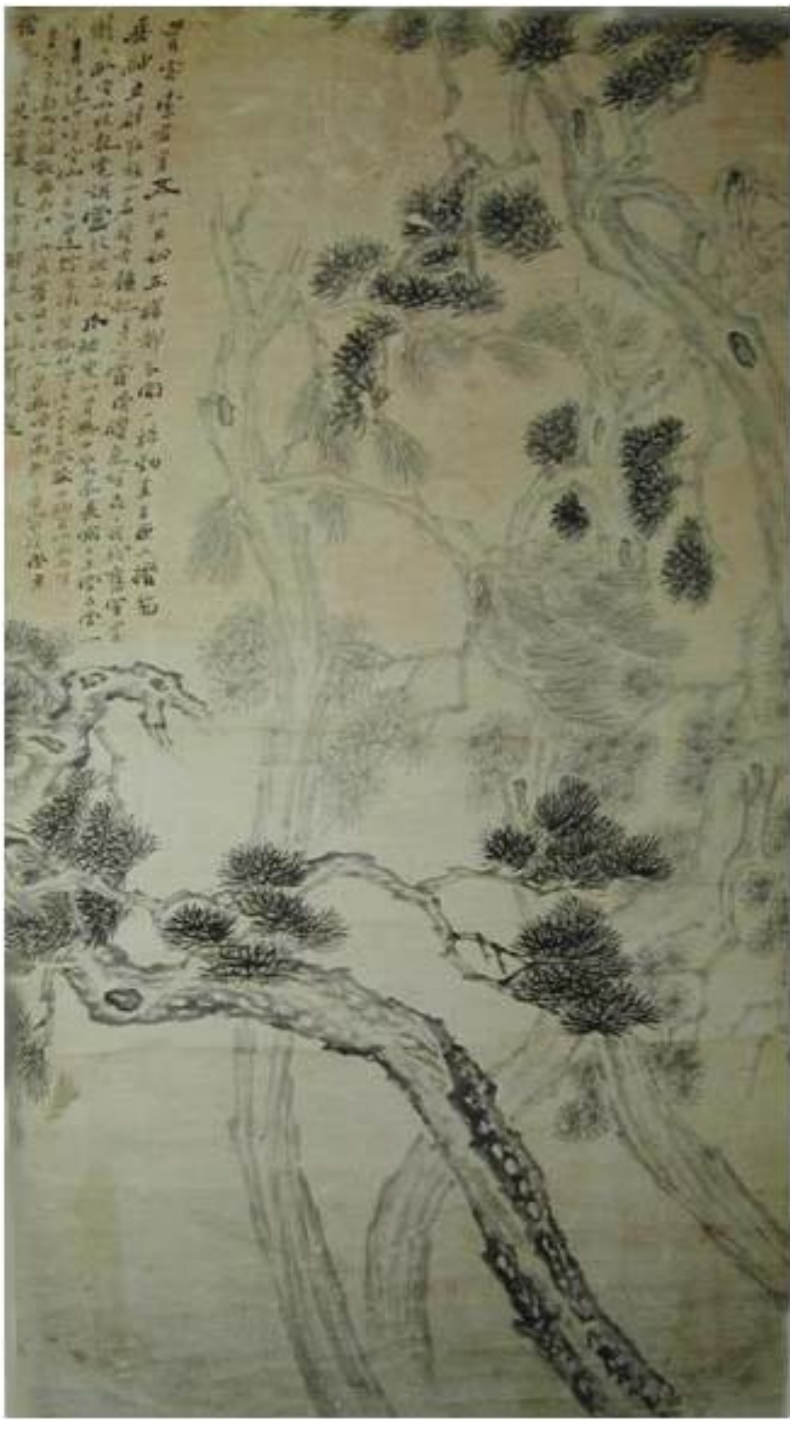

Figure 15.1 Li Shan, Five Pines. Not dated. Ink on paper, $179.7 \times 104.6 \mathrm{~cm}$. The Palace Museum, Beijing.

but no one knows them. There are so many forgeries of my paintings that the forgers are making only small profits at present, but the forgeries will ruin my reputation in future. I can only sigh, and can do nothing.

(Shina Nanga Taisei 1936, vol. 6: 160)

In a colophon on Li Shan's Album of Flowers and Vegetables (Huahui shu guo ce 花卉 疏果冊, collected in Sichuan Museum), Zheng Xie wrote: 
Futang's 復堂 (i.e. Li Shan's) painting style changed three times ... Those who love Futang's painting collect his young and mature works, but burn his weak works and forgeries. Thus, Futang's real spirit and features will exist brightly forever.

(Yangzhou huapai 1985: 50)

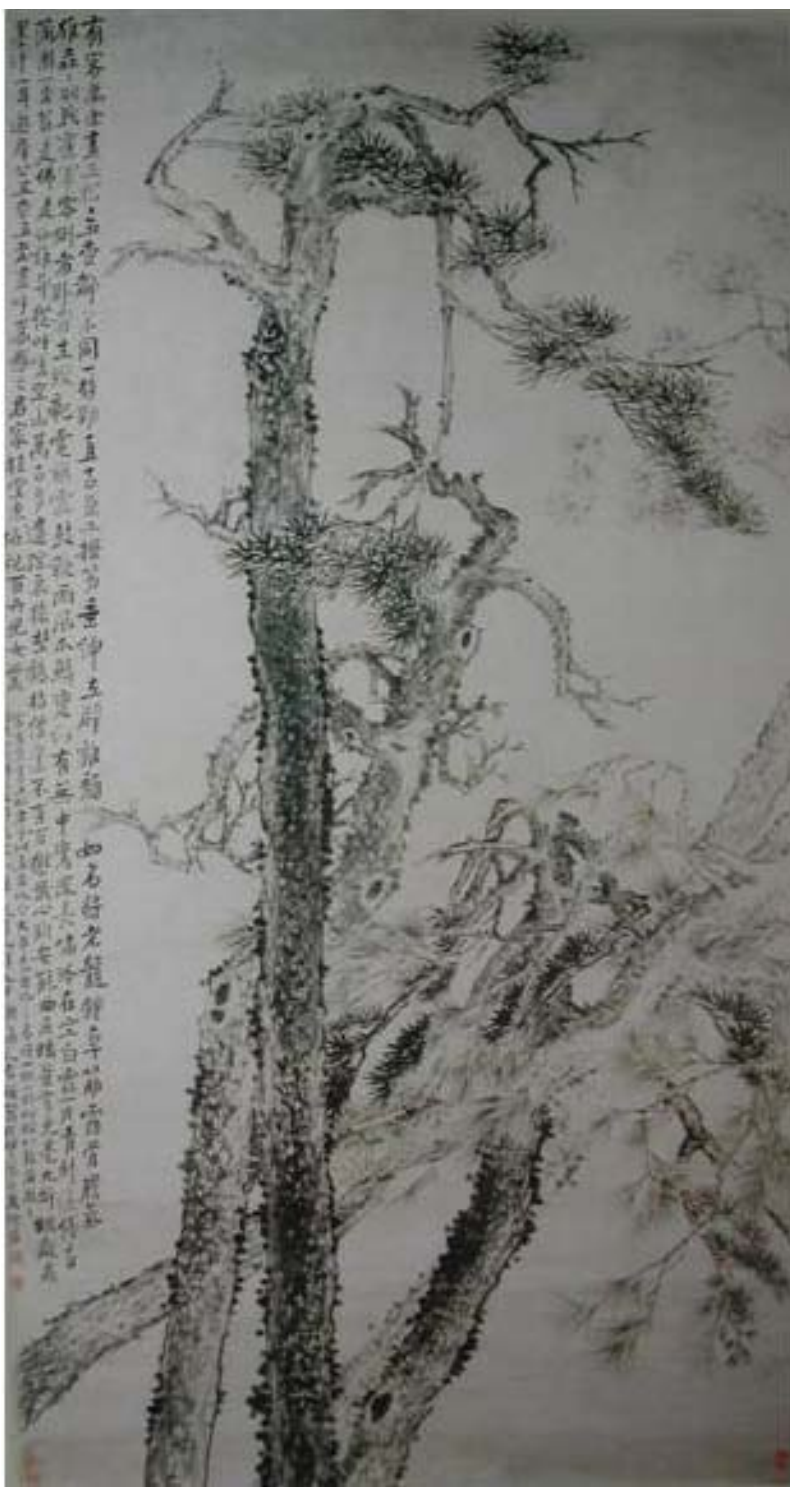

Figure 15.2 Li Shan, Five Pines. 1744. Ink on paper, $192.8 \times 102.6 \mathrm{~cm}$. Chinese History Museum, Beijing. 


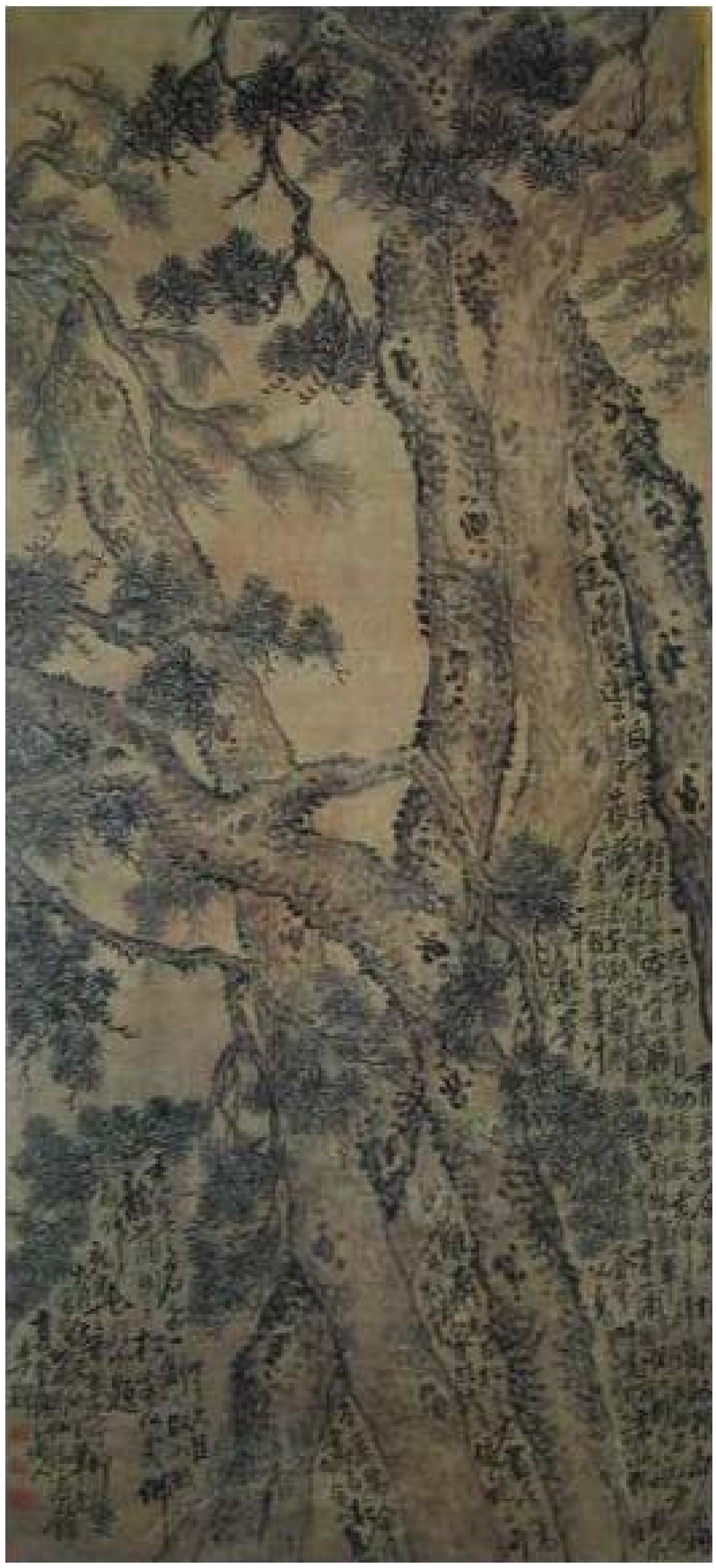

Figure 15.3 Li Shan, Five Pines. 1747. Colours on silk, $193 \times 86 \mathrm{~cm}$. Duoyun Xuan, Shanghai. 


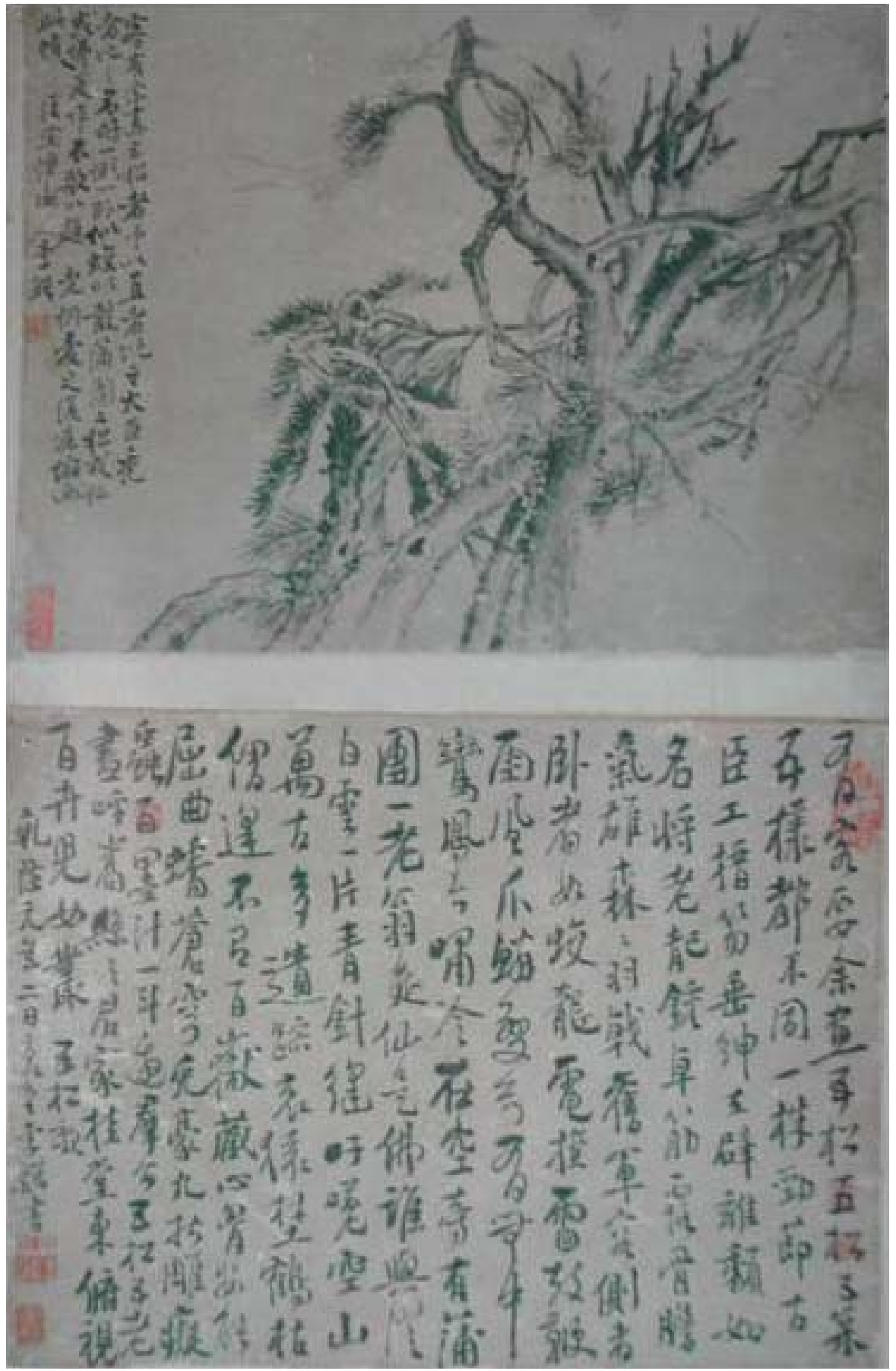

Figure 15.4 Li Shan, Five Pines. Album leaf, 1736. Collector unknown. 
Even though some forgeries of Li Shan's paintings were burnt, as Zheng Xie mentioned, Li Shan's anxiety was not unreasonable. Many works attributed to him today are not authentic.

The above are just some examples of the historical evidence of forgery. They range in time from the lifespan of the Yangzhou Eccentrics to the nineteenth and twentieth centuries. In the course of nearly three hundred years, moreover, not only has there been an increase in the number of forgeries of the Yangzhou Eccentrics' works, but forgers' techniques have become more sophisticated. When

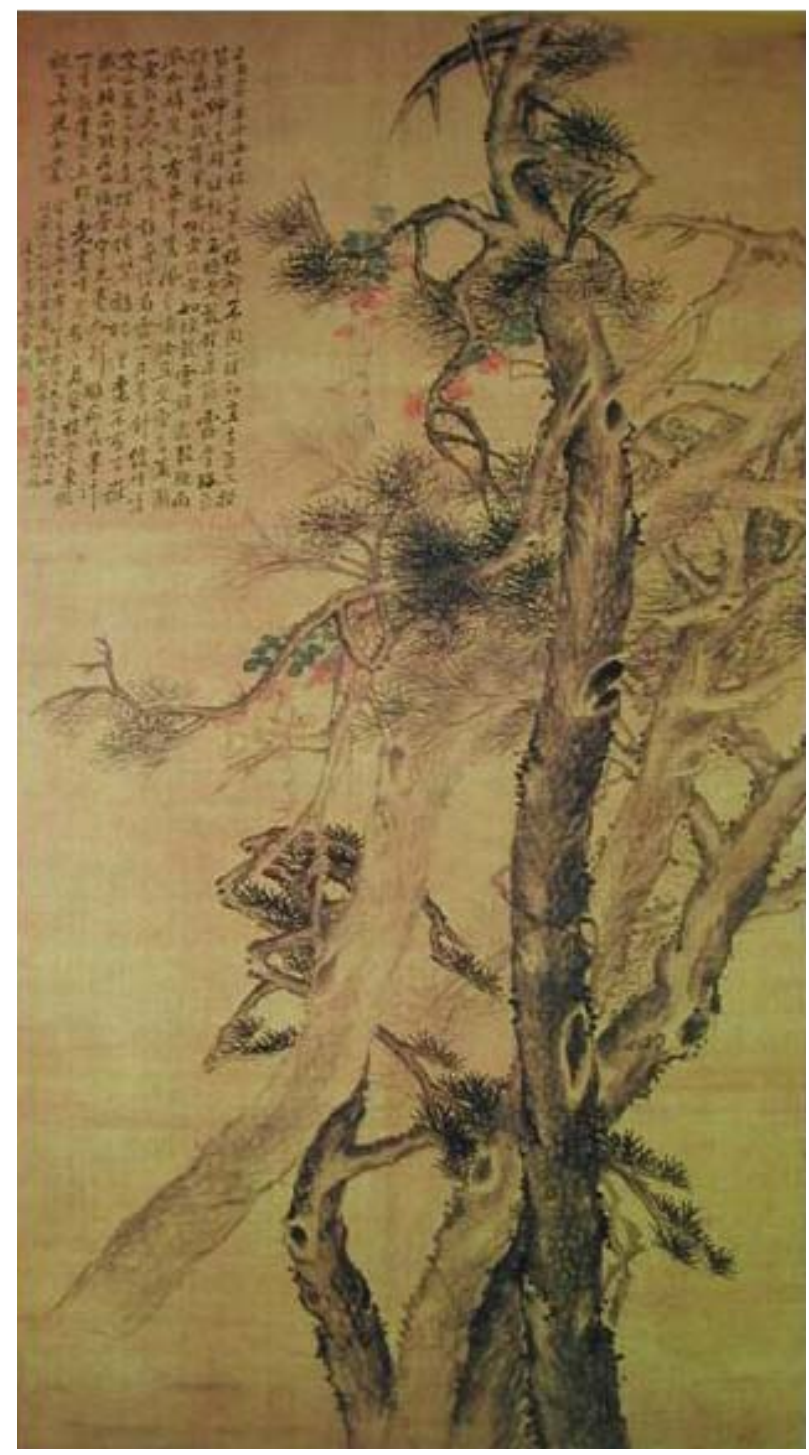

Figure 15.5 Li Shan, Five Pines. Not dated. Ink and light colours on silk, $160 \times$ $88.8 \mathrm{~cm}$. Tokyo National Museum. 


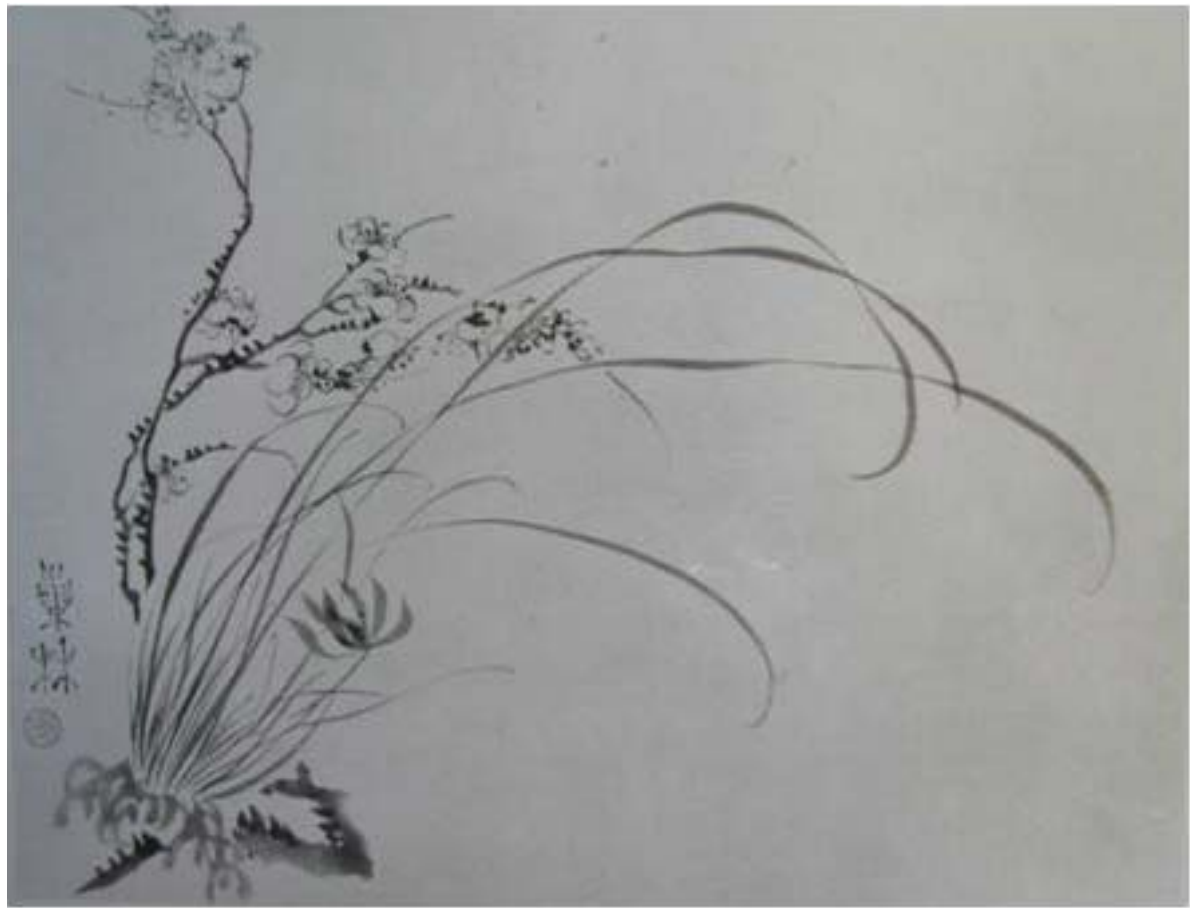

Figure 15.6a Wang Shishen, Plum and Orchid. Leaf 2 of Album of Plum Blossoms. Ink on paper. Tadashi Moriya's Collection (version A).

examining currently existing paintings attributed to the Eccentrics, I found that forging methods were extremely tricky and varied from case to case. Like a detective, I have studied these suspected works for years. Tracing the defects that forgers left either intentionally or carelessly, I have classified forging methods into eight categories.

\section{SEVERAL DIFFERENT VERSIONS OF ONE SUBJECT}

Among the paintings of the Yangzhou Eccentrics, there often occur several different versions of one work. By that I mean pictures which have the same subject title, and a composition, motifs, shapes or inscriptions which are the same or similar. The dates inscribed on them might however vary by some years.

There are, for example, five known versions of Gao Fenghan's Pond of Heaven (Tianchi tu 天池圖), ${ }^{5}$ and at least seven versions of Huang Shen's 黄慎 (I687-ca I770) Willows and Egrets (Liu lu 柳鴽). ${ }^{6}$ The authenticity of the different versions of these paintings needs further examination. For this discussion, Li Shan's picture Five Pines (Wu song tu 五松圖) and its many versions is an excellent case study. 


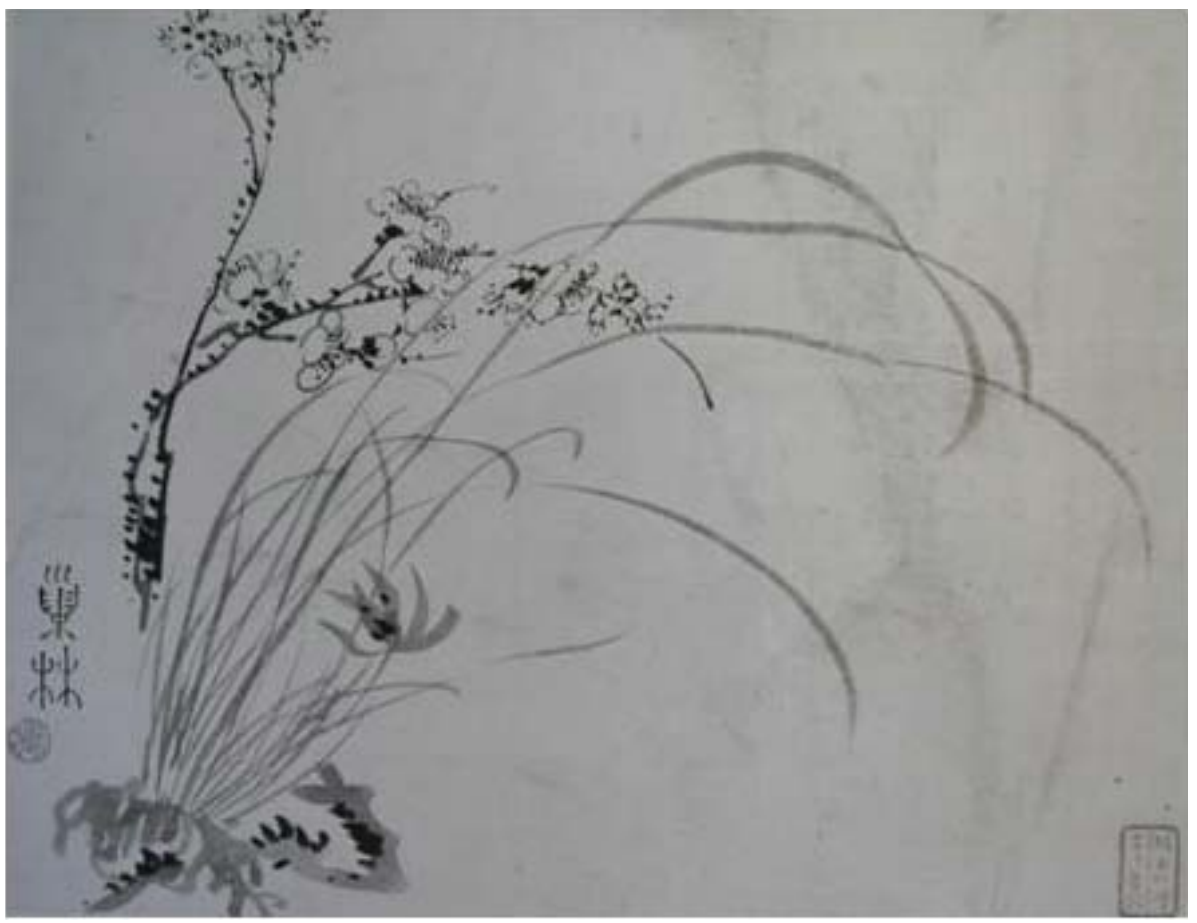

Figure 15.6b Wang Shishen, Plum and Orchid. Leaf 5 of Album of Plum Blossoms. Ink on silk, $23 \times 29.7 \mathrm{~cm}$. Private Collection, USA (version B).

Five Pines was described by Li Shan's contemporary, the art connoisseur Zhang Geng 張庚 in his Guochao huazheng lu 國朝畫徵錄, but he did not discuss the number of versions (ZHANG Geng 1986: 607). In 1992, when I published an article about this painting,7 I knew of nineteen versions. It seems that the number is still increasing; however as at present, I am aware of at least twenty-four versions, the most marked case of multiple versions ever known in Chinese painting history. Among these twenty-four versions, four have never been reproduced, having only been mentioned in scholarly writing. I am therefore not able to consider them. ${ }^{8}$ Are the other twenty pictures genuine?

First, we can identify as forgeries those versions that are technically unskilled/ clumsy. One example is the version from the Beijing Palace Museum (Fig. I5.I). It is undated and without Li Shan's inscription, but with a false inscription by Zheng Xie. Another example, also undated, is from the Nanjing Municipal Museum (Nanjing shi bowuguan 南京市博物館), ${ }^{9}$ and there are two more from the Yangzhou Wenwu store, dated 1753 and 1747 respectively. ${ }^{10}$ Their rough, stiff and immature brush-strokes are definitely not Li Shan's. The brush-strokes of the version from the Nanjing Municipal Museum, for example, are so awkward that they lack any aesthetic sense. 
Second, the styles of some versions are not right for the time they are supposed to have been produced. Examples are the Christie's versions, dated 1744 and $1747,{ }^{11}$ the Chinese History Museum's version, dated 1744 (Fig. 15.2), the Cleveland version, dated $1747,{ }^{12}$ and a version from the Beijing Palace Museum (undated). ${ }^{13}$ Connoisseurs who are familiar with the stylistic development of Li Shan's paintings would be able to detect these forgeries.

Third, the style of some works at first glance is appropriate but the brushstroke technique and the mode of applying ink are not Li Shan's. Examples are the version from Cahill's collection, dated $1735,{ }^{14}$ and the one from the Sotheby's catalogue, dated $1754 .{ }^{15}$ The expression of brush strokes is too weak and the ink used is too dry on the former, while the expression of brush strokes is too stiff on the latter.

Fourth, the rendering of the subject and its meaning is incorrect in some versions; for example, on the paintings from the Nantong Museum (undated), ${ }^{16}$ the Yangzhou Wenwu store (dated 1747), ${ }^{17}$ the Cleveland Museum of Art (dated 1747), ${ }^{18}$ and the Duoyun Xuan collection in Shanghai (dated 1747) (Fig. 15.3). Li Shan's inscription, titled 'The Song of Five Pines' (Wu song ge 五松歌), indicates unambiguously that the pine trees in the painting are upright, bare, slanting, bent and twisted, but none of the just mentioned versions shows this.

Fifth, discrepancies in the calligraphic style of the inscriptions. The calligraphy in the versions from the Yangzhou Wenwu store (dated 1747), ${ }^{19}$ the Cleveland Museum of Art (dated 1747), ${ }^{20}$ and the Duoyun Xuan in Shanghai (dated 1747$)^{21}$ does not conform to Li Shan's calligraphic style. The method of using the brush tip, and the force with which the brush is used, differ from Li Shan's technique. The writings on these paintings only used the side tip of the brush, whereas Li Shan always used both the middle and the side of the brush tip.

Sixth, an investigation of the inscribed text of 'The Song of Five Pines' reveals, in some versions, traces of forgery. For example, the text on the album leaf dated 1736 (Fig. 15.4), in an unknown collection, added two extra words (wu song - five pines) to the second sentence, making it sound strange. The text on the version at Wuxi Museum $^{22}$ lacks the word qiong 穹 (the sky) and therefore makes no sense. These mistakes expose the versions as forgeries, because it was customary for forgers, in order to avoid punishment from the gods, to occasionally make intentional mistakes in an inscription text.

Finally, checking the seals affixed to these paintings, some show poor carving technique. For example, the seal Futang 復堂 on the above mentioned Cahill's version, ${ }^{23}$ or the seal Li zhongding wending zisun 李忠定文定子孫 on the handscroll version in the Chinese History Museum, dated $175 \mathrm{I} .{ }^{24}$ Neither of these seals is genuine.

Space does not permit me to point out every problem in detail in this chapter, as I have done elsewhere. ${ }^{25}$ However, my research has revealed that wherever the quality 
of brush strokes was low, such as to cast doubt on the authenticity of the painting, the calligraphy and seals were usually of a bad quality, too.

Of the twenty versions of Five Pines which I have been able to examine, I consider only three to be genuine: the undated version from the Nanjing Museum; ${ }^{26}$ the version dated I735, also from the Nanjing Museum $;{ }^{27}$ and the undated version from the Tokyo National Museum (Fig. 15.5).

Interestingly, the collections of the Nanjing Museum, the Yangzhou Museum and the Shanghai Museum all have calligraphy titled The Song of Five Pines, derived from the inscription on the painting Five Pines. ${ }^{28}$ But none of them is original.

\section{SEVERAL VERSIONS OF IDENTICAL COMPOSITION}

Copying from extant works is the easiest way to make forgeries. Some works of the Yangzhou Eccentrics were done with exactly the same composition, motif, structure, inscription, signature and date. Apparently, they are the result of forging. The most impressive example is Wang Shishen's 汪士慎 (1686-1759) Album of Plum Blossoms (Meihua ce 梅花冊), dated 174I. There are three versions of it: one is in Tadashi Moriya's collection (version A), a second is in a private collection in the United States (version B), and the third one was reproduced in Hong Kong in 1970 (version C). Comparing leaf 6 of version A with leaf 3 of version B and leaf 2 of version C, they look almost undistinguishable. ${ }^{29}$ Nonetheless, inspecting them carefully, differences can be identified. Leaf 6 of version A was painted in free, well-trained brush-strokes, showing the naive and brisk style typical of Wang Shishen's depiction of thinning plum flowers. In contrast, leaf 3 of version B was drawn in more awkward, heavier and drier strokes. And leaf 2 of version $\mathrm{C}$ was painted with thinner ink lines, rendered in a free manner, but there does not look to be consistency in the thickness of the branches, and the ink used on the flowers is too black. Observing the calligraphies of the three versions, we get the same result. Two other comparisons - leaf I2 of version A with leaf $\mathrm{I}$ of version C; $;^{30}$ leaf 2 of version A (see Fig. 15.6a) - confirm that version $A$ is authentic, and versions $B$ and $C$ false.

There are many other instances, beside those cited above, where several copies are composed that are identical with authentic compositions by the Eccentrics. For example, Gao Xiang's 高翔 (1688-1753) Album of Landscapes at Pingshan Tang (Pingshan tang shanshui ce 平山堂山水冊), or Huang Shen's Dongpo Playing with an Ink Stone (Dongpo wan yan tu 東坡玩硯圖). ${ }^{31}$ 


\section{THE SAME OR A SIMILAR INSCRIPTION USED IN DIFFERENT ARTISTS' WORKS}

Some forgers reproduced different masters' works at the same time, copying inscriptions or colophons from one master's works to another's. For example, Zheng Xie's Orchids in a Pot (Penlan 盆蘭) (undated; Yantai Museum) has been thus inscribed (see Fig. 15.7a):

When buying an orchid, you should get one with a whole root. With full spirit and strong force, it will have abundant descendants. Do not resent that it only has a few flowers this year; please wait to see it flowering next year.

Li Fangying's Orchids in a Broken Pot (Popen lanhua 破盆蘭花) (undated; Yangzhou Museum) has a similar inscription, which reads (see Fig. 15.7b):

When buying an orchid, you should get one with a whole root. With full spirit and strong energy, it will have abundant descendants. Do not resent that it only has a few silver sprouts now; it is waiting to be full ... [one word missing] next year.

Neither the pictorial nor the calligraphic styles of Orchids in a Broken Pot are Li Fangying's; rather, they resemble Zheng Xie's style. The painting was made by a recently deceased Yangzhou resident, however. ${ }^{32}$

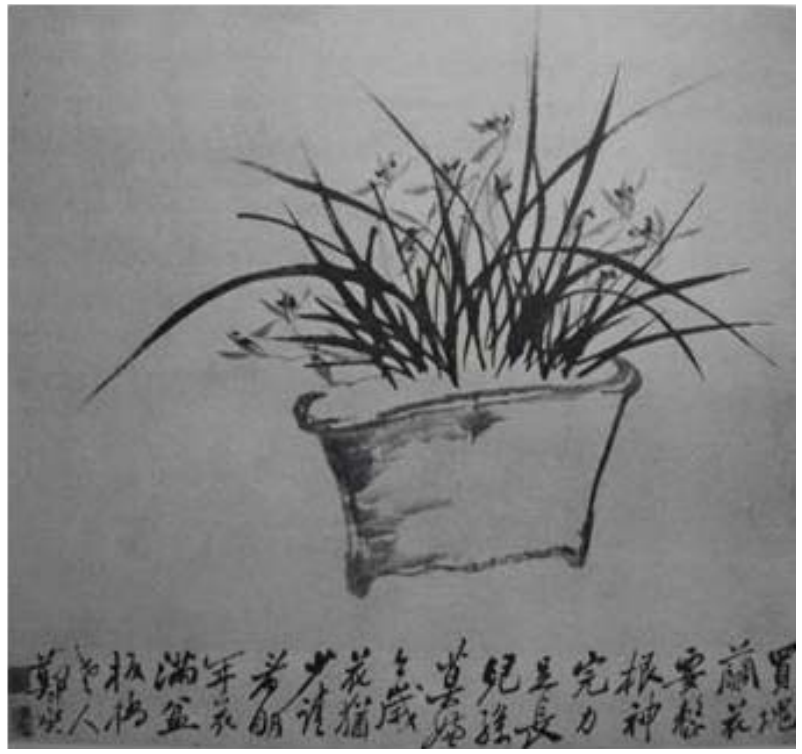

Figure 15.7a Zheng Xie, Orchids in a Pot. Undated. Ink on paper. Yantai Museum. 


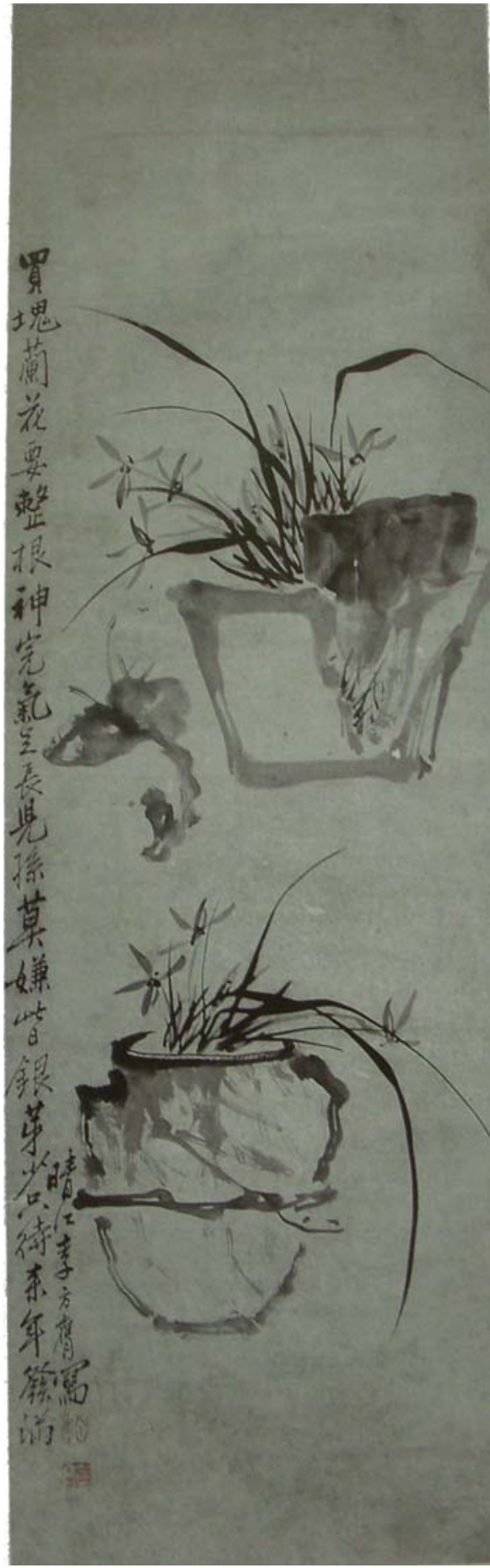

Figure 15.7b Li Fangying, Orchids in a Broken Pot. Undated. Ink on paper, $112 \times$ $34 \mathrm{~cm}$. Yangzhou Museum. 

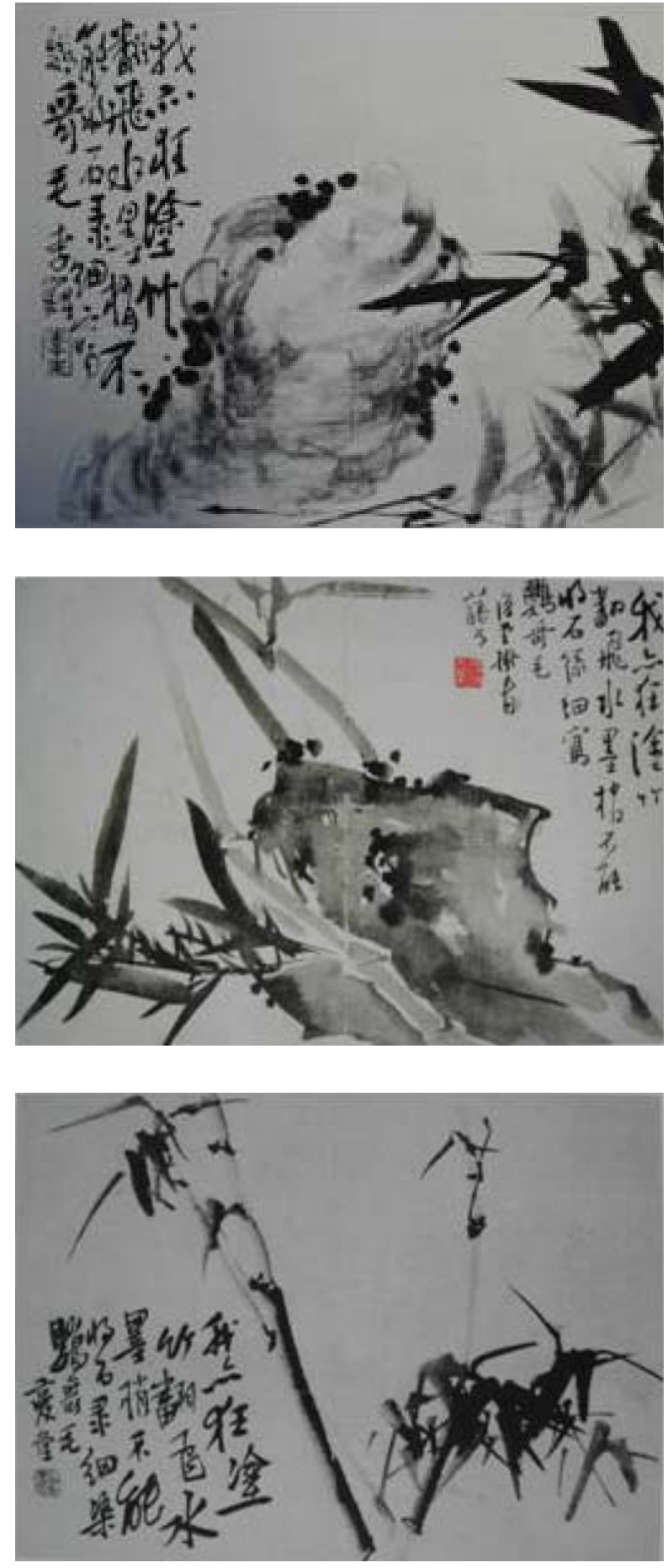

Figure 15.8a Li Shan, Bamboo. Ink on paper, $32.5 \times 46 \mathrm{~cm}$. J. S. Elliott Collection, Princeton University Museum.
Figure 15.8b Li Shan, Bamboo. Ink on paper, $25 \times$ $35 \mathrm{~cm}$. Sichuan Museum.
Figure 15.8c Li Shan, Bamboo. $24.1 \times 30.5 \mathrm{~cm}$. S. M. Nickerson Collection, The Art Institute, Chicago. 


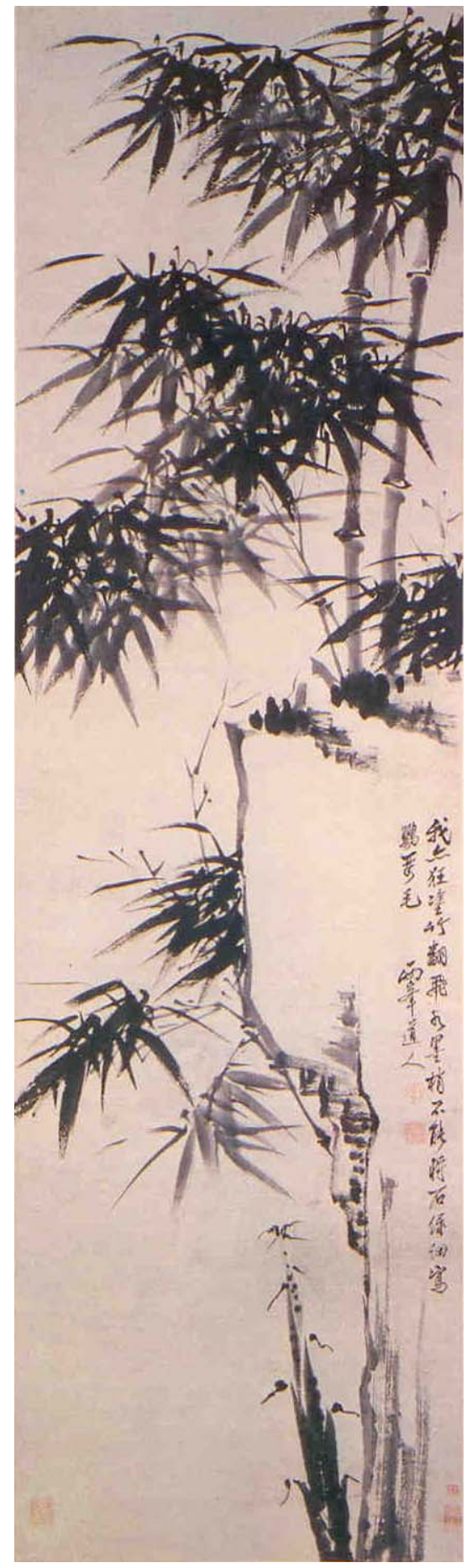

Figure 15.8d Luo Pin, Bamboo. Not dated. Ink on paper, $174 \times 50.2 \mathrm{~cm}$. The Palace Musem, Beijing. 
Looking at other examples, the poetic inscription on Li Shan's Bamboo (undated album leaf; Elliott's collection; see Fig. I5.8a) reads:

\author{
我亦狂塗竹, \\ 翻飛水墨梢。 \\ 不能將石綠, \\ 細染嬰鳥哥毛。 \\ I go crazy daubing bamboo; \\ My brush tip flying over water and ink. \\ I can't use mineral green \\ To pinpoint the colour of the parrot's feathers.
}

His two other album leaves called Bamboo (both undated; Sichuan Museum and Nickerson's collection respectively, see Figs I5.8b and 15.8c), and Luo Pin's Bamboo (undated hanging scroll, Beijing Palace Museum, Fig. 15.8d) were inscribed with a similar poem:

\title{
我亦狂塗竹, \\ 翻飛水墨梢。 \\ 不能將石綠,

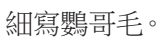

I go crazy daubing bamboo;

My brush tip flying over water and ink.

I can't use mineral green

To depict the colour of the parrot's feathers.

The poem was actually written by the Ming literatus Xu Wei 徐渭 (I52I-I593); it was published in Congshu jicheng xinbian 叢書集成新編 I985, vol. IO. The text on the hanging scroll was correctly remembered; the inscription on the album leaves simply altered one word. Of the four versions, I consider only Li Shan's Bamboo from Sichuan Museum (Fig. I5.8b) to be genuine.

In some other examples, a colophon by Zheng Xie on Li Fangying's Plum Blossoms Handscroll (Meihua juan 梅花卷), dated $1755,{ }^{33}$ was copied to Jin Nong's Plum Blossoms Handscroll (dated 1757; Tokyo National Museum). ${ }^{34}$ A colophon by Hang Shijun 杭世駿 (I696-I773), a scholar and occasional visitor to Yangzhou, on the second handscroll, was copied to another of Jin Nong's handscrolls titled Red and White Plum Blossoms (Hongbai meihua changjuan 紅白梅花長卷) (undated; the late Baochai Huo's collection). ${ }^{35}$ Both of the Jin Nong handscrolls are forgeries as were some of paintings attributed to Li Shan and Li Fangying. 


\section{THE SEALS OF DIFFERENT ARTISTS HAVE THE SAME CHARACTERS AND/OR IDENTICAL OR SIMILAR DESIGN}

In order to convince buyers that a work was 'authentic', the forgers copied the seal seen on a master's painting and reproduced it on a different artist's work.

Li Fangying, one of whose sobriquets was Baiyi shanren 白衣山人, 'the recluse dressed in white,' had a seal carved with the four characters Yibai shanren 衣白山 人 affixed to several of his paintings (see Fig. I5.9-I). It should be noted that seals with the same inscription Yibai shanren were also found on paintings by Li Shan. For example, a Yibai shanren seal was affixed to Li Shan's leaf depicting Lily (Baibe 百合), from the Flower Album (Huahui ce 花卉冊) (I740; Chinese History Museum) (No 3 on Fig. 15.9). Its design is almost identical with the seal reproduced in No 5 of Figure 15.9, which had been carved by Lin Gao 林㚖 (1658- ?), a famous seal carver of the period. ${ }^{36}$ However, they are two different seals. The seal in Figure I5.9-3 is a rectangle; the proportion of its width to its height is I:0.93, while the seal in Figure 15.9-5 is a square. The layout and carving technique of both seals are very good and they are considered genuine. Finally, the Yibai shanren seal could have been forged, too: for example, the seal reproduced in Figure 15.9-2, affixed to Li Shan's Twin Fish (Shuang yu 雙魚), a leaf from Crawford's collection, and the seal in Figure 15.9-4, affixed to Orchids (Lan 蘭), a leaf from the collection at Princeton University. Both were carved and designed in poor quality, and are evidently forgeries.

On some paintings, by either Li Shan or Li Fangying, there might be the seal Mutou Lao zi 木頭老子, but with different designs. It appears on Li Shan's Toad and Calamus (Chanchu changpu 蟾蜍菖蒲) (undated; private collection) ${ }^{37}$ as well as on Li Fangying's Fish ( $Y u$ 魚) (I744; Museum of Fine Arts, Boston), ${ }^{38}$ with the same design. However, both seals are clearly forged. Another identical set of the Mutou

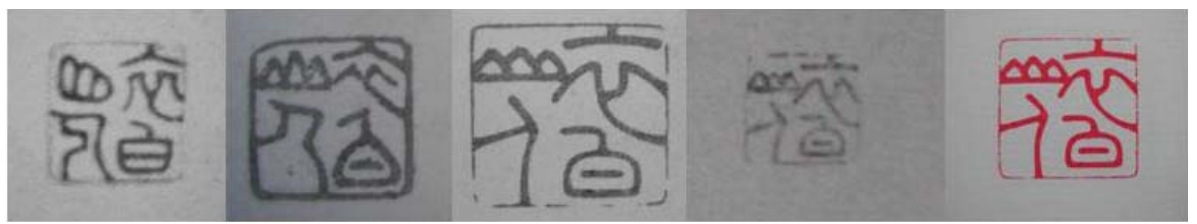

Figure 15.9 Seals of Yibai shanren. From Left: 1.Seal of Li Fangying, from Handscroll of Plum Blossoms, 1754. Nantong Musem. 2. Seal of Li Shan, from Twin fish, a leaf from the Flower album, 1740. John Crawford's Collection. 3. Seal of Li Shan, from Lily, a leaf from the Flower album, 1740. Chinese History Museum. 4. Seal of Li Shan, from Orchids, leaf from the Album of orchids and bamboo. Collection of the Art Museum, Princeton University. 5. Seal of Lin Gao. 


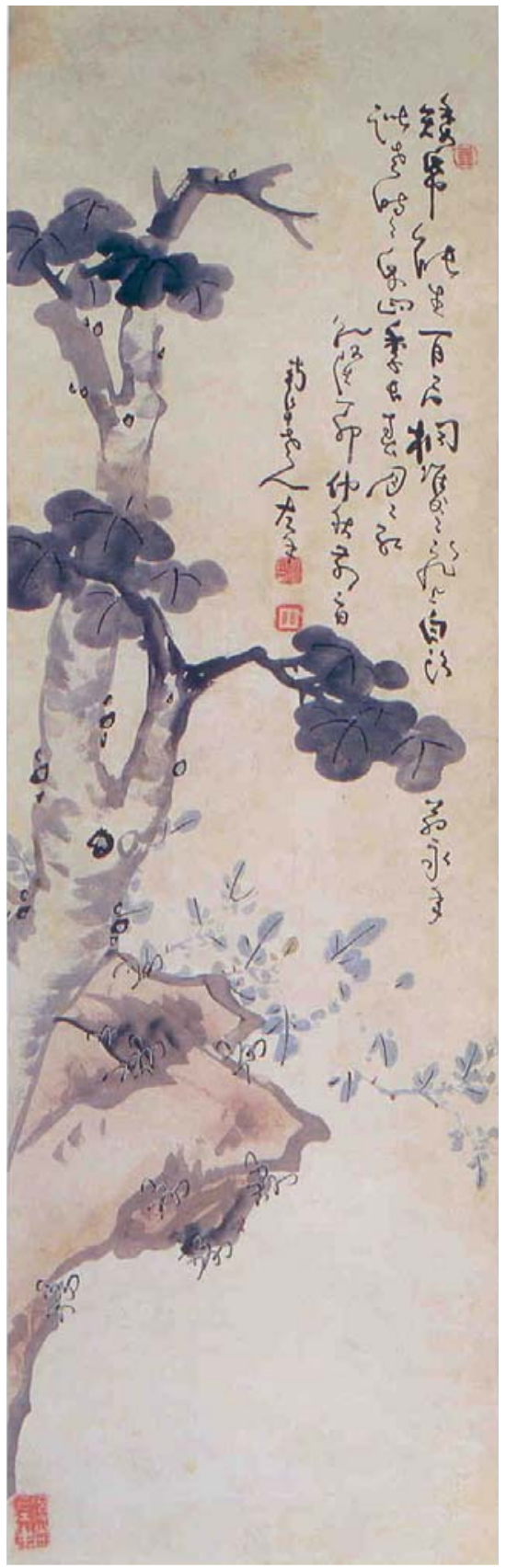

Figure 15.10a Gao Fenghan, Flowers, Tree and Rock, 1749. Ink and colours on paper, $142.5 \times 45 \mathrm{~cm}$. Nanjing Museum.

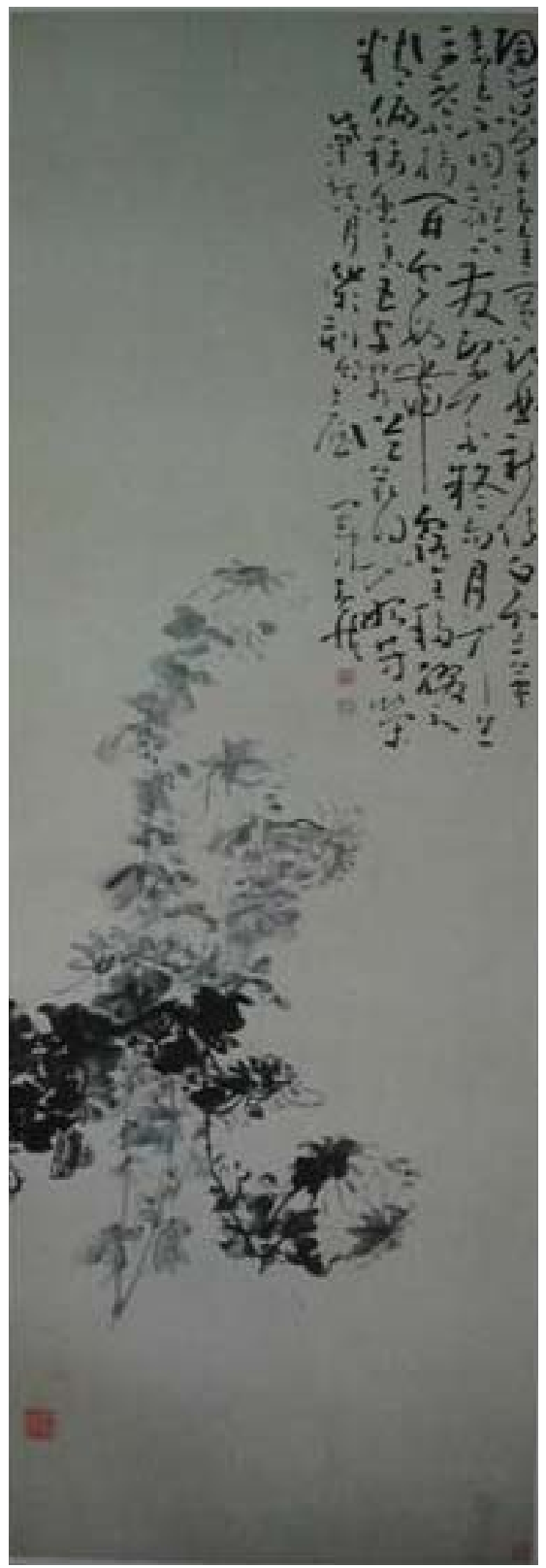

Figure 15.10b Huang Shen, Chrysanthemum, 1728. Ink on paper, $121.3 \times 41.5 \mathrm{~cm}$. The Palace Musem, Beijing. 


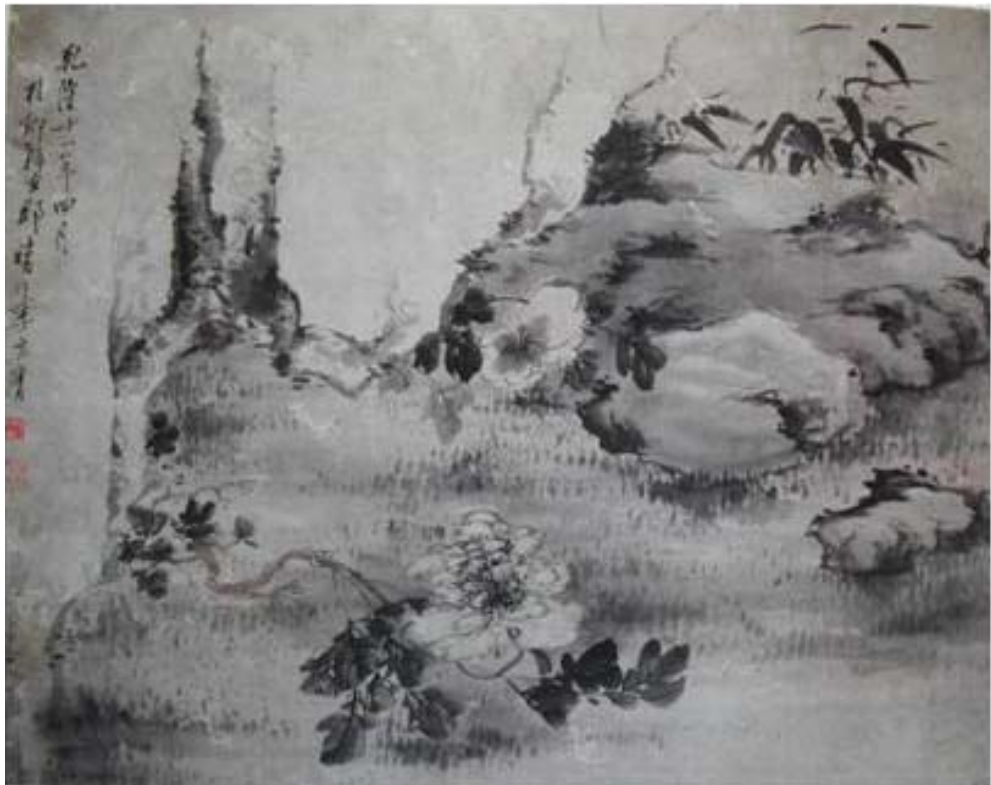

Figure 15.11a Li Fangying, Flowers. Album leaf, 1746. Ink and light colours on paper, 69 $\times 87.5 \mathrm{~cm}$. Shoudu Museum, Beijing.

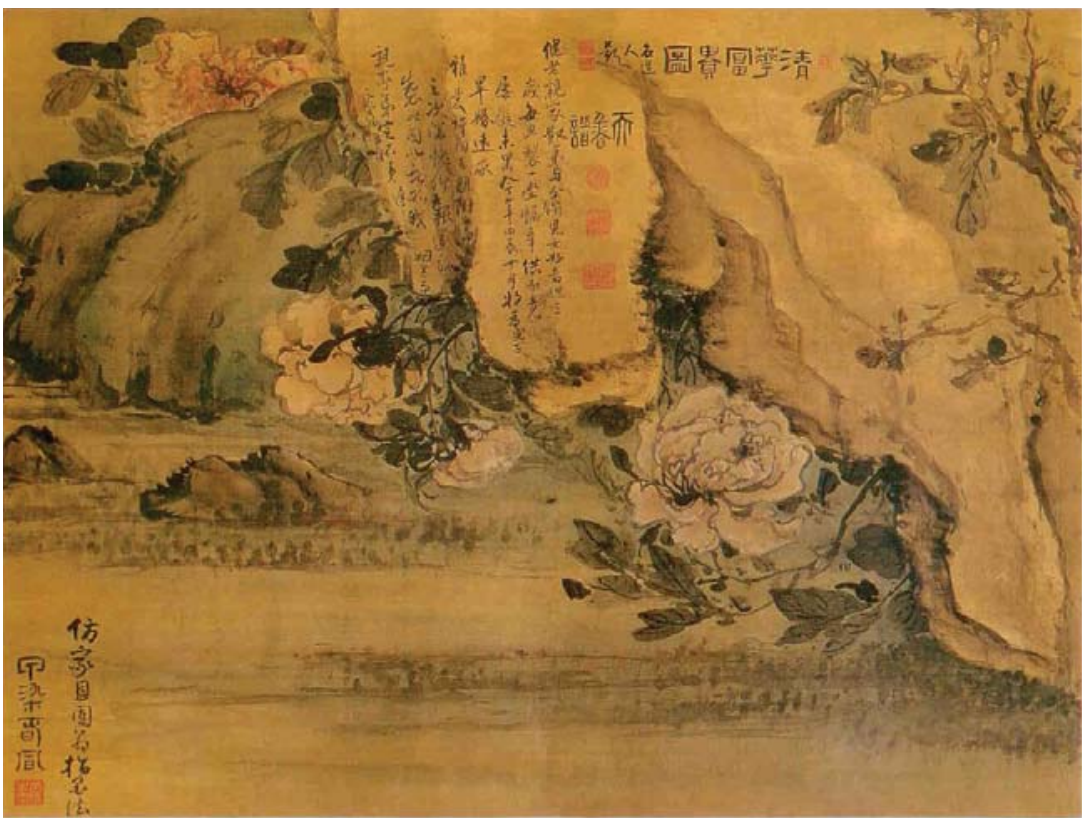

Fig. 15.11b Gao Fenghan, Splendid Peonies. 1736. Ink and colours, $78 \times 103 \mathrm{~cm}$. Collection of Juanqin Zhai. 


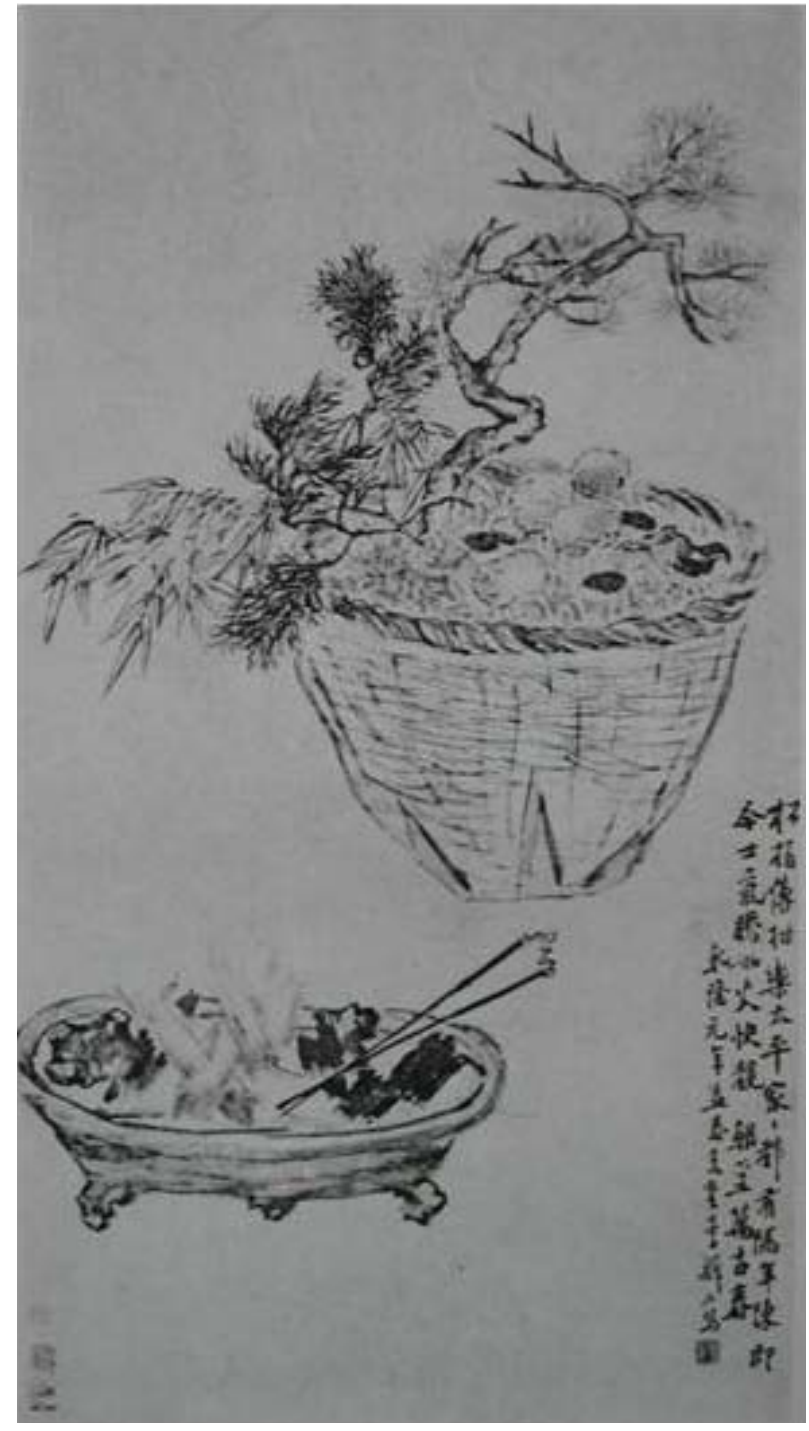

\section{Figure 15.12a Li}

Shan, Charcoal, Pine and Bamboo. 1736.

Association of the Artists of China.

Lao zi seals appears on Li Shan's Banana and Bamboo (Jiao zhu 蕉竹) (undated; Guangzhou Museum of Fine Arts), ${ }^{39}$ and on Li Fangying's Bamboo (Zhu 竹) (dated I75I; Princeton University), ${ }^{40}$ respectively. I nevertheless suspect that the former one is a forgery.

In addition, the seals Da kai xiao kou 大開笑 $\square$ and Lu pang jing shang 路旁井上 also appear on Li Fangying's as well as Li Shan's paintings. ${ }^{41}$ 


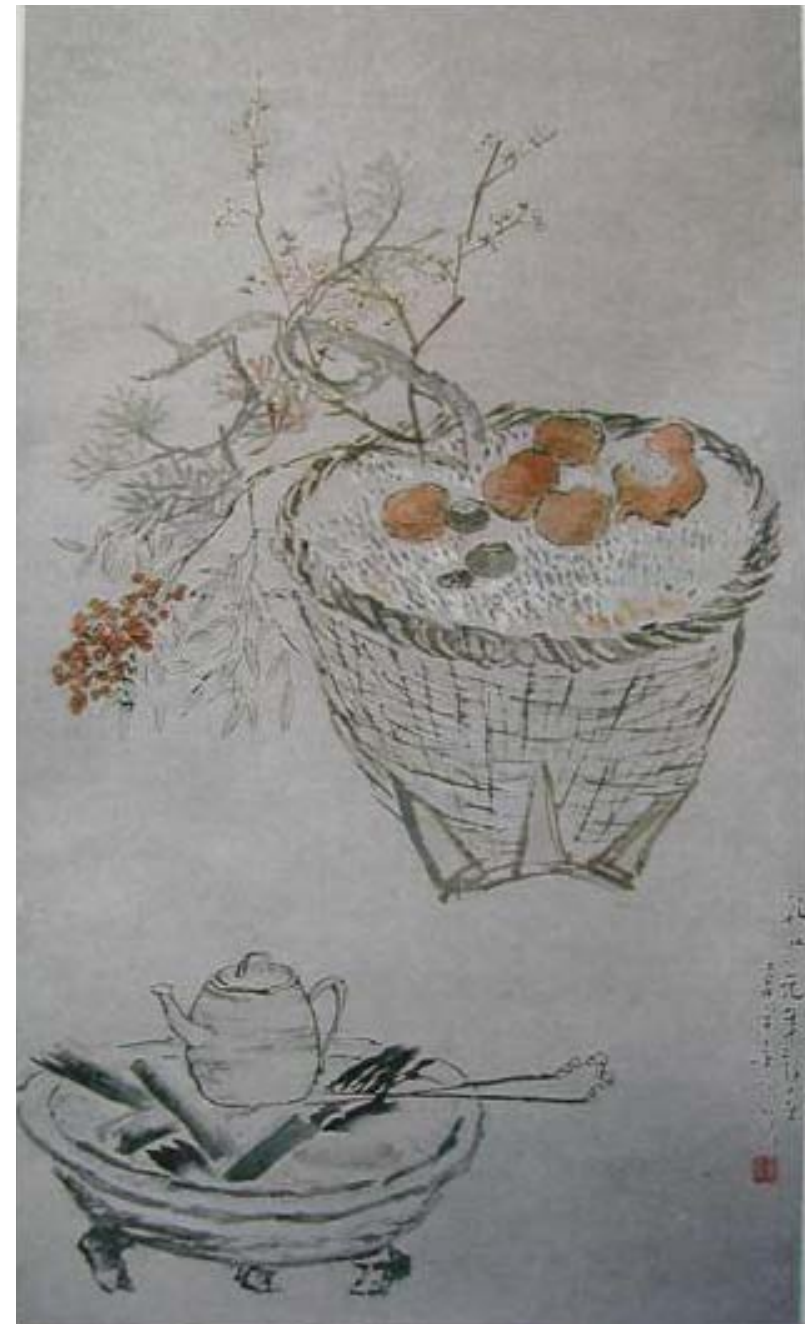

Figure 15.12b Li Shan, New Year Offerings. 1736. Ink and colours on paper. Fine Arts Museum, The Chinese University of Hong Kong.

\section{THE STYLE OF THE FORGERIES OF ONE ARTIST RESEMBLES ANOTHER ARTIST'S WORK}

Some forgers reproduced large numbers of works by the Yangzhou Eccentrics simultaneously, and in so doing adopted a style from one master's works to produce another master's works.

Some of Gao Fenghan's works, such as Chrysanthemum and Rock ( $J u$ shi 菊石) (1737) and Flowers, Tree, and Rock (Huahui shu shi 花卉樹石) (I749) (- I5.IOa) were rendered in slack, trivial, shaking and quick brush-strokes, and the characters of 


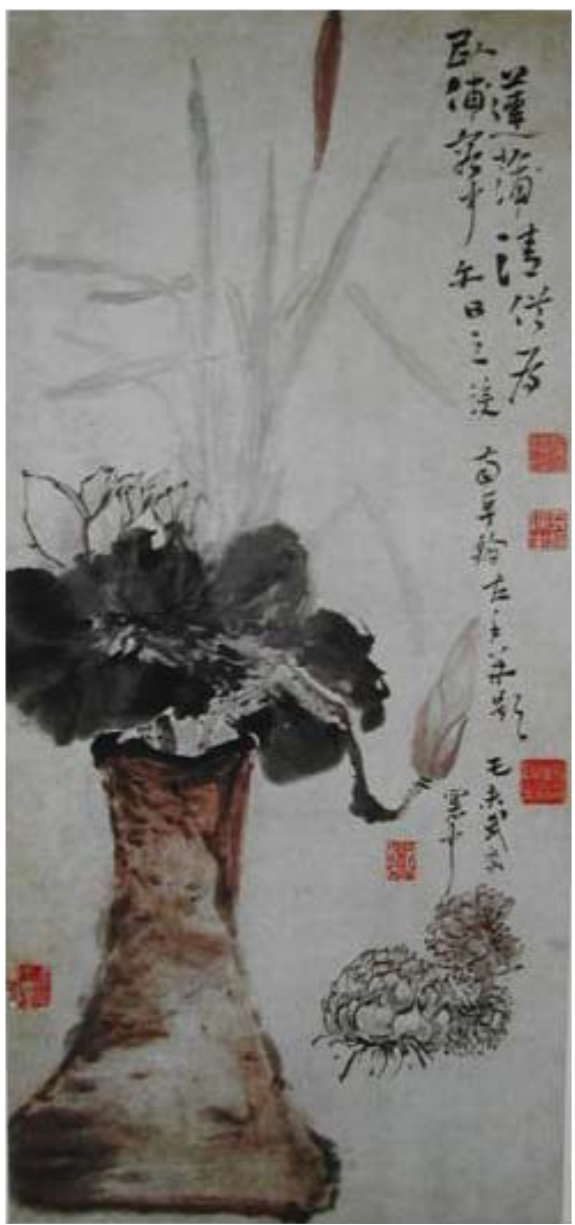

Figure 15.13a Gao Fenghan, Lotus

Offerings. 1739. Ink and Color on paper, 88 $\times 40.6 \mathrm{~cm}$. The Palace Museum, Beijing.

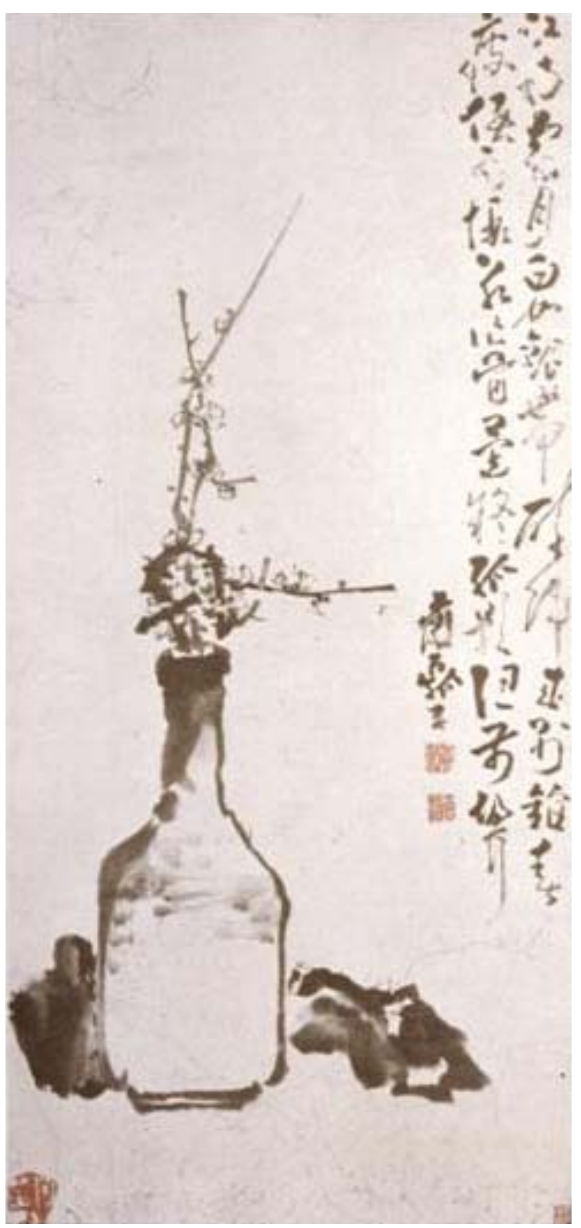

Figure 15.13b Huang Shen, Plum Blossoms in Vase. Collection unknown. 
the inscriptions were written in a scratchy, loose style. Those are not attributes of Gao Fenghan's style; rather, they resemble that of Huang Shen (see Fig. I5.Iob). Analogically, on Wang Shishen's Orchids and Rock (Lan shi 蘭石) (1747), ${ }^{42}$ the orchids and rock are shown in very large and vulgar shapes, which are not in his delicate, tranquil and reserved style, instead, they resemble Zheng Xie's style. ${ }^{43}$ In Birdcalls Amidst Bamboo (Zhujian ti niao 竹間啼鳥) (I753; Guangxi Zhuangzu Autonomous Regional Museum), ${ }^{44}$ a pseudo-work of Li Shan, the fat, heavy song thrush, so very unlike the skinny, slender birds in Li Shan's paintings, is actually replicated from Hua Yan's 華品 (1692-I756) work. ${ }^{45}$ Li Fangying's album leaf of Flowers (Huahui 花 卉) (1746; Shoudu Museum) (see Fig. I5.IIa) resembles a mirror version of Gao Fenghan's Splendid Peonies (Qinghua fugui 清華富貴), dated 1736 (see Fig. I5.Irb). In fact both are forgeries.

\section{THE FORGERIES INCLUDE ANACHRONISMS}

Some forgers of the late nineteenth and twentieth centuries might have studied Western art and gained knowledge of perspective, light and shadow. When making forgeries of the Yangzhou Eccentrics, they used some techniques of Western art unconsciously, ignoring the cultural background and the period style of these artists. When we examine these forgeries, these anachronistic features can easily be seen. For example, Li Shan's Charcoal, Pine, and Bamboo (Tanpen song zhu 炭盆松竹) ( 1736 ; Association of the Artists of China) (see Fig. I5.I2a) shows the traditional method of depicting burning charcoal, in which charcoal was rendered two-dimensional. Meanwhile in another version, titled New Year Offerings (Suichao tu 歲朝圖) (I736; Fine Arts Museum, The Chinese University of Hong Kong) (see Fig. I5.I2b), the charcoal is shown three-dimensionally, as it would be in a Western painting. I therefore consider the latter to be a forgery.

The depiction of the shade of the vase of Li Shan's Sons and Daughters with Riches and Honor (Ernü fugui tu 兒女富貴圖) (I728; Yangzhou Museum) ${ }^{46}$ tells us that the painting was done by an artist who knew Western art well. The same goes for another painting falsely attributed to Li Shan: Vase with Flowers and Fire in the Oven (Pinghua lubuotu 瓶花爐火圖) (I736; Hubei Provincial Wenwu store), ${ }^{47}$ in particular in respect of the perspective of the oven, and the heavy pigment applied for the charcoal. The heavy and dry pigment painted on the vase on Gao Fenghan's Lotus Offerings (Lianpu qinggong 蓮蒲清供) (1739, Beijing Palace Museum) (see Fig. 15.13a) is characteristic of oil rather than ink paintings; and the vase in both that painting and in Huang Shen's Plum Blossoms in Vase (Pingmei 瓶梅) (Fig. I5.13b) both show a Western chiaroscuro effect. But neither Gao Fenghan nor Huang Shen were familiar with Western art. 

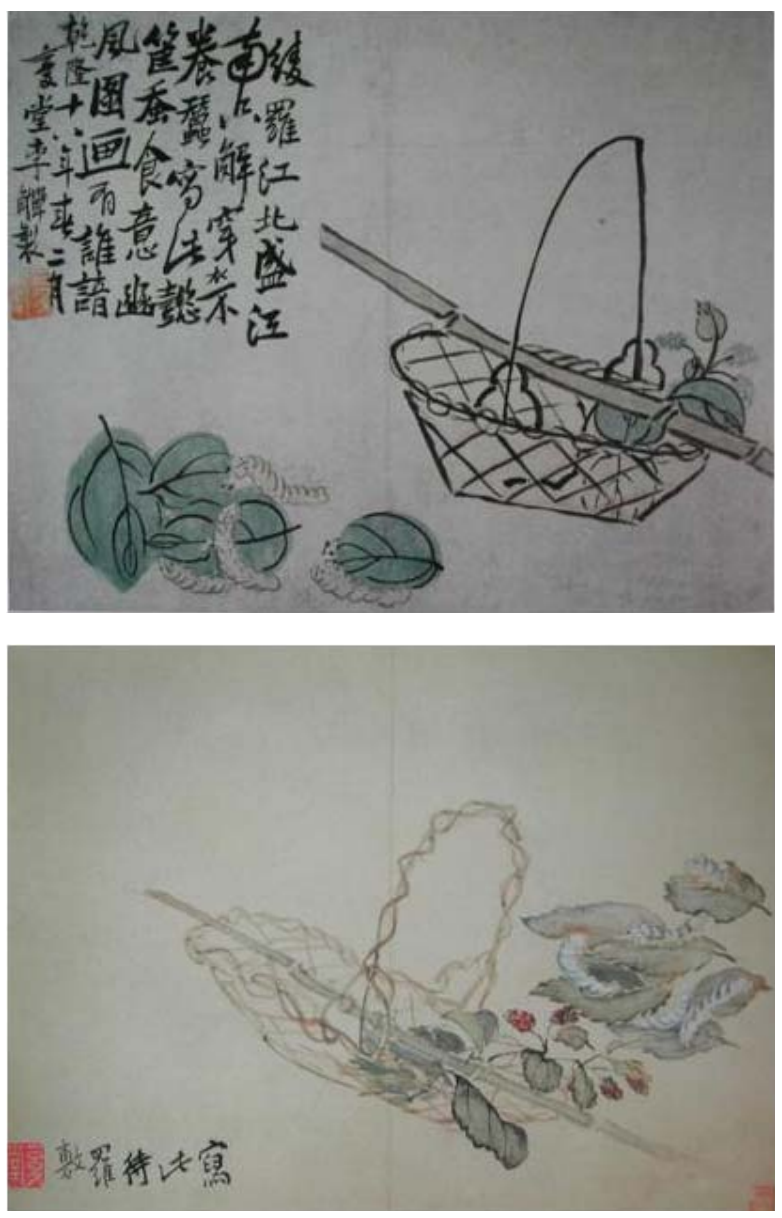

Figure 15.14a Li Shan, Silkworms and Mulberry. A leaf from the Flower Album, 1753. Ink and colours on paper, $25.4 \times$ $32.1 \mathrm{~cm}$. Liaoning Provincial Museum.

Figure 15.14b Li Shan, Silkworms and Mulberry. A leaf from the Flower Album, 1740. Ink and colours on paper, $25.8 \times 40.6 \mathrm{~cm}$. The Palace Museum, Beijing.

\section{INFERIOR FORGERIES CREATE ANOTHER STYLE}

The quality of the forgeries of the works of the Yangzhou Eccentrics varies. Some forgers were quite unskilled, but they still made many forgeries. Because there are so many of these inferior forgeries, after some time they came to be attributed to the masters, and might even come to be regarded as their 'other style,' making it all the easier to confuse connoisseurs.

Some forgeries of Li Shan's paintings, for example Chrysanthemum and Bird (Ju niao 菊鳥) (1734; Beijing Palace Musem) ${ }^{48}$ Sparrow and Fish (Que yu 雀魚) (1740; Shenyang Palace Museum), ${ }^{49}$ Peonies (Mudan 牡丹) (1752; Shanghai Wenwu store), ${ }^{50}$ Silkworms and Mulberry (Can sang 䖝桑) (dated I753; Liaoning Provincial Museum, see Fig. I5.I4a), and Geranium (Tianzhu 天竺) (dated 1754; Guangdong Provincial Museum $)^{51}$ imitated the works of Li Shan's late period. However, their technique is 
so poor that the shapes of objects seem very simple and two-dimensional whilst the brush-strokes are executed in a very stiff, clumsy manner. With such characteristics, these works cannot be considered to be in Li Shan's style, but are still mistakenly attributed to the 'style of Li [Shan].'

The sources for some of these forgeries can be easily found. For example, the originals of Sparrow and Fish (I740; Shenyang Palace Museum) and Silkworms and Mulberry (dated I753; Liaoning Provincial Museum), just mentioned, are the relevant leaves from the Flower Album dated I740, from the Beijing Palace Museum's collection (Fig.I5.I4b).

The same situation also occurred with Gao Fenghan's paintings. When one closely studies various paintings ascribed to him, e.g. Freshness within Mountains (Shanzhong qingwei 山中清味) (I735; Chongqing Museum), ${ }^{52}$ The Red Snow (Hong xue 紅雪) from the Painting and Calligraphy Album (1736; Tianjin Art Museum); ${ }^{53}$ and The Monk Returning to his Monastery (Wang si gui seng 晚寺歸僧) from the Album of Landscapes and Flowers Painted by Fingers (I736; Tianjin Art Museum), ${ }^{54}$ etc., the heavy, awkward, dry strokes, as well as the forms of the depicted objects, plus the black, muddy ink, cannot pass unnoticed; and one soon becomes aware that these flaws are due to the poor techniques of the forgers. They are quite unlike Gao Fenghan's light and deft strokes and his use of light ink, an excellent example of which is found in his River Landscape of Hongji (Hongji jiangtian 弘濟江天), leaf 3 of The Landscape Album dated 1734 (Shandong Museum). ${ }^{55}$ Instead, the forgers created a 'new style' that confused the viewer.

\section{FORGERIES MADE BY THE ARTISTS' DISCIPLES}

Forgers could be the masters' disciples, students, relatives, admirers, dealers or even masters of later periods. As mentioned above, some disciples of the Yangzhou Eccentrics were openly allowed or invited by the masters to produce forgeries. Forgeries of this kind are the most difficult to identify and accordingly confuse connoisseurs the most. Marshall Wu thought, for example, that Jin Nong's Red and White Plum Blossoms (undated; the late Baochai Huo's collection) ${ }^{56}$ was a copy made by Xiang Jun, for the handscroll bears two small seals Xiang 項 and Jun 均 (WU I99I: 282-284). Nonetheless, I believe that those two seals might be forgeries too, for both Jin Nong's inscription and Hang Shijun's colophon on the handscroll were forged, as mentioned earlier. Besides, the quality of drawing of the plum flowers is inferior; for instance, the flower stalks are not drawn, and the petals of flowers are not as thin, sparse and vivid as described in Jin Nong's Inscriptions on Plum Painting, Huamei ti ji 畫梅題記 (Huang Binhong, Deng Shi i963, vol. 3: 9I).

The copies made by another student of Jin Nong, Luo Pin, are easier to identify, partly because many of Luo Pin's works are still in existence. When comparing 
works by Jin Nong and Luo Pin, we can see that Jin Nong's brush-strokes are more naive, the ink is blacker, and the calligraphy is thicker. Wu Erlu 吳爾鹿 believes that

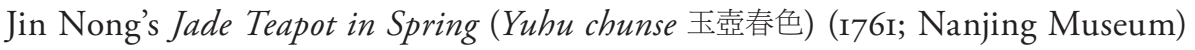
(Fig. 15.15), A Lohan (Luohan 羅漢) (176r; Beijing Palace Museum), ${ }^{57}$ and The Legendary Steed Hualiu (Hualiu tu 驊騮圖) (1760; The Osaka Municipal Museum) ${ }^{58}$ were produced by Luo Pin (Wu Erlu 1988:74). Some other scholars also agree that these paintings might not have been done by Jin Nong.

Finally, I would like to mention some imitations of the works of the Yangzhou Eccentrics done by late nineteenth-century masters. Some of them carry inscriptions by the artist, whereby they clearly state that their painting imitated a particular Yangzhou master, albeit some do not indicate the source of inspiration. Such works were not intended to be forgeries, therefore they do not need to be regarded and scrutinized as such. It would not be difficult to identify them anyway, for anyone familiar with the works of the Yangzhou Eccentrics. To give briefly just a few examples, Ren Xiong's 任熊 (1820-1857) Picking Water Chestnuts (Cai ling tu 採菱圖) (I850-I85I; Beijing Palace Museum) ${ }^{59}$ is an imitation of Jin Nong's painting of the same title (dated 1759; Shanghai Museum). ${ }^{60} \mathrm{Xu}$ Gu's 虛谷 (1824-I896) Hermits in an Autumn Forest (Qiulin yishi 秋林逸士) (dated I876; Shanghai Museum) ${ }^{61}$ was copied from Jin Nong's Talking in an Autumn Forest (Qiulingong hua 秋林共話) (dated 1759; Shanghai Museum). ${ }^{62}$ Chen Nian's 陳年 (1877-1970) Growing Chrysanthemum at a Thatched Cottage (Caotang yi jun 草堂藝 菊) (dated 1909; private collection, Taiwan) ${ }^{63}$ was duplicated from Gao Fenghan's Growing Chrysanthemums at a Thatched Cottage (dated 1727; Wuxi Museum). ${ }^{64}$ And the Buddha on Qi Baishi's 齊白石 (1863-1957) Buddha of Longevity (Wuliang shoufo 無 量壽佛), dated $1936^{65}$ was derived from Jin Nong's Banana and Buddha (Bajiao gufo 芭蕉古佛) (undated; Shanghai Museum). ${ }^{66}$

\section{CONCLUSION}

The eight situations described above exemplify the typical characteristics seen in the forged paintings of the Yangzhou Eccentrics. The enormous number of forgeries of these masters has arisen on account of some obvious factors - their works must have been much loved, much in demand, and their possession very profitable. Identifying a work as a forgery would dent a collector's or dealer's profit, so scholars have usually been reluctant to say so, except when no social considerations were involved. However, when a forgery is treated as authentic, the outcome is unsatisfactory. I would therefore remind scholars to be more aware of the possibility of forgery when studying the work of the Yangzhou Eccentrics. 


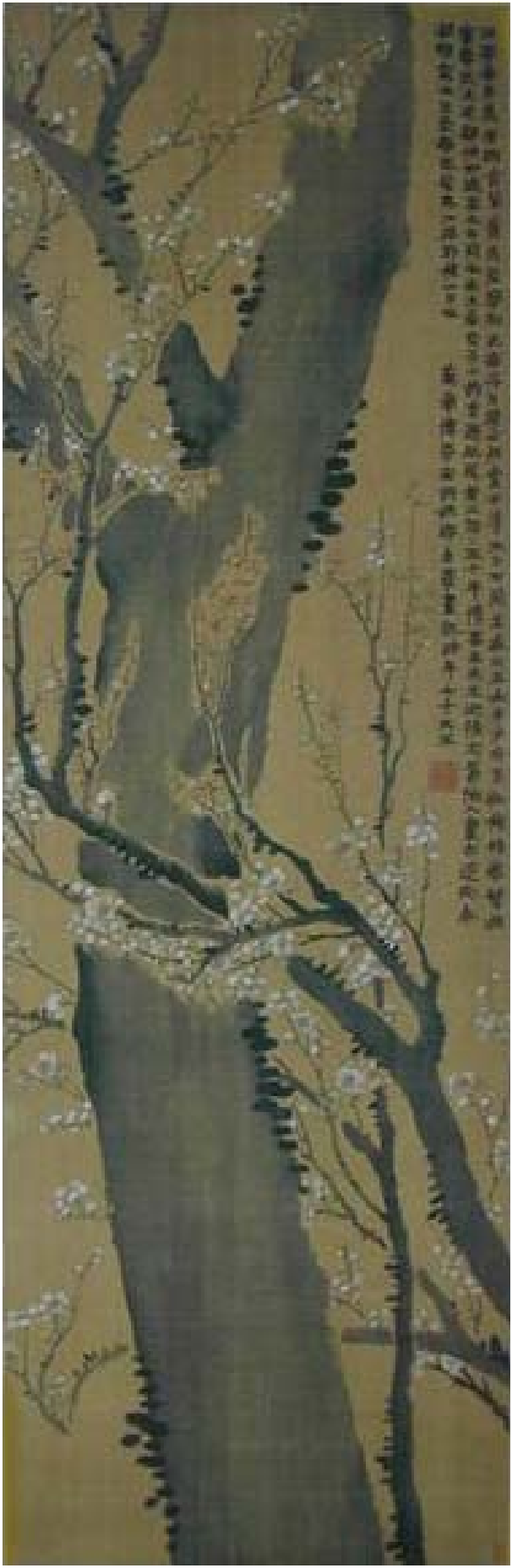

Figure 15.15 Jin Nong, Jade Teapot in Spring. 1761. Ink and colours on silk, 131 $\times 42.5 \mathrm{~cm}$. Nanjing Museum. 


\section{NOTES}

1 The word guai 怪, translated here as 'eccentric,' can mean strange, odd, weird, queer or peculiar.

2 Marshall Wu in his paper 'Jin Nong: The eccentric painter with a wintry heart,' presented at the symposium Chinese Painting under the Qianlong Emperor, Phoenix Art Museum, 1985.

3 Translated by Malcolm McKinnon and John McKinnon.

4 See Jin Nong. Dongxin zixiezhen tiji 冬心自寫真題記 [Inscriptions on Dongxin’s self-portraits]. In Huang Binhong, Deng Shi 1963, vol. 3: II3.

5 ZHUANG Sue 1996: 103-07, plates 19-23.

6 Yangzhou huapai shuhua quanji: Huang Shen 1998, plates 157, I86, and 251.

7 See Zhuang Sue 1992.

8 Those four are to be found in the Nanjing Museum (dated 1735), the Freer Gallery of Art (dated 1747), the Guangzhou Museum of Fine Arts (dated 1755), and in the Jilin Provincial Museum (dated 1749).

9 Reproduced in Yiyuan duoying 1978: 22.

10 The version of I753, see Yangzhou baguai shuhua jingxuan 200I: 31, plate 36. The version of I747, see Zhongguo gudai shuhua tumu, vol. 6, 蘇(Su)II-059.

11 The one of $\mathrm{1744}$, see Christie's Catalogue of 2005, 4, 25, p. 4I8 and 1994, 6, I, no. 204. The one of I747, see Christie's Catalogue of 1990, II.28, no. 48.

12 Eight Dynasties of Chinese Painting 1980: 366, plate 268.

13 YANG Xin I98I, plate I4.

14 Suzuki 1983, vol. I, A30-20.

15 Sotheby's Catalogue 1990, 5, 3, no. 91.

16 Zhongguo gudai shuhua tumu, vol. 6, 蘇 (Su) 8-132.

17 Zhongguo gudai shuhua tumu, vol. 6, 蘇 (Su) II-059.

18 Eight Dynasties of Chinese Painting 1980: 366, plate 268.

19 Zhongguo gudai shuhua tumu, vol. 6, 蘇 (Su) II-059.

20 Eight Dynasties of Chinese Painting 1980: 366, plate 268.

21 The same as in Fig. 15.3, reproduced in Duoyun xuan canghua xuan 1990, plate 23.

22 Zhongguo gudai shuhua tumu, vol. 6, 蘇 (Su) 6-I9I.

23 Suzuki i983, vol. I, A30-20.

24 Reproduced in Yangzhou huapai shuhua quanji: Li Shan 1998, plate I64.

25 For a fuller account see ZHUANG Sue 1992.

26 Yangzhou huapai shuhua quanji: Li Shan 1998, plate 125.

27 Yangzhou huapai shuhua quanji: Li Shan 1998, plate 54.

28 See Yangzhou huapai shuhua quanji: Li Shan 1998, plate I16, plate 149, and Zhongguo gudai shubua tumu, vol. 5, 滬 (Hu) I-37I4, respectively.

29 Leaf 6 of version A reproduced in Suzuki 1983, vol. 4, JP29-3. Leaf 3 of version B, see ibid., vol. I, Ar8-70. Leaf 2 of version C, see Yangzhou baguai shuhua ji 1970, vol. 6, plate 137-2. 
30 Leaf I2 of version A reproduced in Suzuki 1983, vol. 4, JP29-3. Leaf I of version C, reproduced in Yangzhou baguai shuhua ji 1970, vol. 6, plate I37-I.

31 Zhuang Sue 1989: I29-I30, plates I and 2; Yangzhou huapai shuhua quanji: Huang Shen 1998, plate 17; Yangzhou bajia huaji 1994, plate 7I.

32 I discussed the authenticity of this painting with the former director of Yangzhou Museum Jiang Hua 蔣華 in 1990. She admitted that it was done by a Yangzhou painter who had just died.

33 Reproduced in Shina Nanga taisei 1935-1937, vol. 3, plate 136.

34 Reproduced in Suzuki 1983, vol.3, JMi-IO7.

35 Reproduced in SuzuKi 1983, vol.2, S9-I.

36 The seal in Figure 15.9-5 is reproduced in Koвayashi 1982, vol. 9: 49. The commentary at the end of the volume, titled Lin Gao, Gao Fenghan, Zhang Zaixin, and others 林㚖、高鳳翰、張在辛、他, gives no further information about this seal except that it was carved by Lin Gao, who was about a generation older than Li Fangying and Li Shan. Whether it was carved for Lin Gao himself or somebody else is unknown.

37 Yangzhou baguai shuhua ji 1970: 138.

38 ZhUang Sue 199I: I4I, plate 30.

39 Zhongguo meishu quanji, huihua bian 1988, vol. II, plate 54 .

40 See Zhuang Sue i99i: I42, plate 32.

41 See Zhuang Sue 199i: I42, plates 34-40.

42 Yangzhou huapai 1985 , plate 22.

43 See, for example, Zheng Xie's Orchid and Rock (undated), reproduced in Yangzhou baguai shubua ji 1970, vol. 3, plate I05.

44 Yangzhou huapai shuhua quanji: Li Shan 1978, plate 191.

45 See Hua Yan's Thrush (undated), reproduced in Yangzhou baguai huaji 1985: 93.

46 Yangzhou huapai shuhua quanji: Li Shan 1978, plate I8.

47 Yangzhou huapai shuhua quanji: Li Shan 1978, plate 72.

48 Yangzhou huapai shuhua quanji: Li Shan 1978, plate 38.

49 Yangzhou huapai shuhua quanji: Li Shan 1978, plate 93.

50 Yangzhou huapai shuhua quanji: Li Shan 1978, plate 177.

51 Yangzhou huapai shuhua quanji: Li Shan 1978, plate 199.

52 Yangzhou huapai shuhua quanji: Gao Fenghan 1998, plate 103.

53 Yangzhou huapai shuhua quanji: Gao Fenghan 1998, plate II3.

54 Yangzhou huapai shuhua quanji: Gao Fenghan I998, plate 126.

55 Reproduced in Qing Gao Fenghan Shanshui ce 198I.

56 Reproduced in Suzuki 1983, vol. 2, S9-I.

57 Yangzhou huapai shuhua quanji: Jin Nong 1998, plate Io6.

58 Yangzhou huapai $1985: 77$.

59 Ren Xiong, Album of Paintings for Yao Xie's Poetry 任熊姚䝨詩意圖. Shanghai People's Art Publisher. 
60 Yangzhou huapai 1985: 74.

61 Masterworks of Shanghai School Painters from Shanghai Museum Collection 上海博物館藏海上名 畫家精品集. Hong Kong: Da Ye Co., I99I, plate 26-8.

62 Paintings of The Eight Eccentrics of Yangzhou. p. 2I.

63 Modern Chinese Painting, I9II-49: Beijing 民初十二家北方畫壇. Taipei: National History Museum, 1998, p. 87.

64 Yangzhou huapai shuhua quanji: Gao Fenghan 1998, plate 70.

65 Li Chu-Tsing 1979, Fig. 28.

66 Yangzhou huapai shuhua quanji: Jin Nong 1998, plate II6. See Fig. I8.3, p. 4I2 of this book. 


\section{Traveling to the Frontier:}

\section{Hua Yan's Camel in Snow}

\section{Ginger Cheng-chi Hsü}

$\mathrm{I}_{\mathrm{n}}^{\mathrm{n}}$ n 1746, Hua Yan 華品 (1682-1756) painted a picture of a snowy scene with a man peeking out from a Mongolian yurt and an emaciated camel standing right next to the entrance, its rear end facing the viewer (Fig. 16.1). On top of the snowcapped mountain that forms the background to the yurt, a crescent moon hangs next to a flying goose. The painting is rendered mostly in ink monochrome, with the darkened sky a dramatic contrast to the snow-white mountain. A splash of red from within the tent catches the eye of the viewer, echoed by the light red of the finial on top of the tent. With just the camel, goose, and man under the crescent moon, loneliness is written all over the picture, except for the intense looks of the man and the camel, which seem to break the solitude. The two-line colophon on the upper left can be translated as 'The old camel tastes the coldness under the crescent moon, [as] the remaining snow clears the sky for a single goose.' This is the second part of a seven-character quatrain entitled 'Thinking of the Scene on the Frontier' recorded in Hua Yan’s own anthology, Xinluo shanren tihua shiji 新羅山人題畫詩集 [Collection of Poems on Paintings by the Recluse from Xinluo]. ${ }^{1}$ The images described in the remaining two lines of the poem - including yellow sand, gusty wind, thick cloud, and long dark night - not only delineate the morbidity of frontier scenery but are reminiscent of the rhetoric of 'frontier poetry', biansai shi 邊塞詩, which had reached its full flowering during the Tang dynasty.

A closer look at the figure in the painting, with his curly hair, heavy beard and mustache, and hooked nose, reveals that he does not belong to either the Han or the Manchu ethnic group of his time. He is peeking out from the yurt to inspect the camel on the wintry night. It is so cold that he only permits himself a narrow opening, exposing his hatless head with its detail of his face and an earring in his left ear. His eyes downcast, he seems to be listening rather than looking. At the same time, the camel casts its eye upward, creating a certain connection between animal and man (Fig. 16.2). The details of the two subjects are rendered in comparatively fine, descriptive brushwork and color, whereas the background landscape is executed in splashy brushwork and ink wash. The combination of a non-Han figure and a camel, not to mention the yurt, clearly indicate a setting outside of the Great Wall, 


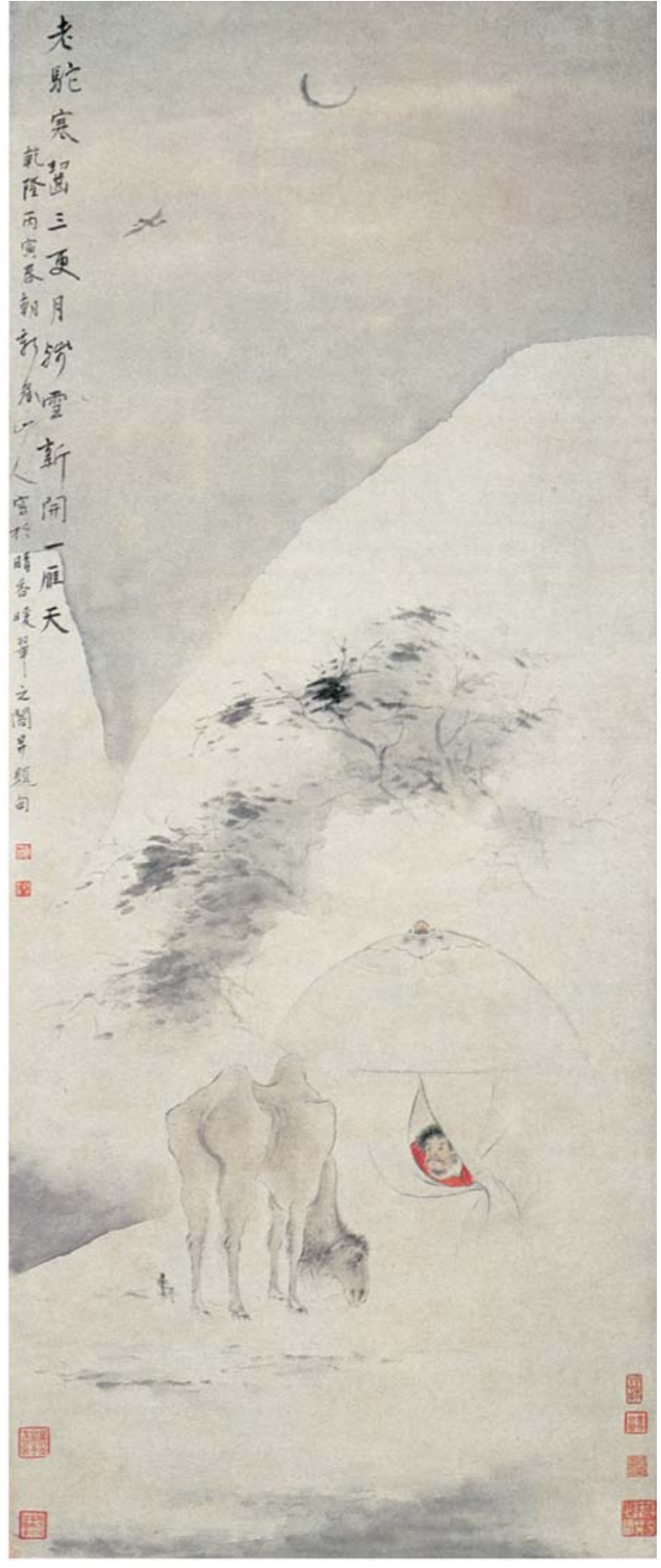

Figure 16.1 Hua Yan,

Camel in Snow. Dated 1746. Hanging scroll, ink and color on paper, 139.5 $\times 58 \mathrm{~cm}$. Palace Museum, Beijing. 
saiwai 塞外. Is this a Mongol with his livestock on a wintry night? The shape of the yurt resembles that of the tents in Qing court paintings depicting imperial banquets at the summer palace, such as the Imperial Banquet in the Garden of Ten Thousand Trees (Wanshuyuan ciyan $t u$ 萬樹園賜宴圖), dated to I755 (Fig. I6.3a-b). But the simple decoration seems to point in a different direction. Could this be a soldier peering out from his military tent? The combination of a camel and a man with an earring also reminds us of people from neighboring areas north and west of China proper, as illustrated in the Ming-dynasty Sancai tubui 三才圖會 [Illustrated Encyclopedia of the Three Realms] (Fig. I6.4).

In this painting, besides adopting the rhetoric of a poetic genre focusing on life on the frontier, Hua Yan borrows the traditional iconography of non-Chinese figures, huren 胡人. Even the use of red for clothing in the snowy scene could be a conventional practice rather than a simple aesthetic choice, for it seems to respond to a practice recorded in Gao Lian's 高濂 Zunsheng bajian 遵生八箋 [Eight Discourses on the Art of Living] (I59I). In the section listing a series of elegant pastimes in the winter month of December, the author maintains that it is most appropriate to dress

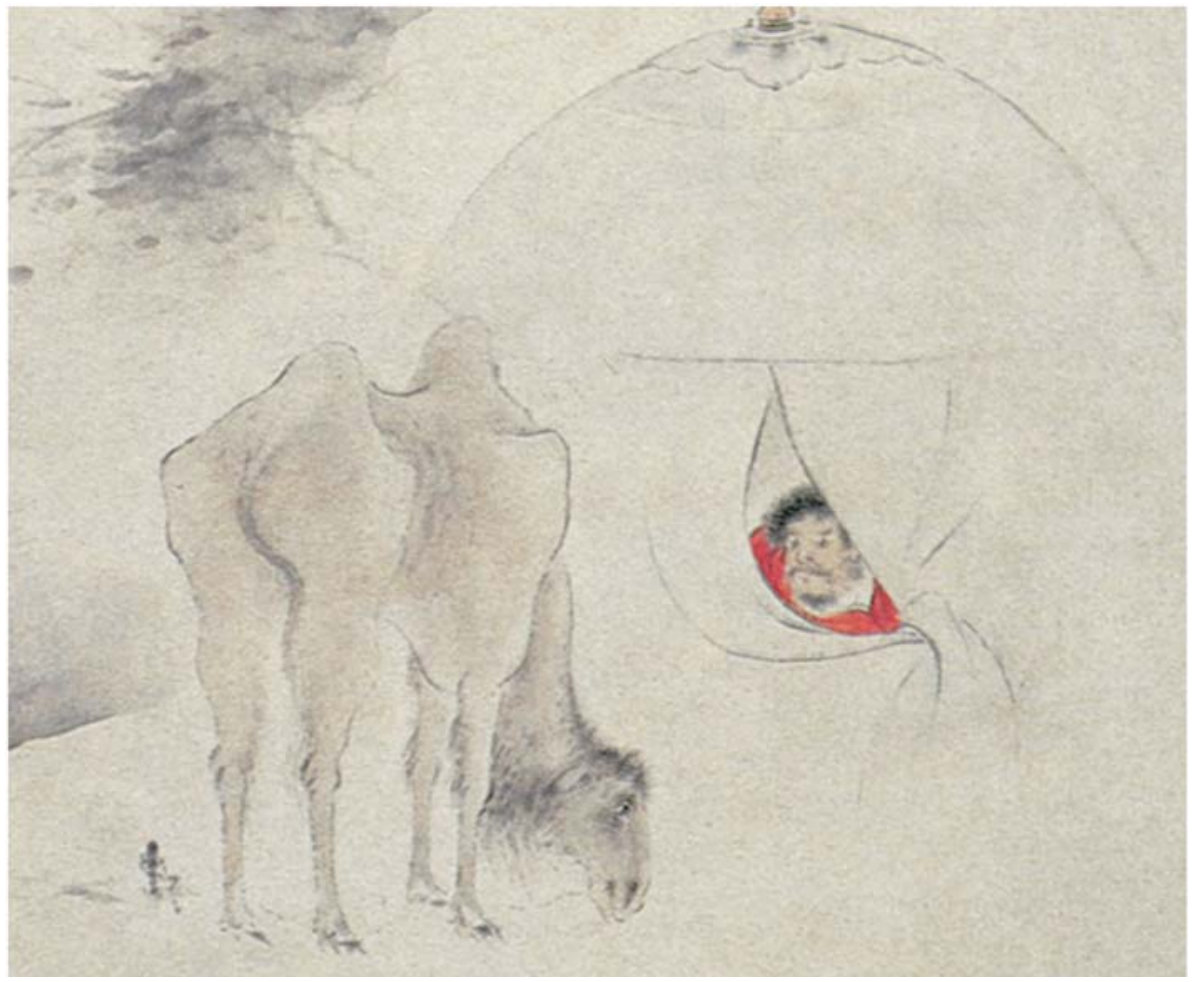

Figure 16.2 Hua Yan, Camel in Snow, detail. 


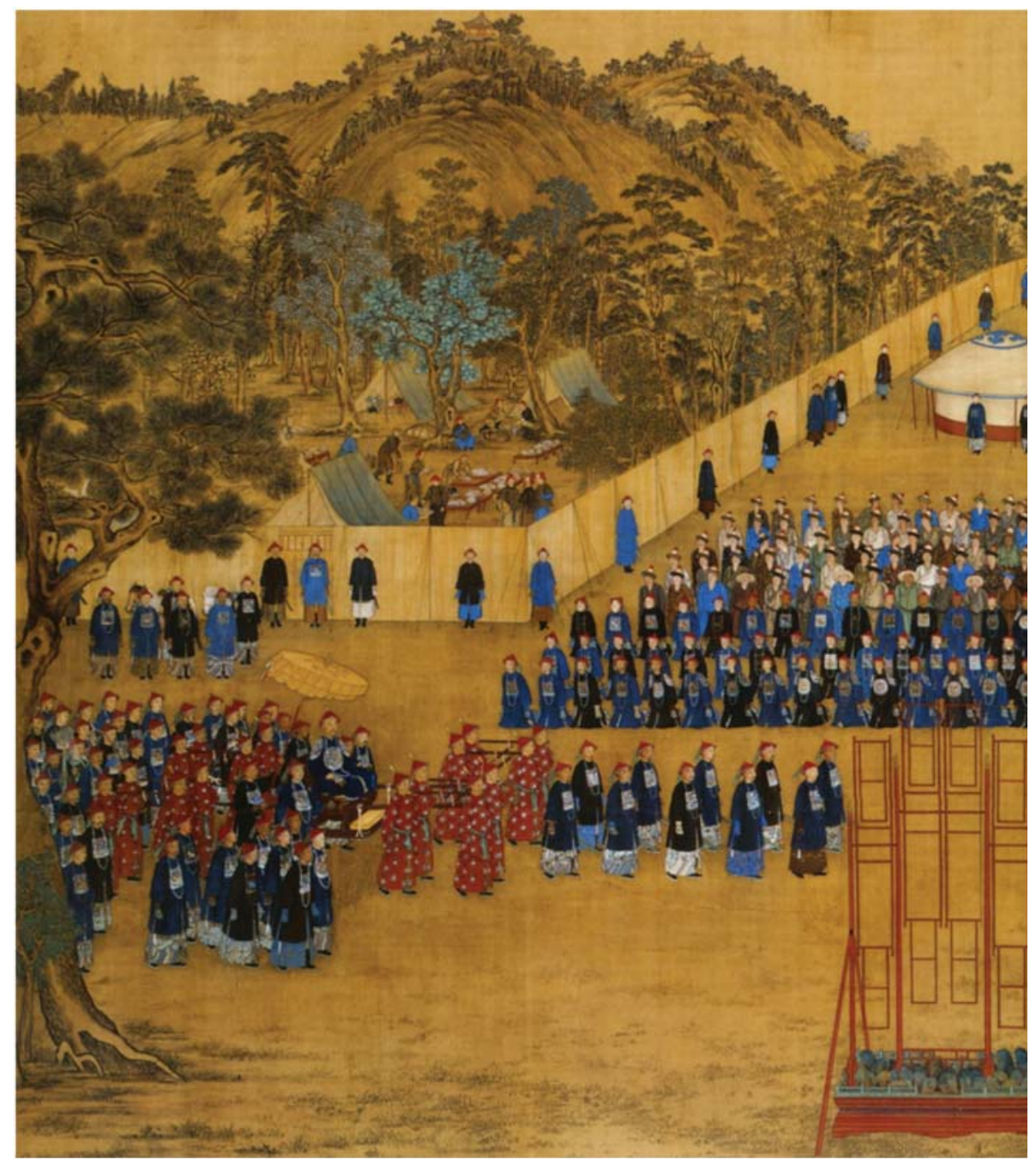

Figure 16.3a-b (both pages) Attributed to G. Castiglione, J.-D. Attiret, I. Sichelbarth and Chinese court painters, Imperial Banquet in the Garden of Ten Thousand Trees. Completed in 1755. Horizontal wall-scroll, ink and color on silk, $221.5 \times 419 \mathrm{~cm}$. The Palace Museum, Beijing.

in red while searching for the blossoming plum. Red adds color to the scenery while blending in with the blossoms when drinking under a flowering plum tree, and also discloses the refined quality of the red-garbed person (GAO Lian I983 [I59I]: 6:35a). Elegant or not, Hua Yan seems to follow convention rather closely and often dresses his winter travelers in red. For example, in his Tianshan under Snow (Tianshan jixue tu 天山積雪圖), dated to I755, a man in red accentuates the contrast to the snowy 


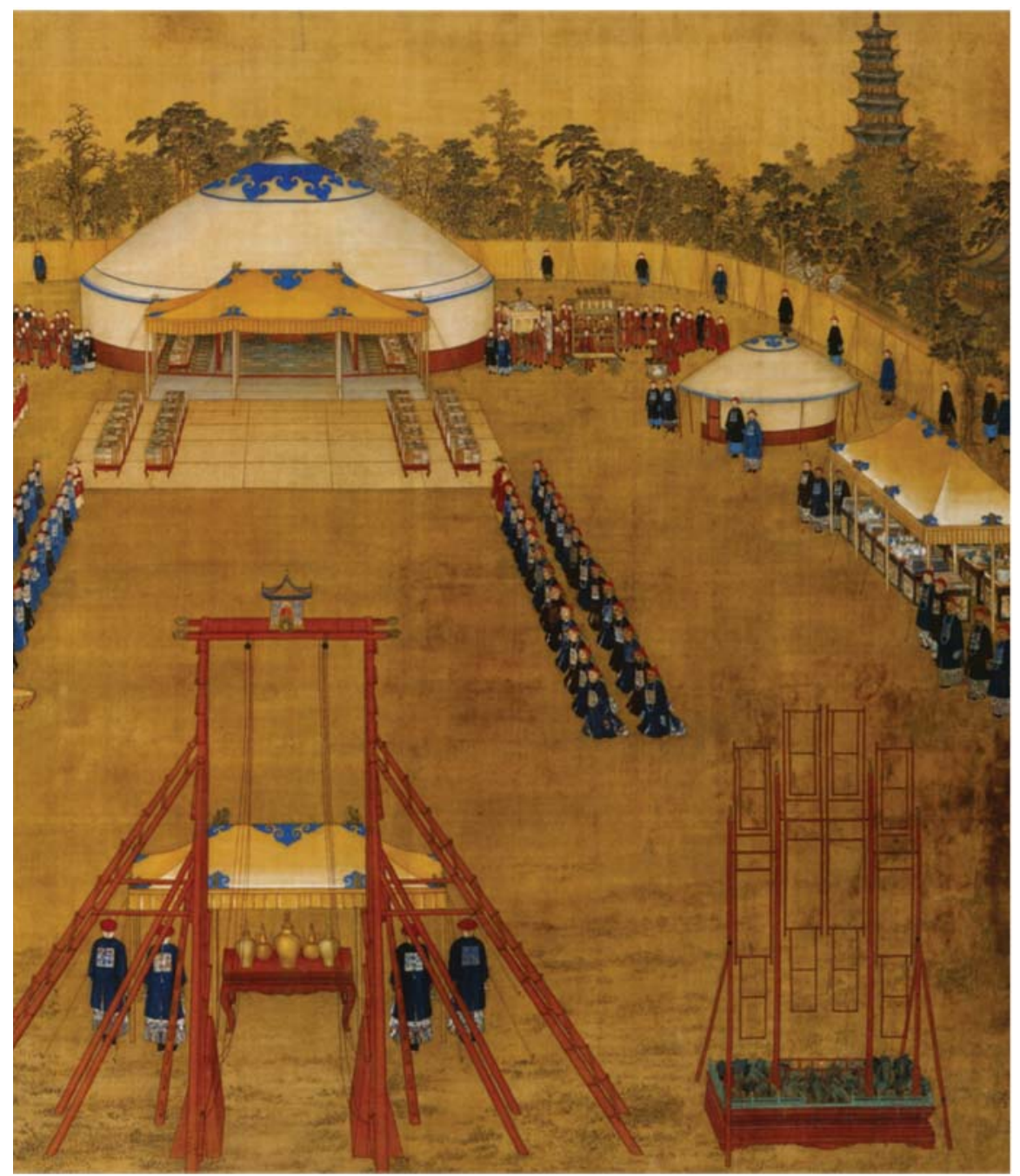

white background (Fig. I6.5). In another painting, Pause at Guan Mountain, a man on horseback, also dressed in red, pauses in front of a snowy mountain. ${ }^{2}$

In his Camel in Snow (Hantuo canxue 寒駝殘雪), Hua Yan has struck a familiar note of melancholy with a tinge of nostalgia. A closer examination of the figure and the animal in the picture, especially the minute detail of the modeling of the camel's thin body and the texture of its fur, as well as its side-view eye and the most unusual back-facing posture, seems to indicate that this is a sketch from real life rather than the illustration of a poetic line or imaginary scene. Against the background of the many saibe $i$ 塞北 (North of the Great Wall) ${ }^{3}$ subjects in the paintings of the Qianlong 乾隆 court, and in the context of Hua Yan's personal experience as a traveler, further 


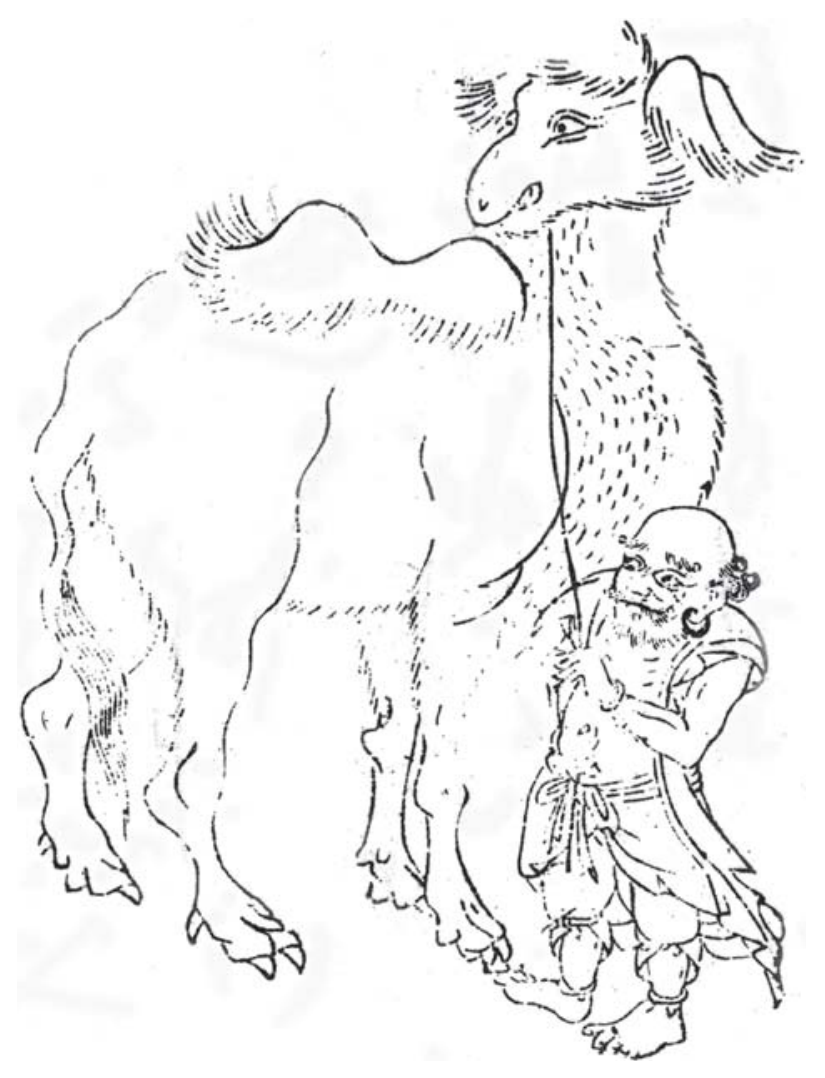

Figure 16.4 Figure.

Woodblock print. Sancai tuhui 13:14a.

examination of this painting provides us with a broader vision. Among other things, it reminds us of the territorial and commercial expansion that followed the Manchus' successful military and diplomatic campaigns, as well as of the multicultural nature of the Qing regime.

\section{SAIBEI SUBJECTS IN QIANLONG COURT PAINTING}

The camel appears in Chinese painting in scenes of nomadic life and as a background to activities outside the Great Wall, but rarely as the main subject of a painting, as seen in Hua Yan's Camel in Snow. ${ }^{4}$ For example, in the parting scene of Lady Wenji Returning to Han, two camels situated next to the chariot, among tents, animals, and fluttering flags, mark the location that Lady Wenji 文姬 referred to as the boundless desert under the 'barbaric sky.' In Liu Guandao's 劉貫道 Kublai Khan Hunting (I280), camels accompany a traveler in non-Han attire emerging from behind a mountain pass, serving as a background for the Mongolian chieftain and his retinue at their hunt ${ }^{6}$ (Fig. 16.6). In the famous Spring Festival on the River 


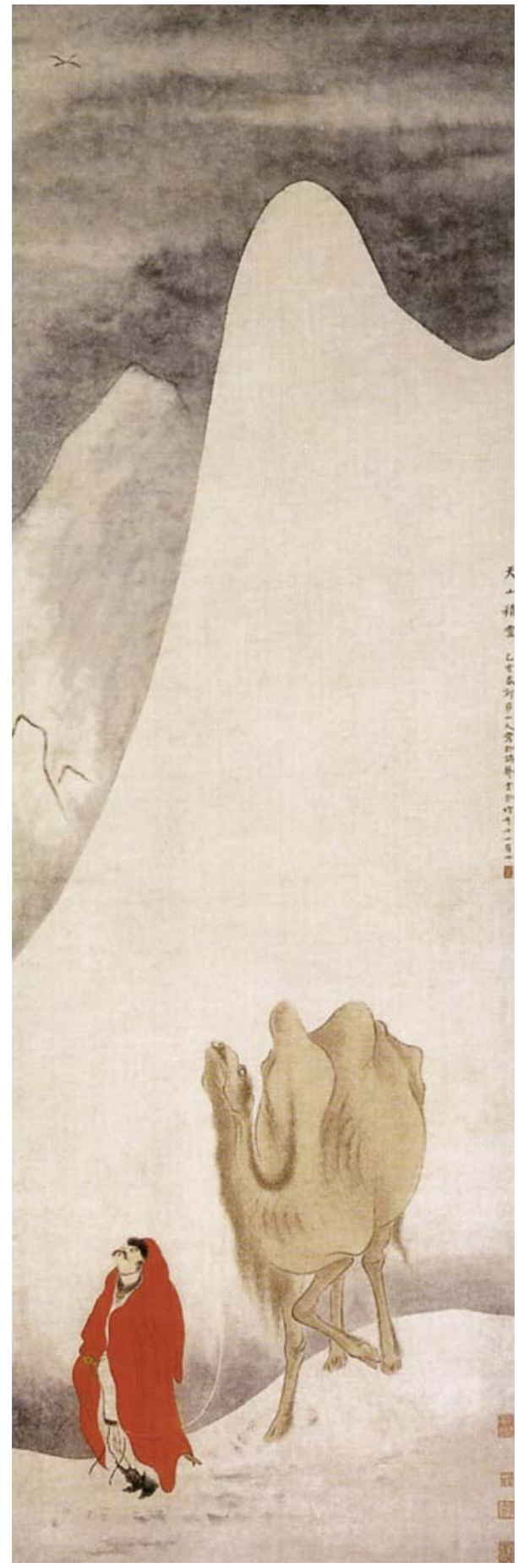

Figure 16.5 Hua Yan, Tian Mountain under the Snow. Dated 1755. Hanging scroll, ink and color on paper. $159.1 \times$ $52.8 \mathrm{~cm}$. The Palace Museum, Beijing. 
(Qingming shanghe tu 清明上河圖), a caravan of camels passing through the city gate is seamlessly integrated into the lively setting of a northern city. As the Song art critic Han Zhuo 韓拙 (active ca I095-ca II25) pointed out, camels and carts are suitable for decorating mountain scenes of the northern region, just as water villages and fish markets are most appropriate for the southern landscape (HAN Zhuo 1983: 2b-3a). Viewing Hua Yan's Camel in Snow in the context of its time, and of other paintings produced in the middle of the eighteenth century, it seems to belong to the genre of court painting that depicted various activities and scenes, as well as the architecture, animals, and plants, of the region referred to as saibei. In other words, this painting can be read against the backdrop of the flourishing of the saibei genre during the Qianlong reign. ${ }^{7}$

In the sixth year of the Qianlong reign (174I), the emperor resumed his annual hunt at Mulan 木蘭, the imperial hunting ground northwest of Chengde 承德 (then Rehe熱河), a practice established by his grandfather Kangxi 康熙 (r. I662-I722) but interrupted during his father Yongzheng's 雍正 (r. 1723-1735) reign. During the same year, Qianglong also started his northern inspection tours, beixun 北巡, and conducted meetings with his non-Han allies north of the Great Wall, especially Mongol nobles from the northeast region. The annual hunt also included Uighur or Muslim notables, Zunghar Mongols, and Tibetan Buddhist prelates, as these groups subsequently pledged allegiance to the Qing court. In other words, the annual hunting trip served multiple functions. It was an act of filial piety, since the emperor always brought his mother along to escape the summer heat of Beijing. It also served as a reminder of the nomadic origin of the Manchus. More importantly, the hunt at Mulan fulfilled several political and cultural agendas. Firstly, it encouraged the old Manchu way of life, which mixed sedentary agriculture with hunting, fishing, and limited herding. Along with the Eight Banners system, mandatory study of the Manchu language, and training in horsemanship and archery, the annual hunt was part of a strategy for maintaining the cultural barriers that separated the conquering elite from the subjugated Chinese population. The problem of maintaining Manchu identity had surfaced in the Yongzheng period (1723-1735) and became more pressing after more than a century of Manchu rule over the Chinese and their assimilation of Chinese culture. The 'sinicization'8 of the Manchu elite worried the Qianlong emperor, especially when he saw his fellow Manchus immersing themselves in reading and writing Chinese, even indulging in poetry and calligraphy, rather than riding and hunting. ' Secondly, the hunt helped Qianlong conduct foreign affairs with both new and old allies in northeast Asia, Mongolia, Tibet, and Xinjiang..$^{10}$ During his annual hunting excursion, he not only hunted with but wined and dined chieftains

Figure 16.6 Liu Guandao, Khublai Khan Hunting. Dated 1280. Hanging scroll, ink and color on silk. The National Palace Museum, Taibei. 


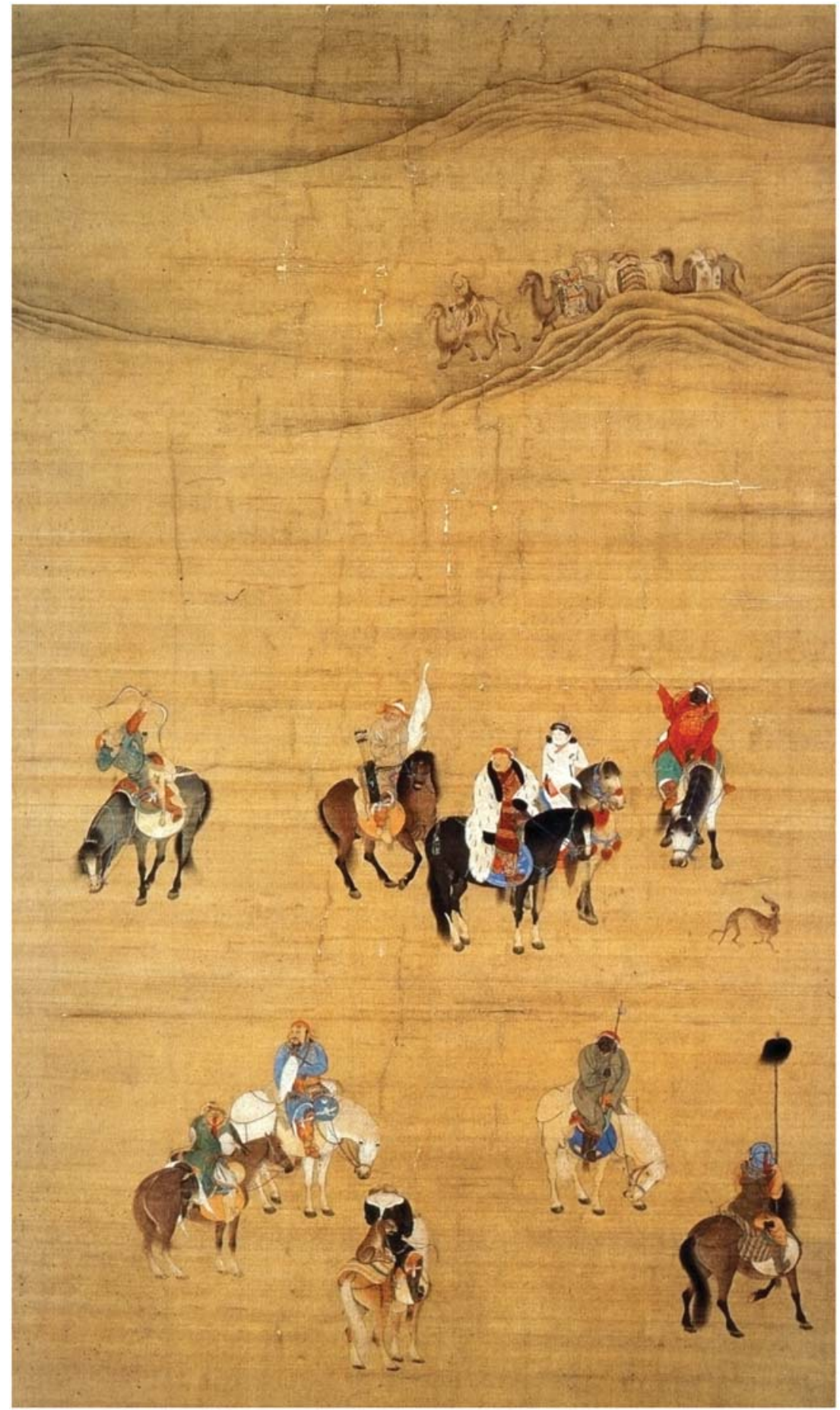


of various ethnic groups. He rewarded them with official titles and with luxury goods from China. In return, tribute horses and camels were presented to him each year, symbolizing the chieftains' homage to Qing rule.

To accommodate the royal entourage in Chengde, Qianlong renovated the Bishu shanzhuang 避暑山莊 (Mountain Villa to Escape the Heat), the summer palace that his grandfather Kangxi had built in 1703. And between 1703 and I820 (the year when the Jiaqing 嘉慶 emperor [r. 1796-I820] died in Chengde, marking the end of the Mulan hunt practice), twenty xinggong 行宮 (imperial stations or travel palaces) were built along the yudao 御 道 (imperial highway) between Beijing and Chengde. Extensive building around the main compound at Chengde, including the Wanshuyuan 萬樹園 (Garden of Ten Thousand Trees) and eight temples surrounding its enclosure, made Chengde an 'architectural wonderland' (Chayet 2004). While away from his residences at Beijing, Qianlong attended to state and foreign affairs at the summer palace, including meeting with Lord Macartney, who headed the visiting British embassy in I793. Thus early Manchu rulers, including Qianlong, adopted the practice of an annual hunt in lieu of the seasonal sojourns of the nomad. By choosing to establish centralized agencies in more than one locality, Qianlong also symbolically linked his reign to the Manchus' pastoral nomadic predecessors, the Liao, Jin, and Yuan. ${ }^{11}$ Each hunting season could last as long as thirty days, and participants could number some thirty thousand, including Manchu nobles, court officials, and Bannermen, as well as newly allied Mongols. The hunt at Mulan could serve as a means of practicing warfare as well, whilst Chengde functioned as a center of this multiethnic empire. The annual excursion and subsequent activities there were meant not only to impress the emperor's allies but also to intimidate potential enemies in the peripheral areas of China.

The Mulan hunt was also an occasion to exhibit the cultural prowess of the Qing ruler. Court artists came on the annual excursion to record all kinds of activities. Paintings depicting hunting, horseback riding, archery contests, wrestling, and banquets increased in quantity and also in quality, especially during the first half of the Qianlong reign. The flourishing of the saibei genre in court painting can also be credited to the gradual institutionalization of the painting academy and to the accumulation of artistic talent in the Qing court. As a cultural patron, Qianlong presented himself as a man of all-encompassing talent and diverse taste. ${ }^{12}$ On the one hand, Qianlong embraced the orthodox landscape style that was deeply rooted in Chinese literati culture; on the other, he supported the style created by a group of court painters led by a number of European Jesuit missionaries who had worked in the court since the Kangxi period. The latter style was a fusion of Chinese brushwork with neutralized light and line perspective, a compromise between European oil painting and traditional Chinese brushwork. It had emerged under the supervision of the Kangxi emperor after he demanded that his Jesuit painters instill 'less Western 
method of chiaroscuro and more Chinese brushstroke.' Although their paintings were criticized as 'wanting in "spirit"' despite the fact that they achieved 'formal likeness' (YANG Boda 1992: 3-II; NIE Chongzheng 1997), this group of court painters won Qianlong's support. They were responsible for functional artwork such as fan paintings, seasonal pictures, occasion or event records, murals, imperial portraiture, and interior decoration. Their activities are well documented in the court archives such as the Archives of the Imperial Workshops, which contain dated accounts of each order and its execution, as well as accounts of the coordination among various workshops. The Qianlong emperor's active involvement in the process of painting production and his constant demands for pictorial records of his activities at Chengde expanded the repertoire of saibei painting and brought this genre to a new height in the history of Chinese painting. The Qing imperial painting academy, huayuan 畫 院, also took its prominent place in the history of painting academies since the Five Dynasties.

In classifying saibei paintings of the Qianlong period using the traditional Chinese dichotomy of xieyi 寫意 (depicting an idea) versus xiesheng 寫生 (sketching from life), they inevitably fall into the latter category. In other words, saibei paintings recording events at, or scenes of, the summer palace were descriptive, functioning more or less like photographs. This is clear from a firsthand observation recorded in a personal letter of 1754 . In that year the French Jesuit painter Jean-Denis Attiret (Chinese name: Wang Zhicheng 王致誠) was summoned to Chengde to record a banquet at Wanshuyuan for Amurasana, the chieftain of the Zunghar Mongols who had submitted to the Qing court for political protection. ${ }^{13}$ Attiret's work of recording this celebratory event included painting portraits of more than ten Mongolian chieftains who were present at the party, ${ }^{14}$ as well as providing a sketch of the event in the form of a mural-sized tieluo 貼落 (appliqué or wall-scroll) entitled Imperial Banquet in the Garden of Ten Thousand Trees (Figs 16.3a-b). ${ }^{15}$ Attiret's decision to portray the moment when Qianlong arrived at the state banquet in a sedan chair, with his subjects, including the newly allied Mongols, waiting respectfully in rows, won him the personal attention of the emperor and admiration from the imperial guests. His excellent draftsmanship in producing a flattering yurong 御容 (imperial countenance) of Qianlong, whose figure is also larger than the rest of those depicted in the painting, earned him the emperor's applause and an official title of the fourth rank, as well as the envy of other court officials (Fig. 16.3a). Accordingly, not only were court officials assigned to wait on the artist but the emperor himself came to visit Attiret's temporary studio at the summer palace on an almost daily basis. Conversing with the Mongolian guests and coping with surprise visits from the emperor while laboring over his work apparently exhausted the painter, who was sick in bed for two weeks after he went back to Beijing, having completed his assignment (Sommer 2004b, Sommer 2004a). The portraits painted by Attiret were later transcribed onto 
the final version of the picture executed by other painters in this collaborative project. The finished tieluo scroll (I755) presents the emperor as a great Khan, as he was referred to by the Mongols, and as the Son of Heaven, whose rule extends beyond the Great Wall. Qianlong is depicted as the great ruler of a multiethnic empire, implicitly bridging the political and cultural divide between pastoral nomadic communities and sedentary civilization. In this painting and in others like it Qianlong's role as art patron, hospitable host, and political leader is carefully orchestrated for an audience that included both his own subjects and viewers of generations to come.

In addition to the depiction of state affairs, landscapes, buildings, figures, wildlife, and flowers became the subjects of saibei paintings, as excursions to Chengde became frequent. Various painters, including scholar-painters, participated in this craze for saibei. For example, during the Kangxi period, bird-and-flower specialist Jiang Tingxi 蔣廷錫 (1669-I732) from Yangzhou produced a long handscroll in bright colors portraying sixty-six different species of flower from outside the Great

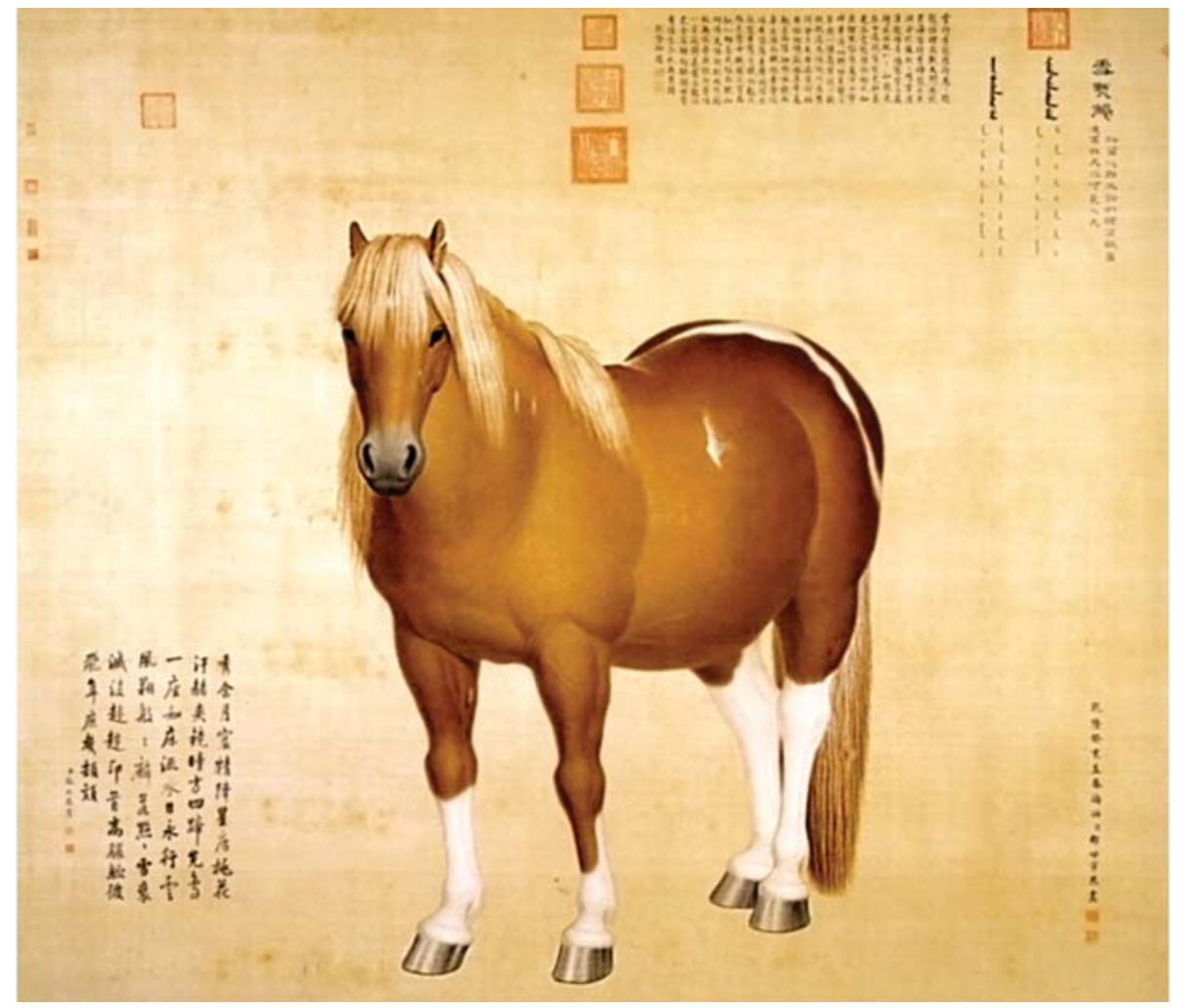

Figure 16.7 G. Castiglione, Xuediandiao from Pictures of Ten Thoroughbreds. Dated to 1743. Hanging scroll, ink and color on silk. $238.2 \times 270.6 \mathrm{~cm}$ The National Palace Museum, Taibei. 


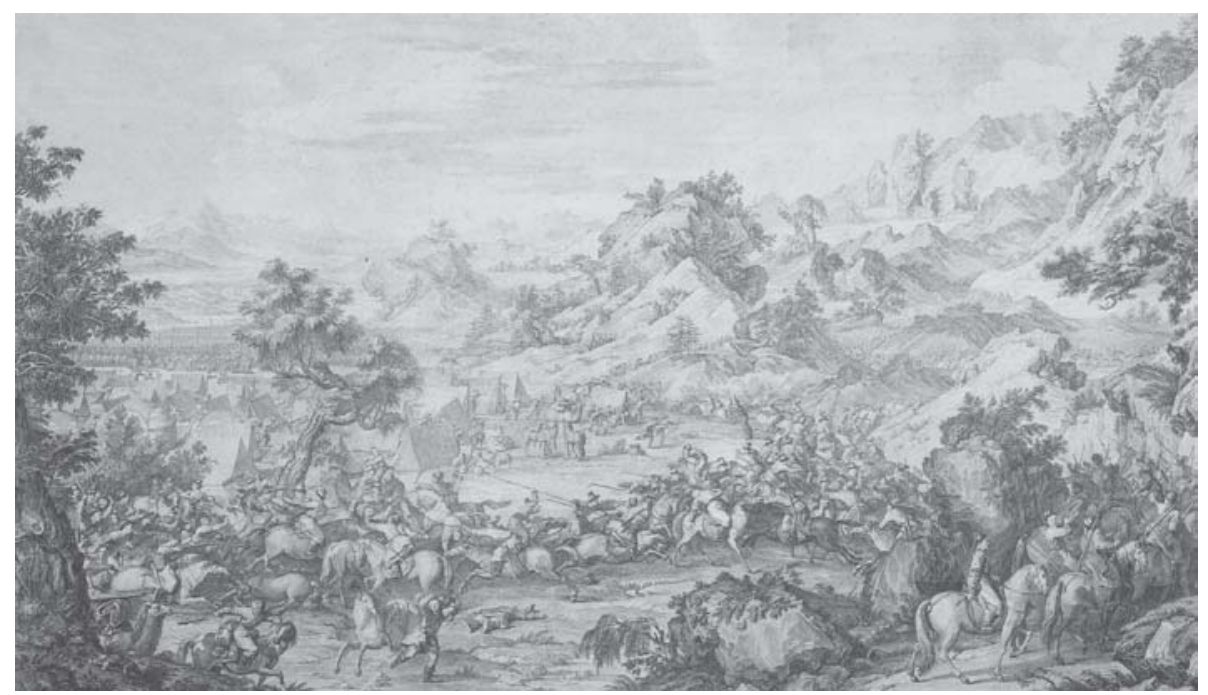

Figure 16.8 Surprise Assault on a Mountain Encampment, from the series The Pacification of the Western Regions. Completed 1773. Copper plate engraving based on a draft by G. Castiglione. Album leaf, $51.4 \times 89.5 \mathrm{~cm}$. The National Palace Museum, Taibei.

Wall. Another scholar-painter, Zhang Ruocheng 張若澄 (jinshi 1745), compiled an elaborate album entitled Twenty-four Leaves of Flowers from Saiwai. ${ }^{16}$ Eagles and falcons, imperial dogs, and especially horses appeared often in saibei paintings. Horses were so special that they were portrayed individually. Sets of painting such as Shijun $t u$ 十駿圖 (Ten Thoroughbreds) not only depicted each individual horse life-sized but included their names in Manchu, Mongolian, and Chinese (Fig. I6.7). Horses also appeared in handscrolls and albums, in addition to narrative scenes such as Kazakh Envoys Presenting Tribute Horses and A Hundred Horses by the famous Jesuit painter Giuseppe Castiglione (Chinese name: Lang Shining 郎世寧, I688-I766). In another example, ten dogs are portrayed on individual album leaves with an elaborate background and a eulogy written by high officials on each opposite leaf. ${ }^{17}$ Camels seem to have received inferior treatment in comparison, despite the fact that they were among the Mongols' annual tribute gifts to the throne (RAwsKI I998: 2I). Reportedly, nine white horses or white camels, called jiubai 九白 ('nine white'), were the most esteemed gift presented by the Mongols. The ritual of presenting the 'nine white' to the emperor marked the beginning of the imperial banquet, followed by performances of music, dance, and wrestling; such banquets ended with gifts of gold and silver, silk and porcelain to the empire's allies. ${ }^{18}$

Unlike tribute horses, no monumental, portrait-style depiction of camels is found in Qing court painting. Camels are not only scarce but they play a subordinate role 
when they are included at all. Camels appear in battle and hunting scenes, and in urban settings, only as a part of the narrative. For example, in Surprise Assault on a Mountain Encampment, depicting a battle against a Mongolian tribe in Zungharia (1755), camels carry the fleeing families from the battleground, while other camels sit unconcernedly next to a yurt (Fig. 16.8). In a painting in which Qianlong heads a hunting procession, a camel with the carcass of a deer on its back is at the end of the patrol. ${ }^{19}$ In another large-scale painting on a similar theme, two camels in a quiet corner are waiting for the hunters to dress the day's kill. ${ }^{20}$ And in an eighteenthcentury copy of a long handscroll recording the celebration of Kangxi's sixtieth birthday, civilians and children riding on camels are among the crowd gathered in front of an outdoor theatrical performance at a busy city corner. ${ }^{21}$

Nevertheless, camels are hardly absent from Qing court documents. They appear frequently in discussions between the emperor and his court officials, such as those documented in the Shengzu ren huangdi yuzhi wenji 聖祖仁皇帝御製文集 [Imperial Collection of the Benevolent Emperor Shengzu (Kangxi)] and Yongzheng zhupi $y u z h i$ 雍正硃批諭旨 [Vermilion Imperial Rescript of the Yongzheng Reign]. Camels were one of the critical military resources under constant discussion at the planning stage of each military operation in the northern and northwestern regions. They were the main means of transporting heavy machinery and other military supplies. The number of camels assigned to soldiers before each battle was recorded from the Shunzhi 順治 reign (1644-I66I) on, just as were food and stipends. One record shows that during Qianlong's time, each soldier from the Eight Banners was regularly supplied with three horses, and every two soldiers with one camel. The first Qianlong campaign against Zungharia in 1755 reportedly drafted about fourteen thousand camels, in addition to sixty thousand battle horses (LaI Fushun 1984: 326-39, 357). In sum, camels were as important as horses in terms of military supply.

However, there does seem to have been a ranking between the two animals. Horses, especially those of Central Asian species, had been tribute gifts since the Han dynasty, as well as objects of pictorial record since the Tang. Most importantly, horses were the object of a wealth of literary allusions and vehicles of political symbolism in Chinese culture. In Chinese literature, the thoroughbred was most commonly associated with the man of talent. The legend of Bole 伯樂 (or Sun Yang 孫陽) of the Spring and Autumn periods, who allegedly could immediately spot a thoroughbred or qianlima 千里馬 ('horse that can go for a thousand $l i$ ') among a herd, added to this lore of the thoroughbred. In the seventeenth century, the high official and art connoisseur Gao Shiqi 高士奇 (1645-1704) reinforced and codified the symbolic meaning of the horse when he commented on various subjects in Chinese painting (Hsü I996b: 158). In sum, the horse is more than an animal of utility; it is an object of appreciation and a symbol of economic and political power. 
In contrast, when we browse through Chinese poems and essays from various periods, camels are most frequently mentioned in connection with their practical functions. For example, camels were used to deliver urgent information from remote inner Asian military posts to the capital. This postal system was also used for delivering a special spice to the imperial consort Yang Guifei 楊貴妃 during the Tang dynasty. Yet the camel prompted no poetic fancy, no historical or political symbolism. Instead, it was the camel's ability to see clearly in the dark and cover '5oo li' (some I50 miles) per day that was most appreciated. In the Ming-Qing period, merchants

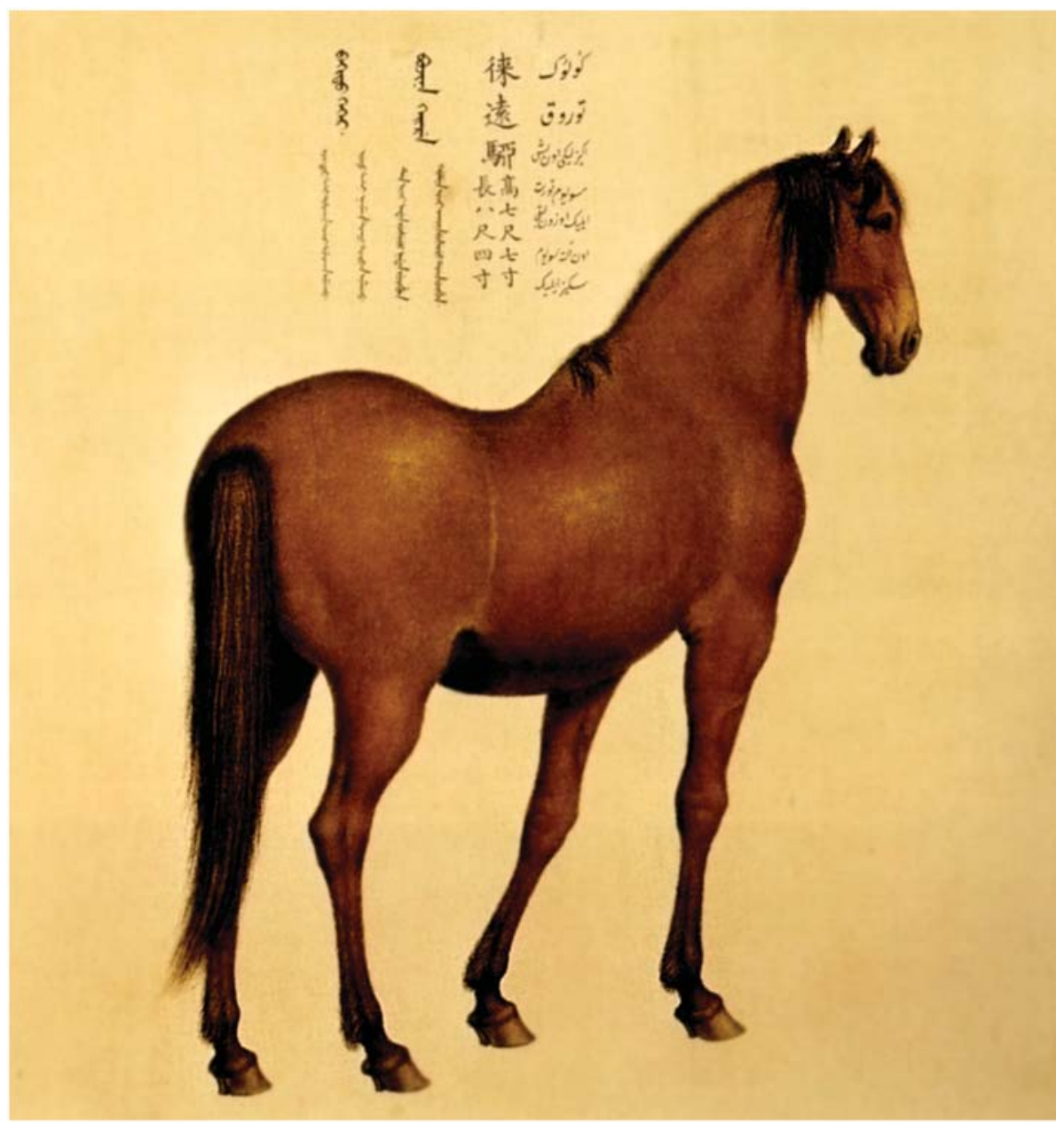

Figure 16.9 G. Castiglione, Laiyuanliu from Four Afghan Horses. Datable to 1763. Handscroll, ink and color on paper. $40.7 \times 297.1 \mathrm{~cm}$ (section 2). The National Palace Museum, Taibei. 
from Anhui were known as Hui luotuo 徽駱駝 (Camels from Anhui). Most likely camels were equated with the hard work and stoicism of Anhui merchants, one of the wealthiest merchant groups since the mid-Ming. Whether there is any negative connotation to this nickname is unknown, though the image of camels, which had no noticeable elegance, seems to be consistent with the belief that Anhui merchants were rich but uncultured. In paintings of the saibei genre, the camel also yields to the horse. Although camels appear in hunting processions to satisfy the documentary function of the works, they seem to have been used only to transport goods, and men of lesser social status or of specific ethnic groups. So it was extremely rare for camels to be the main subject of a painting, because of this lack of aesthetic or literary appeal.

Compared to the portrait-style, mirror-like image of the horses in the imperial stable by the celebrated court artist Castiglione, Hua Yan's camel seems to be wanting, though it exhibits a similar rear view (Fig. 16.9). In presenting a camel in the same posture as a precious steed in the palace, is it possible that Hua Yan is deliberately contrasting the two? The subtle subjugation of the camel seems to be indicative of its inferior status in the eyes of Hua Yan and his contemporaries. In any case, Hua Yan's treatment of the animal points to the same 'sketching from life' (xiesheng 寫生)

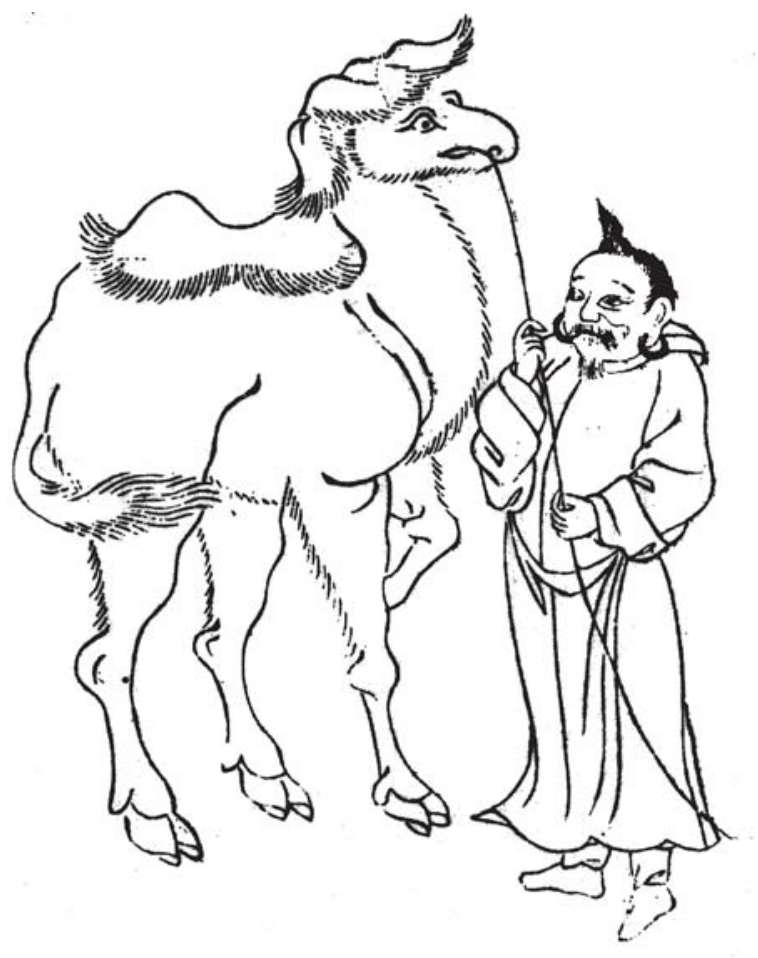

Figure 16.10 Figure. Woodblock print. Sancai tuhui 14: 22a. 


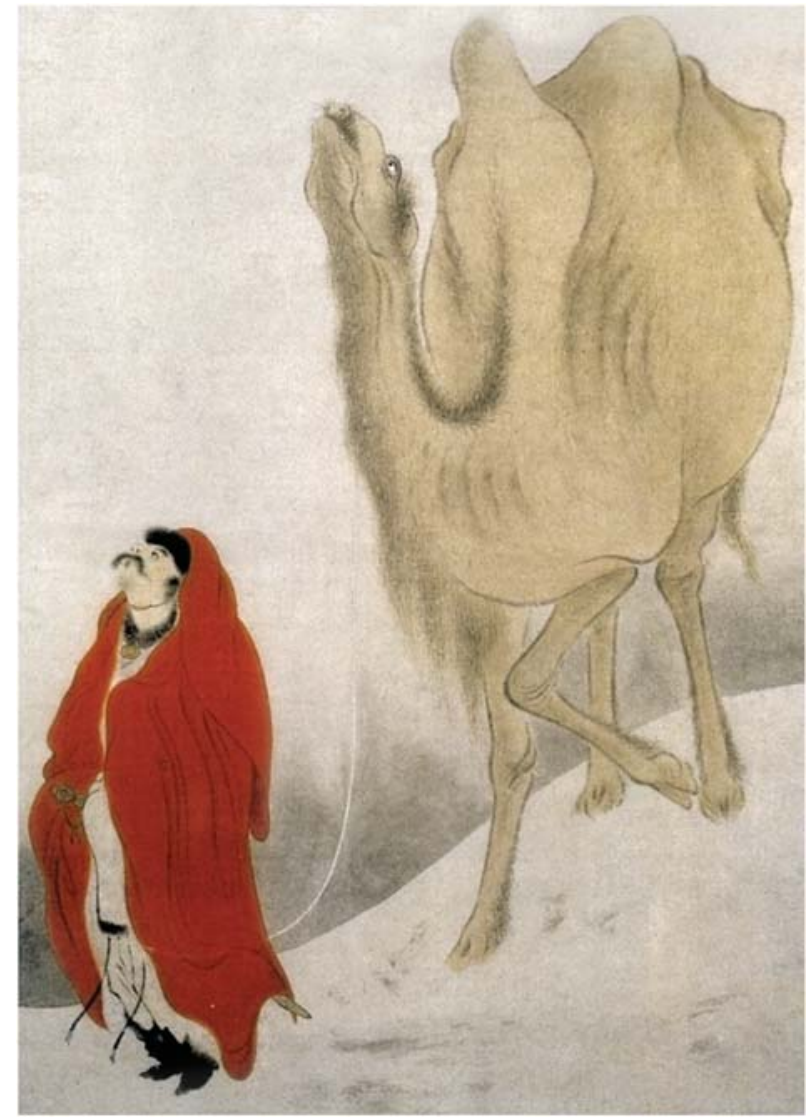

Figure 16.11 Hua Yan, Tian Mountain under the Snow, detail.

approach seen in the works of the court artists. Further examination of Hua Yan's painting confirms this in the proportion and modeling of the camel, and especially in the shading between its humps and the fur around its neck. According to the inscription, this painting was finished in a studio dubbed Qingxiang nuancui 晴香 暖翠 (Verdant Hills in Fragrant Spring). ${ }^{22}$ It is possible that Hua Yan recorded his sketches of camel 'on site' and later transcribed them as part of the overall pictorial design in a studio back home in the south.

The 'sketching from life' approach is also evident in Hua Yan's Tianshan under the Snow dated to 1755 (Fig. 16.5). ${ }^{23}$ In this painting, a non-Han figure walks in front of a camel against a mountainous backdrop rendered in a variety of ink washes alternating with unpainted blank and minimal ink lines. The arrangement of the main motif, man and camel, seems generic, and indeed, when we browse through the sections introducing nomads from the steppes in the Ming illustrated encyclopedia Sancai tuhui more than one illustration shows a similar composition of a camel and a non-Chinese figure, whether Xiongnu, Jurchen, Tartar, or Mongol (Figs I6.4 \& I6.Io). 
Yet the detailed treatment of the figure's facial features and expression, clothing and accessories seem to add a certain life-like quality to the generic composition. Noticeable also is the fact that under the conventional red cloak Hua Yan dressed his hero in white, the most esteemed color of the Mongols, which seems to point to yet another observation from life. ${ }^{24} \mathrm{~A}$ similar approach can also be observed in the depiction of the animal. The camel's upward gaze, mustache, and fur around the neck not only connect the beast iconographically with the similarly depicted man (as the reins do in practice), but also point to an approach of 'sketching from life' rather than copying from earlier illustrations (Fig. I6.II). The landscape background, Tianshan or literally Heavenly Mountain (whether a proper name applied to the mountain range that divides the Zunghar and Tarim basins in Xinjiang or a generic term indicating the height and the holiness of a mountain) probably only existed in Hua Yan's imagination, since there is no record indicating that he ever traveled to Xinjiang. This practice of applying portrait-like images from sketches onto a larger composition parallels the production of the Imperial Banquet in the Garden of Ten Thousand Trees, in which Attiret made portraits of Qianlong and his Mongolian guests on site, which were later transcribed onto a larger painting (YANG Boda I982: II-I3).

\section{TRAVELOGUE AND PERCEPTION OF THE 'OTHER' IN MID-QING PICTORIAL DOCUMENTS}

Coming from a small village in northern Fujian, Hua Yan is said to have shown skill in painting at a young age and to have painted several murals for the Hua family shrine. Biographic accounts also show that in his twenties Hua left his hometown, joined his brother at Hangzhou, and began his life as a sojourner and traveling artist. At the age of 36 Hua Yan started a two-year (I717-I719) journey to the northern regions and first set foot north of the Great Wall. According to a poem Hua Yan sent to his younger brother in the ninth month of 1717 , he was then visiting the capital (Hua Yan 1900 [1835], I:7a). In I718 he visited all Five Sacred Peaks, Wu yue 五获, as well as famous places in Hebei, Shangdong, and Shanxi. ${ }^{25}$ In the autumn of I719 he visited Chengde and composed a poem about a certain Qingchui feng 馨桘峰 (Peak in the Shape of a Mallet), one of the scenic spots in the vicinity of the summer palace. ${ }^{26}$ In addition to poetry, two extant paintings with subjects related to the northern frontier can be dated to 1717 and I718, while another group seems to have appeared decades after he returned to Jiangnan, including Camel in Snow and Tianshan under the Snow. ${ }^{27}$ In other words, Hua Yan's experiences at the northern border expanded his horizons, adding new subjects to his paintings of birds and flowers, for which he is most famous. They also served as an inspiration for painting in his old age.

As a southerner who lived almost all his life in Jiangnan, Hua Yan's fixation on the exotic camel, an animal never seen in the south, is understandable. An 
eighteenth-century travelogue written by one of the members in the 1793 British delegation, George Staunton, provides us with a firsthand account of the route from Beijing to Chengde and Staunton specifically mentions the ubiquity of camels on it. No more than 20 miles north of Beijing, camels were the principal means of transportation. They carried mainly leather goods, but occasionally also low-cost coal and firewood for daily consumption by residents of Beijing. Staunton also noticed that the double-humped camels not only walked faster but bore heavier loads than the single-humped ones. ${ }^{28}$ In his own writings, Hua Yan expresses regret at not being able to record immediately with his paintbrush what he saw during his trips and at having to wait until later in life to incorporate his observations into his work. Hua Yan's painting of Camel in Snow was an image drawn from memory, a memory crystallized and recreated through an image most expressive of the exotic frontier.

Just as the camel and $h u$ 胡 figure encapsulated Hua Yan's frontier travel experience, so saibei paintings functioned like travelogues. Long-distance travel was not uncommon among Hua Yan's contemporaries, especially among men of education. The opening up of tourist spots during the Ming dynasty had already prompted a fad for traveling and outings. For the well-educated of late Ming times, travel not only exemplified the idea that 'Ten thousand miles of traveling is better than ten thousand volumes of book learning' but was a sign of elevated social status (WU Renshu 2003a: I28). This fashion was interrupted during the Ming-Qing transition, to be revitalized during the more stable economic and political conditions of the late Kangxi period, but with a different focus. In addition to traveling for career advancement, civil service examinations, business and personal pleasure, travel became a means of satisfying intellectual curiosity (Wu Renshu 2003b).

For example, Jin Nong 金農 (I687-I764), Hua Yan's contemporary and one of the 'Eight Eccentric Masters of Yangzhou,' traveled far and wide during his middle age. One of his purposes was fangbei 訪碑 ('stele visiting'), since calligraphy was his true passion. In addition to practicing calligraphy in styles that derived from ancient steles of the Wei and Jin periods, Jin researched and composed essays on calligraphy and engaged in discussions with his contemporaries. For example, he wrote an essay for a friend discussing feibai 飛白 ('Alying white'), an ancient script, created by Cai Yong 蔡茞 (I33-I92) of the Han dynasty and promoted by Wu Zetian 武則天 during the Tang, which was facing extinction in his own time. ${ }^{29}$ 'Stele visiting' involved not only traveling to ancient ruins but attaining knowledge of each calligraphic style and its history, connoisseurship, and authentication. It also required practicing the technique of copying. Jin Nong reportedly owned hundreds of rubbings from ancient steles, including precious versions made during the Song dynasty. In other words, he approached artifacts from the past as an archaeologist, turning huaigu 懷古 (reminiscence on antiquity or on ancient ruins) into kaogu 考古 (examination of the ancient relics). Though Hua Yan may have traveled with several purposes 
in mind, like many of his contemporaries, his realistic portrayal of the camel in Camel in Snow can be read as his own pictorial travelogue and as a record of his investigative efforts. ${ }^{30}$

As long-distance travel persisted, the Inner Asian areas opened up new possibilities for Qing travelers. Those who ventured to the 'new territories' have left us with a wealth of records on the customs and activities, foods and people, geography and landscape of the 'other.' Just as paintings in the saibei genre blossomed during the Qianlong reign, so literature with frontier (biansai) themes flourished in the Qing dynasty, creating a second peak in the history of this genre of Chinese literature, comparable to its flourishing during the Tang dynasty. Biansai literature increased both in quantity and in variety during the Qing. For example, the first travelogue on the Xinjiang region, entitled Xiyu wenjian lu 西域聞見錄 [Account of an Experience in the Western Region], was published in the twenty-sixth year of the Qianlong reign (I754) with detailed maps of the area. Another addition to the genre is Hong Liangji's 洪亮吉 (1746-1809) Yili riji 伊犁日記 [Diary of Yili], a day-to-day account of his trying journey to Yili (modern Yining), the northwesternmost city of the Qing empire and the administrative center of the newly conquered Xinjiang. Hong Liangji's long journey started at Beijing along the ancient Silk Road, proceeded through Xian, the Gansu corridor, Hami, and Urumqi, and ended at Yili, taking him more than four months. In addition to writing about the dangers of traveling in the winter months and the hardships he endured as a convicted official en route to exile, Hong Liangji described the landscape through which he passed and incidents of life on the frontier. ${ }^{31}$

Poems, excerpts, comments, and memorials with subjects related to biansai also appear in the miscellaneous notes and anthologies of those who traveled to the frontier. For example, Hua Yan's friend Jin Zhizhang 金志章 (juren 1723), who held an official post at Koubeidao $\square$ 北道, northwest of Beijing, dedicated a whole chapter to biansai poems in his eight-chapter poetry anthology. More than a hundred poems in this work give a vivid picture of life at the frontier. Jin Zhizhang's subjects include leisure outings, the reception of friends and colleagues, relic and antique appreciation, military inspections along the border, reminiscences of the past, and activities as mundane as weeding grass, planting willows, eating crab, and viewing poppy flowers (Jin Zhizhang 1754, 6:I-20). In Jin Zhizhang's view, life at the frontier was neither morbid nor harsh. On the contrary, we can almost detect in his poetry a hint of excitement about living on the frontier, as if it were a great adventure. Jin forsakes traditional images in biansai literature, such as those of deserted land, a lonely goose, the crescent moon, a weary traveler, a homesick soldier. With a more rounded view, he draws the frontier closer. His lively perspective on his experience conveys to his readers, who included his family and fellow townsmen from near Hangzhou, a picture of an unthreatening and approachable frontier. We find a similar approach in 
another collection of poems, entitled Yayus hanren chusai ji 雅雨山人出塞集 [Record of Yayushanren Traveling to the Frontier], by Lu Jianzeng 盧見曾 (I690-I768), a two-term salt commissioner from Yangzhou. The poems in this anthology reveal a life almost as predictable as in a Jiangnan city like Yangzhou, including social gatherings and friendly exchanges among local administrators as well as occasional excursions to local scenic spots and ancient ruins (LU Jianzeng I746: I-25). In this sense Hua Yan's paintings of saibei subjects are similar in approach to the travelogues written by his contemporaries

The acquisition of new territory by the Qing brought new knowledge about the peoples of these areas, instilling a new concept of 'the frontier', both geographically and cognitively, in the minds of Qing Chinese. For the Manchu government, knowledge about things in and around their new territories was a pragmatic necessity as well as a literary interest. To document the Manchus' understanding, while boasting of their 'centrality' among people outside of China proper, the Qianlong emperor ordered an imperial painting project named Pictures of foreign envoys (Zhigong $t u$ 職貢圖) around I750-I75I. This project followed the same model as the sets of paintings of the imperial thoroughbreds, mentioned above, which depicted each horse and included its name in both Manchu and Chinese. In this case foreigners from Korea and Japan, France and Britain, as well as Mongolians, Muslims, and Tibetans from Inner Asia, are included in sets of multiple handscrolls. Minorities from peripheral areas such as Taiwan, Gansu, and Yunnan are also depicted. Each section illustrates both a man and a woman and is accompanied by descriptions in Chinese and Manchu. For example, in the section on people from Yili, local tribal chieftains, chieftains of lower rank, and commoners are arranged in three different sections. The text gives detailed descriptions of the colors and material of their clothes, ornaments, and accessories. The text on commoners reports: 'People from Yili depend on herding instead of plowing; they also depend on Muslims for their food supply. Men wear white hats with yellow tops made of sheep fur, and a single earring made of copper in their left ear. They wear robes made of sheep fur without covers, a fabric belt, and leather boots in either yellow or black. Women braid their hair into two side queues and wear copper earrings [on both sides]. 32 The figures in these paintings are rendered in bright colors, with details meant to illustrate the descriptions in the text. In other words, men and women from remote and unfamiliar places were carefully studied and recorded by local officials so as to facilitate the imperial project. ${ }^{33}$

When we compare the figures on these handscrolls to the sections of renwu人 物 (figures) in the above-mentioned Ming illustrated encyclopedia Sancai tuhui, especially the section introducing people from near and far, an interesting additional contrast appears, other than in the style and the medium. Imaginary figures such as the man with wings, man with an animal torso, man without an abdomen, and the 
like are missing in the eighteenth-century work. Thus we can see that perception of the 'other' had become much clearer and more accurate by the mid-Qing, compared to the period before the visits of Westerners such as Matteo Ricci (I552-I6IO) (GE Zhaoguang 2004: 369). Viewing Hua Yan's frontier paintings in this light, the perception of the 'other' in his paintings is in line with that of his fellow Qianlong-period artists. Thus Camel in Snow reveals a newly acquired knowledge about the 'other,' even though Hua Yan's pictorial motifs are traditional and his artistic expression literal.

\section{TRADE ROUTES AND THE YANGZHOU CONNECTION}

Territorial expansion also meant a more stabilized border, new trade routes, and regulated commercial activities. With the Treaty of Nerchinsk of I689, for example, the Qing government both repelled Russian expansion and authorized Russian merchant trade in Beijing. And in the Treaty of Kiakhta in 1727, it was stipulated that such trade would take place at three-year intervals. The incorporation of the Inner Asian territories - the Mongolian steppe, the Tibetan plateau, and the Zunghar and Tarim Basins - created not only a new Qing empire but a thriving 'domestic' market as well. Mongolian merchants came south with their caravans of camels loaded with furs and leathers, precious herbal medicines, and livestock products. They returned with precious goods such as silk and porcelain, sugar, tobacco and tea, also on the backs of camels. ${ }^{34}$ Even the daunting job of transporting huge jade boulders from Xinjiang to the Beijing imperial workshop relied on camels (Millward 200I: II). Viewed in this light, Hua Yan's traditional iconography of a non-Han figure and his camel seems to refer to the newly expanded commercial activity on the frontier. His picture entitled Tianshan under Snow (Fig. 16.5), of a well-garbed figure in typical Mongolian attire traveling through the heavy snow of the sacred mountain range of Xinjiang, seems to tell the story of a traveler who looks up to the passing geese while listening to the wind. Judging from the man's gold earring and pendant, fur trim around his neck, long sword, and spotless white robe and pants under a crisp red cloak, he could well be a prosperous merchant.

As a painter who was active in Yangzhou, Hua Yan's selection of saibei subjects may have been in response to demand from his city patrons. Yangzhou rose to a high point of prosperity during the eighteenth century owing to its command of the salt trade. It had been a headquarters of salt merchants since late Ming times. Studies of the urbanization of Yangzhou characterize it as a city of immigrants and sojourners, with merchants from Anhui and Shanxi dominating the salt trade. These two merchant groups had been the wealthiest since the Ming dynasty and retained their privileges under Qing rule. Because of their position in the salt trade, they also dominated the economic life of Yangzhou. A close examination of the history of 
the jins hang 晉商 (Shanxi merchants) further reveals that they had been involved in transporting food and other supplies to military garrisons on the northern border since the Ming dynasty. After generations of hard work, the jin shang's trade routes extended well beyond the north and northwest borders. When the official trade between China and Russia opened up, especially the establishment of a treaty port at Kiakhta (Chinese: Qiaketu 恰克圖) in I727, Shanxi merchants immediately added the Russians to the Mongolian steppe trade they had pioneered. In other words, Shanxi merchants dominated, if not monopolized, the trade with the northern borderlands. ${ }^{35}$

As a painter who depended on his art as his sole source of income, Hua Yan may well have realized that frontier scenes would appeal to merchant patrons who wanted paintings depicting the settings of their business expeditions to the northern frontier. His life-long relationship with his student Zhang Sijiao 張四教, who was from a prominent Lingtong 臨潼 (of Shaanxi 陝西) merchant family in the salt trade and the owner of a garden that entertained the Qianlong emperor in 1762, demonstrates his ties with a Yangzhou merchant family whose members may have traveled the trade routes of the northern border. ${ }^{36}$ However, it remains difficult to find a direct connection, as is found with most Chinese painting, between Hua Yan's saibei paintings and specific recipients. The lack of designated recipients, the repetition of subject matter and the rather generic inscriptions on these paintings may suggest that they were more of an in-stock commodity than works created to meet the demand of a specific patron. If this is true, then we may further argue that saibei scenes were simply another new subject for Yangzhou's in-stock art market.

Eighteenth-century Yangzhou was also a lively city with travelers from all parts of the empire and from all walks of life, including even the Emperor Qianlong on his southern tours. Natural scenery, such as the Slender West Lake, Shou Xihu 瘦 西湖, and specially designed gardens around the city, became landmark attractions. Music and theatrical performances from different regions, including Kunqu 昆曲 from Suzhou and singing in the local style from Anhui, attracted both visitors and residents. Restaurants and teahouses along the riverbank at the north side of the city served a variety of food and drink that probably showcased cuisines from different places and ethnic groups. Li Dou's 李斗 mention of a famous chef by the name of Zhang Si Huizi 張四回子 (Muslim Zhang Si) who specialized in whole-lamb feasts was a case in point. ${ }^{37}$ The exposure of Yangzhou residents to things from near and far, and their taste for and tolerance of things that were 'other,' seems to have been well integrated into their urban life. Paintings of exotic scenery on the new frontier could be well received by Yangzhou dwellers, not just by specific groups such as Shanxi merchants.

As mentioned above, Hua Yan's paintings of saibei themes, whether extant or recorded, fall into two groups, one produced around the same time he visited the 
northern region, during the late Kangxi reign, and the other in the first half of the Qianlong reign. The interval between these two included the Yongzheng reign, when the annual Mulan hunt at Chengde was interrupted. This coincidence prompts us to speculate that Hua Yan may have reinvigorated saibei subjects in his work after he learned of the new art fashion at court and the new political conditions on the frontier that promoted more frequent visits. In other words, Hua Yan's saibei paintings could also meet the taste for the new and novel among Yangzhou residents, as observed by the eighteenth-century social commentator Li Dou in his Yangzhou huafang lu揚 州畫舫錄 [Pleasure Boats of Yangzhou] (I795). Of course, frequent communication between the merchants and the court (invitations to the imperial birthday parties, for example) may have provided another way for Yangzhou residents to be exposed to the burgeoning fad of saibei painting in the Qianlong court. The interaction between the artist and craftsmen, between Beijing and Yangzhou as seen in the jade carving project and in the case of Yangzhou painters studying directly under Castiglione at court, provided yet another possible channel. ${ }^{38}$

Read against the backdrop of Qing politics, Hua Yan's saibei-related paintings may also involve an unpleasant twist and a very different set of associations for the elite of Yangzhou society. A painting entitled Leaving for the Frontier (Chusai tu 出塞 圖) (1740), shows three horseback riders garbed in travelers' coats in the foreground and a fourth person pulling a camel loaded with luggage (Fig. I6.I2) ${ }^{39}$ In the middle ground are several Mongolian yurts with two figures in $h u$ attire, one playing a horn instrument while the other seemingly claps his hands to the beat of the music. In the background is a group of traveling horses with a flock of geese flying high in the sky. The elaborate depiction of the objects piled up on the camel, including bedding and a wine container, suggests a well-prepared traveler (at the same time revealing the scarcity of such material supplies at the frontier). In contrast to the loneliness revealed in Hua Yan's painting, this picture is filled with vivid depiction and exquisite colours. This is actually a painting that served as a farewell gift for salt commissioner $\mathrm{Lu}$ Jianzeng on his journey to the frontier. A famous cultural figure of Yangzhou, Lu Jianzeng was accused of nepotism in 1737 and sentenced to exile three years later. In the painting, $\mathrm{Lu}$ Jianzeng was depicted as a traveler accompanied by a student volunteer and an old friend. Inscriptions from a group of illustrious figures in Yangzhou society - salt merchants Cheng Mengxing 程夢星 and Ma Yueguan 馬曰 琯, fiction writer Wu Jingzi 吳敬梓, painters Min Hua 閔華 and Zheng Xie 鄭焳, and many other aspiring scholars and local celebrities - fill the space surrounding the painting proper. The project was put together by Gao Fenghan 高鳳翰 (I683-I748), another official-painter from Lu Jianzeng's home province of Shandong. His diligence in producing this work is clear from the fact that he had invited a famous portrait specialist from Suzhou, Ye Fanglin 葉芳林, and another figure specialist, Zhang Heng 張行, to fill in the figures for him. 


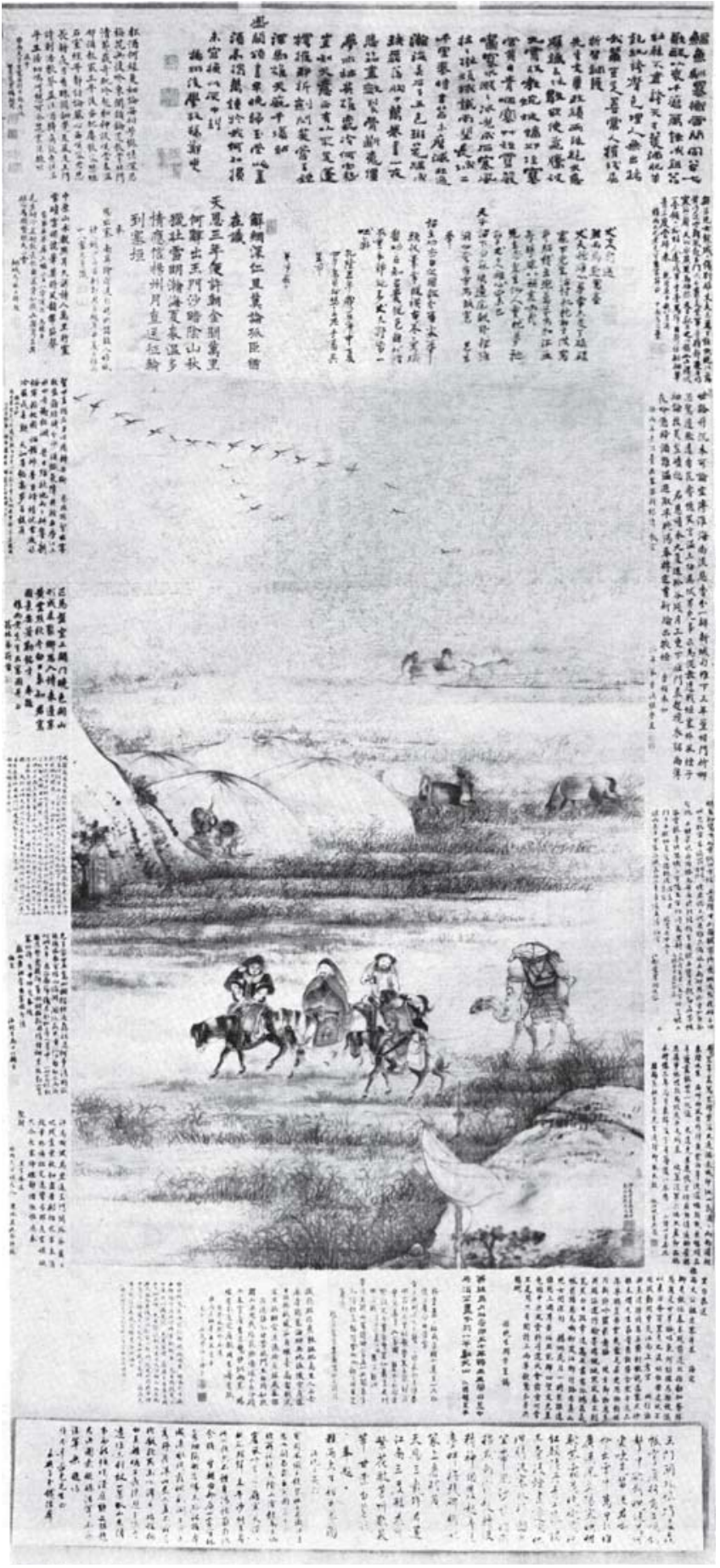

Figure 16.12 Gao

Fenghan, Ye Fanglin, and Zhang Heng, Leaving for the Frontier. Datable to 1740. Hanging scroll, ink and color on silk, $159 \times 83.8 \mathrm{~cm}$. The Palace Museum, Beijing. 
Exile was a risk and a fact of life for Qing officials, despite their accomplishments and contributions to the ruling house. Its incidence was largely a matter of imperial dictates, which could be capricious. For example, Ji Yun 紀昀 (I724-I805, jinshi I754), a reader at the Hanlin Academy and a literary talent whom the Qianlong emperor could not spare, was nonetheless banished in 1777 to Urumqi for his part in a second scandal involving salt commissioner Lu Jianzeng, the grandfather of his son-in-law. He was summoned back after a year in exile and received with great honor by the emperor himself, who later made him the chief editor of the imperial Siku quanshu 四庫全書 [Complete Writings of the Four Treasures] project. Another case involved Hong Liangji (1746-1809), the above-mentioned author of the Yili riji, who was also a court official and the editor of the Siku quanshu, in charge of books submitted from the Jiangsu province. Hong was sentenced to 'decapitation' by the Board of Punishment for having committed the crime of 'extreme indecorum' in submitting a letter commenting on state affairs, including the actions of the throne. $\mathrm{He}$ survived only because the emperor commuted the sentence to exile, and he was then summoned back to court less than a year later (Hummel 1943: 374). It also seems to have become routine for men with literary attainments to record and publish their personal experiences in exile. Lu Jianzeng, Ji Yun, and Hong Liangii all later published records of their time in exile, contributing to the biansai literature of the Qing dynasty.

The verdict of exile not only posed a mortal threat but was a humiliation that extended to family and clan alike. In the Qianlong period, convicted officials were regularly sent to the twenty-nine frontier garrisons, as administrators serving in place of military personnel. However the usual term of only three years must have made the trip to the frontier tolerable, in comparison to the outlook of those who were banished for indefinite periods of time, or who ended up being killed en route. As time went on, the development of trade routes, along with the official postal system, facilitated frequent communication and made life in exile relatively bearable. In $\mathrm{Lu}$ Jianzeng's anthology Yayu shanren chusai ji, we see that communication between the frontier and Beijing was well established, with postal stations along the route and express delivery to the court. Communication was also satisfactory between the frontier and the Jiangnan areas from where most Han civil servants came. While in exile, Lu Jianzeng seems to have regularly received letters and supplies from friends and family, including birthday greetings. Lu Jianzeng was summoned back from exile, and was even reappointed to his old post of chief salt commissioner of the Lianghuai district (1753-1763) after several terms of office elsewhere. His anthology, like the painting dedicated to him by his friend Gao Fenghan, had prefatory comments from many well-known figures of his generation. Moreover, Lu Jianzeng's exile in I74I was well documented by his contemporaries and by later generations. It is recorded in both Yuan Mei’s 袁枚 (I716-I797) Suiyuan shihua 隨園詩話 [Miscellaneous Notes 
about the Poetry of the Sui Garden] and Li Dou's Yangzhou huafanglu. In other words, publications on exile, with annotations and prefaces written by friends and colleagues, circulated among readers who were not within reach, no doubt making the 'frontier' a topic of conversation in Qing society. Examining Hua Yan's saibei pictures in this light, it is fair to say that they record the collective memory of eighteenth-century frontier travelers, including merchants, officials, artists, soldiers, and emperors.

With the technical proficiency only a professional artist could offer, Hua Yan crafted a life-like pictorial record of things beyond the Great Wall. By adopting the representative motif of frontier scenery - a camel and a non-Chinese figure he created such paintings as Camel in Snow and Tianshan under the Snow. In this fashion, Hua Yan breathed new life into traditional composition. His representation of the frontier not only connected him to the new style of painting practiced by the European artists at the court, but also placed Hua Yan among his contemporaries in creating a new genre of saibei subject in both art and literature. Just as Hua Yan engaged his viewers with his picture's immediate visual appeal, so he evoked both memories and imagery associated with the subject: the celebration of military victory, the hardship of frontier journey, the investigative effort in obtaining knowledge of the 'other.' Ultimately, Hua Yan's frontier-themed pictures offer a glimpse into a period of expansion that created a vast and diverse new Qing empire.

\section{ACKNOWLEDGEMENTS}

I am indebted to Dr. Ming Yang, Academic Computing Consultant, and to Ms. Teodora Bozhilova, Curator of the Visual Resources Collection, at UC Riverside for their technical support in editing and processing the included illustrations.

\section{NOTES}

1 Hua Yan I900 [I835]: 4:6b. Li E and Xu Fengji's prefaces in the four-volume Xinluo shanren tihua shiji (i.e. HuA Yan 1900 [I835]), which are dated to I73I, are among the earliest records of the circulation of Hua Yan's anthology. Hua Yan's anthology was also published under the title of Ligou ji 離垢集 (HuA Yan 1997).

2 The undated painting is in the collection of the Shanghai Museum.

3 For a definition of the geographical area of saibei and painting of saibei subjects, see YANG Boda 1984: $35-36$.

4 Among recorded paintings, Yan Liban of the Tang dynasty seems to be the only artist for whom a camel was a main theme, not a background character. See ZHou Mi 1983 [ca I275], 3:I2a.

5 See catalogue illustration no. 19. Wu Tung 1997: 61.

6 For a treatment of the frontier theme in nineteenth-century painting, see LAI Yu-chih 2004. For twentieth-century painting, see TsENG 200I. 
7 For the increasing number of saibei paintings during the Qianlong reign and the content of the paintings, see YANG Boda 1984: 35 .

8 Recent research challenges the traditional view of a China-centered tribute system of Qing government and proposes viewing the Qing empire as an Asian regime that encompassed multiple ethnic groups, including those in Inner Asia. Rawski 2004.

9 For ethnic identity and its relationship with the institution of the Eight Banners, see Elliott 200I: $8-35$.

10 Instead of 'Chinese Turkestan' or 'East Turkestan', I am using 'Xinjiang' (the 'new frontier', a term first introduced in the late eighteenth century) to signify the military and political developments in this area during the eighteenth century, though Xinjiang did not become one of the Qing administrative units (provinces) until the late nineteenth century.

11 For a discussion of the system of multiple capitals, see RAWSKI I998: I8-I9, RAWSKI 2002: II.

12 For a discussion of Emperor Qianlong's taste in art, see KAHN 1985.

13 For the history of the Zungaria Mongols and their relationship with Qing court, see RAwskI 2004, MillWARD 2004.

14 One of the portraits apparently survived. See plate I, NIE Chongzheng I997: 72.

15 For a discussion of tieluo as a type of painting used in interior decoration as wallpaper unique to the Qing court, see YANG Boda 1993: 197.

16 Both works are in the collection of the Palace Museum, Beijing. See Zhongguo gudai shuhua tumu 2000: 23:84 and 23:194-96.

17 See Rawski and Rawson 2005: 188-I89 for illustrations.

18 See the detailed account of the ceremony and banquet following the imperial hunt in WANG Shuyun 1989: 28-29.

19 For illustration, see ZHANG Hongxing 2002: 74 (cat. no. 30).

20 RAWSKI and RAWSON 2005: II2 (cat. no.28).

21 RAWSKI and RAWSON 2005: I05 (cat. no. 24).

22 This is one of the studio names Hua Yan adopted. The location of this studio cannot be identified. Nevertheless, the name suggests a place in spring, a deliberate contrast to the pictorial presentation of a winter scene.

23 For a study of the painting, see YANG Xin 1994: 30I-03.

24 Mongols considered the color white most auspicious, in contrast to the Chinese association of white with funerals and other inauspicious events. For example, Mongols wore white to celebrate festive events such as the New Year. The above-mentioned 'nine white' tribute was also connected to a practice in effect since the Yuan dynasty, when each Mongolian tribal chieftain presented 'nine times nine' (jiujiu 九九) white horses to his leader. Liv Lu, Ao Jianhua 1993: 53-54, and Li Ziran I994.

25 Hua Yan I90o [1835], I: 7a-Ira. His grand journey to the northern region is also mentioned by Chen Yunshan in his preface to Xinluo shanren tihua shiji (i.e. Hua Yan I90o [1835]), 'preface' section, 2. See also WANG Jingxian 2003: 130-32.

26 Xinluo shanren tihua shiji (i.e. HuA Yan 1900 [1835], r:IOa. No written documentation of the peak has been located. A mallet-shaped rock on the east side of the palace shown in a painting entitled 'Mountain Villa to Escape the Heat,' by court painter Leng Mei, dated to I713, was perhaps the one Hua Yan visited. For the illustration, see Rawski and Rawson 2005: III. 
27 A painting entitled Shooting Geese with Friends, dated to I7I7 and a Three Chivalrous Warrior Travelers dated to $17 \mathrm{I} 8$.

28 Si Dangdong 1997 [I797]: 337. For an account of the publication and the background of this book, see HuAng Yinong 2002.

29 For a discussion of Jin Nong and feibai script, see Hsü (forthcoming): 13-15.

30 Hua Yan reportedly traveled to Beijing with the expectation of gaining an official appointment through recommendation. Xue Yongnian 2003a: 244-246.

31 See diary entries cited in CHen Jinling 1995: 184-247.

32 See Zhuang Jifa 1989: 133 for text and illustration. The earliest possible date for the inception of the project is 175 I. The first handscroll was probably completed no later than I76I. ZHUANG Jifa 1989: I2-I3.

33 For a brief account of the process of making the multiple sets of Huangqing zhigong tu, see WeI Dong 1995: 23.

34 Lu Minghui 1994: 46. For a study of the Mongolian trade and ethnic Mongol merchants during the Ming-Qing period, see ZHANG Zhengming 2003: 38-53.

35 For studies on Shanxi merchants and their role in the frontier trade during the Qing dynasty, see ZHANG Zhengming 2003: 16-64, and HUANG Jianhui 2002: I-I36.

36 For Zhang Sijiao's clan and family property in Yangzhou, see Li Dou I795: 15:Irb-I4b. See also Zhang Sijiao's own account of their friendship in the preface of Ligou ji buchao in Hua Yan 1917: I-3. There is also a portrait of Hua Yan attributed to Zhang Sijiao.

37 Li Dou I795: II:3b. For a treatment of Muslim food in Yangzhou, see ZHeng Qi 199I: 95-96.

38 Reportedly, painter Zhang Weibang and his son Zhang Tingyan from Yangzhou both served as court painters during the Qianlong period and studied under Castiglione. Zhang Weibang is therefore considered one of the earliest oil painters in China. His father Zhang Zhen also served as court painter under the Kangxi reign. NIE Chongzheng 1987.

39 For illustration and discussion of this painting, see QIU Liangren 1983. 


\section{The Landscape Albums of}

\section{Huang Shen}

\section{Yi-li Kao}

\section{HUANG SHEN AS A 'LITERATICIZED' PROFESSIONAL ARTIST AND HIS LANDSCAPE PAINTING}

$\mathrm{T}$ he patronage and taste of the influential emerging merchant class in eighteenthcentury Yangzhou led in time to a blurring of the boundary between the once distinct practices of professional and literati artists and to the shaping of a new style of painting. ${ }^{1}$ Huang Shen 黃慎 (I687-after 1768 ) in particular, an artist of craftsman origin who became one of the inventive 'Eight Eccentric Artists of Yangzhou,' Yangzhou baguai, 揚州八怪, is a prime example of a 'literaticized' professional artist of the era. Originally from Ninghua 寧化 in Fujian province and trained as a portrait painter, Huang Shen was a professional artist throughout his life, traveling extensively and regularly in provinces such as Anhui, Jiangxi, Jiangsu, Hunan, and Shangdong to sell his work. ${ }^{2}$ He was also proficient in landscape and flower painting, but he is considered, in general, a master artist of figure painting and is credited with introducing spontaneous cursive brushstrokes into this popular and highly marketable genre (Fig. I7.I). It was mostly because he adopted the calligraphic style prized by the literati tradition, and because of his self-taught book learning, that Huang Shen was considered to have overcome the barrier that separated the professional from the scholar artist and to have been able to associate himself with the well-respected practices of the latter. However, low-ranked by his status as a professional artist, Huang Shen was largely excluded from social gatherings of high officials and literary men until his later years. ${ }^{3}$

Of Huang Shen's prolific and diverse body of works, his landscape paintings are the fewest in number and have largely been overshadowed by his accomplishments in figure painting. ${ }^{4}$ However discussions on the art of Huang Shen have begun to acknowledge his efforts in landscape painting, a genre traditionally dominated by literati artists. For instance, Li Wancai notes that by drawing on his own travels and first-hand observation of nature, Huang Shen was able to break away from the formulaic practices of orthodox Qing artists (LI Wancai I999: II-I2). 


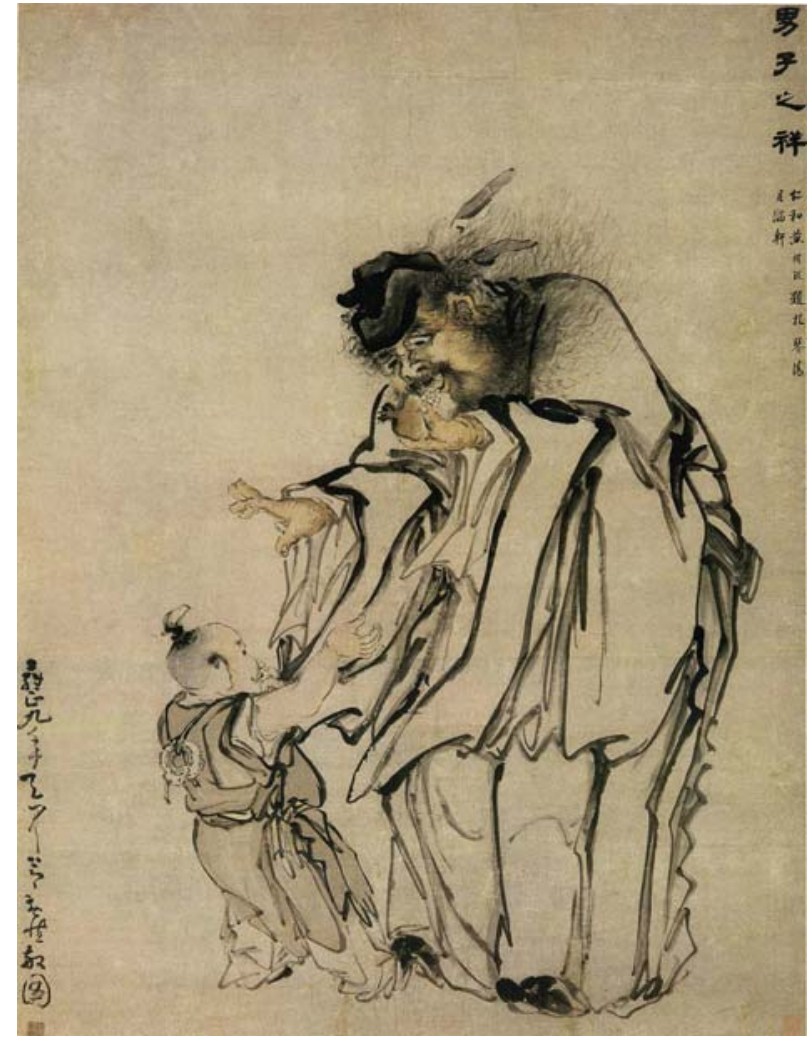

Figure 17.1 Huang Shen, Zhong Kui, the Demon Queller, 1731. Nanjing Museum (Yangzhou huapai shuhua quanji: Huang Shen 1998).

Among Huang Shen's landscape paintings, the series of landscape albums, shanshui ceye 山水冊頁, that he created over a span of thirty years particularly stand out as a unique and rich group of works (Fig. 17.2). These landscape albums, painted mostly in the more expressionistic xieyi 寫意 style characteristic of literati painting, are like travelogues, recording memorable scenic as well as cultural and historical sites that Huang Shen had visited during his extensive travels. As they are often inscribed with Huang Shen's own poetry, the albums also reveal his personal, often ambivalent, feelings towards his uncertain life as a traveling artist. Unlike the majority of Huang Shen's works, which inevitably catered somewhat to the tastes of the Yangzhou merchants who bought them, these landscape albums were mostly prepared for those who shared with him a common literary and art historical knowledge and were true to the artist's creative mind and private inner world. In many ways, Huang Shen's landscape albums, imbued with poetic insights and genuine sentiments, truly mark his entry into the rank of a literati artist and show that his virtuosity extended beyond the figure painting from which he made a living. My essay will look at several of Huang Shen's landscape albums but focus in particular on a ten-page 
album he produced when he was sixty-nine years old, in I755. Possibly his last known landscape album, this 1755 work has only been published once, in a catalogue edited by Toda Teisuke and Ogawa Hiroshi, and it has not been shown publicly except at the San Diego Museum of Art, where it is now housed. ${ }^{5}$

\section{HUANG SHEN'S LANDSCAPE ALBUMS}

Critiques of Huang Shen's landscape painting during the Qing dynasty have mentioned that he attempted to combine the styles of the Yuan painters Ni Zan 倪 瓉 (I3OI-I373) and Huang Gongwang 黄公望 (I269-1354), and also to adopt that of another Yuan master, Wu Zhen 吳鎭 (I280-1354) (Peng Yuncan 1962: juan 3I; Dou Zhen 1962: juan I). However Ginger Hsü has observed that 'following the spirit of $\mathrm{Ni}$ and Huang' - the two literati masters of the past - was a standard phrase in art historical writings in the seventeenth and eighteenth centuries that was used simply to indicate that the artist had chosen the proper style and lineage (Hsü 200r: I26). In Huang Shen's case, however, not only did he closely follow the earlier Yuan tradition, he went further back, to the Song. Both the desolate landscapes of Ni Zan and the

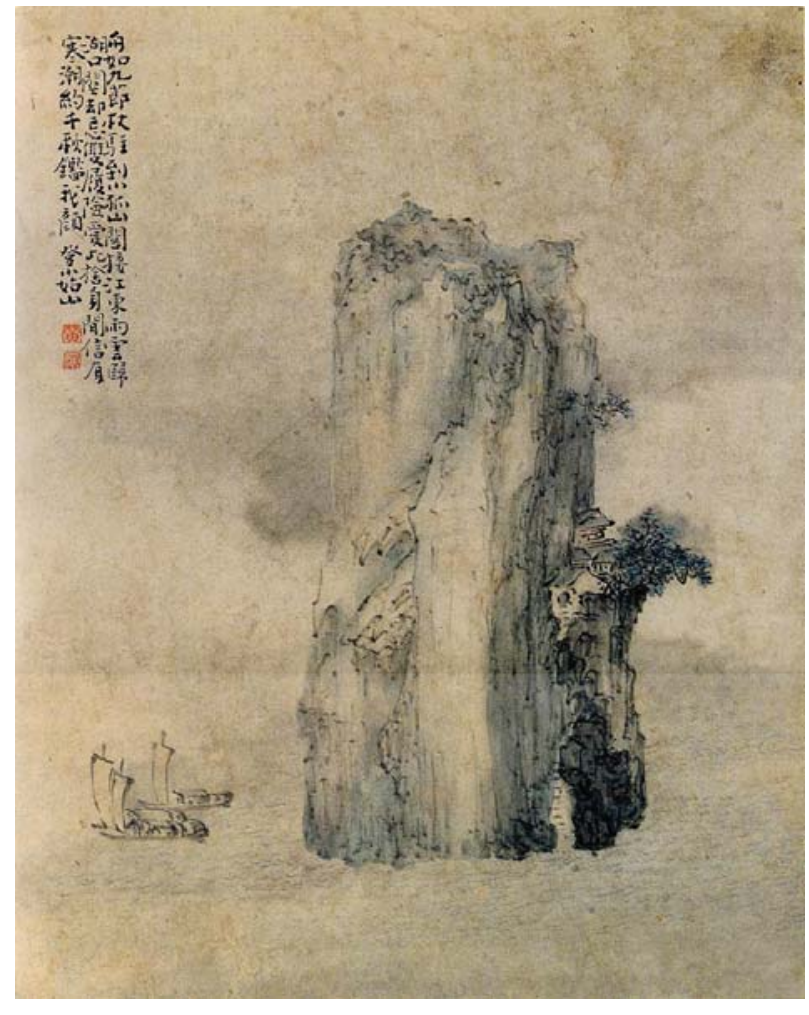

Figure 17.2 Huang Shen, Climbing Xiaogu Mountain, album leaf, 1740. Ji'nan Municipal Museum (Yangzhou huapai shuhua quanji: Huang Shen 1998). 


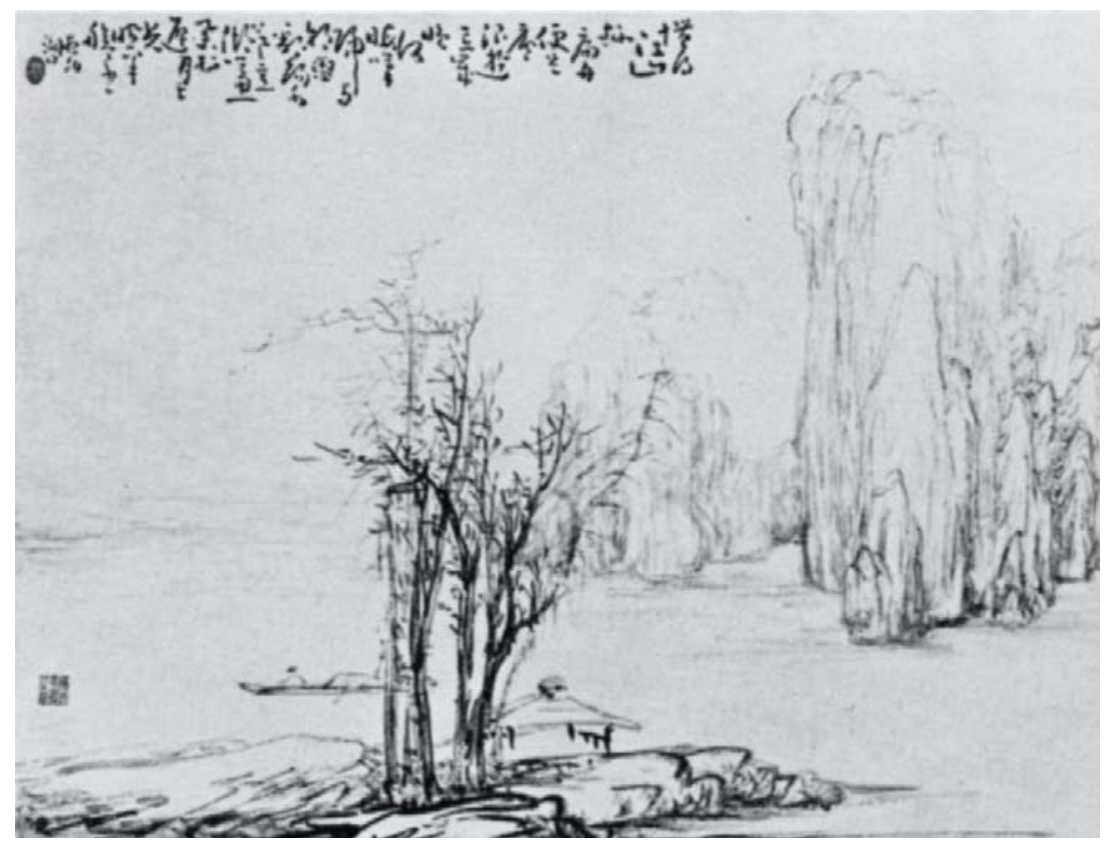

Figure 17.3 Huang Shen, Mooring at Hukou through the Night, album leaf, 1729. Museum Rietberg, Zürich (SUZUKı 1982, vol. 2).

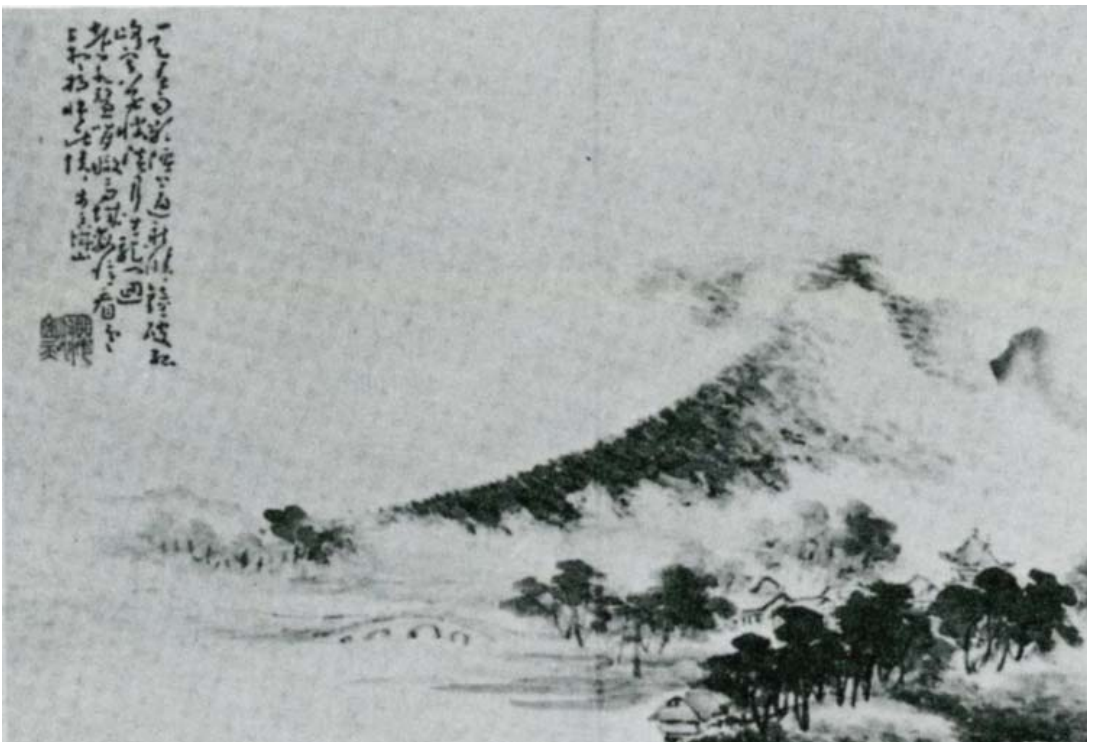

Figure 17.4 Huang Shen, Strolling in Xiangcheng Mountain, album leaf, 1729. Museum Rietberg, Zürich (SuzuKı 1982, vol. 2). 
misty mountains of the Song artist Mi Fu 米蒂 (IO5I-IIO7) had a particularly strong influence on Huang Shen, and he frequently applied their signature brushwork.

In a landscape album titled Reminiscences of the Han River of 1729, which details Huang Shen's personal travel in Jiangnan, we witness his fluent use of the styles of Ni Zan and Mi Fu (Figs 17.3 \& 17.4). ${ }^{6}$ Likely a gift to Yang Xinglou 楊星嶁 or his nephew Yang Kaiding 楊開鼎, who were natives of Yangzhou and who both obtained official degrees, this album seems to be Huang's earliest known travel landscape painting of this kind. ${ }^{7}$ The Yang family is said to have enabled Huang Shen to make this first long-term stay in Yangzhou, which started in 1724 and lasted for just over a decade. ${ }^{8}$ In this album Huang Shen adopted the rapid and abbreviated method of painting derived originally from the wild-cursive writing of the famous Tang monk calligrapher Huaisu 懷素 (725-785) and closely associated with the literati tradition (Fig. 17.5). Produced five years after Huang Shen's arrival in Yangzhou and presumably when he was on the verge of a significant stylistic transformation from the more polished gongbi 工筆 to the more expressionistic xieyi manner, this early album demonstrates a fairly mature style that served, as we will see, as a solid foundation for later work.?

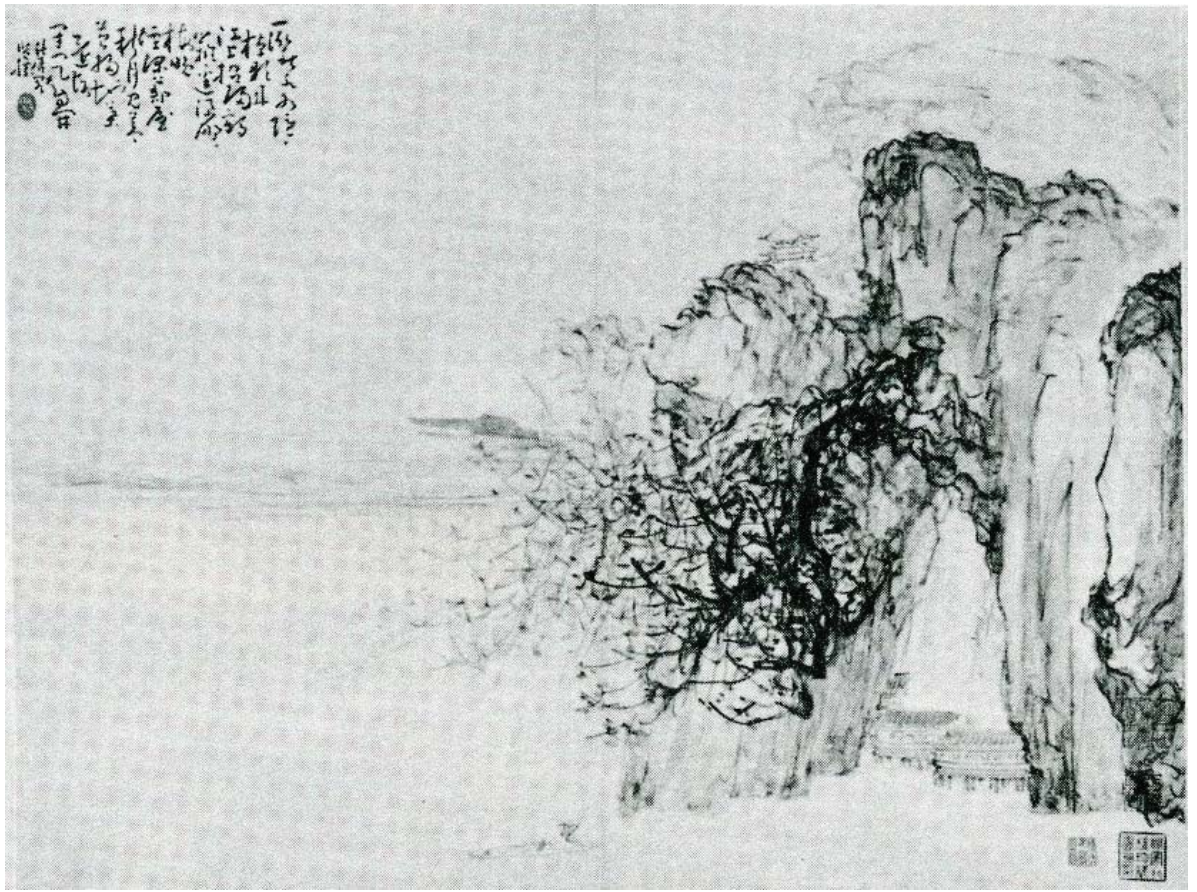

Figure 17.5 Huang Shen, Sightseeing in Qiuping Pavilion, album leaf, 1729. Museum Rietberg, Zürich (SuzUKı 1982, vol. 2). 


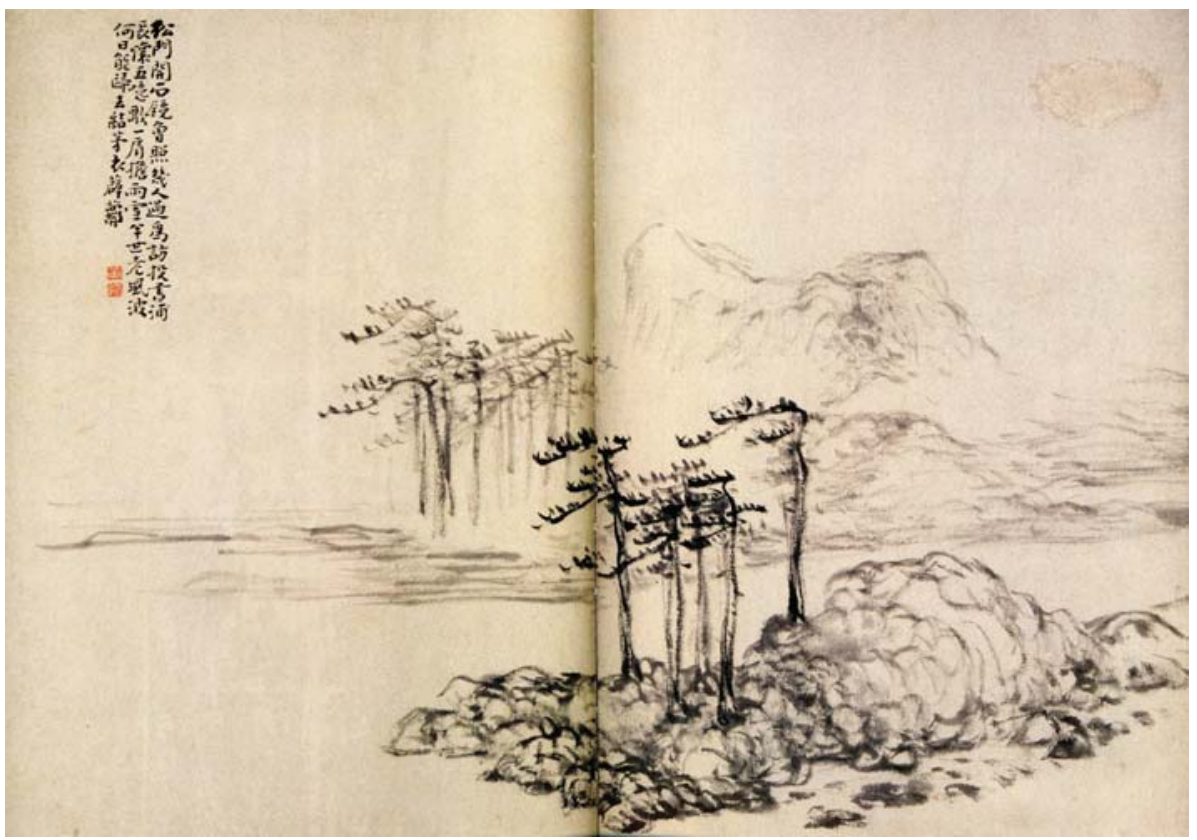

Figure 17.6 Huang Shen, Songmen Mountain, album leaf, 1734. Guangdong Provincial Museum (Yangzhou huapai shuhua quanji: Huang Shen 1998).

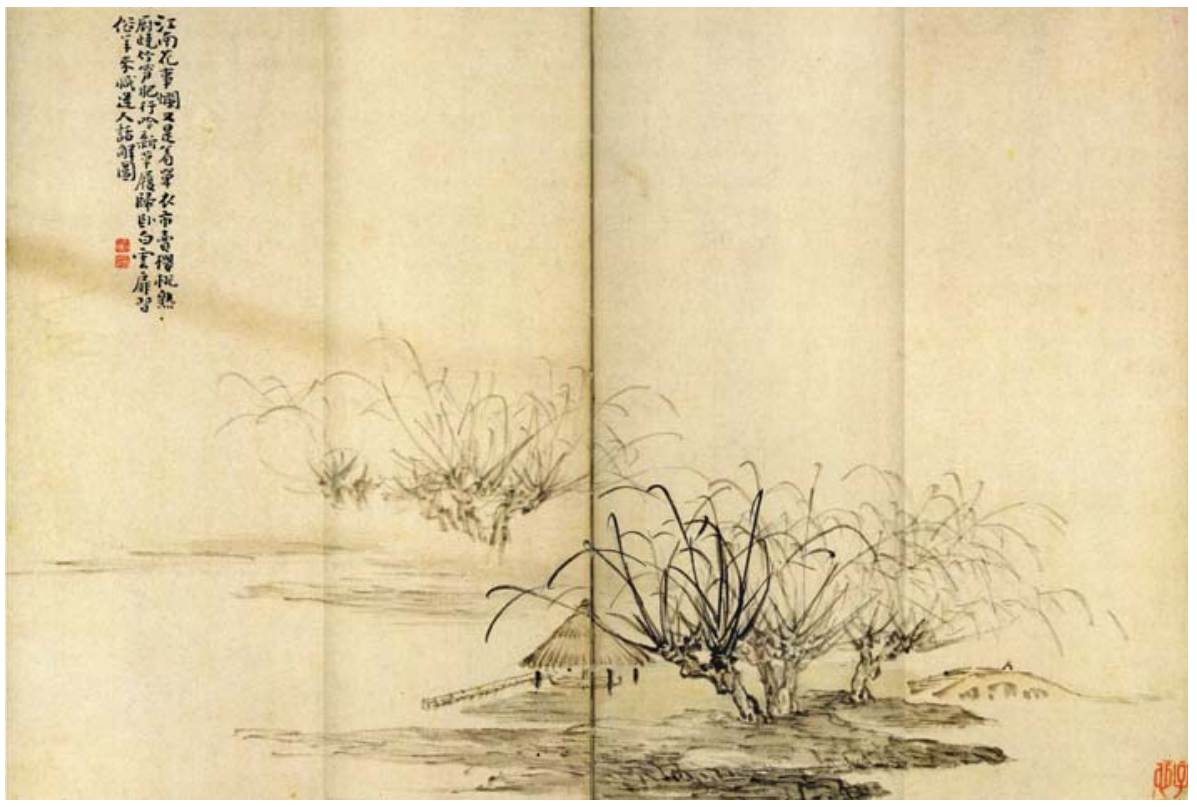

Figure 17.7 Huang Shen, Jiangnan Scene, album leaf, 1734. Guangdong Provincial Museum (Yangzhou huapai shuhua quanji: Huang Shen 1998). 
Another series of Huang Shen's travel landscapes done in Yangzhou was an eightleaf album that he painted in $\mathbf{1 7 3 4}$, shortly before he returned to his native Fujian. ${ }^{10}$ This album records Huang Shen's travels mostly in Jiangsu and Zhejiang provinces. He did not specify the sites in the painting, as he had in the 1729 album, but each leaf still comes with an inscribed five-character four-lines poem. In the painting of the Songmen Mountain, which emulates Ni Zan's grim rendering of the landscape (Fig. 17.6), Huang Shen laments:

I have carried rain and snow on one shoulder,

And swallowed winds and waves for half of my life.

$\mathrm{Oh}$, when can I return home?

To build a thatched house and be clothed in the garments of a recluse. $^{11}$

The album was painted when Huang Shen was 48 years old, and had been away from home for over ten years. In such circumstances, the middle-aged man could not but grieve over his uncertain life as an itinerant artist. But he also could not resist depicting the lovely Jiangnan village scenes that he had come to admire dearly (Fig. 17.7). In his landscape painting Huang Shen frequently used the device of 'level distance,' pingyuan 平遠, which extends the landscape and makes it agreeable. As Lang Shaojun points out, such a choice might have derived from the painting of Ni Zan, but perhaps even more from Huang Shen's own extensive travels in China (LANG Shaojun 1999: 169). This personal element is a trait of Huang Shen's landscape that distinguishes it from Qing orthodox style.

In the fall of 1734, Huang Shen, a dutiful son, escorted his mother, who had come earlier to stay with him in Yangzhou, back to their hometown of Ninghua in Fujian. During the four years after Huang Shen left the glorious city of Yangzhou, between I735 and 1738, he produced several landscape albums, some containing leaves of figure as well as flower paintings. ${ }^{12}$ As many of the landscape paintings in these albums are similar in composition and style and sometimes even depict the same locales, they can be read as an interrelated series of emotional, highly personal recollections. ${ }^{13}$ For instance, in the albums of 1735 and 1738 , now in the collections of the Palace Museum in Beijing and the Sen-oku Hakko kan Museum in Kyoto, respectively, we see two leaves of similar composition inscribed with the same poem (Figs I7.8 \& I7.9):

In the evening rain and cold tides, I remember my old cottage.

Life is only good to old fishermen and woodcutters.

By the five lakes my eyes are confused.

Better to return to the green mountains where I can write my books.

While the poem seems to express a mood of letting-go and transcendence as Huang Shen retired to Fujian, we know, from his multiple depictions and personalized 


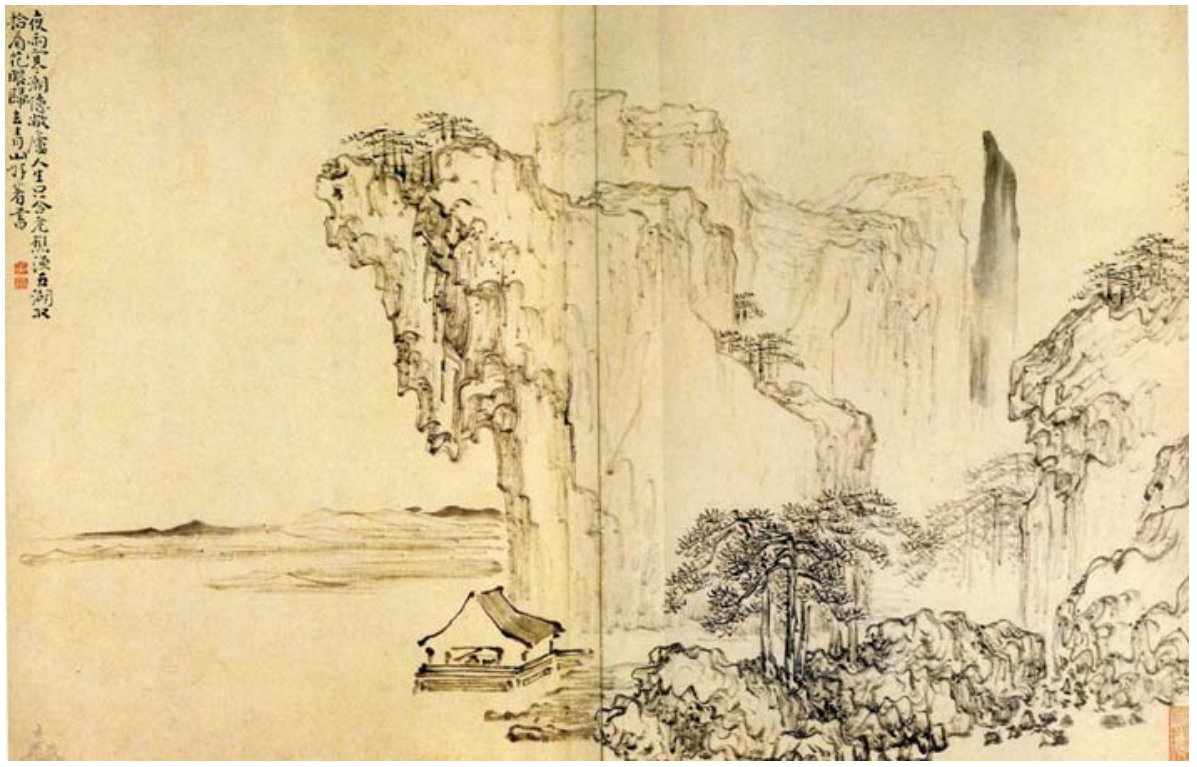

Figure 17.8 Huang Shen, album leaf, 1735. The Palace Museum, Beijing (Yangzhou huapai shuhua quanji: Huang Shen 1998).

renderings of Jiangnan scenes, that the artist's heart had remained tied to the unforgettable Jiangnan area, particularly the city of Yangzhou where he had gained fame and which had become a second home for him (Figs I7.IO-I2).

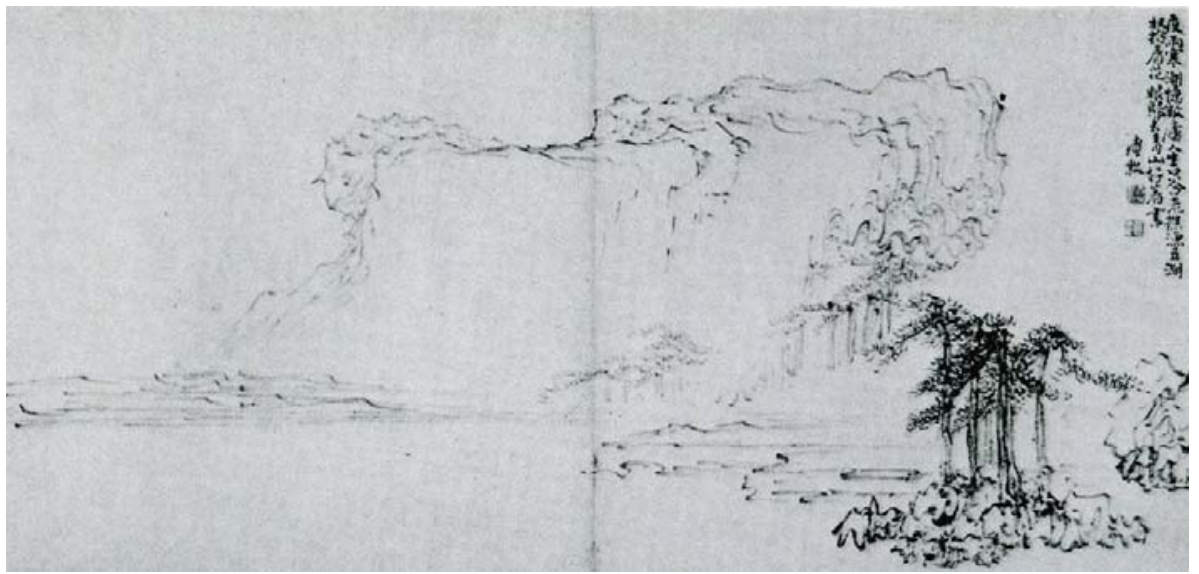

Fig. 17.9 Huang Shen, album leaf, 1738. Sen-oku Hakko kan Museum, Kyoto (SuzUKı 1982, vol. 3). 


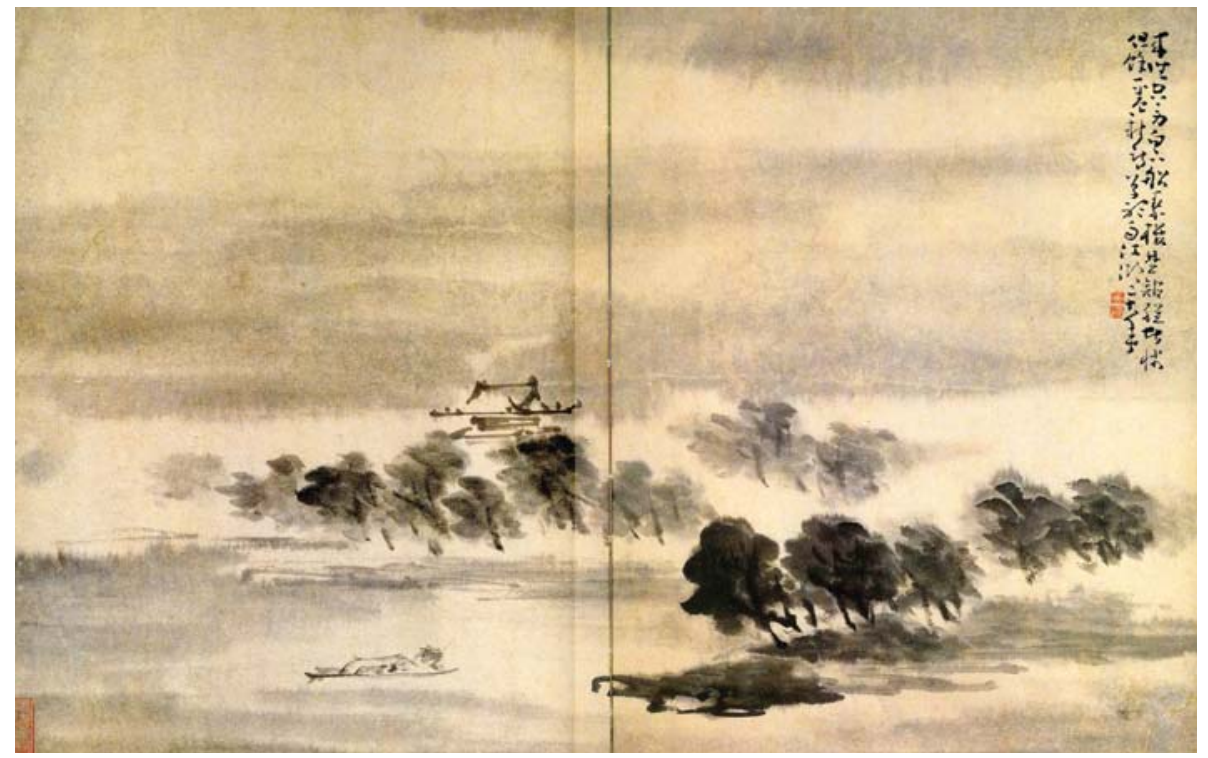

Figure 17.10 Huang Shen, album leaf, 1735. The Palace Museum, Beijing (Yangzhou huapai shuhua quanji: Huang Shen 1998).

Another feature of Huang Shen's landscape painting is the inclusion of figures and their related activities amidst landscapes. A lone figure, perhaps representing the artist himself, can be seen roaming across a expansive terrain; a fisherman is hooded in a straw hat in the rain; a herd boy rides on the back of a buffalo through a mountain path (Figs 17.7, 17.IO, 17.II). A traditional literati artist like Gong Xian 壟 賢 (I619-1689), who valued hua 畫, i.e. pictures of fictive landscapes, over $t u$ 圖, i.e. pictures that capture the physical appearance of an object or person, might well have called such paintings vulgar, $s u$ 俗. ${ }^{15}$ However, one can argue that these everyday figures make Huang Shen's landscape all the more convincing. As Lang Shaojun points out, Huang Shen's landscapes are in stark contrast to those of the orthodox Qing artists who pursued mere form and style. They depict an intimate and lively relationship between man and nature that also approximates to Song and Yuan traditions (LANG Shaojun 1999: I69).

Of all of Huang Shen's travel landscape series, the album that he painted for the Dingzhou prefect Wang Xiang 王相 (1689-after 1768 ) in 1740 is the most elaborate, and has been considered one of his most important works. ${ }^{16}$ The album, now in the collection of the Ji'nan Municipal Museum in Shandong, consists of a total of twenty-four leaves, with twelve devoted to paintings and another twelve, each mounted adjacent to its corresponding painting, containing poetry written in Huang Shen's famed cursive script (Figs 17.13, 17.14, 17.2). Scenes in Huang Shen's 


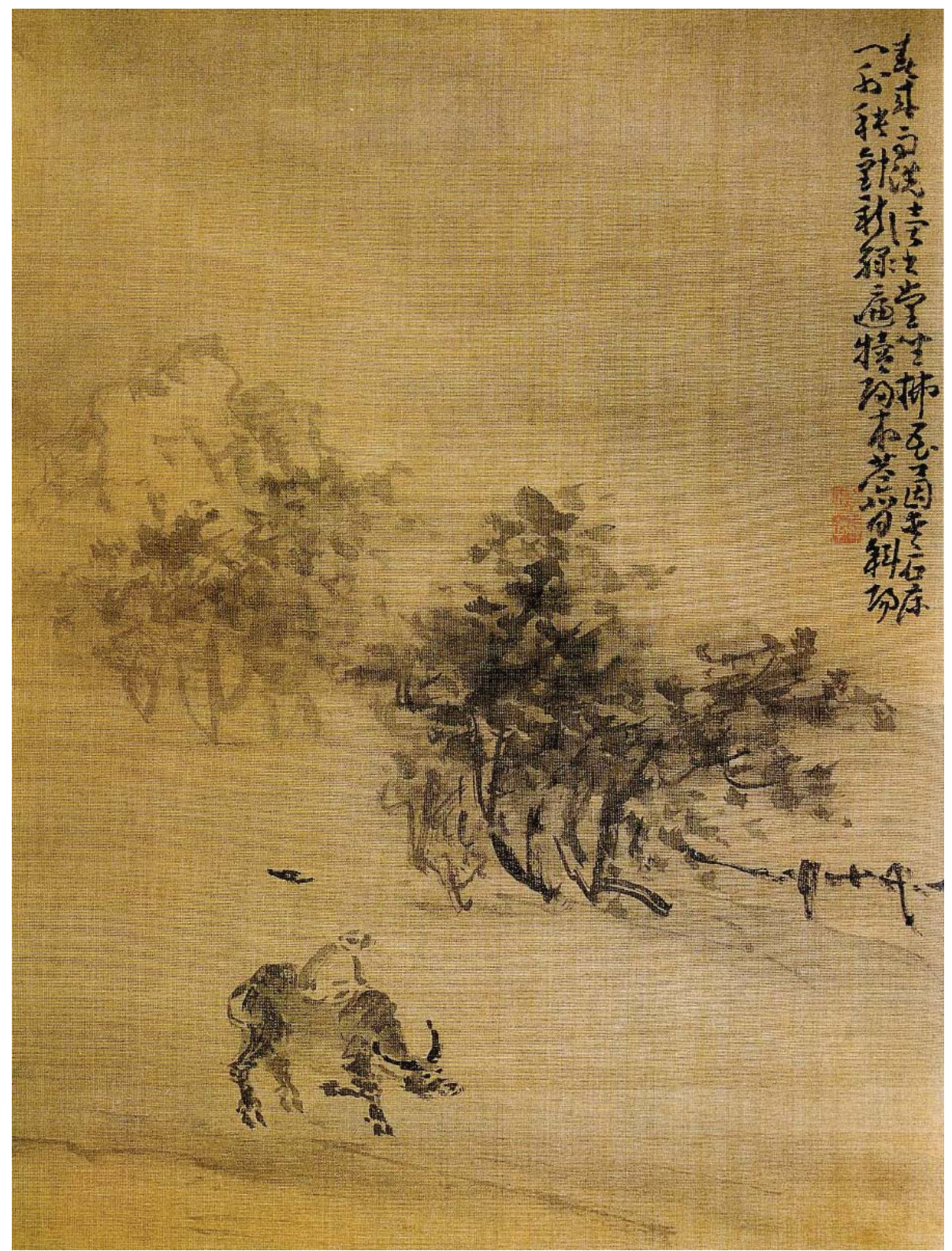

Figure 17.11 Huang Shen, album leaf, 1737. Guangdong Provincial Museum (Yangzhou huapai shuhua quanji: Huang Shen 1998). 


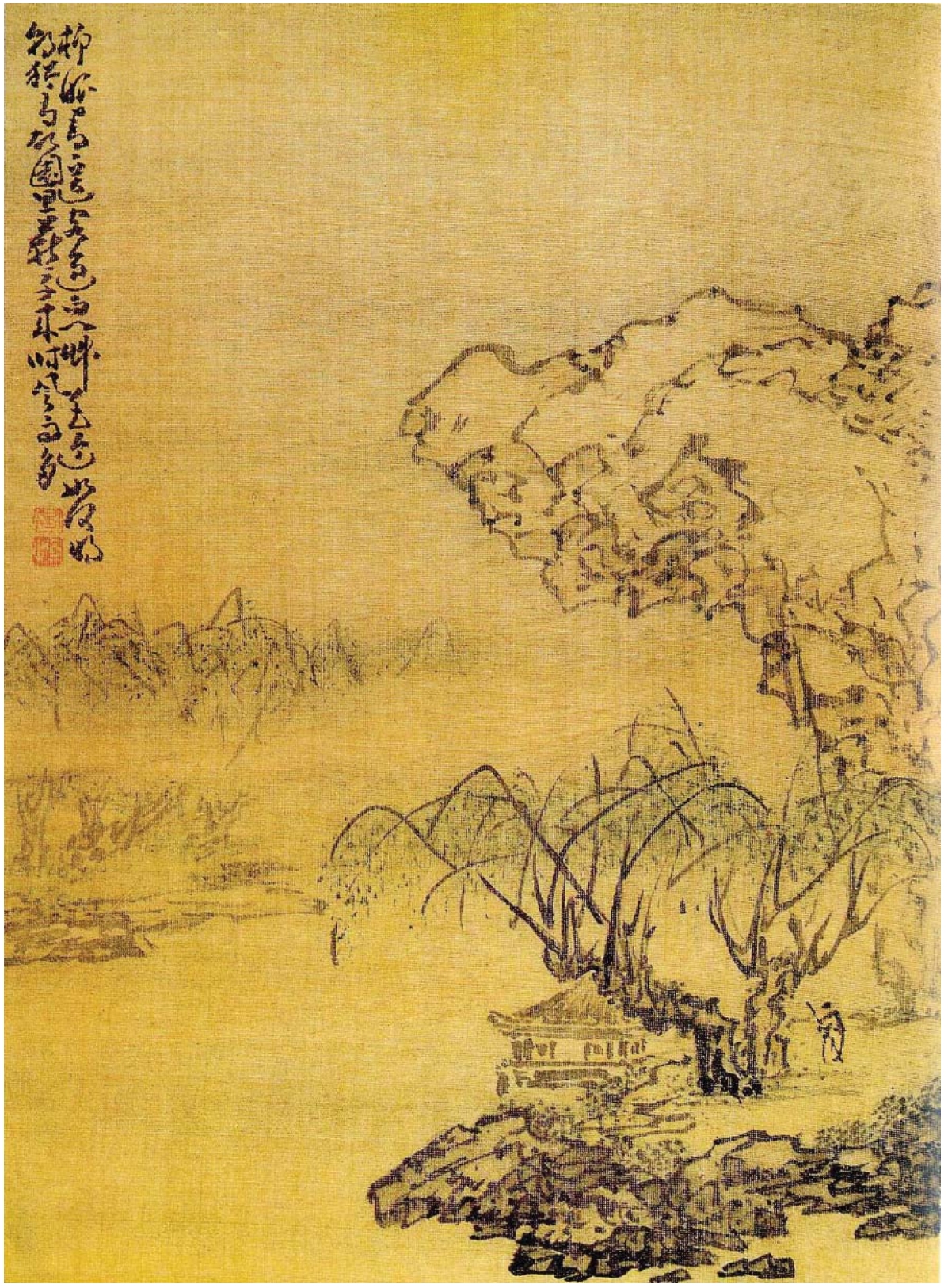

Figure 17.12 Huang Shen, album leaf, 1737. Guangdong Provincial Museum (Yangzhou huapai shuhua quanji: Huang Shen 1998). 

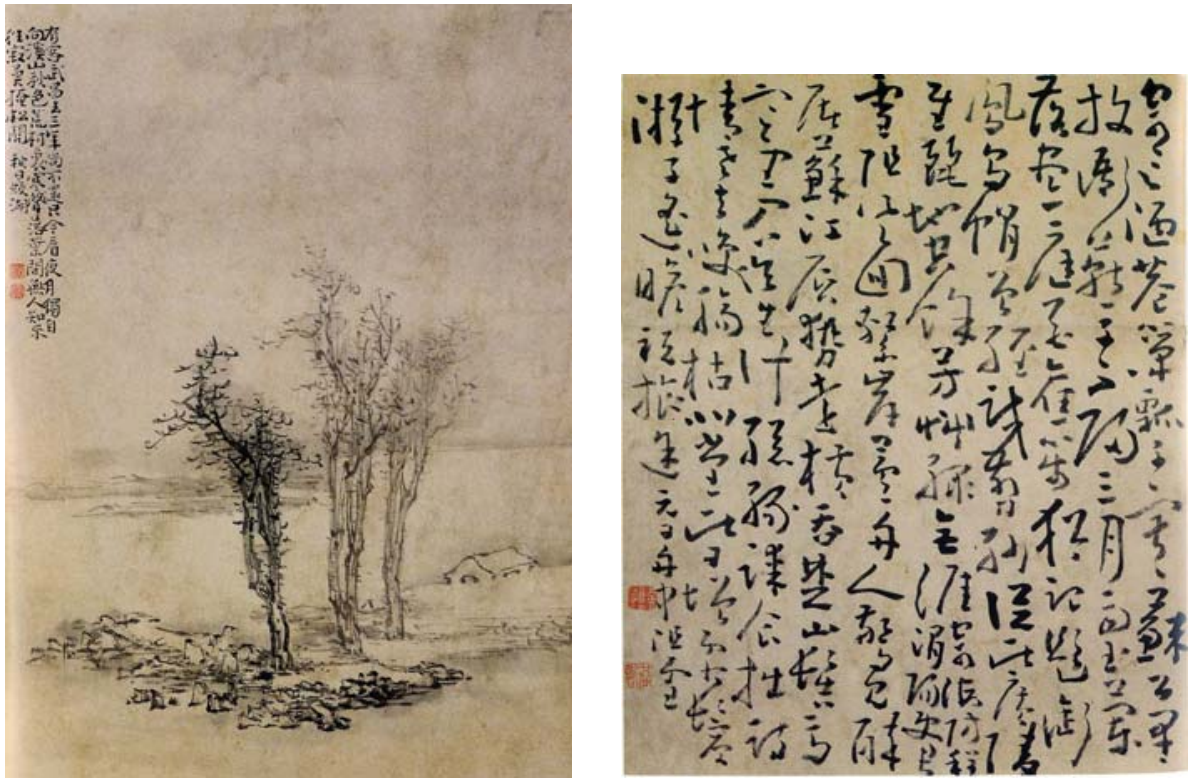

Figure 17.13a-b Huang Shen, Jiaohu in Autumn, 1740. Ji'nan Municipal Museum (Yangzhou huapai shuhua quanji: Huang Shen 1998).

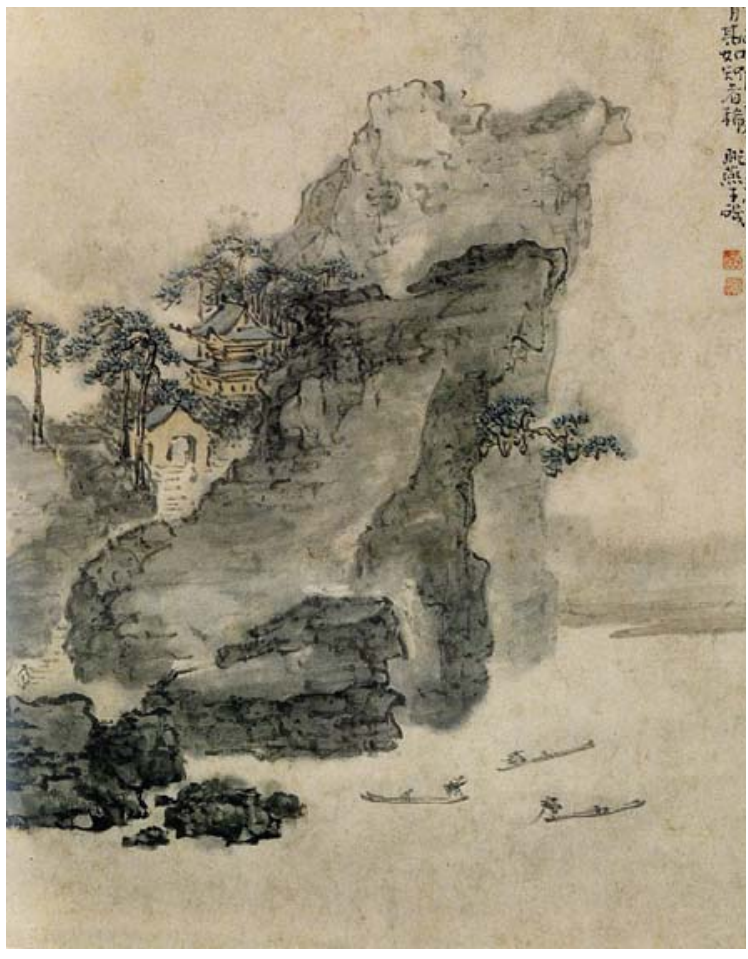

Figure 17.14 Huang Shen, Overlooking Yangziji, 1740. Ji'nan Municipal Museum (Yangzhou huapai shuhua quanji: Huang Shen 1998). 


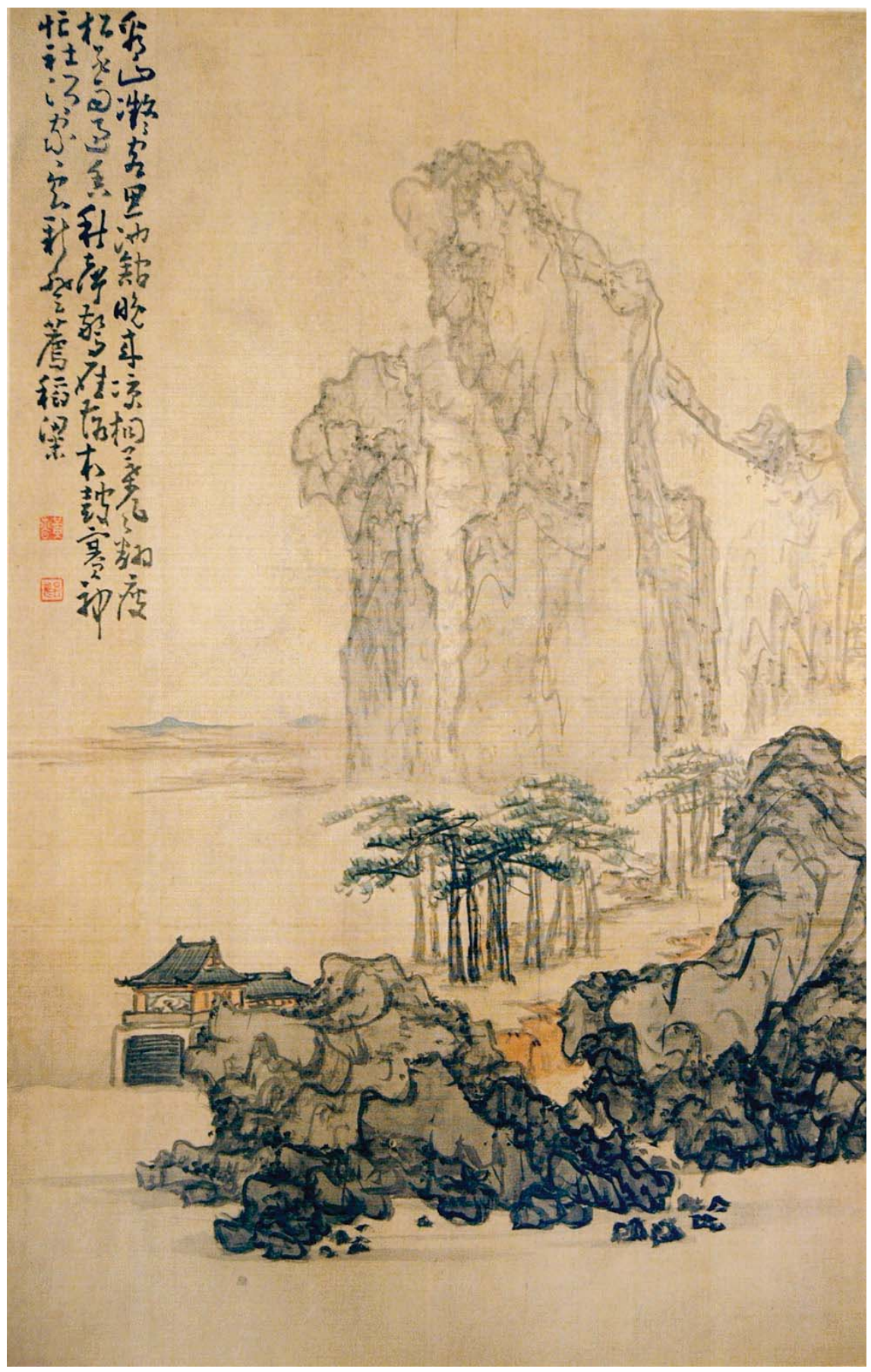

Figure 17.15 Huang Shen, leaf 1 from the album dated 1755. San Diego Museum of Art. 


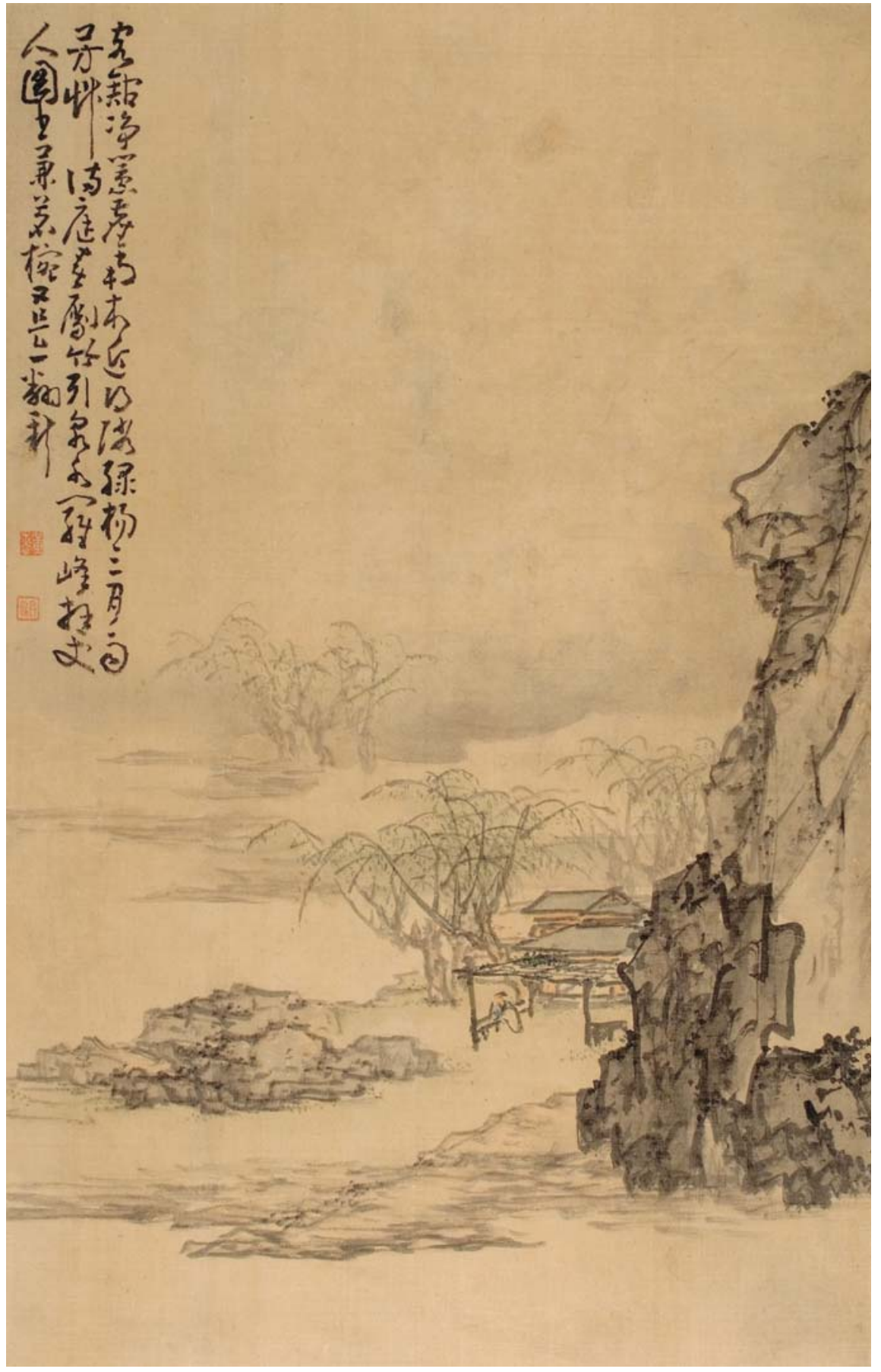

Figure 17.16 Huang Shen, leaf 2 from the album dated 1755. San Diego Museum of Art. 


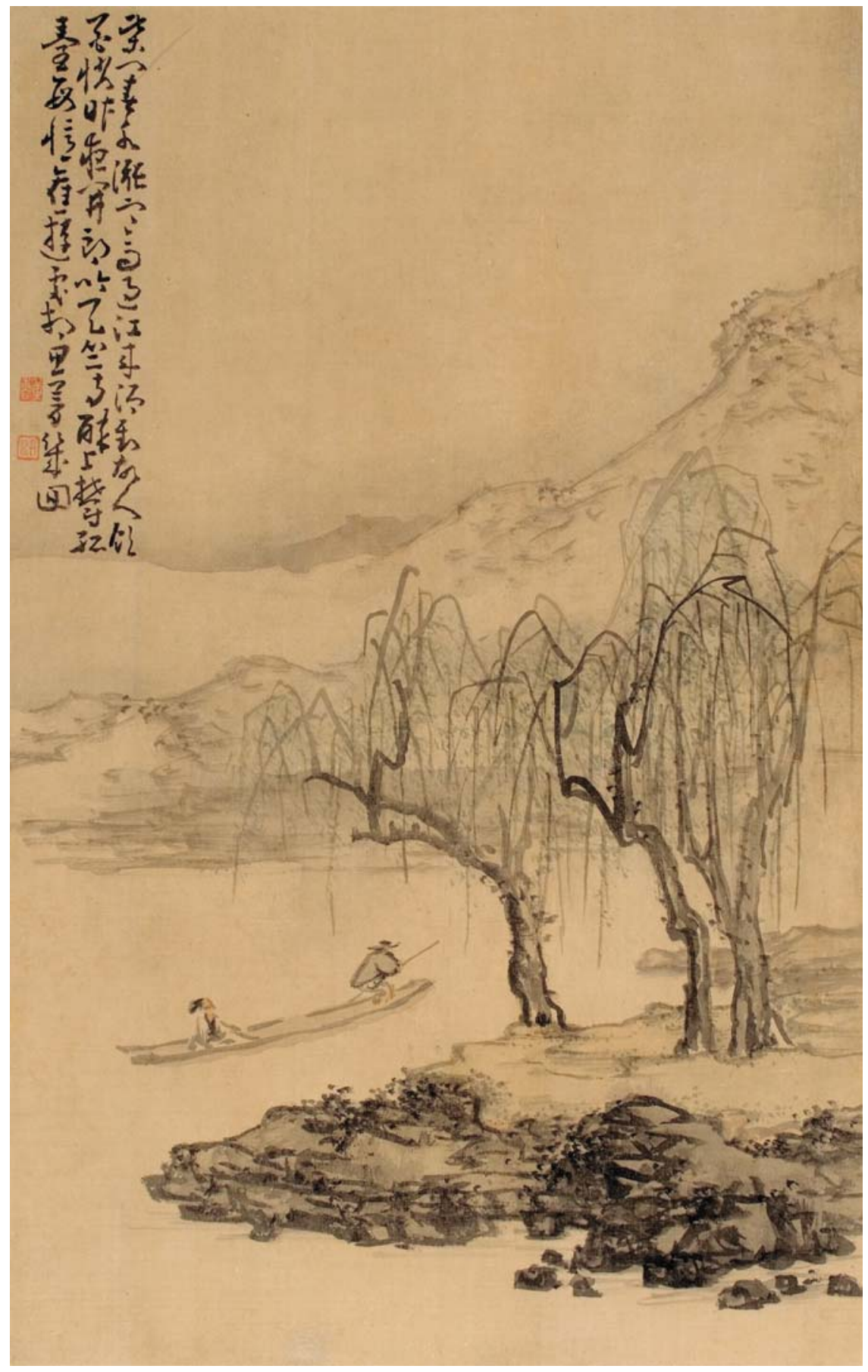

Figure 17.17 Huang Shen, leaf 5 from the album dated 1755. San Diego Museum of Art. 


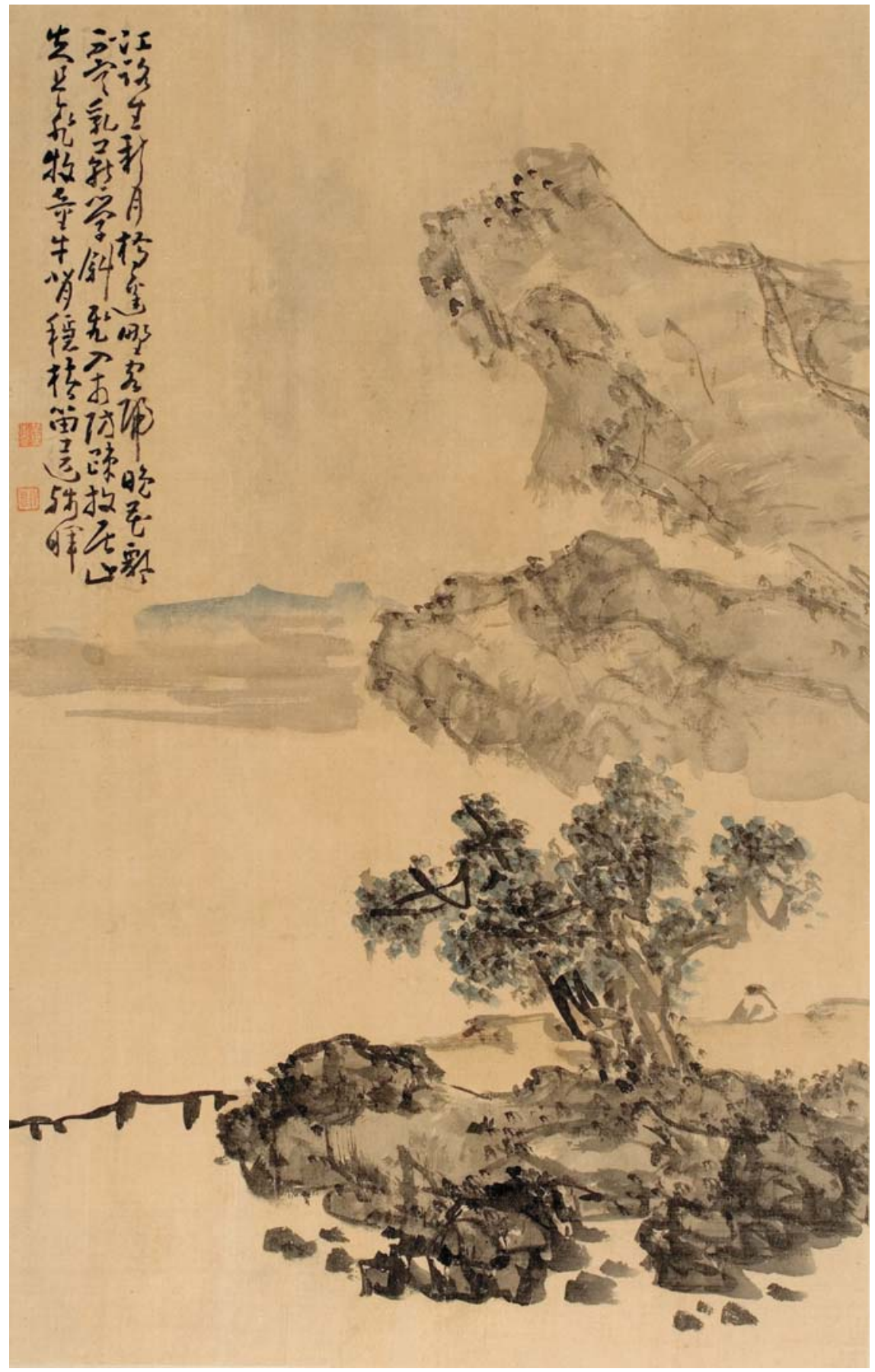

Figure 17.18 Huang Shen, leaf 7 from the album dated 1755. San Diego Museum of Art. 


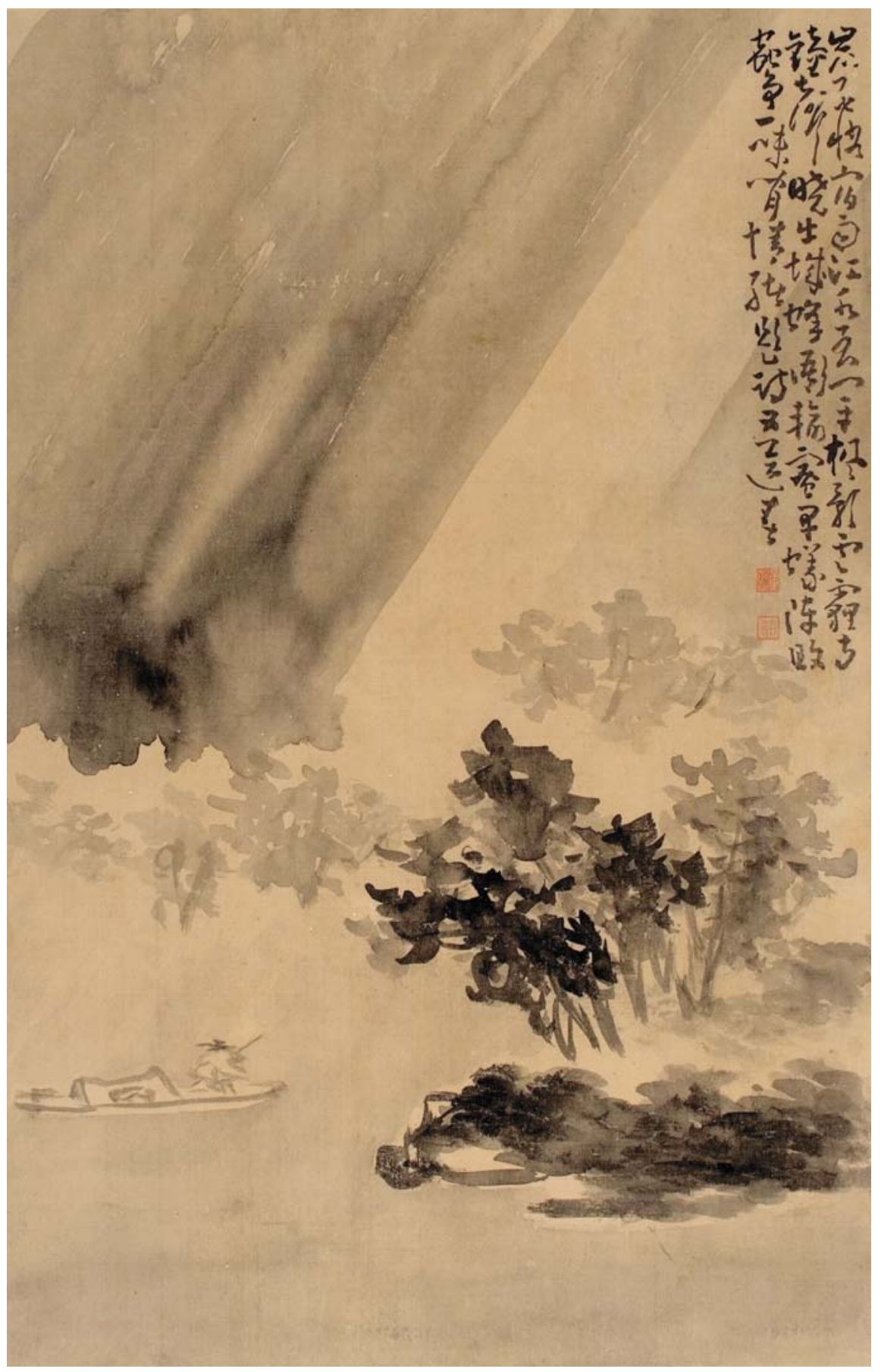

Figure 17.19 Huang Shen, leaf 3 from the album dated 1755. San Diego Museum of Art. 


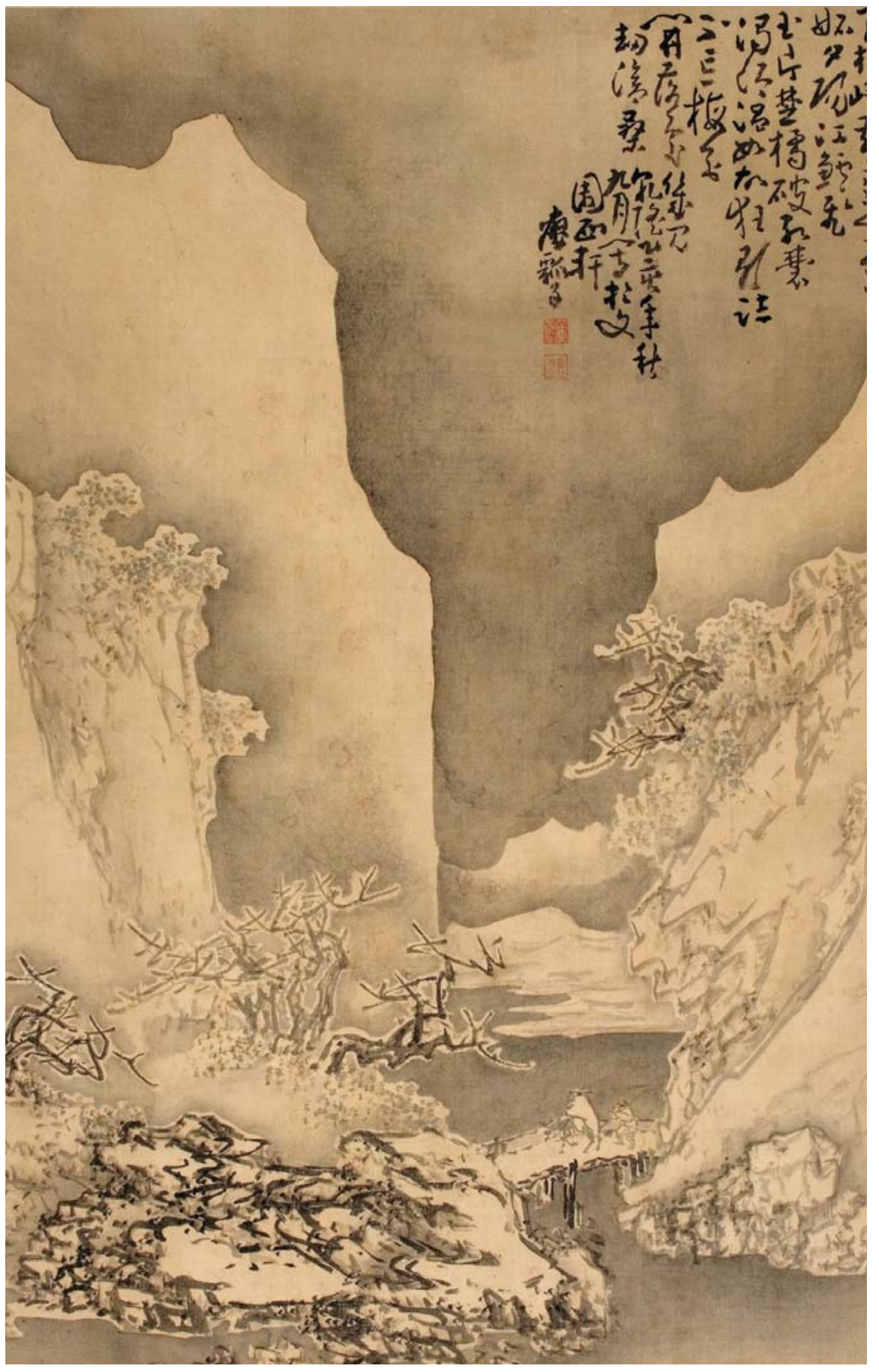

Figure 17.20 Huang Shen, leaf 10 from the album dated 1755. San Diego Museum of Art. 
home province of Fujian and in Jiangnan are depicted, including Jiaohu 晈湖 in Fujian, Yanziji 燕子磯 near Nanjing, and Xiaogu 小姑 mountain in Anhui. Huang Shen painted this album when he had already returned to Ninghua from Yangzhou; the artist felt very isolated in Fujian, and was deeply affected by his memories of Jiangnan. For instance, a poem inscribed on Huang Shen's depiction of Jiaohu in autumn conveys his deep feelings of loneliness in southern China; and like many of his landscapes painted in the style of Ni Zan, the painting itself evokes sorrow and solitude (Fig. 17.I3). To a great extent, the celebrated Yuan artist's desolate landscape was internalized and personalized by Huang Shen. That Huang Shen was able to maintain his own individualized brushwork in his appropriation of Song-Yuan traditions, especially the styles of $\mathrm{Ni} \mathrm{Zan}$ and $\mathrm{Mi} \mathrm{Fu}$, is particularly laudable. The dry, quick, and almost agitated manner of Huang's painting is a signature of his work.

\section{THE LANDSCAPE ALBUM OF 1755}

During the I740s, Huang Shen compiled several albums which combine figure, landscape, and flower paintings. It was not until 1755 that he painted another important album of landscapes, the one I introduced earlier. ${ }^{17}$ This I755 album of ten leaves was painted during Huang Shen's second visit to Yangzhou, from I75I to 1756. It was very likely a gift to Huang Shen's friend Wang Zhiheng 汪之珀 (?-1766, other name Wang Puzhuang 汪橏莊), a famous poet whose residence, the Wen 文 Garden in Rugao county was at that time a gathering place for many poets and painters. In I755 Huang Shen stayed in the Wen Garden for six months and painted several largescale scroll paintings, including a handscroll of the portrait of the renowned literary figure Ding Youyu 丁有显 (1682-1764) which was later inscribed by Zheng Xie 鄭孌 (I693-I765) and Yuan Mei 袁枚 (I7I6-I798). ${ }^{18}$ As a travelogue augmented with poetic insights, the format of Huang Shen's 1755 landscape album follows his earlier works of this type (Fig. 17.15). The places depicted in the album are not specified, but the inscriptions of poetry on the paintings indicate that they are mostly in either Jiangxi or Anhui province. As with Huang Shen's previous albums, this later work depicts its settings in various seasons, autumn and spring respectively (Figs 17.16, I7.17), at different times of the day, e.g. the setting sun (Fig. 17.18) and in varied weather conditions, e.g. rain and snow (Figs I7.I9 \& 17.20). It is an ensemble which expresses some of the most subtle representations of Jiangnan landscape.

This particular travelogue may look similar to Huang Shen's previous landscape albums from the late I720s. However, the loosening up of Huang Shen's style is readily seen: his brushwork is extremely rapid and unfettered, and the rocks and mountains are often suggested by only a few strokes (Figs 17.21 \& 17.22). For this sketch-like style in what is possibly Huang Shen's last landscape album Qiu Youxuan coined the phrase 'self-created cursive landscape painting' (QIU Youxuan 2002: 280). 


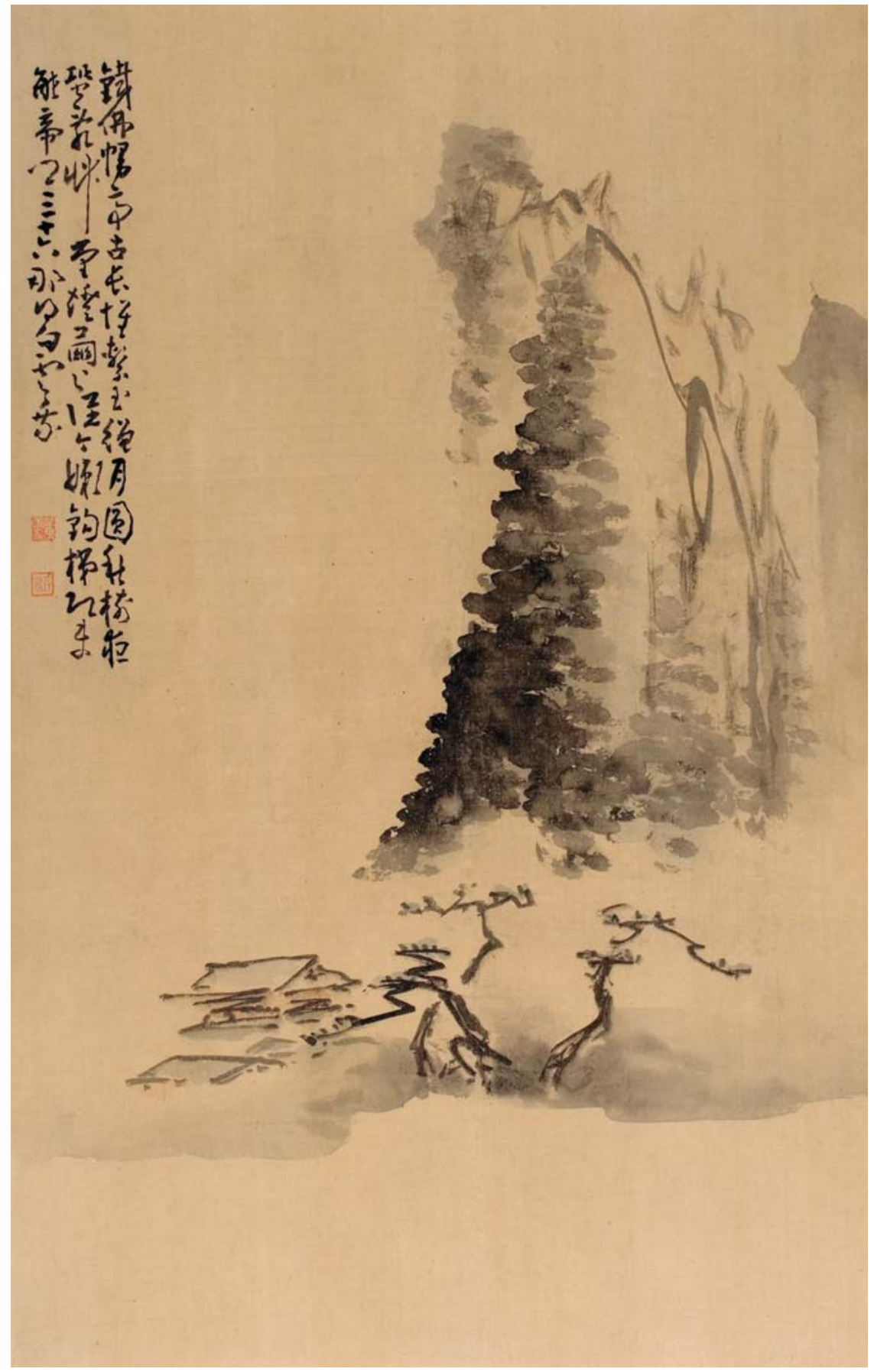

Figure 17.21 Huang Shen, leaf 6 from the album dated 1755. San Diego Museum of Art. 


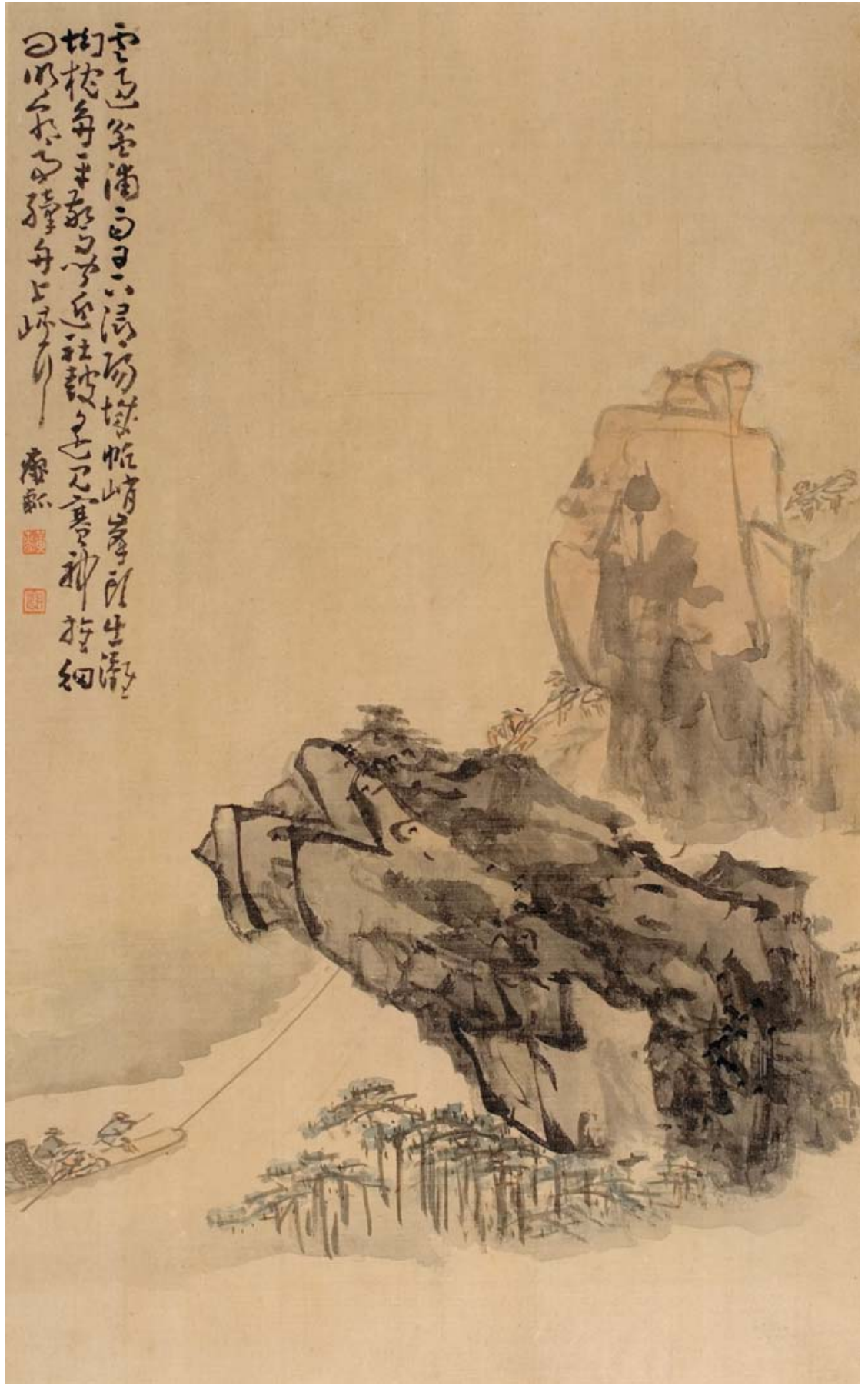

Figure 17.22 Huang Shen, leaf 9 from the album dated 1755. San Diego Museum of Art. 


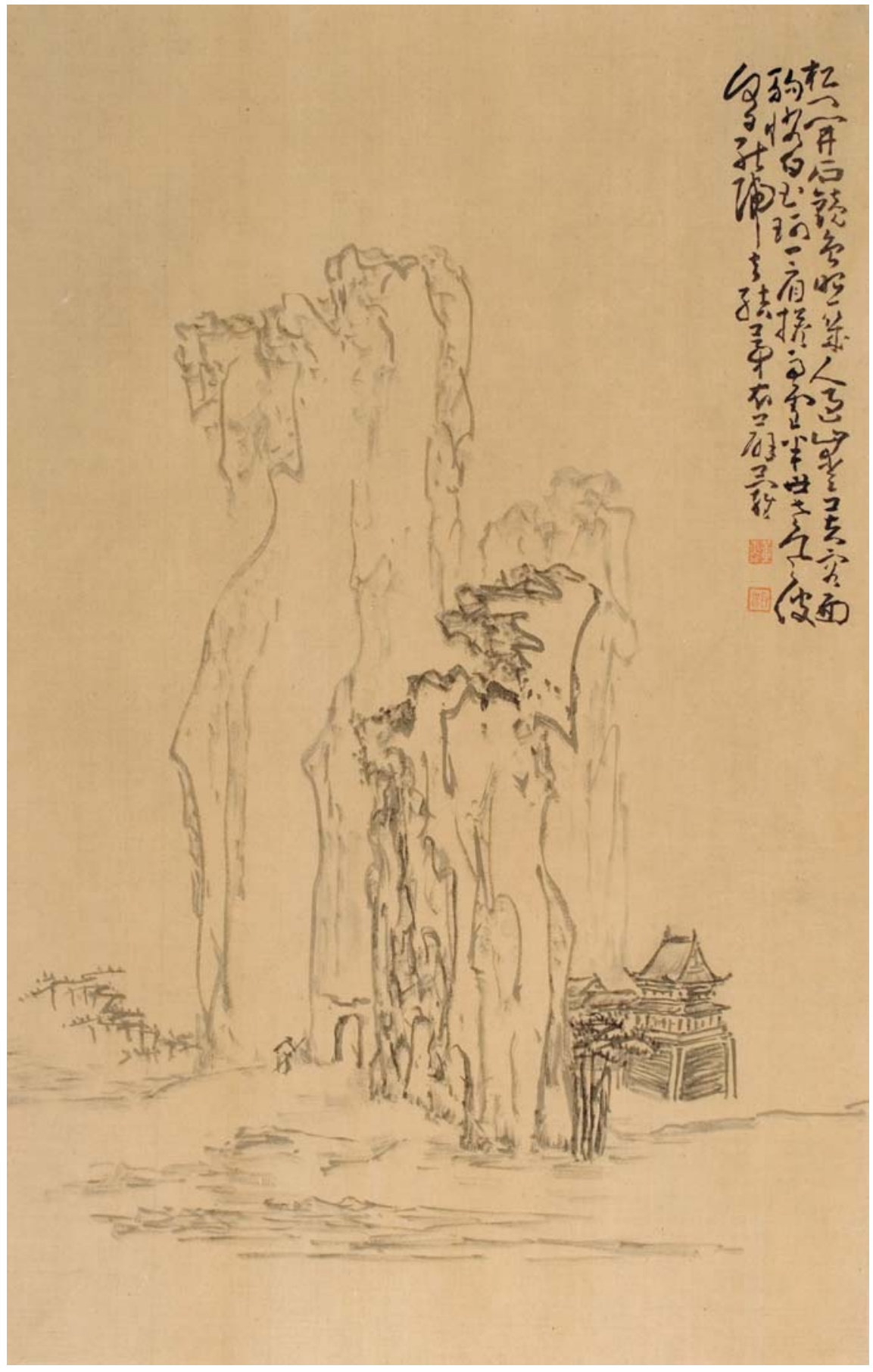

Figure 17.23 Huang Shen, leaf 8 from the album dated 1755. San Diego Museum of Art. 


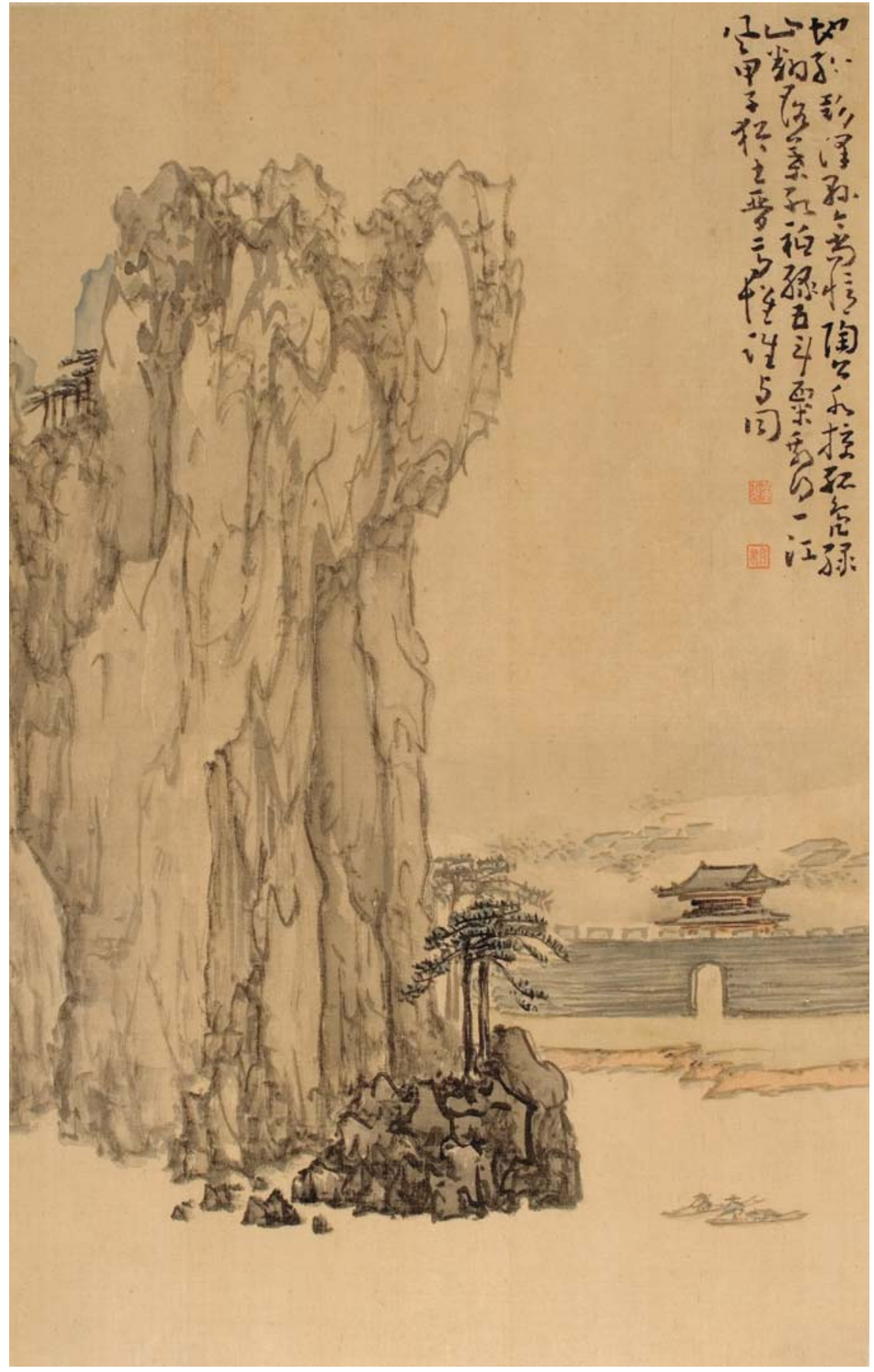

Figure 17.24 Huang Shen, leaf 4 from the album dated 1755. San Diego Museum of Art. 
Perhaps these simple and free strokes reflect the restlessness that afflicts an artist who, although elderly, had to be constantly on the road to support his family. On one leaf which depicts Songmen 松門 mountain in Jiangxi, Huang Shen writes the same poem which expresses his longing for home as in a painting in his 1734 album discussed earlier (Figs I7.23 \& 17.6). ${ }^{19}$ Approaching seventy years of age, Huang Shen's choice of this poem written some twenty years ago shows his ever more profound yearning to retire to his home; the unsettled state of his mind is aptly captured by the painting's dry and pale brushwork. ${ }^{20}$

Another of Huang Shen's old poems also cited in the 1755 album is one that pays tribute to the admired literary figure Tao Qian 陶潛 $(365-427)$; it is inscribed on Huang Shen's painting of Pengze 彭澤 in Jiangxi, where Tao Qian served briefly as a magistrate before he resigned (Fig. I7.24):

Traveling through the city of Pengze,

My thoughts remain with Master Tao.

A waterfowl swoops down to the blue river;

The fallen leaves redden the hills beyond.

A humble rejection of five pecks of grain

Left him with but a riverful of wind.

An ever-loyal subject after the fall of Jin,

His lofty sentiment is without equal. ${ }^{21}$

Prior to I755, Huang Shen had painted scenes from his travel to Pengze in two other landscape albums, in 1729 and 1740 respectively, both of which are seen as major works of his. ${ }^{22}$ Huang Shen must have had a certain personal attachment to Pengze as well as to Tao Qian, an honorable Jin dynasty poet-official who refused to humble himself to a visiting inspector because he (Tao Qian) was paid with a pitifully low salary. Perhaps Huang Shen, who remained a commoner throughout his life without pursuing official degrees, shared the same pride as Tao Qian in his modest life. Or perhaps, as these albums were mostly gifts to officials, some of whom were retired or soon to retire, Huang Shen was honoring his patrons by comparing them to Tao Qian. ${ }^{23}$ In the painting, the loftiness of the Jin poet-official is represented by a landscape of grandeur (Fig. 17.24).

It is interesting that in virtually all of Huang Shen's landscape albums he painted snow scenes on the last page, where he would sign his name and sometimes add a long inscription. The 1755 album is no exception, ending with a painting of Tianzhu 天䇥 mountain in Jiangxi covered in snow (Fig. 17.20). Huang Shen's choice of a wintry landscape as the final image may simply acknowledge the seasonal cycle. But perhaps the artist traveled at this presumably most arduous time to challenge himself and test his will. As he proclaims in the poem reproduced here: 'Where plum blossoms open and fall, one witnesses the verve [that has] survived from life's downturns.' 


\section{CONCLUSION}

Biographical notes of the Qing period, such as Wang Yun's 汪釷 Yangzhou huayuan $l u$ 揚州畫苑錄, have recognized Huang Shen to be skilled in the three perfections, sanjue 三絕, of poetry, calligraphy, and painting, collectively considered the supreme expression of literati accomplishment. ${ }^{24}$ Although constituting only a small portion of Huang Shen's prolific body of work, his splendid series of landscape albums, all aptly incorporating the esteemed three-sister arts are perhaps the most powerful proof that Huang Shen escaped from the confines of the low-ranked status of a professional painter and established himself as a true literati artist.

\section{NOTES}

1 For a discussion on how the patronage of Yangzhou salt merchants shaped a new style of painting, see Hsü 1989. Also see Xue Yongnian 1996.

2 For Huang Shen's biography, see Li Dou 200I [I795]: 43; CHOU and Brown 1985: 2II-2I3, and LANG Shaojun 1999 .

3 According to Ginger Hsü, Huang Shen was rarely included in any known social gatherings or poetry club meetings, except one in 1756 that was recorded by Zheng Xie. See Hsü 200I: IO7.

4 According to Li Wancai's rough estimation of Huang Shen's extant paintings, there are some 300 figure paintings, some 200 flower-and-bird paintings, and some Ioo landscape paintings. See Li Wancai 1999: Ir. Qiu Youxuan's extensive study of Huang Shen, however, shows more exact numbers: 477 figure paintings, 472 flower-and-bird paintings, and 256 landscape paintings. QIU Youxuan 2002: 252-282. In either case, Huang Shen's landscape painting is the least in number among all three genres.

5 See Toda and Ogawa 1998: 239. The 1755 landscape album by Huang Shen came into the collection of the San Diego Museum of Art in 1970 ; its size is $48 \mathrm{~cm}$ by $30.5 \mathrm{~cm}$.

6 This album is now in the collection of the Museum Rietberg in Zürich. See CHOU and BRown 1985: 214-217. Also see Suzuki 1983, vol. 2: E7-055.

7 For Huang Shen's relation and friendship with Yang Xinglou and Yang Kaiding, see Hsü 20oI: IO6, and Qiu Youxuan 2002: 373-374.

8 Huang Shen is said to have stayed in the Yang family's residence, the Hall of Twin Pines, Shuangsong tang 雙松堂, when he first arrived in Yangzhou (QIU Youxuan 2002: 373).

9 Huang Shen's stylistic transformation is recorded in Xie Kun's 謝枋 Shuhua suojian lu 書畫所見 錄, see CHOU and Brown I985: I2-13.

10 This 1734 album is now in the collection of the Guangdong Provincial Museum. See Yangzhou huapai quanji: Huang Shen 1998: plates 22-29.

11 Translated by Yi-li Kao.

12 Between the years 1735 to 1738 , Huang Shen probably compiled at least five albums. They include a I2-leaf album of figure and landscape paintings of 1735, now in the collection of the Palace Museum, Beijing, and a I2-leaf album of figure and landscape paintings of 1737 in the 
collection of the Guangdong Provincial Museum. See Yangzhou huapai shuhua quanji: Huang Shen 1998: plates 30-4I and plates 43-53. There is also a I2-leaf album of figure, flower, and landscape paintings of 1736 , now in the collection of the Wuxi Museum in Jiangsu. See Yangzhou huapai shuhua quanji: Huang Shen. 1998: plates 2II-222. In addition, there is a landscape album of I736 that belongs to a private collection in Switzerland, recorded in QIU Youxuan 2002: 590-59I. Furthermore, in 1738 Huang Shen made a I4-leaf album of landscapes - now in the collection of the Sen-oku Hakko kan Museum in Kyoto. See Suzuki 1983, vol. 3: 25I-252.

13 Lang Shaojun has already proposed such a reading, see LANG Shaojun 1999: I70.

14 Suzuki 1983, plates 8 and 9. The translation is adapted from that of Giacalone 1990: 55.

15 See Anonymous (or Jin Yuan 金瑗), Shibaizhai shuhualu 十百齋書畫錄), in Lu Fusheng 2000, gui 癸, p. 6ro-6ri. Also note Ginger Hsü's discussion on Gong Xian's preference for hua over tu, in Hsü 200I: II8. On the question of the authorship of Shibaizhai shubualu, see CaHILl I982: 237.

16 See Cur Mingquan 1982: 78-83. The complete leaves of this 1740 album are published now in Yangzhou huapai quanji: Huang Shen 1998: plates 290-303.

17 Huang Shen painted three albums which include landscape paintings during the I740s. The first one is a I2-leaf album of figure, flower, and landscape paintings of 1743 , now in the collection of the Nanjing Museum. See Qiu Youxuan 2002: 637-39. The second and third albums are in a catalogue by Vito Giacalone: a 6-leaf album of landscape, figure, and flower paintings of 1747 in the Ching Yuan Chai Collection - now housed at the Berkeley Art Museum, and an 8-leaf album of figure and landscape of 1750 in the collection of the Detroit Art Institute. See Giacalone 1990: 54-55.

18 Other scroll paintings that Huang Shen painted in Wang Zhiheng's Wen Garden are all hanging scroll paintings - they include: $S u W u$ Herding Sheep ( $S u W u$ muyang tu 蘇武牧羊圖), now in the collection of the Xinjiang Museum; Laozi Riding on an Ox (Hanguan ziqi tu 函關紫氣圖) in the Chinese History Museum, and Magu Wishing for Long Life (Magu xian shou tu 麻姑獻壽圖) in the Qingdao Municipal Museum in Shandong. The handscroll of Ding Youyu is in the Nantong Museum in Jiangsu. See QiU Youxuan 2002: 698-705.

19 Note that Huang Shen has altered slightly on the second line of this poem.

20 This poem of Songmen mountain was written during the Yongzheng reign (1723-1735) and is recorded in Huang Shen's collection of poetry Jiahu shichao. See Huang Shen 1989: 204.

21 Ju-hsi Chou and Claudia Brown's translation, in CHOU and Brown 1985: 215.

22 The 1729 album is now in the collection of the Museum Rietberg, Zürich, see CHOu and BRown 1985: 214-217. The 1740 album is in the Ji'nan Municipal Museum in Shandong, see Yangzhou huapai quanji: Huang Shen 1998: plate 300.

23 For instance, the recipient of Huang Shen's 1740 album Wang Xiang 王相, a Tingzhou 汀 州 prefect, is said to have very likely brought back the album to his hometown Shandong as a souvenir after his service in Fujian (Hsü 200I: IIO).

24 See WANG Yun 1995b [I883]: 670. Also see Jiang Baoling 蔣寶齡, Molin jinhua 墨林今話, juan I, cited in Gu Linwen 1962: 17. 


\section{Illustrious Icons and Flower}

\section{Garlands}

\section{Defining Buddhist Imagery in}

\section{Eighteenth-Century Yangzhou Painting}

\section{Kristen E. Loring}

A rtists of eighteenth-century Yangzhou lived in a complex society, where local elite patrons rose from dubious origins and artists assumed roles as eccentric cultural figures. The cosmopolitan city of Yangzhou, legendary for its history of painting, poetry, garden culture and Buddhism, was not only rife with opportunities for upward social mobility but also provided a ready site for lifestyles steeped in arts and leisure. ${ }^{1}$ Such social conditions were particularly advantageous for the arts: the eighteenth century saw artists investigating their roles in society, questioning the traditional underpinnings of the artistic canon and forging creative innovations in subject matter and style. Although scholars have scrutinized this inventive spirit as well as the social conditions that shape Yangzhou's unique visual culture, ${ }^{2}$ the pictorial manifestations of Buddhism have yet to be defined. This study examines the rich exchange between Yangzhou's eighteenth-century artistic and religious culture by exploring the intersection of painting with popular Buddhist beliefs and the lay practices of artists and patrons. Using the paintings of two Yangzhou artists, Jin Nong 金農 (I687-I764) and Hua Yan 華品 (I682-I756), as case studies, I argue that contemporary social and artistic concerns motivated their representations of Buddhist imagery. As the paintings of these two artists demonstrate, Buddhist imagery communicated a multiplicity of religious and secular concerns that underscore the cultural and social tensions of eighteenth-century Yangzhou.

Buddhism has historically intersected with Yangzhou's arts and leisure culture. In the seventh century, the Sui dynasty Emperor Yangdi 煬帝 (r. 605-6I8), a Buddhist patron and devotee, spent his final days indulging in banquets and revelry at his Yangzhou palaces (Meyer-Fong 2003: I2-I3). And during the Tang dynasty, the monk Jianzhen's 堅貞 (Jap. Ganjin, 688-763) voyages between Yangzhou and Japan not only propagated Buddhism among the Japanese aristocracy, but also transmitted 
Chinese religious sculpture and cultural knowledge of this specific locale. By the late Ming, the spread of Buddhism among the gentry of this lower Yangzi region drew religion even closer to elite culture, with monasteries acting as sites of tea tasting, landscape tourism and other cultural pursuits (BROOK I993: IO8-I3). After the devastating Yangzhou massacre of 1645 , members of the elite community played a critical role in the restoration of Buddhist temples, which also came to function as sites for social gatherings and points of interest along the Southern Tours of the Kangxi 康熙 (r. I662-I722) and Qianlong 乾隆 (r. I736-I795) emperors. ${ }^{3}$ Many Yangzhou artists and poets were Buddhist devotees, such as Shitao 石濤 (I642-I707), the illustrious Ming prince, monk, painter and early Qing resident. ${ }^{4}$ By the eighteenth century, Yangzhou's economic prosperity brought further patron involvement, representing a vibrant crossroads of both Buddhism and the arts in what Susan Naquin and Evelyn Rawski describe as 'the heartland of Chinese Buddhism' (NAQUin and RAWSKI 1987: 156). This rich environment attracted cultural figures such as Luo Pin 羅聘 (I733-I799), a Buddhist and professional painter who described his faith in a collection of essays entitled Woxin lu 我信錄 or 'Record of My Beliefs.' less, although Buddhism has historically represented a pillar of Yangzhou culture and popular beliefs, religious themes are often neglected in the interpretation and contextualization of eighteenth-century Yangzhou painting.

The objective of this study is to locate pictorial representations of Buddhist imagery within the enterprising spirit, rich complexities and intriguing contradictions of eighteenth-century Yangzhou. It considers the contentious intersection of popular Buddhist beliefs and social concerns as they relate to themes commonly cited in accounts of contemporary Yangzhou such as extravagance, modesty, wealth and desire. For example, the Yangzhou poet Yuan Mei 袁枚 (I7I6-I798) highlights a tension between popular Buddhist values and contemporary social paradigms, here criticizing the Buddhist denial of human desires and feelings: 'A [Buddhist] householder, who must block out sound and form or cut off thoughts and actions, may be alive but lives like the dead; he is a human being who treats himself like a tree or rock' (SCHMIDT 2003: 6I). By suggesting that one should feel and indulge in the thoughts and actions that constitute one's life, this passage reveals a tension between Buddhist beliefs and eighteenth-century Yangzhou social practices. I argue that the subject matter, style and themes of contemporary paintings similarly suggest these anxieties.

This study unveils the intersection of Buddhist themes and contemporary concerns in the paintings of Jin Nong and Hua Yan. Analysis of later works by these two artists demonstrates the complexity and diversity of approaches to Buddhist imagery in Yangzhou painting. Furthermore, the biographical similarities between Jin Nong and Hua Yan relate to their experiences of contemporary Yangzhou society first as outsiders, then as social voyeurs and participants. Both artists came to Yangzhou from the nearby city of Hangzhou later in their careers in search of 
patronage, and became friends due to their shared interests in poetry, painting and Buddhism. ${ }^{6}$ Each constructed a distinct social persona in Yangzhou. Jin Nong was a flamboyant character and highly erudite poet, artist and devout Buddhist known to frequent elite Yangzhou social gatherings. Hua Yan, in contrast, is known for his reclusive temperament and love of nature. Upon arrival in Yangzhou, each artist comes to specialize in subjects of local popularity; for instance, Jin Nong's works depict figures, bamboo and plum blossoms while Hua Yan's include birds, flowers and insects. ${ }^{7}$ Despite differences in subject and style, each artist employs Buddhist imagery through popular genres and subject matter of religious figures, daily-life scenes and bird-and-flower paintings. ${ }^{8}$

I contend that although both Jin Nong and Hua Yan aligned their visual modes with contemporary tastes through subject matter, novel styles and allusions to historical models, each demonstrates a unique approach to Buddhist imagery through self-referential nuances and social observations through juxtaposition of word and image. For instance, Jin Nong's bold, iconic Buddhist figures prompt a reconsideration of historical approaches to style, subject matter and composition. This approach satisfies contemporary artistic preferences through its inventive representation of popular Buddhist iconography. However, Jin Nong's use of words and images also reflects his personal religious beliefs, which he enacts through his artistic practices. Hua Yan's bird-and-flower paintings also utilize and challenge traditional visual modes through word and image, yet frame these seemingly secular garden subjects amid Buddhist concepts of desire and worldly attachment. Thus, despite different selections of popular subjects and styles, Jin Nong and Hua Yan's approaches to Buddhist imagery both highlight a constellation of factors including their individual spiritual beliefs, creative interests and experiences of eighteenth-century Yangzhou society.

As I will demonstrate, Buddhist imagery in Jin Nong's and Hua Yan's paintings highlights similar artistic and cultural concerns over wealth and excess, traditional elite values and the novelty of the historical present. Due to the complicated connotations of these works, the analysis of Jin Nong and Hua Yan's paintings necessitates a multilayered methodological approach. My discussion of each work moves from an iconographic analysis to a historical contextualization of the artistic and social relevance of the Buddhist imagery, drawing upon both image and inscribed text to define the two artists' approaches.

\section{JIN NONG STRATEGIES OF REPRESENTATION VIA BUDDHIST ICONS}

Jin Nong's pictorial approach to Buddhist imagery is situated amid religious beliefs, aesthetic pursuits and an intimate, though potentially litigious, relationship with 
contemporary Yangzhou society. As a scholar, collector and painter, Jin Nong's artistic concerns and pictorial modes closely mirrored other aspects of his life including his study of epigraphy, collections of stone engravings and devout Buddhist beliefs. Yuan Mei inscribed a poem upon Luo Pin's 1782 portrait of Jin Nong, positioning his religious and artistic interests amid contemporary concerns over social distinction, worldliness, vulgarity and purity. A passage from this inscription reads:

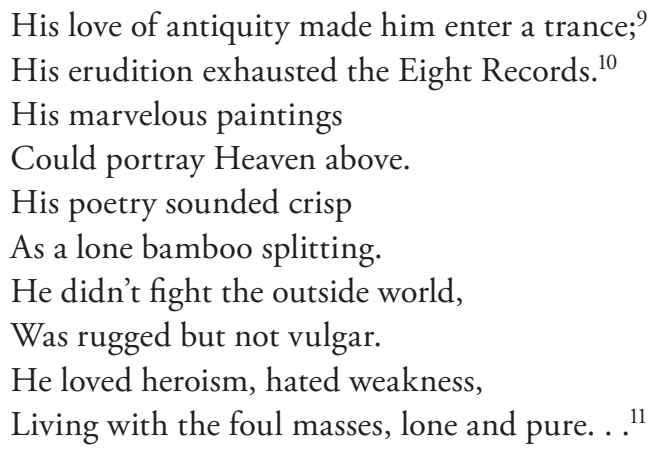

Jin Nong's pictorial approach to Buddhist imagery relates not only to his own creative and spiritual interests but also to lay practices and artistic tastes in eighteenthcentury Yangzhou. While Buddhist figures represent only a handful of Jin Nong's figural depictions, the combination of word and image in the following works exemplifies the artist's distinctive pictorial mode while underscoring the works' thematic relevance to contemporary society. Sakyamuni (I760), Banana Tree and Buddha Figure (undated) and Offering to the Buddha (I759) depict the Buddhist figures Sakyamuni, Bodhidharma and Pratyekabuddha, respectively. The iconography of these three Buddhist figures corresponds to Jin Nong's personal beliefs as well as lay practices in eighteenth-century Yangzhou such as the individual, private devotional practices of Chan 禪 (Jap. Zen) Buddhists. Chan Buddhism emphasizes immediate enlightenment through experiential practice rather than scriptural study. While Buddhist icons can be used either as material objects of worship or as mental aids for meditation through visualization, ${ }^{12}$ the pictorial representation and inscribed text of each of Jin Nong's works clearly emphasizes the significance of Chan Buddhist practices to himself and contemporary devotees.

In addition to parallels between the selection of Buddhist iconography and contemporary religious practices, Jin Nong's pictorial representation of these three Buddhist icons also investigates and challenges traditional Chinese pictorial depictions of Buddhist subject matter. By subtly departing from revered historical models such as Liang Kai 梁楷 (act. ca early thirteenth century), Jin Nong destabilizes traditional approaches and emphasizes the contemporary, local flavor of his own artistic contribution. Through analysis of the following three works, I suggest that 


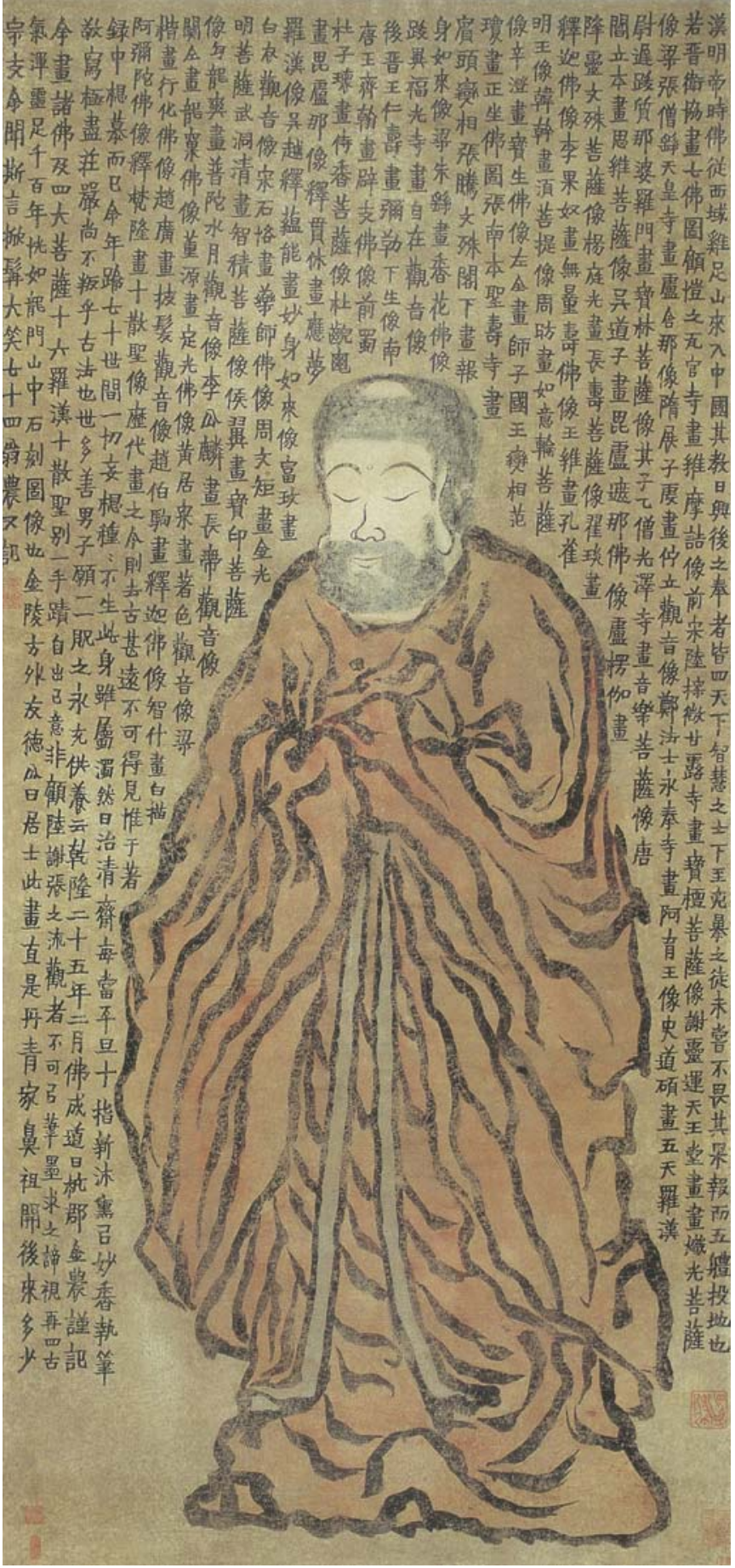

Figure 18.1 Jin Nong, Sakyamuni. 1760. Hanging scroll, ink and color on paper. $133 \times 62.4 \mathrm{~cm}$. Tianjin Museum. 
Jin Nong's approach to Buddhist imagery reflects contemporary artistic tastes for originality and tradition and, in so doing, highlights secular concerns regarding lay practices and social behavior. Furthermore, through his use of words and images, Jin Nong relates the act of painting to his personal devotional practice.

\section{Sakyamuni}

Through its striking composition and elaborate inscription, Jin Nong's Sakyamuni employs religious iconography to reflect his beliefs as a Buddhist devotee while also investigating traditional approaches to Buddhist painting (Fig. I8.I). Jin Nong derives his style from renowned portrayals of the subject through word and image, yet his innovative pictorial approach and self-referential comments position the work amid its context of eighteenth-century Yangzhou. In this section, I demonstrate that Jin Nong's approach to Buddhist imagery is motivated by both religious and artistic concerns while also appealing to contemporary tastes for splendor and novelty.

The subject matter of Sakyamuni relates to Chan Buddhist beliefs popular in eighteenth-century Yangzhou. The painting depicts a scene from the story of 'Sakyamuni Descending the Mountain,' a scene from the life of the Buddha that is among the moments most frequently depicted in Chan Buddhism. The image recalls the moment at which Sakyamuni (Prince Siddartha, the historical Buddha) descends from his mountain abode after a six-year period of practicing extreme asceticism. Sakyamuni is identifiable by his patriarchal robe, the principal emblem of transmission in Chan Buddhism. ${ }^{13}$ Although he has not attained wisdom, he comes down from the mountain and opts to pursue the 'middle path' which allows him to live a life between two extremes: neither decadent nor austere. This moderated approach to life, supplemented by individual practices such as meditation rather than scriptural study or asceticism, contributed to the popularity of Chan Buddhism in eighteenth-century Yangzhou. Here, the artist's Buddhist interests relate to contemporary spiritual beliefs and motivate his choice of subject matter.

Jin Nong's calligraphic inscription underscores his personal devotion as an inspiration for Sakyamuni's Chan Buddhist subject matter. The inscription begins with a brief yet significant mention of the Buddha and his Buddhist devotees as 'gentlemen of wisdom from all over the world.' This statement suggests that the artist views Buddhism as prevalent throughout the world and that it is of interest to astute gentlemen. He further attests to the popularity of Buddhism by stating, 'Even [down to] those violent and evil, there was not one who was not fearful of the karma and prostrated themselves [in worship].' Thus, the combination of the Chan subject matter of Sakyamuni and the inscribed text not only reveals Jin Nong's personal spirituality, but also suggests the prominence of lay Buddhism in eighteenth-century Yangzhou. 


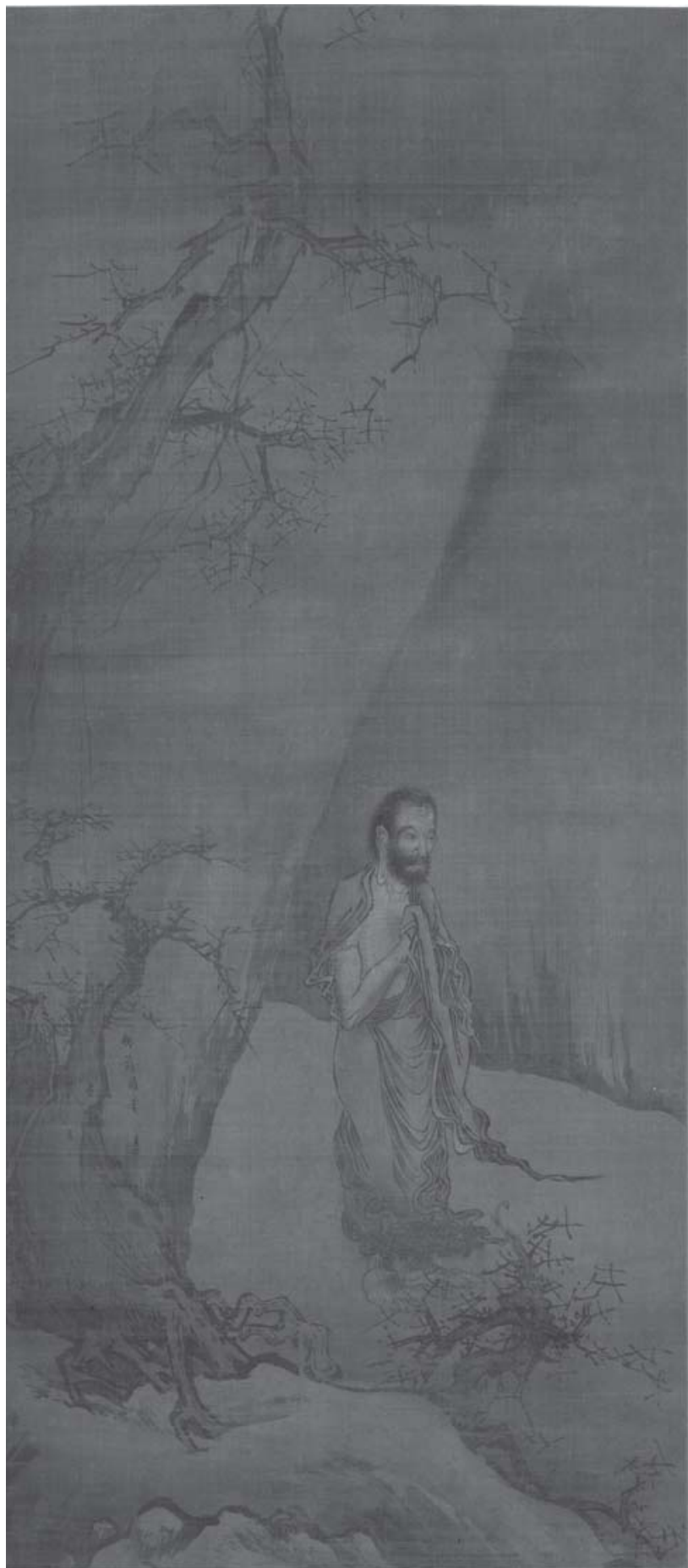

Figure 18.2 Liang Kai, Sakyamuni Descending the Mountain after Asceticism. Southern Song dynasty, thirteenth century. Hanging scroll, ink and color on silk, $117.6 \times 51.9 \mathrm{~cm}$. Tokyo National Museum. (TNM Image Archives, TnmArchives.jp/.) 
After relating Sakyamuni to personal and contemporary interests in Buddhism, Jin Nong's secondary objective is offer an original stylistic response to traditional subject matter. While Sakyamuni's iconography can be compared with several Chinese depictions of this subject, Jin Nong modifies his composition to emphasize the dramatic figural depiction of Sakyamuni. The work cleverly departs from traditional approaches to Buddhist imagery through conflation of iconographic and stylistic models including early pictorial depictions of Buddhist subject matter, Confucian rubbings and the Buddhist Longmen 龍門 sculptures. ${ }^{14}$ A prime example of historical approaches to this subject, and also the earliest extant depiction, is Liang Kai's thirteenth-century Sakyamuni Descending from the Mountain in the Tokyo Museum (Fig. I8.2). ${ }^{15}$ Liang Kai depicts Sakyamuni returning from a mountain landscape of trees and rocks, at a three-quarter stance, draped in a red robe, shoeless and with noticeable facial and body hair. Jin Nong's Sakyamuni, in contrast, portrays the figure in a stunning frontal position with the ushnisha, or bump protruding from the top of the Buddha's head, his eyes cast downwards or closed, and hands clasped within his billowing robes. The artist omits landscape details and, in so doing, emphasizes the portrayal of Sakyamuni in a contemplative moment as he descends from his period of asceticism. The bold stylistic depiction of the figure is further emphasized by Jin Nong's dramatic brushwork which differs from Liang Kai's detailed, descriptive approach. Rather than careful depiction of form, Jin Nong favors broad and tapering lines to create a stark, powerful image. Thus, Jin Nong's imposing figural proportions, reduced composition and animated brushwork highlight his interest in artistic innovation and differentiate his work from traditional models.

The content of Jin Nong's extensive calligraphic inscription on Sakyamuni further emphasizes his interest in artistic innovation through reference to famous painters. The inscription offers a terse history of Buddhist imagery by forty-seven masters from the late-third through early-thirteenth century (see Appendix at the end of this chapter). It lists two painters from the Jin 晉 dynasties (265-420), five from the Northern and Southern dynasties (420-589), two from the Sui 隋 (58I-6I8), thirteen from the Tang 唐 dynasty (618-907), fourteen from the Five Dynasties period (907-960), and eleven from the Song 宋 dynasty (960-I279). Jin Nong presents these great masters and their legendary works as the history for his own painting, as he mentions in his inscription:

I painted the images of the many Buddhas, as well as the Four Great Bodhisattvas, the Sixteen Arhats, and the Ten Saints in a different style. It is all my own idea, one that is unlike the precedents of Gu [Kaizhi 顧愷之, 344-406], Lu [Tanwei 陸探微, later fifth century], Xie [He 謝赫, late fifth-early sixth centuries] and Zhang [Sengyu 張僧乿, early sixth century]. ${ }^{16}$ Viewers should not seek in it only my brushwork. Looking at my paintings over and over again, one senses the flavor of antiquity and profound spirit that lasts for hundreds 
and thousands of years, and its radiance is like the stone-carved images in the caves of Longmen.

Jin Nong clearly states that his stylistic approach has the resonance of antiquity, but differs from the famous styles of the masters listed in his inscription. Many of the works by these masters appeared in Buddhist temples and the majority of the artists served as court painters. ${ }^{17}$ Unlike the works listed in the inscription, Jin Nong's bold style and minimal iconographic features privilege creativity and novelty over completeness and accuracy. For example, Jin Nong mentions Zhi Shi's fine-lined, or baimiao, rendition of the Amitabha Buddha, which marks a contrast with the thick, undulating lines of Sakyamuni. Furthermore, Jin Nong's distinctive mode of calligraphy, which draws from his study of epigraphy, highlights another innovative feature of his painting. Since many of the works listed in Jin Nong's inscription were painted at Buddhist sites, they likely did not contain personal inscriptions of the artists and were perhaps more concerned with accuracy in portrayal of the religious subject matter than expression of personal beliefs. Jin Nong's pictorial mode appears unprecedented in contrast to the traditional models of this inscribed lineage for its heavy ink application, distinctive calligraphic inscription and bold brushwork. Thus, the contrast between the legacy of the artists listed in the inscription and Jin Nong's stylistic approach to Sakyamuni suggests an inventive twist in the historical depictions of Buddhist imagery.

The stylistic features of Sakyamuni suit the well-known tastes for flamboyance and eccentricity in eighteenth-century Yangzhou. Ginger Hsü extensively discusses this unique social climate, citing Li Dou's famous passage on the excesses and extravagances of Yangzhou from Yangzhou huafang lu [Pleasure Boats of Yangzhou]. In describing the eccentric acts of the salt merchants of Yangzhou, he concludes, 'For quite some time these people vied with one another in novelty and eccentricities too numerous to be described in full' (Hsü 200I: I3-I5). Li Dou's comments easily relate to the final line of Jin Nong's inscription, which deny traditional restraint and modesty through boastful self-endorsement. In his final note at the end of the inscription, Jin Nong records a comment made by Layman Bai of Jinling (Nanjing) who offers that Sakyamuni is 'by a master of painting who started a tradition and initiated the way for several later generations,' to which the artist laughs and brushes his beard. This inclusion of Layman Bai's comment serves to summarize the remarkable degree of candor that was acceptable and, perhaps even requisite, in eighteenthcentury Yangzhou. Therefore, Sakyamuni not only relates to contemporary religious beliefs, but it also suits Yangzhou tastes for artistic novelty.

Through his allusions to traditional models and creative departures from them, Jin Nong's Sakyamuni investigates the art historical foundations of a popular Chan Buddhist subject and, thereby, unveils contemporary religious interests and cultural anxieties over tradition and novelty, restraint and decadence. 


\section{Banana Tree and Buddhist Figure}

Whereas Sakyamuni offers a novel response to traditional depictions of Buddhist imagery, Jin Nong's approach to Banana Tree and Buddhist Figure emphasizes local features and recognizable lay practices. Through analysis of image and inscribed text, I suggest that Jin Nong locates his own devotional practices in the local environment and familiar, lay Buddhist rituals. By merging his own devotional and artistic practices in Banana Tree, Jin Nong defines the role of religious beliefs in his creative process of visualization, image creation and pictorial representation (Fig. I8.3). ${ }^{18}$

Unlike Sakyamuni, there are few comparable art historical precedents for Jin Nong's Banana Tree and Buddhist Figure. I argue that the painting depicts Bodhidharma, a popular icon in Chan Buddhism that relates the painting to individual practices of meditation. Bodhidharma is the first patriarch of the Chan sect, reputed as an austere practitioner of meditation who emphasized the teaching of emptiness, absence of self and other, and denial of reality (FAURE 1986: I89). He is usually depicted as non-Chinese in appearance, often with prominent facial features and a curly beard. He is often pictured wearing a red robe and gold hoop earrings, seated under a tree in meditation. Here, Jin Nong portrays the figure in meditation and seated under a tree, with a curly, non-Chinese beard, a bulbous nose, and hoop earrings, all features of which suggest the figure's identity as Bodhidharma. However, Jin Nong's depiction of the figure in profile and the lack of a specific identification of the figure in his inscription suggest a degree of ambiguity, as if the figure could be either a lay practitioner or a Buddhist icon. Thus, on the one hand, the identification of the figure as Bodhidharma signifies Chan practices of meditation popular among Jin Nong and his contemporaries and, on the other hand, the slight ambiguity of the icon underscores its visual comparison with familiar lay practices.

As in his stylistic approach to Sakyamuni, Jin Nong reduces the composition of Banana Tree to a few significant iconographic elements. In Banana Tree, the reduction of compositional elements serves to emphasize the local features of the painting. Here, only three elements, the seated Bodhidharma, the mat upon which he sits and the banana palms, dominate the composition. The banana palm frequently appears as a landscape feature in depictions of Yangzhou gardens and scholarly huts, and it is native to the lush lower Yangzi climate. For example, it appears in portraits of elite Yangzhou residents to suggest an atmosphere of elegant leisure, such as Fang Shishu 方士庶 and Ye Fanglin's 葉芳林 A Literary Gathering at Xing'an on the Double Nine (1743). ${ }^{19}$ The banana palm is also a favorite motif in Yangzhou painting due to its association with Tang and Song poetry, which often describes the sound of rain on its broad leaves or brushing against the walls of a poet's study. Additionally, the Tang dynasty monk Huaisu 懷素 (725-785) was said to paint directly on the banana palm, which relates to its history as a medium for Buddhist sutras (SHIvely 1953: 158). 


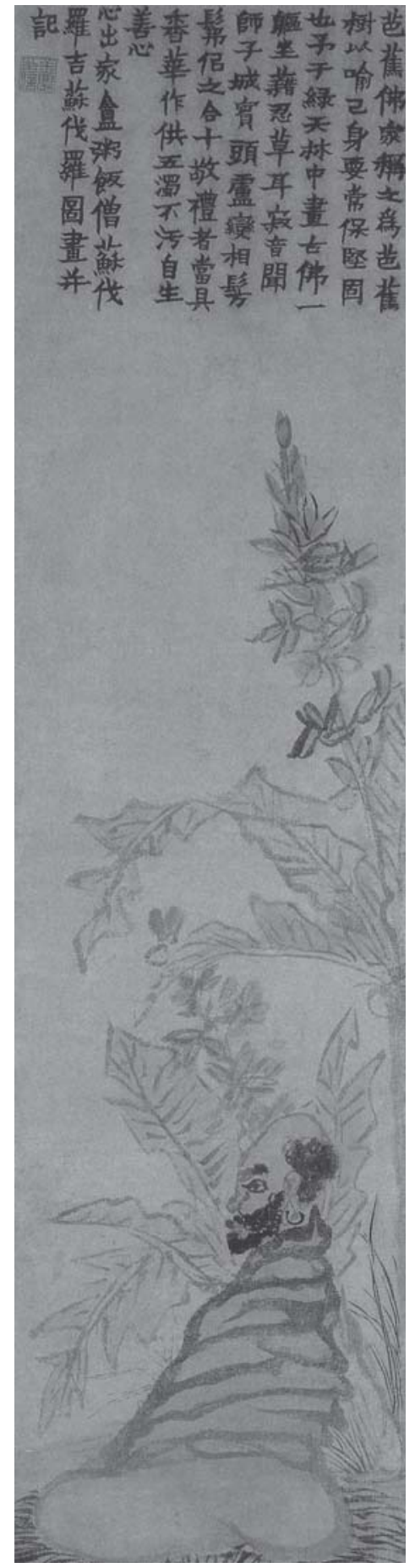

Figure 18.3 Jin Nong, Banana Tree and Buddhist Figure. Undated. Hanging scroll, ink and color on paper. $124.5 \times 27 \mathrm{~cm}$. Shanghai Museum. 
By depicting Bodhidharma in profile beneath the banana palm, Jin Nong presents the figure in a practicing, meditative state that bears close resemblance to religious customs and the local cultural environment.

The pairing of Bodhidharma and the banana palm also has metaphorical significance. ${ }^{20}$ The inscribed text describes Bodhidharma and the banana tree as a message of denial of reality and lack of distinction between self and other. Jin Nong's inscription reads:

\section{芭蕉, 佛家稱之為芭蕉樹, 以喻已身要常保聖固也 - 子于綠天林中, 畫古佛一身區, 坐藉忍 草·耳寂音聞師子城, 實頭盧變相, 髣髦侶之, 合十敬禮者。當具香, 華作供, 五濁不污, 自 生善心·心出家豱矿飯僧. 蘇伐羅吉蘇伐羅圖畫并記·}

The banana palm, Buddhists call it the 'banana tree,' to denote how the self will always preserve its innate sagacity. In a grove beneath the green heavens, I painted an ancient Buddhist entity, sitting in meditation on the rencao [grass]. ${ }^{21}$ Silently listening to the dharma of the Lion City, ${ }^{22}$ which in reality comes from the transformation tableaux, ${ }^{23}$ and it looks like he is a double. Thus, I close ten fingers together and bow to it respectfully. I should also prepare the incense and flowers as an offering, that way the five impurities ${ }^{24}$ won't defile me and goodness will emerge.

Monk Xinchujia'an zhuofan, ${ }^{25}$ Sufaluo blessed Sufaluo ${ }^{26}$ painted and inscribed this. ${ }^{27}$

Here, the inscription describes Chan Buddhist beliefs and lay practices from Jin Nong's perspective as a Buddhist devotee and artist. Jin Nong emphasizes his personal devotion by detailing the act of worship in the inscription: he closes his fingers to bow and prepares offerings of incense and flowers to achieve goodness. He also highlights elements of the composition that relate not only to local tastes such as the banana palm, but also elements that underscore Buddhist concepts. For example, the term rencao 忍草 refers to the grass that grows in the Indian Himalayas and appears in the Nirvana Sutra as a metaphor for Buddhist teachings, enlightenment, and nirvana (Soothill and Hodous 1937). In defining compositional elements through his inscribed text, Jin Nong relates the Buddhist attributes of the image to his personal devotional practices.

The combination of word and image further unveils the artist's self-reflexive, creative inquiry and reconsideration of traditional artistic practices. Like Sakyamuni, the inscription not only tempers the Buddhist subject matter with the artist's concerns as a devotee but also demonstrates his interest in artistic practices. The artist creatively includes his signature at the bottom by writing Sufaluo, which is a transliteration for the Sanskrit word for gold and the translation of his surname Jin 金. ${ }^{28}$ In other works of non-Buddhist subject matter, Jin Nong similarly signs his name Jin ji Jin 金吉金 which is the Chinese equivalent of Sufaluo ji Sufaluo 蘇伐羅吉 
蘇伐羅. ${ }^{29}$ The novelty of Jin Nong's signature demonstrates his creative inquiry into the use of image and text while exemplifying his knowledge of traditional artistic practices and Buddhist terminology.

Jin Nong's investigation of artistic practices by way of Buddhist imagery is further apparent in the artist's inscribed reference to bianxiang 變相, or transformation tableaux. Transformation tableaux are pictorial representations of miraculous transformations from Buddhist texts but, as Eugene Wang discusses, their visual manifestations are often created by laypeople or patrons and, consequently, may draw upon a multiplicity of ideas and images from contemporary visual culture (WANG, Eugene 2005). In Banana Tree, the artist's inscription suggests that Bodhidharma's meditative gaze is captured while visualizing the transformation tableaux; he writes, 'Silently listening to the dharma of the Lion City, which in reality comes from the transformation tableaux.' In other words, the painting depicts Bodhidharma visualizing an image to recall a miraculous transformation from a sutra, rather than first reading the texts or bianwen 變文 (WU Hung 1992: II2). This process of visualizing an image in order to recall the text, rather than the other way around, emphasizes the self-created and culturally-contingent nature of pictorial imagery. In this process, the

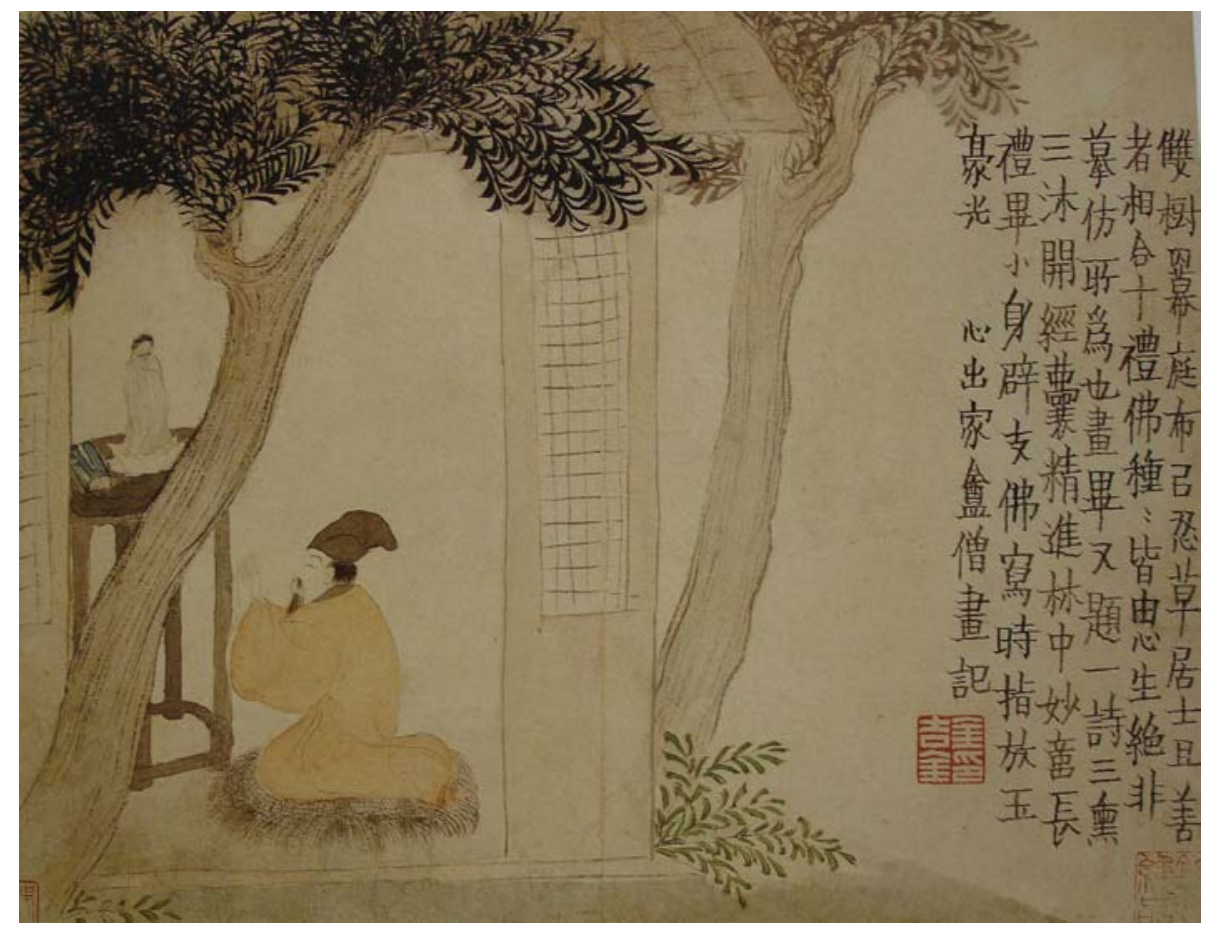

Figure 18.4 Jin Nong, Figure and Landscape Album, leaf 2. Dated 1759. Ink and color on paper. $24.3 \times 31 \mathrm{~cm}$. The Palace Museum, Beijing. 
specific icon or complete image is created from the individual's mind and supported by text or teachings. Here, Jin Nong's mention of bianxiang emphasizes the role of visualization as both an individual ritual as well as artistic practice. Thus, Banana Tree is both a description of Chan practices and an enacting of the ritual itself.

Both Sakyamuni and Banana Tree and Buddhist Figure relate to contemporary Buddhist beliefs and lay practices through their association with the artist's personal devotional practice, which he reveals via pictorial image and inscribed text. However, while Sakyamuni challenges traditional approaches to Buddhist imagery through reference to historical precedents and development of an innovative style, Banana Tree utilizes local features such as the banana palm and the rencao grass to associate the subject with familiar Buddhist practices and concepts. These features not only recall popular landscape attributes of eighteenth-century Yangzhou, but also convey Buddhist connotations and self-reflexive messages that blur the boundary between artistic and devotional practice.

\section{Offering to the Buddha}

Whereas the previous two works depict Buddhist icons in their characteristic scenes of 'Sakyamuni Descending the Mountain' or Bodhidharma in meditation, the final work by Jin Nong discussed in this study is a genre scene, or scene of daily life. It is a conventional scene depicting the worship of a Pratyekabuddha icon by a lay Buddhist devotee. Through investigation of Jin Nong's self-referential remarks and the iconography of the Pratyekabuddha, I unveil the social status and personal qualities of this lay devotee and suggest that the depiction may refer to the artist himself. Based on its subject matter and similarity with a hanging scroll by Jin Nong in the Palace Museum, Beijing, I shall refer to this leaf from his 1759 album of figures of landscapes as Offering to the Buddha (Fig. 18.4).

The subject matter of Offering depicts the private devotional practice of an elite gentleman. The ritual takes place in a screened room that opens to a garden setting. A man kneels on a round mat and clasps his hands, worshipping the icon that is placed upon the table in front of him. He wears long robes and the cap of a Confucian scholar, and his act of devotion is evidenced not only by his gestures but also by the sutra box that sits beside the icon on the table. The text describes this devotional event:

\section{雙樹内幕庭布, 以忍草居士且善者, 相合十禮佛, 種種皆由心生, 絕非摹仿所為也。畫畢 又題一詩: 三熏三沐, 開經襄, 精進林中妙赤長, 禮辟支佛。寫時指放玉豪光。心出家盎 僧畫記。}

Between the two trees in a screened room, on the rencao [grass] is the virtuous Buddhist devotee, ${ }^{30}$ who is closing his hands in respect to the Buddha, bring- 
ing forth everything within his own heart, not merely simulating [the act of worship]. After painting I added this poem:

[After] scenting the air and cleansing three times, I open the sutra and indulge myself in the mysterious realm of the grove to advance my spirit. I pay respect to the Pratyekabuddha. ${ }^{31}$ At the moment of writing this, my fingers are releasing pure and unrestrained brilliance.

Painted and inscribed by Monk Xinchujia'an. ${ }^{32}$

Jin Nong's identification of the Pratyekabuddha icon, or Pizhi fo 辟支佛, further supports the private nature of this Buddhist ritual. The Pratyekabuddha is an ascetic in a period without a Buddha or dharma, the Buddha's teachings. The reclusive Pratyekabuddha seeks individual salvation privately and through study of the nidana, or the twelve origins of human suffering, attaining enlightenment without guidance from others. In Offering, a lone devotee worships an icon of the Pratyekabuddha, which is identifiable by its long coil of hair, wrapped upon the Buddha's head in a cone-like manner. ${ }^{33}$ The sutra box suggests that the worship of this icon is paired with private study of scripture. The devotee's worship relates to Chan Buddhist interests in individual practice and personal salvation while suggesting that he, like the Pratyekabuddha, is seeking personal salvation through the privacy of his own study and devotional practices.

Jin Nong specifically underscores the elite social status of this lay devotee through his highly-detailed assemblage of conventional markers of an elite lifestyle. The composition of this work markedly differs from the prior two works, here privileging copious figural and landscape details rather than the stark, reduced compositions of Sakyamuni and Banana Tree and Buddhist Figure. The artist's descriptive fine-lined brushwork departs from the bold, thick brushstrokes of his prior works. Here, the variety of compositional elements and descriptive brushwork emphasize the details of a private devotional ritual. The inscription further specifies that the central figure is making a ritual offering and that he is a virtuous Buddhist devotee. However, his attire of a cap and robe, the elegant household furnishings and private, wooded setting indicate that this figure is both a scholar and Buddhist devotee enjoying a comfortable lifestyle.

Jin Nong's combination of word and image suggests several parallels to the artist, himself a scholar and Buddhist devotee. First, this image of a scholarly Buddhist devotee highlights the popular cultural paradigm exemplified by Confucian scholarofficials and Buddhist devotees such as the Song dynasty luminaries Su Shi 蘇軾 (IO37-IIOI) and Li Gonglin 李公麟 (IO49-IIO6). ${ }^{34}$ Jin Nong relates this traditional paradigm to his own Yangzhou social persona through word and image; namely, the inscription describes Buddhist practices while the image depicts a figure that is both a Buddhist devotee and scholarly, elite layperson. Jin Nong's inscription 
briefly describes the scene, and then discusses the ritual of cleansing, opening the sutra and making offerings to the icon. The scholar sits upon rencao grass that, as mentioned in the analysis of Banana Tree, suggests enlightenment or nirvana. The inscription also suggests that this image may refer to the artist himself. Since the classical Chinese inscription lacks a distinct personal pronoun, Jin Nong's inscription could be read from either the first person or the third person. However, the phrase 'At the moment of writing this, my fingers are releasing pure and unrestrained brilliance' indicates that the text should be read in the first person since it is the artist himself who is recording the inscription. Like Banana Tree, the artist is both inscribing the painting as well as describing his performance of a ritual act. Yet while Jin Nong similarly merges artistic and religious practice in Offering, his pictorial depiction and self-referential text specifically highlight the secular, elite nature of his ritual.

These three works by Jin Nong each correspond to contemporary lay beliefs and suggest ritual practices such as meditation and icon worship. However, Jin Nong links the practice of painting with his own devotional ritual through the careful selection of subject matter and inscribed self-referential remarks, which position him as a Buddhist devotee and elite gentleman in eighteenth-century Yangzhou. Thus, Jin Nong's approach to Buddhist imagery not only appeals to the interests of lay Buddhists, but also highlights contemporary concerns for artistic novelty and social distinction. As I shall discuss, Hua Yan's paintings similarly utilize word and image to underscore contemporary religious, artistic and cultural concerns but, unlike Jin Nong's depictions of Buddhist icons and lay practices, Hua Yan employs bird-and-flower imagery and metaphorical poetic inscriptions to convey his unique perspective.

\section{HUA YAN: STRATEGIES OF TRANSCENDENCE VIA BIRDS AND FLOWERS}

Hua Yan, like Jin Nong, came to Yangzhou later in life and became known for his versatility in painting styles and genres. He is most reputed for his animated depictions of birds and flowers in a sparse, elegant style paired with poems replete with literary allusions. Many eighteenth-century Yangzhou artists took up the subject matter of birds and flowers, because they evoked the sophisticated flavor of Song court paintings while also embodying the whimsical flair and literati style of Yangzhou garden culture. Bird-and-flower subject matter communicated contemporary aesthetic values of elegance, or fengya 風雅, a term that connotes taste and refinement as opposed to vulgarity or audacity. ${ }^{35}$ For this reason, the subject is well-suited to Yangzhou interests in the literary gatherings, poetry 
and traditional scholarly pursuits that served to define one's social status and cultural prestige.

Hua Yan's later bird-and-flower paintings respond to these contemporary concerns, as evidenced by the notable developments in subject and style within the artist's oeuvre around the time of his move to Yangzhou in his forties. For example, while landscapes and figure paintings represent a significant artistic interest prior to his move from Hangzhou to Yangzhou, his Yangzhou-era oeuvre abruptly shifts to include a large proportion of bird-and-flower subjects. ${ }^{36}$ As Ginger Hsü observes, landscapes did not enjoy the same popularity as depictions of birds and flowers in eighteenth-century Yangzhou (Hsü 200I: 6-9). As a professional artist seeking commissions in Yangzhou, Hua Yan swiftly came to specialize in bird-and-flower subject matter with animated pictorial styles and stark compositions. His works relate to contemporary demands for elegant and alluring images through his innovative interpretation of traditional pictorial qualities.

In this section, I will analyze Hua Yan's combination of bird-and-flower images and poetic inscriptions. These poetic inscriptions define birds and flowers as symbols of Buddhist imagery, while relating the works to larger religious, poetic and philosophical themes. However, the variation between Hua Yan's and Jin Nong's pictorial style and inscriptions necessitate a slightly different methodological approach in defining their use of Buddhist imagery. While Jin Nong's works include extensive prosaic inscriptions detailing the artist's religious and creative interests, Hua Yan's inscriptions are concise, poetic quatrains with self-referential metaphors and Buddhist themes. In this way, Hua Yan's seemingly conventional subject matter of birds and flowers actually becomes a multivalent motif that relates religious and philosophical concepts.

Like Jin Nong, Hua Yan similarly launches a creative inquiry into historical modes of painting, perhaps realizing that success as a Yangzhou artist demands an original approach to contemporary interests in traditional, scholarly ideals as well as Buddhism. As for scholarly ideals, Ginger Hsü comments that Hua Yan sought to transcend his background as a craftsman through the use of literary elements in his paintings (Hsü 200I:I27-29). Ka Bo Tsang finds further evidence for such social ambitions on a portrait of Hua Yan by Zhang Sijiao 張四教 (active mid-eighteenth century), where the artist recounts the advice provided by Hua Yan on their first meeting in Yangzhou:

Although painting is an art, one receives low treatment when one's art is accomplished. Therefore you should first establish yourself in order that those in power could not belittle the value of your art. In this way, you should broaden your knowledge by studying, and cultivate yourself to correct your conduct. My painting principle is as simple as this. ${ }^{37}$ 
In addition to conveying his scholarly erudition through literary aptitude and selfcultivation, Hua Yan also aligns himself with contemporary Buddhist interests. To begin with, his name, Hua Yan 華嚴, translates as 'Cliff of Blossoms.' This is a term often used in temple sites or the dwelling places of recluses who escape from the world to mountainous caves. ${ }^{38}$ It also alludes to Northern Song scholar-painters and Buddhist devotees such as Li Gonglin, whose Mountain Villa scroll contains the inscription 'Raining Blossoms Cliff,' or Yuhua yan 雨華嚴, that identifies a garden site where scholar-officials retreat from worldly endeavors. Furthermore, Hua Yan's name is a homophone of the Flower Ornament Scripture, or the Avatamsaka Sutra (Chin. Huayan jing 華嚴經). This is the key text of the Huayan sect of Buddhism, which was popular in the Yangzhou region, along with Chan, Pure Land, Tiantai 天台 and Weishi 唯識. ${ }^{39}$ It contains thirty-nine chapters of highly ornate language relating the abstract truths of the universe. Chapters include the 'Flower Bank World,' 'Dwelling Places of Enlightening Beings,' 'Detachment from the World,' and 'Entry into the Realm of Reality.' The 'Flower Bank World,' for example, is a place of freedom for the enlightened or those who expound the words of the Buddha.

In the Flower Bank World, adorned with wondrous jewels Enlightening beings travel throughout the ten directions, Expounding the universal vows of the Great Hero: This is their power of freedom in enlightenment sites. ${ }^{40}$

Hua Yan's name, in its likeness to the Flower Ornament Scripture, offers rich visual imagery that compliments his specialty of bird-and-flower painting.

Hua Yan's personal poetry collection, Ligou ji 離垢集 [Leaving the Filth of the World], further underscores the literary and Buddhist nature of his works. This five-volume collection of his poems, poetic inscriptions on his paintings, and biographical anecdotes, is rife with allusions to the 'net of the world' and 'the dusty world' of human attachments. Through the scholarly vehicle of poetry, Hua Yan mentions his daily Buddhist rituals and indicates his Buddhist philosophy through disdain for the ostentatious and the adoration of natural beauty. Thus, Ligou ji further locates Hua Yan's painting and poetry amid Buddhist concepts, aesthetic elegance and traditional literary prowess.

Hua Yan's approach to Buddhist imagery markedly differs from Jin Nong's bold approach to Buddhist subjects and innovation of traditional pictorial modes, yet I contend that the works of both artists appeal to artistic tastes for novelty and social values of decadence in Yangzhou society. While Hua Yan's works relate to the religious and artistic interests of contemporary Yangzhou, his inscriptions use Buddhist themes to voice subtle criticisms of the excesses of society. Through the use of both word and image, the following works underscore the artist's conflict in favoring the refined rather than the ostentatious, the subtle and modest over the bold and dramatic. 


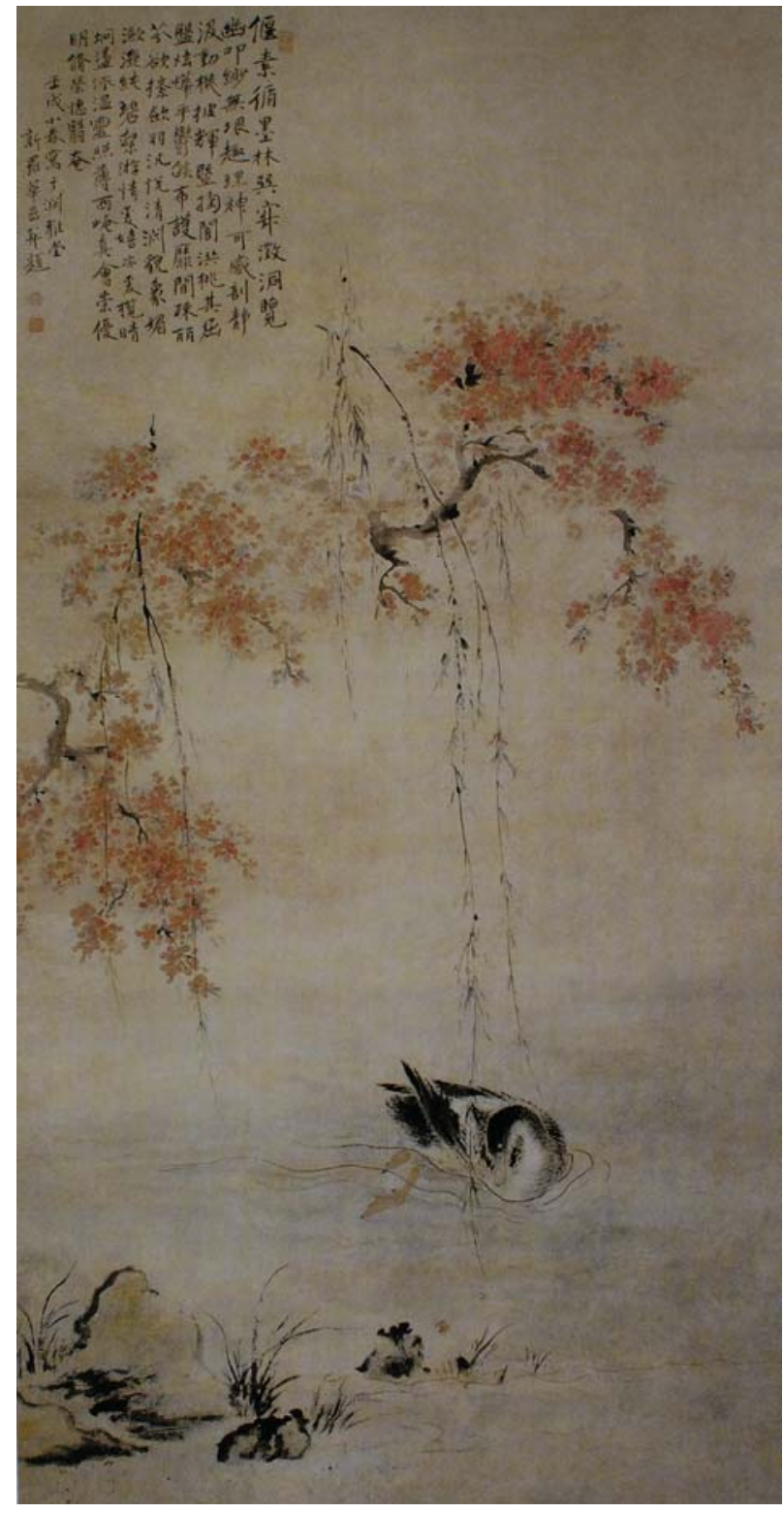

Figure 18.5 Hua Yan, A Duck Bathing in an Expanse of Peaches. 1742. Hanging scroll, ink and color on paper, 271.5 $\times 137 \mathrm{~cm}$. The Palace Museum, Beijing.

\section{A Duck Bathing in an Expanse of Peaches}

In his 1742 hanging scroll, $A$ Duck Bathing in an Expanse of Peaches, Hua Yan's inventive use of traditional painting motifs and poetic metaphor gives rise to Buddhist messages (Fig. 18.5). The Buddhist messages of Hua Yan's bird-and-flower subject matter are defined through his poetic inscription. The composition depicts 
one mandarin duck swimming beside the banks of a river, which seems odd because ducks are typically painted in pairs to represent everlasting love. An additional insight into this baffling image of a lone duck is found in the inscription, which contains significant parallels to the Flower Ornament Scripture. Hua Yan writes:

\author{
偃素循墨林,巽寂溦洞覽 \\ 幽叮紗無垠, 剖靜汲動機 \\ 趣理神可感,披輝暨掬闇

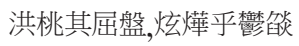 \\ 布護靡閒疎,丽芬欲紊歛 \\ 羽泛悅清渊,貌象姻浴澧隐 \\ 純碧繫游情,爱嬉亦爱攬 \\ 晴㭣盪流溫,靈照薄西崦 \\ 真會崇優明,修榮憓鷖奄 \\ 王戎小春寫于渊雅堂,新羅華嵒并題.
}

I set out the white silk in accordance with the forest of ink, modest and tranquil to clearly examine the abstruse

In the darkness I knock, it is vast without limit

Pursuing the principle, my spirit is moved

Dispensing with silence I draw upon the spring of movement, opening to brightness I grasp in my hands the darkness

Floating peach blossoms swirl on the surface [of the pond], radiant and flowery they are dense and brilliant

The arrangement [of flowers] cannot be separated, the splendid fragrance is concentrated

The feathered [bird] swims and is delighted by the pure pool, its appearance complements the ripples of the water

The pure emerald of the waters attracts the impulse to swim, at one moment delighted and at another taking in the scene

Sunlit earth is warmed by shimmering rays, the setting sun draws near the western hills

True understanding prizes cosmic enlightenment, its beautiful appearance removes all impediments [to understanding].

In early spring of the renxu year [1742], Hua Yan of Xinluo also inscribed. ${ }^{41}$

The first four lines of the inscription describe the artist's act of laying out his silk and ink, then preparing his mind for the painting experience which he describes as 'examining the abstruse.' In line five, Hua Yan focuses on the painting proper, utilizing the dense and flowery imagery of the Flower Ornament Scripture. In this sutra, 
sites of enlightenment are adorned with flowers which represent the multitudes of things and spiritual powers:

Banks of precious stones are the flowers,

Reflections shining like patterned clouds;

The encircling trees perfume all around:

The enlightenment site's adorned everywhere. ${ }^{42}$

Hua Yan's inscription describes cliffs of flowers, shimmering reflections, and fragrant trees which typically adorn the site of enlightenment. Thus, image and text suggest that this is a site of enlightenment as described in the Flower Bank world.

The themes of visual beauty and Buddhist enlightenment in the text and image position this work amid both contemporary interests in Huayan Buddhism as well as artistic tastes for vivid, innovative compositions. In line ten, Hua Yan merges these two motives by inscribing that beauty is a principle for enlightenment. Specifically, the beauty of the natural world is symbolized by his depiction of the duck, whose 'beautiful appearance removes all impediments [to understanding].' Since the pursuit of beauty is in harmony with Buddhist objectives, this statement acts as a principle for stylistic embellishments and alluring features. For example, the pictorial style of the lone duck is particularly intriguing as the painting's early-spring date traditionally symbolizes a time for new love. A single duck should be a lonely sight but here Hua Yan employs peach and red tones, giving an elegant golden glow to this early-spring composition. The painting evokes Song dynasty bird-and-flower paintings through meticulous brush treatment of the fowl and the bird-beneath-branches composition, but the artist adds brilliant colors and enlivens the swimming bird by depicting its outstretched leg amid rippling waves. Hua Yan's subject of a single duck, the vivid use of color, and the animated brushstrokes all evidence the artist's innovation of traditional pictorial modes, while also affirming the concept of beauty as a principle for Buddhist enlightenment.

In highlighting visual beauty as a concept related to Buddhist and artistic principles, Hua Yan also suggests a message about worldly attachments that relates to the complexities of its social context. As mentioned earlier, poets and historians often describe eighteenth-century Yangzhou as a society mesmerized by beauty and tempted by worldly desires. This cultural observation provides insight into the attributes of $A$ Duck Bathing, which stem from the image of a single duck in its atypically rosy, early-spring environment, and are further underscored by lines six through nine of the inscription. In this realm of the enlightened, 'dense and brilliant' peach blossoms 'cannot be separated,' meaning that Buddhism is the web of the universe of which everything is a part. Thus, worldly desires like love and 
partnership are inconsequential. Accordingly, Hua Yan's inscription suggests that the bird is not lonely but rather delights in the spontaneous action of swimming and cleansing itself amid peach blossoms. In being separated from its mate, the creature is detached from worldly attachments and free of suffering. This subject has particular relevance to eighteenth-century Yangzhou as a place reputed for desire and obsession about leisure, art and beauty. Thus, while this painting seemingly builds upon principles of beauty conveyed via traditional bird-and-flower motifs, attractive colors and a dynamic composition, the message of the poetic text and Buddhist imagery subtly cautions that beauty can enlighten, but it can also lead to desire and worldly attachment.

Like Jin Nong's works, Hua Yan's paintings convey multiple messages that are bound to contemporary anxieties through his use of Buddhist themes and artistic innovations. Unlike Jin Nong's portrayal of Buddhist icons, Hua Yan's depictions of birds and flowers rely heavily on poetry full of symbol and metaphor. For example, in A Duck Bathing, Buddhist imagery appears in text and subject matter of contemporary interest, creating a disjunction between the pictorial representation of beauty and Buddhist concerns of worldly attachment. The following album leaves, while differing in format from the large hanging scroll of $A$ Duck Bathing, also display spontaneous, often witty, depictions of birds and flowers in a more intimate format suited to smaller audiences. My analysis of Hua Yan's poetic allusions to Buddhism in combination with his pictorial mode in the following album leaves unveils the contradictions of the contemporary condition and perhaps even serves as an admonition to the viewer.

\section{Bird and Flower Album: Net of the World}

The remainder of this study will consider this constellation of Buddhist imagery and artistic concerns in three leaves from Hua Yan's 1742 bird-and-flower album in the Shanghai Museum. ${ }^{43}$ Like A Duck Bathing, Hua Yan's album leaves utilize traditional bird-and-flower motifs and textual allusions to suggest a Buddhist message. However, I argue that the smaller format of the album leaf offers a more intimate viewing experience that can be used to convey the artist's religious or philosophical beliefs and self-referential messages. These messages are supported by Hua Yan's poetry collection and his exchanges between friends and patrons.

To begin, Leaf 7 depicts a brown garden sparrow seated upon a single branch, without ornamentation other than the fiery red marking on the top of its head (Fig. 18.6). The pictorial depiction of the simple bird relates to Buddhist principles of nets and traps which are discussed in the inscription as metaphors for greed and desire. The artist's inscription relates the qualities of the bird: 


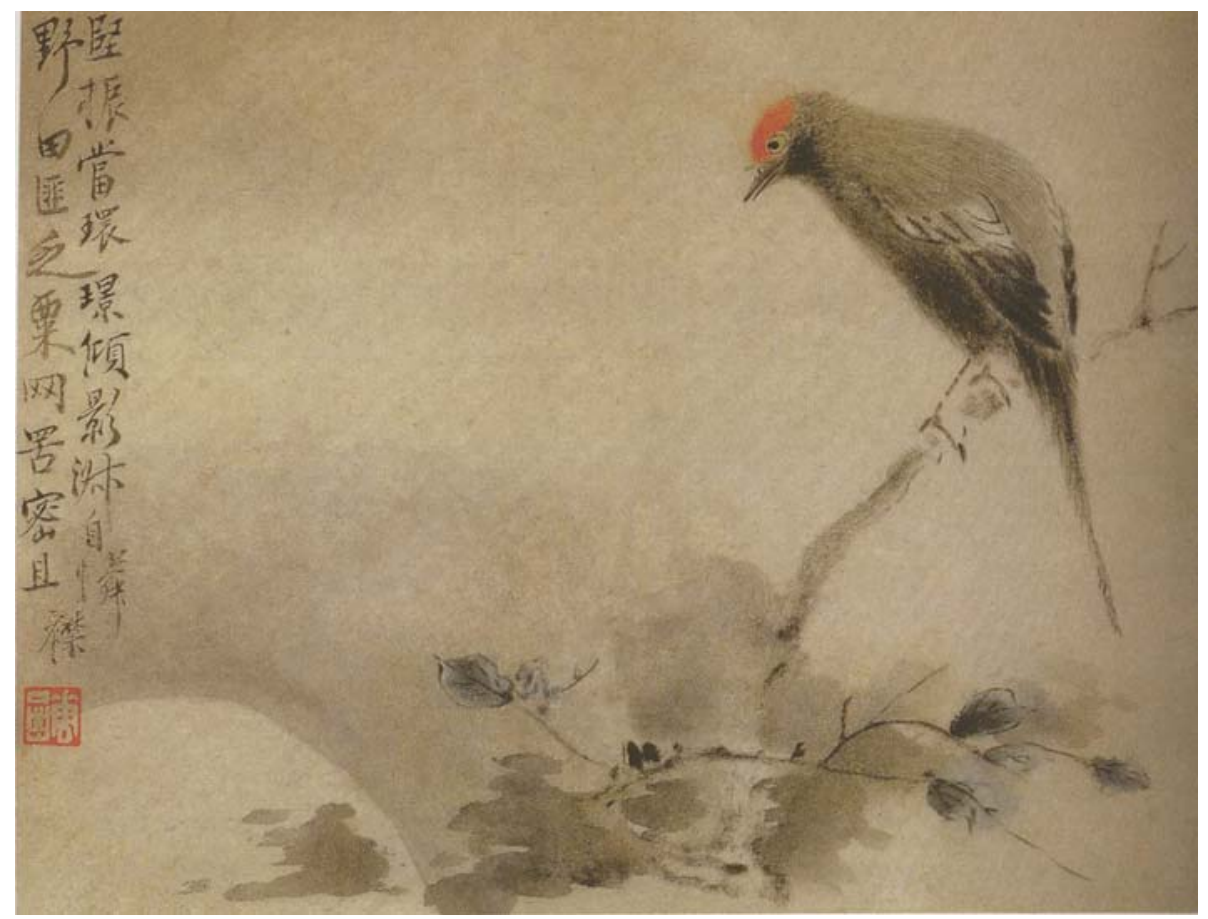

Figure 18.6 Hua Yan, Bird and Flower Album, leaf 7. 1742. Ink and color on paper, 20.5 $\times 27.5 \mathrm{~cm}$. Shanghai Museum.

掔振當環璟
傾影淑自憐
野田匪乏栗
網罟密且襟

Its firm feathers resemble the radiance of jade, Casting its reflection it pities its refined nature. The rustic field does not lack grain, Nets and traps are numerous and spread all over. ${ }^{44}$

Hua Yan's inscription begins by contrasting the bird's inner qualities with the landscape. Its physical features are compared with the radiance of jade to symbolize inner strength and perseverance, while the landscape is uncultivated and hazardous. This bird is faced with a quandary: there is a wealth of grain to be had in the fields below, but only at the risk of entrapment. Thus, the bird is a symbol of resistance to the unenviable traits of greed and desire. The inscription clearly refers to the Buddhist concept of the world as a net, comprised of desire and attachments that are responsible for human suffering. In this way, Hua Yan's pictorial depiction of a 
lone bird gazing over a rustic field suggests the dilemma suggested by his inscription. Thus, the combination of word and image conveys the message that one must not indulge in worldly desires for one will be quickly captured in worldly nets and traps.

The artist's use of birds to allude to Buddhist principles is also highlighted in his poetry, as in the poem Bird by the Leisure Pavilion:

\author{
好鳥息庭柯 \\ 寓目自幽蔚 \\ 蕭籟無比鳴 \\ 櫂謳薄清味 \\ 獨與區塵遙 \\ 胡有羅網畏 \\ 樂此石泉深 \\ 長煙毉秋卉 \\ The lovely bird rests in the branches by the pavilion \\ It rests its eyes on the secluded vegetation \\ Music from pipes cannot compare with its cries \\ Rower's songs have a less pure flavor \\ It alone is far removed from the dusty world \\ How could it have fear of its nets? \\ It takes pleasure in the depths of the rocks and streams \\ Long mists obscure the autumn blossoms. ${ }^{45}$
}

In the first stanza, Hua Yan describes the 'pure flavor' of the lovely bird's song. He then notes that it is 'far removed from the dusty world,' meaning that it is far from the frustrations, strife and ills of the world. The Flower Ornament Scripture frequently employs this phrase:

Among sentient beings who have no blessings,

Buddha's arrays of great blessing majestically shine,

Showing them the way of serenity, beyond the dusts of the world:

Causing Flowers to Bloom Everywhere realizes this way. ${ }^{46}$

In the painting, Hua Yan uses the bird to express purity and serenity, as a being that delights in the depths and mysteries of the world. In this way, Hua Yan visually conveys the Buddhist concept of 'beyond the dusts of the world.' This work serves as a reminder of the value of being modest and unpretentious while warning against the threat of desire and attachment. Like Jin Nong, Hua Yan's pictorial strategy offers a stylistic response to the established literati mode, but also manipulates this mode to suggest Buddhist messages relevant to contemporary Yangzhou society. Thus, by entrusting the object of the bird or flower with his individual perspective, Hua Yan 


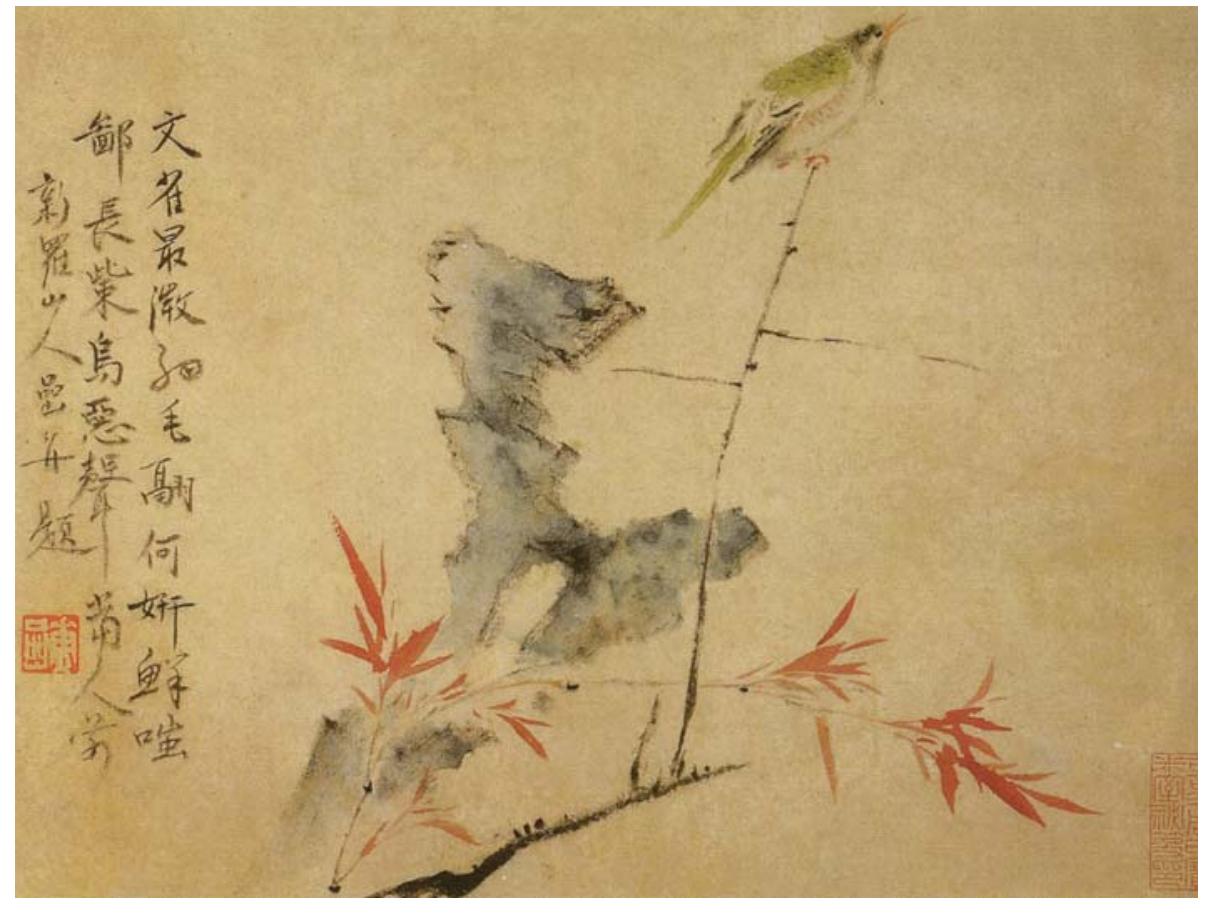

Figure 18.7 Hua Yan, Bird and Flower Album, leaf 8. 1742. Ink and color on paper, 20.5 $\times 27.5 \mathrm{~cm}$. Shanghai Museum.

expresses otherworldly thoughts of a philosophical and contemporary nature. The additional messages conveyed by Hua Yan's use of word and image will be further examined in the following works.

\section{Bird and Flower Album: The Sparrow}

In Leaf 8 of the Shanghai album, the Buddhist message conveyed by the bird-andflower motif uncovers a contradiction between contemporary artistic tastes for novelty and traditional values of elegance (Fig. 18.7). In this leaf, the inscription describes the sparrow as a simple, unassuming garden bird: 
The patterned sparrow, the finest and most delicate of all birds, How beautiful and fresh its fur and plumage,

Disdaining the birds with long beaks, Whose vile songs are dispelled before us. ${ }^{47}$

Here, the simple sparrow marks a contrast with the long-beaked birds 'whose vile songs are dispelled before us.' As suggested by A Duck Bathing, enlightenment is to be found in the profundity and beauty of the austere, natural world - not in flagrant charm or ostentatious behavior.

In addition to the sparrow as a symbol of purity and refinement, the rock and bamboo represent traditional symbols of scholarly wisdom and integrity. ${ }^{48}$ In this leaf, the rock and bamboo frame the colorful sparrow, providing the image with a sense of nobility. This combination of a sparrow and bamboo also appears in Hua Yan's poetry, where the artist specifically relates their symbolic values to himself and his patron-friend, Yuan Guotang 貟果堂. Hua Yan's second inscription on a New Year's poem that he wrote for Yuan Guotang, Inscribing Plum, Bamboo and Pine, reveals their shared concerns:

\section{竹陰款語味脩林 \\ 冷事相關共此心 \\ 世網弗羅塵外雀 \\ 聲聲詣子報佳音}

In the shade of the bamboo, I speak slowly and savor the tall trees

Aloof matters are our concern, we share the same heart

The net of the world does not ensnare the sparrow that is beyond the dusty world

Note after note of its song comes to you conveying good tidings ${ }^{49}$

The phrase 'aloof matters are our concern, we share the same heart' indicates that Hua Yan and his patron and friend, Yuan Guotang, are of the same mind and share the same values. Both appreciate the enlightened sparrow that is not ensnared by the dusty world. In the shade of the bamboo, Hua Yan and Yuan Guotang are distant from the dusty world yet within close range of the sparrow, whose song they enjoy amid the tall trees. As in Hua Yan's paintings, this setting of the natural beauty of flora and fauna suggests that Hua Yan and Yuan Guotang are enlightened in their recognition of the obscurities of the natural world.

The style and composition of this album leaf redefine contemporary concerns for elegance by merging traditional bird-and-flower motifs with an attractive color palette and a simplified composition. Ka Bo Tsang suggests that the singing birdon-branch motif is derived from woodblock prints (Tsang 1987). This particular 


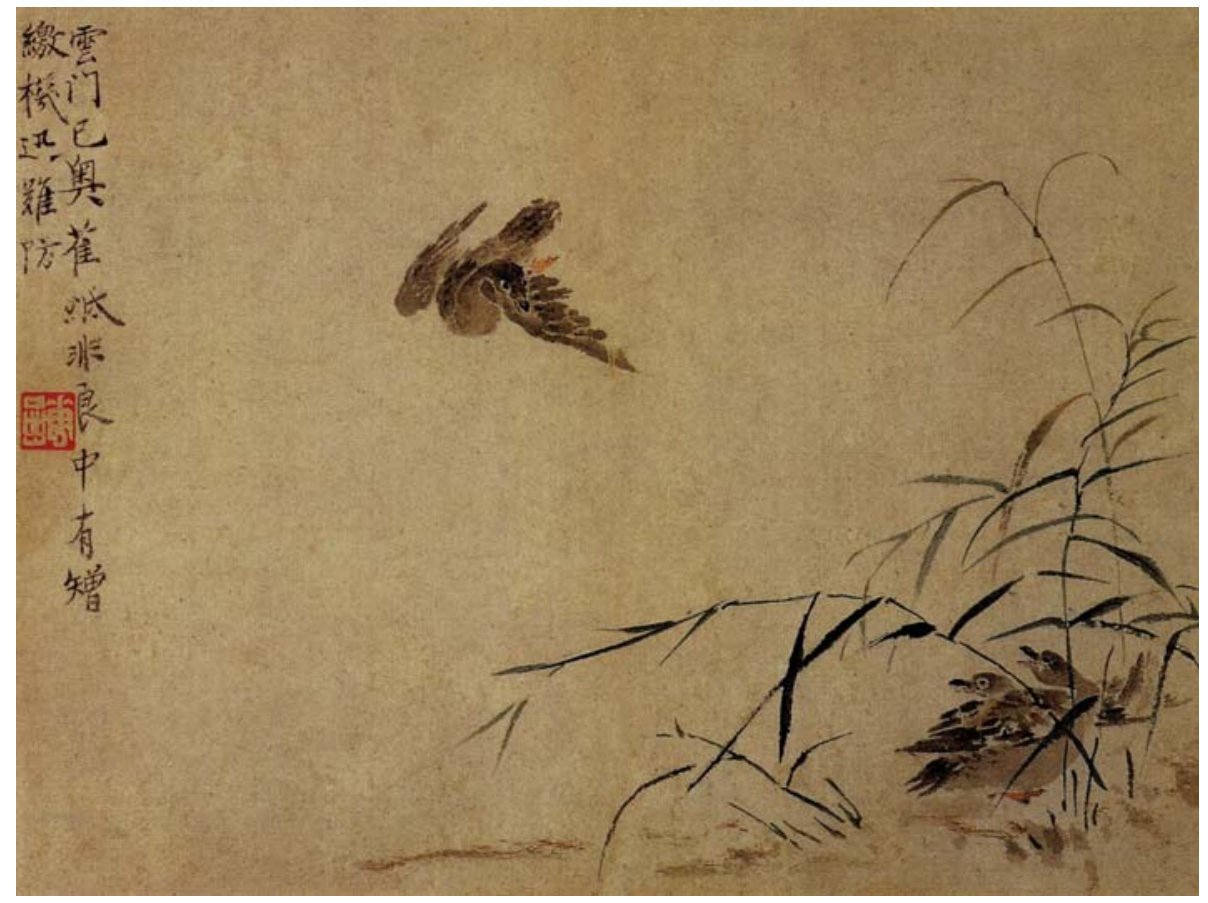

Figure 18.8 Hua Yan, Bird and Flower Album, leaf 2. 1742. Ink and color on paper, 20.5 $\times 27.5 \mathrm{~cm}$. Shanghai Museum.

depiction of a sparrow may relate to the 'Pose of a Bird Chirping in Spring' from the encyclopedia Sancai tuhui, as pointed out by Tsang. ${ }^{50}$ As in woodblock prints, Hua Yan carefully depicts the anatomical features of the sparrow through meticulous brushwork. However, the artist departs from historical approaches to bird-andflower subject matter through the application of brilliant colors, quick and animated brushstrokes, and reduced compositional elements. The minimal elements of a rock and a tiny green sparrow perched upon a sprig of bamboo convey the elegance of traditional motifs but with an inventive, spontaneous execution and a vibrant composition. As in the previous album leaf, this work redefines traditional modes to relate to eighteenth-century artistic concerns about charm and novelty while still incorporating the historical paradigms of elegance and scholarly flavor. Thus, this album leaf highlights two distinct tensions: on the one hand, the image of the sparrow and supporting text convey Buddhist admonitions against extravagance and vanity, while on the other hand, Hua Yan manipulates traditional modes to present a dynamic image that suits eighteenth-century Yangzhou artistic tastes.

The sparrow, presented here as a symbol for Buddhist principles, underscores the competing concerns of novelty and refinement in eighteenth-century Yangzhou 
painting. The disjunction between these concerns relates to contemporary tensions between extravagance and austerity, wealth and poverty, vulgarity and elegance.

\section{Bird and Flower Album: The Cloud Gate}

Leaf 2 in the Shanghai album, the final work of this study, subtly evokes the relationship between the Song dynasty scholar-artist tradition and Buddhism through pictorial image and poetic allusions (Fig. I8.8). Unlike the earlier albums that relate to Huayan Buddhism, the combination of word and image in this album leaf specifically relate to Chan Buddhism. Thus, this work suggests that Hua Yan, as a lay practitioner in eighteenth-century Yangzhou, drew inspiration from a variety of Buddhist sects in order to emphasize broader cultural concerns.

The composition depicts one duck with a wing extended as if turning in mid-air towards several other ducks taking cover under thin, green reeds. The brushwork appears animated due to its abbreviated strokes, and the sparse application of ink and color leaves much of the composition unpainted to give further emphasis to the ducks. As I noted in my analysis of A Duck Bathing, a duck separated from its partner or its flock is typically an unnatural and unfortunate sight. Here, Hua Yan portrays the duck in an imperiled situation, as supported by the inscription:

雲門已奧
藮紙非良
中有矰繳
機迅難防
The Cloud Gate is already obscure,
Grass is no good.
All about there are bows and arrows,
So fast once shot, they are hard to avoid. ${ }^{51}$

Hua Yan explains that the central bird in flight is unable to find the 'Cloud Gate,' Yunmen 雲門, and that grass provides insufficient cover from the threat of bows and arrows. This term, Yunmen, represents an important allusion to Northern Song Buddhism, and possibly to the scholar-artist Su Shi (IO36-IIOI), as well. In her study on Buddhism in the life and writings of Su Shi, Beata Grant notes that Yunmen refers to a famous Chan Buddhist monastery in Guangdong that was founded in the early tenth century, ${ }^{52}$ and that several of its disciples were Su Shi's teachers (Grant 1994: 15). ${ }^{53}$ Yunmen is likely a reference to this Chan sect of Buddhism which was known for enlightenment through one-word questions and, secondarily, for its allusion to Su Shi and his Northern Song coterie. In recalling the Buddhist devotee, poet and artist, Su Shi, Hua Yan reflects upon the traditional ideal epitomized by 
these illustrious Northern Song scholar-artists and positions this work in a lineage of Song dynasty luminaries. In this way, the painting highlights concepts of Chan Buddhism, such as enlightenment through discourse, and relates to the traditional culture of Song scholar-artists.

As in the two previous works, Hua Yan's assemblage of pictorial style and poetic inscription conveys several layers of historical, religious and social messages. While the style and subject matter of ducks and reeds is particularly conventional, and the reference to Su Shi is fashionable in eighteenth-century Yangzhou, the image of a duck separated from its flock suggests peril in the form of bows and arrows. The inscription further specifies that bows and arrows, like the nets of riches and traps of attachments, are swift and difficult to avoid. Thus, like the other two leaves, this image with its text conveys an additional message about the difficulty of finding a safe haven, a specifically Buddhist haven removed from the riches and attachments, the symbolic bows and arrows, of the world.

Like Jin Nong, Hua Yan frames his multi-layered approach to Buddhist imagery by utilizing alluring visual modes while creatively referring to traditional paradigms of scholarly elegance. Fundamentally, Hua Yan's choice of bird-and-flower subject matter suits traditional paradigms of elegance as well as contemporary Yangzhou garden culture. These concerns are then complicated by subtle twists in pictorial approaches to conventional iconography and inscribed references to Buddhist concepts. Birds are visually and textually associated with the nets and traps of the dusty world, thereby framing a tension between two opposing values: purity and refinement in contrast to wealth and attachment.

\section{CONCLUSION}

In this study of paintings by two eighteenth-century Yangzhou artists, I have suggested that Buddhist imagery can be conveyed through various artistic approaches to word and image. For example, Jin Nong relates his visual representation of Buddhist imagery to his own devotional practices by using innovative pictorial styles and selfreferential inscriptions. Hua Yan, in contrast, rephrases the traditional features of the bird-and-flower genre to incorporate Buddhist imagery via poetic inscriptions. These approaches both underscore the artists' unique representations of Buddhist themes and reveal contemporary tensions about the novel and the traditional, the vulgar and the elegant, the indulgent and the refined.

The implications of this study are twofold. Firstly, this investigation argues for an integrated analysis of religious culture and the arts by recognizing the versatile nature of pictorial manifestations of Buddhism. Jin Nong's works reveal that although the subject matter of a painting conveys a fundamental Buddhist message, it may also communicate additional layers of personal, social and artistic concerns. 
On the other hand, Hua Yan's works suggest that Buddhist imagery is not always immediately evident in the subject matter of the image but, rather, it may be initially suggested through textual allusions. Thus, the second contribution of this study is to emphasize the interrelationship between Buddhist imagery and additional secular, contemporary interests. Works by both artists suggest that Buddhism often represents one of several themes in painting which may be religious, philosophical, social or artistic in nature. Although works by Jin Nong and Hua Yan suggest a wide range of approaches to Buddhist imagery, they represent only two examples of painting modes from eighteenth-century Yangzhou. This research, therefore, sets a much-needed precedent for further studies to discern the degree to which these two artists' approaches to Buddhist imagery are representative of this city's social and religious context. This study invites further art historical research on Buddhism as a critical aspect of eighteenth-century Yangzhou society.

Finally, this study explores new avenues for examining the relationship between word and image in Chinese painting. Whereas the religious, literary and artistic aspects of painting have been considered separately in scholarship, I have demonstrated the ways that Jin Nong and Hua Yan utilized both word and image to relate Buddhist imagery to their unique religious, social and artistic perspectives. Historically, literary historians have revealed Buddhist themes in eighteenth-century Yangzhou poetry (SCHMIDT 2003), and art historians have discussed Buddhist iconography in regard to contemporary cultural concerns (Hsü 200I; HAY I999; VINOGRAD 1992). However, it is clear that these artists had creative expertise in both literary and visual mediums and, consequently, they often conveyed Buddhist imagery through unexpected combinations of word and image. The approach I have taken is innovative precisely because it considers the multiple layers of meanings that can be suggested through juxtaposition of word and image, and this highlights the creative scope of Jin Nong and Hua Yan. Therefore, this study yields a fuller understanding of the works of these particular artists, the modes in which they convey Buddhist imagery, and the relevance of these themes to eighteenth-century Yangzhou culture.

\section{APPENDIX}

\section{Jin Nong's Inscription on Sakyamuni}

漢明帝時, 佛從西域雞足山來, 入中國, 其教日興· 後之奉者, 皆四天下智慧之士. 下至兇暴之 徒, 未嘗不畏其果報而五体投地也.

若晋衛協畫七佛圖, 顧愷之瓦官寺畫維摩詰像, 前宋陸探微甘露寺畫寶檀菩薩像, 謝靈 運天王堂畫畫熾光菩薩像, 梁張僧缶天皇寺畫盧舍那像, 隋展子虔畫佇立觀音像, 鄭法士永 泰寺畫阿育王像, 史道碩畫五天羅漢, 尉遲跋質那婆羅門畫寶林菩薩像, 其子乙僧光澤寺畫音 樂菩薩像, 唐閻立本畫思維菩薩像, 吳道子畫毗盧遮那佛像, 盧楞伽畫降靈文殊菩薩像, 楊 
庭光畫長壽菩薩像, 翟琰畫釋迦佛像, 李果奴畫無量壽佛像, 王維畫孔雀明王像, 韓幹畫 須菩提像, 周昉畫如意輪菩薩像, 辛澄畫寶生佛像, 左全畫師子國王變相, 范瓊畫正坐佛 圖, 張南本聖壽寺畫賓頭盧變相, 張騰文殊閣下畫報身如來像, 梁朱繇畫香花佛像, 跋異福 光寺畫自在觀音像, 後晋王仁壽畫彌勒下生像, 南唐王齊翰畫辟支佛像, 前蜀杜子環畫侍香菩 薩像, 杜輗龜畫毗盧那像, 釋貫休畫應夢羅漢像, 吳越釋蓝能畫妙身如來像, 富玫畫白衣觀 音像, 宋石恪畫藥師佛像, 周文矩畫金光明菩薩像, 武洞清畫智積菩薩像, 侯翼畫寶印菩薩 像, 勾龍爽畫普陀水月觀音像, 李公麟畫長帶觀音像, 關同畫龍窠佛像, 董源畫定光佛像, 黃 居寀畫著色觀音像, 梁楷畫行化佛像, 趙廣畫披髮觀音像, 趙伯駒畫釋迦佛像, 智什畫白描 阿彌陀佛像, 釋梵隆畫十散聖像, 歷代畫之.

今則去古甚遠, 不可得見 - 惟于著錄中想慕而已 - 余年逾七十, 世間一切妄想種種不 生. 此身雖屬濁, 然日治清齊每當平旦, 十指新沐, 熏已妙香, 執筆敬寫極莊嚴尚不叛乎古法 也. 世多善男子, 愿一一貺之, 永充供養云.

乾隆二十五年二月佛成道日, 杭郡金農, 謹記.

余畫諸佛, 及四大菩薩, 十六羅漢, 十散聖別一手蹟. 自出已意, 非顧, 陸, 謝, 張之流. 觀者不 可己筆墨求之. 諦視再四, 古氣潭哥足千百年, 光如龍門山中石刻圖像也. 金陵方外友德公白居 士・此畫真是丹青家鼻祖, 開後來多少宗支. 余聞斯言, 掀䰅大笑,七十四翁農又記·

\section{Translation ${ }^{54}$}

At the time of Han Mingdi [Liu Zhuang 劉莊, r. 58-75], the Buddha came from the western region to Chicken Foot Mountain, ${ }^{55}$ entered the Central Kingdom, and his teaching prospered daily. Later those who worshipped him were all gentlemen of wisdom from all over the world. Even [down to] those violent and evil, there was not one who was not fearful of the karma and prostrated themselves [in worship].

In the Jin dynasty Wei Xie [late 3rd century] painted a Seven Buddha painting, ${ }^{56}$ Gu Kaizhi [344-406] painted a Vimalakīrti icon at Waguan si, ${ }^{57}$ in the Former Song dynasty Lu Tanwei [d. 485?] painted the cherished sandalwood Bodhisattva icons at Ganlu si, ${ }^{58}$ Xie Lingyun [385-422] painted a Buddha of Extreme Radiance (S. Tejaprabha) in the Tianwang tang, ${ }^{59}$ in the Liang dynasty Zhang Sengyu [active 500-550] painted a Vairocana icon in Tianhuang si, ${ }^{60}$ Zhan Ziqian [active ca 58I-609] of the Sui dynasty painted a standing Avalokiteśvara icon, ${ }^{61}$ Zheng Fashi [active late 6th century] painted a King Aśoka icon at the Yongtai si, ${ }^{62}$ Shi Daoshi [active late 6th-early 7 th century] painted Five Heavenly Arhats, ${ }^{63}$ Weichi Bazhina [ca 7 th century] painted a Bodhisattva icon in the groves of a [Pure Land], ${ }^{64}$ his son [Weichi] Yiseng [d. ca 710] at Guangtan si painted Harmonious-Sound Bodhisattva icons, ${ }^{65}$ in the Tang dynasty Yan Liben [c. 700-764] painted a pensive Bodhisattva icon, ${ }^{66} \mathrm{Wu}$ Daozi [active ca 710-760] painted a Piluzhena (S. Māhāvairocana) Buddha icon, ${ }^{67}$ Lu Lengjia [active ca 730-760] painted a descending Mañjuśrí Bodhisattva icon, ${ }^{68}$ Yang Tingguang [active early 8 th century] painted a Longevity Bodhisattva icon, ${ }^{69}$ 
Cui Yan [active during the Tang dynasty (618-907)] painted a Śākyamuni Buddha, ${ }^{70}$ Li Guonu [active during the Tang dynasty] painted an Amitābha Buddha icon, ${ }^{71}$ Wang Wei [699-759] painted a Kongque Mingwang (S. Mahāmayūrī Vidyārājñī) icon, ${ }^{72}$ Han Gan [ca 7I5-after 78I] painted a Subhūti icon, ${ }^{73}$ Zhou Fang [ca 730-80o] painted a Talismanic-Wheel Bodhisattva icon, ${ }^{74}$ Xin Cheng [active end of Tang dynasty] painted a Ratnsambhava Buddha icon, ${ }^{75}$ Zou Quan [active end of the Tang dynasty] painted a transformation image of the Lion King [Buddha], ${ }^{76}$ Fan Qiong [active mid 9th century] painted a frontally-seated Buddha, ${ }^{77}$ Zhang Nanben [active during the Five Dynasties] painted a transformation image of Bintoulu (S. Pindolabhāradvāja) at Shengshou si, ${ }^{78}$ Zhang Teng [Five Dynasties] painted a Reward Body [Buddha] icon below the Mañjuśrí Pavilion, ${ }^{79}$ in the Liang dynasty Zhu Yao [Five Dynasties] painted a Fragrant-Flower Buddha icon, ${ }^{80} \mathrm{Ba}$ Yi [Five Dynasties] painted an Avalokiteśvara icon in the Fuguang si, ${ }^{81}$ in the Later Jin Wang Renshou [Five Dynasties] painted a descending Maitreya Buddha icon, ${ }^{82}$ in the Southern Tang Wang Qihan [early Ioth century] painted a Pratyeka Buddha icon, ${ }^{83}$ in the Former Shu Du Zihuan [Five Dynasties] painted a Fragrant-Attendant Bodhisattva icon, ${ }^{84}$ Du Nijun [Five Dynasties] painted an Vairocana icon, ${ }^{85}$ the Buddhist Guan Xiu [832-9I2] painted a Dream-Answering Arhat icon, ${ }^{86}$ in the $\mathrm{Wu}$ and Yue dynasties the Buddhist Yun Neng [active during the Later Shu, Five Dynasties (934-965)] painted icons of marvelous bodies of those who have attained perfect wisdom, ${ }^{87} \mathrm{Fu}$ Mei [active in end of Tang] painted a White-Robed Avalokiteśvara icon, ${ }^{88}$ in the Song dynasty Shi Ke [active in Northern Song] painted a Bhaisajya-guru Buddha icon, ${ }^{89}$ Zhou Wenju [fl. 942-96I] painted a Golden-Light Bodhisattva icon, ${ }^{90} \mathrm{Wu}$ Dongqing [fl. IIth century] painted a Wisdom-Amassing Bodhisattva icon, ${ }^{91}$ Hou Yi [active in Song dynasty] painted a Precious Symbol Bodhisattva icon, ${ }^{92}$ Gou Longshuang [active ca I068-IO85] painted a Water-Moon Avalokiteśvara icon, ${ }^{93} \mathrm{Li}$ Gonglin [I047-IIO6] painted an Long-Sash Avalokiteśvara icon, ${ }^{94}$ Guan Tong [fl. 907-923] painted a Dragon-Nest Buddhist icon, ${ }^{95}$ Dong Yuan [ca 900] painted a Dipamkara Buddha icon, ${ }^{96}$ Huang Jucai [933-after 993] painted a Resplendent-Color Avalokiteśvara icon, ${ }^{97}$ Liang Kai [early I3th century] painted a Transformation Buddha icon, ${ }^{98}$ Zhao Guang [dates unknown] painted a Flowing-Hair Avalokiteśvara icon, ${ }^{99}$ Zhao Boju [d. ca II52] painted Sākyamuni Buddha icons, ${ }^{100}$ Zhi Shi [active in the Song] painted a fine-lined Amitabha Buddha, ${ }^{101}$ and the Buddhist Fan Long [active ca IIOO-II5O] painted ten carefree sages. ${ }^{102}$ Throughout history, [this icon] has been painted.

Now the ancients have long passed, and it is unattainable to see [their paintings]. [One] can only imagine and admire them through these records. At over seventy some years of age, I have completely transformed and have no more wild thoughts. Although my body is disdained by nature, I nourish it to be pure and clean every day. Every early dawn, I wash my ten fingers, scent myself with a marvelous fragrance, 
and solemnly hold my brush to depict these supreme images in order not to betray the ancient method. In the world there are many laymen, humbly I offer this single gift, to be forever worshipped and eternally blessed.

In the twenty-fifth year [1760], second month of Qianlong's reign, on the Attainment of Buddhahood Day which is the fourteenth day, Jin Nong of Hangzhou respectfully inscribes this.

I painted the images of the many Buddhas, as well as the Four Great Bodhisattvas, the Sixteen Arhats, and the Ten Saints in a different style. It is all my own idea, one that is unlike the precedents of Gu [Kaizhi, 344-406], Lu [Tanwei, later fifth century], Xie [He, late fifth-early sixth centuries] and Zhang [Sengyu, early sixth century]. ${ }^{103}$ Viewers should not seek in it only my brushwork. Looking at my paintings over and over again, one senses the flavor of antiquity and profound spirit that lasts for hundreds and thousands of years, and its radiance is like the stonecarved images in the caves of Longmen. Layman Bai is a friend of a priest living in Jinling [Nanjing]. [He commented that] this work is done by a master of painting who started a tradition ${ }^{104}$ and initiated the way for several later generations. Upon hearing these words, I brush my beard with a great laugh. At the old age of seventyfour, I inscribe it again.

\section{NOTES}

1 While Yangzhou has a romantic history of poetry and leisure, as exemplified by the exploits of luminaries including the Sui dynasty Emperor Yangdi 煬帝 (r. 605-618) and the Tang dynasty poet $\mathrm{Du} \mathrm{Mu}$ 杜牧 (803-852), Qing dynasty Yangzhou grew as an economic center of the salt administration. The increasing prosperity of the salt merchants in the seventeenth through the eighteenth century gave rise to a unique social fabric characterized by an innovative, enterprising spirit. As Tobie Meyer-Fong writes, 'This was an age of permeable categories and fluid boundaries, an age of instability and creative potential' (MeYer-Fong 2003: 23).

2 In A Bushel of Pearls, Ginger Hsü illuminates the complex social and economic exchanges between artists and patrons to foreground the distinctive innovations and creative developments of eighteenth-century Yangzhou (Hsü 200I).

3 Meyer-Fong writes, 'Famous historical sites, including the most prominent Buddhist temples of the region, became the object of intensifying patronage activity among the elites, especially during the Kangxi period' (Meyer-Fong 2003: 90-9I).

4 Born into the Ming royal house on the eve of its fall to the Manchurians, Shitao escaped disaster by becoming a Buddhist monk and then, after fifty years of travels, he came to reside amid the secular world of seventeenth-century Yangzhou (HaY 200I).

5 This compilation, completed in I79I, attests to the syncretic nature of Luo Pin's Buddhist beliefs, including Chan, Pure Land, Huayan, and Tantrism, which are representative of popular beliefs and lay practices in eighteenth-century Yangzhou (KARLSSON 2004: II3).

6 Both Jin Nong and Hua Yan moved from Hangzhou to Yangzhou late in life to pursue their artistic careers, and their acquaintance is documented by several poems and paintings (Tsang 
1985: 18). Hsü extensively discusses Jin Nong's move from Hangzhou to Yangzhou in 1750 due to insufficient patrons, and specifically describes his painting production as both a form of self-expression and a source of income (Hsü 200I: I84). Hua Yan similarly came to Yangzhou in search of patronage for painting; however, he was less successful in attracting patrons and participating in social endeavors.

7 Jin Nong began painting most ambitiously during his mid-sixties, after his move to Yangzhou (Hsü 200I: 179). Hua Yan was a professional painter in Hangzhou with a specialty in landscapes and poetry (this shift is discussed extensively below; see footnote 36 ).

8 While a thorough discussion of Chinese painting genres lies beyond the scope of this study, it should be mentioned that the classical notion of xiang xing 象形, or the depiction of forms, falls under various genres depending on its subject matter and the contemporary classification system. As Shou-chih Yen describes in his study of the zahua 雜畫, or the miscellaneous genre, historical classifications of Chinese genres frequently evidence reconsiderations of objects, religious figures, genre or daily scenes, etc. For this reason, this study privileges the analysis of Buddhist imagery through various subject matters, such as Jin Nong's Buddhist figures and Hua Yan's bird-andflower paintings, rather than evaluating their relevance to contemporary genre classifications of 'Buddhist painting' (YEN 2004: I43-6I).

9 Sanmei 三昧 (S. samädhi) likely refers to the trance-like state of Buddhist meditation (SCHMIDT 2003: 473).

10 The 'eight records' balu八錄 could refer to either the eight categories of Daoist texts or the eight methods of calligraphy (SснміDт 2003: 49I, niI2).

11 Translation of the poem, Inscribed on a Portrait of Jin Nong, in entirety can be found in (SснміDт 2003: 469-7I).

12 As Bernard Faure describes, both visual forms of icons are 'traps for power' and function as substitute bodies for the deity (FAURE 1998: 798).

13 The word to describe the patriarchal robe is xin 信, which is also the word for 'faith' or 'worthy of faith,' as well as 'seal' or 'tessera' (FAURE I998: 797, n8I).

14 Jonathan Hay extensively discusses the possible stylistic prototypes of this work in regard to issues of culture, ethnicity and power (HAY 1999: 2IO-2I3).

15 Fontein and Hickman suggest that this work probably dates from the first decade of the thirteenth century when Liang Kai was a member of the Imperial Academy (Fontern and Hickman I970: 69). This is corroborated in BARnharT 1997: 136. Additionally, Liang Kai is mentioned in Jin Nong's inscription, though the work listed is not Sakyamuni, but a Transformation Buddha icon. (See Appendix.)

16 This section of the translation is adapted from: HaY 1999: 2II. All other translation is my own.

17 While most of their works do not survive, textual records frequently detail the pictorial modes and biographical information of the artists. See the Appendix for an annotated list of artists and possible early textual sources for the works mentioned in Jin Nong's inscription.

18 Concerns have been raised in regard to the authenticity of this work. Having not personally viewed this scroll, I will set aside issues of authenticity and consider this work as a worthy example of Jin Nong's aesthetic concerns. See also Richard Vinograd's discussion of this work (VInOgRAD 1992). 
19 Fang Shishu and Ye Fanglin, A Literary Gathering at Xing'an on the Double Nine, dated 1743. Handscroll, ink and light color on silk, $31.7 \times 20 \mathrm{I} \mathrm{cm}$. In the collection of the Cleveland Museum of Art.

20 Richard Vinograd discusses the iconographic significance of the banana palm as a common motif in Jin Nong's works. He suggests that banana palms can act as a shady spot for summer leisure, but can also act as a Buddhist metaphor for the floating, transient life of the self (VINOGRAD I992: IOO).

21 'Patience grass' or rencao, written as 忍草 or renruncao 忍辱草, is defined in the Northern Song Nirvana Sutra, chapter 27 (北本涅槃經卷二十七), cited in Soothill and Hodous 1937.

22 The shizi 獅子, sometimes written as 師子, or the lion, is an epithet of the Buddha as the lion is the king of all beasts (Soothill and Hodous 1937).

23 Bianxiang 變相, or 'transformation tableaux,' are miraculous transformations recorded in religious texts and presented in image form (Wu Hung I992: II2). For example, they include illustrations of transformative experiences such as human beings born into a Buddhist paradise or other forms due to karmic consequence (see also WANG 2005).

24 The five impurities, or the five defilements, are: the impurity of the age, the impurity of desire, the impurity of living beings, the impurity of view, and the impurity of life span (WATSON I993: 330).

25 This is one of Jin Nong's sobriquets. It could be translated as, 'the monk whose mind is outside of the secular domain and who only lives on rice gruel.'

26 The Sanskrit word 'suvarna,' is transliterated in Chinese as sufala 蘇伐刺 or sufaluo 蘇伐羅 and translates as 'gold' (Soothill and Hodous 1937: 479).

27 Although this is my translation, please see Richard Vinograd's translation for additional reference (VINOGRAD I992: IOO).

28 Jin Nong's use of this signature is also noted in HaY I999: 2 I2.

29 One example is Jin Nong's Branch of Plum Blossoms in the Musée National des Arts AsiatiquesGuimet (REY 2006, plate 69).

30 This is the same term (rencao 忍草) used in Jin Nong's inscription on Banana Tree and Buddhist Figure in reference to the circular grass mat upon which Bodhidharma in Banana Tree and the Buddhist devotee in Offering are seated. See footnote 2I.

31 The Pratyekabuddha is 'one who seeks enlightenment for himself, defined in the Lotus Sütra as a believer who is diligent and zealous in seeking wisdom, loves loneliness and seclusion, and understands deeply the nidanas [the cycle of twelve phenomenal causes] . . He attains his enlightenment alone, independently of a teacher, and with the object of attaining nirvana and his own salvation rather than that of others, as is the object of a bodhisattva' (Soothill and Hodous 1937).

32 Xinchujia'an is an abbreviation of the same sobriquet found on Jin's Banana Tree and Buddhist Figure. See footnote 25 .

33 Three early sculptural examples of this iconography are found in the Asian Art Museum, San Francisco, and the University of Pennsylvania Museum. In the Asian Art Museum, there is a limestone, standing Pratyekabuddha from the Northern Qi (550-577), while the University of Pennsylvania Museum contains a standing and head of a Pratyekabuddha. Each sculpture is depicted with long, draping robes, hands clasped in front of the chest, and hair coiled atop the head in a cone-like manner. 
34 Yangzhou society has a history of recalling these Song dynasty luminaries as popular cultural paradigms. For example, during Yangzhou's seventeenth-century reconstruction, local elite residents frequently recalled these scholar-official and Buddhist devotees to emphasize their own comparable virtues, talents and social distinction. Meyer-Fong discusses multiple examples of this phenomenon. To name two: the official Wang Maolin 汪惁麟 (I639-I688) renovated Yangzhou's Pingshan Hall as a Confucian shrine which was originally founded by Ouyang Xiu 歐陽修 (IOO7-IO72) on the grounds of a Buddhist temple; the official Wang Shizhen 王士禎 (I634-I7II) sponsored gatherings at Red Bridge in the fashion of Su Shi (Meyer-Fong 2003: 153-156; 45-47).

35 The concepts of elegance and vulgarity in eighteenth-century Yangzhou are extensively discussed in Hsü $200 I$.

36 While the enormous quantity of forgeries and highly questionable works makes it impossible to calculate the number of landscapes versus bird-and-flower works, nonetheless, there are very few bird-and-flower subjects dated or attributed to Hua Yan's Hangzhou period. The artist's roughly chronological, five-volume collection of poetry, Ligou ji, further attests to his growing specialization in bird-and-flower subjects during his Yangzhou period. For example, the majority of entries in the first volume are landscape and travel-related, while the majority of entries in the fifth volume are whimsical quatrains on bird-and-flower subjects.

37 Translation from TsANG 1982: 71.

38 Hua Yan's original name is Desong 德嵩, style name Qiuyue 秋岳, and he took the sobriquet Xinluo shanren 新羅山人 or 'the recluse of Xinluo' when he left his hometown of Xinluo, Fujian province. He also frequently used another sobriquet, Buyi sheng 布衣生 or 'born of plain clothes,' highlighting his impoverished family background (XUE Yongnian 2003b: 2I).

39 The characteristics of these sects are discussed in Cоок: 1977. Meyer-Fong also notes that, according to local legend, the Avatamsaka sutra was translated by the foreign monk Buddhabhadra in the early fifth century at the site that later became the Tianning temple in Yangzhou, which indicates the local history of the Huayan sect (Meyer-Fong 2003: I69).

40 Translation from Cleary I993: 206.

41 Translation by Ronald Egan, Guo Mianyu and Kristen E. Loring. Unpublished Appendix for my dissertation, tentatively entitled Region and Artistic Strategy: Hua Yan's (I682-I756) Painting in Yangzhou. University of California, Los Angeles, forthcoming. Hereafter cited as Loring: Dissertation Appendix.

42 Translation from Cleary I993: I4I.

43 Although this album is not dated, the poems on the leaves appear in the Ligou ji around the year 1742 (Hua Yan 1997, vol. 3).

44 Wang 網, are nets or traps that refer to luowang 羅網, or the nets made from strings of jewels (Soothill and Hodous 1937). Translation by Ronald Egan, Guo Mianyu and Kristen E. Loring. Loring: Dissertation Appendix.

45 The mention of autumn blossoms suggests the autumn harvest, which is symbolized by the Nine Plants of Autumn that represent the ninety days of the three autumnal months. The final two lines of the poem suggest that the bird delights in the natural environment and cannot see the autumnal blossoms that represent food (BARTHOLOMEW 2006: 234). Translation by Ronald Egan, Guo Mianyu and Kristen E. Loring. Loring, Dissertation Appendix.

46 Translation from CleARY I993: IOI. 
47 Translation by Ronald Egan, Guo Mianyu and Kristen E. Loring. Loring, Dissertation Appendix.

48 The bamboo is a symbol of integrity due to its upright and pliant nature, and jie 節, the word for its joints, is the same word used for 'moral integrity' (BARTHOLOMEW 2006: 60).

49 Translation by Ronald Egan, Guo Mianyu and Kristen E. Loring. Loring, Dissertation Appendix.

50 Tsang argues that book illustration was a source for many of Hua Yan's pictorial motifs. This particular album leaf bears close resemblance to an image from the Sancai tubui encyclopedia reproduced in his article (Tsang 1987: 159, fig. 17). See also WANG Qi 1974 [1607], vol. I.

51 Translation by Ronald Egan, Guo Mianyu and Kristen E. Loring. Loring, Dissertation Appendix. For an extensive discussion of the Cloud Gate, see Grant 1994.

52 Yunmen Wenyan derived his name, Zhang Xuefeng 張雪峯, from this Chan monastic site (Soothill and Hodous 1937: 394).

53 Biographies of the disciples that appear in Su Shi's writings, as listed by Grant 1994, are described in Chen Zhongzhe 2004: 45-63.

54 Translated by the author. See also note I03.

55 Chicken Foot Mountain refers to Kukkatārāma, a monastery on the Chicken Foot Mountain built by Aśoka (Sоothill and Hodous i937: 470).

56 The Seven Buddha painting is recorded in Gu Kaizhi lunhua [Gu Kaizhi's Treatise on Painting], among other texts (Peiwenzhai shuhua pu 1983 [1708], vol. 45).

57 Recorded in: Xuanhe huapu: vol. I. This temple was in Jiankang (Hangzhou), and the painting was on its north wall, according to Zhang Yanyuan's 9th-century Lidai minghua ji [Record of the Famous Painters of All the Dynasties], vol. 5 .

58 Recorded by Zhang Yanyuan: vol. 3. This temple burned in IIoo, though it was visited by Mi Fu and Su Shi prior to this (ACKer 1979: 382).

59 Recorded by Zhang Yanyuan 1983, vol. 3 .

60 Recorded in Li Fang's Ioth-century Taiping guangji [Records of Taiping], vol. 43, see Li Fang 1983.

61 Recorded in the Song Zhongxing guange chucang tuhua ji 1983.

62 Zhang Yanyuan records that Zheng's King Aśoka icon entered the Buddhist temple of Sui Wendi, and he later notes that Zheng's paintings are in Yongtai si, though the King Aśoka icon is not specified (Zhang Yanyuan 1983, vol. 45).

63 This description matches the Song Zhongxing guange chucang tubua ji 1983, vol. 97.

64 Recorded in: Gu Qiyuan's early 17th-century Shuo Lüe (Gu Qiyuan 1983, vol. 16). Pure Land groves can also refer to the monastery of Huineng, the sixth patriarch of the Chan sect in Dianjiang 典江, Shaozhou 韶州, Guangdong province (Soothill and Hodous 1937: 477).

65 Recorded in Zhang Chou's early I7th-century Qinghe shuhua fang (ZHANG Chou 1983, vol. 6). Guangtan si is mentioned in Zhu Jingxuan's 8th-century Tangchao minghua lu (ZHU Jingxuan 1983).

66 The Tang painters Qu Daozi, Xin Cheng and Wu Daoyuan all painted this subject, but it is not listed among works of Yan Liben (Xuanhe huapu 1983, vol. 3).

67 Bian Yongyu I983, vol. 32. 
68 Though it is not a descending Mañjuśrī, a comparable entry is listed in Xuanhe huapu 1983, vol. 2.

69 Recorded in Xuanhe huapu 1983, vol. 2.

70 Recorded in Song zhongxing guange chucang tuhua ji 1983, vol. 97.

71 This painting is listed in several references as the work of Li Gonglin, Lu Danwei, Zhu Yao and Lu Lengjia, among others. Xuanhe huapu 1983, vol. 3. It is also listed as a Tang dynasty stele by Wu Zhili, according to the Jinshi lu 金石錄 [Records of Metal and Stone] in Peiwenzhai shuhua pu 1983 [I708], vol. 26. However, there appears to be no association with Li Guonu.

72 Recorded in: Song Zhongxing guange chucang tuhua ji 1983, vol. 97.

73 Recorded ibidem.

74 This work is listed as by the artists: Yang Tingguang, Cao Zhongyuan and Xin Cheng, but not Zhou Fang. Zhou Fang's bodhisattvas are listed in Lidai minghua ji, Tangchao minghua ji and Xuanhe huapu but even these are not specified as Wheel-Turning Bodhisattvas.

75 This is the first entry under Xin Cheng in Xuanhe huapu 1983, vol. 2. Ratnasambhava is one of the five Dhyāni-Buddhas, the central figure in the southern 'diamond' mandala; also the realm of Subhūti on his becoming a Buddha (Soothill and Hodous I937: 477).

76 In its introduction to the painter Zuo Quan, Cao Xuequan's I7th-century Shuzhong guangji lists a 'Transformation Portrait of the Lion King with Bodhisattvas' (CAO Xuequan 1983, vol. I05).

77 Recorded ibidem. Also recorded in Gu Qiyuan 1983, vol. I6.

78 Recorded in CAO Xuequan 1983, vol. I06. Also in: Huang Xiufu's IIth-century Yizhou minghua lu (Huang Xiufu 1983, vol. I). Pindola-bhāradvāja is the first of the sixteen arhats who became the old man of the mountains with white hair, beard and bushy eyebrows (SoOTHILL and Hodous 1937: 429).

79 Recorded in Cao Xuequan I983, vol. I05. Also in Huang Xiufu 1983, vol. I. The 'Reward Body' refers to the sambhoga-kāya of a Buddha, in which he enjoys the reward of his labors (SoothilL and Hodous 1937: 369).

80 Recorded in: Xuanhe huapu 1983, vol. 3.

81 The icon is not mentioned, though the artist is associated with the Fuguang si, in Guo Ruoxu's IIth-century Tuhua jianwen zhi (Guo Ruoxu 1983, vol. 2).

82 Recorded ibidem.

83 Recorded in Song Zhongxing guange chucang 1983, vol. 97. The Pratyeka-buddha is one who seeks enlightenment for himself, defined in the Lotus sūtra as a believer who is diligent and zealous in seeking wisdom, loves loneliness and seclusion, and understands deeply the nidānas (Soothill and Hodous i937: 4I4).

84 This work is recorded as the work of Xin Cheng, but the artist is discussed separately in Xia Wenyan's I4th-century Tuhui baojian (XIA Wenyan 1983, vol. 2).

85 Recorded in CAO Xuequan I983, vol. Io6.

86 Recorded in several sources, including the above.

$\mathbf{8 7}$ There is a work recorded as 'glorious-sound icons of perfect wisdom', Beifang miaosheng Rulai xiang 北方妙聲如來像, with some possible correspondence to this artist in ZHANG Chou 1983, vol. 4.

88 Recorded in Guo Ruoxu 1983, vol. 2.

89 The Medicine Buddha, or Bhaisajya-guru-vaidūrya-prabhāsa (Soотнill and Hodous I937: 472). Though Shi Ke is listed as an academy painter in the Xuanhe huapu, there is no Bhaisajyaguru listed in association (Xuanhe huapu 1983, vol. 7). 
90 Listed ibidem. The Golden Light Sutra, Jinguang (ming) jing 金光 (明) 經, is used by the founder of Tiantai Buddhism (Soothill and Hodous 1937: 280).

91 Listed in Song Zhongxing guange chucang tuhua ji 1983, vol. 97. This refers to the eldest son of Mahābhujña, also said to be Aksobhya; or, a bodhisattva in the retinue of Prabhūtratna in the Lotus sūtra (SoOTHill and Hodous i937: 375).

92 Hou Yi is listed as a figure painter in the Xuanhe huapu and his biography is in: Liu Daochun's IIth-century Songchao minghua ping (LiU Daochun 1983). However, this painting is not listed in association.

93 The work is listed in Song Zhongxing guange chucang tuhua ji 1983, vol. 97. Gou's biography is in Liu Daochun i983, vol. I.

94 Recorded in: Song Zhongxing guange chucang tuhua ji 1983, vol. 97.

95 Guan Tong is described as a painter of Buddhist and Daoist figures in several sources, but without mention of this work in particular (Xuanhe huapu 1983, vol. 7). Recorded in Xuanhe циари 1983, vol. Iо.

96 Recorded in Song Zhongxing guange chucang tuhua ji 1983, vol. 97. Sākyamuni offered five lotuses to Dipamkara when he was a bodhisattva, and was thereupon designated as a coming Buddha; he appears wherever a Buddha preaches the Lotus sūtra (Soothill and Hodous I937: 254).

97 Listed in Song Zhongxing guange chucang tuhua ji 1983, vol. 97.

98 The artist is frequently mentioned as a master of figure painting in Li E's (I692-I752) Nan Song yuan hualu, among others, but the work is not mentioned in association with his name (Li E 1983). Rather, Yang Tingguang is listed in Song Zhongxing guange chucang tuhua ji 1983, vol. 97.

$99 \mathrm{Wu}$ Daozi and Zhu Yao were known to paint this subject, and it was popular in the Latter Tang. However, Zhao Guang is not recorded as its artist (Peiwenzhai shuhua pu 1983 [1708], vol. 97).

100 The artist is listed in Li E 1983, vol. I, among others. Immortals and other historical figures are frequently attributed to him, though works of specifically Buddhist subject matter are not.

101 A fine-lined Buddhist figure is attributed to the Song-dynasty Monk Zhi Shi in Hua shi hui yao [Compendium of Painting History] (Peiwenzhai shuhua pu 1983 [I708], vol. 53).

102 Luohans and other icons are attributed to Monk Fan Long in Peiwenzhai shuhua pu 1983 [1708], vol. 52, 84 .

103 This section of the translation is adapted from HaY 1999: 2II. All other translation is my own.

104 Danqing 丹青 is a term used by Zhang Yanyuan in reference to the mastery of painting (ACKER I979: II2). 


\section{References}

Acker, William Reynolds Beal. 1979. Some T'ang and Pre-T'ang Texts on Chinese Painting, Translated and Annotated. Sinica Leidensia 8. Westport, CT: Hyperion Press.

Adshead, S.A.M. 1992. Salt and Civilization. Houndmills, Basingstoke, England: Macmillan.

Bakhtin, Mikhail Mikhailovich. 1981. The Dialogic Imagination. Michael Holquist, ed. Austin: University of Texas Press.

Barlow, Tani E., ed. 1997. Formations of Colonial Modernity in East Asia. Durham, NC: Duke University Press.

Barnhart, Richard, et al. 1997. Three Thousand Years of Chinese Painting. New Haven: Yale University Press.

Bartholomew, Terese Tse. 2006. Hidden Meanings in Chinese Art. San Francisco: Asian Art Museum.

Bender, Mark. 2003. Plum and Bamboo. China's Suzhou Chantefable Tradition. Champaign: University of Illinois Press.

BIAN Yongyu 市永譽. 1983. Shigutang shuhua huikao 式古堂書畫录考 [Survey of Painting and Calligraphy from the Studio of Conforming Antiquity]. In Yingyin Wenyuange siku quanshu 影印文淵閣四庫全書, vol. 827-29. Taibei: Taiwan shangwu yinshuguan.

Bickford, Maggie. 1996. Ink Plum: the Making of a Chinese Scholar-Painting Genre. Cambridge - New York: Cambridge University Press.

Børdahl, Vibeke. 1996. The Oral Tradition of Yangzhou Storytelling. Nordic Institute of Asian Studies Monograph 73. Richmond: Curzon Press.

— - ed. 1999. The Eternal Storyteller. Oral Literature in Modern China. Richmond: Curzon Press.

2003. The Storyteller's Manner in Chinese Storytelling. Asian Folklore Studies. 62.1: 65-112.

- 2004a. The Voice of Wang Shaotang in Yangzhou Storytelling. CHINOPERL Papers 25: 1-34.

- 2004b. Tiger, tiger! Wu Song og tigeren i kinesisk historiefortalling [Tiger, Tiger! Wu Song and the Tiger in Chinese Storytelling]. With photos by Jette Ross. Copenhagen: Vandkunsten Forlag.

2005. Storytellers' Scripts in the Yangzhou Pinghua Tradition. Acta Orientalia (Oslo) 66: 227-296.

— Fei Li and Huang Ying, eds. 2004. Four Masters of Chinese Storytelling. Complete repertoires of Yangzhou Storytelling on Video. I Yangzhou pinghua sijia yiren quanshu 
biaoyan luxiang mulu 揚州評話四家藝人全書表演錄像目錄. Bilingual edition. With DVD 60 minutes. Copenhagen: NIAS Press.

— and Jette Ross. 2002. Chinese Storytellers. Life and Art in the Yangzhou Tradition. Boston: Cheng \& Tsui.

Børdahl, Vibeke, see also Yi Debo

Borota, Lucie. 1996. The Painted Barges of Yangzhou: Excerpts, by Li Dou. Renditions 46: 58-68.

Borotová, Lucie. 1997. Yangzhouské malované bárky [Pleasure Boats of Yangzhou].

Ph.D. dissertation, Charles University, Prague.

Borota, Borotová, see also Olivová

Bray, David. 2005. Social Space and Urban Governance in Urban China: the Danwei System from Origins to Urban Reform. Stanford: Stanford University Press.

Brokaw, Cynthia J. 2005. Reading the Best-Sellers of the Nineteenth Century: Commercial Publishing in Sibao. In Cynthia Brokaw and Kai-wing Chow, eds. Printing and Book Culture in Late Imperial China. Berkeley: University of California Press, 184-234.

2007. Commerce in Culture: The Sibao Book Trade in the Qing and Republican Periods. Cambridge, Massachusetts - London: Harvard University Asia Center.

and Kai-wing CHow, eds. 2005. Printing and Book Culture in Late Imperial China. Berkeley: University of California Press.

Broок, Timothy. 1993. Praying for Power: Buddhism and the Formation of Gentry Society in Late-Ming China. Harvard-Yenching Institute Monograph Series 38. Cambridge, Massachusetts: Harvard University Press.

Cahill, James. 1960. Confucian Elements in the Theory of Painting. In Arthur F. Wright, ed. The Confucian Persuasion. Stanford: Stanford University Press, 1960: 115-140.

— 1980. An Index of Early Chinese Painters and Paintings: T'ang, Sung, and Yuan. Berkeley: University of California Press.

1982. The Compelling Image: Nature and Style in Seventeenth-century Chinese Painting. Cambridge, MA - London: Harvard University Press.

Cambridge History of China vol. 11, Late Ching 1800-1911 part 2. 1980. Cambridge: Cambridge University Press.

CAO Xiaoyun 曹小雲. 2003. Qingfengzha zhong Yangzhou fangyan ci li shi 清風閘中揚州 方言詞例釋 [Examples of Yangzhou Dialect Words in Qingfengzha Explained]. Fuyang shifan xueyuan xuebao. Shehui kexue ban 阜陽師範學院學報・社會科學版 93.3: 31-34.

CAO Xuequan 曹學佺. 1983. Shuzhong guangji 蜀中廣記 [Records of Shu]. In Yingyin Wenyuange siku quanshu 影印文淵閣四庫全書, vol. 591-92. Taibei: Taiwan shangwu yingshuguan.

CJBQ, see SHI Chengjin. 1936.

Changshu Weng shi cangshu tulu 常熟翁氏藏書圖錄 [Illustrated Catalogue of Books in the Collection of the Weng Family of Changshu]. 2000. Zhongguo Jiade guoji paimai youxian gongsi 中國嘉德國際拍賣有限公司, ed. Shanghai: Shanghai kexue jishu wenxian chubanshe. 
Chartier, Roger. 1987. The Cultural Uses of Print in Early Modern France. Translated by Lydia G. Cochrane. Princeton: Princeton University Press.

Chayet, Anne. 2004. Architectural Wonderland: An Empire of Fictions. In James Millward et al., eds. New Qing Imperial History: The Making of Inner Asian Empire at Qing Chengde. London - New York: RoutledgeCurzon, 32-52.

Chen Congzhou 陳從周. 1980. Yangzhou yuanlin yu zhuzhai 揚州園林與住宅 [Gardens and Mansions of Yangzhou]. In Chen Congzhou. Yuanlin tancong 園林談叢 [Collected discourses on (Chinese) gardens]. Shanghai: Shanghai wenhua chubanshe, 52-89.

__ 1983. Yangzhou yuanlin tuji 揚州園林圖記 [Gardens of Yangzhou, Illustrated]. Shanghai: Shanghai kexue jishu chubanshe.

— 1988. Shuo yuan 說園 [On (Chinese) Gardens]. Shanghai: Tongji wenxue chubanshe. 4th edition.

Chen Fan Ben. 2004. Visions for the Masses. Chinese Shadow Plays from Shaanxi and Shanxi. New York: Cornell University East Asia Program.

Chen Henghe 陳恒和, ed. 1995 [1930-34]. Yangzhou congke 揚州叢刻 [Yangzhou Collectanea]. 4 vols. Yangzhou: Guangling guji keyinshe. Reprint.

CHEN Jinling 陳金陵. 1995. Hong Liangji pignzhuan 洪亮吉評傳 [A Critically Annotated Biography of Hong Liangji]. Beijing: Renmin daxue chubanshe.

Chen Pingyuan 陳平原, WAng Dewei 王德威 and Shang Wei 商偉, eds. 2002. Wan Ming yu wan Qing: lishi chuancheng yu wenhua chuangxin 晚明與晚清: 歷史傳承與文化 創新 [Late Ming and Late Qing: Historical Continuities and Cultural Innovations]. Wuhan: Hubei jiaoyu chubanshe.

Chen Weisong 陳維崧. 1965. Chen Jialing wenji 陳迦陵文集 [Collected Prose by Chen Jialing]. 2 vols. Taibei: Taiwan shangwu yinshu guan.

CHEN Wulou 陳午樓 (pseudonym Si Su 思蘇). 1962. Shuoshu you wu jiaoben? 說書有無腳 本 [Do Storyteller's Scripts Exist in Storytelling?]. Quyi 曲藝 4: 44-45.

1994. Jiu shi chong ti - shuo huaben 舊事重提 — 說話本 [Old Questions Discussed Anew - On Huaben]. Dushu 讀書 10: 148-150.

1998. Old Questions Discussed Anew - On Huaben. Translated by Lucie Borotová and Vibeke Børdahl. Asian Folklore Studies 57.1: 134-139.

1999. Some Topics in My Study of Yangzhou Storytelling. In Vibeke Børdahl 1999 ed. The Eternal Storyteller. Oral Literature in Modern China. Richmond: Curzon Press, 210-217.

CHEN Zhongzhe 陳中浙. 2004. Su Shi shuhua yishu yu fojiao 蘇軾書畫藝術與佛教 [Su Shi's Art of Painting and Calligraphy, and Buddhism]. Beijing: Shangwu yinshuguan.

Chen Zuyin 陳祖荫 and Deng Gengxin 鄧更新, eds. 1994. Qing Menggu Chewangfu zang zidishu 清蒙古車王府藏子弟書 [Gentry Tales from the Mansion of the Mongolian Chewangfu of the Qing Dynasty]. Beijing: Guoji wenhua chubanshe.

CHeng Yizhong. 程毅中 1980 [1964]. Song Yuan huaben 宋元話本 [Huaben from Song and Yuan]. Beijing: Zhonghua shuju.

ChIn, Sandy and Hsü, Ginger Cheng-chi. 1981. Anhui Merchant Culture and Patronage. In James Cahill, ed. Shadows of Mt. Huang: Chinese Painting and Printing of the Anhui School. Berkeley: University Art Museum, Berkeley. 
China Review 2005, vol. 5, No. 2. Special issue. Collective memories of the Cultural Revolution.

Chongxiu Yangzhou fuzhi 重修揚州府志 [Revised Gazetteer of Yangzhou Prefecture]. 1810. Yao Wentian 姚文田 et al., eds. Yangzhou: Yangzhou fushu.

Chongxiu Yangzhou fuzhi 重修揚州府志 [Revised Gazetteer of Yangzhou Prefecture]. 1974 [1810]. Yao Wentian 姚文田 et al., eds. In Zhongguo fangzhi congshu: Hua zhong difang 中國方志叢書: 華中地方 145.16 vols. Taibei: Chengwen chubanshe. Reprint.

Chou, Ju-hsi and Claudia Brown, eds. 1985. The Elegant Brush: Chinese Painting Under the Qianlong Emperor, 1735-1795. Phoenix Art Museum.

1991. Chinese Painting under the Qianlong Emperor. The Symposium Papers in Two Volumes. Phoebus 6, No. 1-2. Tempe: School of Art, Arizona State University.

Chuang Su-O, see Zhuang Sue

CHye Kiang Heng. 1999. Cities of Aristocrats and Bureaucrats: the Development of Medieval Chinese Cities. Honolulu: University of Hawai'i Press.

Cleary, Thomas. 1993. The Flower Ornament Scripture: A Translation of the Avatamsaka Sutra. Boston - London: Shambhala.

Cole, James. 1981. The People Versus the Taipings: Bao Lisheng's Righteous Army of Dongan. China Research Monographs 21. Berkeley: Center for Chinese Studies.

Cook, Francis H. 1977. Hua-Yen Buddhism: The Jewel Net of Indra. University Park London: Pennsylvania State University Press.

Cur Mingquan 崔明泉. 1982. Huang Shen 'xiesheng shanshui, shihua he ce' 黃慎寫生山 水, 詩畫合冊 [Huang Shen's 'Sketches from Life - Album of Landscapes, Poems and Calligraphy']. Wenwu 文物 7: 78-83.

DAI Bufan 戴不凡. 1980. Xiaoshuo jianwen lu 小說見聞錄 [Recorded Information about Fiction]. Hangzhou: Zhejiang renmin chubanshe.

DAI Jian 戴健. 2006. Shilun 'Yuhua xiang' yu 'Tongtian le' de quanshan sixiang 試論 《雨花 香》與 《通天樂》的勸善思想 [An Examination of the Thought Regarding the Promotion of Good Deeds in Yuhua xiang and Tongtian le]. In Yangzhou daxue xuebao. Renwen shehui kexue ban 揚州大學學報。人文社會科學版 10.6: 38-41.

Davis, Julie Nelson. 2004. Artistic Identity and Ukiyo-e Prints: The Representation of Kitagawa Utamaro to the Edo Public. In Takeuchi, Melinda, ed. The Artist as Professional in Japan. Stanford: Stanford University Press.

Ding Xigen 丁錫根, ed. 1996. Zhongguo lidai xiaoshuo xu ba ji 中國歷代小說序跋集 [A Collection of the Prefaces and Colophons of Chinese Fiction from Every Dynasty]. Beijing: Renmin chubanshe.

Dingyuan xian zhi 定遠縣志 [Gazetteer of Dingyuan County]. 1995. Dingyuan difang zhi bianzuan weiyuan hui 定遠地方志編纂委員會, ed. Hefei: Huangshan shushe.

Dong Guoyan 董國炎 and YANG Fang 楊芳. 2005. Gudian xiaoshuo de zhuanxing jiqi jingyan: Aina Jushi yu Shi Chengjin xiaoshuo yanjiu 古典小說的轉型及其經驗: 艾衲居士 與石成金小說研究 [The Transformation of Classical Chinese Fiction and its Experience: Studies on the Fiction of Aina Jushi and Shi Chengjin]. In Yangzhou daxue xuebao. Renwen shehui kexue ban 揚州大學學報。人文社會科學版 9.3: 9-13. 
Dong Yushu 董玉書. 2002 [1878?]. Wucheng huaijiu lu 無城懷舊錄. [Remembrances of Wucheng]. Nanjing: Jiangsu guji chubanshe. (In one volume with Xu Qianfang 徐謙 芳: Yangzhou fengtu jilüe 揚州風土記略 [An Account of Yangzhou Customs and Lore])

Dou Zhen 竇鎭. 1962. Guochao shuhuajia bi lu 國朝書畫家筆錄 [Glosses on Painters and Calligraphers of Our Dynasty]. In Gu Linwen 顧麟文, ed. Yangzhou bajia shiliao 揚州 八家史料 [Historical Materials on the Eight Masters of Yangzhou]. Shanghai: Shanghai renmin meishu chubanshe.

Dougherty, Niklas. 2006. Prostitution in Contemporary China. The Case of Shanghai Jiading. M.A. dissertation, Lund University.

Du Hai 杜海. 2002. He yuan 何園 [The He yuan Garden]. Nanjing: Nanjing daxue chubanshe.

Du Xinfu 杜信孚 and Du Tongshu 杜同書, eds. 2001. Quan Mingfensheng fenxian keshu kao 全明分省分縣刻書考 [Examination of Ming Xylographic Editions Arranged According to Province and District of Publication]. 10 vols. Beijing: Xianzhuang shuju.

Eastman, Lloyd. 1988. Family Fields and Ancestors. Oxford: Oxford University Press.

Eberhard, Wolfram. 1986. A Dictionary of Chinese Symbols. Hidden Symbols in Chinese Life and Thought. Translated by G.L. Campbell. London - New York: Routledge \& Kegan Paul.

Edgren, Sören, ed. 1984. Chinese Rare Books in American Collections. New York: China Institute.

1989. Southern Song Printing at Hangzhou. Bulletin of the Museum of Far Eastern Antiquities 61: 1-212.

1994. The Weng Family Rare Book Collection. East Asian Library Journal VII.2: 72-132.

Eight Dynasties of Chinese Painting: The Collections of the Nelson Gallery-Atkins Museum, Kansas City, and The Cleveland Museum of Art. 1980. Cleveland Museum of Art, with Indiana University Press.

Elliott, Mark C. 2001. The Manchu Way: The Eight Banners and Ethnic Identity in Late Imperial China. Stanford: Stanford University Press.

Entwhistle, Joanne. 2000. The Fashioned Body: Fashion, Dress, and Modern Social Theory Cambridge: Polity Press.

FAure, Bernard. 1986. Bodhidharma as Textual and Religious Paradigm. History of Religions 25. 3, Feb 1986: 187-198.

Faure, Bernard 1998. The Buddhist Icon and the Modern Gaze. Critical Inquiry 24.3, Spring 1998: 768-813.

FEI Faye Chunfang, ed. and trans. 1999. Chinese Theories of Theater and Performance from Confucius to the Present. Ann Arbor: The University of Michigan Press.

FEI Junliang 費駿良 and FEI Li 費力. 1986. Guo wu guan, zhan wu jiang 過五關, 斬五將 [Crossing Five Passes, Beheading Six Generals]. Nantong: Jiangsu wenyi chubanshe.

FEI Li 費力. 1991. Shuchang fengqing 書場風情 [The Traditional Style of The Storytellers' House]. In Yangzhou fengqing 揚州風情 [The Traditional Lifestyle of Yangzhou]. Nanjing: Jiangsu wenyi chubanshe, 114-123. 
Fei Tuo quan zhuan 飛跎全傳 [The Braggart's Tale]. 1995 [1817]. Beijing: Huaxia chubanshe. Reprint.

FEI Xingjian 費行簡. 1985. Jindai mingren xiaozhuan 近代名人小傳 [Short Biographies of

Modern Age Personages]. In Zhou Junfu 周駿富, ed. Qingdai zhuanji congkan 清代傳記 叢刊 202. Taibei: Mingwen shuju. Reprint.

FENG Menglong 馮夢龍, ed. 1987 [1624]. Jing shi tongyan 警世通言 [Common Words to Warn the World]. Shanghai: Shanghai guji chubanshe.

FENG Mingzhu 馮明珠 et al. 2002. Emperor Ch'ien-lung's Grand Cultural Enterprise. Taibei:

National Palace Museum.

Feng Zhongping. 1994. The Chinese People's Recognitions of Natural Landscape

Beauty Versus the Creation of the Gardens. In The Universal Garden. Proceedings, 1st Session, International Conference East and West - The Universal Garden - From Idea to Realization. Shanghai - Suzhou, 19-30.

Finnane, Antonia. 1993. Yangzhou: A Central Place in the Qing Empire. In Linda Cooke Johnson, ed. Cities in Jiangnan in Late Imperial China. Albany, NY: University of New York Press, 117-149.

1994. A Place in the Nation: Yangzhou and the Idle Talk Controversy of 1934. The Journal of Asian Studies 53.4: 1150-1174.

1996. What Should Chinese Women Wear? A National Problem. Modern China 22.2: 99-131.

1999. Military Culture and Chinese Dress in the Early 20th Century. In Valerie Steele and John S. Mason, eds. China Chic: East Meets West. New Haven - London: Yale University Press, 118-131.

_ 2003. Yangzhou's 'Mondernity': Fashion and Consumption in the Early-NineteenthCentury World. Positions: East Asia Cultures Critique 11.2: 395-425.

- 2004. Speaking of Yangzhou, A Chinese City, 1550-1850. Cambridge, Massachusetts - London: Harvard University Asia Center.

- 2007. Changing Clothes in China: Fashion, History, Nation. London: Hurst.

Finnegan, Ruth. 1992 [1977]. Oral Poetry. Bloomington: Indiana University Press.

1992. Oral Traditions and the Verbal Arts. London: Routledge.

Fong, Grace S. 2001. Signifying Bodies: The Cultural Significance of Suicide Writings by Women in Ming-Qing China. Nan Nü: Men, Women, and Gender in China 3:1 (June 2001): 105-142.

Fontein, Jan and Money L. Hickman. 1970. Zen Painting and Calligraphy. Boston: Museum of Fine Arts.

Foote, Stephanie. 2001. Regional Fictions: Culture and Identity in Nineteenth-Century American Literature. Madison: University of Wisconsin Press.

Forster, E.M., see Fusite.

Fortune, Robert. 1979 [1847]. Three Years Wandering in the Northern Provinces of China. New York: Garland. Reprint.

1987 [1852]. Journey to the Tea Countries of China. London: Mildmay Books Ltd. Reprint. 
Fu Nanqiao 符南樵. Xianfeng sannian bikou riji 咸豐三年避寇日記 [A Diary of Escaping the Rebels in 1853]. Unpaginated manuscript, Beihai Branch Library, Beijing.

Fusite 佛斯特 (E.M. Forster). Xiaoshuo mian mianguan: xiandai xiaoshuo xiezuo de zyishu 小說面面觀 : 現代小說寫作的藝術 [Aspects of the Novel]. Translated by Li Wenbin 李文 涁. Taibei: Zhiwen chubanshe, 1973.

GAO Lian 高濂. 1983 [1591]. Zunsheng bajian 遵生八箋 [Eight Discourses on the Art of Living]. In Yingyin Wenyuange sikuquanshu 影印文淵閣四庫全書. Taibei: Taiwan shangwu yingshuguan. Reprint.

Ge Liangyan. 2001. Out of the Margins. The Rise of Chinese Vernacular Fiction. Honolulu: University of Hawai'i Press.

Ge Zhaoguang 葛兆光. 2004. Shanhaijing, Zhigongtu he lüxing ji zhong de yiyu jiyi: Li Madou lai Hua qianhou Zhongguoren guanyu yiyu de zhishi ziyuan ji qi bianhua 山海經、職貢圖和旅行記中的異域記憶：利瑪竇來華前後中國人關於異域的知識資源及其變 化 [The Memory of Foreign Countries in Shanhaijing, Zhigongtu and Travelogues: Concerning the Sources and Transformations of Knowledge of Foreign Countries by the Chinese, Before and After Ricci's Arrival to China]. In Zhong Caijun 鍾彩 鈞 and Yang Jinlong 楊晉龍, eds. Ming Qing wenxue yu sixiang zhong zhi zhutiyishi yu shehui: xueshusixiang pian 明清文學與思想中之主體意識與社會：學術思想篇 [Principal Awareness and Society in Ming and Qing Literature and Thought: Works of Science and Thought]. Taibei: Zhongyang yanjiuyuan wenzhe yanjiusuo.

GENG Jianting 耿鑒庭. 2005. Yangzhou Kunqu congtan 揚州崑曲叢談 [Discourses on Yangzhou Kunqu]. Kunqu.net/article 20.htm

Giacalone, Vito. 1990. The Eccentric Painters of Yangzhou. New York: China House Gallery, China Institute of America.

Giddens, Anthony. 1990. The Consequences of Modernity. Stanford: Stanford University Press.

Gimpel, Denise. 2001. Lost Voices of Modernity: a Chinese Popular Fiction Magazine in Context. Honolulu: University of Hawai'i Press.

Goodrich, L. Carrington and FANG, Chaoying, eds. 1976. Dictionary of Ming Biography. 2 vols. New York - London: Columbia University Press.

Grant, Beata. 1994. Mount Lu Revisited: Buddhism in the Life and Writings of Su Shi. Honolulu: University of Hawai'i Press.

Great Britain. Parliament. China No. 2 (1869). 1869. London: Harrison and Sons.

Gu Linwen 顧麟文, ed. 1962. Yangzhou bajia shiliao 揚州八家史料 [Historical Materials on the Eight Masters of Yangzhou]. Shanghai: Shanghai renmin meishu chubanshe.

Gu Qiyuan 顧起元. 1983. Shuo lüe 說略 [Critical Points]. In Yingyin Wenyuange siku quanshu 影印文淵閣四庫全書, vol. 964. Taibei: Taiwan shangwu yingshuguan. Reprint. Gu Yiping 顧一平 and Z HU Zhu 祝竹, eds. 1989. Yangzhou youji sanwen xuan 揚州遊記散文 選 [A Collection of Yangzhou Travelogues]. Yangzhou: Hanjian yinshua.

Guangxu Huai'an fuzhi 光緒淮安府志 [Gazetteer of Huai' an Prefecture, Guangxu Edition]. 1991. Nanjing: Jiangsu guji chubanshe. 
Gur Bangjie 桂邦傑. 1937 [1925]. Xuxiu Jiangdu xian zhi 續修江都縣志 [Revised Gazetteer of Jiangdu County]. Yangzhou: Wenxuanlou.

Gui Chaowan 桂超萬. 1972. Huanyou jilüe 宦游紀略 [Record of Official Travels]. Taibei: Wenhai chubanshe.

Guo Qinghua. 2002. A Visual Dictionary of Chinese Architecture. Mulgrave, Victoria: Images Publishing.

Guo Ruoxu 郭若虛. 1983. Tuhua jianwen zhi 圖畫見聞誌 [An Account of My Experiences with Paintings]. In Yingyin Wenyuange siku quanshu 影印文淵閣四庫全書, vol. 812. Taibei: Taiwan shangwu yingshuguan. Reprint.

Guy, R. Kent. 1987. The Emperor's Four Treasuries. Cambridge, Massachusetts: Harvard University Council on East Asian Studies.

HaIl, William James. 1964 [1927]. Tseng Kuo-Fan and the Taiping Rebellion, With a Short Sketch of His Later Career. New York: Paragon Book Reprint Corporation.

HaN Bangqing 韓邦慶. 1998. Haishang hua liezhuan 海上華列傳 [Biographies of Shanghai Flowers]. Taibei: Sanmin shuju.

- 2005. Flowers of Shanghai. Translated by Eileen Chang, revised and edited by Eva Hung. New York: Columbia University Press.

Han Zhuo 韓拙. 1983. Shanshui chun quanji 山水純全集 [Harmonious and Complete Compilation on Landscape]. In Yingyin Wenyuange siku quanshu 影印文淵閣四庫全書. Taibei: Shangwu.

Hanan, Patrick. 1967. The Early Chinese Short Story: A Critical Theory in Outline. Harvard Journal of Asiatic Studies 27: 168-207.

- 1973. The Chinese Short Story. Studies in Dating, Authorship, and Composition. Cambridge, Massachusetts: Harvard University Press.

1981. The Chinese Vernacular Story. Cambridge, Massachusetts - London: Harvard University Press.

1998. Fengyue Meng and the Courtesan Novel. Harvard Journal of Asiatic Studies 58.2: 345-372.

- 2004. Illusion of Romance and the Courtesan Novel. In Patrick Hanan. Chinese Fiction of the Nineteenth and Early Twentieth Centuries: Essays. New York: Columbia University Press, 33-57.

Handlin Smith, Joanna F. 1998. Social Hierarchy and Merchant Philanthropy As Perceived in Several Late-Ming and Early-Qing Texts. Journal of the Economic and Social History of the Orient 41.3: 417-51.

Hanshang Mengren 邗上蒙人. 1988 [1848]. Fengyue meng 風月夢 [Illusion of Romance].

Beijing: Beijing daxue chubanshe.

1990 [1848]. Fengyue meng 風月夢 [Illusion of Romance]. In Guben xiaoshuo jicheng 古本小説集成. Shanghai: Shanghai guji chubanshe. Reprint.

Hao Yen-p'ing. 1986. The Commercial Revolution in Nineteenth-Century China: The Rise of Sino-Western Mercantile Capitalism. Berkeley: University of California Press.

Harrist, Robert E., Jr. 1998. Painting and Private Life in Eleventh-Century China: Mountain Villa by Li Gonglin. Princeton: Princeton University Press. 
2005. Clothes Make the Man: Dress, Modernity, and Masculinity in China, ca. 1912-1937. In Wu Hung and Katherine R. Tsiang, eds. Body and Face in Chinese Visual Culture. Cambridge, Massachusetts: Harvard University Asia Center, 171-196.

HaY, Jonathan. 1999. Culture, Ethnicity, and Empire in the Work of Two EighteenthCentury 'Eccentric' Artists. Res Monographs in Anthropology and Aesthetics 35: 20123.

2001. Shitao: Painting and Modernity in Early Qing China. Cambridge - New York: Cambridge University Press.

— 2005. The Kangxi Emperor's Brush-Traces: Calligraphy, Writing, and the Art of Imperial Authority. In Wu Hung and Katherine R. Tsiang, eds. Body and Face in Chinese Visual Culture. Cambridge, Massachusetts - London: Harvard University Asia Center, 311-334.

Henriot, Christian. 1996. From a Throne of Glory to a Seat of Ignominy. Shanghai Prostitution Revisited (1849-1949). Modern China 22.2: 132-163.

Hershatter, Gail. 1999. Dangerous Pleasures. Prostitution and Modernity in Twentieth Century Shanghai. Berkeley: University of California Press.

2007. Women in China's Long Twentieth Century. Berkeley - Los Angeles - London: University of California Press.

Hibbert, Christopher. 1970. The Dragon Wakes: China and the West, 1793-1911. Harlow - London: Longman.

Ho Ping-ti. 1954. The Salt Merchants of Yang-chou: A Study of Commercial Capital in Eighteenth-Century China. Harvard Journal of Asiatic Studies 17: 130-168.

Ho, Wai-kam. 1987. Late Ming Literati: Their Social and Cultural Ambience. In Chutsing Li and James C.Y. Watt, eds. The Chinese Scholar's Studio: Artistic Life in the Late Ming Period. London: Thames and Hudson, 23-36.

Hong Weizhu 洪惟助, ed. 2002. Kunqu cidian 崑曲詞典 [Encyclopaedia of Kunqu]. 2 vols. Taibei: Guoli chuantong yishu zhongxin.

Honig, Emily. 1992a. Creating Chinese Ethnicity: Subei People in Shanghai, 1859-1930. New Haven: Yale University Press.

_ 1992b. Native-Place Hierarchy and Labor Market Segmentation: the Case of Subei People in Shanghai. In Rawski, Thomas G. and Lillian M. Li, eds. Chinese History in Economic Perspective. Berkeley: University of California Press, 271-295.

HrduičKová, Věna. 1965. The Professional Training of Chinese Storytellers and the Storytellers' Guilds. Archiv Orientálni 33: 225-248.

Hsiung Ping-chen. 1999. Treading the Weedy Path: T'ang Chen (1630-1704) and the World of the Confucian Middlebrow. In Kai-wing Chow, On-cho $\mathrm{Ng}$ and John B. Henderson, eds. Imagining Boundaries: Changing Confucian Doctrines, Texts, and Hermeneutics. Albany: State University of New York Press, 195-212.

Hsü, Ginger Cheng-chi. 1989. Merchant Patronage of Eighteenth Century Yangchou Painting. In Chu-tsing Li, ed. Artists and Patrons: Some Social and Economic Aspects of Chinese Painting. Lawrence: University of Kansas Press, 215-221. 1996a. Incarnations of the Blossoming Plum. In Ars Orientalis XXVI: 23-45. 
1996b. The Drunken Demon Queller: Chung K'uei in Eighteenth-Century Chinese Painting. Guoli Taiwan daxue Meishushi yanjiu jikan 國立臺灣大學美術史研究 集刊 / Taida Journal of Art History 3 (1996): 141-115.

2001. A Bushel of Pearls: Painting for Sale in Eighteenth-Century Yangchow. Stanford: Stanford University Press.

(forthcoming). Painting, Enlightenment, and Economics: Chin Nung and his Buddhist Paintings. In Richard Vinograd, ed. Images in Exchange: Cultural Transactions in Chinese Pictorial Arts. Berkeley: University of California Press.

Hu Dongchu. 1991. The Way of the Virtuous. Beijing: New World Press.

Hu Ji 胡忌 and Liu Zhizhong 劉致中. 1989. Kunju fazhan shi 昆劇發展史 [History of the Development of Kun Drama]. Beijing: Zhongguo xiju chubanshe.

Hu Shi 胡適. 1967 [1937]. Introduction to Zhui baiqiu 経白震 [The Patched White Fur Cloak]. Annotated by Wang Xieru 汪 協如. Taibei: Zhonghua shuju, vol. 1: 3-12.

Hu Shiying 胡士營. 1980. Huaben xiaoshuo gailun 話本小說概論 [A General Survey of the Vernacular Story]. 2 vols. Beijing: Zhonghua shuju.

Hua Yan 華品. 1900 [1835]. Xinluo shanren tihua shiji 新羅山人題畫詩集 [Collection of Poems on Paintings by the Hermit from Xinluo]. Hangzhou: Deji.

__ 1917. Ligou ji buchao 離垢集補鈔 [Supplement to Ligou ji]. Shanghai: Shanghai juzhen fangsongyin shuju.

1997. Ligou ji 離垢記 [Leaving the Filth of the World]. Xu Fengji 徐逢吉, ed. In Siku weishou shu jikan 四庫未收書輯刊, vol. 8, No. 29. Beijing: Beijing chubanshe.

Huai'an fuzhi, see Guangxu Huai'an fuzhi

Huang Binhong 黃賓虹 and Deng Shi 鄧實, eds. 1963. Meishu Congshu 美術叢書 [Fine Arts Collectanea]. Taibei: Guangwen shuju.

HuANG Jianhui 黃監睴. 2002. Ming Qing Shanxi shangren yanjiu 明清山西商人研究 [Research on the Shanxi Merchants of the Ming-Qing period]. Taiyuan: Shanxi jingji chubanshe.

HUANG Jilin 黄繼林. 2005. Yangzhou ming xiang 揚州名巷 [Famous Lanes of Yangzhou]. Yangzhou: Guangling shushe.

Huang, Martin W. 1995. Literati and Self-Re/Presentation: Autobiographical Sensibility in the Eighteenth-Century Chinese Novel. Stanford: Stanford University Press.

Huang Shen 黄慎. 1989. Jiaohu shichao jiazhu 蛟湖詩抄校註 [Poems from the Dragon Lake, Annotated Edition]. Qiu Youxuan 丘幼宣, ed. Fuzhou: Haixia wenyi chuban.

Huang Xiufu 黄休復. 1983. Yizhou minghua lu 益州名畫錄 [A Record of the Famous Painters of Yizhou]. In Yingyin Wenyuange siku quanshu, vol. 812. Taibei: Taiwan shangwu yinshuguan. Reprint.

HuANG Yinong 黄一農. 2002. Views Exchange between the Dragon and the Lion: A Case Study on the Publications in the Aftermath of the Macartney Envoy to China. Paper presented at the Symposium on China and the World in the Eighteenth Century 'Shiba shiji de Zhongguo yu shijie' xueshu yantaohui «十八世紀的中國與世界》 學術研討會, December 13-14. Taibei: National Palace Museum.

HuANG Yongnian 黃永年 and JiA Erqiang 賈二強. 1997. Qingdai banben tulu 清代版本圖錄 [Illustrated Catalogue of Qing Editions]. 5 vols. Hangzhou: Zhejiang renmin chubanshe. 
Hummel, Arthur W., ed. 1943. Eminent Chinese of the Ching Period. 2 vols. Washington: United States Government Printing Office.

__ ed. 1967 [1943]. Eminent Chinese of the Ch'ing Period. Taibei: Ch'eng Wen Publishing Company. 2nd printing 1970.

Huters, Theodore, R. Bin Wong and Pauline Yu, eds. 1997. Culture and State in Chinese History. Stanford: Stanford University Press.

Idema, Wilt L. 1974. Chinese Vernacular Fiction: The Formative Period. Leiden: Brill.

IGUCHI, Junko 井口淳子. 2003. Zhongguo beifang nongcun de kouchuan wenhua 中國北方 農村的口傳文化 [Oral Literature from Villages in Northern China]. Sanming: Xiamen daxue chubanshe.

Ji Cheng. 1988. The Craft of Gardens. Translated by Alison Hardie. New Haven - London: Yale University Press.

Ji Xiaofeng 季唖風, ed. 1996. Zhongguo shuyuan cidian 中國書院辭典 [Dictionary of Chinese Academies]. Hangzhou: Zhejiang jiaoyu chubanshe.

Ji Yun 紀昀 et al., eds. 1997. Qinding Siku quanshu zongmu 欽定四庫全書總目 [Annotated Catalogue of the Complete Library of the Four Treasuries]. 2 vols. Beijing: Zhonghua shuju.

JIA Jia 賈佳. 2003. 'Yuhua xiang' 'Tongtian le’ yu Qing chu zhishi jieceng zhi yasu wenhua xuanze 《雨花香》 《通天樂》與清初知識階層之雅俗文花選擇 [Yuhua xiang, Tongtian le and the Choices Between High and Low Culture for the Educated Class in the Early Qing]. In Chuanshan xuekan 船山學刊 1(2003): 87-91.

JIAN Youwen 簡又文. 1964. Wushi nian lai Taiping Tianguo shi yanjiu 五十年來太平天 國史研究 [Research on the Taiping Heavenly Kingdom from the Past Fifty Years]. In Hong Kong University History Department, ed. Xianggang daxue wushizhounian jinian lunwen ji 香港大學五十周年紀念論文集. Hong Kong: Hong Kong University Press, 237-314.

JIANG Bingzheng 姜秉正. 1984. Yanjiu Taiping Tianguo shi zhushu zongmu 研究太平天国史 著述综目 [Catalogue of Research Works on the Taiping Heavenly Kingdom]. Beijing: Shumu wenxian chubanshe.

JIANG Yin 蔣寅. 2001. Wang Yuyang shiji zheng lüe 王漁洋事跡征略 [An Annotated Biography of Wang Yuyang]. Beijing: Renmin wenxue chubanshe.

Jiangdu xianzhi 江都縣志 [Gazetteer of Jiangdu County]. 1997 [1597]. Ji'nan: Qi Lu shushe. Jiangdu xianzhi, see Gui Bangjie

Jiangsu sheng wenwu baohu danwei mingdan 江蘇省文物保護單位名單 [List of Protected Monuments in Jiangsu]. 1982. Jiangsu sheng renmin zhengfu wenjian 江蘇省政府文件 51. Compiled by Jiangsu sheng wenwu guanli weiyuanhui 江蘇省文物管理委員會.

Jiangsu sheng Yangzhou fuzhi 江蘇省揚州府志 [Gazetteer of Yangzhou Prefecture in Jiangsu Province]. 1963 [1810]. Akedang'a 阿克當阿, Yao Wentian 姚文田, eds. In Zhongguo fangzhi congshu 中國方志叢書. Taibei: Chengwen chubanshe youxian gongsi. Reprint. Jiangsu yiwenzhi: Yangzhou juan 江蘇藝文志：揚州卷 [Bibliography of Jiangsu Province: Yangzhou]. 1995. Nanjing shifan daxue guwenxian zhengli yanjiusuo 南京師範大學古 文獻整理研究所, ed. 2 vols. Nanjing: Jiangsu renmin chubanshe. 
JiAo Xun 焦循. 1960 [1805]. Ju shuo 劇説 [On Theatre]. In Zhongguo xiqu yanjiu yuan 中國戲曲 研究院, ed. Zhongguo gudian xiqu lunzhu jicheng 中國古典戲曲論著集成 [Collected Works on Chinese Classical Theatre]. 10 vols. Beijing: Zhongguo xiju chubanshe, vol. 8: 73-220.

1960 [1819]. Huabu nongtan 花部農譚 [Peasant Chats on Popular Theatre]. In Zhongguo xiqu yanjiu yuan 中國戲曲研究院, ed. Zhongguo gudian xiqu lunzhu jicheng 中國古典戲曲論著集成 [Collected Works on Chinese Classical Theatre]. 10 vols. Beijing: Zhongguo xiju chubanshe, vol. 8: 221-31.

JiAODONG Zhou Sheng 焦東周生. 1978. Yangzhou meng 揚州夢 [Dream of Yangzhou]. Taibei: Shijie shuju.

Jin Changfu 金長福. Guangling jinshi, Guangling jiushi 廣陵近事廣陵舊事 [Old Events in Yangzhou and Recent Events in Yangzhou]. Unpaginated manuscripts, Chinese Academy of Sciences Library, Beijing.

—. Guihai riji 癸亥日記 [1863: A Diary]. Unpaginated manuscript, Chinese Academy of Sciences Library, Beijing.

—, et al. Hailing zhuzhici liujuan xu erjuan 海陵竹枝詞六卷續二卷 [Hailing Bamboobranch Songs, Six Chapters and Two More]. Unpaginated manuscript, Nanjing Library.

- Hongxue yinguan shiji 紅雪吟館詩集 [Poems from the Red Snow Poetry Studio]. Unpaginated manuscript, Nanjing Library.

Jin Liang 金梁, ed. 1985. Jinshi renwu zhi 今世人物志 [Biographies of Our Contemporaries]. In Zhou Junfu 周駿富, ed. Qingdai zhuanji congkan 清代傳記叢刊, vol. 062. Taibei: Mingwen shuju. Reprint.

JiN Nong 金農. 1963. Dongxin zixiezhen tiji 冬心自寫真題記 [Recorded Inscriptions on (Jin) Dongxin’s Self-portraits]. In Huang Binhong 黃賓虹, Deng Shi 鄧實, eds. Meishu congshu 美術叢書 [Fine arts collectanea]. Taibei: Guangwen shuju, vol. 2.

JiN Zhizhang 金志章. 1997 [1754]. Jiangsheng caotang shiji 江聲草堂詩集 [Collection of Poems from the Thatched Hall Within the Sound of the River]. In Siku quanshu chunmu congshu, ji bu 四庫全書存目叢書, 集部, vol. 274. Ji'nan: Qi Lu shushe. Reprint.

Johnson, Linda Cooke. 1994. Shanghai, from Market Town to Treaty Port, 1074-1858. Stanford: Stanford University Press.

Jones, Andrew F. 2001. Yellow Music: Media Culture and Colonial Modernity in the Chinese Jazz Age. Durham, NC: Duke University Press.

Kahn, Harold. 1985. A Matter of Taste: The Monumental and Exotic in the Qianlong Reign. In Ju-hsi Chou and Claudia Brown, eds. The Elegant Brush: Chinese Painting under the Qianlong Emperor, 1735-1795. Phoenix: Phoenix Art Museum, 288-302.

Karlsson, Kim. 2004. Luo Ping: The Life, Career, and Art of an Eighteenth-Century Chinese Painter. Bern: European Academic Publishers.

Keulemans, Pieter. 2004. Sounds of the Novel: Storytelling, Print-culture, and Martial-arts Fiction in Nineteenth-century Beijing. Ph.D. dissertation, University of Chicago.

Ko, Dorothy. 2005. Cinderella's Sisters: A Revisionist History of Footbinding. Berkeley: University of California Press. 
KoвAYASHi Toan 小林斗盒, ed. 1982. Chügoku tenkoku sōkan 中國管刻叢刊 [A Catalogue of Collected Chinese Seals]. Tokyo: Nigensha.

Kung Tzu-chen. 1994. Passing through Yang-chou again. In Strassberg, Richard, ed. Inscribed Landscapes. Travel Writings from Imperial China. Berkeley - Oxford: University of California Press, 418-422.

Kuzay, Stefan. 2003. The Colloquial Text Collection of the Finnish Sinologist Hugo Lund. In Remota Relata. Essays on the History of Oriental Studies in Honour of Harry Halén. Studia Orientalia 97: 127-140.

2007. The Wopao zhuan and Other Dramas in Shan'ge and Shidiao Songs from Late Qing China. In CHINOPERL Papers 27: 139-172.

Kwok, D.W.Y. 1997. The Urban Imagination. Dubuque, Iowa: Kendall/Hunt Publishing Company.

LAI Fushun 賴福順. 1984. Qianlong zhongyao zhanzheng zhi junxu yanjiu 乾隆重要戰爭 之軍需研究 [Research on the Military Supplies of the Important Battles during the Qianlong Period]. Taibei: Palace Museum.

LaI Yu-chih. 2004. Remapping Borders: Ren Bonian's Frontier Paintings and Urban Life in 1880 Shanghai. Art Bulletin 83.3: 550-571.

LANG Shaojun 郎紹君. 1999. Huang Shen he ta de yishu 黃慎和他的藝術 [Huang Shen and His Art]. In Shan Guolin 單國霖, ed. Yangzhou huapai yanjiu wenji 揚州畫派研究文集 [Collected Studies on the Yangzhou School of Painting]. Tianjin: Tianjin renmin meishu.

Lauwaert, Françoise. 1990. Comptes des dieux, calculs des hommes: essai sur la notion de retribution dans les contes en langue vulgaire du 17e siècle. T'oung Pao 76: 62-94.

Lee, Leo Ou-fan. 1999. Shanghai Modern. The Flowering of a New Urban Culture in China, 1930-1945. Cambridge, Massachusetts: Harvard Unversity Press.

LÉvy, André. 1965. Etudes sur trois recueils anciens de contes chinois. T'oung Pao LII, 1-3: 97-148.

— 1971. Etudes sur le conte et le roman chinois. Paris: Ecole Française d'ExtrêmeOrient.

- 1981. Le conte en langue vulgaire du XVIIe siècle. Paris: Bibliothèque de l'Institut des hautes études chinoises.

- 1999. About the Chinese Storyteller's Change of Name. In Vibeke Børdahl, ed. The Eternal Storyteller. Richmond: Curzon Press, 33-39.

Li Baohua 李保華, ed. 2001. Yangzhou shiyong 揚州詩詠 [Poems about Yangzhou]. Suzhou: Suzhou daxue chubanshe.

LI Chu-Tsing. 1979. Trends in Modern Chinese Painting (The C.A. Drenowatz Collection). Ascona: Artibus Asiae Publishers.

—, ed. 1989. Artists and Patrons: Some Social and Economic Aspects of Chinese Painting. Lawrence: University of Kansas Press.

Li Dou 李斗. 1960, 1997, 2004 [1795]. Yangzhou huafang lu 揚州畫舫錄 [Pleasure Boats of Yangzhou]. Wang Beiping 汪北平, ed. Beijing: Zhonghua shuju.

— 1963, 1977 [1795]. Yangzhou huafang lu 揚州畫舫錄 [Pleasure Boats of Yangzhou]. Taibei: Shijie shuju. 
1984 [1795]. Yangzhou huafang lu 揚州畫舫錄 [Pleasure Boats of Yangzhou]. Zhou Guangpei 周光培, ed. Yangzhou: Guangling guji keyinshe.

2001 [1795]. Yangzhou huafang lu 揚州畫舫錄 [Pleasure Boats of Yangzhou]. In Lidai biji xiaoshuo xiao pin xuankan 歷代筆記小説小品選刊 [Excerpts from Historical Jottings, Stories and Sketches]. Wang Jun 王軍, ed. Beijing: Xueyuan chubanshe.

Li E 厲鶚. 1983. Nan Song yuan hualu 南宋院畫錄 [Catalogue of the Southern Song Academy]. In Yingyin Wenyuange siku quanshu, vol. 829. Taibei: Taiwan shangwu yingshuguan. Reprint.

Li Fang 李昉. 1983. Taiping guangii 太平廣記 [Extensive Gleanings of the Taiping Reign, 976-983]. In Yingyin Wenyuange siku quanshu 影印文淵閣四庫全書, vol. 1043-1046. Taibei: Taiwan shangwu yingshuguan. Reprint.

Li Fuqing 李福清 (Boris Riftin). 1997 [1970]. Sanguo yanyi yu minjian wenxue chuantong 三國演義與民間文學傳統 [The Romance of Three Kingdoms and the Traditions of Folk Literature]. Shanghai: Shanghai guji chubanshe.

Li Hsiao-t'i, see Li Xiaoti

Li Huimin 李慧敏. 2004. Jianghuai guanhua de guishu yu tezheng yanjiu gaishu 江淮 官話 的歸屬與特徵研究概述 [A General Overview of Research on the Categorization and Characteristics of Jianghuai Mandarin]. Anhui shifan daxue xuebao. Renwen shehui kexue ban 安徽師範大學學報。人文社會科學版 32.5: 602.

Li Kanghua 李康化. 2001. Ming Qing zhi ji Jiangnan cixue sixiang yanjiu 明清之際江南詞 學思想研究 [Reflections on Ci Poetics in Jiangnan during the Ming-Qing Transition]. Chengdu: Ba Shu shushe.

Li Siu Leung. 2003. Cross-Dressing in Chinese Opera. Hong Kong: Hong Kong University Press.

Li Wancai 李萬才. 1999. Huang Shen shuhua ji 黄慎書畫集 [Paintings and Calligraphy by Huang Shen]. Beijing: Renmin meishu chubanshe.

Li Xiaoti 李孝悌. 2001. Qingmo de xiaceng shehui qimeng yundong, 1901-1911 清末的下層 社會啟蒙運動, 1901-1911 [Lower Class Enlightenment in the Late Qing Period, 19011911]. Taiwan xueshu congshu 台灣學術叢書. Shijiazhuang: Hebei jiaoyu chubanshe.

2002. Lianlian hongchen: Zhongguo de chengshi, yuwang yu shenghuo 戀戀紅塵：中 國的城市、欲望與生活 [Love of This World: City, Desire and Life in China]. Taibei: Yifang chuban.

— 2005a. Shidafu de yile - Wang Shizhen zai Yangzhou 士大夫的逸樂一王士禛在揚 州 (1660-1665) / Pleasures of a Gentry-Literatus: Wang Shizhen in Yangzhou, 16601665. Zhongguo yanjiuyuan lishi yuyan yanjiusuojikan 中央研究院歷史語言研究所集刊 76.1: 81-116.

—, ed. 2005b. Zhongguo de chengshi shenghuo 中國的城市生活 [City Life in China]. Taibei: Lianjing chuban gongsi.

Li Xiufang 庽秀芳. 1897. Zhenzhou fengtu ji 真州風土紀 [Zhenzhou's Natural Conditions and Social Customs]. In Wang Xiqi 王錫祺, ed. Xiaofanghu zhai yudi congchao 小方壳齋 興地叢鈔 [Writings on Geography from the Xiaofanghu Studio]. Shanghai: Zhuyitang Nanqinghe Wangshi zhubanyin 著易堂南清河王氏鑄版印, vol. 6. 
1985 [1897]. Zhenzhou fengtu ji 真州風土紀 [Zhenzhou’s Natural Conditions and Social Customs]. In Wang Xiqi 王錫祺, ed. Xiaofanghu zhai yudi congchao 小方輕齊舆 地叢鈔 [Writings on Geography from the Xiaofanghu Studio]. Hangzhou: Hangzhou guji shudian. Reprint.

Li Yande. 1994. Jiangnan Gardens are Poetic and Picturesque. In The Universal Garden. Proceedings, 1st Session, International Conference East and West - The Universal Garden - From Idea to Realization. Shanghai - Suzhou, 338-341.

Li Yu 李漁. 1986. Shier lou 十二樓 [Twelve Towers]. Xiao Rongbiao 蕭容標, ed. Shanghai: Shanghai guji chubanshe.

Li Ziran 李自然. 1994. Mengguzu shangbai yuanyin ji qi biaoxian fangshi 蒙古族尚白原 因及其表現方式 [The Representation and Origin of the Mongolian Custom of 'White Esteem']. Heilongjiang minzu congkan 黑龍江民族叢刊 3 (1994): 115-117.

Liangjiang zhongyi lu 兩江忠義錄 [The Record of the Loyal and Righteous in Liangjiang]. 1887. Compiled and published by Liangjiang caifang zhongyi ju 兩江採訪忠義局.

Lin Liyue 林麗月. 1999. Yishang yu fengiiao: wan Ming de fushi fengshang yu 'fuyao' yilun 衣 裳與風教：晚明的服飾風尚與「服妖」議論 [Costumes and Customs: Late Ming Clothing Trends and the Discourse of 'Outrageousness']. Xinshixue 新史學 10.3: 111-157.

Lin Li-yueh, see Lis Liyue

Lin Sumen 林蘇門. 1808. Hanjiang sanbai yin 干阝江三百吟 [Three Hundred Tunes from the Han River]. Yangzhou.

LiN Xin 林金金. 2000. Yang kun jianlun 揚崑簡論 [A Short Discussion on Yangzhou Kunqu]. Yangzhou daxue xuebao. Renwen shehui kexue ban 揚州大學學報。人文社會科學版 4.4 .

Ling Mengchu 凌濛初. 1960 [1632]. Erke paian jingqi二刻拍案驚奇 [Striking the Table in Amazement: the Second Collection]. Li Tianyi 李田意, ed. Taibei: Zhengzhong shuju.

Liu Baonan 劉寶楠. 1871. Shengchao xunyang lu 勝朝殉揚錄 [Record of Yangzhou Martyrs of the Conquered Dynasty]. Yangzhou: Huainan shuju.

Liv Cunren 柳存仁. 1982. Lundun suojian Zhongguo xiaoshuo shumu tiyao 倫敦所見中國 小説書目提要 [Catalogue and Abstracts of Chinese Fiction Seen in London]. Beijing: Shumu wenxian chubanshe.

Liu Daochun 劉道醇. 1983. Songchao minghua ping 宋朝名畫評 [Critique of Famous Painters of the Song Dynasty]. In Yingyin Wenyuange siku quanshu 影印文淵閣四庫全書, vol. 812. Taibei: Taiwan shangwu yingshuguan. Reprint.

Liu Lu 柳陸 and Ao Jianhua 敖建華. 1993. Mengguzu de baise xinyang 蒙古族的白色信 仰 [Mongolian’s Cult of White Color]. Minjian wenxue luntan 民間文學論壇 3: 53-54.

Liu Shide 劉世德, ed. 1998. Zhongguo gudai xiaoshuo baike quanshu 中國古代小說百科 全書 [Encyclopedia of Old Chinese Fiction]. Beijing: Zhongguo da baike quanshu chubanshe. Revised edition.

Liu Yanjun 劉彦君. 2001. Tushuo Zhongguo xiqu shi 圖説中國戲曲史 [Illustrated History of Chinese Traditional Drama]. Hangzhou: Zhejiang jiaoyu chubanshe.

Liu Yongqiang 劉勇強. 2001. Xihu xiaoshuo: chengshi gexing he xiaoshuo changjing 西湖 小說: 城市個性和小說場境 [West Lake Fiction: the Individual Character of the City and the Scene of Fiction]. Wenxue yichan 文學遺產 5: 60-72. 
2002. Wan Ming Xihu xiaoshuo zhi yuanliu yu beijing 晚明西湖小說之源流與背 景 [The Origin, Development and Background of Late Ming West Lake Fiction]. In Chen Pingyuan 陳平原 et al., eds. Wan Ming yu wan Qing: lishi chuancheng yu wenhua chuangxin 晚明與晚清: 歷史傳承與文化創新 [Late Ming and Late Qing: Historical Continuities and Cultural Innovations]. Wuhan: Hubei jiaoyu chubanshe, 377-391.

Liu Zhengyun 劉鋝雲. 1993. Heng, fan, pi, nan: Qingdai dao, fu, ting, zhou, xian deng jichu tan 衝、繁、疲、難: 清代道、府、廳、州、縣等級初探 [A Preliminary Enquiry into the Four Kinds of Taxation in Different Administrative Levels under the Qing Dynasty]. Zhongyang yanjiuyuan lishi yuyan yanjiusuo jikan 中央研究院歷史語言研究所 集刊 64.1: 175-240.

Lowry, Kathryn A. 2005. The Tapestry of Popular Songs in Sixteenth-and SeventeenthCentury China: Reading, Imitation, and Desire. Sinica Leidensia. Leiden: Brill.

Lu Hanchao. 1999. Beyond the Neon Lights: Everyday Life in Shanghai in the Early Twentieth Century. Berkeley - Los Angeles - London: University of California Press.

Lu Hsun. 1964 [1923, 1959]. A Brief History of Chinese Fiction. Beijing: Foreign Languages Press.

Lu Fusheng 盧輔聖, ed. 1990. Duoyun xuan canghua xuan 朵雲軒藏畫選 [Selected Paintings from Duoyun Xuan Collection]. Shanghai: Shanghai shuhua.

— , ed. 2000. Zhongguo shuhua quanji - di qi ce 中國書畫全集, 第七冊 [The Complete Collection of Chinese Painting and Calligraphy, Volume 7]. Shanghai: Shanghai shuhua.

, ed. 2003. Hua Yan yanjiu 華品研究 [A Study of Hua Yan]. Duoyun 杂雲 57. Shanghai: Shanghai shuhua chubanshe.

Lu Jianzeng 盧見曾. 1746. Yayu shanren chusai ji 雅雨山人出塞記 [Record of Yayu Shanren's Traveling to the Frontier]. In Shen Qiyuan 沈起元, ed. Yayu tang ji 雅雨堂集 [Anthology of the Yayu Studio].

Lu Minghui 盧明輝. 1994. Qingdai beibu bianjiang minzu jingji fazhanshi 清代北部邊疆民 族經濟發展史 [History of the Economic Development of the Northern Border during the Qing Dynasty]. Harbin: Heilongjiang jiaoyu chubanshe.

Lu Xun 魯迅. 1973. Lu Xun quanji 魯迅全集 [Collected Works by Lu Xun]. Beijing: Renmin wenxue chubanshe.

Lu Xun, see also Lu Hsun

Lu Yingkun 路應昆. 1999. Yangju 揚劇 [Yangzhou Drama]. In Meshuyi, Angwangyongkuan 么書儀, 昂王永寬 et al., eds. Xiju tongdian 戲劇通典 [Comprehensive Encyclopedia of Theatre]. Beijing: Jiefang jun wenyi chubanshe, p. 694.

LuAN Guijuan 欒桂娟. 1998. Zhongguo quyi yu quyi yinyue 中國曲藝與曲藝音樂 [Quyi in China and the Music of Quyi]. Beijing: Renmin yinyue chubanshe.

Lufrano, Richard John. 1997. Honorable Merchants: Commerce and Self-Cultivation in Late Imperial China. Honolulu: University of Hawai'i Press.

Luo Ergang 羅爾綱. 1978 [1958]. Yangzhou soufang ji 揚州艘舫記 [Record of Yangzhou Warjunks]. In Luo Ergang: Taiping tianguo shiji diaocha ji 太平天國事跡調查記 [Investigation 
of the Events of the Taiping Heavenly Kingdom]. Beijing: Shenghuo - dushu - xinzhi, Sanlian shudian, 272-290.

— - ed. 2004. Xian Tong Guangling shigao 咸同廣陵史稿 [History of Guangling during the Xianfeng and Tongzhi Reigns]. Yangzhou: Guangling shushe.

MA, Y.W. 1979. Kung-an Fiction: A Historical and Critical Introduction. T'oung Pao 65: 200-259.

Mackerras, Colin. 1971. The Growth of the Chinese Regional Drama in the Ming and Ch'ing. Journal of Oriental Studies 9.1: 58-91.

1972. The Rise of the Peking Opera, 1770-1870: Social Aspects of the Theatre in Manchu China. Oxford: Clarendon Press.

1976. Theatre and the Taipings. Modern China, An International Quarterly II.4: 473-501.

MaIr, Victor. 1997. The Prosimetric Form in the Chinese Literary Tradition. In Joseph Harris and Karl Reichl, eds. Prosimetrum: Cross-cultural Perspectives on Narrative in Prose and Verse. Woodbridge: D.S. Brewer, 365-85.

—_, ed. 2001. The Columbia History of Chinese Literature. New York: Columbia University Press.

Mao Dun. 1979. Ziye: a Romance of China in the 1930s. Translated by Sidney Shapiro. Beijing: Foreign Language Press. 2nd edition.

MaO Pijiang 冒辟疆, see MaO Xiang

MaO Xiang 冒襄. 1997 [1673]. Tongren ji 同人集 [My Friends' Letters and Writings]. In Siku quanshu cunmu congshu 四庫全書存目叢書, jibu 集部 vol. 385. Tainan: Zhuangyan wenhua shiye. Reprint.

Mark, Lindy Li. 1990. The Role of Avocational Performers in the Preservation of Kunqu. CHINOPERL Papers 15: 95-114.

Marmé, Michael. 2005. Suzhou: Where the Goods of All the Provinces Converge. Stanford: Stanford University Press.

McKenna, Richard. 1962. The Sand Pebbles. New York: Harper \& Row.

McLaren, Anne E. 1998. Chinese Popular Culture and Ming Chantefables. Leiden: Brill.

McMahon, Keith. 2000. Opium and Sexuality in late Qing Fiction. Nan Nü, Men, Women and Gender in China 2.1: 129-79.

2002. Fleecing the Male Customer in Shanghai Brothels of the 1890s. Late Imperial China 23.2: 1-32.

Melvin, Sheila and CaI Jindong. 2005. Rhapsody in Red: How Western Music Became Chinese. New York: Algora.

Meng Xianjun 孟憲鈞. 2006, 2007. Jin Dongxin zhuzuo banben zhijianlu 金冬心著作 版本知見錄 [Bibliographical Descriptions of Jin Nong's Works]. Cangshujia 藏書家 11 (2006): 65-78; 12 (2007): 73-86.

Meng Yue. 2002. Re-envisioning the Great Interior: Gardens and the Upper Class Between the Imperial and the 'Modern'. Modern Chinese Literature and Culture 14.1: 1-49.

_ 2006. Shanghai and the Edges of Empires. Minneapolis: University of Minnesota Press. 
Meng Zhaolian 孟昭連. 1998. Zuozhe, xushuzhe, shuoshuren. Zhongguo gudai xiaoshuo xushi zhuti zhi yanjin 作者, 敘述者, 說書人。中國古代小說敘事主體之演進 [Author, Narrator, Storyteller. The Development of the Narrative Form of Chinese Fiction in the Early Period]. Ming Qing xiaoshuo yanjiu, 明清小說研究 4 (1998): 137-152.

Meyer-Fong, Tobie. 1999. Making a Place for Meaning in Early Qing Yangzhou. Late Imperial China 20.1: 49-84.

— 2003. Building Culture in Early Qing Yangzhou. Stanford: Stanford University Press.

2004a. Civil War and Urban Form: The Taiping Rebellion in Yangzhou. In Senda Minoru, ed. Urban Morphology and the History of Civilization in East Asia. Kyoto: International Center for Japanese Studies, 213-235.

— 2004b. Packaging the Men of Our Times: Literary Anthologies, Friendship Networks, and Political Accommodation in the Early Qing. Harvard Journal of Asiatic Studies 64:1: 5-56.

2004c. Seeing the Sights in Yangzhou from 1600 to the Present. In Huang Ko-wu, ed. When Images Speak. Visual Representation and Cultural Mapping in Modern China. Taibei: Academia Sinica, Institute of Modern History, 213-251.

Mi Fu 米蒂. 1983. Hua shi 畫史 [The History of Painting]. In Yingyin Wenyuange siku quanshu 影印文淵閣四庫全書, vol. 813. Taibei: Taiwan shangwu yingshuguan. Reprint. Millward, James. 2001. Not just China: Qing Dynasty Expansion and Eclecticism. Journal of the International Chinese Snuff Bottle Society, Spring 2001: 4-17.

— et al., eds. 2004a. New Qing Imperial History: The Making of Inner Asian Empire at Qing Chengde. London - New York: RoutledgeCurzon.

_ 2004b. Qing Inner Asian Empire and the Return of the Torghuts. In James Millward et al., eds. New Qing Imperial History: The Making of Inner Asian Empire at Qing Chengde. London - New York: RoutledgeCurzon, 91-106.

Mori, Yuria. 2002. Identity and Lineage: The Taiyi jinhua zhongzhi and the Spirit-Writing Cult to Patriarch Lü in Qing China. In Livia Kohn and Harold D. Roth, eds. Daoist Identity: History, Lineage, and Ritual. Honolulu: Hawai'i University Press, 165-184.

Morse, Hosea Ballou. 1926. The Chronicles of the East India Company, Trading to China, 1635-1834. 3 vols. Oxford: Clarendon Press.

Naikaku Bunko sōhon shoei 内閣文庫宋本書影 [Illustrations of Song Editions in the Naikaku Bunko Library]. 1984. Nihon shoshi gakkai 日本書誌學會, ed. Tokyo: Kyūko shoin.

Naquin, Susan and Rawski, Evelyn S. 1987. Chinese Society in the Eighteenth Century. New Haven: Yale University Press.

Ni Zhongzhi 倪鍾之. 1991. Zhongguo quyi shi 中國曲藝史 [History of Quyi in China]. Liaoning: Chunfeng wenyi chubanshe.

NiE Chongzheng 聶崇正. 1987. Qing gongting huajia Zhang Zhen, Zhang Weibang, Zhang Tingyan 清宮廷畫家張震、張為邦、張廷彥 [Qing Court Painters Zhang Zhen, Zhang Weibang, and Zhang Tingyan]. Wenwu 文物 12: 89-92.

1997. Cong cunshi wenwu kan Qingdai gongtingzhong de Zhong Xi meishu jiaoliu 從存世文物看清代宮廷中的中西美術交流 [A Study of the Interaction between Chinese 
and Western Art from Extant Artifacts of the Qing Imperial Court]. Wenwu 文物 5: 71-78.

Nienhauser, William H., Jr., ed. 1986. The Indiana Companion to Traditional Chinese Literature. Bloomington: Indiana University Press.

Olivová, Lucie. 2001. Reminiscences from the Pleasure Boats of Yangzhou: a Book about City. Acta Universitatis Carolinae - Philologica 1, Orientalia Pragensia XIV: 127-149.

— 2002. Li Dou and Theatre: The Case of an Eighteenth Century Yangzhou Playwright. In Anders Hansson, Bonnie S. McDougall and Frances Weightman, eds. Chinese at Play: Festivals, Games and Leisure. London: Kegan Paul, 109-136.

Olivová, see also Borota, Borotová

OTsuka Hidetaka 大塚秀高. 1987. Chügoku tsūzoku shōsetsu shomoku 中國通俗小說書目 [A Catalogue of Chinese Popular Fiction]. Tokyo: Kyuko shoin.

Ouyang Yuqian 歐陽予倩. 1957. Shitan yueju 試談粤劇 [On Cantonese Theatre]. In Ouyang Yuqian 歐陽予倩, ed. Zhongguo xiqu yanjiu ziliao chuji 中國戲曲研究資料初輯 [First Volume of Chinese Traditional Drama Research Material]. Beijing: Zhongguo xiju chubanshe, 109-157.

OUYANG Zhaoxiong 歐陽兆熊 and JiN Anqing 金安清. 1997 [1877]. Shuichuang chunyi 水 窗春囈 [Spring Murmurs at a Water-side Window]. In Qingdai shiliao biji congkan 清 代史料筆記叢刊. Beijing: Zhonghua shuju. Reprint.

Owen, Stephen, ed. 1996. An Anthology of Chinese Literature, Beginnings to 1911. New York: W.W. Norton.

— 1997. Salvaging Poetry: The 'Poetic' in the Qing. In Theodore R. Huters, R. Bin Wong and Pauline Yu, eds. Culture and State in Chinese History. Stanford: Stanford University Press.

Peiwenzhai shuhua pu 佩文齋書畫譜 [Encyclopedia on Calligraphy and Painting Commissioned by the Kangxi Emperor]. 1983 [ca 1708]. Sun Yueban, ed. In Yingyin Wenyuange siku quanshu 影印文淵閣四庫全書, vol. 819-823. Taibei: Taiwan shangwu yingshuguan. Reprint.

PeNG Yuncan 彭蕴璨. 1962. Lidai hua shi hui zhuan 歷代畫史匯傳. In Gu Linwen 顧麟文, ed. Yangzhou bajia shiliao 揚州八家史料 [Historical Materials on the Eight Masters of Yangzhou]. Shanghai: Shanghai renmin meishu chubanshe.

PING Buqing 平步青. 1982. Xia wai jun xie 霞外㒣屑 [Fragments Picked Up Above the Clouds]. 2 vols. Shanghai: Shanghai guji chubanshe.

Polumbaum, Judy. 2002. From Evangelism to Entertainment: The YMCA, The NBA and The Evolution of Chinese Basketball. Modern Chinese Literature and Culture 14.1: 178-230.

Pomeranz, Kenneth. 2000. The Great Divergence: China, Europe and the Making of the Modern World Economy. Princeton: Princeton University Press.

Porter, Deborah Lynn. 1991. The Style of 'Shui-hu chuan.'Ph.D. dissertation, Princeton University, Princeton.

PrůšEK, Jaroslav. 1967. The Origins and the Authors of the Hua-pen. Praha: Academia.

— 1968. The Beginnings of Popular Chinese Literature: Urban Centers - The Cradle of Popular Fiction. Archiv Orientálni 36: 67-121. 
Qi Senhua 齊森華, Chen Duo 陳多 and Ye Changhai 葉長海 et al., eds. 1997. Zhongguo quxue da cidian 中國曲學大辭典 [Encyclopedia of the Study of Chinese Qu]. Hangzhou: Zhejiang jiaoyu chubanshe.

QIAN Zhonglian 錢仲聯, ed. 1989. Qingshi jishi 清詩紀事 [Qing Poetry on Events]. Nanjing: Jiangsu guji chubanshe.

Qing Gao Fenghan shanshui ce 清高鳳翰山水冊 [Landscape Album by Gao Fenghan of the Qing Dynasty]. 1981. Beijing: Wenwu chubanshe.

Qing zhengfu zhenya Taiping tianguo dang'an shiliao 清政府鎮壓太平天國檔案史料 [Documents on the Qing Government's Suppression of the Taiping Heavenly Kingdom]. 1994. Diyi lishi dang'an guan 第一歷史檔案館, eds. Beijing: Shehui kexue chubanshe.

Qingdai baokan tushu jicheng 清代報刊圖書集成 [Complete Collection of Qing Newspaper Illustrations] (2001). 13 vols. Taibei: Quanguo tushuguan wenxian suowei fuzhi zhongxin.

Qingfengzha 清風閘 [Qingfeng Sluice]. 1993 [1819]. Taibei: Hanyuan wenhua. Reprint.

Qingshi liezhuan 清史列傳 [Biographies from the Qing Dynastic History]. 1928. Shanghai: Zhonghua shuju.

QIU Liangren 丘良任. 1983. Lu Jianzeng ji qi ‘Chusaitu’ 盧見曾及其《出塞圖». Gugong bowuyuan yuankan 故宮博物院院刊 2: 43-48, 96.

QIU Youxuan 丘幼宣. 2002. Huang Shen yanjiu 黃慎研究 [A Study of Huang Shen]. Quanzhou: Fujian jiaoyu chuban.

Qu Mianliang 翟冕良. 1999. Zhongguo guji banke cidian 中國古籍版刻辭典 [Dictionary of Traditional Chinese Bibliography and Printing]. Ji'nan: Qi Lu shushe.

Quan Tang shi 全唐詩 [Complete Collection of Tang Poems]. 1985. Beijing: Zhonghua shuju.

QZZY, see Qing zhengfu zhenya Taiping tianguo dang'an shiliao.

Rawski, Evelyn. 1998. The Last Emperors: A Social History of Qing Imperial Institutions. Berkeley: University of California Press.

_ 2002. Re-imagining the Qianlong Emperor: A Survey of Recent Scholarship. Paper presented at the Symposium on China and the World in the Eighteenth Century «十八 世紀的中國與世界》學術研討會, December 13-14. Taibei: National Palace Museum.

— 2004. The Qing Empire during the Qianlong Reign. In James Millward et al., eds. New Qing Imperial History: The Making of Inner Asian Empire at Qing Chengde. London - New York: RoutledgeCurzon, 15-21.

Rawski, Evelyn and Jessica Rawson, eds. 2005. China: The Three Emperors, 1662-1795. London: Royal Academy of Arts.

Reclus, Jacques. 1972. La révolte des Taiping (1851-1864). Paris: Le Pavillon.

Rey, Marie-Catherine. 2006. Les très riches heures de la cour de Chine: chefs-d'ouvre de la peinture impériale des Qing 1662-1796. Paris: Réunion des Musées Nationaux.

Riftin, Boris, see Li Fuqing

Rofel, Lisa. 1999. Other Modernities: Gendered Yearnings in China after Socialism. Berkeley: University of California Press. 
Rowe, William T. 1984. Hankow: Commerce and Society in a Chinese City, 1796-1889. Stanford: Stanford University Press.

Rudelsberger, Hans, translated. 1926. Chinesische Novellen. Wien: Kunstverlag Anton Schroll.

Scherer, Renate. 1983. Das System der chinesischen Prostitution, dargestellt am Beispiel Shanghais in der Zeit von 1840-1949. Ph.D. dissertation, Freie Universität, Berlin.

Schmidt, J.D. 2003. Harmony Garden: The Life, Literary Criticism, and Poetry of Yuan Mei (1716-1798). London: RoutledgeCurzon.

Shan'e tu 善惡圖 [The Chart of Good and Evil]. 1990. In Guben xiaoshuo jicheng 古本小説 集成. Shanghai: Shanghai guji chubanshe. Reprint.

SHEN Fu 沈復. 1967. Fou-sheng liu-chi 浮生六記 / Six Chapters of a Floating Life. ChineseEnglish edition by Lin Yutang 林語堂. Taibei: Xinlu shuju.

1983. Six Chapters of a Floating Life. Translated by Leonard Pratt and Chiang Suhui. Harmondsworth, Middlesex: Penguin Books Ltd.

SHEN Jiarong 沈嘉榮 and JiANG Zhiliang 姜志良. 1993. Jiangsu shigang: Jindai juan 江 蘇史綱。近代卷 [Outline History of Jiangsu. Modern Period]. Nanjing: Jiangsu guji chubanshe.

SHI Chengjin 石成金. 1936. Chuan jia bao quanji 傳家寶全集 [Family Treasure: the Complete Collection]. Zhou Weili 周惟立, ed. 4 vols. Shanghai: Guangyi shuju.

— 1990a. Tongtian le 通天樂 [Heaven-reaching Joy]. Zhang Bing 張兵 and Chu Lingzhen 儲玲珍, eds. In Shi Changyu 石昌渝 et al., eds. Xiong Longfeng kanxing xiaoshuo si zhong deng si zhong 熊龍峰刊行小說四種等四種 [Four Stories Published by Xiong Longfeng and Four Other Items]. In Zhongguo huaben daxi 中國話本大系. Nanjing: Jiangsu guji chubanshe.

- 1990b. Yuhua xiang 雨花香 [Rain-flower Scent]. Zhang Bing 張兵, Chu Lingzhen 儲 玲珍, eds. In Shi Changyu 石昌渝 et al., eds. Xiong Longfeng kanxing xiaoshuo si zhong deng si zhong 熊龍峰刊行小說四種等四種 [Four Stories Published by Xiong Longfeng and Four Other Items]. In Zhongguo huaben daxi 中國話本大系. Nanjing: Jiangsu guji chubanshe.

- 1990c. (Xinke Yangzhou jinshi) Yuhua xiang (新刻揚州近事) 雨花香[(Newly Printed Recent Events in Yangzhou) Rain-flower Scent]. (Xinke Yangzhou jinshi) Tongtian le (新 刻揚州近事) 通天樂 [(Newly Printed Recent Events in Yangzhou) Heaven-reaching Joy]. In Guben xiaoshuo jicheng 古本小說集成. Shanghai: Shanghai guji chubanshe. Reprint. - 2002. Chuan jia bao 傳家寶 [Family Treasure]. Yu Yueheng 喻岳衡, ed. 4 vols. Changsha: Yuelu shushe.

SHI Tianji 石天基. (Chongke tianbu) Chuan jia bao: liyan xinben (重刻添補) 傳家寶: 俚言新 本. [(Newly Printed and Enlarged) Family Treasure: New Edition in Vulgar Language]. 32 ce, 4 ji, [n.p.]. Jinglun tang 經綸堂. Guangxu edition.

SHIH, Vincent Y.C. 1967. The Taiping Ideology. Seattle - London: University of Washington Press.

Shina Nanga taisei 支那南畫大成 [Conspectus of Chinese Paintings of the Southern School]. 1935-1937. Tokyo: Kobunsha. 
Shively, Donald H. 1953. Basho: The Man and the Plant. Harvard Journal of Asiatic Studies 16.1/2: 146-161.

Si Dangdong 斯當東 (George Staunton). 1997 [1797]. Yingshi yejian Qianlong jishi 英使 謁見乾隆紀實 [An Authentic Account of an Embassy from the King of Great Britian to the Emperor of China]. Translated by Ye Duyi 葉篤義. Shanghai: Shanghai shudian chubanshe.

Sieber, Patricia. 2003. Theaters of Desire: Authors, Readers, and the Reproduction of East Chinese Song-Drama, 1300-2000. New York: Palgrave - Houndmills, Basingstoke: Macmillan.

SIMA Qian 司馬遷. Shi ji 史記 [Records of the Historian]. (Undated). 6 vols. Hong Kong: Guangzhi shuju.

Sommer, Deborah. 2004a. The Art and Politics of Painting Qianlong at Chengde. In James Millward et al., eds. New Qing Imperial History: The Making of Inner Asian Empire at Qing Chengde. London - New York: RoutledgeCurzon, 136-145.

2004b. A Letter from a Jesuit Painter in Qianlong's Court at Chengde. In James Millward et al., eds. New Qing Imperial History: The Making of Inner Asian Empire at Qing Chengde. London - New York: RoutledgeCurzon, 171-184.

Sommer, Matthew. 2000. Sex, Law and Society in Late Imperial China. Stanford: Stanford University Press.

Song Zhongxing guange chucang tuhua ji 宋中興舘閣儲藏圖畫記 [Painting Collection of the Song Central pavilion]. 1983. In Peiwenzhai shuhua pu 佩文齋書畫譜, vol. 97. Sun Yueban, ed. In Yingyin Wenyuange siku quanshu 影印文淵閣四庫全書, vol. 819-823. Taibei: Taiwan shangwu yingshuguan. Reprint.

Song Ci 宋詞. 1955. Yangju 揚劇 [Yangzhou Drama]. In Huadong xiqu juzhong jieshao 華 東戲曲劇種介绍 [Introduction to Traditional Drama Types from East China]. Huadong xiqu yanjiuyuan 華東戲曲研究院, ed. 3 vols. Shanghai: Xin wenyi chubanshe, vol. 1: 32-45.

SoNG Lihua 宋莉華. 2006. 19 shiji xiren hanyu duben zhong de xiaoshuo 19 世紀西人 漢語讀本中的小說 [Narrative Literature in Chinese Textbooks for Westerners in the Nineteenth Century]. Ming Qing xiaoshuo yanjiu 明清小說研究 79: 126-140.

Soотніll, William Edward and Lewis Hodous. 1937. A Dictionary of Chinese Buddhist Terms: With Sanskrit and English Equivalents and a Sanskrit-Pali Index. London: K. Paul and Trench, Trubner \& Co., Ltd.

Spence, Jonathan D. 1988 [1966]. T'ao Yin and the K'ang-hsi Emperor, Bondservant and Master. New Haven - London: Yale University Press.

— 1996. God's Chinese Son. The Taiping Heavenly Kongdom of Hong Xiuquan. New York - London: W.W. Norton.

Staunton, George Thomas. 1824. Notes of Proceedings and Occurrences during the British Embassy to Pekin in 1816. London: Havant Press.

Staunton, George, see also Si Dangdong

Steele, Valerie and John S. Major, eds. 1999. China Chic: East Meets West. New Haven - London: Yale University Press. 
Stevens, Catherine. 1973. Peking Drumsinging. Ph.D. dissertation, Harvard University, Cambridge.

Strassberg, Richard. 1983. The World of K'ung Shang-jen: A Man of Letters in Early Ch'ing China. New York: Columbia University Press.

Struve, Lynn A., ed. 2004. Qing Formation in World-Historical Time. Cambridge, Massachusetts: Harvard University Press.

Sun Yancheng 孫言誠, ed. 1992. Wang Shizhen nianpu 王士禎年譜 [A Chronological Biography of Wang Shizhen]. Beijing: Zhonghua shuju.

Suzuki Kei 鈴木敬 et al., eds. 1982. Chügoku kaiga sōgō zuroku 中國繪畫總合圖錄 [Comprehensive Illustrated Catalog of Chinese Paintings]. Tokyo: Tokyo daigaku shuppankai (University of Tokyo Press).

Takeuchi, Melinda, ed. 2004. The Artist as Professional in Japan. Stanford: Stanford University Press.

TAN Zhengbi 譚正璧 and TAN Xun 譚尋, eds. 1985. Pingtan tongkao 評彈通考 [Research on Pinghua and Tanci]. Beijing: Zhongguo quyi chubanshe.

TAO Muning 陶慕寧. 1993. Qinglou wenxue yu Zhongguo wenhua 青樓文學與中國文化 [Literature of the Green Lofts and Chinese Culture]. Beijing: Dongfang chubanshe.

Teng Ssu-yü. 1966. New Light on the History of Taiping Rebellion. New York: Russell \& Russell.

1971. The Taiping Rebellion and the Western Powers. A Comprehensive Survey. Oxford: Clarendon Press.

Tian Yirong 田益榮, YANG Zhengwu 楊正吾, Zhang Peng 張鵬, Guo Bingzhen 郭秉箴 et al., eds. 1995. Zhongguo xiqu juzhong da cidian 中國戲曲劇種大辭典 [Encyclopedia of Chinese Traditional Genres of Drama]. Shanghai: Shanghai Cishu chubanshe.

TianHua Zhuren 天花主人. 1983. Yun xian xiao 雲仙笑 [The Laughter of Immortals in the Clouds]. Shenyang: Chunfeng wenyi chubanshe.

Toda Teisuke 戶田禎佑 and Ogawa Hiromitsu 小川裕充, eds. 1998. Chūgoku kaiga sōgō zuroku 國繪畫總合圖錄 [Comprehensive Illustrated Catalog of Chinese Paintings]. Tokyo: Tokyo daigaku shuppankai (University of Tokyo Press).

Tsang, Ka Bo. 1982. Portraits of Hua Yan and the Problem of his Chronology. Oriental Art 28.1: 64-79.

1985. The Relationships of Hua Yan and Some Leading Yangzhou Painters as Viewed from Literary and Pictorial Evidence. Journal of Oriental Studies 23.1: 1-28.

1987. A Case Study: The Influence of Book Illustration on Painting as Viewed in the Work of Hua Yan. Oriental Art 33. 2: 150-164.

TsenG, Lan-ying. 2001. Interchange of the Self and the Other: Wu Tso-jen's Visual Representation of the Northwestern Frontier. In Quyu yu wanglu guoji xueshu yantaohui lunwen ji 區域與網絡: 國際學術研討會論文集 [Proceedings of the International Symposium on Regions and Networks: The Study of the History of Art in the Last Millennium]. Taibei: Graduate Institute of Art History, National Taiwan University, 669-700.

TTL, see SHI Chengjin. 1990a. Tongtian le 
Vinograd, Richard. 1992. Boundaries of the Self: Chinese Portraits, 1600-1900. New York - Cambridge: Cambridge University Press.

Volpp, Sophie, see Yuan Shufei

WAN, Margaret Baptist. 2004. The Chantefable and the Novel: The Cases of Lü mudan and Tianbao tu. Harvard Journal of Asiatic Studies 64.2: 367-397.

WANG Chang 王永. 1988 [1803]. Puhe shanfang shihua xinbian 蒲褐山房詩話新編 [A New Edition of Poetics from Puheshan Studio]. Ji'nan: Qi Lu shushe.

WANG Cheng 王澄, ed. 2001. Yangzhou lishi renwu cidian 揚州歷史人物辭典 [A Dictionary of Yangzhou Historical Personages]. Nanjing: Jiangsu guji chubanshe.

_ 2003. Yangzhou keshu kao 揚州刻書考 [A Study of Book-printing in Yangzhou]. Yangzhou: Guangling shushe.

WANG, Eugene Y. 2005. Shaping the Lotus Sutra: Buddhist Visual Culture in Medieval China. Seattle - London: University of Washington Press.

WANG Hong 王鴻. 2000 [1985]. Yangzhou sanji 揚州散記 [Essays about Yangzhou]. Yangzhou: Jiangsu guji chubanshe.

— - 2001. Lao Yangzhou. Yanhua mingyue 老揚州. 煙花明月 [Old Yangzhou. Mist, Flowers, Bright Moon]. Nanjing: Jiangsu meishu chubanshe.

WANG Jingxian 王靖憲. 2003. Hua Yan de yishu sixiang ji qi chengjiu 華品的藝術思想及其成就 [Hua Yan's Ideas on Art and His Accomplishments]. In Lu Fusheng 盧輔聖, ed. Hua Yan yanjiu 華品研究 [Research on Hua Yan]. Shanghai: Shanghai shuhua chubanshe, 126-160.

WANG Qi 王圻. 1974 [1607]. Sancai tuhui 三才圖會 [Illustrated Encyclopedia of the Three Realms]. Taibei: Chengwen chubanshe youxian gongsi. Reprint.

WANG Shaotang 王少堂. 1979. Wode xueyi jingguo he biaoyan jingyan 我的學藝經過和表演 經驗 [My Education as an Artist and the Experience of Performance]. In Shuo xinshu 說 新書 [On New Storytelling]. Shanghai: Shanghai wenyi chubanshe, vol. 2: 286-310.

—_ 1984 [1959]. Wu Song 武松 [Wu Song]. 2 vols. Huaiyin: Jiangsu renmin chubanshe.

Wang Shilu zhuan 王士祿傳 [The Biography of Wang Shilu]. 1928. In Qingshi liezhuan 清史列傳 [Biographies from the Qing Dynastic History]. Shanghai: Zhonghua shuju, vol. 70: 132-133.

WANG Shizhen 王士禎. 1983 [1709]. Fen gan yuhua 分甘餘話 [Some Notes after Spreading Fruits]. In Wenyuan ge siku quanshu 文淵閣四庫全書 vol. 870. Taibei: Taiwan shangwu yinshuguan. Reprint.

- 1997a [1691]. Chibei outan 池北偶談 [Random Talks North of the Pond]. 2 vols. Beijing: Zhonghua shuju.

1997b. Yuyang shanren wenlüe 漁洋山人文略 [A Collection of Yuyang Shanren's Essays]. In Congshu jicheng sanbian 叢書集成三編. Taibei: Xinwenfeng chuban gongsi. Reprint. 1997c. Yuyang shiji 漁洋詩集 [Collected Poems by (Wang) Yuyang]. In Siku quanshu cunmu congshu 四庫全書存目叢書, jibu 集部 vol. 227. Tainan: Zhuangyan wenhua shiye. Reprint.

1999 [1700]. Yuyang jinghualu jishi 漁洋精華錄集釋 [Masterpieces by (Wang) Yuyang Compiled and Explained]. Li Yufu 李毓芙 et al, eds. Shanghai: Shanghai guji chubanshe. 
WANG Shuyun 王淑雲. 1989. Qingdai beixun yudao he saiwai xinggong 清代北巡御道和塞外 行宮 [Imperial Highways and Frontier Travel Palaces from the Northern Tours of the Qing Dynasty]. Beijing: Zhongguo huanjing kexue chubanshe.

WANG Wan 汪琬. 1997. Chunweng qianhou leigao 純翁前後類稿 [Categorized Manuscripts of (Wang) Chunweng]. In Siku quanshu cunmu congshu 四庫全書存目叢書, jibu 集部 vol. 227. Tainan: Zhuangyan wenhua shiye. Reprint.

WANG Wenqing 王文清. 1993. Jiangsu shigang: Gudai juan 江蘇史綱。古代卷 [Outline History of Jiangsu. Ancient Period] Nanjing: Jiangsu guji chubanshe.

WANG Xiaotang 王篠堂. 1992. Yi hai ku hang lu藝海苦航錄 [Memoirs of a Difficult Voyage on the Sea of Art]. Zhenjiang: Jiangsu wen shi ziliao bianjibu.

WANG Xiuchu 王秀楚. 1964. Yangzhou shiri ji 揚州十日記 [Ten-Day Diary of Yangzhou]. In Zhongguo jindai neiluan waihuo lishi gushi congshu 中國近代内亂外禍歷史故事叢 書 [Collected Historical Tales of Internal Chaos and External Calamity in Modern China]. Taibei: Guangwen shuju, vol. 2: 229-245.

- 2004. Yangzhou shiri ji 揚州十日記 [Ten-Day Diary of Yangzhou]. Yangzhou: Guangling shushe.

WANG Yu 王瑜, ed. 1993. Yangzhou lidai mingren 揚州歷代名人 [Yangzhou Historical Personages through the Dynasties]. Nanjing: Jiangsu guji chubanshe.

WANG Yun 汪栓. 1995a [1883]. Yangzhou huayuan lu 揚州畫苑錄 [Biographical Accounts of Painters in Yangzhou]. In Chen Henghe 陳恒和, ed. Yangzhou congke 揚州叢刻 [Yangzhou Collectanea]. Yangzhou: Guangling guji keyin she. Reprint.

— 1995b [1883]. Yangzhou huayuan lu 揚州畫苑錄 [Biographical Accounts of Painters in Yangzhou]. In Xuxiu siku quanshu 續修四庫全書 1087 - zibu 子部 - yishu lei 藝術類. Shanghai: Shanghai guji chubanshe.

WANG Zhaowen 王肇文. 1990. Guji Song Yuan kangong xingming suoyin 古籍宋元刊工姓 名索引 [Index to the Names of Block-cutters in Song and Yuan Books]. Shanghai: Shanghai guji chubanshe.

WANG Zhenzhong 王振忠. 1996. Ming Qing Hui shang yu Huaiyang shehui bianqian 明清 徽商與淮揚社會變遷 [Huizhou Merchants of the Ming and Qing Dynasties and Social Changes in Huai' an and Yangzhou]. Beijing: Sanlian shudian.

_ 2002. 'Wu Hui bu cheng zhen' tu shuo - Xiuning Fang Shi yu Dingyuan Luqiao zhen《無徽不成鎮》 圖說一休寧方氏與定遠爐橋鎮 ['Without Huizhou Merchants, There Would Be No Town': An Illustration of the Xiuning Fang Clan and Luqiao Town in Dingyuan]. Xungen 尋根 2: 28-33.

WANG Zhiying 王志英 (illustrations) and PAN Chuanrui 潘傳瑞 (text). 1986. Penjing zaoxing yishu 盆景造型藝術 [The Art of Making Scenery in Pots]. Chengdu: Sichuan kexue jishu chubanshe.

Watson, Burton, translator 1993. The Lotus Sutra. New York: Columbia University Press.

WeI, Betty Peh-t'i. 2006. Ruan Yuan, 1764-1849: The Life and Work of a Major ScholarOfficial in Nineteenth-Century China Before the Opium War. Hong Kong: Hong Kong University Press. 
Wei Dong. 1995. Qing Imperial 'Genre Painting': Art as Pictorial Record. Orientations 26.7: 18-24.

WEI Minghua 韋明鏵. 1995. The Thin Horses of Yangzhou. Translated and introduced by Antonia Finnane. East Asian History 9: 47-66.

— 1998. Yangzhou shouma 揚州瘦馬 [The Thin Horses of Yangzhou]. Fuzhou: Fujian renmin chubanshe.

— 2000. Yangzhou ershisi qiao mingyue ye 揚州二十四橋明月夜 [Yangzhou's Twenty-Four Bridge on a Moonlit Night]. Shanghai: Shanghai guiji chubanshe.

—_ 2001. Yangzhou zhanggu 揚州掌故 [Yangzhou Topics]. Suzhou: Suzhou daxue chubanshe.

— 2003. Zhuxi huashi xiaolu yu wan Qing Yangzhou kunqu «竹西花事小錄》與晚清揚州崑曲 ['Brief Accounts of Zhuxi' and Yangzhou Kunqu in Late Qing]. In Yangzhou wenhua gang / Xinhua gang 揚州文化網/新華網 [Yangzhou Culture/ Xinhua Net]. 2003. (Web version).

— 2004a. Yangzhou wenhua tanpian 揚州文化談片 [Remarks on Yangzhou Culture]. Yangzhou: Guangling shushe.

— 2004b. Yangzhou shouma. Zhongguo gudai funü shenghuoshi zhi yi ye 揚州瘦馬. 中國 古代婦女生活史之一頁. [The Thin Horses of Yangzhou: a Page in the History of Women's Lives in Ancient China]. In Wei Minghua 韋明鏵. Yangzhou wenhua tanpian 揚州文化談 片 [Remarks on Yangzhou Culture]. Yangzhou: Guangling shushe, 201-214.

WEI Ren 韋人. 1999. Yangzhou xi kao 揚州戲考 [A Study of Yangzhou Theatre]. Yangzhou: Jiangsu guji chubanshe.

Wei Ren 韋人 and Chen Depu 陳徳溥. 1995. Yangju 揚劇 [Yangzhou Drama]. In Tian Yirong 田益榮, Yang Zhengwu 楊正吾, Zhang Peng 張鵬, Guo Bingzhen 郭秉箴 et al., eds. Zhongguo xiqu juzhong da cidian 中國戲曲劇種大辭典 [Encyclopedia of Chinese Traditional Genres of Drama]. Shanghai: Shanghai Cishu chubanshe, 404-408.

WEI Ren 韋人 and WEI Minghua 韋明鏵. 1983. Yangzhou qingqu. 揚州清曲 (Yangzhou Ballads). In Zhang Geng 張更, Zhao Jingshen 趙景深 et al., eds. Zhongguo da baike quanshu. Xiqu quyi 中國大百科全書. 戲曲曲藝 [China Encyclopedia, Traditional Drama and Storytelling]. Beijing - Shanghai: Zhongguo da baike quanshu chubanshe, page 529.

— 1985. Yangzhou quyi shi hua 揚州曲藝史話 [On the History of Yangzhou Quyi]. Beijing: Zhongguo quyi chubanshe.

WeIdner, Marsha. 1994. Latter Days of the Law: Images of Chinese Buddhism, 850-1850. Lawrence: Spencer Museum of Art, University of Kansas.

— 2001. Cultural Intersections in Later Chinese Buddhism. Honolulu: University of Hawai'i Press.

WeNG Lianxi 翁連溪, ed. 2004. Qingdai neifu keshu tulu 清代内府刻書圖錄 [Illustrated Catalogue of Qing Palace Publications]. Beijing: Beijing chubanshe.

Werner, E.T.C. 1932. A Dictionary of Chinese Mythology. Shanghai: Kelly and Walsh. Wilson, Ming. 2006. What Do Books Tell Us About Their Buyers - a Case Study of the Guyu Tupu. In Ming Wilson and Stacey Pierson, eds. The Art of the Book in China. London: Percival David Foundation for Chinese Art, 105-115. 
Wu Baitao 吳白匋. Yangju 揚劇 [Yangzhou Drama]. In Zhang Geng 張庚, Zhao Jingshen 趙 景深 et al., eds. Zhongguo da baike quanshu. Xiqu quyi 中國大百科全書. 戲曲曲藝 [China Encyclopedia, Traditional Drama and Storytelling]. Beijing - Shanghai: Zhongguo da baike quanshu chubanshe, 527-528.

Wu Changyuan 吳長元. 1965 [1934]. Yanlan xiaopu 燕蘭小譜 [Records of Beijing's Orchids]. In Zhang Cixi 張次溪 et al., eds. Qingdai Yandu liyuan shiliao 清代燕都梨園 史料 [Historical Materials on the Theatre of Beijing during the Qing Dynasty]. 4 vols. Taibei: Taiwan xuesheng shuju, vol. 1: 65-164. Reprint.

Wu Chunyan 吴春彦 and Lu Lin 陆林. 2004. 'Jiaodong Zhou Sheng' ji Dantu Zhou Boyi: Qingdai wenyan xiaoshuo Yangzhou meng zuozhe kao 焦東周生及丹徒周伯仪：清 代文言小説揚州夢作者考 [Jiaodong Zhou Sheng is Zhou Boyi of Dantu: Research into the Author of the Qing Literary Work Dream of Yangzhou]. Ming Qing xiaoshuo yanjiu 明清小説研究 71.1: 84-94.

Wu Erlu 吳爾鹿. 1988. Jin Nong he tade daibihua 金農和他的代筆畫 [Jin Nong and His Forgers]. In Wenwu 文物 12: 69-78.

Wu Hung. 1992. What is Bianxiang? - On the Relationship between Dunhuang Art and Dunhuang Literature. Harvard Journal of Asiatic Studies 52.1: 111-192.

Wu Jen-shu, see Wu Renshu

Wu Jiaxing 吳家興, Li Baohua 李保華 and ZHANG Xinji 張金基. 1988. Yangzhou gugang shi 揚 州古港史 [History of the Old Port of Yangzhou]. Beijing: Renmin jiaotong chubanshe.

Wu Jianhua 吳建華. 1990. Nanxun jicheng 南巡紀程 [The Itinerary of the Southern Journeys]. Fuyin baokan ziliao 複印報刊資料 7: 49-53.

Wu Marshall P. S. 1988. Jin Nong: The Eccentric Painter with a Wintry Heart. In Juhsi Chou and Claudia Brown, eds. Chinese Painting under the Qianlong Emperor. Exhibition catalogue. Tempe: School of Art, Arizona State University.

Wu Renshu 巫仁恕. 1999. Mingdai pingmin fushi de liuxing fengshang yu shidafu de fanying 明代平民服飾的流行風尚與士大夫的反應 [Popular Styles of Clothing among the Common People of Ming Times, and the Reaction of the Gentry]. Xinshixue 新史學 10.3: 55-109.

2003a. Wanming de lüyou huodong yu xiaofei wenhua: yi Jiangnan wei taolun zhongxin 晚明的旅遊活動與消費文化：以江南為討論中心 [The Culture of Travel and Consumption during the Late Ming Period: a Discussion Centered on the Jiangnan Region]. Zhongyang yanjiuyuan jindaishi yanjiusuo jikan 中央研究院近代史研究所集刊 41: 87-141.

_ 2003b. Qingdai shidafu de lüyou huodong yu lunshu: yi Jiangnan wei taolun zhongxin 清代士大夫的旅遊活動與論述：以江南為討論中心 [Travel Activities among Men of Letters during the Qing Dynasty: a Discussion Centered on the Jiangnan Region]. Paper delivered at the International Conference on Everyday Life in the Jiangnan Area during the Ming-Qing Period, December 18-20.

2007. Pinwei shehua: wan Ming de xiaofei shehui yu shidafu 品味奢華一一晚明的消費 社會與士大夫 [Luxurious Tastes: Late Ming Consumer Society and the Gentry]. Taibei: Lianjing chuban gongsi. 
Wu Runsheng 吳潤生. 2003. Bujin fengliu shou Yangzhou 不盡風流瘦揚州 [Endless Charms of 'Things Slender' in Yangzhou]. Beijing: Beijing tuanjie chubanshe.

Wu Tung, ed. 1997. Tales from the Land of Dragons: 1000 Years of Chinese Painting. Boston: Boston Museum of Fine Arts.

Wu Yenna. 2001. Vernacular Stories. In Victor H. Mair, ed. The Columbia History of Chinese Literature. New York: Columbia University Press, 595-619.

Wu Youru huabao 吳友如畫寶 [Treasury of Paintings by Wu Youru]. 1983. Shanghai: Shanghai guji chubanshe.

Wu Zihui 吳子煇. 2001. Yangzhou jianzhi bitan 揚州建置筆談 [Notes on Establishing Yangzhou]. Nanjing: Jiangsu guji chubanshe.

Wu Zongxi 吳宗錫, ed. 1996. Pingtan wenhua cidian 評彈文化辭典 [Encyclopedia on Pingtan Culture]. Shanghai: Hanyu dacidian chubanshe.

Wurm, S.A., Li Jung, Theo Baumann and Mei W. Lee, eds. 1988. Language Atlas of China. Hong Kong: Longman Group (Far East) Ltd.

XIA Chuntao 夏春濤. 2002. Ershi shiji de Taiping tianguo shi yanjiu 二十世紀的太平天國史 研究 [Research on the History of the Taiping Heavenly Kingdom from the Twentieth Century]. Lishi yanjiu 歷史研究 2: 162-81.

XIA Wenyan 夏文彥. 1983. Tuhui baojian 圖繪寶鑑 [Precious Mirror for Examining Painting]: In Yingyin Wenyuange siku quanshu 影印文淵閣四庫全書, vol. 814. Taibei: Taiwan shangwu yingshuguan. Reprint.

XIaO TIEDI Daoren 小鐵笙道人. 1965 [1934]. Rixia kanhua ji 日下看花紀 [Records of Looking at Beijing's Flowers]. In ZHANG Cixi 張次溪 et al., eds. Qingdai Yandu liyuan shiliao 清代燕都梨園史料 [Historical Materials on the Theatre of Beijing during the Qing Dynasty). 4 vols. Taibei: Taiwan xuesheng shuju, vol. 1: 167-288. Reprint.

XIAO Xiangkai 蕭相愷. 1988. Guanyu xiaoshuo shi yanjiu ruogan wenti de kaobian 關於 小說史研究若干問題的考辨 [Investigations into Several Questions in the Study of the History of Fiction]. Ming Qing xiaoshuo yanjiu 明清小説研究 4 (1988): 9-16.

- 1994. Shi Chengjin kaolun 石成金考論 [A Study on Shi Chengjin]. Wenxue yichan 文學遺產 6 (1994): 109-112.

—— and ZHANG Hong 張虹. 1994. Zhongguo gudian tongsu xiaoshuo shilun 中國古典 通俗小說史論 [Studies on the History of Chinese Classic Popular Fiction]. Nanjing: Nanjing chubanshe.

- and Liu Fuyuan 劉福元. 2003. Huaben xiaoshuo shi 話本小說史 [A History of the Vernacular Story]. Hangzhou: Zhejiang guji chubanshe.

Xu Duanrong 許端容. 2002. Qingfengzha yanjiu 清風閘研究 [Research on Qingfengzha]. Huagang wenke xuebao 25: 71-95.

Xu Ling 徐陵, ed. 2001. Yutai xinyong 玉臺新詠 [New Songs of the Jade Terrace]. Shanghai: Shijie shuju.

Xu Wei 徐渭. 1985. Qingteng shuwu wenji 青藤書屋文集 [Writings from Qingteng's Studio]. Congshu jicheng xinbian 叢書集成新編. Taibei: Xin Wenfeng.

Xu Yan 徐雁. 2005. Zhongguo jiushuye bainian 中國舊書業百年 [One Hundred Years of the Chinese Antiquarian Book Trade]. Beijing: Kexue chubanshe. 
Xu Yinong. 2000. The Chinese City in Space and Time: The Development of Urban Form in Suzhou. Honolulu: University of Hawai'i Press.

Xuanhe huapu 宣和畫譜 [Catalogue of Paintings in the Xuanhe Collection]. 1983. In Yingyin Wenyuange siku quanshu 影印文淵閣四庫全書, vol. 813. Taibei: Taiwan shangwu yingshuguan. Reprint.

XuE Yongli 薛永力. 1996. Shanghai jinshi 上海禁史 [The Forbidden History of Shanghai]. Hong Kong: Haifeng chubanshe.

XuE Yongnian 薛永年. 1996. Shangpin jingji yu Yangzhou baguai 商品經濟與揚州八怪 [Commercial Economy and the Eight Eccentrics of Yangzhou]. In Xue Yongnian 薛永 年, ed. Heng kan cheng ling ce cheng feng 横看成嶺側成峰 [Low Hills When Viewed from the Horizontal Side; High Peaks when Viewed from the Vertical Side]. Taibei: Dongda tushu gufen youxian gongsi, 397-405.

2003a. Hua Yan yu minting Hua shi zupu 華品與閩汀華氏族譜 [Hua Yan and the Genealogy of the Minting Area Hua Clan]. In Lu Fusheng 盧輔聖, ed. Hua Yan yanjiu 華品研究 [Research on Hua Yan]. Shanghai: Shanghai shuhua chubanshe, 226-248.

2003b. Hua Yan tonglun 華品通論 [An Introduction to Hua Yan]. In Lu Fusheng 盧 輔聖, ed. Hua Yan yanjiu [A Study of Hua Yan]. Shanghai: Shanghai shuhua chubanshe, $15-75$.

Xuzuan Yangzhou fuzhi 續纂揚州府志 [Continued Gazetteer of Yangzhou Prefecture]. 1874. Fang Junyi 方濬頣, Yan Duanshu 晏端書, Yingjie 英傑, eds. Yangzhou: Yangzhou fushu.

YAN Dichang 嚴迪昌. 1998. Qingshi shi 清詩史 [The History of Qing Poetry]. Taibei: Wunan tushu.

YANG Boda 楊伯達. 1982. 'Wanshuyuan siyan tu' kaoxi 《萬樹園賜宴圖》考析 [Analysis of the 'Banquet in the Garden of Ten Thousand Trees']. Gugong bowuyuan yuankan 故宮 博物院院刊 4: 3-21.

1984. Qingdai Qianlongchao saibei ticai yuanhua chutan 清代乾隆朝塞北題材院畫 初探 [An Initial Study of the Northern Frontier Subjects in Court Painting of the Qianlong period]. In Zhongguo hua 中國畫 2: 35-36, 49.

1992. Qing Qianlong chao huayuan yange 清代乾隆朝畫院沿革 [The Changes at the Court Academy under Qianlong]. In Gugong bowuyuan yuankan 故宮博物院院刊 55.1: 3-11, 89.

— 1993. Qingdai yuanhua 清代院畫 [Court Academy Painting of the Qing Dynasty]. Beijing: Zijincheng (Forbidden City) chubanshe.

YANG Shuhui. 1998. Appropriation and Representation: Feng Menglong and the Chinese Vernacular Story. Ann Arbor: Center for Chinese Studies, University of Michigan.

YANG Xin 楊新. 1981. Yangzhou baguai 揚州八怪 [The Eight Eccentrics of Yangzhou]. Beijing: Wenwu chubanshe.

— 1994. Yang Xin meishu lunwen ji 楊新美術論文集 [Collection of Essays on Art by Yang Xin]. Beijing: Zijincheng (Forbidden City) chubanshe.

Yangzhou baguai huaji 揚州八怪畫集 [Paintings of the Eight Eccentrics of Yangzhou.] 1985. Nanjing: Jiangsu meishu chubanshe. 
Yangzhou baguai shuhua ji 揚州八怪書畫集 [Selected Painting and Calligraphy of the Eight Eccentrics of Yangzhou]. 1970. Zhang Wanli 張萬里, Hu Renmao 胡仁惁, eds. 8 vols. Hong Kong: Kaifa.

Yangzhou baguai shuhua jingxuan 揚州八怪書畫精選 [Masterpieces of Paintings and Calligraphy by the Eight Eccentrics of Yangzhou]. 2001. Nanjing: Jiangsu guji chubanshe. Yangzhou Museum Collection.

Yangzhou bajia huaji 揚州八家畫集 [Selected Paintings of the Eight Yangzhou Masters]. 1994. Tianjin: Tianjin renmin meishu chubanshe.

Yangzhou fangyan cidian 揚州方言詞典 [A Dictionary of Yangzhou Dialect]. 1996. Li Rong 李榮, WANG Shihua 王世華 and HuANG Jilin 黃繼林, eds. Nanjing: Jiangsu jiaoyu chubanshe.

Yangzhou fuzhi 1810, see Chongxiu Yangzhou fuzhi; Jiangsu sheng Yangzhou fuzhi

— 1874, see Xuzuan Yangzhou fuzhi

Yangzhou huapai 揚州畫派 [The Yangzhou School of Painting]. 1985. Lin Xiuwei 林秀薇, ed. Taibei: Yishu tushu gongsi.

Yangzhou huapai shuhua quanji: Gao Fenghan 揚州畫派書畫全集 : 高鳳翰 [A Complete Compilation of Paintings and Calligraphy by the Yangzhou School: Gao Fenghan]. 1998. Tianjin: Tianjin renmin meishu chubanshe.

——: Hua Yan 揚州畫派書畫全集：華品 [A Complete Compilation of Paintings and Calligraphy by the Yangzhou School: Hua Yan]. 1998. Zhang Wanfu 張萬夫, ed. Tianjin, Tianjin renmin meishu chubanshe.

-: Huang Shen 揚州畫派書畫全集 : 黃慎 [A Complete Compilation of Paintings and Calligraphy by the Yangzhou School: Huang Shen]. 1998. Zhang Wanfu 張萬夫, ed. Tianjin: Tianjin renmin meishu chubanshe.

— : Jin Nong 揚州畫派書畫全集 : 金農 [A Complete Compilation of Paintings and Calligraphy by the Yangzhou School: Jin Nong]. 1998. Wang Zhihai 王之海, ed. Tianjin: Tianjin renmin meishu chubanshe.

——: Li Shan 揚州畫派書畫全集 : 李鱓 [A Complete Compilation of Paintings and Calligraphy by the Yangzhou School: Li Shan]. 1998. Tianjin: Tianjin renmin meishu chubanshe.

Yangzhou jiu wen 揚州舊聞 [Old Yangzhou News]. 2003. Wei Minghua 韋明鏵, edited and annotated. Wan Qing shehui xinwen tulu 晚清社會新聞圖錄 [Illustrated News from the Late Qing Society]. Suzhou: Guwuxuan chubanshe.

Yangzhou minjian gushi ji 揚州民間故事集 [Yangzhou Folktales]. 1989. Yangzhoushi minjian wenxue santao jicheng bian weihui 揚州市民間文學三套集成編委會, ed. Beijing: Zhongguo minjian wenyi chubanshe.

Yangzhou quyi zhi 揚州曲藝志 [Records of Yangzhou Quyi]. 1993. Nanjing: Jiangsu wenyi chubanshe.

Yangzhou shi wenwu baohu danwei. Qingkuang dengji biao 揚州市文物保護單位。情況登記 表 [Yangzhou City Protected Monuments: a Listing Registering Their Current State]. Undated manuscript, compiled by Jiangsu sheng wenhua ting 江蘇省文化廳.

YeH Catherine Vance. 1998. Reinventing Ritual: Late Qing Handbooks for Proper Customer Behaviour in Shanghai Courtesan Houses. Late Imperial China 19.2: 1-63. 
Yen Shou-chih Isaac. 2004. Xu Wei's Zahua: A Study of Genres. Ph.D. dissertation, Yale University, New Haven.

YHX, see SHI Chengjin. 1990b. Yuhua xiang

YI Debo 易德波 (Vibeke Børdahl). 2006. Yangzhou pinghua tantao 揚州平話探討 [Investigation into Yangzhou Storytelling]. Translated by the author in collaboration with Mi Feng 米鋒 and Lee Chinyun 李今芸. Beijing: Renmin wenxue chubanshe. (Augmented and revised Chinese rendition of Vibeke Børdahl, The Oral Tradition of Yangzhou Storytelling, 1996.)

YI Junzuo 易君左. 1934. Xianhua Yangzhou 閒話揚州 [Chatting at Leisure about Yangzhou]. Shanghai: Zhonghua shuji.

YIN Kuiyou 尹奎友 and Jin Yong 靳永, eds. 2001. Zhongguo gudai xiaolin si shu 中國古代笑 林四書 [Four Books of Old Chinese Jokes]. Ji'nan: Shandong youyi chubanshe.

Yiyuan duoying, 1 藝苑捜英 1 [Gathering Flowers in the Garden of Arts, No. 1]. 1978. Shanghai: Renmin meishu chubanshe.

You Zi'an 游子安. 1999 Quanhua jinzhen: Qingdai shanshu yanjiu 勸化金箴: 清代善書研究 I Admonishing the Age for the Maxim: A Study of Morality Books in Qing China. Tianjin: Tianjin renmin chubanshe.

- 2005. Shan yu ren tong: Ming Qing yilai de zishan yu jiaohua 善與人同: 明清以來的 慈善與教化 / In Company with Goodness: Charity and Morality in China, 1600-1930. Beijing: Zhonghua shuju.

Yu Dafu 郁達夫. 1935. Yangzhou jiu meng ji Yutang 揚州舊夢寄玉堂 [The Old Dream of Yangzhou: To (Lin) Yutang]. Renjianshi 人間世 28: 3-6.

Yu Youchun 余又春 et al. 1985. Pi Wu lazi 皮五辣子 [Pi Wu the Scoundrel]. Nanjing: Jiangsu wenyi chubanshe.

YuAN Shufei 袁書非 (Sophie Volpp). 2002. Ru shi ganlan - shiqi shiji Zhongguo dui nanling de wenxue xiaoshou 如食橄欖一十七世紀中國對男伶的文學消受 (Like Eating Olives: the Literary Consumption of Male Actors in Seventeenth Century China). In Chen Pingyuan 陳平原, Wang Dewei 王德威 and Shang Wei 商偉, eds. Wan Ming yu wan Qing: lishi chuancheng yu wenhua chuangxin 晚明與晚清 : 歷史傳承與文化創新 [Late Ming and Late Qing: Historical Continuities and Cultural Innovations]. Wuhan: Hubei jiaoyu chubanshe, p. 291-297.

Yuyang shanren ji qizhong 漁洋山人集七種 [Seven Collections of Writings by Yuyang Shanren (Wang Shizhen)]. Qianlong edition, kept in Fu Sinian 傅斯年 Library, Academia Sinica, Taiwan.

YWB, see Yangzhou shi wenwu baohu danwei

Zeitlin, Judith T. 1998. Spirit Writing and Performance in the Work of You Tong (16181704). T'oung Pao 84: 102-134.

- 2003. Disappearing Verses: Writings on Walls and Anxieties of Loss. In Writing and Materiality in China: Essays in Honor of Patrick Hanan. Lydia Liu and Judith Zeitlin, eds. Harvard-Yenching Institute Monograph Series 58. Cambridge: Harvard East Asia Center, 73-132.

ZHANG Bing 張兵. 1991. 'Yuhua xiang' chu yi «雨花香》媰議 [My Humble Opinion on Yuhua xiang]. In Ming Qing xiaoshuo yanjiu 明清小説研究 4: 149-160. 
ZHANG Chou 張丑. 1983. Qinghe shuhua fang 清河書畫舫 [Qinghe Painting and Calligraphy Barge]. In Yingyin Wenyuange siku quanshu 影印文淵閣四庫全書, vol. 817. Taibei: Taiwan shangwu yingshuguan. Reprint.

Zhang Dai 張岱. 1990. Six Essays / Sanwen liupian 散文六篇. Translated by David E. Pollard, and Soh Yong Kian. Renditions 33/34: 155-166.

- 1995. Yangzhou shouma 揚州瘦馬 [The Thin Horses of Yangzhou]. In Tao'an mengyi 陶庵夢憶 [Dream Memories of Tao'an]. Tu Youxiang 屠友祥, ed. Shanghai: Shanghai yuandong, 160-162.

ZHANG Daoyou 張道由 and HuANG Jilin 黃繼林. 2001. Luori huihuang hua Yangzhou 落 日輝煌話揚州 [The Sunset of Splendour, Speaking of Yangzhou]. Hefei: Huangshan shushe.

ZHANG Dunyi 張敦頣. 1967. Liuchao shiji bianlei 六朝事跡編類 [Categorized Materials on the Six Dynasties]. In Baibu congshu jicheng 百部叢書集成. Taibei: Yiwen chubanshe.

ZHANG Geng 張庚. 1986. Guochao huazheng lu 國朝畫徵錄 [Recorded Evidence about Paintings of Our Dynasty]. In Meishu Congkan 美術叢刊, vol. 2. Taibei: Guoli bianyi quan.

ZHANG Geng 張庚 and Guo Hancheng 郭漢城, eds. 1981. Zhongguo xiqu tongshi 中國戲曲通史 [General History of Chinese Traditional Theatre]. 3 vols. Beijing: Zhongguo xiju chubanshe.

——, Zhaо Jingshen 趙景深 et al., eds. 1983. Zhongguo da baike quanshu. Xiqu quyi 中國大百科全書. 戲曲曲藝 [China Encyclopedia, Traditional Drama and Storytelling]. Beijing - Shanghai: Zhongguo da baike quanshu chubanshe.

Zhang Hongxing. 2002. The Qianlong Emperor: Treasures from the Forbidden City. Edinburgh: National Museums of Scotland.

ZHANG Nan 張南. 2002. Lao Yangzhou yishi 老揚州遺事 [Tales of Old Yangzhou]. Ji'nan: Shandong renmin chubanshe.

ZHANG Shunhui 張舜徽. 2004. Qingdai Yangzhou xueji 清代揚州學紀 [Studies of Qing Yangzhou]. Yangzhou: Guangling shushe.

Z HANG Xiumin 張秀民 and HaN Qi 韓琦, eds. 2006. Zhongguo yinshua shi 中國印刷史 [History of Chinese Printing]. 2 vols. Hangzhou: Zhejiang guji chubanshe. Revised edition.

ZHANG Yanyuan 張彥遠. 1983. Lidai minghua ji 歷代名畫記 [Record of the Famous Painters of All the Dynasties]. In Yingyin Wenyuange siku quanshu 影印文淵閣四庫全書, vol. 812. Taibei: Taiwan shangwu yingshuguan. Reprint.

ZHANG Yiguo 張靖國. 2004. Zixu Yangzhou shi 自敍揚州事 [My Own Account of Events in Yangzhou]. In Luo Ergang 羅爾綱 and Wang Qingcheng 王慶成, eds. Taiping Tianguo 太平天國 [Taiping Heavenly Kingdom] In Zhongguo jindai shiliao congkan xubian 中國 近代史料叢刊續編. Guilin: Guangxi shifan daxue chubanshe, vol. 4: 322-324.

ZHANG Yunhe 張允和. 1982. Yi kunqu Quanfuban 憶芘曲全福班 [Remembering the Quanfu Kunqu Troupe]. In Xiqu luncong 戲劇論叢, vol. 1.

ZHANG Yusheng 張宇聲. 1996. Wang Yuyang Yangzhou wenxue huodong pingshu 王漁洋揚 州文學活動評述 [A Critical Account of Wang Yuyang's Literary Activities in Yangzhou]. Zibo shizhuan xuebao 淄博師專學報1: 50-57. 
ZHANG Zhengming 張正明. 2003. Ming Qing Jin shang ji mingfeng 明清晉商及民風 [Shanxi Merchants and Their Customs in the Ming and Qing Periods]. Beijing: Renmin chubanshe.

ZHAO Jingshen 趙景深. 1980. Zhongguo xiaoshuo congkao 中國小說叢考 [A Series of Studies on Chinese Fiction]. Ji'nan: Qi Lu shushe.

Zhao Weihang 趙莘航, Song Jianguo 宋建國, Le Hesong 勒鶴松 and Cheng Xiaoquan 成小全. 1991. Yangzhou lishi wenhua fengmao 揚州歷史文化風貌 [Historical Culture and Customs of Yangzhou]. Shanghai: Tongji wenxue chubanshe.

Z HaO Yu 趙瑜. Jinzhuan shi shicun 晉瓧室詩存 [Extant Poems from the Jinzhuan Study]. Tongzhi edition.

ZHENG Changgan 鄭昌淦. 1989. Ming Qing nongcun shangpin jingji 明清农村商品经济 [The Rural Commodity Economy in Ming Qing Times]. Beijing : Zhongguo renmin daxue chubanshe.

ZHENG Qi 鄭奇. 1991. Lun Yangzhou yisilanjiao yinshi wenhua 論揚州伊斯蘭教飲食文化 [On Islamic Dietary Culture in Yangzhou]. In Wei Paichun 魏培春, ed. Yisilan jiao zai Yangzhou 伊斯蘭教在揚州 [Islam in Yangzhou]. Nanjing: Nanjing daxue chubanshe, 91-101.

ZHENG Weizhang 鄭偉章. 1999. Wenxianjia tongkao 文獻家通考 [A Comprehensive Study of Textual Scholars]. 3 vols. Beijing: Zhonghua shuju.

Zheng Xie 鄭煷. 1985. Zheng Banqiao quan ji 鄭板橋全集 [Complete Writings by Zheng Banqiao]. Bian Xiaoxuan 市孝萱, ed. Ji'nan: Qi Lu shushe.

Zheng Yuanxun. 2004. A Personal Record of My Garden of Reflection. Translated by Duncan Campbell. Wellington, New Zealand: Asian Studies Institute, Victoria University of Wellington.

Zhongguo banke tulu 中國版刻圖錄 [Illustrated Catalogue of Chinese Rare Editions]. 1961. Beijing tushuguan 北京圖書館, ed. 8 vols. Beijing: Wenwu chubanshe.

Zhongguo chengshi jianshe shi 中國城市建設史 [History of Chinese City Planning]. 1982. Bei Tongji daxue 北同濟大學, ed. Beijing: Jianzhu gongye chubanshe.

Zhongguo da baike quanshu. Xiqu - Quyi 中國大百科全書, 戲曲 - 曲藝 [Encyclopedia of China. Drama and quyi ]. 1983. Beijing - Shanghai: Zhongguo da baike quanshu chubanshe.

Zhongguo gudai shuhua tumu 中國古代書畫圖目 [Illustrated Catalogue of Ancient Chinese Calligraphy and Paintings]. 1986-2000. Zhongguo gudai shuhua jianding zu 中國古代 書畫鑑定組, ed. 23 vols. Beijing: Wenwu chubanshe.

Zhongguo guji shanben shumu 中國古籍善本書目 [National Union Catalogue of Chinese Rare Books]. 1985-1996. Zhongguo guji shanben shumu bianji weiyuanhui 中國古籍 善本書目編輯委員會, ed. 9 vols. Shanghai: Shanghai guji chubanshe.

Zhongguo meishu quanji, huihua bian, 11 中國美術全集, 繪畫編 11 [Complete Collection of Chinese Art; Painting, vol. 11]. 1988. Shanghai: Shanghai renmin meishu chubanshe. Zhongguo tongsu xiaoshuo zongmu tiyao 中國通俗小說總目提要 [Chinese Popular Fiction: General Catalogue and Abstracts of Contents]. 1990. Jiangsu sheng shehui kexueyuan Ming Qing xiaoshuo yanjiu zhongxin 江蘇省社會科學院明清小說研究中心 and Jiangsu 
sheng shehui kexueyuan wenxue yanjiusuo 江蘇省社會科學院文學研究所, eds. Beijing: Zhongguo wenlian chuban gongsi.

Zhou Cun 周邨. 1956. Taiping jun san xia Yangzhou 太平軍三下揚州 [How the Taipings Seized Yangzhou Three Times]. Nanjing: Jiangsu renmin chubanshe.

— 1957. Taiping jun zai Yangzhou 太平軍在揚州 [The Taiping Army in Yangzhou]. Shanghai: Shanghai renmin chubanshe.

Zhou Mi 周密 1983 [ca 1275]. Yunyan guoyanlu 雲煙過眼錄 [Record of Clouds and Mists Passing through Ones' Eyes]. In Yingyin Wenyuange siku quanshu 影印文淵閣四庫全書. Taibei: Shangwu. Reprint.

ZHou Sheng, see Jiaodong Zhou Sheng

Zhou Xinhui 周心慧, ed. 1998. Mingdai banke tushi 明代版刻圖釋 [Illustrated Survey of Ming Editions]. 4 vols. Beijing: Xueyuan chubanshe.

Zhou Yibai 周貽白. 1953. Zhongguo xiju shi 中國戲劇史 [History of Chinese Drama]. 3 vols. Shanghai: Zhonghua shuju.

Zhou Zhaoxin 周兆新. 1994. 'Huaben' shiyi «話本»釋義 [Explaining the Meaning of 'Huaben']. In Guoxue yanjiu, di er juan 國學研究, 第二卷. Beijing daxue Zhongguo chuantong wenhua yanjiu zhongxin 北京大學中國傳統森化研究中心, ed. Beijing: Beijing daxue chubanshe, 195-209.

ZHU Jiang 朱江. 2002. Yangzhou yuanlin pinshang lu 揚州園林品賞錄 [Sampling Yangzhou’s Gardens]. Shanghai: Shanghai Wenhua chubanshe.

ZHu Jingxuan 朱景玄. 1983. Tangchao minghua lu 唐朝名畫錄 [Record of Famous Painters of the Tang Dynasty]. In Yingyin Wenyuange siku quanshu 影印文淵閣四庫全書, vol. 812. Taibei: Taiwan shangwu yingshuguan. Reprint.

ZHu Mouyin 朱謀垔. 1983. Hua shi hui yao 畫史會要 [Compendium of Painting History]. In Peiwenzhai shuhua pu 佩文齋書畫譜, vol. 53. In Yingyin Wenyuange siku quanshu 影 印文淵閣四庫全書, vol. 819-823. Taibei: Taiwan shangwu yingshuguan. Reprint.

Zhu Yixuan 朱一玄, ed. 1989. Ming Qing xiaoshuo ziliao xuanbian 明清小説資料馔編 [Selected Collection of Materials on Ming Qing Novels]. Ji'nan: Qi Lu shushe.

ZHu Zhu 祝竹 et al. 1989. Yangzhou daoyou 揚州導遊 [Yangzhou Guide]. Shanghai: Shanghai wenhua chubanshe.

ZHu Ziqing 朱自清. 1981. Wo shi Yangzhouren 我是掦州人 [I Am a Man of Yangzhou]. In Zhu Jinshun 朱金順, ed. Zhu Ziqing yanjiu ziliao 朱自清研究資料 [Research Materials on Zhu Ziqing]. Beijing: Shifan daxue chubanshe.

1989 [1929]. Yangzhou de xiari 揚州的夏日 [Yangzhou Summer Days]. In Gu Yiping 顧一平 and ZHu Zhu 祝竹, eds. Yangzhou youji sanwen xuan 揚州遊記散文選 [A Collection of Yangzhou Travelogues]. Yangzhou: Hanjian yinshua, 78-80.

ZHu Zongzhou 朱宗宙. 1991. Qingdai Yangzhou yanshang jutou - Jiang Chun 清代揚州 鹽商巨頭 - 江春 [Jiang Chun - the Giant Salt Merchant of Qing Yangzhou]. Yangzhou shi zhi 揚州史志 19.3: 17-20.

ZhuANG Jifa 莊吉發. 1989. Xie Zhui 'Zhigong tu' manwen tushuo jiaozhu 謝遂 《職貢圖》滿 文圖說校注 [Annotated Manchu Commentary on Xie Zhui's 'Pictures of the Envoys]. Taibei: National Palace Museum. 
Zhuang Sue 莊素娥. 1989. Gao Xiang he tade shanshuihua 高翔和他的山水畫 [Gao Xiang and His Landscape Painting]. Yishu pinglun 藝術評論 (Taibei National University of the Arts) 1: 125-142.

1991. Li Fangying he Li Shan de guanxi 李方膺和李鱓的關係 [The Relationship of Li Fangying and Li Shan]. In Gugong xueshu jikan 故宮學術季刊 8.2: 111-142.

1992. Li Shan de Wusong tu 李鱓的五松圖 [Li Shan's Five Pines]. Yishu pinglun 藝術 評論 (Taibei National University of the Arts) 4 (1992): 77-127.

1996. Gao Fenghan huihua yanjiu 高鳳翰繪畫研究 [The Study of Gao Fenghan's Painting]. Taibei: Yishujia chubanshe. 


\section{Index}

Page reference in italic typeface $=$ illustration .

A Ying 阿英, I8

academies (shuyuan 書院), IO, I2, I6, 33 n39, 53, IO9, IIO, II5, I53

accessories, 67, 68, 69, 70, 72, 306, 364, 367

actors, I45, 208, 2II, 2I2, 2I3, 2I4-216, 2I8-22I, 222, 223 n7, 224 nio, 225, 228-230, 235, 242, 293, 301, 303

female,- 2II-2I2, 229, 230, 233,

29I-293

administrative offices, 5, 6, 7-8, I7, 20, 21, 22, 3I ni6, 32 n25, 33 n33, 34 n5I, 36 n69, 4I, 47, $53,59 \mathrm{nI} 4,89, \mathrm{II} 2, \mathrm{I} 63, \mathrm{I} 68,207,2 \mathrm{I} 2-2 \mathrm{I} 4$

Ai Xuan 艾煊，28，35 n64

Alcock, Rutherford, 9I

alcohol, I3, I66, I97, 294, 305; see also wine architecture, 3, I6-I7, I8, 33 n43, 34 n53, 35 $\mathrm{n} 62, \mathrm{n} 63, \mathrm{n} 64,75,92,97,356$

artisans / craftsmen, I7, 33 n40, 78, 79, II2, $\mathrm{I} 23, \mathrm{I} 67,225,3 \mathrm{I} 8,376$

Attiret, Jean-Denis, 350-35I, 357-358, 364

Auden, W. H., 95

authorship, I54, I74 ni8, I79, I95, 203 n3I

Avatamsaka Sutra, 4I9, 42I-422, 425, 437 n39

Bai jushi 白居士 (Layman Bai), 4IO, 434

Bai Juyi 白居易, 50, IO3

Bakhtin, Mikhail M., 197

ballads, see drum ballads, Yangzhou qingqu

Banqiao shichao 板橋詩鈔 [Selected Poetry of Zheng Xie], I24

Bao Rong 鲍溶, 76

Bao Zhao 鲍照, 5

Beijing, 9, I7, I8, 69, 88, 89, II8, I23, I26, I32,

I35, I4O, I4I, I42, 208, 2II, 2I3-2I4, 2I5, 2I 8 , 222, $223 \mathrm{n} 7,225,226,227,229,237-238,3 \mathrm{I} 3$ n29, 356, 357, 365, 366, 368, 370, 4I5

Bender, Mark, 247

bianxiang 變相 (transformation tableau), 4I44I5, $436 \mathrm{n} 23$ biographies, biographers, $32 \mathrm{n} 28,40,45,51,52$, 53-54, I2I, I26, I33, I5I, I53, I59, I79-I8O, I92, 223 n5, 224 nI4, 230, 253, 364, 400, 4I9, $435 \mathrm{nI} 7,438 \mathrm{n} 53$

birthday (celebration), I43, I44, I45, I46, I5I, I69, 208, 2I3, 226, 233, 235, 360, 370

Bodhidharma, 4II, 4I3

Bole, 伯樂 360

books, book culture, xxiii, I6, 2I, 44, 5I-54, I09-I3O, I77, 224 ni6, 234, 250, 365 collecting, I8, 52, II2-II3, II7, I42 illustrations, IO, $32 \mathrm{n} 29,65$, I5O, I8O, I8I, 290, 438 n50 prohibited , 2OI nI2, 3I2 n7 See also libraries; publishing

Børdahl, Vibeke, 2oI ns

bridge(s), 8, 9, I7, 24, 25, 29, 33 n4I, 34 n48, 4I, 95, I60, I63; see also Red Bridge

Brokaw, Cynthia, I77

brothel, IO, I87, I94, 202 n2O, 2II-2I2, 286-288, 29I-3I4, 3I2 n7; see also pleasure house

Buck, Pearl S., 9I

Buddhism, Buddhist xxiii, I6, I7, I27, I35, I37, I48 nI2, I5I, I54, I69, I70, I75 n24, I76 n37, 2IO, 219, 233, 235-236, 24I, 354,

- painting 342, 402-440, 406, 408, 4I2, 4I4, 42O, 424, 426, 428, 43I-434

bureaucracy, see administration; salt officials burials / tombs / cemeteries / funerals, I3, I6, 22, 24, 30 n 3, 30 n5, 30 n7, 30 n9, 34 n46, 38, 48, 54, 6I n32, I64, I69, I75 n25, 233

Cai Yong 蔡䠛, 365

calligraphy, 23, 89, II2, II4, II9, I24, I36, I39, $225,253,273,285,317,354,365,376,380$, 384, 399, 4IO, 435 nio; see also epigraphy canals, 5, 7, 8, 9, IO, I2, I3, I6, 2I, 26-27, 34 n50, 50, 51, 70, 93, 99; see also Grand Canal Cao Juren 曹聚仁, 34 n 44 
Cao Xueqin 曹雪芹 (Cao Zhan 曹露), II

Cao Yin 曹寅, II7, II9, 242

Castiglione, Giuseppe, 350-35I, 358, 359, 36I, 362, 370, $375 \mathrm{n} 38$

chantefable 178 , see tanci

characters (Chinese script), $13,58 \mathrm{n} 8, \mathrm{15} 6$, 254-255, 256, 262, 265, 266, 269 ni 4,270 n2O, 276, 294, 314 n3o

characters (literary -), I56-157, I59, I63, I67-I69, I86-I88, I95, 242, 270 nI7

charity, 6I n32, I5I, I63, I8O, 202 n2I

Chartier, Roger, 204 n36

Chen Henghe 陳恒和, I27

Chen Lüheng 陳履恒, I27

Chen Nan 陳楠, from Fenghua, II4-II5

Chen Nan 陳楠, from Shangyu, II6

Chen Nian 陳年, 342

Chen Qinian 陳其年, I37, I39, I4I, I45-I46

Chen Qinghua 陳清華, I29 n4

Chen Weisong 陳維崧, see Chen Qinian

Chen Wulou 陳午樓, 246-247

Chen Yucheng 陳玉成, 219

Chen Zhang 陳章, I2I

Chen Zhenhui 陳貞慧，I45

Cheng Bangrui 程邦瑞，I26

Cheng Mengxing 程夢星, 370

Cheng Qiande 程謙德, 230

Cheng Yourong 程有容, I63

Chibei outan 池北偶談 [Random Talks at the

North of the Pond], I32-I33

childhood / child(ren), xxiii, 23, IOI, I03, I44, I69, 2II-2I2, 2I6, 2I8, 223, 223 n7, 248, 360

Chuan jia bao 傳家寶 [Family Treasure], I5O, I5I-I53, I7I

city novel, 64, 69-7I, 98, I77

city walls / fortification, IO, II, I9, 33 n35, 35

n65, 40, 4I, 48, 9I, 93, 99, 166; see also gates

clothing, xxii, 62-74, 96, 100, 180, 182, 219,

223, 291, 306, 309, 349-350, 364, 367, 368,

374 n24, 409, 4II, 435 nI3

comicality, I5I, I90, 192, 197, 202 nI3, 2II, 215, 235-237

commoners, common folk, $32 \mathrm{n} 25,38,45-47$, 76, IO2, I4I-I43, I52, I69, I72, I75-I76 n35, I78, $437 \mathrm{n} 38$

communism, communist, $20,33 \mathrm{n} 32,37,58-59$ n8, 94, 100
Confucius, Confucian, 52, 57, I33, I46, I5I, I53, I70, 190, 2I2, 416

construction / reconstruction, I6-I7, I9, 25, 43, $48,51,52$

countryside / rural regions, xxii, I2, I9, 20, 29, $38,47,69,85,93,99, \mathrm{I} 44, \mathrm{I} 5 \mathrm{I}, \mathrm{I5} 8, \mathrm{I67}, \mathrm{I70}$, I78, 183, 199, 200, 208, 216, 247, 292, 302, 303, 305, 354, 364, 382; see also peasant couplets (duilian 對聯), I5I, 255, 26I

courtesans, xxiii, 67, 70, 98, 225, 232, 233, 291-293, 295-296, 300, 303, 305-306, 310, $314 \mathrm{n} 35$; see also prostitutes

Cui Hua 崔華, I69

Cole, James, $58 \mathrm{n} 3$

Cultural Revolution, I6, 22-23, 34 n50, 35 n54, $227,234,250$

Cunsu tang wenji 存素堂文集 [Collected Prose Writings of Cunsu tang (Fashishan)], I26

Dai Buzhang 戴步章, 250-253, 25I, 255, 257-258

Dai Chunlin 戴春林, 69

Dai Shanzhang 戴善章, 250, 273, 277

Daode jing [Classic of the Way and the Virtue], II4

Daoism, Daoist, I7, II4, I57, I70, 233, 435 nIO decline, xxii, II, I2, I7, 45, $60 \mathrm{n} 24,62,90,98$, IO2, I26, I58, 222, 226, 230, 292

destruction, I7, $30 \mathrm{n} 4,37,40,48,5 \mathrm{I}$

Dexing'a 德興阿, I5

dialect, xxii, 69, I77, I78, I83-184, I85, 196, 202 nI4, ni6, ni8, 203 n22, 208, 22I, 225, 229-230, 237-242, 244 n9, 256, 265, 286, $287,289,3 \mathrm{I} 3 \mathrm{n} 25$

dialogue, I83, I86, $202 \mathrm{nI}, 226,228,230,234$, 238, 254, 26I, $270 \mathrm{nI}, 295-304$

diaries, xxii, II, 39, 43-46, 59 nI4, 98, I29 nII, 366

Ding Changshan 丁長山, 219

Ding Richang 丁日昌, 2OI nI2

Ding Yin 丁㻆，I42

Ding Youyu 丁有煜, 394

Dong Qichang 董其昌, 69

Dong Yushu 董玉書, 232

Dongxin xiansheng ji 冬心先生集 [Collected

Writings of Mr Dongxin], I24

drama, see play, theatre

drum ballads / songs (dagu, guci), I86, 247 
Du Ganquan 杜乾全， 20

$\mathrm{Du} \mathrm{Fu}$ 杜甫, $\mathrm{I} 34$

$\mathrm{Du} \mathrm{Mu}$ 杜牧, 3, 9, 287, $434 \mathrm{nI}$

Du Xinfu 杜信孚, I29 n9

Edgren, J.S., 312 nI4

elite / gentry, xxii, 7, 8, 18, 22, 33 n43, 45-47,

50, 53, 54, 57, 6r n36, 64, 65, I36, I3I-I47,

I5I, I52, I62, I68, I69, I72, I78, I80, 29I, 403, $4 \mathrm{I} 6,434 \mathrm{n} 3$

embroidery, 62, 66, 73, 249

epigraphy / inscriptions, 23, 26, 29, 50, I24-I26, I36-I37, I39, 224 n9, 365, 4IO; see also paintings, inscriptions on -

eroticism / sex, 58 n6, I66, I74 n2I, I88, 203 n27, 21I, 2I5-216, 217-218, 219, 287,

295-300, 302-304, 313 n22, n24

Erya yintu爾雅音圖 [Erya Lexicon with Illustrations], II9

Fan Da 樊大, 215, $224 \mathrm{nI} 3$

Fan Zizhang 樊紫章, 273

Fang Fu 方輔, IO2

Fang Junyi 方浿頣，16, 39, 43, 49-5I, 52-53, 58 n6, 60 n29, 6I n3I

Fang Shishu 方士庶, 4II

Fang Zhixing 方之杏，55-56

fashion, xxii, II, 62-74, 96

Fashishan 法式善, I23, I26

Faure, Bernard, 435 nI2

Fei Junliang 費駿良，258, 259-260, 265, 270 n2O, 277

Fei Li 費力 (Fei Zhengliang), 259-260, 262, 263, 265, $270 \mathrm{n} 2 \mathrm{I}$

Fei Tuo quan zhuan 飛跎全傳 [The Braggart's Tale], I77, I86, $202 \mathrm{nI} 3$

Fei Xiaotong 費孝通，33 n42

Fei Zhengliang 費正良, see Fei Li

Feng Menglong 馮夢龍, I54-I55, I70

Fengyue meng 風月夢 [Illusion of Romance], 64, 70, 98, I77, I78, I84, I85, I87, I92-I95, 20I n2, $286,295,297,302,305,306$

Fenlituo xingzhe 芬利它行者, 228

festival, festive day, 40, 68, I39-I4O, I4I, I44, I45, I8I, I92, 2I6-2I7, 226, 232, 235, 427, 434; see also birthday

filial (piety), 55, I51, I53, I67, I96, 354, 382
Finnane, Antonia, 3I ni6, 89, 92, I78, I84, 200, 204 n35, 213

Fong, Grace S., 54

Fonteyn, Margot, 95

food / cuisine, 3, 4O, 4I, 44, 59 nI5, 72, 89, 93, I36, I76 n36, I80, I93, 273, 276-278, 294, 299, 300, 301, 303, 310, 314 n31, 36I, 369, 375 $\mathrm{n} 37,437$ n 45

- supply I2, I3, I4-I5, I9, 42

See also restaurants

foreign (Western) goods \& trends, I8, 29, 35 n63, 63, 64-65, 69, 70, 71, 73, 88-89, 92, 94-98, 226, 306, 314 n36, 339, 356-357, 367

Forster, E.M., 146

Fortune, Robert, 98-99

Foyin Liaoyuan 佛印了元, see Liaoyuan

$\mathrm{Fu}$ Chai 夫差, the king of Wu, 5

Fu Zehong 傅澤洪, I68

Fu Zhi 傅䅏, II2

Fukang'an 福康安, 68

Fusheng liuji 浮生六記 [Six Chapters of a Floating Life], II

gambling, I3, I69, I70, I79-182, I89, I94-196, 204 n34, 294, 295, 297-298, 30I, 304

Gao Degui 高得貴, I69

Gao Fenghan 高鳳翰, 318, 324, 334-335, 337-339, 338, 341, 342, 370, 371, 372

Gao Heng 高恆, 32 n29

Gao Jie 高傑, 7

Gao Lian 高濂, 349

Gao Ming 高明, 217

Gao Shiqi 高士奇, 360

Gao Xiang 高翔, 327

gardens \& parks / garden culture, xvi, xxii, 3 , 7, 9, IO, II, I6-23, 24-25, 26, $32 \mathrm{n} 26,32 \mathrm{n} 27$, $34 \mathrm{n} 45,34 \mathrm{n} 55,35 \mathrm{n} 60,44,49,59$ nil, 64, 75-86, 87, 88-89, 9I, I36, I66, I96, 204 n35, 213, 218, 369, 394, 402, 4I5, 4I7, 430; see also He yuan

gates, 4, I6, I9, 34 n47, 34 n5I, 36 n69, 6I n37, I4I, I42, I63-I66

gathering, social / party, xxi, 38-39, 43-46, 49, $52,79,89,98, \mathrm{I} 3 \mathrm{I}, \mathrm{I} 33, \mathrm{I} 35, \mathrm{I} 36-\mathrm{I} 37, \mathrm{I} 42, \mathrm{I} 45$, I46, I47 n8, I66, I82, 2I9, 232, 243, 246, 376, 400 n3, 404, 4II, 4I7 
gazetteer, 7, 3I ni9, 42, 48, 49-50, 5I-56, 65,

7I, II3, II5, I26, I5I, I52, 2I6, 29I

Geng Tianbao 耿天保, 85

Geng Jianting 耿鑒庭, 233

gentry, see elite

Giddens, Anthony, IO2

Gong Xian 龔賢, 384, 40I nIs

Gong Zizhen 竟自珍, II

Grand Canal, 4, 5, I0, I2, I3, 22, 64, 72, 91, 94, 95, I84, 207, 225, 229, 245

Grant, Beata, 429

Gu Aiji 顧譪吉, I22

Gu Kaizhi 顧愷之, 409, 434, 438 n56

Gu Lienüzhuan 古列女傳 [Biographies of

Exemplary Women of the Past], I26

Gu Qiyuan 顧起元, 66

$\mathrm{Gu} \mathrm{Xi}$ 顧禧, II2

Guan Yu 關羽 / Guandi 關帝 / Guan gong 關 公, I32, 232, 233, 244 n4, 265, 270 n2I

Guangling jinshi, Guangling jiushi 廣陵近事廣陵 舊事 [Old Events in Yangzhou and Recent Events in Yangzhou], 60 n27

Guinness, Geraldine, 92, 98

Guo Hancheng 郭漢城, 2I4

Guochao huazheng lu 國朝畫徵錄 [Recorded Evidence about Paintings of Our Dynasty], 325

Guyu tupu 古玉圖譜 [Illustrated Catalogue of Ancient Jades], I2I

Hahn, Emily, 92

hair, 63, 68, 72, 100, 167, 367, 416

Haishang hua liezhuan 海上花列傳 [Lives of

Shanghai Flowers], 98, 313 n25

Halferty, Bruce W., 36 n66

Han Bangqing 韓邦慶, I78, 3I3 n25

Han Yu 韓愈, I2I

Han Zhuo 韓拙, 354

Hanan, Patrick, 64, 98, I54, I7I, I75 n32, I89

Hang Shijun 杭世駿, 332

Hangzhou, 9, 53, 66, 7I, 75, 80, I05 n35, I09, II2, I2I, I28, I39, I59, I89, 22I, 226, 364, 366, 403, 4I8, 434

Hanjiang sanbai yin 干阝江三百吟 [Three Hundred Tunes of River Han], II Hanshang Mengren 邗上蒙人, 72, 3II nI Hao Tianxiu 郝天秀, 213, 215 hats / headwear, 66, 68

Hay, Jonathan, 102

He Jun 何俊, 99, I05 n37

He Ruchi 何汝持, 97

He yuan 何園, 23, 24, 35 n55, 35 n6o, 77, 80, 8I, $83,84,97$

He Zhidao 何芷舠, 35 n6o

Heshen 和珅, $215,224 \mathrm{nII}$

homosexuality, I45-I46, 2I5, 314 n32

Hong Chongshi 洪充實, 229

Hong Fuxiang 洪福祥, I7

Hong Liangji 洪亮吉, 366, 372

Hong Xiuquan 洪秀全, 33 n32, 219

Honglou meng 紅樓夢 [Dream of the Red Chamber], II7, I94-195, 200

Hongqiao changhe $j i$ 紅橋唱和集 [Collection of Poems from the Red Bridge (Ceremony)], $\mathrm{I} 37$

Honig, Emily, 305

Hou Jing 侯景, 5

Hrdličková, Věna, 247

Hsü, Ginger, 89, I02, I29 ni6, 378, 40I nI5, $4 \mathrm{IO}, 4 \mathrm{I} 8,434 \mathrm{n} 2,435 \mathrm{n} 6$

Hu Hong 胡紅, 87-88

Hu Shi 胡適, 237

$\mathrm{Hu}$ Shiying 胡士瑩, I55

$\mathrm{Hu}$ Zhaozhang 胡兆章, 250, 252

Hua Yan 華品，xxiii， IOI, IO5 n40, 339, 347-352, $348-349,353,362-366,363,365,368-373$, 402-404, 417-43I, 420, 424, 426, 428, 434-435 n6, n7, n8, 437 n38, 438 n5o

Huabu nongtan 花部農譚 [Peasant Chats on Popular Theatre], 207-208

Huaihai ji 淮海集, IIO-II2

Huaisu 懷素, 380, 4II

Huang Gongwang 黄公望，378

Huang Shen 黃慎, xxiii, 324, 327, 334, 338, 339, 376-40I, 377-38I, 383-393, 395-398

Huang Sheng 黃晟, I22

Huang Yuande 黃元德, 230

Huang Zhijun 黃至笉, 35 n6o

Hui Dong 惠棟, I35

huiguan 會館, see regional associations

Huizhou 惠州 (Anhui), 8, I0, 35 n62, 63, 89, I60, I63, I78-180, I84-I85, I95-I97, I99, 213, 301, 362, 368, 369; see also Shexian

hydraulic works / dikes, 7, I2, I9, 34 n5O 
Ibn Kherdadbeh, 5

Iguchi, Junko, 247

imperial lodge / travel palace (xinggong 行

宮), 8, 9, 50, 356

industry, $12,19,20,63,67,93-94$

Japan, Japanese, 6, 19, 34 n48, 35 n63, 62, 87,

$93,96,227,276,287,312 \mathrm{n} 5,367,402$

Ji Cheng 計成, 78, 80

Ji Yun 紀昀, 372

Jia Jia 賈佳，I73 n9

Jia Sidao 贾似道, 75

Jianzhen 堅貞, 3, 26, 30 nI, 402

Jiang Chaobo 蔣超伯, 49, 50

Jiang Chun 江春, IO, 32 n24, 32 n25, I2I-I22, 2I2-2I $4,215,222,223 \mathrm{n} 5,230$

Jiang Hua 蔣華, 345 n32

Jiang Kui 姜薊, 30 n8, 75, 288

Jiang Shoushan 江壽山, 253

Jiang Tingxi 蔣廷錫，358

Jiang Zemin 江澤民，26, 29

Jiao Tinghu 焦廷琥，216, 224 nI4

Jiao Xun 焦循，I26, I27, 200 nI, 207, 215-219,

$224 \mathrm{nI} 4$

jiaoben 腳本, see scripts

Jiaochang 教場 (Parade Ground), IO, II, 25, 68, 272, 278

Jiaodong Zhou Sheng 焦東周生, see Zhou Sheng

Jin Anqing 金安清, I5, 59 nII

Jin Changfu 金長福, 40,43-48, 52-53,58 nI, $60 \mathrm{n} 27,60 \mathrm{n} 33,98$

Jin Nong 金農, xxiii, IOI, IO2, I24, 318, 332, $34 \mathrm{I}-342,343,365,402-4 \mathrm{I} 7,406,4 \mathrm{I} 2,425$,

$430-434,434-435 \mathrm{n} 6,435 \mathrm{n} 7, \mathrm{n} 8, \mathrm{nI} 5,436$

n2o, n25, n28, n29, n3o, n32

Jin Xiaofang 金小舫，59 nI2

Jin Yuan 金瑗, 4OI nI5

Jin Zhaoyan 金兆燕, I28, I79, I80

Jin Zhen 金鎮，169

Jin Zhizhang 金志章, 366

Jingju 京劇 ('Peking Opera'), 208, 210,

2I3-2I4, 215, 222, 224 nI2, 237

Jingshi tongyan 驚世通言 [Comprehensive

Words to Admonish the World] I86

Jingyi kao 經義考 [Examination of the

Classics], I23

Jinkang 至康, 42
Juedaoren 覺道人, see Shi Chengjin

Kangxi 康熙, emperor, 8, 3I nI7, II3, II7, 242, 354,360

Kong Luhua 孔璐華, 67

Kong Shangren 孔尚任, 32 n27, 62

Korea, Korean, 69

Koxinga, see Zheng Chenggong

Kunqu, xvi, xxii, 89, 178, 208-209, 212, 213, 2I8, 220, 224 ni3, 225-244, 246, 369; see also qingchang

Lai Wenguang 賴汶光，15

Lang Shaojun 郎紹君, 382, 384, 4OI nI3

Lang Shining 郎世寧, see Castiglione

language (Chinese), 54, 60 n25, I79, I84, I88, 200, 230, 237-242, 359, 367

stage , 229-230, 237-242, 244 n9,

249, 255-256, 257, 263-264, 264-265

written - (wenyan, baihua), I46, I52,

I78, I79, 254-257, 26I, 264-265, 266,

270 n22, 289, 293-294, 298, 4I7

See also dialect

letters (correspondance), 3I n22, 44, I34, I35,

$\mathrm{I} 43,254,273,3 \mathrm{I} 8,372$

Level Mountain Hall, see Pingshan tang

Li Bai 李白, 87

Li Dongyang 李東陽, I26

Li Dou 李斗, IO, 3I n22, 32 n28, 67-68, 7I, 72, 79, 89, I24, I77, I78, I86, I92, 208, 2II, 2I2,

2I4, 215, $223 \mathrm{n} 4,227-233,369,370,373,410$

$\mathrm{Li}$ E 厲鶚, I2I, 373 nI, 440 nIoo

Li Fangying 李方膺, IOO, 318, 328, 329, 332,

$333-336,335,339$

Li Gan 李涂, 62-63, 67-68

Li Gang 李綱, 9

Li Gonglin 李公麟，416, 4I9

Li Jiarui 李家瑞, 313 n29

Li Jing 李敬, I4I

Li Kaifang 李開芳, 13, 33 n36

Li Kuangji 李匡濟，I7

Li Shan 李鱓, 318-327, 319-323, 330, 332,

$333-336,335-337,339,340,340$

Li Wancai 李萬才, 376, $400 \mathrm{n} 4$

Li Xiaochuan 李孝傳, I48 nII

Li Xiufang 庽秀芳, 217

$\mathrm{Li} \mathrm{Xu}$ 李煦, II7

Li Yaru 李亞如, 285 
$\mathrm{Li} \mathrm{Yu}$ 李漁, I45, I55, I74 nI9

Li Zicheng 李自成， I75 n29

Liang Kai 梁楷, 405, 408, 409, 435 nI5

Liang Sicheng 梁思成, 26

Liao Keting 廖可亭, $33 \mathrm{n} 43$

Liaoyuan 了元, I39-I40, I48 nI2

Libian 隷辨 [Dictionary of Clerical Script], I20, $\mathrm{I} 22$

libraries, 9, I6, I8, 33 n32, 35 n63, 58, II2-II3, II7, I2I, I26, I29 n4, I73 n4, I74 nIO, nII

Ligou ji 離垢集 [Leaving the Filth of the

World], 373 nI, 4I9, 437 n36, n43

Lin Fengxiang 林鳳祥, I3, 33 n36, 40

Lin Gao 林者, 333, $345 \mathrm{n} 36$

Lin Gudu 林古度, I42, I46

Lin Ji 林佶, II9

Lin Ji 林機, III

Lin Li-yueh 林麗月, 65

Lin Sumen 林蘇門，II, 66, 69-70, 7I, 72, 2II

Lin Xin 林金金, 233

Lin Yutang 林語堂, 64

Ling Mengchu 凌濛初, I54-I55, I58, I70

Litang daoting lu 里堂道聽錄 [(Jiao) Litang's

Scholarly Notes], I27

literary criticism, I3I, I 48 nI2, I58

- genres I7I; see also biographies; city novel; diaries; letters; morality book; novel; poetry; theatre; vernacular story; vignette; zhuzhici

Liu Baonan 劉寶楠, 53

Liu Gongmian 劉恭冕，53

Liu Guandao 劉貫道，352，354，355

Liu Jingting 柳敬亭，245

Liu Maoji 劉茂吉, 32 n29,

Liu Shisan 劉式三，86

Liu Yanjun 劉彦君, 223 n4

Liu Yueting 劉躍庭，I27

Liu Zongyuan 柳宗元, I2I

Liuye qupu 六也曲譜 [Liuye Kunqu

Scores], 238, 239-24I, 243

local identity, 56, I58-I59, I77, I84 4II

locals (versus immigrants), I0, 67, 69, I04 n9,

I78, I80, I84, 196

Lou Qi 樓錡, I2I

loyal, loyalty, loyalist, 9, 37, 4I, 44, 46-48, 53-56, I40, I42, I43-I 44, I76 n38

Lü Dongbin 呂洞賓，I57, 233
Lu Jianzeng 盧見曾，I23， I 47 n8, 367, 370

Lu Qi 陸圻, I35

Lu Tanwei 陸探微, 409, 434

$\mathrm{Lu} \mathrm{You}$ 陸游, 50

Lund, Hugo, 286, 289, 310, 311 n2

Luo Pin 羅聘，I00, I24, I38, 318, 331, 332, 342, 403, 405, $434 \mathrm{n} 5$

Luo Rongtai 羅榮泰, 2I4

luxury, luxurious, xxii, 9, II, I7, I8, 40, $58 \mathrm{n} 6$, 225

$\mathrm{Ma} \mathrm{Yu}$ 馬裕, I2I

Ma Yueguan 馬曰琯, 33 n39, I2I, I23, 370

Ma Yuelu 馬曰璐，I2I

Ma Zuchang 馬祖常, II3

Macartney, George, 70, 356

Manchu, 7, 37, 42, 63, 71, 96, II7, 215, 224 n8, $347,352-356,359,367,434 \mathrm{n} 4$

Mao Pijiang 冒辟疆, I34, I36, I39, I4I, I42, I43-I44, I45, I46, I47 ns

Mao Xiang 冒襄, see Mao Pijiang

Mark, Lindy Li, 246

Massacre of Yangzhou (I645), 7, 3I ni3, 67, II7, I40, I59-I62, I75 n29, 403

McKenna, Richard, IO4 nI4

McQueen, Steve, 9I

Medhurst, British consul, 9I

Meisheng 眉生, see Jin Anqing

Meng Yue, 64, 65, 74, 97

merchants, see salt merchants

Meyer-Fong, Tobie, I3I, 434 nI, n3, 437 n34, 437 n39

$\mathrm{Mi} \mathrm{Fu}$ 米蒂, 80, 380, 394, 438 n58

middlebrow culture, I49-I5O, I72

Min Hua 閔華，370

Min Shizhang 閔世璋，163

Min Zhen 閔貞, 103

missionaries (Christian), 37, 89-90, 90, 9I,

I73, 356-360, 368

modernity, xxii, xxiii, 18, 26, 62-66, 88-102, IO5 n4I

monastery, see temple

Mongol, Mongolian, 30 n9, 69, 76, 347-360, 363, 374n24, 368, 371, 374 nI3, n24, 375 n34 moral, moralist, morality, I49, I5I, I53-I54, I56, I69-I7I, I89, 204 n36, 438 n48 morality book (shanshu 善書), I52, I70, I7I 
music, xvi, I2, 76, 89, 93, 96, го3, І36, I37, 2IO, 2II, 2I5, 2I9, 22I, 226, 228, 229, 234, 236, 248, 29I, 30I, 302, 305-306, 370

Nanjing, xvi, 7, I2-I5, I7, I9-20, 33 n35, 33 n37, $35 \mathrm{n} 66,40,42-43,53,66,69,88,89,91,92$, IO9, II4-II5, II7, I27, I34, I4I, I42, I47 n4, $227,234,238,242-243,245$, 29I, 3OI, 394, 434

$n a n q u$ 南曲 (Southern songs), I42

Nanyou ji 南遊記 [Record of a Journey to the South], 8

Naquin, Susan, 403

narrative, narration, xxii, 99, I33, I49, I58, I59, I7O, I7I, I77, I83, I87, 200, 226, 249, 254, 265,266

narrator, I57, I60, I66, I67, I69-I7I, I74 ni4, n24, I75 n25, I87, I9I, I94-I95, 203 n26, n32

Ni Zan 倪瓉, 378, 380, 382, 394

novel, xxii, 64, 98, I77-204, 257, 265, 294, 3I2 n7, 3I3 n25; see also city novel

officials, see salt officials

Olivová, Lucie, I29-I30 nI7, I30 ni8 opera, see theatre

opium, I3, 70, 277, 287, 288, 293, 294, 297, 30I, 3O2, 3O4-3II, 3I4 n37

oral saga / repertoire, see Three Kingdoms; Western Han

orality / oral transmission, xxii, I77-I80, I82-I83, I86, I98-I99, 204 n36, 2I9, 22I, $245-270$

Ouyang Xiu 歐陽修, 3, 30 nI, 49, 50, 75, I37, 437 n34

Ouyang Xun 歐陽詢, II2

painter(s), $60 \mathrm{n} 26,69,75,79,99, \mathrm{I} 24, \mathrm{I} 66,225$, $285,3 \mathrm{I} 7-43 \mathrm{I}, 43 \mathrm{I}-433$

painting, xxiii, I7, 70, 77, 86, IOO-IO2, IO5 n4I, I36, I37, 273, 29I, 3I7-440

Buddhist , see Buddhism court - , 350-35I, 356-360, 370, 374 ni5, $375 \mathrm{n} 38$

- genres / subject matters, 317, 356, $358,376,400 \mathrm{n} 4,404,4 \mathrm{I} 7,4 \mathrm{I} 8,435 \mathrm{n} 8$, 437 n36 inscriptions on $-, 318,324,325,326,327$, 328-332, 34I, 382, 399, 405, 43I-434, 409-4IO, 4I3, 4I5-4I7, 4I8-429, 435 nI5, ni6

pairs, antithetical, I56, I74 n23, I96

Pan Xiyun 潘喜云，218，219，220，22I

Pan Yulan 潘玉蘭, 22I

Parade Ground, see Jiaochang

patronage of arts / theatre, xxii, 8, 97, IOO, IO2, IO4 n7, 2I2-2I4, 2I8-2I9, 222, 292, 369, $376,402,427,434$ n2, n3, 434-435 n6

peasant / villager, 37, I5I, I67, I7I, 210, 2II, 2I6, 2I8, 291

Peiwen zhai 佩文齋 publications, II7-II8, II9, I29 $\mathrm{nI}$

performance, xxii, 33 n32, 82, 89, I36, I79, 2IO-2II, 2I5-2I8, 220, 223, 23I, 233-237, $242,246-248,255-257,264-265,278-279$, 282

performers, see actors; storytellers periodicals (newspapers, journals), I8, 34 n44, 65,96

photography, 65, 90, 93, 96, 97, I05 n29, I24 $\mathrm{Pi}$ Wu Lazi 皮五辣子, I99, 202 nis; see also Qingfengzha

Ping Buqing 平步青, I73 n8, I76 n40 pinghua 評話, see storytelling Pingshan tang 平山堂, 6, 7, 9, 16, 23, 31 nI9, 49-50, 67, 75, 76, 78, I37, I39, I4I, I42, $\mathrm{I} 64,327,428 \mathrm{n} 34,437$ n34; see also Level Mountain Hall

play / drama, I42, I45, I76 n4I, 2IO, 22I, 224 nI7, 23I, 235-237, 243, 3I3 ni8; see also theatre

pleasure boats (huafang 畫舫), 9, 32 n28, IO3, I62, I66, 229, 232, 289

pleasure district, II, 2I, 27, 28, $32 \mathrm{n} 28,56, \mathrm{I} 87$, I92, 228, 233, 286, 288, 293-3II

pleasure house, 7, I42, see also brothel poetry, poems, xxii, 39, 44, 45, 46, 52, 54, 58 n6, 59 nis, 59 ni2, 6i n34, 6i n35, 75, 89, IIo, II2, II7, I3I-I48, I48 nI2, I56, 226, 249, 253, $254,255,257,26 \mathrm{I}, 265,3 \mathrm{I} 3 \mathrm{n} 27,347,354,364$, 366, $373 \mathrm{nI}, 377,384,394,399,401 \mathrm{nI} 9, \mathrm{n} 2 \mathrm{O}$, 402, 404, 4II, 4I7, 4I9-429, $435 \mathrm{n} 7$

- about Yangzhou, 3, 5, 9, II, 32 n26, 59 nI6, 75, 87, 27I, 288 
- clubs/societies, 45, 50, IO2, I3I, I45 - quoted, 40, 55, $58 \mathrm{n6}, 60 \mathrm{nI} 7, \mathrm{ni} 8$, 67, 87, I03 n2, n3, I36, I37, I47 n6, I88, 203, 288 n32, 27I, 318, 382, 399, 405, 42I, 424-429

See also gathering

Polo, Marco, 3, 6

Pommeranz, Kenneth, IO2

population, of Yangzhou, 6 nio, 7, 20, 3I nio, $34 \mathrm{n} 49$

printing, xxii, I7, 5I, 53, I09-I30, I52-I53, I77-I78, $2 \mathrm{OI}$ n3, 289, 3IO-3II, 3I2 nI3, nI4, 428

- styles, II2, II4, II9, I2I, I22, I24, I3O nig

props / requisities, 220, 228, 229, 248, 277, 278-279

prostitutes, prostitution, I3, 62, 63, 68, 72, 74, I69, I87-I88, 2II-2I2, 287, 29I-3I4, 3I4 n35; see also brothel; courtesans; pleasure district; singsong girl

Pu Lin 浦琳, I78-I80, I92, I99, 20I n7, nio, $202 \mathrm{nI}, 203 \mathrm{n} 3 \mathrm{I}$

publishing, xvi, xxii, I8, 5I, 53, 74, I09-I30, I72, I78, I83, 2OI n2, nIo, 22I

official \& private -, IO9-IIO, II5 See also printing

Puhaddin, 24, 30 n9

Qi Baishi 齊白石, 342

Qian Qianyi 錢謙益, I42, I43, I46

Qian Zhenlun 錢真論, 53

Qianlong 乾隆 emperor, 9, 3I n2O, 32 n29, 70, 89, II3, I2O, 208, 2II, 2I3, 2I5, $224 \mathrm{nII}, 225$, $228,354,357-358,360,364,369,372$

Qin Enfu 秦恩復, I26

Qin Guan 秦觀，IIO

Qinding Quan Tang wen 欽定全唐文 [Imperially Authorized Complete Prose of the Tang Dynasty], II9, I26

Qing Huidian shili 清會典事例 [Qing Institutes,

Precedents and Sub-statutes], 46 qingchang 清唱 (pure song), 23I-233, 234 Qingfengzha 清風閘 [Qingfeng Sluice], xxii, 177-204, I85

Qingming shanghe tu 清明上河圖 [Spring

Festival on the River], 354

Qishan 琦善, I3, I4, 42
Qiu Xiangsheng 丘象升, I4I

Qiu Youxuan 丘幼宣, 394, 400 n4

Quan Tang shi [Complete Tang Poetry], 8, II6, 117

railway, I8, 29, 35 n66, I04 n6, 226

Rawski, Evelyn, 403

Red / Rainbow Bridge (Hong qiao 紅/虹橋), 7, 25, 40, I3I, I35-I37, I42, I 47 nIo, I62, I66, I75 n3I, 428 n34, 437 n34

regional associations (buiguan 會館), II, 32 n3O, $34 \mathrm{n} 53$

religious worship / beliefs, 33 n40, 6I n36, I3I, I32-I33, I34-I35, I40, I57, I63, I66, I70-I7I, I75 n24, n26, 176 n38, 193, 210, 216-217,

2I $8,219,235,270$ n2I, 402-434

Ren Xiong 任熊, 342

Ren Yongzhang 任永章, 252 restaurants, 3, IO, 44, 59 nI5, 89, 93, 97, 369

Ricci, Matteo, 368 role-types, 209-210

Ruan Yuan 阮元, I2, 30 n5, 34 n45, 44, 55, 6I n37, 67, I24-I26, I29 ni7

Rui Mingyang 茌名揚, I27

Rulin waishi 儒林外史 [Unofficial History of the Literati], I28, I75 n32

rural, see countryside

rustic, 99, 229, 302, 424-425; see also vulgar

salt / salt industry, 6, 7-8, II, I3, 3I nı6, $32 \mathrm{n} 24$, 34 n5I, 45, 50, 5I, 59 nII, 65, 70, 100, I05 n37, II9, I63, I77, 207, 225, 226, 3I7, 368, $434 \mathrm{nI}$ - merchants, xv-xvi, 8, IO, II, I2, 32 $\mathrm{n} 24,33 \mathrm{n} 39,33 \mathrm{n} 43,63,64,65,75,79$, 89-90, 99, I2I, I40, I56, I60, I63, I67, I78, 204 n35, 207, 2I2-2I 4, 218, 222 , $228,317,370,393 \mathrm{nI}, 376,434 \mathrm{nI}$ - officials, IO, I5, I6, 3I ni6, 32 n29, 35 n6o, 39, 43, 49-50, 75, 89, II5, II7, I23, I62, I69, 367, 370

See also administrative offices

Sancai tuhui 三才圖會 [Illustrated Encyclopedia of the Three Realms], 349, 352, 362, 363, $367,428,438$ n5o scripts, of performers, xxii, I55, I79, 221, 234, $237,243,245-270,252,259,310-3 \mathrm{II}$ 
seal ( $y$ in 印), 318, 326, 333-336, 333, 345 n36 sex, see eroticism

Shan'e tu 善惡圖 [Chart of Good and

Evil], I77, I85, I86, $202 \mathrm{nI} 3,203 \mathrm{n} 30$ Shanghai, xxii, II, I7, 35 n63, n66, 58 nI, 62, 63, 64-65, 69, 7I, 74, 87, 9I, 94-98, I04 n2I, IO5 n36, I27, I77, 20I n2, 2OI n3, 219-220, 225, 226, 227, 245, 276, 286, 29I-292, 305, 313 nI5, 423

Shao Qian 邵潛，I42, I46

Shaoyao pu 药藥譜 [A Treatise on Shaoyao Peonies], 85

Shen Fu 沈復, II, 78

Shexian 㰸縣, 35 n62, I21, I22, I28, 212; see also Huizhou

Shi Chengjin 石成金, xxii, I40-I76, I50

Shi Kefa 史克法, 7, 9, 23, 31 n22, I44, I60

Shi Shennian 石莘年，152

Shi Shilun 施世綸， 156, I68

Shi Songnian 石訔年，I52

Shi Tianji 石天基, see Shi Chengjin

Shi Wu, 3I nı3

Shi Yaochen 施克臣, IIS

Shi Yufang 石玉芳, 22I

Shi Yuanzhi 施元之, II2

shidiao xiaoqu 時調小曲 (current popular songs), 286-3I4, 296, 3I2 nI2

Shi'er lou 十二樓 [Twelve Storey Buildings], 156, $174 \mathrm{n} 20$

Shisan jing zhushu jiaokanji 十三經注疏校勘

記 [Text-critical Notes to the Thirteen

Classics with Commentary], I26

Shitao 石濤, 23, IO2, 403, $434 \mathrm{n} 4$

shoes, 63, 66, 68, 69, 70, 71, 72

shop / shopping / shopkeepers, IO, 20, 2I, 59

nI5, 66, 68, 69, 75, 92, 93, I67, I82, I92, 194, I96, 197,295

Shou Xihu 瘦西湖, 9, 87, 90; see also Slender

West Lake

shouma 瘦馬 ('thin horses of Yangzhou'), see prostitutes

shrine (ci, citang 祠堂), IO, 3I nI9, n22, I69, I75 $\mathrm{n} 34$; see also temple

Shuijing zhu 水經注 [Classic of Waterways with

Annotations], I22

shuochang 説唱, see storytelling

Shuokui shangren 碩揆上人， I39-I40
Si $z i$ 四子 [The Four (Daoist)

Philosophers], II4, I29 n8

Sichelbarth, Ignaz, 350-35I

Siku quanshu [The Complete Library of the

Four Treasuries], 9, 15, 16, 91, 120-122, 372 silk, 6, 62, 63, 66, 67, 69, 72, 98, 225, 226, 242, $321,323,325,343,350,353,354,358,368,371$, 408

singing (airs), 67, I46, I66, 169, 219, 286-314,

369

- societies, 225

See also Yangzhou qingqu

singsong girl, 233, 286, 292-3I4

Slender West Lake (Shou Xihu), xvi, 9, I8, 24, 28, 103,369

Song Ci 宋詞, 219

Song Luo 宋犖, II2

songbooks, I29 nio, 286-313

songs, 52, I42, I5I, 210, 215, 22I, 234, 244 n7,

287, 3II n3, 3I3 n29; see also shidiao xiaoqu

Songshi jishi 宋詩紀事 [Recorded Events about

Song Poems], I2I

Southern tours (nanxun 南巡), 8, 3I nI7, n20, $50,78,89,94,113,162,211,213,225,228$,

369, 403

state (official) honors, 4I, 45, 46-47, 53, 57, 60 n2o

statuary / sculpture, I6, 22, 403, 409, 436 n33

Staunton, George, 365

Stenberg, Josh, xvi

Stevens, Kate, 247

stock phrase / narrative marker, I83, 254, 26I, 268, $269 \mathrm{ni} 3$

storyhouse (shuchang 書場), xvi, xxiii, IO, 248, 27I-285, 274-275, 284, 29I-292

storyteller, xvi, xxiii, I49, I56, I74 nI8, I77, I84,

245-270, 272-285

female -, 29I-293, 313 n22, n23, n26

storytelling, xxii, II, I74, I78-I80, I83, $200 \mathrm{nI}$,

245-270, 288, 29I-292

- genres; see drum ballads; Suzhou

tanci; tanci; xin huaben; Yangzhou

pinghua; Yangzhou xianci

- (language) registers, 202 nI5, 256, $270 \mathrm{nI} 7$

Su Dongpo 蘓東坡, 3, 30 nI, I37, I39, I48 nII, I48 nI2, 327; see also Su Shi 
Su Shi 蘇輕, 50, 80, 82, II2-II3, I40, 4I6, 429,

437 n34, 438 n53, n58, see also Su Dongpo

Su Zhe 蘇轍, I40

Sui Yangdi 隋煬帝，3，5，75, 87, I39, 402, $434 \mathrm{nI}$ suicide, I5, 3I ni3, 33 n38, 40, 45, 54-56, 6I n34,

n35, n37, I44, I62, I64, I8I, 219

Suiyuan shibua 隨園詩話 [Miscellaneous

Notes about the Poetry of the Sui

Garden], 372-373

Sun Jiagan 孫嘉淦, 8

Sun Yancheng 孫言誠, 133

Sun Yang 孫陽, see Bole

supernatural, 56, I32-I33, 233, 234, 235, 272

Suzhou, xxii, II, I2, 20, 53, 64, 69, 7I, 75,

79-80, I05 n36, I09, I28, I35, I4I, I47 nI,

I57, I75 n3O, 2II, 2I2, 215, 227, 229, 230, 233,

238, 24I, 286, 289, 291, 292, 300, 369, 370

Suzhou tanci 蘇州彈詞, 247, $269 \mathrm{n} 7$

Taiping Rebellion, xxii, I2-I7, I9, 32 n3I, 33

n32, 37-6I, 72, 9I, 98, 99, II7, II9, I24,

I26-I27, I29 nI2, 207, 2I8, 219, 220, 222,

$225,226,228,230,233,292$

tale, 3I-32 n24, 60 n27, I33, I77, I79

plain (pinghua 平話), 245

See also vignette

Tan Qian 談遷, 3I nI4

Tan Yunlong 譚雲龍, 318

Tan Zhengbi 譚正璧, 203 n24

tanci 彈詞 (storysinging, chantefable), xvi, I86,

$247,273,276,286,288,29 \mathrm{I}-292,3 \mathrm{I} 2 \mathrm{n} 6$

Tang Shaozu 唐紹祖, I73 nI

Tang Xianzu 湯顯祖, 226

Tang Ying 唐英, 208

Tao Qian 陶潛, 3I nI4, 399

Taylor, Howard, see Guinness

tax, 5, I3, I9, 5I, I35

tea, 8, 78, 89, 98, II2-II3, I94, 277-278, 282, 295, 299, 308, 368, 403

teahouses, xxii, xxiii, 7, I0, 26, 59 nI5, I94, 2II, 27I, 286-314, 369

temple / monastery, xvi, 8, 9, I6, I9, 2I, 2I, 22,

24, 25, 34 n53, 35 n58, n59, 4I, 44, 6I n36,

67, 100, 136, I37-139, I64, I76 n38, 204 n35,

217, 219, 232, 235, 300-30I, 31I, 403, 434 n3,

$437 \mathrm{n} 34$

See also shrine; Tianning si textile / fabrics, I2, I9, 63, 64-65, 67-70, II7, 306, 3I4 n36; see also silk

theatre, xvi, xxii, I2, 33 n32, 34 n47, 89, I04 n7, I36, I78, 207-224, 225-244, 290, 300

local / popular - ( huabu 花

部), 207-224, 225, 229, 230

- troupes / companies, xxii, 209, 210,

2II, 2I2-2I5, 220, 222, 223 n7, 224 n9,

226, 227, 228-233, 236, 244

See also Jingju, Kunqu, Yangju

Three Kingdoms (oral saga), 259-265, 266-267, $270 \mathrm{ni} 9,272$

Tianhua Zhuren 天花主人, $175 \mathrm{n} 27$

Tianning si 天寧寺, $8,9, \mathrm{I} 6,24,30 \mathrm{n} 2,50,60$ n2I, II7, 437 n39

tombs, see burials

Tongtian le 通天樂 [Heaven-Reaching Joy], $153-176$

tourism, 19, 24, $35 \mathrm{n} 58,35 \mathrm{n} 62$

trade, 5, 6, II, I3, 45, 69, 70, 89, 95, 99, I00, IO2, I63, I89, 225, 368-369, 375 n34

traveling / travellers, xxii, $34 \mathrm{n} 46,67,87$, I4O-I4I, I84, 347, 35I, 364-373, 376, 377,

382, 394, $434 \mathrm{n} 4$; see also tourism

Tsang, Ka Bo, 418, 427-428

Tseëlon, Efrat, 7I

vernacular story (buaben 話本), I49, I58, I7I, I72, I88, 245, 268; see also vignette

village, see countryside

vignette (literary ), xxii, I49-I76

Vinograd, Richard, 435 nI8, 436 n20, n27

virtue, virtuous, 46, 5I, 55-56, 99, I67, I74 n23,

I87, $437 \mathrm{n} 34$

vulgar, I29 nio, I55, 4I7, 437 n35; see also rustic

Wan, Margaret B., 269 ns

Wang Chang 王衵, 32 n29

Wang Cheng 王澄, II3, II6, II9

Wang, Eugene, 4I4

Wang Guan 王觀，85

Wang Hong王鴻, 20

Wang Jian 王建, 288

Wang Jingwei 汪精衛，I9

Wang Maolin 汪惁麟，16, 68, 437 n34

Wang Niansun 王念孫, I26

Wang Puzhuang 汪璞莊, see Wang Zhiheng 
Wang Qisun 王芑孫, I26

Wang Qiyuan 汪啟原, 229

Wang Ruanting 王阮亭, see Wang Shizhen

Wang Shaotang 王少堂, 22, 34 n52, 277

Wang Shihu 王士祜， I34-I35

Wang Shilu 王士祿， I34, I35, I37, I40, I47 n6

Wang Shishen 汪士慎, I24, 324-325, 327, 339

Wang Shizhen 王士禎, xxii, 7, 25, 50, II9,

I3I-I47, 437 n34

Wang Wan 汪琬, I33, I39, I4I

Wang Xiang 王相, 384, 4OI n23

Wang Xiangjin 王象晉, I47 n3

Wang Xiuchu 王秀楚, 3I ni3, 67, I29 nII

Wang Yinzhi 王引之, I26

Wang Yongyi 王泳沂, $33 \mathrm{n} 43$

Wang Yun 汪塉, 60 n26, 317, 400

Wang Yushu 汪玉樞, I7

Wang Yuyun 王與允，I44

Wang Zaiguo 王在國，22I

Wang Zhenglai 王正來, 228, 234, 236

Wang Zhicheng 王致誠, see Attiret

Wang Zhiheng 汪之珩, 394, 4OI nI8

war, 3, 6, $30 \mathrm{n} 8$, 3I nII, 52, 53, 9I

anti-Japanese,- I9, 34 n 48

Opium - , 70, 72, 98

See also Taiping Rebellion

waterways, see canals

wedding, I89-192, 193-194, 235, 236

Wei Changsheng 魏長生, 2I3-216, 222, $224 \mathrm{nII}$

Wei Minghua 韋明鏵，69, 7I

Wei Ren 韋人, 220

Wei Xi 魏禧, 62, 67, 69

Wei Yuanyi 魏元嶷, I73 nI

Weng Fanggang 翁方綱，II2

Weng Tonghe 翁同棆，II2

Wenhui ge 文匯閣, 9, I6, I2I

Western, see foreign

Western Han (oral saga), 250-258, 266-267, 272

Western regions (Xi yu) / Xinjiang, 354, 359, $364,366,368,374$ nio

wine, wineshops, $59 \mathrm{nI}, 72,89$, I3I, I36, I42, I44, 203 n32, 2II, 253, 260, 27I, 308, 3II

women, IO, II, I3, 3I nI3, 42, 45, 47, 53, 54-56, 6r n34, 62-74, 65, 90, 96, 98, 99, 100, 102, I26, I33, I34, I42, I60, I62, I74 n23, I76 n38, I79, I80, I87, I89-194, 197-198, 202 n20,
2IO, 2II-2I2, 2I7-2I8, $224 \mathrm{nI}, 229,230$,

232, 236, 289, 29I-310, 318-319, 352, 354, 36I, 367

White pagoda, 9-IO, 17, 19, 24, 3In24, 35 n58

Woxin lu 我信錄 [Record of My Beliefs], 403, 434 n5

Wu Changyuan 吳長元, 215

Wu Erlu 吳爾鹿, 342

Wu Guoliang 吳國良, 259

Wu Jen-shu 巫仁恕，65

Wu Jiaji 吳嘉紀, I43

Wu Jingzi 吳敬梓, I28, I75 n32, 370

Wu, Marshall, 3I8, 34I

Wu Meicun 吳梅村, I43, I46

Wu Shaoxi 伍少西，69

Wu Songshan 吳松山, 86

Wu Weiye 吳偉業, see Wu Meicun

Wu Xiu 吳秀, 7

Wu Yinsun 吳引孫, 35 n63

Wu Youru 吳友如, 65

Wu Zetian 武則天, 365

Wu Zhen 吳楨, 55, 378

Wulana 伍拉納, $224 \mathrm{n} 8$

Wuying dian 武英殿, II8

Xiang Jun 項均, 3I8, 34I

Xiang Rong 向榮, $13,33 \mathrm{n} 38$

Xiang Yin 項絪, I22

xianghuoxi 香火戯, 210, 217, 219-22I

Xianhua Yangzhou 閒話揚州 [Chatting At

Leisure About Yangzhou], I8, 62, 74

Xiao Tiedi Daoren 小鐵遂道人, 215

xiaoshuo 小說 (fiction), I54-155, I79, I82

Xiao Xiangkai 蕭相愷, I73 n9

Xie An 謝安 (Xie Dongshan 謝東山), 8

Xie He 謝赫, 409, 434

$x i e y i$ 寫意 (depicting an idea), 317, 357, 377, 380

xin huaben 新話本 (new tale book), 250, 260

Xing'an 惺庵, 27I

Xinluo shanren 新羅山人, see also Hua Yan

Xinluo shanren tihua shiji 新羅山人題畫詩集

[Collection of Poems on Paintings by

Xinluo shanren], 347, 373 nI, 374 n25, n26

Xiong Kaichu 熊開楚，157, I68

Xu Baoshan 徐寶山, I8, 34 n45

Xu Fengji 徐逢吉, 373 nI

$\mathrm{Xu} \mathrm{Gu}$ 虛谷, 342 
Xu Hongzhang 許鴻章, 252

Xu Ning 徐凝, IO3

Xu Qinjun 徐沁君, 234

Xu Shangzhi 徐向志, 212, 229

Xu Wei 徐渭, 332

Xu Yangcheng xunnan lu 續揚城殉難錄 [A

Record of Martyrs at Yang(zhou) City,

Sequel], 55

$\mathrm{Xu}$ Yinong, I75 n3o

$\mathrm{Xu} \mathrm{Yu}$ 許玉, 92

Xu Zhanzhi 徐湛之, 75

Xu Ziyun 徐紫雲, I45-I46

Xuesong 雪松, 23

Xunyang 旬陽, the Princess of, 30 n7

Yan Duanshu 晏端書, 46, 53, 60 n29, 6I n33

Yan Liben 閻立本, 373

Yan Zhenqing 彥真卿, 23

Yang Baguan 楊八官，213，215

Yang $\mathrm{Fa}$ 楊法，69

Yang Guang 楊廣, see Sui Yangdi

Yang Guifei 楊貴妃, 36I

Yang Kaiding 楊開鼎，380, 400 n7

Yang Weizhen 楊維楨, II4

Yang Xinglou 楊星嶁，380, $400 \mathrm{n} 7$

Yangcheng xunnan lu揚城殉難錄 [A Record of

Martyrs at Yang(zhou) City], 55

Yangju 揚劇 (Yangzhou drama), 2IO, 220, 22I, 227

Yangzhou, passim

- city layout, 4-6, 20-22, 93

destruction / rebuilding of $-, 3,5,5 \mathrm{n} 4$,

7, I5-29, I27, I60

- districts, administrative divisions, 20,

I09, I63, I64, 202 nI9, 233

- history, 5-20, I37, I58, I72, I77

- monuments, 4, 8, I6-I7, 20-29, 34

$\mathrm{n} 45,35 \mathrm{n} 54, \mathrm{n} 56, \mathrm{I} 39$

Yangzhou Club, xv

Yangzhou ditties (xiaochang 小唱, xiaoqu 小曲), see Yangzhou qingqu

Yangzhou eccentrics (ba guai 八怪), xxiii, 76 96-9, 79, 99-IO2, I0I, I03, IO5 n38, 3II-32, 317-346, 376

Yangzhou huafang lu 揚州畫舫錄 [Pleasure

Boats of Yangzhou], 3, IO, 3I n22, 32 n28, 68, 7I, 79, 89, I23, I24, I77, 208, 227-233,
29I, 313 n2I, 370, 373, 4IO

Yangzhou huayuan lu 揚州畫苑錄 [Biographical Accounts of Painters in Yangzhou], 317, 400

Yangzhou jinshi 揚州近事 [Recent Events in Yangzhou], I49, I55, I58

Yangzhou meng 揚州夢 [Dream of Yangzhou] (by Jiaodong Zhou Sheng), 70, 72, 74

Yangzhou Museum, xvi, 24, 29, 33 n32, I27, 2I4, 327, $345 \mathrm{n} 32$

Yangzhou pinghua 揚州評話 (Yangzhou storytelling), I83, I86, 202 nI5, 245-270, 27I-285

Yangzhou qingqu 揚州清曲 (Yangzhou ballads), xvi, 2II, 232-233, 248, 287

Yangzhou School of Learning (Yangzhou xuepai), 12, 216

Yangzhou shiri ji 揚州十日記 [A Ten-Day Diary of Yangzhou], I29 niI

Yangzhou xianci 揚州弦詞 (Yangzhou string tales), 249, $269 \mathrm{n} 7$

Yao Guangxiao 姚廣孝, 158

Yao He 姚合, 32 n26, 75

Yao Zhitong 姚志同, 85

Yayu tang congshu 雅雨堂叢書 [Yayu tang

Collectanea], I23

Ye Fanglin 葉芳林, 370, 37I, 4II

Yen, Shou-chih, $435 \mathrm{n} 8$

Yi 怡, the Prince, I6

Yi Junzuo 易君左， I8, 34 n44, 62, 63, 69, 74

Yicun qupu 佚存曲譜 [Music Scores Lost and Found], 228, 233-237, 243

Yingyuan ziji 影園自記 [A Personal Record of the Garden of Reflection], 77

Yizhuan 易傳 [Tang Commentary on the Yijing], I22, I23

You Tong 尤侗, I37, I45

Yu Chu 虞初, I82, 20I n9

$\mathrm{Yu} \mathrm{Da}$ 俞達, $3 \mathrm{I} 2 \mathrm{n} 7$

Yu Dafu 郁達夫, 19, 64,

Yu Nianchun 郁念純, 234

Yu Sansheng 余三勝, 213

Yu Yue 俞戥, I86

Yuan Guotang 負果堂, 427

Yuan Jin 袁錦, 59 nI2

Yuan Mei 袁枚, 32 n29, I33, I46, 208, 372, 394, 403, 405

Yuan Shikai 袁世凱，I8 
Yuan Siliang 袁思亮, II3

Yuan Zaixi 袁載錫，I53

Yuanye 園冶 [The Craft of Gardens], 78

Yuhua xiang 雨花香 [Rain-Flower

Scent], I53-176, I55

Yun xian xiao 雲仙笑 [Laughter of Immortals in the Clouds], I75 n27

Yunguang 雲光, I54

Yuxiang yigao 于湘遺稿 [Posthumous Writings of (Lou) Yuxiang], I2I

Yuyang shanren ji 漁洋山人集 [Collected Writings of Wang Shizhen], I43

Yuyang shanren jinghua lu 漁洋山人精 華錄 [Recorded Writings of Wang

Shizhen], II9, I47 n9

Zeng Guofan 曾国藩，I5, 47, 53, 58 n2, 60-6I n3I

Zeng Yu 曾燠, II

Zeng Guofan 曾国藩，I5，47

Zhang Da'an 張大安, 230

Zhang Dai 張岱, 3I4 n33

Zhang Dejian 張德堅，59 nI2

Zhang Feng 張鳳, 32 n25

Zhang Geng 張庚 (I685-I760), 325

Zhang Geng 張庚 (I9II-2003), 2I4

Zhang Hao'an 張浩庵, 56

Zhang Heng 張珩, 370, 371

Zhang Huangyan 張煌言, I47 n4

Zhang Linzhe 張霖者, I44

Zhang Qiren 張其仁，86

Zhang Ruocheng 張若澄, 359

Zhang Sengyu 張僧乿, 409, 434

Zhang Shuhe 張叔和, 97

Zhang Shunhui 張舜徽, 224 nI4

Zhang Sijiao 張四教, 369, 375 n36, 418

Zhang Sui 張繸, 85

Zhang Tingyan 張廷彥, 375 n38

Zhang Weibang 張為邦, 375 n38

Zhang Xianzhong 張獻忠, 175 n29

Zhang Xuefeng 張雪峯, 438 n52

Zhang Xun 張巡, 176 n38

Zhang Youxin 張友新, 8

Zhang Zhen 張震, 375 n38

Zhao Gou 趙構, emperor Gaozong 高宗 of

Southern Song, $30 \mathrm{n} 8$

Zhao Jingshen 趙景深, I73 n3, 234
Zhao Mengfu 趙孟煩, II4

Zhao Tong 趙通, II2

Zhao Yu 趙瑜, 59 nII,

Zheng Banqiao 鄭板橋, 3, 23, 30 nI, 79, I3I, I37-I39, I40, I46; see also Zheng Xie

Zheng Changchun 正長春, 17

Zheng Chenggong 鄭成功, I34, I35, I47 n4

Zheng Xie 鄭卒, I24, 318-323, 325, 328, 328,

332, 339, 370, 394, 400 n3; see also Zheng

Banqiao

Zheng Yu 鄭羽, II2

Zheng Yuanxun 鄭元勳, 3I ni3, 77, 79,

Zhenjiang, I3, I5, I8, $30 \mathrm{n} 8,36 \mathrm{n} 66,39,40,42$, 59 ni6, 62, 63, 67, 69, 72-73, I2I, I34

Zhi Shi 智什, 4IO, 440 nioI

Zhong Songyan 仲松岩, 273, 277

Zhongding kuanzhi 鐘鼎識 [Inscriptions on

Bronze Vessels], I25, I26

Zhou Boyi 周伯義, see Zhou Sheng

Zhou Cun 周邨, $58 \mathrm{n} 8$

Zhou Lianggong 周亮工, I43

Zhou Ronggen 周榮根, 218, 219

Zhou Sheng 周生, 72

Zhou Yibai 周貽白, 2II

Zhu Dechun 朱德春, 277

Zhu Dongpo xiansheng shi 註東坡先生

詩 $[\mathrm{Mr}(\mathrm{Su})$ Dongpo's Poems with

Annotation], III, II2, I29 n 4

Zhu Kesheng 朱克生, I44

Zhu Yizun 朱彞尊, I23, I38, I40-I4I, I48 nI4

Zhu Ziqing 朱自清, 24, 34 n44, IO2, 3I3 nis

Zhuxi huashi xiaolu 竹西花事小錄 [Jottings on the Flowers of Zhuxi], 228, 233

zhuzhici (bamboo-branch poems), II, 59 nis, $202 \mathrm{n} 2 \mathrm{O}$

Zi buyu 子不語 [What Confucius Would Not Have Talked About], 133

Zong Hao 宗影, 3I ni3

Zong Yuanding 宗元鼎，I39

Zuo Bifan 左必蕃, I52 